\title{
Die Atmung der verholzten Organe von Altbuchen (Fagus sylvatica L.) in einem Kalk- und einem Sauerhumusbuchenwald
}

\author{
Dissertation \\ zur Erlangung des Doktorgrades \\ der Mathematisch-Naturwissenschaftlichen Fakultäten \\ der Georg-August-Universität zu Göttingen
}

\author{
vorgelegt von \\ Jörg Strobel \\ aus Salzgitter
}

Göttingen 2004 
D7

Referent: Prof. Dr. Michael Runge

Korreferent: Prof. Dr. Christoph Leuschner

Tag der mündlichen Prüfung: 28.04.2004 


\section{Inhaltsverzeichnis}

Inhaltsverzeichnis ...................................................................................................................... 1

Abbildungsverzeichnis.............................................................................................4 4

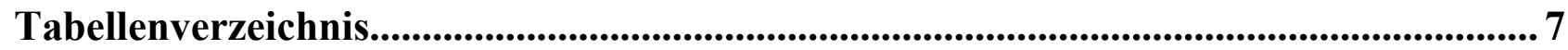

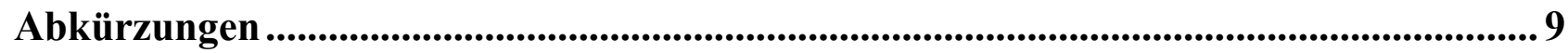

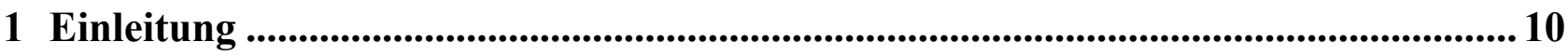

2 Die Untersuchungsflächen ........................................................................................... 13

2.1 Die topographische Lage der Untersuchungsflächen ..................................................... 13

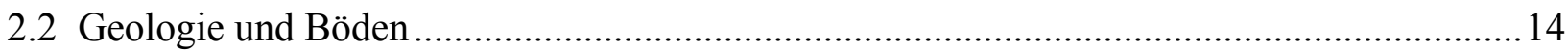

2.3 Regionalklima und Witterung im Untersuchungszeitraum ............................................ 15

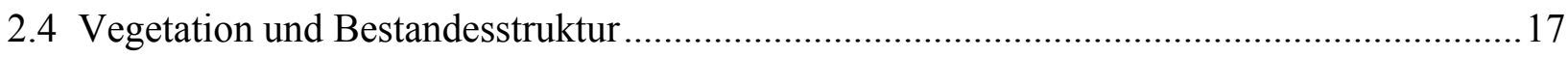

3 Methoden ............................................................................................................................ 19

3.1 Die Dauermessung der Holzatmung............................................................................ 19

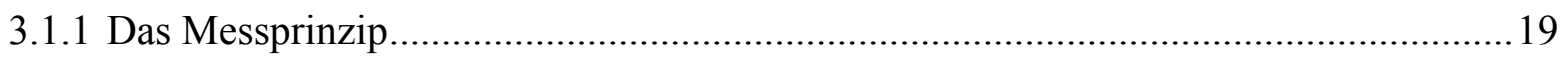

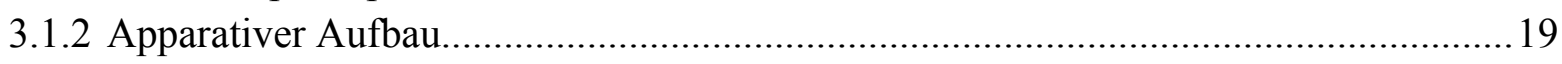

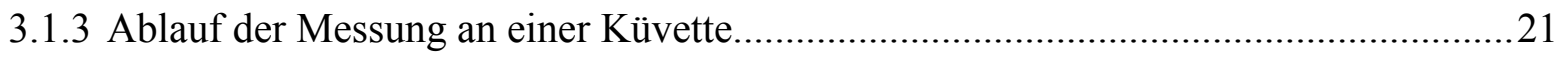

3.1.4 Auswahl und Einrichtung der Dauermessstellen ...................................................21

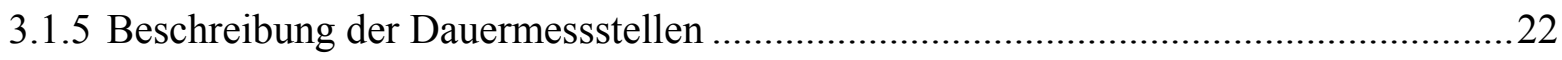

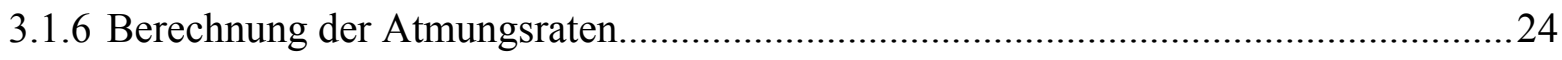

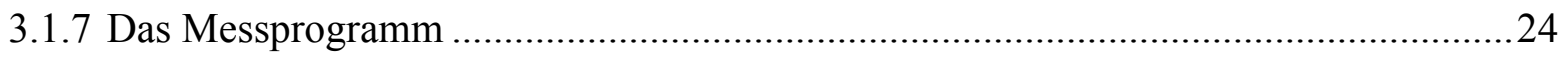

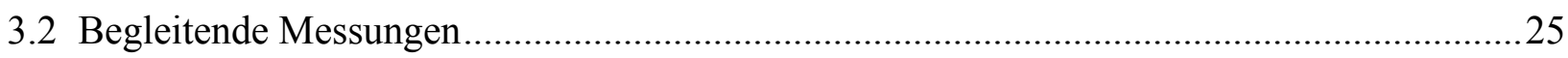

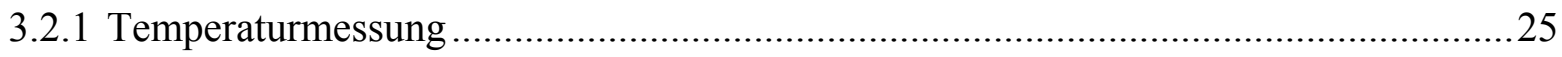

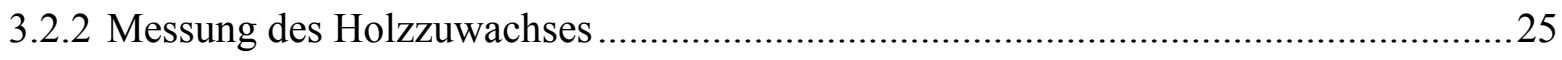

3.2.3 Ergänzende Messung der Holzatmung: „Punktmessungen“......................................26

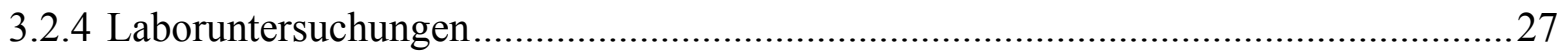

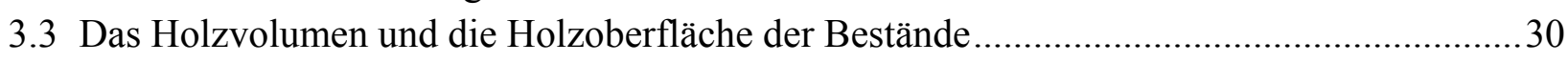

3.3.1 Bestimmung des Derbholzvolumens ..................................................................... 30

3.3.2 Der relative Volumenanteil verschiedener Durchmesserklassen.................................31

3.3.3 Berechnung der ober- und unterirdischen Holzvolumina und -oberflächen der

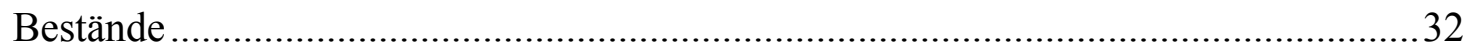

3.4 Auswertung der Atmungsraten..................................................................................... 33

3.4.1 Berechung des Jahresgangs der Gesamtatmung an den Messstellen.............................34

3.4.2 Differenzierung der Gesamtatmung in die Teilkomponenten Erhaltungs- und

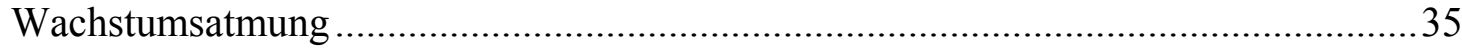

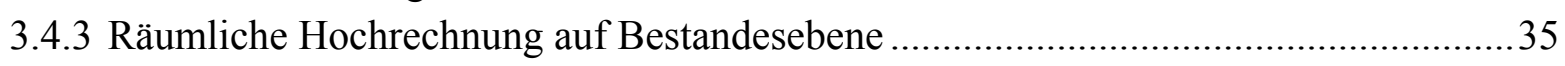

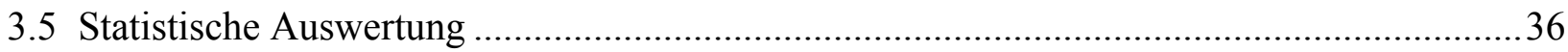

4 Ergebnisse........................................................................................................ 38

4.1 Die Variabilität der Holzatmung im zeitlichen Verlauf ................................................... 38 


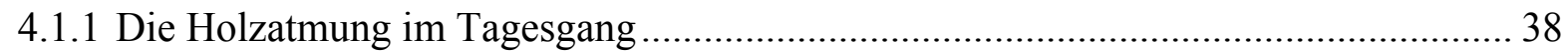

4.1.2 Der Einfluss des Temperaturgradienten im Holz auf den Tagesgang der $\mathrm{CO}_{2}$-Abgabe

4.1.3 Der Einfluss von Rindenphotosynthese und $\mathrm{CO}_{2}$-Transport im Xylemsaft auf die

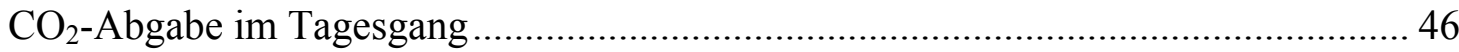

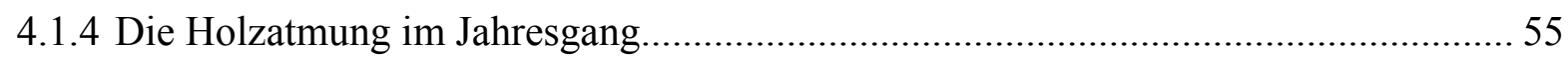

4.1.5 Die Temperaturabhängigkeit der Holzatmung im Jahresgang .................................... 61

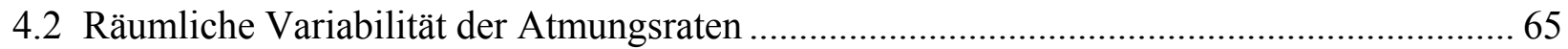

4.2.1 Der Einfluss von Bezugsgröße und Durchmesser der Sprossachse ............................ 65

4.2.2 Der Zusammenhang zwischen $\mathrm{CO}_{2}$-Abgabe, Probendimension,

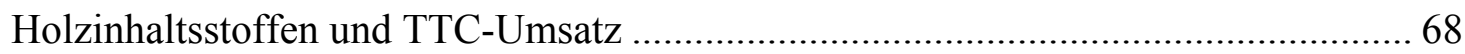

4.2.3 Das radiale Profil des TTC-Umsatzes und der Stickstoffkonzentration ...................... 73

4.2.4 Die Variabilität der Stammatmung innerhalb eines Baumes ...................................... 76

4.2.5 Der Einfluss der Messposition und der Kronenstruktur auf die Astatmung ................ 79

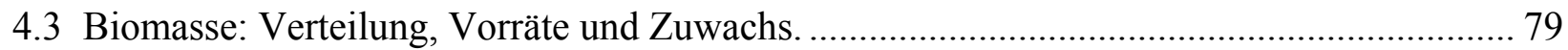

4.3.1 Verteilung der oberirdischen Biomasse auf verschiedene Durchmesserklassen.......... 79

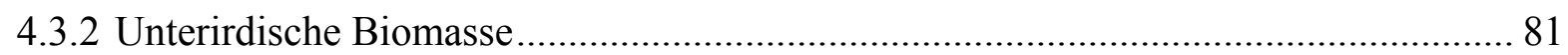

4.3.3 Biomassevorräte und Jahreszuwachs der Bestände.................................................... 82

4.4 Zeitliche und räumliche Hochrechnung der Atmungsraten als Teil der

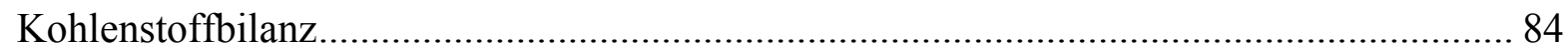

4.4.1 Zeitliche Hochrechnung der Atmungsraten............................................................. 84

4.4.2 Räumliche Hochrechnung der Atmungsraten ........................................................... 90

5 Diskussion

5.1 Die $\mathrm{CO}_{2}$-Abgabe über die Oberfläche verholzter Organe von Bäumen und die

Temperaturabhängigkeit der Holzatmung ...

5.1.1 Die Phasenverschiebung von $\mathrm{CO}_{2}$-Abgabe und Temperatur im Tagesgang.....

5.1.2 Der Einfluss von Rindenphotosynthese und $\mathrm{CO}_{2}$-Transport mit dem Xylemsaft auf die $\mathrm{CO}_{2}$-Abgabe verholzter Baumorgane

5.1.3 Vergleich der Rindenphotosynthese und $\mathrm{CO}_{2}$-Transportraten mit Literaturangaben.

5.1.4 Bedeutung der Effekte von Hysterese, Rindenphotosynthese und $\mathrm{CO}_{2}$-Transport für die Bestimmung der Temperaturbeziehung

5.2 Die Holzatmung im Jahresgang

5.3 Die räumliche und zeitliche Variabilität des Temperaturkoeffizienten $\mathrm{Q}_{10} \ldots \ldots \ldots \ldots \ldots \ldots \ldots . . . . . . . . .117$

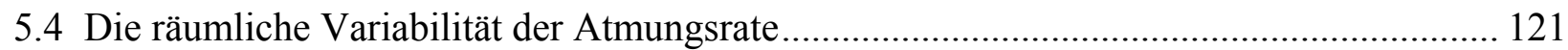

5.4.1 Die Durchmesserabhängigkeit der Holzatmungsraten .......................................... 122

5.4.2 Die Variabilität der $\mathrm{CO}_{2}$-Abgabe und des Stickstoff- und Proteingehalts .................. 125

5.4.3 Der TTC-Umsatz als Maß für die Aktivität der lebenden Zellen............................... 126

5.4.4 Der Einfluss der Messposition am Stamm und in der Krone .................................... 128

5.4.5 Die räumliche Variabilität der Erhaltungsatmung: Ursachen und

Schlussfolgerungen für die Extrapolation der Küvettenmessungen.......................... 131

5.5 Diskussion der Ergebnisse der zeitlich und räumlich extrapolierten Atmungsraten ............ 134

5.5.1 Die Anteile von Erhaltungs- und Wachstumsatmung und des respirativen

Kohlenstoffbedarf für den Holzzuwachs.... 
5.5.2 Die Bestandesatmung: die Abhängigkeit der Ergebnisse von dem zur Extrapolation der Daten gewählten Modell 139

5.5.3 Die Holzatmung als Teil der Kohlenstoffbilanz 145

5.5.4 Die Bedeutung der Rindenphotosynthese für die Kohlenstoffbilanz der Buchenwälder. 154

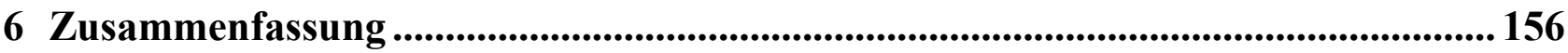

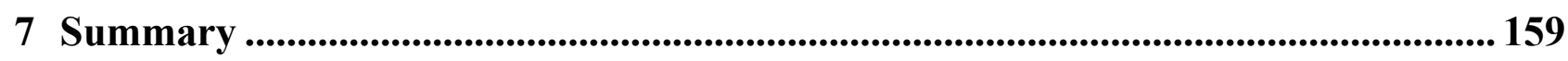

8 Literaturverzeichnis ................................................................................. 162

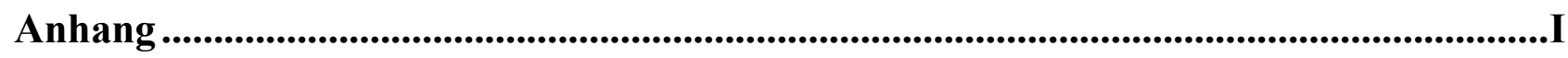

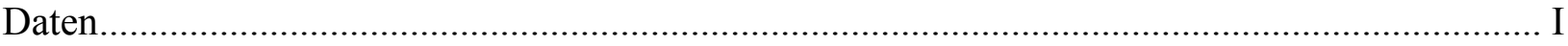

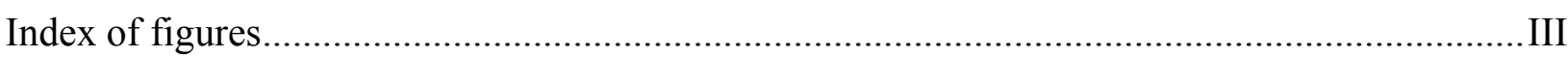

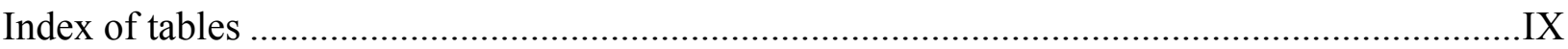




\section{Abbildungsverzeichnis}

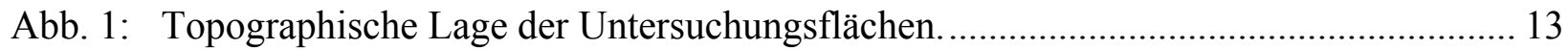

Abb. 2: Klimadiagramme der Wetterstationen Silberborn und Göttingen............................... 15

Abb. 3: Jahresverlauf der Monatsmittelwerte von Temperatur und der monatlichen Niederschläge in den Jahren 1997 und 1998

Abb. 4: vereinfachtes Schaubild des Mehrkanal-Küvettensystems zur Erfassung der $\mathrm{CO}_{2}$ Abgabe von Ästen, Stämmen und Grobwurzeln

Abb. 5: Tagesgänge der Atmungsraten und Xylemtemperaturen, der Lufttemperatur und der PAR sowie die Temperaturfunktionen der Atmungsraten von Ästen, Stämmen und Grobwurzeln.

Abb. 6: Tagesgänge der Atmungsraten und Xylemtemperaturen sowie die

Temperaturfunktionen der Atmungsraten von Stämmen im Göttinger Wald mit signifikanter Temperaturabhängigkeit und ohne Reaktion der Atmung auf Temperaturänderungen.

Abb. 7: Tagesgänge der Atmungsraten und Xylemtemperaturen sowie die

Temperaturfunktionen der Atmungsraten von Ästen und Grobwurzeln.

Abb. 8: Tagesgänge der Atmungsraten von Stamm 4 (Solling) sowie der Lufttemperatur, der PAR und der Xylemtemperaturen, die in 0.5, 1.5, 2.5, 6.5 und $12.5 \mathrm{~cm}$ Tiefe unter der Stammoberfläche gemessen wurden..

Abb. 9: Auftragung der Atmungsraten von Stamm 4 (Solling) gegen die Lufttemperatur und die Xylemtemperatur in verschiedenen Tiefen.

Abb. 10: Auftragung der Atmungsraten von Stamm 4 (Solling) gegen die Lufttemperatur und die Xylemtemperatur in 5 verschiendenen Holztiefen.

Abb. 11: Auftragung der Atmungsraten gegen die Temperatur und Tagesgänge der gemessenen und berechneten Atmungsraten von Grobwurzel 4 und Ast 4 (Göttinger Wald).

Abb. 12: Temperaturabhängigkeit der Atmungsraten und Temperaturfunktionen für die Nachtdaten der Messung bei lichtdurchlässigen und bei abgedeckten Küvetten.

Abb. 13: Zweijahresgänge der mittleren Atmungsraten und Xylemtemperaturen von Ästen, Stämmen und Grobwurzeln im Solling und im Göttinger Wald. ................................ 56

Abb. 14: Auftragung der Atmungsraten gegen die Temperatur. ............................................... 58

Abb. 15: Zweijahresgänge der $10^{\circ} \mathrm{C}$-Atmungsraten und der mittleren Wachstumsraten............ 60

Abb. 16: Jahresverläufe der $\mathrm{Q}_{10}$-Werte der Temperaturabhängigkeit der Holzatmung. .............. 62

Abb. 17: Zweijahresgänge der Temperaturfunktionen der Atmungsraten. ................................. 63

Abb. 18: Vergleich der oberflächen- und volumenbezogenen $10^{\circ} \mathrm{C}$-Erhaltungsatmung. ............ 66

Abb. 19: Beziehung zwischen dem Durchmesser der Sprossachsen und der auf die Oberfläche und das Volumen bezogenen $10^{\circ} \mathrm{C}$-Erhaltungsatmung. 66

Abb. 20: Beziehung zwischen oberflächen- und volumenbezogener $10^{\circ} \mathrm{C}$-Atmungsrate und dem Durchmesser von Stämmen und Ästen. Die Messungen wurden bei drei Messkampagnen im November und Dezember im Göttinger Wald durchgeführt.

Abb. 21: Beziehung zwischen Erhaltungs- $\mathrm{CO}_{2}$-Abgabe bei $10{ }^{\circ} \mathrm{C}$ und Oberfläche, Volumen, der Menge umgesetzten TTC sowie dem Stickstoff- und Proteingehalt. 
Abb. 22: Erhaltungsatmungsrate von Ästen, Stämmen und Grobwurzeln bei $10{ }^{\circ} \mathrm{C}$ bezogen auf Oberfläche, Volumen, TTC-Umsatz sowie Stickstoff und Proteingehalt.

Abb. 23: Beziehungen zwischen volumenbezogener $10^{\circ} \mathrm{C}$-Erhaltlungsatmung und der pro Volumeneinheit extrahierten TTF-Menge sowie der Stickstoffkonzentration.

Abb. 24: Die radiale Verteilung des auf das Volumen des Bohrkernstückes bezogenen TTC-Umsatzes und der Stickstoffmenge bei drei Ästen und einer Grobwurzel im Göttinger Wald sowie je zwei Stämmen im Solling und Göttinger Wald.

Abb. 25: Die radiale Verteilung der mittleren volumenbezogenen TTC-Umsätze und Stickstoffgehalte von Stämmen, Ästen und Grobwurzeln.

Abb. 26: Volumenbezogene $10{ }^{\circ} \mathrm{C}$-Erhaltungsatmung je eines Stammes in Solling und Göttinger Wald, an denen die Messungen an der Stammbasis, auf mittlerer Höhe und nahe dem Kronenansatz jeweils in nördlicher und südlicher Exposition erfolgten.

Abb. 27: Höhengradient der mittleren $10^{\circ} \mathrm{C}$ Atmungsrate eines Stammes im Solling und im Göttinger Wald sowie der Jahreszuwachsrate des Stammes im Solling.

Abb. 28: Verteilung der $\mathrm{r}^{2}$-Werte aller linearen Regressionen für die Beziehungen zwischen den $10^{\circ} \mathrm{C}$-Atmungsraten von sechs Messstellen, die an einem Individuum in unterschiedlicher Höhe und Exposition $\left(\mathrm{S}_{\mathrm{V}} 7\right.$ bis $\left.\mathrm{S}_{\mathrm{V}} 12\right)$ und an fünf bzw. sechs verschiedene Individuen (S 1- S 6) gemessen wurde.

Abb. 29: $10^{\circ} \mathrm{C}$-Erhaltungsatmung der Äste beider Standorte aufgetragen gegen die ihnen zugeordnete Klasse von Kronenvolumen und Kronenposition

Abb. 30: Beziehung zwischen Holzvolumenanteil von Sprossachsen verschiedener

Durchmesserklassen am Gesamtvolumen von fraktioniert geernteten Buchen und deren BHD.

Abb. 31: Beziehung zwischen den Logarithmen der Grobwurzelbiomasse und dem BHD von vier 1968 im Solling geernteten Buchen.

Abb. 32: Durchmesserverteilung, Baumhöhen und BHD-Höhenbeziehung der beiden

Untersuchungsbestände.

Abb. 33: Beziehung zwischen dem jährlichen Durchmesserzuwachs und dem BHD

bestandesrepräsentativer Buchen im Solling und im Göttinger Wald.

Abb. 34: Volumenvorräte der verholzten oberirdischen Biomasse zu Beginn des

Untersuchungszeitraumes, ihre Verteilung auf 7 Durchmesserklassen sowie der

Volumenzuwachs während der zwei Untersuchungsjahre.

Abb. 35: Temperaturfunktionen der Erhaltungsatmung und der Atmungsraten aller

Messkampagnen 1997 eines Astes, eines Stammes und einer Grobwurzel sowie die daraus berechneten Jahresgänge der Atmung...

Abb. 36: Vergleich der drei verschiedenen Methoden zur Bestimmung des

Umfangzuwaches von Ästen.

Abb. 37: Jahresverlauf des kumulativen Umfangzuwachses dreier Äste im Göttinger Wald aus Messungen mit Noniusmaßbändern.

Abb. 38: Auftragung der Jahressumme der Atmung gegen den jährlichen Zuwachs von

Stämmen und Ästen für das Jahr 1998.

Abb. 39: Zweijahresgänge der auf die Bestandesgrundfläche bezogenen Gesamt-,

Erhaltungs- und Wachstumsatmung der Buchen im Solling und im Göttinger

Wald. 
Abb. 40: Beziehung zwischen $10^{\circ} \mathrm{C}$ Erhaltungsatmung und Durchmesser von Ästen und Grobwurzeln nach Daten verschiedener Autoren und der vorliegenden Arbeit.

Abb. 41: Zweijahresgänge von Atmungs- und Zuwachsrate von Ästen und Stämmen im Göttinger Wald und im Solling.

Abb. 42: Durchmesserabhängigkeit der gemessenen und berechneten volumenbezogenen Atmungsraten aller Kompartimente.

Abb. 43: Durchmesserabhängigkeit der oberflächen- und volumenbezogenen Atmungsraten der nach Kronenposition differenzierten Äste.

Abb. 44: Die Beziehung zwischen temperaturnormierter Erhaltungsatmung und relativer Wachstumsrate von Ästen und Stämmen 30-jähriger Buchen sowie von Ästen und Stämmen der Altbuchen im Solling und Göttinger Wald.

Abb. 45: Beziehung zwischen oberirdischer und gesamter jährlicher Holzatmung und Bruttoprimärproduktion von Solling und Göttinger Wald.

Abb. 46: Beziehung zwischen der jährlichen oberirdischen Holzatmung von vier verschiedenen Buchenbeständen unterschiedlichen Alters und der GPP. 


\section{Tabellenverzeichnis}

Tab. 1: Vergleich der Temperaturmittelwerte und Niederschlagssummen der Wetterstationen Silberborn und Göttingen für die Untersuchungsjahre 1997 und 1998 und dem langjährigen Mittel.

Tab. 2: Vergleich einiger Rahmendaten zur Bestandesstruktur der beiden untersuchen Buchenbestände.

Tab. 3 : Kenndaten der Dauermessstellen. Neben den in den Küvetten eingeschlossenen Oberflächen und Volumina der Sprossachsen ist der Durchmesser, die mittlere Höhe der Messstelle über dem Boden, die Exposition der Stammküvetten, die Längsorientierung der Äste und ihr Abweichungswinkel von der Horizontalen angegeben.

Tab. 4: Grenzen der Holzdurchmesserklassen $1-7$.

Tab. 5: Bestimmtheitsmaß und $\mathrm{Q}_{10}-$ Werte der Temperaturfunktionen der Atmungsraten, die für alle Daten ohne und mit Zeitverzögerung $\left(\mathrm{TL}_{\mathrm{opt}}\right)$, für die sich maximale $\mathrm{r}^{2}$ Werte ergaben, sowie für die während der Nacht gemessenen Daten, berechnet wurden.

Tab. 6: Mittlere und maximale volumenbezogene Atmungsraten und Xylemtemperaturen aller drei untersuchten Kompartimente

Tab. 7: Bestimmtheitsmaß $r^{2}$ und Irrtumswahrscheinlichkeit $P$ der in Abb. 21 dargestellten Beziehungen zwischen $\mathrm{CO}_{2}$-Abgabe und Probendimension, Stoffumsatz bzw. - gehalt.

Tab. 8: Derbholz- und Gesamtvolumen sowie die prozentuale Verteilung der Volumina auf 7 Durchmesserklassen von zwei für die Untersuchungsbestände repräsentativen Buchen mittleren Durchmessers und mittlerer Höhe.

Tab. 9: Vorräte verholzter Biomasse Anfang 1997, ihre Verteilung auf verschiedene Durchmesserklassen der Sprossachsen und der Zuwachs von Derb-, Reis- und Wurzelholz in den beiden Untersuchungsjahren.

Tab. 10: Jahressummen der volumenbezogenen Gesamt-, Erhaltungs- und Wachstumsatmung der verholzten Kompartimente.

Tab. 11: Mittlerer volumenbezogener Jahreszuwachs und mittlere Wachstumskoeffizienten beider Untersuchungsjahre von Ästen, Stämmen und Grobwurzeln beider Standorte.

Tab. 12: Monatssummen der Gesamtatmung $\mathrm{R}_{\mathrm{t}}$ der Buchenbestände im Göttinger Wald und im Solling.

Tab. 13: Beispielhafte Berechnung des Fehlers der Jahressumme der Holzatmung für den Bestand im Solling und das Jahr 1997.

Tab. 14: Vergleich der jährlichen Bestandes-C-Flüsse verholzter Organe ohne und mit Berücksichtigung der Durchmesserabhängigkeit der Reisig- und Wurzelatmung .96

Tab. 15: Rindenphotosynthese und $\mathrm{CO}_{2}$-Transport mit dem Xylemsaft als relativer Anteil an der Tagessumme der berechneten Atmungsrate sowie die Spanne oberflächenbezogener Refixierungsraten von Ästen, Stämmen und Grobwurzeln, die während des Winterhalbjahres (Nov. - April) und der Vegetationsperiode beider Untersuchungsjahre beobachtet wurden. 
Tab. 16: Jahressumme der auf die Bestandesgrundfläche bezogenen C-Flüsse der verschiedenen Holzfraktionen von Solling und Göttinger Wald.

Tab. 17: Absolute und relative Photosyntheseraten der Rinde von Ästen und Stämmen.......... 105

Tab. 18: Maximale Raten des $\mathrm{CO}_{2}$-Transports mit dem Xylemsaft. ....................................... 106

Tab. 19: Relativer Anteil der Rindenphotosynthese, der Summe von Rindenphotosynthese und $\mathrm{CO}_{2}$-Transport und des $\mathrm{CO}_{2}$-Transportes an der Tagessumme der $\mathrm{CO}_{2}$ Abgabe über die Oberfläche verholzter Organe.

Tab. 20: Vergleich der mit verschiedenen Temperaturfunktionen berechneten Tagessummen der $\mathrm{CO}_{2}$-Abgabe.

Tab. 21: Zusammenstellung von Literaturangaben zu volumenbezogenen Atmungsraten verschiedener Baumarten und -kompartimente. Aus den Quellen wurden die Jahresminima- und maxima bei ambienten Temperaturen, sowie die Spanne der auf $10^{\circ} \mathrm{C}$ normierten Atmungsraten übernommen und bei Bedarf umgerechnet.

Tab. 22: Vergleich der Ergebnisse der Jahressummen oberirdischer Holzatmung, bei deren Berechnung die räumliche Variabilität der volumen- oder oberflächenspezifischen Atmungsraten sowie die Variabilität des $\mathrm{Q}_{10}$-Wertes in unterschiedlicher Weise berücksichtigt wurde.

Tab. 23: Vergleich der Jahressummen der oberirdischen und unterirdischen Holzatmung mit der autotrophen Bestandesatmung, der im Holzzuwachs festgelegten Kohlenstoffmenge, der Rindenphotosynthese und der Bruttoprimärproduktion. 


\section{Abkürzungen}

\begin{tabular}{ll}
$\mathrm{B}$ & Äste, (Branches) \\
$\mathrm{BHD}$ & Brusthöhendurchmesser $(1.3 \mathrm{~m})$ \\
$\mathrm{CL}$ & Kronenniveau (Crown Level) \\
$\mathrm{CR}$ & Grobwurzeln (Coarse roots) \\
$\mathrm{CV}$ & Kronenvolumen (Crown Volume) \\
{$\left[\mathrm{CO}_{2}\right]$} & $\mathrm{CO}_{2}$-Konzentration \\
$\mathrm{D}$ & Durchmesser mit dem Index a und die für außen und innen \\
$\mathrm{d}$ & Tag \\
$f$ & molare Flussrate (mol s ${ }^{-1}$ ) \\
$\mathrm{G}$ & Zuwachs mol C pro Zeiteinheit \\
$\mathrm{IA}$ & Ionenäquivalente \\
$\mathrm{IRGA}$ & Infrarot Gasanalysator \\
$\mathrm{P}$ & Druck \\
$\mathrm{Rg}$ & allgemeine Gaskonstante \\
$\mathrm{R}_{\mathrm{A} / \mathrm{V} / \mathrm{Vsplint}}$ & Atmungsrate (oberflächen-, volumen- und splintvolumenspezifisch) \\
$\mathrm{R}_{\mathrm{g}}$ & Wachstumsatmung \\
$\mathrm{R}_{\mathrm{m}}$ & Erhaltungsatmung \\
$\mathrm{R}_{\mathrm{t}}$ & Gesamtatmung \\
$\mathrm{S}_{(\mathrm{V})}$ & Stämme, (Stem), Index (V) für Vertikales Profil am Stamm \\
$\mathrm{T}$ & Temperatur \\
$\mathrm{TB}$ & Trockenboden \\
$\mathrm{TL}$ & Zeit/Phasenverschiebung (time lag) \\
$\mathrm{V}$ & Volumen \\
$\ddot{u} . \mathrm{M}$. & über Meereshöhe \\
& \\
\hline
\end{tabular}




\section{Einleitung}

Der Kohlenstoffumsatz von Waldökosystemen hat infolge des anthropogen bedingten Anstiegs der $\mathrm{CO}_{2}$-Konzentration in den vergangenen Jahrzehnten zunehmend an Interesse gewonnen. Jährlich gelangen ca. 8.1 Gt C bei der Verbrennung fossiler Energieträger, der Zementproduktion und durch die Zerstörung tropischer Regenwälder in die Atmosphäre (MACILWAIN 1997). Davon werden ca. 1-3 Gt C im Boden und der Biomasse terrestrischer Ökosysteme festgelegt, an deren Bruttoprimärproduktion die Wälder der tropischen, temperaten und borealen Zone den weitaus größten Anteil haben (MALHI et al. 1999).

Der Anstieg der atmosphärischen $\mathrm{CO}_{2}$-Konzentration und die damit einhergehenden Klimaänderungen wirken auf die Photosynthese und die respirative $\mathrm{CO}_{2}$-Abgabe. Sie können dadurch die Netto-C-Aufnahme von Waldökosystemen und damit deren Rolle im globalen C-Haushalt beeinflussen (RYAN 1991). Ein zentrales Ziel der Waldökosystemforschung ist es daher, mit Modellen vorherzusagen, unter welchen klimatischen Bedingungen Waldbestände Kohlenstoff akkumulieren oder eine zusätzliche $\mathrm{CO}_{2}$-Quelle sein können (VALENTINI et al. 2000).

Eine Prognose der jährlich in der Biomasse festgelegten Kohlenstoffmenge für verschiedene Klimaszenarien auf Grundlage eines empirisch-statistischen Modells, das die Beziehungen zwischen Jahrringbreite und Witterungsverlauf beschreibt, ist nach den Ergebnissen von MAKOWKA et al. (1991) für Buchen-Altbäume nicht möglich. Die Zusammenhänge zwischen Witterung und dem Stammholzzuwachs haben keinen ausreichenden Erklärungswert. Die Ursache hierfür ist darin zu sehen, dass der Zuwachs das Saldo aus photosynthetischen C-Einnahmen und respiratorischen CVerlusten ist und die Witterung in unterschiedlicher Weise auf die Teilprozesse Photosynthese und Atmung wirkt. Für eine Prognose des Wachstums, d.h. der Nettoprimärproduktion (NPP) ist es daher erforderlich, die Wirkung des Witterungsverlaufs auf die Photosynthese und die Atmung in Prozessmodellen zu beschreiben.

Die autotrophe Atmung macht bei Wäldern oft mehr als $50 \%$ der jährlichen Bruttophotosynthese (GPP) aus (RYAN 1991, RYAN et al. 1994b, LAW et al. 1999). Der Anteil der Atmung der verholzten Organe an der GPP liegt bei Koniferen zwischen 3 und 36 \% (KINERSON 1975, RYAN et al. 1997) und bei sommergrünen Laubbäumen zwischen ca. 5 und $31 \%$ (GOULDEN et al. 1996b, DAMESIN et al. 2002), so dass ihre Bedeutung für die Kohlenstoffbilanz von Waldbeständen unterschiedlich bewertet wird. Vielfach wird die Ursache für den Rückgang der Produktivität mit zunehmendem Bestandesalter in der Akkumulation von Biomasse und der damit zunehmenden Holzatmung gesehen (LARCHER 1994, BARNES et al. 1998). Andere Untersuchungen zeigen aber, dass die gesamte Holzatmung älterer Wälder nur wenig von der jüngerer Bestände abweicht (RYAN \& WARING 1992, RYAN et al. 2004)

Die hohe Variabilität der Anteile der Holzatmung an der GPP kann in standort- und artspezifischen Eigenschaften begründet sein. Jedoch hängen die Ergebnisse zur Holzatmung auf Bestandesebene zunächst wesentlich von den bei der Messung und Berechnung verwendeten Verfahren ab (GRANIER et al. 2000).

Um den jährlichen Kohlenstoffbedarf für die Atmung der verholzten Organe eines Waldbestandes auf Grundlage von $\mathrm{CO}_{2}$-Gaswechselmessungen $\mathrm{zu}$ bestimmen, muss die diskontinuierlich und an kleinen Einheiten der Bäume gemessene $\mathrm{CO}_{2}$-Abgabe zeitlich und räumlich hochgerechnet werden. Hierzu ist es notwendig, die steuernden Einflussgrößen für die zeitliche Variabilität und die räumliche Verteilung der atmungsphysiologischen Eigenschaften der Bäume zu kennen. 
Zwischen Atmung und Temperatur besteht eine enge Beziehung, so dass diese Umgebungsvariable zur Berechung der zeitlichen Variabilität herangezogen werden kann (AMTHOR 1989, SPRUGEL \& BENECKE 1991). Die für den Tagesgang ermittelten Temperaturfunktionen können aber die saisonale Variabilität der Holzatmung oft nicht erklären. Temperaturunabhängige endogen bedingte Variationen der Atmungsaktivität z.B. im Zusammenhang mit dem Biomassezuwachs (JOHANSSON 1933, LINDER \& TROENG 1981, SPRUGEL 1990) führen dazu, dass die Temperaturbeziehungen hinsichtlich des Niveaus, d.h. der temperaturnormierten Atmungsrate (LAVIGNE \& RYAN 1997, RYAN et al. 1997), und der Sensitivität gegenüber Temperaturänderungen (der Q 10 -Wert) (HAGIHARA \& HOZUMI 1991, STOCKFORS \& LINDER 1998) im saisonalen Verlauf variieren können.

Selbst auf Ebene des Tagesganges kann die $\mathrm{CO}_{2}$-Abgabe durch Rindenphotosynthese (FOOTE \& SCHAEDLE 1974, BENECKE 1985, GANSERT 1995) und die Verlagerung von $\mathrm{CO}_{2}$ mit dem Xylemsaft (NEGISI 1979, MARTIN et al. 1994, LEVY et al. 1999) vom Temperaturverlauf entkoppelt sein.

Abhängig von der Bezugsgröße (Oberfläche, Volumen, Splintholzvolumen, Trockengewicht, $\mathrm{N}$-Gehalt) variiert die spezifische $\mathrm{CO}_{2}$-Abgabe $\mathrm{zu}$ einem Zeitpunkt bei gleicher Temperatur zwischen verschiedenen Baumarten (RYAN 1990, LAVIGNE \& RYAN 1997), Individuen (NEGISI 1974, SPRUGEL 1990) und innerhalb eines Individuums mit dem Durchmesser (MÖLLER et al. 1954, NEGISI 1974) oder bei dem Vergleich verschiedener Organe (BENECKE 1985, SPRUGEL et al. 1996, RYAN et al. 1996) um bis zu zwei Größenordnungen (CESCHIA et al. 2002). Der Auswahl der geeigneten Bezugsgröße und der Berücksichtung der räumlichen Variabilität der spezifischen Atmungsrate kommt bei der Bilanzierung der Holzatmung eine entscheidende Bedeutung zu.

Der Notwendigkeit bei der Untersuchung des Kohlenstoffhaushalts von Bäumen Assimilations- und Biomassemessungen um solche der Holzatmung zu ergänzen trugen bereits JOHANSSON (1933), GEURTEN (1950) und MÖLLER et al.(1954) Rechnung. Erste Schätzungen des respirativen C-Bedarf ganzer Bäume oder Baumbestände auf Grundlage langfristiger Gaswechselmessungen stammen z. B. von WOODWELL \& BOTKIN (1970) und LINDER \& TROENG (1981). Neuere Studien, in denen die Atmung der verholzten Organe auf Bestandesebene extrapoliert wird, haben auch zum Ziel, die Ergebnisse mikrometeorologischer Untersuchungen des $\mathrm{CO}_{2}$-Austausches zwischen Waldökosystemen und der Atmosphäre (Eddy-Kovarianz-Methode) zu ergänzen (VALENTINI et al. 1996) oder zu validieren (GOULDEN et al. 1996b, LAVIGNE et al. 1997, LAW et al. 1999, GRANIER et al. 2000). Mit Ausnahme der Untersuchung von GRANIER et al. (2000) bleibt die räumliche Variabilität der Holzatmung insbesondere zwischen verschiedenen Organen meist unberücksichtigt.

Die überwiegende Zahl spezieller Untersuchungen zur Holzatmung unter Berücksichtigung der atmosphärischen $\mathrm{CO}_{2}$-Konzentration, des Wachstums oder der Stickstoffverfügbarkeit wurde an Koniferen durchgeführt. Die meisten Studien an Laubbäumen erlauben wegen der geringen zeitlichen Auflösung der Gaswechselmessung keine realistische Hochrechnung der Atmungsraten auf Baum- oder Bestandesebene (MÖLLER et al. 1954, STEINBORN et al. 1997), entbehren der biometrischen Grundlagen zur Extrapolation (BENECKE 1985) oder beschränken sich auf die Stammatmung (WOODWELL \& BOTKIN 1970, RYAN et al. 1994a, GOULDEN et al. 1996a). Umfassender sind die um die Grobwurzelatmung ergänzten Untersuchungen von (RYAN et al. 1997), die vollständige Erfassung der Atmung nicht grüner Organe von Jungbuchen (GANSERT 1995) sowie Studie von DAMESIN et al.(2002) zur oberirdischen Holzatmung 30-jähriger Buchen. 
In der vorliegenden Untersuchung wurde die Atmung von Stämmen, Ästen und Grobwurzeln zweier Altbuchenbestände (120 bzw. 150 Jahre) über einen Zeitraum von zwei Jahren gemessen. Die monatlichen Messungen an jedem Kompartiment umfassten zwei bis vierzehn vollständige Tagesgänge auf deren Grundlage der Einfluss der Holztemperatur, der Rindenphotosynthese und des $\mathrm{CO}_{2}$-Transportes mit dem Xylemsaft untersucht wurde. Die saisonal variierenden Temperaturbeziehungen wurden für die zeitliche Interpolation der gemessenen Atmungsraten herangezogen. Aus den Jahressummen von Atmung und Biomassezuwachs jeder Messstelle konnte der Wachstumskoeffizient $\mathrm{r}_{\mathrm{G}}$ ermittelt werden.

Der Vergleich der Atmungsraten der verschiedenen Organe mit Indikatoren für die Vitalität des Gewebes (z. B. Protein- oder Stickstoffgehalt) gab Hinweise auf die Ursachen für die räumliche Variabilität der Atmungsaktivität.

Für die Berechnung der Holzatmung auf Ebene des Bestandes wurden die Biomassevorräte der Untersuchungsbestände ermittelt und auf verschiedene Durchmesserklassen verteilt, so dass eine umfassende Berücksichtung der räumlichen Variabilität bei der Extrapolation möglich war.

Die vorliegende Studie war Bestandteil eines größeren Projekts, in dem zeitgleich auch alle anderen Komponenten der autotrophen Atmung, die photosynthetische Bruttoprimärproduktion, der Zuwachs und die Streuproduktion ermittelt wurden um vollständige Kohlenstoffbilanzen der beiden Altbuchenbestände aufzustellen. Die Jahressumme der Holzatmung der Bestände wurde den anderen Posten der C-Bilanz gegenübergestellt und ihre Bedeutung für den Kohlenstoffhaushalt diskutiert. 


\section{Die Untersuchungsflächen}

\subsection{Die topographische Lage der Untersuchungsflächen}

Solling Der Solling ist ein waldreicher Gebirgszug, der sich als Teil des Weserberglandes $80 \mathrm{~km}$ südlich von Hannover und östlich der Weser über $25 \mathrm{~km}$ in Nord-Süd- und über $30 \mathrm{~km}$ in Ost-WestRichtung erstreckt. Die Untersuchungsfläche liegt nahe der Ortschaft Silberborn im Forstamtsbezirk Neuhaus (Abt. 50, 51 46’ N, $9^{\circ} 35^{\prime}$ E) (Abb. 1). Sie befindet sich in einer Höhe von 510 ü.M. im Hochsolling, dessen höchste Erhebung, die Große Blöße, $528 \mathrm{~m}$ erreicht. Die Fläche ist mit 2 - $3^{\circ}$ leicht nach Südosten geneigt.

Bei dem ca. 1 ha großen umzäunten Areal handelt es sich um die Kernfläche B1 des SollingProjektes, auf der im Rahmen des Internationalen Biologischen Programms (IBP) schon seit Mitte der 60er Jahre intensive Untersuchungen zu unterschiedlichen Fragen der Waldökosystemforschung durchgeführt werden (ELLENBERG et al. 1986).

Göttinger Wald Die zweite Untersuchungsfläche liegt etwa $7 \mathrm{~km}$ östlich von Göttingen am östlichen Rand des Göttinger Waldes oberhalb der Ortschaft Mackenrode (51 $32^{\prime} \mathrm{N}, 10^{\circ} 03^{\prime} \mathrm{E}$ ). Die ebene Fläche gehört zum Forstamt Reinhausen (Abt. 166) und befindet sich in einer Höhe von 420 m ü.M. auf dem Plateau des Göttinger Waldes, dessen höchste Erhebungen, die Mackenröder Spitze und der Staneberg, mit $428 \mathrm{~m}$ und $426 \mathrm{~m}$ nur wenig höher reichen.

Die Untersuchungen wurden auf einem Teilstück des 12 ha umfassenden, eingezäunten Areals des ehemaligen Sonderforschungsbereichs „Ökosysteme auf Kalkgestein“ (SFB 135) der Universität Göttingen durchgeführt.

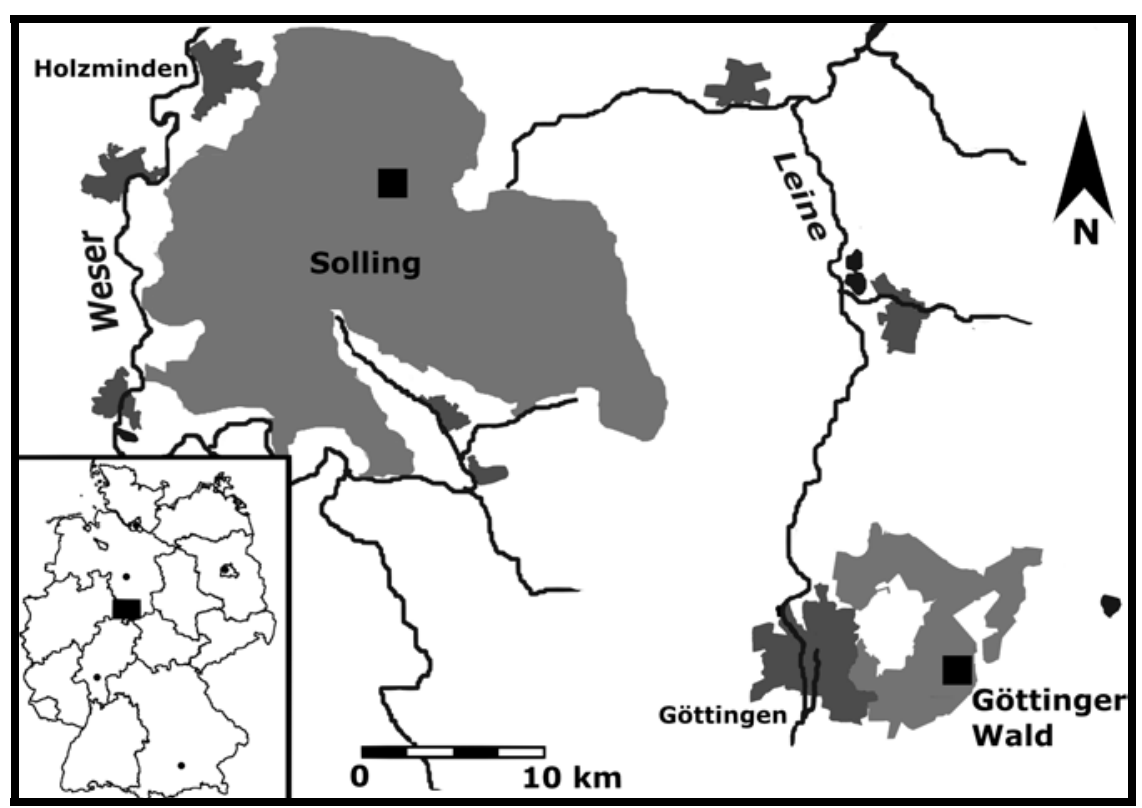

Abb. 1: Topographische Lage der Untersuchungsflächen $\mathbf{m}$ im Solling und im Göttinger Wald. 


\subsection{Geologie und Böden}

Solling Der Solling ist ein ausgedehntes Buntsandstein-Plateau, das sich etwa $200 \mathrm{~m}$ über das Umland erhebt. Es ist durchweg von unterschiedlich mächtigem, periglazial umgelagertem Löß überdeckt. Im Bereich der Untersuchungsfläche steht in ca. $1.5 \mathrm{~m}$ Tiefe das Gestein der „SollingFolge“ des mittleren Buntsandsteins an, das von zwei deutlich unterscheidbaren Fließerdeschichten überlagert wird. Die obere, 40 - $60 \mathrm{~cm}$ mächtige Schicht besteht aus locker gelagertem Löß, ihre Bodenart ist lehmiger bis toniger Schluff. Die untere Schicht ist aus dem Verwitterungsmaterial des anstehenden Buntsandsteins hervorgegangen. Sie besteht vorwiegend aus lehmigem Schluff bis schluffigem Lehm und ist mäßig bis stark steinig.

Auf diesem Ausgangsmaterial hat sich eine schwach podsolige und schwach pseudovergleyte Braunerde mit der Horizontabfolge $A_{(e) h}-B_{v}-C_{v}$ entwickelt. Sie wird von einer ca. $6 \mathrm{~cm}$ dicken organischen Auflage bedeckt, die sich in drei Horizonte $\mathrm{O}_{\mathrm{l}}, \mathrm{O}_{\mathrm{f}}$ und $\mathrm{O}_{\mathrm{h}}$ mit einer Mächtigkeit von 3, 2 und $1 \mathrm{~cm}$ untergliedert (U. BABEL in ELLENBERG et al. 1986) und als typischer bis rohhumusartiger Moder bezeichnet werden kann (ELLENBERG et al. 1986).

Der Boden ist durch eine tiefreichende Versauerung und Nährstoffarmut gekennzeichnet (MATZNER 1985). In wässriger Lösung wird ein pH-Wert von 3.7, 3.5 und 4.7 in der organischen Auflage, dem A- und dem B-Horizont gemessen (BARTSCH \& BAUHUS 1990). Der $\mathrm{pH}_{(\mathrm{KCl})}$ des Oberbodens liegt um 3.0. Nach der Klassifizierung von ULRICH (1981) befindet sich der Oberboden im Aluminium-Pufferbereich. Die Kationenaustauschkapazität beträgt 68-108 $\mu$ mol IÄ

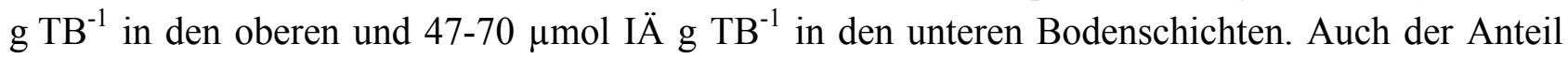
der $\mathrm{K}-$, $\mathrm{Ca}$ - und $\mathrm{Mg}$-Ionen an der $\mathrm{AK}_{\mathrm{e}}$ ist mit ca. $5 \%$ sehr gering.

Göttinger Wald Östlich des Leinetalgrabens haben sich auf den flach ansteigenden Schichten des Muschelkalks vor allem im Bereich des oberen und unteren Muschelkalks ebene Plateaus ausgebildet, an deren Rändern der Übergang von harten Kalken zu weichen Tonschichten zur Ausbildung charakteristischer Schichtstufen geführt hat. Im östlichen Teil des Göttinger Waldes, in dem auch die Untersuchungsfläche liegt, bildet der untere Muschelkalk eine ausgedehnte Hochfläche, die nach Osten von einer steilen Abbruchkante zum oberen Buntsandstein, dem Röt, begrenzt wird (NAGEL \& WUNDERLICH 1976).

Auf der Untersuchungsfläche hat sich ein kleinräumiges Mosaik verschiedener Bodentypen der Muschelkalk-Bodengesellschaften entwickelt. Dort, wo das Substrat der Bodenbildung überwiegend aus der periglazialen Muschelkalk-Frostschuttdecke bestand, entwickelte sich eine flachgründige Rendzina. Wurden in Klüften tertiäre und pleistozäne Verwitterungsrückstände akkumuliert und von pleistozänem Frostschutt überdeckt, bildeten sich Terra fusca-Rendzinen. In tiefgründigeren Bereichen haben sich neben dem Bodentyp der Terra fusca bei hoher Lößbeteilung kleinräumig auch Braunerden ausgebildet (MEIWES et al. 1981). Das Feinbodenmaterial des $\mathrm{A}_{\mathrm{h}}$-Horizontes besteht aus tonigem Schluff, sein Skelettanteil liegt in $25 \mathrm{~cm}$ Tiefe bei etwa $20 \%$. Auf dem nährstoffreichen und intensiv von Bodenorganismen durchgearbeitetem Mineralboden ist als organische Auflage nur eine dünne $\mathrm{O}_{\mathrm{l}}$-Schicht vorhanden. Die Humusform ist als L-Mull zu beschreiben.

Die bodenchemische Situation stellt einen deutlichen Gegensatz zu der des Bestandes im Solling dar. So liegt der $\mathrm{pH}_{(\mathrm{KCl})}$-Wert der Rendzina im neutralen Bereich des Carbonat-Puffersystems

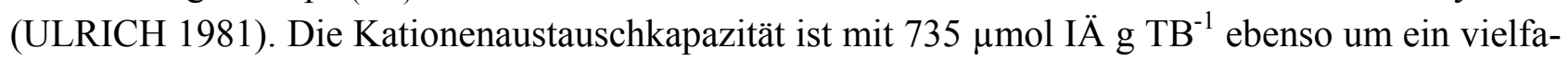


ches höher als im Solling wie der Anteil der K-, Mg- und Ca-Ionen an der $\mathrm{AK}_{\mathrm{e}}$, der nahezu 100 \% beträgt.

\title{
2.3 Regionalklima und Witterung im Untersuchungszeitraum
}

Solling Im Hochsolling herrscht ein kühlgemäßigtes, subozeanisches Klima. Die Höhenlage am Nordrand der deutschen Mittelgebirge bedingt eine niedrige Jahresmitteltemperatur $\left(6.9^{\circ} \mathrm{C}\right)$ und hohe, relativ gleichmäßig über das Jahr verteilte Niederschläge $(1031 \mathrm{~mm})$, die den montanen Charakter des Klimas im Hochsolling unterstreichen (Abb. 2). Der Januar ist mit einer mittleren Temperatur von $-1.4{ }^{\circ} \mathrm{C}$ der kälteste Monat, das Temperaturmaximum von $15.1{ }^{\circ} \mathrm{C}$ fällt in den Juli. Hohe Niederschläge und das Ausbleiben längerer Trockenperioden in den Sommermonaten machen den Solling $\mathrm{zu}$ einem gut wasserversorgten Standort. Eine geringe Anzahl von Sommertagen (10 - 20 Tage mit $\left.\mathrm{T}>25^{\circ} \mathrm{C}\right)$ und moderate Sommertemperaturen halten auch die Transpirationsbeanspruchung in Grenzen.
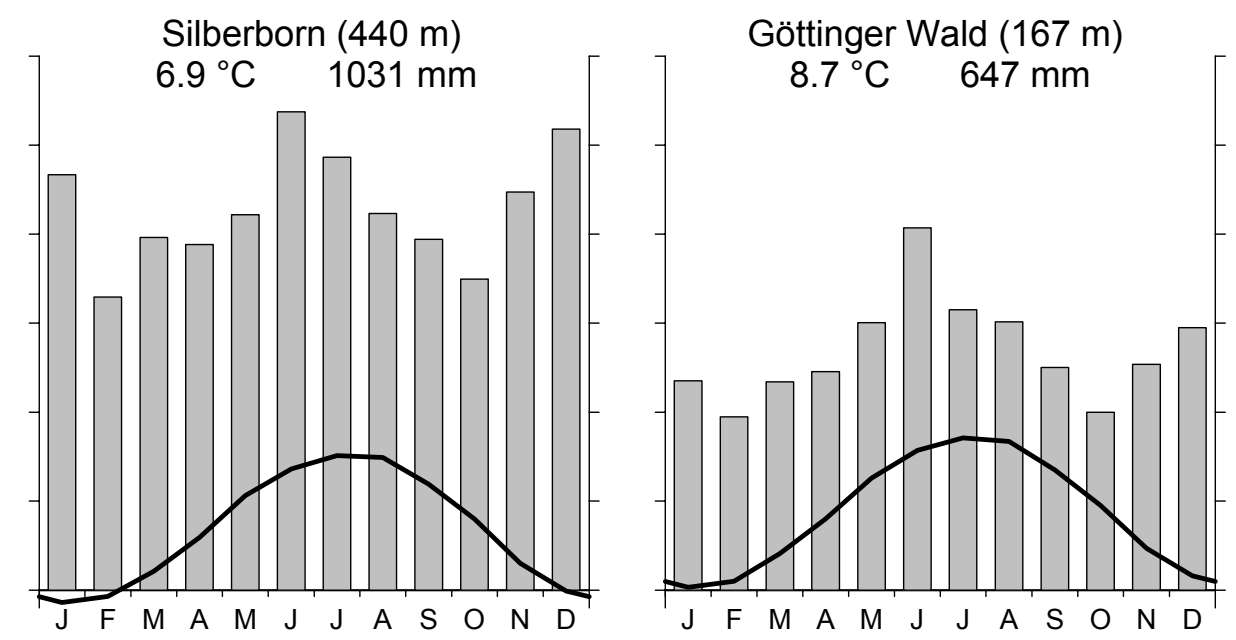

\begin{abstract}
Abb. 2: Klimadiagramme der Wetterstationen Silberborn und Göttingen: Mittelwerte der Jahre 1961-1990 (DEUTSCHER WETTERDIENST 1999)(ein Teilstrich $=10^{\circ} \mathrm{C}$ bzw. $20 \mathrm{~mm}$ Niederschlag).
\end{abstract}

Die Jahresmitteltemperatur lag 1997 knapp 1 K über, die Niederschlagsmenge leicht unter den langjährigen Mittelwerten (Tab. 1). Der Jahresverlauf zeichnete sich durch einen trockenen, zunächst kalten, im weiteren Verlauf milden Winter, einen durchschnittlich warmen und mäßig trockenen Frühling und einen warmen, mäßig feuchten Frühsommer aus. Auf einen außergewöhnlich heißen und trockenen August folgte ein mäßig kühler, trockener Herbst.

Im Jahr 1998 lag das Temperaturmittel nur wenig unter dem des Vorjahres. Der Witterungsverlauf unterschied sich bei hohen Niederschlägen vor allem in der zweiten Jahreshälfte sehr deutlich von 1997. Einem milden Winter mit durchschnittlichem Niederschlag folgte ein feuchter, warmer Frühling. Bis in den Juni hinein lagen die Temperaturen stets über dem langjährigen Mittel. Der Hochsommer hingegen war relativ kühl und mäßig feucht. Im niederschlagsreichen September und Oktober kühlte sich die Luft rasch ab. Mitte November setzte eine kalte Wetterperiode mit häufigen Frösten ein, die kurz vor dem Jahreswechsel endete (Abb. 3). 
Göttinger Wald klimatisch liegt der Göttinger Wald in einem Übergangsbereich von subozeanischem zu subkontinentalem Charakter. An der Wetterstation Göttingen (167 m) beträgt das Jahres-
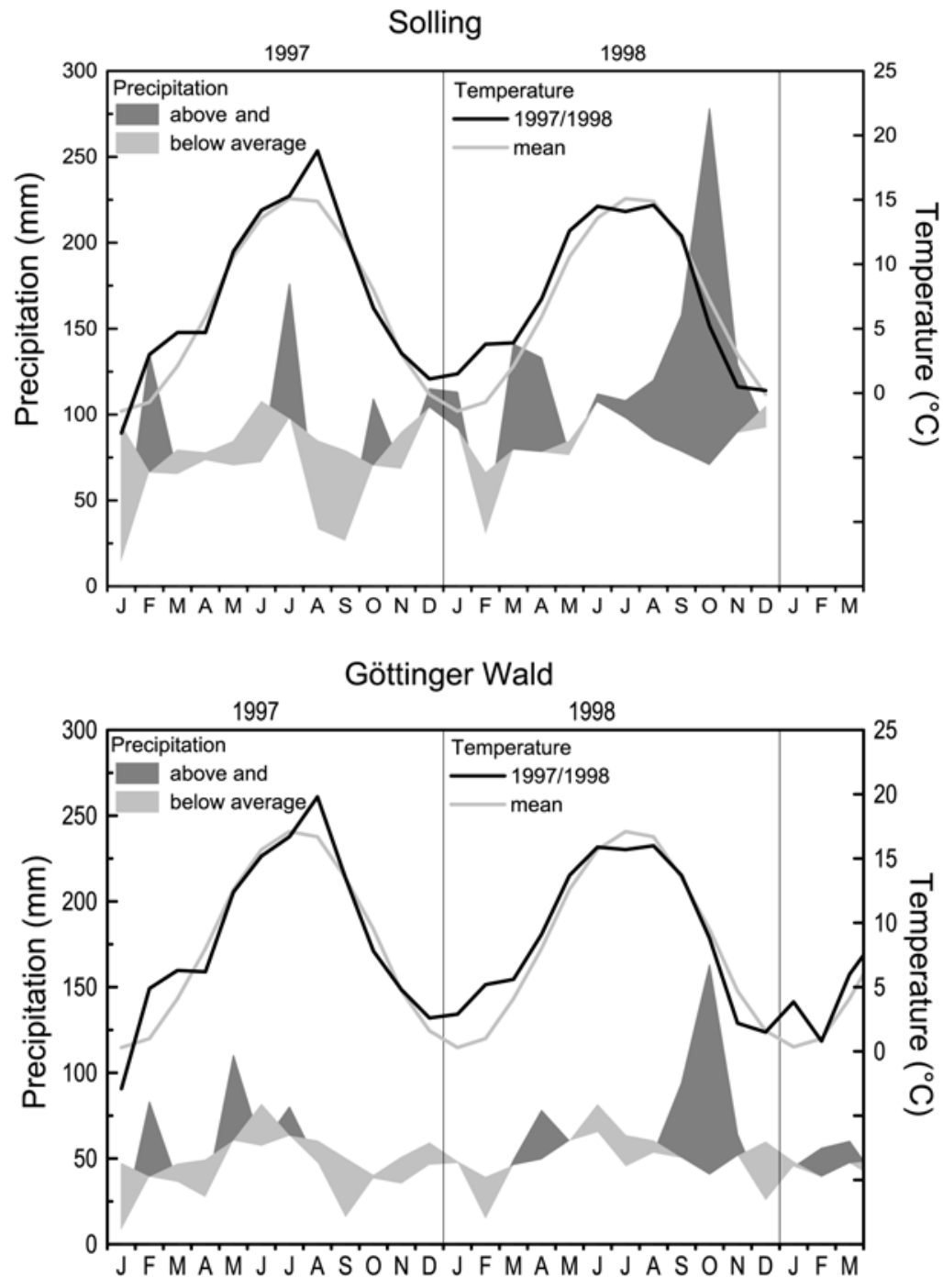

Abb. 3: Jahresverlauf der Monatsmittelwerte der Temperatur und der monatlichen Niederschläge in den Jahren 1997 und 1998 im Vergleich mit dem Werten langjähriger Messungen. mittel der Lufttemperatur $8.7^{\circ} \mathrm{C}$ und die Temperaturspanne der Monatsmittel reicht von $0.3{ }^{\circ} \mathrm{C}$ im Januar bis $17.1{ }^{\circ} \mathrm{C}$ im Juli. An der im Vergleich zum Solling deutlich niedriger gelegenen Station beträgt die jährliche Niederschlagsmenge $646 \mathrm{~mm}$, deren Verteilung mit einem deutlichen Maximum im Sommer und einem schwächer ausgeprägtem Niederschlagsmaximum im Winter einen leicht kontinentalen Einfluss erkennen lässt (Abb. 2). In der Zeit von Mai bis Oktober fallen $55 \%$ der jährlichen Niederschlagsmenge.

Auf dem $250 \mathrm{~m}$ höher gelegenen Plateau des Göttinger Waldes ergeben sich abweichende Temperaturund Niederschlagswerte. Die auf der Untersuchungsfläche in den Jahren 1997 und 1998 gemessenen Lufttemperaturen liegen $1.7 \mathrm{~K}$ unter den Angaben für die Wetterstation Göttingen. Eggert (1985) und Schipka (2003) geben für die Jahre 1981 1984 und 1995 - 1997 vergleichbare Temperaturabweichungen (-1.7 und $-1.3 \mathrm{~K}$ ) an, so dass die Differenz auch für das langjährige Mittel Bestand haben dürfte. Mehrjährige Niederschlagsmessungen der Niedersächsischen Forstlichen Versuchanstalt auf dem Kerstlingeröder Feld in etwa gleicher Höhe mit der Untersuchungsfläche ergeben mittlere Niederschlagsmengen von $710 \mathrm{~mm}$ pro Jahr. Anders als bei den Werten für die Wetterstationen Silberborn/Holzminden und Göttingen sind die Temperaturunterschiede zwischen den Untersuchungsflächen weniger ausgeprägt, die Differenz der Niederschlagssummen hingegen ist fast ebenso hoch wie bei den Stationen.

Die für den Untersuchungszeitraum charakteristischen Witterungsverläufe sind im Göttinger Wald denen des Sollings ähnlich, die Abweichungen vom Verlauf der langjährigen Monatsmittel jedoch weniger ausgeprägt als im Solling. Im Göttinger Wald begann das Jahr 1997 ebenfalls trocken und kalt. Der ungewöhnlich milden zweiten Hälfte des Winters folgte ein mäßig warmer und mäßig feuchter Frühling und Frühsommer. Nach dem heißen und trockenen August herrschten im Herbst und Winter durchschnittliche Temperaturen bei vergleichsweise geringen Niederschlägen. 
Auch im Göttinger Wald war 1998 die erste Jahreshälfte wärmer und durchschnittlich feucht und der Sommer kühler als im langjährigen Mittel. Im feuchten September und regenreichen Oktober, in dem das Niederschlagsaufkommen das langjährige Mittel um das vierfache überstieg, fielen die Temperaturen rasch ab, so dass ab Mitte November mehrtägige Fröste auftraten.

Die Strahlungssummen, in Tab. 1 als Summen der photosynthetisch aktiven Strahlung angegeben, unterschieden sich zwischen den Standorten unabhängig vom betrachteten Zeitraum nur geringfügig. Entsprechend der größeren Zahl an Regentagen bleibt die Strahlungssumme im Jahr 1998 deutlich hinter der des Vorjahres zurück.

Tab. 1: Vergleich der Temperaturmittelwerte und Niederschlagssummen der Wetterstationen Silberborn und Göttingen für die Untersuchungsjahre 1997 und 1998 und dem langjährigen Mittel. Die photosynthetisch aktive Strahlung (PAR) wurde auf den Untersuchungsflächen selbst gemessen. Die Sensoren waren oberhalb des Kronedachs in $30 \mathrm{~m}$ (Solling) und $42 \mathrm{~m}$ (Göttinger Wald) installiert. Für die Messjahre charakteristische Abweichungen vom langjährigen Mittel sind grau hinterlegt und in Fettdruck.

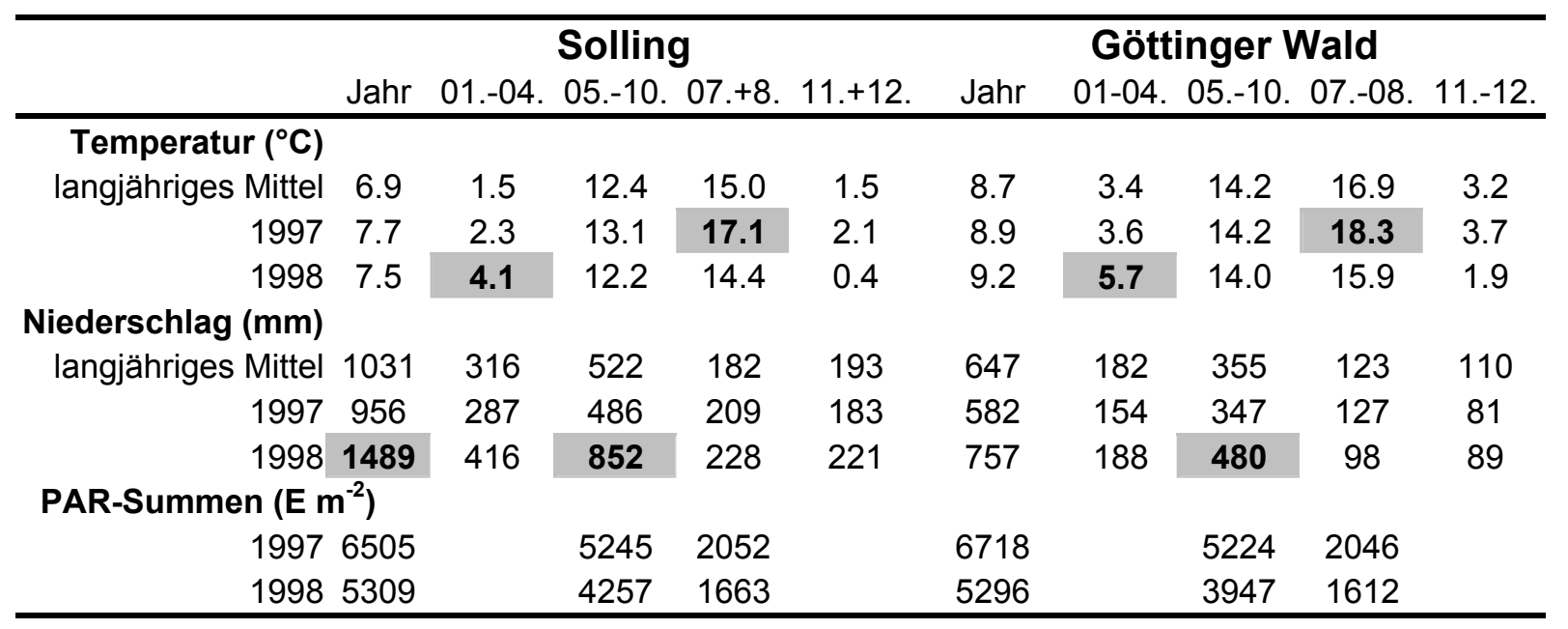

\subsection{Vegetation und Bestandesstruktur}

Solling Der Wald im Solling ist ein ca. 150 Jahre alter Buchenreinbestand, der aus Naturverjüngung hervorgegangen ist. Die Bäume erreichen heute eine mittlere Höhe von gut $29 \mathrm{~m}$ und bilden ein Kronendach, das in einigen Bereichen Lücken durch das Absterben einzelner Bäume aufweist. In diesen Bereichen kommt Jungwuchs von Buche und Fichte auf. Dort, wo das Kronendach geschlossen ist, ist keine Strauchschicht ausgebildet und die Krautschicht ist artenarm und lückig. Luzula luzuloides, Avenella flexuosa und Oxalis acetosella sind am häufigsten, Carex pilulifera und Dryopteris carthusiana sind in geringerer Zahl anzutreffen. Pflanzensoziologisch ist der Bestand als Luzulo-Fagetum typicum einzuordnen (ELLENBERG et al. 1986) und entspricht weitgehend der natürlichen Vegetation dieses Standortes.

Der seit den 40er Jahren nicht mehr durchforstete Bestand weist mit 212 Stämmen pro Hektar eine hohe Stammdichte und mit $47 \mathrm{~cm}$ einen hohen mittleren BHD auf. Bei sehr sporadisch aufkommendem Jungwuchs weisen nur wenige unterdrückte Bäume (6\%) einen BHD unter $30 \mathrm{~cm}$ auf.

Göttinger Wald Auf dem nährstoffreichen Standort im Göttinger Wald stockt ein 110 - 125 Jahre alter baum- und krautartenreicher Buchenwald. Neben der herrschenden Buche sind mit ca. $6 \%$ aller Stämme Fraxinus excelsior, Acer platanoides, A. pseudoplatanus, Quercus robur, Q. petraea 
und Ulmus glabra am Aufbau des Kronedachs beteiligt. Eschen und der Jungwuchs der beiden Ahorn-Arten bilden eine lückige, aber gleichmäßig verteilte Strauchschicht. Typischer Weise tritt eine sehr dichte, artenreiche Krautschicht auf, in der Geophyten wie Allium ursinum, Anemone nemorosa, A. ranunculoides, Arum maculatum und Ranunculus auricomus den Frühjahrsaspekt bilden. Im Frühsommer kommen Dentaria bulbifera, Lathyrus vernus, Lilium martagon, Mercurialis perennis, Polygonatum multiflorum und Primula elatior zur vollen Entwicklung, um im Sommer von Asarum europaeum, Dryopteris filix-mas, Galium odoratum, Hordelymus europaeus, Lamium galebodolon, Oxalis acetosella abgelöst zu werden. Pflanzensoziologisch ist der Bestand im Göttinger Wald dem Hordelymo-Fagetum zuzuordnen (DIERSCHKE \& SONG 1982).

Werden nur die Bäume der herrschenden Baumschicht zusammengefasst, erreichen die Buchen im Göttinger Wald mit durchschnittlich $34 \mathrm{~m}$ eine deutlich größere Höhe als die Buchen im Solling und einen vergleichbaren mittleren BHD $(47 \mathrm{~cm})$. Die Stammzahl der herrschenden Baumschicht bleibt mit 181 hinter der des Solling zurück. Der Anteil der Stämme mit einem BHD zwischen 10 und $30 \mathrm{~cm}$ ist im Göttinger Wald bei regelmäßiger aufkommendem Jungwuchs deutlich höher (15\%) als im Solling.

Tab. 2: Vergleich einiger Rahmendaten zur Bestandesstruktur der beiden untersuchen Buchenbestände. BHD und Höhe nach Angaben der Niedersächsischen Forstlichen Versuchsanstalt 1996. LAI aus Hertel (1999). Zu den Biomassevorräten siehe Kap. 4.3 und Tab. 9.

\begin{tabular}{rll}
\hline & Solling & Göttinger Wald \\
\hline Alter $^{*}$ & 150 & 120 \\
Stammzahl & $200(217)$ & $181(251)$ \\
mittlere Höhe $(\mathrm{m})^{*}$ & 29.5 & 34 \\
mittlerer BHD $\left(\mathrm{cm}^{*}\right.$ & $47(45)$ & $47(41)$ \\
LAl $\left(\mathrm{m}^{2} \mathrm{~m}^{-2}\right)$ & 6.5 & 6.3 \\
\hline
\end{tabular}

*Angaben für die herrschende Baumschicht, in Klammern alle Bäume 


\section{Methoden}

\subsection{Die Dauermessung der Holzatmung}

\subsubsection{Das Messprinzip}

Zur kontinuierlichen Messung der $\mathrm{CO}_{2}$-Abgabe verholzter Baumorgane wurde eine Weiterentwicklung des Mehrkanal-Küvetten-Messsystems eingesetzt, das von Kakubari (1988) am Geobotanischen Institut der Universität Göttingen konzipiert und 1986 erstmals zur Messung der Holz- und Feinwurzelatmung im Solling verwendet wurde. Im Rahmen der vorliegenden Untersuchung wurde die von GRIES (2004, in Vorb.) entwickelte Atmungsmessanlage verwendet, mit der die kombinierte Messung der Holzatmung im kontinuierlichen Luftstrom und der Feinwurzelatmung im Anreicherungsverfahren möglich war. Im Folgenden wird lediglich die Messung der Holzatmung beschrieben.

Die $\mathrm{CO}_{2}$-Abgabe der verholzten Kompartimente wurde im offenen System gemessen. Hierfür wurden an Stämmen, Ästen und Grobwurzeln Messküvetten installiert und über Schlauchleitungen mit der Messanlage verbunden. Aus der Umgebung angesaugte Luft wurde durch die Messanlage zu den Küvetten geleitet, die kontinuierlich von Luft durchströmt wurden. Das darin eingeschlossene, atmende Gewebe reicherte die Luft mit $\mathrm{CO}_{2}$ an, die zurück zur Messanlage und dort zur Bestimmung der absoluten $\mathrm{CO}_{2}$-Konzentration $\left(=\left[\mathrm{CO}_{2}\right]\right)$ durch einen Infrarot-Gasanalysator (IRGA) gleitet wurde. Im Wechsel mit dem Messgas aus den Küvetten wurde als Referenz die $\left[\mathrm{CO}_{2}\right]$ von Luft bestimmt, die mit Ausnahme der zwischengeschalteten Küvette den gleichen Luftweg wie das Messgas, d.h. Messanlage - Schlauchleitung - Messanlage und $\mathrm{CO}_{2}$-Analysator passierte.

Aus der Differenz der $\left[\mathrm{CO}_{2}\right]$ in Mess- und Referenzgas und über die Flussrate der Luft in den Küvetten wurde die $\mathrm{CO}_{2}$-Abgabe pro Zeiteinheit ermittelt. Die spezifische Atmungsrate des beprobten Ast-, Stamm- oder Grobwurzelsegments wurde als Quotient zwischen $\mathrm{CO}_{2}$-Abgabe pro Zeiteinheit und der Oberfläche oder dem Gesamt- oder Splintholzvolumen des beprobten Segments berechnet.

\subsubsection{Apparativer Aufbau}

Der Aufbau der Messanlage ist in Abb. 4 dargestellt. Zur Dämpfung kurzfristiger Schwankungen der $\mathrm{CO}_{2}$-Konzentration wurde die Umgebungsluft von der Pumpe durch ein 50 Liter fassendes Puffergefäß angesaugt und nach dem Passieren eines Kondensatabscheiders der Messanlage zugeführt. Die Anlage verteilte die Luft auf 6 Messkanäle sowie einen Referenzkanal und schaltete diese im Wechsel auf den Gasweg zur Messung von Durchflussrate und $\mathrm{CO}_{2}$-Konzentration. Während der Messung erfasste je ein thermoelektrischer Massenflussmesser (WFM011, Manger \& Wittmann, Garching) die Gasmenge, die von der Anlage zur Küvette gepumpt und die Menge, die von der Küvette zurückgeleitet wurde. Das Messgas aus der Küvette strömte vor dem Eintritt in die Messanlage durch einen Kondensat- und Staubabscheider und schließlich durch den Infrarot-Gasanalysator (LI6262, LICOR, Lincoln, NE, USA), der die $\mathrm{CO}_{2}$-Konzentration erfasste.

Der Luftdurchfluss jedes Kanals wurde mittels Nadelventilen so eingestellt, dass die maximal zu erwartende $\mathrm{CO}_{2}$-Konzentration innerhalb des Messbereich des IRGA $\left(\left[\mathrm{CO}_{2}\right]_{\max .}=1500 \mu \mathrm{mol} / \mathrm{mol}\right)$ 
lag. Dazu waren Flussraten zwischen 0.5 und $1.01 \mathrm{~min}^{-1}$ erforderlich. Durch die Pneumatik der Messanlage war sichergestellt, dass zu jeder Zeit, also während der Messung und in den Messpausen, eine konstante Gasmenge durch die Küvette gepumpt wurde. Somit konnte sich zwischen $\mathrm{CO}_{2}$-Konzentration im Holz- und Rindengewebe, der Luft in der Küvette und dem rückführenden Gasweg ein Gleichgewicht einstellen. Dieses ist für die korrekte Bestimmung der $\mathrm{CO}_{2}$ Abgabe eine unabdingbare Voraussetzung, da nach dem Verstellen der Flussrate erst nach 3 bis 20 min eine konstante $\mathrm{CO}_{2}$-Konzentration gemessen wurde. Die Antwortzeit des Systems hing von der Flussrate und dem Gesamtvolumen des Gasweges (Küvette, Schlauchleitung, Anlage) ab, das zwischen 1.0 und 11.0 Litern lag. Kurzfristige oder kontinuierliche Änderungen der Flussraten würden dann zur fehlerhaften Bestimmung der Atmungsrate führen, wenn die Messung von Flussrate und $\left[\mathrm{CO}_{2}\right]$ erfolgt, bevor das Gasvolumen in der Küvette und der rückführenden Schlauchleitung vollständig ausgetauscht ist und sich eine Gleichgewichts- $\mathrm{CO}_{2}-\mathrm{Konzentration}$ eingestellt hat.

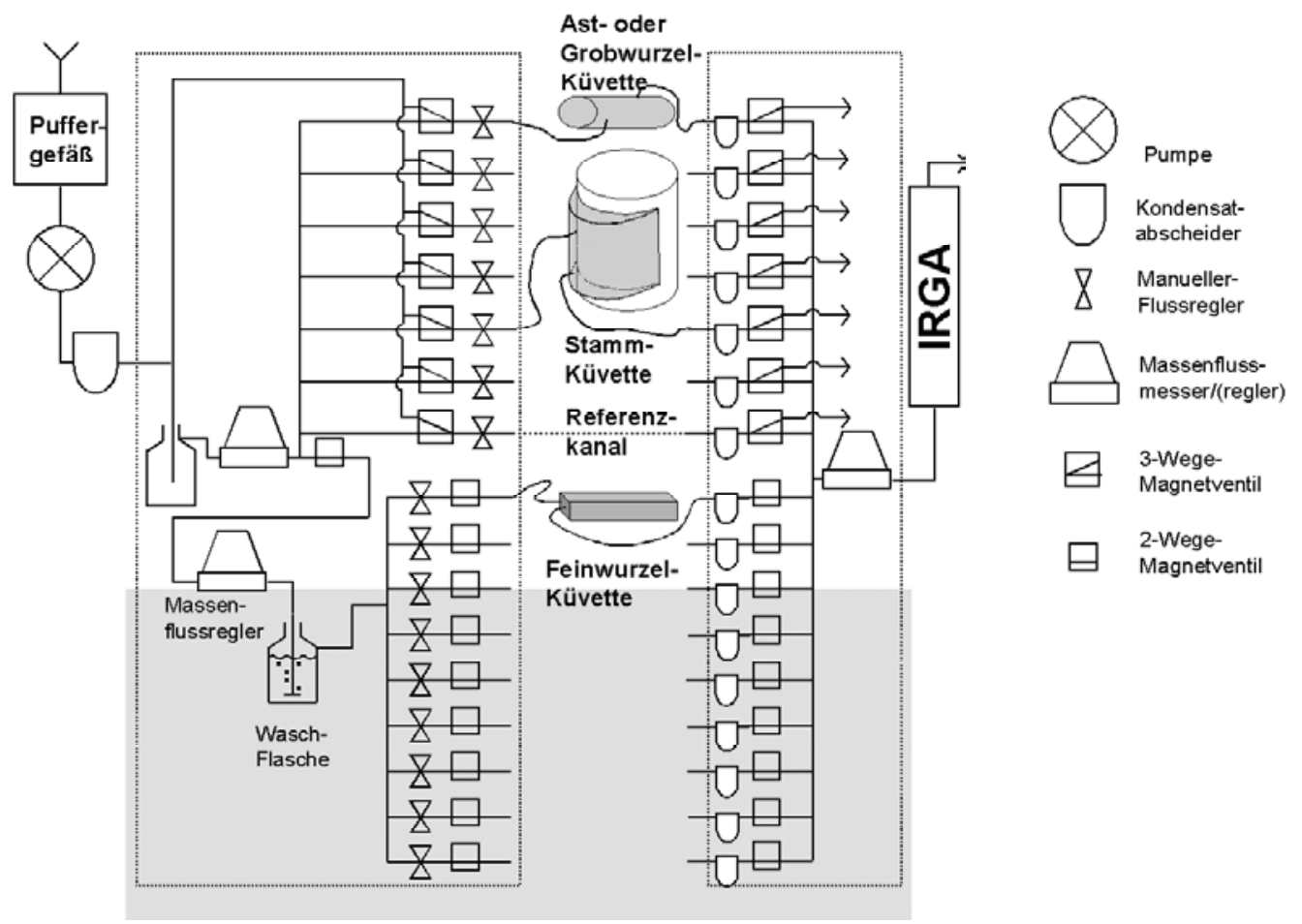

\begin{abstract}
Abb. 4: vereinfachtes Schaubild des Mehrkanal-Küvettensystems zur Erfassung der $\mathrm{CO}_{2}$-Abgabe von Ästen, Stämmen und Grobwurzeln bei kontinuierlichem Luftstrom und von Feinwurzeln im Anreicherungsverfahren (grau hinterlegt, zur Messung der Feinwurzelatmung siehe GRIES (2004, in Vorb.)(nach GRIES 2004, in Vorb., verändert)
\end{abstract}

Die Luft wurde durch je $50 \mathrm{~m}$ lange PVC-Schläuche $\left(\mathrm{D}_{\mathrm{a}}=8 \mathrm{~mm}, \mathrm{D}_{\mathrm{i}}=5 \mathrm{~mm}\right)$ von der Anlage zu den Küvetten und wieder zurück geleitet. Die Küvetten für die Äste und Grobwurzeln bestanden aus längs aufgesägten, aufklappbaren Plexiglasrohren (SPRUGEL \& BENECKE 1991). Sie hatten eine Länge von $40 \mathrm{~cm}$ und je nach Durchmesser des zu beprobenden Ast- bzw. Grobwurzelabschnitts Innendurchmesser von $4-15 \mathrm{~cm}$. Die Enden wurden mit schlauchförmig verklebten Manschetten aus Zellkautschuk (Länge ca. $10 \mathrm{~cm}$ ) gegen die Küvetten- und Ast- bzw. Grobwurzeloberfläche mit Schlauchschellen gasdicht verschlossen. Neben den um $25 \mathrm{~cm}$ versetzt und gegenüberliegend angeordneten Anschlüssen für den zu- und abführenden Schlauch wurde das Kabel des Temperatursensors durch eine weitere gasdicht verschlossene Öffnung ins Innere der Küvette geleitet. 
Die Küvetten für die Messung der Stammatmung bestanden aus längs halbierten Plexiglasrohren (Höhe $=29.5 \mathrm{~cm}$, Breite $=34.5 \mathrm{~cm}$ ) deren Stirnseiten durch plane Plexiglasplatten verschlossen waren. Diese Platten wurden durch Aussägen von Kreissegmenten individuell an die Kontur des Stammes an der Messstelle angepasst und die Küvetten mit Spanngurten auf eine Dichtung aus Zellkautschuk und Baumharz gegen die Stammoberfläche gepresst. Sie wiesen ebenso wie die Astküvetten Anschlüsse für die Schlauchleitungen und das Kabel des Temperatursensors auf.

Durch die Aufzeichnung der von der Anlage zur Küvette gepumpten Luftmenge und der Menge, die von der Küvette in die Anlage gelangte, wurde der gesamte Gasweg dauernd auf Lecks überwacht. Der IRGA wurde wöchentlich mit $\mathrm{N}_{2}$ und Eichgas $\left(\left[\mathrm{CO}_{2}\right]=800 \mathrm{ppm} \pm 0.5 \mathrm{ppm}\right)$ kalibriert.

\subsubsection{Ablauf der Messung an einer Küvette}

Mit Hilfe eines Campbell CR-10 Daten-Loggers (Campbell Scientific Inc., Leicestershire, UK) wurde die Messanlage gesteuert und die Daten aufgezeichnet. Während eines 30 bzw. 60 Minuten dauernden Messzyklus wurde jeder der 6 Kanäle für die Holzatmung (und 9 Feinwurzelkanäle) jeweils im Wechsel mit dem Referenzkanal gemessen.

Die Beprobung und Datenerfassung eines Kanals verlief nach folgendem Schema:

1. Messung der $\mathrm{CO}_{2}$-Konzentration und der Durchflussrate im Referenzkanal über 20 Sekunden. Erfassung von 5 Konzentrationswerten und der Flussrate während der letzten 5 Sekunden und Speicherung der Mittelwerte.

2. Messung der $\mathrm{CO}_{2}$-Konzentration der zu beprobenden Küvette:

a. Umschalten des Messweges der zu beprobenden Küvette auf Massenflussmesser und IRGA.

b. Registrieren der Temperaturen aller Thermistoren (Kap. 3.2.1). Berechnung und Speicherung des Temperaturmittelwertes des aktuell zu messenden Kanals aus 16 Einzeltemperaturen der vorangegangenen 30 bzw. 60 Minuten. Während der Dauer der Temperaturmessung (16 Sekunden) wurde die Messkammer des IRGA mit Messgas bis zum Erreichen einer konstanten $\mathrm{CO}_{2}$-Konzentration gespült.

c. fünfmalige Messung der $\mathrm{CO}_{2}$-Konzentration und der Flussraten und Speicherung des Mittelwertes von $\left[\mathrm{CO}_{2}\right]$ und Flussrate (Dauer $5 \mathrm{~s}$.).

In einem Messzyklus wurde für jede Küvette ein Datensatz aufgenommen, der aus folgenden Werten bestand:

Messkanalnummer, Zeit (Jahr, Julianischer Tag, Ortszeit), Xylemtemperatur $\left({ }^{\circ} \mathrm{C}\right)$ der Probe in der Küvette, Flussrate des hin- und rückführenden Anteils des Referenzkanals, $\left[\mathrm{CO}_{2}\right]$ des Referenzkanals, Flussrate zur Küvette und Flussrate von der Küvette zur Anlage (1/min) sowie $\left[\mathrm{CO}_{2}\right]$ des Messkanals ( $\mu \mathrm{mol} / \mathrm{mol})$.

Pro Tag und Kanal bzw. Messstelle wurden abhängig von der Dauer des Messzyklus 24 bis 48 Datensätze aufgenommen. Auf dem Speichermodul des Daten-Loggers konnten Datensätze von 7bzw. 14-tägigen Messkampagnen gespeichert werden. Diese wurden auf einen PC übertragen und mit einem BASIC-Programm vorausgewertet.

\subsubsection{Auswahl und Einrichtung der Dauermessstellen}

Die Dauermessstellen wurden ausschließlich an Bäumen der herrschenden Baumschicht eingerichtet. Für die Auswahl der Messstellen an den verschiedenen Organen galten folgende Kriterien: Die beprobte Sprossachse sollte eine glatte homogene Oberfläche besitzen und keine Verlet- 
zungen, Verzweigungen oder Narben abgestorbener Äste aufweisen. Sie sollte frei von Moosbewuchs oder epiphytischen Algen oder Flechten sein. Die Grobwurzeln mussten ausreichend oberflächennah aufzufinden sein, um eine übermäßige Störung des Bodens auf den Untersuchungsflächen beim Freilegen der Wurzeln zu vermeiden. Die Äste mussten für die Installation der Küvetten vom Messturm oder mit dem Hubwagen und später für Wartungsarbeiten und das Ablesen der Zuwachsmaßbänder mindestens durch Seilklettertechnik ausreichend leicht erreichbar sein.

Vor der Installation der Küvetten wurden die freigelegten Grobwurzeln mit Wasser gewaschen und anhaftender Boden mit einer Bürste entfernt. Bei den Stämmen und Ästen wurden die Oberflächen vor dem Anbringen der Küvetten mit einer Drahtbürste von Staub und evtl. anhaftenden Algen befreit.

Oberfläche und Volumen wurden aus dem Umfang und aus dem Abstand zwischen den Schlauchschellen (Ast und Grobwurzeln) berechnet. Bei den in 1.5 - $2.5 \mathrm{~m}$ Höhe installierten Stammküvetten wurde der Stammumfang auf mittlerer Höhe der Küvetten, deren Länge und der von den Küvetten eingeschlossene Kreisbogen an der Ober- und Unterkante ermittelt.

Innerhalb jeder Küvette war ein Temperaturfühler in das oberflächennahe Xylem eingebracht und unterhalb der Messstelle ein hochauflösendes Zuwachsmaßband (Kap. 3.2.2) installiert.

\subsubsection{Beschreibung der Dauermessstellen}

Zur Untersuchung der räumlichen Variabilität der Atmungsaktivität wurden auf beiden Untersuchungsflächen Dauermessstellen an je 6 Ästen, Stämmen und Grobwurzeln eingerichtet und deren Oberfläche, Volumen und Durchmesser bestimmt. Außerdem wurde die Variabilität innerhalb eines Stammes an jedem Standort an einem Baum mit jeweils sechs Messstellen untersucht. Diese befanden sich in drei verschiedenen Höhenstufen: 1.3 m über dem Boden nahe der Stammbasis, im mittleren Bereich des Stammes und knapp unterhalb des Kronenansatzes. In jeder Höhenstufe war eine Messstelle in nördliche und eine weitere in südliche Richtung exponiert.

Bei den Ästen wurden außerdem Angaben zur Position der Messstelle in der Krone wie die absolute Höhe über dem Boden, der Neigungswinkel gegenüber der Horizontalen und die Orientierung der Längsachse festgehalten. Strukturparameter der Äste wie das Kronenvolumen distal der Messstelle konnten aufgrund der eingeschränkten Zugänglichkeit der Krone und der teils großen Ausdehnung der Äste in vivo nicht quantitativ erfasst werden. Eine vollständige Ernte der Äste verbot sich aus Gründen der Nachhaltigkeit, da die von den Messtürmen aus zugänglichen Bäume bis zu 20 \% ihrer Krone eingebüßt hätten. Stattdessen wurde der Ast oberhalb der Messstelle halbquantitativ hinsichtlich seiner Kronenposition und seines Volumens klassifiziert. Hierfür wurden folgende Klassen definiert:

1. Kronenniveau (Crown level, CL): der wesentliche Anteil des von dem Ast eingenommenen Kronenvolumens befand sich:

- in der Schattenkrone :

CL 1

- im mittleren Kronendrittel :

CL 2

- in der Sonnenkrone :

CL 3

2. Kronenvolumen (Crown volume, $\mathrm{CV}$ ): der Ast hat am Kronenvolumen einen:

- geringen Anteil, Länge des laubtragenden Bereichs < $1.5 \mathrm{~m}$ :

CV 1

- mittleren Anteil, Länge des laubtragenden Bereichs 1.5 - $4 \mathrm{~m}$ : $\quad$ CV 2

- wesentlichen Anteil, Länge des laubtragenden Bereichs $>4 \mathrm{~m}$ : $\quad$ CV 3

Die Kenngrößen aller Dauermessstellen sind in Tab. 3 a und b zusammengefasst. 
Tab. 3 a: Kenndaten der Dauermessstellen im Solling. Neben den in den Küvetten eingeschlossenen Oberflächen und Volumina der Sprossachsen ist der Durchmesser, die mittlere Höhe der Messstelle über dem Boden, die Exposition der Stammküvetten, die Längsorientierung der Äste und ihr Abweichungswinkel von der Horizontalen angegeben. $\left(\mathrm{S}_{\mathrm{V}}=\right.$ Stämme, an denen die Atmung im vertikalen Profil untersucht wurde).

\begin{tabular}{|c|c|c|c|c|c|c|c|c|c|c|c|c|}
\hline Solling & \multicolumn{6}{|c|}{ Stämme S } & \multicolumn{6}{|c|}{$\begin{array}{l}\text { Stämme } S_{v} \text {, Höhenprofil und } \\
\text { Exposition an einem Stamm }\end{array}$} \\
\hline \multirow{2}{*}{$\begin{array}{r}\text { Küvette Nr. } \\
\text { Baum Nr. }\end{array}$} & S1 & S2 & S3 & S4 & S5 & S6 & $\mathrm{S}_{\mathrm{V}} 7$ & $\mathrm{~S}_{\mathrm{V}} 8$ & $\mathrm{~S}_{\mathrm{V}} 9$ & $S_{V} 10$ & $\mathrm{~S}_{\mathrm{v}} 11$ & $S_{v} 12$ \\
\hline & B57 & B58 & B97 & B124 & B119 & B132 & B140 & B140 & B140 & B140 & B140 & B140 \\
\hline Durchmesser $(\mathrm{cm})$ & 46 & 47 & 55 & 47 & 41 & 47 & 40 & 40 & 33 & 33 & 30 & 30 \\
\hline Höhe $(\mathrm{m})$ & 2.5 & 2 & 2 & 2 & 2 & 2 & 1.3 & 1.5 & 7.5 & 7.5 & 13.00 & 13.20 \\
\hline Oberfläche $\left(\mathrm{m}^{2}\right)$ & 0.11 & 0.11 & 0.103 & 0.109 & 0.112 & 0.110 & 0.060 & 0.060 & 0.061 & 0.061 & 0.061 & 0.061 \\
\hline Volumen $\left(\mathrm{m}^{3} \times 10^{-3}\right)$ & 12.7 & 12.9 & 14.2 & 12.9 & 11.6 & 12.8 & 6.0 & 6.0 & 5.1 & 5.1 & 4.6 & 4.6 \\
\hline \multirow[t]{2}{*}{ Orientierung } & $\mathrm{N}$ & $\mathrm{N}$ & $\mathrm{N}$ & $\mathrm{N}$ & $\mathrm{N}$ & $\mathrm{N}$ & $\mathrm{N}$ & S & $\mathrm{N}$ & $\mathrm{S}$ & $\mathrm{N}$ & S \\
\hline & \multicolumn{6}{|c|}{ Äste } & \multicolumn{6}{|c|}{ Grobwurzeln } \\
\hline \multirow{2}{*}{$\begin{array}{r}\text { Küvette } \mathrm{Nr} \text {. } \\
\text { Baum } \mathrm{Nr} \text {. }\end{array}$} & A1 & A2 & A3 & A4 & A5 & A6 & G1 & G2 & G3 & G4 & G5 & G6 \\
\hline & B68 & B68 & B89 & B89 & B140 & B132 & B34 & B41 & B18 & B59 & B140 & $\mathrm{B} 132$ \\
\hline Durchmesser $(\mathrm{cm})$ & 7.1 & 5.9 & 6.0 & 3.0 & 3.7 & 9.2 & 3.5 & 2.3 & 1.0 & 7.0 & 3.4 & 3.8 \\
\hline Oberfläche $\left(\mathrm{m}^{2}\right)$ & 0.114 & 0.091 & 0.088 & 0.041 & 0.053 & 0.148 & 0.042 & 0.031 & 0.012 & 0.120 & 0.046 & 0.055 \\
\hline Volumen $\left(\mathrm{m}^{3} \times 10^{-3}\right)$ & 2.02 & 1.35 & 1.31 & 0.31 & 0.48 & 3.41 & 0.37 & 0.18 & 0.03 & 2.10 & 0.39 & 0.51 \\
\hline Höhe (m) & 24 & 21 & 21.5 & 22 & 19 & 21 & & & & & & \\
\hline Orientierung & - & $S$ & $\mathrm{~N}$ & $\mathrm{O}$ & SW & W & & & & & & \\
\hline Winkel $\left(^{\circ}\right)$ & 90 & 30 & 45 & 0 & 0 & 30 & & & & & & \\
\hline Kronenposition & 3 & 2 & 3 & 3 & 1 & 1 & & & & & & \\
\hline Kronenvolumen & 3 & 2 & 2 & 1 & 3 & 2 & & & & & & \\
\hline
\end{tabular}

Tab. 3 b: Kenndaten der Dauermessstellen im Göttinger Wald, Erläuterungen wie Tab. 3 a.

\begin{tabular}{|c|c|c|c|c|c|c|c|c|c|c|c|c|}
\hline \multirow{3}{*}{$\begin{array}{r}\text { Göttinger Wald } \\
\text { Küvette Nr. } \\
\text { Baum Nr. }\end{array}$} & \multicolumn{6}{|c|}{ Stämme S } & \multicolumn{6}{|c|}{$\begin{array}{l}\text { Stämme } S_{v} \text {, Höhenprofil und } \\
\text { Exposition an einem Stamm }\end{array}$} \\
\hline & S1 & S2 & S3 & S4 & S5 & S6 & $\mathrm{S}_{\mathrm{V}} 7$ & $\mathrm{~S}_{\mathrm{v}} 8$ & $\mathrm{~S}_{\mathrm{v}} 9$ & $\mathrm{~S}_{\mathrm{v}} 10$ & $S_{V} 11$ & $\mathrm{~S}_{\mathrm{V}} 12$ \\
\hline & B1 & B2 & B3 & B4 & B5 & $\mathrm{B} 6$ & B12 & B12 & B12 & B12 & B12 & B12 \\
\hline Durchmesser $(\mathrm{cm})$ & 52 & 50 & 48 & 61 & 47 & 44 & 50 & 50 & 41 & 41 & 34 & 34 \\
\hline Höhe $(\mathrm{m})$ & 1.8 & 2 & 2 & 1.3 & 1.8 & 1.5 & 1.5 & 1.5 & 9.7 & 9.7 & 16.3 & 16.3 \\
\hline Oberfläche $\left(\mathrm{m}^{2}\right)$ & 0.109 & 0.113 & 0.116 & 0.109 & 0.102 & 0.115 & 0.059 & 0.059 & 0.060 & 0.060 & 0.061 & 0.061 \\
\hline Volumen $\left(\mathrm{m}^{3} \times 10^{-3}\right)$ & 14.1 & 14.0 & 14.0 & 16.6 & 12.0 & 12.6 & 7.3 & 7.3 & 6.1 & 6.1 & 5.1 & 5.1 \\
\hline \multirow[t]{2}{*}{ Orientierung } & $\mathrm{N}$ & $\mathrm{N}$ & $\mathrm{N}$ & $\mathrm{N}$ & $\mathrm{N}$ & $\mathrm{N}$ & $S$ & $\mathrm{~N}$ & $S$ & $\mathrm{~N}$ & $S$ & $\mathrm{~N}$ \\
\hline & \multicolumn{6}{|c|}{ Äste } & \multicolumn{6}{|c|}{ Grobwurzeln } \\
\hline Küvette Nr. & $\mathrm{A} 1$ & $\mathrm{~A} 2$ & A3 & A4 & A5 & A6 & G1 & $\mathrm{G} 2$ & G3 & G4 & G5 & G6 \\
\hline Baum Nr. & B97 & B97 & B97 & B1 & B2 & B2 & B10 & B11 & B1 & B2 & $B$ & $B$ \\
\hline Durchmesser $(\mathrm{cm})$ & 3.1 & 3.1 & 5.8 & 4.9 & 7.5 & 4.3 & 4.3 & 2.1 & 3.8 & 9.3 & 3.7 & 2.1 \\
\hline Oberfläche $\left(\mathrm{m}^{2}\right)$ & 0.052 & 0.044 & 0.096 & 0.086 & 0.130 & 0.064 & 0.071 & 0.033 & 0.062 & 0.158 & 0.054 & 0.030 \\
\hline Volumen $\left(\mathrm{m}^{3} \times 10^{-3}\right)$ & 0.38 & 0.32 & 1.23 & 0.96 & 2.11 & 0.62 & 0.70 & 0.17 & 0.54 & 3.03 & 0.46 & 0.15 \\
\hline Höhe $(\mathrm{m})$ & 28.75 & 28 & 26.5 & 27 & 26 & 32 & & & & & & \\
\hline Orientierung & so & NO & so & $S$ & w & $\mathrm{O}$ & & & & & & \\
\hline Winkel $\left(^{\circ}\right)$ & 30 & 45 & 30 & 45 & 30 & 30 & & & & & & \\
\hline Kronenposition & 3 & 3 & 2 & 3 & 3 & 3 & & & & & & \\
\hline Kronenvolumen & 1 & 2 & 2 & 3 & 3 & 2 & & & & & & \\
\hline
\end{tabular}




\subsubsection{Berechnung der Atmungsraten}

Der Infrarotgasanalysator misst die $\mathrm{CO}_{2}$-Konzentration als molare Konzentration (mol / Gesamtvolumen), da die Infrarotabsorption des Messgases direkt von der Zahl der $\mathrm{CO}_{2}$-Moleküle in der Messzelle des Analysators abhängt. Für die Angabe der $\mathrm{CO}_{2}$-Konzentration als Molenbruch (ppm, bzw. $\mu \mathrm{mol} / \mathrm{mol}$ ) wird das Gasvolumen in der Messzelle des Analysators mittels der Zustandsgleichung für ideale Gase (1) in die Stoffmenge umgerechnet:

$$
n=\frac{P \times V}{R g \times T}
$$

Es sind $\mathbf{P}$ der Druck, $\mathbf{V}$ das Volumen der Messkammer des Analysators, Rg die allgemeine Gaskonstante $\left(8.314 \mathrm{Jmol}^{-1} \mathrm{~K}^{-1}\right)$, $\mathbf{T}$ die absolute Temperatur des Messgases im Analysator. Der Luftdruck in der Messkammer des Analysators wurde dabei dem Umgebungsluftdruck gleichgesetzt, der mit einem externen elektronischen Drucksensor erfasst, an den IRGA übermittelt und intern verrechnet wurde. Der Analysator gab die $\mathrm{CO}_{2}$-Konzentration somit in der Einheit ppm bzw. $\mu \mathrm{mol} \mathrm{mol}{ }^{-1}$ aus.

Die von den Massenflussmessern erfasste Flussrate ist der durchströmenden Menge von Luftmolekülen direkt proportional und wird in der Einheit Normliter min $^{-1}$ (NL, bei Standarddruck $=101300$ $\mathrm{Pa}$ und Standardtemperatur $=273.14 \mathrm{~K}$ ) ausgegeben. Eine Druck- und Temperaturkorrektur war somit nicht notwendig, so dass die Flussrate entsprechend der Zustandsgleichung für ideale Gase (1) linear in die molare Flussrate $f\left(\mathrm{~mol} \mathrm{~s}^{-1}\right)$ umgerechnet werden konnte (2) :

$$
f\left(\mathrm{~mol} \mathrm{~s}^{-1}\right)=\text { Flussrate }\left(\mathrm{NL} \mathrm{min}^{-1}\right) \times 7.434 \times 10^{-4}
$$

Die $\mathrm{CO}_{2}$-Abgabe pro Küvette und Zeiteinheit ergab sich aus dem Produkt der molaren Flussrate $f$ der Luft, die zur Küvette gepumpt wurde und der Differenz der $\mathrm{CO}_{2}$-Konzentrationen von Messund Referenzkanal. Bezogen auf die Oberfläche, das Volumen oder das Splintholzvolumen ergaben sich die spezifischen Atmungsraten $\mathrm{R}_{\mathrm{A}}, \mathrm{R}_{\mathrm{V}}$ und $\mathrm{R}_{\mathrm{VSplint}}$.

Bei der Oberflächen- und Volumenberechnung der Äste und Grobwurzeln wurde von einer Zylinderform und einem mittleren Umfang von drei Messungen (in der Mitte des Ast- bzw. Grobwurzelabschnitts und auf Höhe der Schlauchschellen) ausgegangen. Bei den Stämmen ergab sich das Holzvolumen, dem die $\mathrm{CO}_{2}$-Abgabe in die Küvetten zugeordnet wurde, aus dem Zylindervolumen des Stammes auf Höhe der Küvetten, das mit dem Verhältnis zwischen dem von der Küvette eingeschlossenen Kreisausschnitt und dem Stammumfang multipliziert wurde. Das Splintholzvolumen wurde nur für die Stämme als Bezugsgröße verwendet und errechnete sich aus dem Hohlzylindervolumen, dessen Innenradius dem halben Kernholzdurchmesser entsprach. Die Splintholz-Kernholzgrenze wurde anhand der radialen Verläufe der TTC-Umsätze im Holz ermittelt (vergl. Kap. 3.2.4.2).

\subsubsection{Das Messprogramm}

Die Holzatmung wurde von März 1997 bis November 1998 im Solling und bis März 1999 im Göttinger Wald gemessen. Die Messung der Tagesgänge der Atmungsraten und der Xylemtemperaturen erfolgte an jedem Standort und Kompartiment, d.h. an Stämmen (S), dem mit 6 Küvetten bestückten Einzelbaum $\left(\mathbf{S}_{\mathbf{V}}\right)$, Ästen $(\mathbf{B})$ und Grobwurzeln $(\mathbf{C R})$ etwa einmal im Monat für mindes- 
tens zwei und maximal 14 Tage. Die Zuwachsmaßbänder wurden während der Vegetationsperiode etwa alle 2 bis 3 (5) Wochen, außerhalb der Vegetationsperiode alle 6 bis 12 Wochen abgelesen.

\subsection{Begleitende Messungen}

\subsubsection{Temperaturmessung}

Zur Messung der Xylemtemperaturen waren Thermistoren (NTC-Widerstände $10 \mathrm{k} \Omega 20^{\circ} \mathrm{C}, \mathrm{Fa}$. Siemens, Deutschland) 3 - $10 \mathrm{~mm}$ unter Oberfläche in die äußeren 2 - $4 \mathrm{~mm}$ des Xylems eingebracht.

Die Messungen erfolgten im Xylem jeder der 18 in die Atmungsküvetten eingeschlossenen Holzproben eines Standortes. Außerdem wurden zur Erfassung der vertikalen Temperaturverteilung an jeweils einen Baum pro Standort 10 zusätzliche Temperaturfühler installiert, die sich in verschiedenen Höhen und jeweils in nördlicher und südlicher Exposition befanden.

Neben der Messung der oberflächennahen Temperaturen wurde an einem Stamm im Solling der Tagesgang der Holztemperaturen in unterschiedlicher Entfernung von der Stammoberfläche aufgezeichnet. Hierzu diente ein, aus einem $15 \mathrm{~cm}$ langen PVC-Rohr $\left(\mathrm{D}_{\mathrm{a}}=8 \mathrm{~mm}, \mathrm{D}_{\mathrm{i}}=6 \mathrm{~mm}\right)$ bestehender Temperaturfühler, in dem fünf Thermistoren in unterschiedlichen Abständen eingebracht und in Wärmeleitpaste eingebettet waren. Der Fühler wurde $15 \mathrm{~cm}$ oberhalb einer Stammküvette in die durch eine Bohrkernentnahme entstandene Bohrung eingeschoben und hatte engen Kontakt zum Xylemparenchym. Die Temperaturen wurden in einer Entfernung von 0.5 (entsprechend der Messposition in den Küvetten), 1.5, 2.5, 6.5 und $12.5 \mathrm{~cm}$ von der Stammoberfläche gemessen.

Die Thermistoren waren über einen externen Relaismultiplexer (Campbell AM 416, Campbell Scientific Inc., UK) an den Daten-Logger angeschlossen. Die Temperaturen wurden im oben beschriebenen Messzyklus 16 mal in 30 bzw. 60 Minuten gemessen und der Mittelwert am Ende jedes Zyklus gespeichert.

\subsubsection{Messung des Holzzuwachses}

Zur Bestimmung des Holzzuwachses der Probestellen wurden in unmittelbarer Nähe zu den Atmungsküvetten an Stämmen, Ästen und Grobwurzeln hochauflösende Zuwachsmaßbänder zur Umfangmessung installiert.

Bei den Stämmen waren seit Anfang 1996 Zuwachsmaßbänder aus Kunststoff mit einem geringen Ausdehnungskoeffizienten installiert, die neben der $\pi$-Skala der forstlichen Biometrie mit einer Noniusskala versehen waren. Diese erlaubte eine Ablesegenauigkeit von $0.25 \mathrm{~mm}$. Bei den Grobwurzeln und Ästen bestanden die Zuwachsmaßbänder aus handelsüblichem Stahlmaßband mit Zentimeterskala. Auch hier wurde durch das zusätzliche Aufbringen eines Nonius die Ablesegenauigkeit auf $0.1 \mathrm{~mm}$ erhöht. Zur Prüfung dieser Methode wurde der Zuwachs an den Ästen mit zwei weiteren Verfahren aufgenommen. Bei einer zweiten Ausführung von Zuwachsmaßbändern wurde der Abstand zwischen zwei durch Einbringen von Messingnieten markierte Punkten mit einer Zeigerschieblehre (Auflösung $\pm 0.02 \mathrm{~mm}$ ) gemessen. Die Abstandsmessung zwischen den Nieten erfolgte nicht berührungsfrei, vielmehr wurde die Schieblehre an die Nieten angesetzt und zusammengedrückt, wodurch sich das Maßband spannte. Nach dem Loslassen stellte das Maßband die Schieblehre auf den Ablesewert ein. Um den Fehler beim Ansetzen der Schieblehre zu minimieren, wurde die Abstandmessung jeweils 10 mal wiederholt und die Ablesewerte gemittelt. Dieses Verfahren hatte den Vorteil, dass sich die Maßbänder nicht erst setzen mussten, sondern 
gleich nach der Installation eine Messung mit hoher Auflösung möglich war (VOGEL 1992). Bei einigen Messstellen, die nur kletternd erreicht werden konnten, war diese Methode wegen der Handhabung der Schieblehre technisch etwas problematischer. Für die Messung des Grobwurzelzuwachses war das Verfahren ungeeignet, da in den 20 bis $40 \mathrm{~cm}$ tiefen Gruben zwischen den oft eng benachbarten Grobwurzeln nur selten ausreichend Platz zum Ansetzen der Schieblehre gewesen wäre.

An den sechs Ästen im Göttinger Wald wurde schließlich der Durchmesser mit der Zeigerschieblehre gemessen. Dafür wurden je zwei um $90^{\circ}$ versetze Punkte oberhalb und unterhalb der Küvette markiert. Der Mittelwert der vier Durchmesser wurde den Ergebnissen der anderen Verfahren gegenübergestellt.

Der Umfang- bzw. Durchmesserzuwachs errechnete sich aus der Differenz zwischen dem aktuellen Messwert und dem mit der ersten Messung erhobenen Ausgangswert. Für die Berechnung des Volumenzuwachses der Holzproben in den Küvetten wurde dieser Zuwachs für die gesamte Länge der Probe angenommen und der bei der Installation der Küvette ermittelte Umfang der Küvette um den entsprechenden Betrag erhöht. Der Volumenzuwachs ergab sich analog zum Durchmesserzuwachs aus der Differenz zwischen aktuellem und Ausgangsvolumen. Bei den Laboruntersuchung wurden die Dichte und der Kohlenstoffgehalt des Xylems der Messstellen ermittelt (Kap. 3.2.4). Mit diesen Größen konnte schließlich die im Holzzuwachs gebundene Kohlenstoffmenge berechnet werden.

\subsubsection{Ergänzende Messung der Holzatmung: „Punktmessungen“}

Zur Untersuchung der Abhängigkeit der Atmungsraten vom Stamm- und Astdurchmesser wurden im Göttinger Wald an drei Terminen im November und Dezember 1998 mit kleinen Küvetten und einem mobilen $\mathrm{CO}_{2}$-Analysegerät Atmungsmessungen an einer größeren Zahl von Stämmen und Ästen durchgeführt.

Hierbei wurde das Kompakt-Miniküvetten-System CMS 400 (Fa. Walz, Effeltrich, Deutschland) verwendet. Die $\mathrm{CO}_{2}$-Konzentrationen wurde mit Hilfe des integrierten IRGA (Fa. Leybol-Heraeus, Hanau, Deutschland) im offenen System im Differenzverfahren ermittelt. Die zentrale Regel- und Messeinheit war über Teflonschläuche mit einer lichtundurchlässigen PVC-Messküvette (Innenmaße: Länge $=16.2 \mathrm{~cm}$, Breite $9 \mathrm{~cm}$, Höhe $=2 \mathrm{~cm}$ ) und einem Referenzgefäß gleicher Größe verbunden. Zur Bestimmung der Oberflächentemperatur der Messpunkte war die Küvette mit einem Thermistor ausgestattet, der während der Messung in engem Kontakt zur Rinde stand. Die Messküvette wurde gegen die Stamm- bzw. Astoberfläche mit einer Dichtung aus Zellkautschuk abgedichtet, indem sie mit Spanngurten gegen die Dichtung gepresst wurde. Dieses Verfahren ermöglichte ein zuverlässiges Abdichten sowie einen schnellen Wechsel der Messstelle und damit eine hohe Zahl von Wiederholungsmessungen.

Durch ein Puffergefäß (V = 20 1) wurde Umgebungsluft angesaugt und von der zentralen Regeleinheit zur Mess- und Referenzküvette geleitet. Der IRGA gab die Differenz der $\mathrm{CO}_{2}$-Konzentrationen zwischen Mess- und Referenzgas an. Für eine korrekte Erfassung der Konzentrationsdifferenz stellten Masseflussregler der Steuereinheit sicher, dass die Flussraten von Mess- und Referenzkanal gleich waren. Neben der $\mathrm{CO}_{2}$-Differenz wurden die Flussraten, die Oberflächentemperatur und der Probenumfang auf mittlerer Höhe der Küvette registriert. Die Berechnung der Atmungsraten, Volumina und Oberflächen erfolgte analog zu dem in Kap. 3.1.6 beschriebenen Verfahren. 


\subsubsection{Laboruntersuchungen}

Die Laboruntersuchungen hatten einerseits das Ziel die biometrischen Daten mit Werten zur Mächtigkeit des Splintholzes, der Holzdichte und dem C-Gehalt zu ergänzen. Außerdem sollten die Inhaltsstoffe bzw. der TTC-Umsatz Erklärungsansätze für die beobachtete Variabilität der spezifischen Atmungsintensität liefern. Schließlich können Größen wie der Stickstoffgehalt des Holzes geeignet sein, die Atmungsaktivität anderer Bestände abzuschätzen.

\subsubsection{Probenentnahme und -aufbreitung}

Nach Abschluss der Atmungsmessungen im März 1999 wurden den in die Küvetten eingeschlossenen Sprossachsen für die Laboruntersuchungen Proben entnommen. An jeder Messstelle wurde zunächst an drei Punkten mit einem Korkbohrer $(\mathrm{D}=12 \mathrm{~mm}$ bei Stämmen und $\mathrm{D}=8 \mathrm{~mm}$ bei Ästen und Grobwurzeln) Rindengewebe entnommen und anschließend an den gleichen Positionen mit einem Kernbohrer $\left(D_{i}=5.2 \mathrm{~mm}\right)$ Holzbohrkerne gewonnen. Rindenstücke und Bohrkerne wurden sofort in Frischhaltefolie verpackt und für den Transport ins Labor bei $3{ }^{\circ} \mathrm{C}$ gekühlt.

Die Bohrkerne und Rindenstücke für den TTC-Test wurden unmittelbar nach der Entnahme für den Test vorbereitet, diejenigen für die $\mathrm{C} / \mathrm{N}$-Analysen getrocknet ( 3 Tage bei $80{ }^{\circ} \mathrm{C}$ im Trockenschank) und Proben für die Proteinanalyse bei $-18^{\circ} \mathrm{C}$ eingefroren.

Zur Bestimmung der Dichte der Rinde wurde das Volumen aus dem Innendurchmesser des Korkbohrers und der bei der Ernte registrierten Rindendicke berechnet. Die für den TTC-Test vorgesehenen Rindenproben wurden frisch gewogen und der Wassergehalt der Probe durch Bestimmung des Frisch- und Trockengewichts an Teilstücken der Probe bestimmt.

Die Holzproben für den TTC-Test und die C/N-Analyse wurden aus jeweils einem Bohrkern gewonnen. Dazu wurde dieser in ca. $1 \mathrm{~cm}$ lange Teilstücke aufgeschnitten, die in zwei ca. 7 bzw. $3 \mathrm{~mm}$ lange Stücke geteilt wurden. Mit einer Zeigerschieblehre wurde die genaue Länge und der Durchmesser dieser Teilstücke ermittelt und ihr Frischgewicht bestimmt. Zur Berechnung der Holzdichte wurde das Trockengewicht der Proben vor der C/N-Analyse bestimmt. Das Trockengewicht der Proben, an denen der TTC-Test durchgeführt wurden, wurde nach dem TTC-Test bestimmt.

Für die Proteinanalysen wurden die Bohrkerne in ca. $10 \mathrm{~mm}$ lange Teilstücke geschnitten, vermessen, gewogen und zunächst tiefgekühlt zwischengelagert.

\subsubsection{Der TTC-Test}

Beim TTC-Test wird die Tatsache genutzt, dass in Wasser gelöstes, farbloses 2,3,5 Triphenyltetrazoliumchlorid (TTC) aktiv von lebenden Zellen aufgenommen wird. Dort wirkt es als Wasserstoffakzeptor, der sich leicht in die Redoxketten des Zellstoffwechsels einschaltet und zu Triphenyltetrazolium-Formazan (TTF) reduziert wird. Das Endprodukt wird als stark gefärbte Kristalle in der Zelle akkumuliert (LARCHER 1969). Die Auswertung kann dann auf verschiedene Weise erfolgen.

In Voruntersuchungen wurden an Bohrkernen von drei Stämmen die lebenden Zellen anhand des TTF-Gehaltes sowie durch das Anfärben der Speicherstärke (mit Lugolscher Lösung) unter dem Mikroskop identifiziert. Zur quantitativen Auswertung wurde der relative Flächenanteil der Markstrahlen im Tangentialschnitt und des Holzparenchyms im Radialschnitt mit einem Zeichenmikroskop auf Papier übertragen. In Teilausschnitten der Markstrahlen und des Holzparenchyms wurde der relative Anteil lebender Zellen an der Gesamtzellzahl ermittelt und mit deren relativen 
Anteil an der Fläche gleichgesetzt. Die Flächenanteile von Markstrahlen und Holzparenchym und ihre Lebendzellgehalte wurden mit ihren Volumenanteilen gleichgesetzt, so dass der relative Anteil lebender Zellen am Gesamtvolumen der Probe ermittelt werden konnte. Zur Identifizierung der Splintholz-Kernholzgrenze wurden die Bohrkerne in $1 \mathrm{~cm}$ lange Teilstücke unterteilt und Radialund Tangentialschnitte jedes dieser Teilstücke untersucht. Die Ergebnisse bei der Ansprache lebender Zellen erschienen jedoch zweifelhaft, weil nur ca. ein Drittel aller als vital betrachteten Zellen sowohl TTF-Kristalle als auch Stärke enthielten. Die verbleibende Zellzahl enthielt entweder TTF oder Stärke. Die Verhältnisse streuten stark und variierten selbst bei verschiedenen Präparaten von einem $1 \mathrm{~cm}$ Teilstück über einen weiten Bereich. Diese Unsicherheit rührte vermutlich daher, dass die gestreckten Zellen bei der Präparation angeschnitten wurden und dabei ungleichmäßig in der Zelle verteilte TTC-Kristalle und Amyloplasten in wechselnder Anzahl im Präparat zu erkennen waren. Wegen dieser methodischen Unsicherheiten wurden diese Voruntersuchungen nicht quantitativ ausgewertet. Das Verfahren fordert außerdem einen erheblichen Zeitaufwand, so dass die Bearbeitung des Holzes aller Messstellen mit einer radialen Auflösung von $1 \mathrm{~cm}$ mit dieser Methode nicht möglich gewesen wäre.

Der TTC-Test wurde daher leicht modifiziert nach dem von STEPONKUS \& LANPHEAR (1967) entwickelten Verfahren durchgeführt, bei dem das kristalline TTF mit Ethanol extrahiert und photometrisch quantifiziert wird. Die frischen ca. $7 \mathrm{~mm}$ langen Proben der Bohrkernteilstücke wurden in $3 \mathrm{ml}$ wässriger Lösung mit $0.6 \%$ TTC und $0.5 \%$ Propanol als Netzmittel gegeben. Um ein optimales Infiltrieren in die Proben zu gewährleisten, wurde der Luftdruck über der Lösung im Exsikkator für 30 min auf 23 Millibar gesenkt. Die Holzproben wurden dann für 15 Stunden bei $30{ }^{\circ} \mathrm{C}$ im Wasserbad inkubiert.

Anschließend wurde die TTC-Lösung dekantiert, die Proben mit destilliertem Wasser abgespült, trockengetupft und in graduierte Reagenzgläser überführt, die mit Ethanol auf $5 \mathrm{ml}$ aufgefüllt wurden. Bei $80^{\circ} \mathrm{C}$ für $20 \mathrm{~min}$ im Wasserbad konnte das TTF quantitativ aus den Zellen extrahiert werden. Nach dem Abkühlen wurde das Endvolumen ermittelt, die Lösung über Faltenfilter filtriert, das Filtrat geschüttelt und dessen Absorption im Photometer bei $530 \mathrm{~nm}$ gegen einen Ethanolblindwert gemessen. Aus der Absorption konnte die TTF-Konzentration mit Hilfe einer zuvor erstellten Eichreiche berechnet werden. Für die Eichreihe wurde aus einer 0.6 \%-igen TTFStammlösung eine Verdünnungsreihe mit Konzentrationen von 0.3 - $60 \mathrm{mg}$ TTF/1 Ethanol hergestellt, deren Absorption ebenfalls bei $530 \mathrm{~nm}$ gemessen wurde. Aus der Eichreihe ergab sich für die Konzentrationsberechnung folgende Gradengleichung:

$$
[\mathrm{TTF}]=26.53 \times \mathrm{Abs}_{530}-0.01812\left[\mathrm{mg} \mathrm{l}^{-1}\right], \mathrm{r}^{2}=0.99
$$

Das Produkt aus dem Volumen der Ethanol-TTF Lösung und der TTF-Konzentration ergab die Gesamtmenge extrahierbaren TTF für jede Holzprobe.

\subsubsection{Proteinanalyse}

Die Bestimmung der Menge löslicher Proteine erfolgte photometrisch nach der Reaktion mit FolinCiocalteus-Phenolreagenz (LOWRY 1951). Da phenolische Verbindungen wie Tannin, Lignin oder Gerbsäuren einerseits Proteine binden oder deaktivieren, andererseits das Folin-Reagenz reduzieren und damit die Proteinanalyse beeinflussen können, wurden sie mit unlöslichem Polyvinylpolypyrolidon (PVPP) gebunden (LOOMIS \& BATTAILE 1966, LOOMIS 1969). 
Die tiefgekühlten, $1 \mathrm{~cm}$ langen Bohrkernabschnitte (150 - $200 \mathrm{mg}$ FG) wurden zunächst zerkleinert und unter flüssigem Stickstoff gemörsert. Nach weitgehender Zerkleinerung des Gewebes wurde unlösliches, gereinigtes PVPP im Gewichtsverhältnis 1:1 zugegeben und gründlich im Mörser vermengt. Dazu wurden $2 \mathrm{ml}$ Phosphatpuffer $(75 \mathrm{mM}, \mathrm{pH}=7.4)$ gegeben und das Auftauen der Mischung im Mörser abgewartet. Währenddessen wurde das Probenmaterial weiter intensiv mit dem Puffer und dem PVPP vermischt und schließlich quantitativ in Zentrifugenröhrchen überführt. Nach dem Zentrifugieren wurde der Überstand für die Proteinanalyse abpipettiert.

Für die Bestimmung des Proteingehaltes wurden folgende Reaktionslösungen verwendet:

\section{Lösung A: $2 \% \mathrm{Na}_{2} \mathrm{CO}_{3}$ in $0.1 \mathrm{~N} \mathrm{NaOH}$}

Lösung B: $0.5 \% \mathrm{CuSO}_{4} \cdot 5 \mathrm{H}_{2} \mathrm{O}$ in $1 \%$ Kalium-Natriumtartrat (in $\mathrm{H}_{2} \mathrm{O}$ )

Lösung C: $100 \mathrm{ml} \mathrm{Lsg.} \mathrm{A}+2 \mathrm{ml} \mathrm{Lsg.} \mathrm{B} \mathrm{(täglich} \mathrm{erneuert)}$

Lösung D: Folin-Ciocalteus-Phenolreagenz : $\mathrm{H}_{2} \mathrm{O}$ im Verhältnis $1: 2$

Bei der Analyse ist auf die genaue Einhaltung der erforderlichen Reaktionszeiten zu achten. Zunächst wurde zu 50 - $100 \mu$ l Puffer-Proteinlösung $1 \mathrm{ml}$ der Lösung C gegeben. Nach 15 min wurden $100 \mu \mathrm{l}$ der Lösung D hinzu pipettiert und sofort geschüttelt. Die Absorptionsmessung erfolgte nach 30 min am Photometer gegen einen Blindwert aus Pufferlösung und Folin-Reagenz.

Für die Berechnung der Proteinkonzentration wurde eine Eichreihe mit kristallinem Rinderserumalbumin in Konzentrationen von $1.0-83.8 \mu \mathrm{g} / \mathrm{ml}$ in $1.2 \mathrm{ml}$ Endvolumen erstellt, für die folgende Beziehung mit $\mathbf{A b s}_{\mathbf{7 5 0}}=$ Absorption bei $750 \mathrm{~nm}$ ermittelt wurde:

$$
\log [\text { Protein }]=1.064 \times \log \mathrm{Abs}_{750}+1.928
$$

Aus der Konzentration und dem Endvolumen des Versuchsansatzes (1150 - $1200 \mu \mathrm{l})$ wurde die Menge löslichen Proteins in jeder Holzprobe berechnet.

\subsubsection{C/N-Analysen}

Die ca. $3 \mathrm{~mm}$ langen Bohrkernabschnitte wurden bei $80{ }^{\circ} \mathrm{C}$ bis zur Gewichtskonstanz getrocknet und ihr Trockengewicht ermittelt. Wegen der geringen Probenmenge wurden die Proben nicht gemahlen, sondern mit einer Rasierklinge in Stücke mit einer Kantenlänge unter $1 \mathrm{~mm}$ zerteilt. Nach dem Einwiegen einer Probenmenge von ca. $8 \mathrm{mg}$ in Zinnkapseln wurden die Stickstoff- und Kohlenstoffgehalte im C/N-Analysator (Nitrogen/Carbon NA1500, Fa. CARLO ERBA STRUMENTIAZONE, IT) bestimmt. Dabei werden die bei der Verbrennung der Proben entstehenden Gase $\mathrm{CO}_{2}$ und $\mathrm{N}_{2}$ gaschromatographisch getrennt und quantitativ analysiert. Die relativen Gewichtsanteile von Stick- und Kohlenstoff ergeben mit der Einwaage multipliziert den Gehalt in Milligramm.

\subsubsection{Berechnung der Gehalte an Inhaltsstoffen für Stamm-, Ast- und Grobwurzel- abschnitte in den Atmungsküvetten}

Durch die nach Holztiefe differenzierten Analysen war es einerseits möglich, die radiale Verteilung der Stoffgehalte und der umgesetzten TTC-Menge zu untersuchen, andererseits konnte der Gesamtgehalt bzw. die Gesamtmenge umgesetzten TTC von jeder in den Messküvetten eingeschlossenen Probe berechnet werden. 
Die Analysenwerte wurden auf das Volumen der analysierten Bohrkernteilstücke bezogen. Das Volumen, das die Probe in der jeweiligen Holztiefe repräsentierte, errechnete sich als Hohlzylinder mit einer Dicke, die sich aus der Länge des Bohrkernteilstücks ergab und dem Außenradius, der aus dem Abstand des Teilstücks von der Organoberfläche und dem Gesamtradius der Atmungsprobe bestimmt wurde. Bei den Stämmen wurde das Volumen des Hohlzylinders analog zur Berechnung des Probenvolumens mit dem Verhältnis zwischen dem von der Küvette eingeschlossenem Kreisbogen und dem Stammumfang multipliziert (Kap. 3.1.6). In die Berechnung der TTC-Umsätze und $\mathrm{C} / \mathrm{N}-$ Gehalte ging die Gesamtlänge der Bohrkernteilstücke ein, von denen jeweils ein Teil für den TTC-Test und die C/N-Analyse verwendet wurden (Kap. 3.2.4.1).

Die Summe der Stoffgehalte jeder Rinden- und Holzschicht ergab den Gesamtgehalt der Atmungsprobe, mit dem die $\mathrm{CO}_{2}$-Abgabe ins Beziehung gesetzt werden konnte.

\subsection{Das Holzvolumen und die Holzoberfläche der Bestände}

Um die spezifischen Atmungsraten auf Bestandesebene hochzurechnen sind neben Informationen zur räumlichen Variabilität der Atmung auch detaillierte Kenntnisse über die Menge und die Verteilung der Biomasse, des Volumens und der Oberfläche auf die verschiedenen Organe und Durchmesserklassen erforderlich.

Während das Derbholzvolumen $(\mathrm{D} \geq 7 \mathrm{~cm})$ von Bäumen und Waldbeständen mit hoher Genauigkeit anhand dendometrischer Verfahren aus BHD und Baumhöhe ermittelt werden kann, sind die Informationen zur Bestimmung des Reisigvorrats $(\mathrm{D}<7 \mathrm{~cm})$ weniger umfangreich und beschränken sich in der Regel auf Masseangaben (für die Buche siehe: BURGER 1939, 1949, HELLER \& GÖTTSCHE 1986, HAGEMEIER 2002). Damit geht bereits die Berechnung des Gesamtvolumens eines Baumes über die Standardverfahren der Forstertragskunde hinaus. Soll schließlich die räumliche Variabilität und die Durchmesserabhängigkeit der spezifischen Atmungsrate bei der Hochrechnung Berücksichtigung finden, ist außerdem die Differenzierung der Holzvolumina auf die zwei Durchmesserklassen Derbholz und Reisig nicht ausreichend fein abgestuft.

Zur Bestimmung des gesamten Volumenvorrates der untersuchten Bestände und seiner Verteilung auf verschiedene Durchmesserklassen wurden Standardverfahren zur Berechnung der Derbholzvolumenvorräte mit allometrischen Beziehungen kombiniert. Diese ergaben sich aus der differenzierten Auswertung der Erntedaten von Buchen, die im Rahmen des Solling-Projektes erhoben wurden (HELLER \& GÖTTSCHE 1986, H. HELLER, pers. Mitteilung).

\subsubsection{Bestimmung des Derbholzvolumens}

Die für die Berechnung des Derbholzvolumens $(\mathrm{D} \geq 7 \mathrm{~cm})$ der einzelnen Bäume im Folgenden beschriebene Vorgehensweise ist eng an das von Nagel (1999) beschriebene Verfahren angelehnt.

Als Datengrundlage standen Erhebungen der Niedersächsischen Forstlichen Versuchsanstalt zur Verfügung, die auf den Untersuchungsflächen in langjährigen Beobachtungsreihen alle 3 bis 5 Jahre den BHD und die Baumhöhe ermittelt. Die in Kap 4.3 berücksichtigten Messungen erfolgten 1996 im Göttinger Wald auf einer Fläche von 0.31 ha wobei der BHD von 69 und die Höhe von 38 Buchen gemessen wurde. Außerdem wurden entsprechende Größen von 11 Bäumen anderer Arten (Kap. 2.4) erfasst. Die Erhebungen für den Bestand im Solling waren aus dem gleichen Jahr und umfassten den BHD von 212 und die Höhen von 37 Buchen. 
Das Derbholzvolumen eines Baumes errechnete sich nach:

$$
V_{d}=A_{1.3} \times H \times F_{d}
$$

mit $\mathbf{A}_{\mathbf{1 . 3}}=$ Stammquerschnittfläche in $1.3 \mathrm{~m}$ Höhe $\left(\mathrm{m}^{2}\right), \mathbf{H}=$ Baumhöhe $(\mathrm{m})$ und $\mathbf{F}_{\mathbf{d}}=$ Derbholzformzahl der Buche, die nach Gleichung (7) ermittelt wurde.

Die Höhe derjenigen Bäumen, von denen Messwerte vorlagen, ging direkt in die Berechnung von Formzahl und Derbholzvolumen ein. Die Höhen der übrigen Bäume wurde anhand von bestandesspezifischen Höhenkurven aus dem BHD ermittelt. Dazu wurden unter Verwendung verschiedener Modellfunktionen (SCHMIDT 1967, NAGEL 1999) Höhenkurven im iterativen Verfahren an die gegen den BHD aufgetragenen Baumhöhen angepasst und nach den Kriterien von NAGEL (1999) diejenige Funktion ausgewählt, mit der die Baumhöhe am besten beschrieben werden konnte. Für die Messdaten der beiden Buchenbestände von 1996 wurde die Gleichung nach Peterson (6) verwendet:

$$
H=1.3+\left(\frac{B H D}{y 0+a \times B H D}\right)^{3}
$$

Die Derbholzformzahl $F_{d}$ jeder Buche wurde aus dem BHD (in $\mathrm{cm}$ ) und der Baumhöhe (m) nach der von BERGEL (1973) empirisch ermittelten Gleichung errechnet:

$$
F_{d}=0.4039-\frac{118.18779}{B H D^{3}}+4.2 \times 10^{-6} \times B H D^{2}+\frac{1.1267}{H}+0.0017335 \times H
$$

\subsubsection{Der relative Volumenanteil verschiedener Durchmesserklassen}

Zur Untersuchung der Verteilung des Volumens auf die verschiedenen Stamm- und Astdurchmesser der Bestände wurden die im Rahmen des Solling-Projektes 1967 und 1968 erhobenen Daten von 29 fraktioniert geernteten Buchen mit Brusthöhendurchmessern von 6 bis $39.5 \mathrm{~cm}$ ausgewertet.

Bei der Ernte wurde das Derbholz in Stücke von jeweils $1 \mathrm{~m}$ Länge zersägt und der obere und untere Durchmesser festgehalten. Teilstücke von $10 \mathrm{~cm}$ Länge wurden zur Ermittlung des Frischund Trockengewichts zunächst gewogen, bei $110{ }^{\circ} \mathrm{C}$ bis zur Gewichtskonstanz getrocknet und erneut gewogen. Das Reisig jeden Baumes $(\mathrm{D}<7 \mathrm{~cm}$ ) wurde sieben Durchmesserklassen (Klassenbreite $=1 \mathrm{~cm}$ ) zugeordnet. Jeder Ast wurde in Teilstücke mit Durchmessern von $7-6,6-5, .$. und $\mathrm{D}<1 \mathrm{~cm}$ aufgeteilt und die Länge aller Teilstücke für jede der Durchmesserklassen registriert.

Zusätzlich lagen die Daten eines im Göttinger Wald 1996 gefällten Baumes (BHD = $52 \mathrm{~cm}$ ) vor, der noch im gleichen Jahr vermessen wurde. Dabei wurde am Stamm und an den Ästen in Abständen von 1.5 bis $2.0 \mathrm{~m}$ der Durchmesser ermittelt und zusammen mit der Länge des jeweiligen Teilstücks festgehalten. Bei Ästen mit einem Durchmesser unter $3 \mathrm{~cm}$ wurde zunächst nur der Durchmesser in einer Entfernung von $5-10 \mathrm{~cm}$ vom Ansatz ermittelt. Achtzehn dieser Äste aus allen Höhenstufen der Krone wurden später im Labor detailliert vermessen. In Teilstücke geschnitten, wurde deren Länge sowie der größte und kleinste Durchmesser ermittelt und das Volumen dieser Teilstücke berechnet. Allometrische Beziehungen zwischen dem Ansatzdurchmesser der Äste und 
den auf zwei Durchmesserklassen $(3 \mathrm{~cm} \geq D>1 \mathrm{~cm}$ und $\mathrm{D} \leq 1 \mathrm{~cm})$ verteilten Volumina wurden zur Berechnung des Volumens der nicht vermessenen Äste verwendet.

Im Rahmen der vorliegenden Untersuchung wurden die Volumina aller ausgemessenen Teilstücke der 30 Buchen aus den Längen- und Durchmesserangaben als Kegelstumpf neu berechnet. Der Mittelwert der Durchmesser diente der Zuordnung dieser Teilvolumina zu den verschiedenen Holzdurchmesserklassen (Tab. 4). Diese wurden aufsummiert und mit dem Gesamtholzvolumen des Baumes ins Verhältnis gesetzt. Die Volumenanteile der Durchmesserklassen 2 bis 7 standen in Beziehung zum BHD und ließen sich durch nichtlineare Beziehungen beschreiben. Der Volumenanteil dieser Durchmesserklassen konnte so für jeden Einzelbaum bestimmt und der Anteil der Durchmesserklasse 1 mit D $>40 \mathrm{~cm}$ aus der Differenz zwischen 100\% und der Summe der Anteile der Durchmesserklassen DK1 2-7 ermittelt

Tab. 4: Grenzen der Holzdurchmesserklassen $1-7$.

\begin{tabular}{cc}
\hline $\begin{array}{c}\text { Durchmesser- } \\
\text { klasse }\end{array}$ & $\begin{array}{c}\text { Klassengrenze } \\
\text { (cm) }\end{array}$ \\
\hline DKI. 1 & $\mathrm{D}>40$ \\
DKI. 2 & $40 \geq \mathrm{D}>25$ \\
DKI. 3 & $25 \geq \mathrm{D}>15$ \\
DKI. 4 & $15 \geq \mathrm{D}>7$ \\
DKI. 5 & $7 \geq \mathrm{D}>3$ \\
DKI. 6 & $3 \geq \mathrm{D}>1$ \\
DKI. 7 & $1 \geq \mathrm{D}$ \\
\hline
\end{tabular}
werden.

\subsubsection{Berechnung der ober- und unterirdischen Holzvolumina und -oberflächen der Bestände}

Für jeden Baum des Bestandes wurde aus BHD und Höhe das Derbholzvolumen nach Gleichung (5) und dessen relativer Anteil am Gesamtvolumen (Kap. 3.3.2) berechnet. Das Gesamtvolumen des Baumes ergab sich dann aus dem Quotienten von Derbholzvolumen und seinem relativen Anteil am Gesamtvolumen. Die allometrischen Beziehungen zwischen den Volumenanteilen der einzelnen Durchmesserklassen und dem BHD erlaubten die Verteilung des Gesamtvolumens eines Baumes auf die sieben Durchmesserklassen. Die oberirdische Biomasse des Bestandes pro Hektar entsprach der Summe der Teilvolumina aller Bäume.

Ausgehend von den Volumenvorräten der Durchmesserklassen 1 bis 7 konnte nun auch die Holzoberfläche abgeschätzt werden. Hierfür wurde die Gesamtlänge aller Äste bzw. Stämme jeder Durchmesserklasse unter Verwendung der den Klassengrenzen entsprechenden minimalen und maximalen Radien und der Formel für Kegelstümpfe berechnet. Die Oberfläche der jeweiligen Durchmesserklasse entsprach dem Produkt aus der Gesamtlänge aller Achsen und dem mittleren Umfang der Klasse.

Für die Ermittlung der unterirdischen Biomasse lagen Daten von vier Buchen vor, deren Wurzelmassen ebenfalls im Rahmen des Solling-Projektes ermittelt (HELLER \& GÖTTSCHE 1986, H. HELLER, pers. Mitteilung) und den Durchmesserklassen $\mathrm{D}>10 \mathrm{~mm}, 10 \geq \mathrm{D}>5 \mathrm{~mm}$ und $\mathrm{D} \leq 5 \mathrm{~mm}$, zugeordnet wurden. Die Volumina der Grobwurzeln wurden aus den Trockengewichten und der im Rahmen der Laboruntersuchungen bestimmten Grobwurzeldichte (Kap. 3.2.4.1) ermittelt. Das Volumen der Grobwurzeln wurde für jeden Baum mit Hilfe einer allometrischen Beziehung zwischen BHD und Wurzelvolumen ermittelt und ebenso wie die oberirdischen Vorräte für den Bestand aufsummiert. Das Gesamtvolumen der Grobwurzeln konnte nach Ergebnissen von CONERS (1996) zu $37 \%$ den Wurzeln mit Durchmessern von 0.5 bis $2 \mathrm{~cm}$ und zu $63 \%$ den 2 bis $10 \mathrm{~cm}$ starken Wurzeln zugeordnet werden. 


\subsection{Auswertung der Atmungsraten}

Grundlegendes Ziel dieser Untersuchung war es, im Rahmen der Bilanzierung des Kohlenstoffhaushalts der Buchenwälder Aussagen zum jährlichen Kohlenstoffbedarf der verholzten Organe zu machen. Dabei sollte der Bedarf für die Erhaltung der lebenden Biomasse sowie die Kosten für den Zuwachs von Rinden- und Holzparenchym ermittelt werden. Dazu mussten die Werte der diskontinuierlichen Atmungsmessungen zeitlich und räumlich interpoliert werden.

Die Atmung als enzymkatalysierte Reaktion steigt bei schnellen Temperaturänderungen exponentiell mit der Temperatur an. Die Temperatur-Reaktionsgeschwindigkeits-Beziehungen kann durch die als Arrheniusfunktion bezeichnete Gleichung (8) beschrieben werden:

$$
R=\exp (c-\Delta H a /(R g \times T))
$$

Dabei sind $\mathbf{R}$ die Atmungsrate, $\mathbf{R g}$ die allgemeine Gaskonstante und $\mathbf{T}$ die absolute Temperatur in Kelvin. Die Skalierungskonstante $\mathbf{c}$ und die Aktivierungsenergie $\Delta \mathbf{H a}$ beschreiben den Verlauf der Temperaturbeziehung der als Einschritt-Reaktion betrachteten Atmungsreaktionen (MORTIMER 1987).

Ebenso gebräuchlich ist die Beschreibung der Temperaturabhängigkeit der Atmung gemäß der RGT-Regel von VAN'T HOFF (LARCHER 1994), die ebenfalls eine exponentielle Änderung der Reaktionsgeschwindigkeit mit der Temperatur beschreibt. Die Erhöhung der Reaktionsgeschwindigkeit bei einer Temperaturerhöhung um $10{ }^{\circ} \mathrm{C}$ wird durch den Temperaturkoeffizienten $\mathrm{Q}_{10}$ ausgedrückt. Die aktuelle Atmungsrate R bei der Temperatur T lässt sich gemäß der Gleichung:

$$
R=R_{S} \times Q_{10}^{\left(\frac{T-T_{S}}{10}\right)}
$$

aus der Atmungsrate $\mathbf{R}_{\mathbf{S}}$ bei der Bezugstemperatur $\mathbf{T}_{\mathbf{S}}$ und dem Temperaturkoeffizienten $\mathbf{Q}_{\mathbf{1 0}}$ beschreiben.

Die Temperaturabhängigkeit der Atmungsraten jeder Messkampagne und jeder Küvette wurde analysiert, indem Modellfunktionen nach Gleichung (8) angepasst und die Parameter $\mathbf{c}$ und $\Delta \mathbf{H a}$ bestimmt wurden. Zur Beurteilung der Qualität der Kurvenanpassung dienten das Bestimmtheitsmaß $r^{2}$ und die Irrtumswahrscheinlichkeit $P$ (LOZAN 1992). Außerdem wurde für jeden dieser Datensätze nach Gleichung (10) der $\mathrm{Q}_{10}$-Wert aus der Steigung der Auftragung von $\log _{10} \mathrm{R}$ gegen die Temperatur in ${ }^{\circ} \mathrm{C}$ berechnet (ATKIN et al. 2000):

$$
Q_{10}=10^{(10 \cdot \text { Steigung })}
$$

\section{Das Zwei-Komponenten-Modell der Atmung}

Schon JOHANSSON (1933) weist darauf hin, dass der Anstieg der Holzatmung während der Vegetationsperiode nicht allein auf die Temperaturabhängigkeit der Atmung zurückzuführen ist. Vielmehr besteht neben dem ganzjährigen Energiebedarf für den Erhaltungsstoffwechsel der lebenden Zellen ein zusätzlicher Bedarf für den Aufbau neuer Biomasse. JOHANSSON (1933) differenziert die Gesamtatmung in die funktionellen Komponenten „dormant respiration“ und 
„productive respiration“. Dieser Unterscheidung entspricht auch das von McCREE (1970) für krautige Arten vorgeschlagene Modell.

Dieses Zwei-Komponenten-Modell der Atmung wird seit Beginn der 80er Jahre auch wieder von Studien zur Holzatmung aufgegriffen. Die Wachstumsatmung steht abhängig von der chemischen Zusammensetzung des neu gebildeten Gewebes in relativ festem Verhältnis zum Biomassezuwachs. Sie ist in dem Sinne temperaturunabhängig, dass pro Einheit Kohlenstoff im Zuwachs unabhängig von den herrschenden Temperaturbedingungen die gleiche Kohlenhydratmenge veratmet wird. Die Höhe der jährlichen Wachstumsatmung lässt sich aus dem Holzzuwachs ermitteln, wenn der respirative C-Bedarf pro Einheit C im Zuwachs bekannt ist. (SPRUGEL \& BENECKE 1991).

Die Erhaltungsatmung deckt den Energiebedarf, der für die Aufrechterhaltung der Lebensfunktionen der ausdifferenzierten Zellen in Rinden- und Holzparenchym notwendig ist. Sie ändert sich exponentiell mit der Temperatur und kann daher über weite Bereiche variieren (siehe Kap. 5.3). Sie kann insbesondere bei Bäumen mit ihrer hohen Biomasse einen erheblichen Anteil am gesamten respirativen $\mathrm{C}$-Bedarf ausmachen.

\subsubsection{Berechung des Jahresgangs der Gesamtatmung an den Messstellen}

Die Berechnung der Jahresgänge der Atmungsraten erfolgte separat für jede einzelne Messstelle aus deren sich saisonal ändernden Temperaturbeziehungen und den Luft- bzw. Bodentemperaturen. Die Klimadaten beider Standorte wurden vom Institut für Bioklimatologie der Universität Göttingen in stündlicher Auflösung zur Verfügung gestellt. Die Lufttemperaturen wurden als Höhenprofil in $1 \mathrm{~m}, 2 \mathrm{~m}$ und darüber hinaus alle $6 \mathrm{~m}$ bis in eine Höhe von $32 \mathrm{~m}$ (Solling) bzw. $40 \mathrm{~m}$ (Göttinger Wald) gemessen. Für die Stammatmung wurden die Lufttemperaturen des Stammraumes (1 $16 \mathrm{~m}$ ) und für die Astatmung die des Kronenraumes $(16-32 \mathrm{~m})$ gemittelt. Die Bodentemperaturen wurden in 5 und $20 \mathrm{~cm}$ Tiefe erfasst und zur Berechnung der Grobwurzelatmung gemittelt. Der zeitlichen Änderung der Reaktionsnorm der Atmung auf Temperaturänderungen zwischen zwei Messkampagnen wurde dadurch Rechnung getragen, dass die Atmungsraten aus den Temperaturfunktionen jeweils zweier aufeinander folgender Messkampagnen berechnet wurden. Diese Raten wurden als Funktion der Zeit (in Tagen) für den aktuellen Zeitpunkt linear interpoliert. Die aktuelle Atmungsrate $\mathrm{R}_{\text {aktuell }}$ errechnete sich also nach:

$$
R_{\text {aktuell }}=R_{d_{-}}+\frac{\left(R_{d_{+}}-R_{d_{-}}\right)}{d_{+}-d_{-}} \times\left(d_{\text {aktuell }}-d_{-}\right)
$$

Dabei sind $\mathrm{R}_{\mathrm{d} \text { - }}$ und $\mathrm{R}_{\mathrm{d}+}$ die Atmungsraten, die mit den Temperaturfunktionen der dem aktuellen Zeitpunkt vorausgehenden und folgenden Messkampagne für die aktuelle Temperatur berechnet

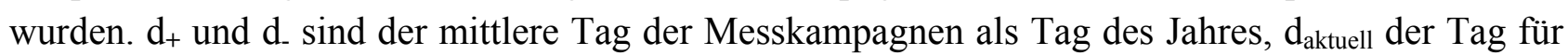
den $\mathrm{R}_{\text {akuell }}$ berechnet werden sollte.

Die Atmungsraten wurden nur dann nach Gleichung (8) berechnet, wenn die Temperaturbeziehung der Atmung für die jeweilige Kampagne signifikant ( $\mathrm{P}<5 \%$ ) war. Für Kampagnen, bei denen sich keine signifikante Temperaturfunktion ergab, wurde die Atmungsrate nach Gleichung (9) berechnet. Hierbei fand der mittlere $\mathrm{Q}_{10}$ aller signifikanten Temperaturbeziehungen der jeweiligen Messstelle Verwendung. $\mathrm{R}_{\mathrm{S}}$ und $\mathrm{T}_{\mathrm{S}}$ entsprachen dem Mittelwert von Atmungsrate und Temperatur der fraglichen Messkampagne. Zur Bestimmung der täglichen $\mathrm{CO}_{2}$-Abgabe einer Messstelle wurde aus der 
für jede Stunde berechneten Atmungsrate die stündliche $\mathrm{CO}_{2}$-Abgabe berechnet und die 24 Stundenwerte eines Tages aufsummiert.

\subsubsection{Differenzierung der Gesamtatmung in die Teilkomponenten Erhaltungs- und Wachstumsatmung}

Die Differenzierung der Gesamtatmung ihre Komponenten Erhaltungs- und Wachstumsatmung erfolgte in der vorliegenden Untersuchung nach der ,,mature tissue“-Methode. Dabei wird die Atmung, die in Phasen gemessen wird, in denen kein Radialzuwachs stattfindet, allein der Erhaltungskomponente zugeordnet. Vereinfachend wird angenommen, dass die Erhaltungsatmung bei gegebener Temperatur im Jahresverlauf konstant ist. Das bedeutet auch, dass sich der $\mathrm{Q}_{10}$-Wert im Jahresverlauf nicht ändert und so der Jahresgang der Erhaltungsatmung aus einer einheitlichen Temperaturfunktion berechnet werden kann.

In der vorliegenden Studie wurde die Temperaturfunktion der Erhaltungsatmung für jede Messstelle bestimmt, indem 4 bis 5 Temperaturantwortkurven verschiedener Messkampagnen gemittelt wurden. Die Messwerte stammten jeweils aus Phasen, in denen kein Radialzuwachs beobachtet wurde. Es wurden außerdem gezielt solche Temperaturantwortkurven ausgewählt, die einen niedrigen Ordinatenabschnitt sowie einen niedrigen bis mittleren $\mathrm{Q}_{10}$-Wert besaßen. Eine subjektive Auswahl war deshalb notwendig, weil sich bei den Messungen während des Winterhalbjahres oft überhöhte $\mathrm{Q}_{10}$-Werte ergaben. Hohe Temperaturkoeffizienten wurden häufig bei nur sehr geringen Temperaturamplituden ermittelt, wobei messtechnisch bedingt streuende Atmungsraten in einer zufälligen Beziehung zu den wenig variierenden Temperaturen standen. Die Berücksichtigung solcher Temperaturfunktionen bei der Berechnung der Erhaltungsatmung hätten bei höheren Temperaturen im Sommer zu überhöhten Atmungsraten geführt.

Für die mittlere Temperaturfunktion wurden die Parameter $\mathbf{c}$ und $\Delta \mathbf{H a}$ bestimmt und der Jahresgang der Erhaltungsatmung aus den stündlich gemessenen Temperaturen berechnet. Die Wachstumsatmung ergab sich aus der Differenz zwischen den berechneten Tagessummen von Gesamt- (Kap. 3.4.1) und Erhaltungsatmung.

\subsubsection{Räumliche Hochrechnung auf Bestandesebene}

Zur Hochrechnung der Atmungsrate auf Bestandesebene wurden die berechneten Tagessummen der spezifischen Ast-, Stamm- und Grobwurzelatmung mit dem Volumen bzw. der Oberfläche der sieben verschiedenen Durchmesserklassen pro Hektar (bzw. $\mathrm{m}^{2}$ Bestandesgrundfläche) multipliziert. Anschließend wurde die Atmung aller Durchmesserklassen zur Tagessumme der oberirdischen bzw. gesamten Holzatmung des Bestandes aufsummiert.

Dabei wurden die Atmungsraten der verschiedenen Kompartimente den Durchmesserklassen in unterschiedlicher Weise zugeordnet. Im einfachsten Ansatz errechnete sich die Holzatmung des Bestandes $\mathrm{R}_{\text {Stand }}$ nach:

$$
R_{S \tan d}=R_{V, B} \times \sum V_{D K l .5-7}+\frac{R_{V, B}+R_{V, S}}{2} \times V_{D K l .4}+R_{V, S} \times \sum V_{D K l .1-3}+R_{V, C R} \times V_{C R}
$$

Hierbei sind $R_{V}$ die volumenbezogenen Atmungsraten von Ästen (B), Stämmen (S) und Grobwurzeln $(\mathrm{CR})$ und $\mathrm{V}_{\mathrm{DKl} \text {.i-1..i }}$ die Volumina der Durchmesserklassen 1 bis 7 des oberirdischen Holzvorrates und $\mathrm{V}_{\mathrm{CR}}$ das Grobwurzelvolumen. 
Sollte darüber hinaus die durch eine Funktion beschriebene Durchmesserabhängigkeit der Atmungsraten berücksichtig werden, so wurden mit dieser Funktion zunächst die Atmungsraten für den mittleren Durchmesser jeder Holzdurchmesserklasse berechnet. Das Verhältnis zwischen diesen Raten und der mittleren Atmungsrate des fraglichen Kompartiments eines Standortes entsprach einem konstanten Korrekturfaktor $\boldsymbol{k}_{D K l . i-1 . . i}$, der in die Berechnung der Atmungsrate jeder Durchmesserklasse einging. Beispielsweise wurde die Durchmesserabhängigkeit der Astatmung nach:

$$
R_{\mathrm{Re} i s i g}=\sum_{i=5-7} R_{V, B} \times k_{D K l . i} \times V_{D k l . i}
$$

bei der Berechnung der Reisig-Atmung der Bestände berücksichtigt. Zur Prüfung des Einflusses des gewählten Extrapolationsverfahrens auf das Ergebnis der Holzatmung der Bestände wurden die Holzoberfläche und das Volumen als Bezugsgrößen und Durchmesserbeziehungen der spezifischen Atmungsrate verwendet. Auf welcher Datengrundlage die Berechnungen im Einzelfall basieren, ist in den jeweiligen Abschnitten der Ergebnis- und Diskussionskapitel dargestellt.

\subsection{Statistische Auswertung}

Die Berechnung der Parameter der Temperaturantwortkurven $\mathbf{c}$ und $\Delta \mathbf{H a}$ erfolgte unter Anwendung der Gleichungen (14) und (15) (Y. KNYAZIKHIN, pers. Mitteilung) nach der Methode der kleinsten Abweichungsquadrate ebenso im analytischen Verfahren wie die Ermittlung des Bestimmtheitsmaßes $r^{2}$ und der t-Statistik (LOZAN 1992) der Temperaturfunktionen:

$$
c=\frac{\left(\sum \ln R \times \sum \frac{1}{T^{2}}-\sum \frac{\ln R}{T} \sum \frac{1}{T}\right)}{n \times\left(\sum \frac{1}{T^{2}}-\frac{1}{n}\left(\sum \frac{1}{T}\right)^{2}\right)}
$$

$$
\Delta H a=-\frac{\sum \frac{\ln R}{T}-\frac{1}{n} \sum \frac{1}{T} \sum \ln R}{\sum \frac{1}{T^{2}}-\left(\sum \frac{1}{T}\right)^{2}} \times R g
$$

Dabei sind $\mathrm{R}$ die Stundenwerte der Atmungsraten, $\mathrm{T}$ die Stundenwerte der absoluten Temperatur in $\mathrm{K}$, $\mathrm{n}$ die Anzahl der Wertepaare und Rg die allgemeine Gaskonstante.

Zum Vergleich linearer Regressionsfunktionen wurden die zu vergleichenden Datensätze mit einem paarweisen t-Test auf Unterschiede der Steigung und des Achsenabschnitts getestet. Unterschieden sich Steigung oder Achsenabschnitt signifikant voneinander $(\mathrm{P}<0.05)$, wurden auch die Regressionsgeraden als verschieden betrachtet (LOZAN 1992).

Stichproben, die nach dem Shapiro-Wilk-Test normalverteilt waren $(\mathrm{P}>0.1)$, wurden mit einer einfaktoriellen Varianzanalyse daraufhin getestet, ob der Einfluss der unabhängigen Variablen 
signifikant ist und einem Mittelwertsvergleich für unbalancierte, unabhängige Stichproben nach Scheffé unterzogen.

Mehr als zwei nicht normalverteilte Stichproben wurden mit einem Kruskal-Wallis-Test auf signifikante Unterschiede getestet. Der Vergleich zweier Stichproben erfolgte dann mit dem U-Tests nach Mann \& Whitney. Die Tests wurden mit dem Computerprogramm SAS (Statistical Analysis System, SAS Institute Inc., Cary, NC, USA) durchgeführt.

Soweit nicht anders vermerkt werden in den Abbildungen und Tabellen das arithmetische Mittel und die Standardabweichung angegeben. 


\section{Ergebnisse}

Mit dem Ziel, den Kohlenstoffbedarf für den Atmungsstoffwechsel der verholzten Kompartimente beider untersuchten Bestände zu berechnen, wird im Folgenden zunächst die Variabilität der Atmung im zeitlichen Verlauf auf Ebene von Tages- und Jahresgängen dargestellt. Anschließend wird die räumliche Variabilität innerhalb der Kompartimente, der Individuen und zwischen den Standorten untersucht. Die Berechnung der Biomassevorräte und ihrer Verteilung auf die Kompartimente sowie innerhalb derselben ergänzt die Datengrundlage, mit der schließlich die Atmungsraten auf Bestandesebene ermittelt werden.

\subsection{Die Variabilität der Holzatmung im zeitlichen Verlauf}

Um ein Bild über die Datengrundlage für alle späteren Betrachtungen zu geben, werden zunächst typische Tagesverläufe der $\mathrm{CO}_{2}$-Abgabe von Ästen, Stämmen und Grobwurzeln und der Einfluss biotischer und abiotischer Faktoren untersucht.

Die quantitativen Betrachtungen der Atmung und ihrer Temperaturabhängigkeit erfolgen bei der Darstellung des jahreszeitlichen Verlaufs.

\subsubsection{Die Holzatmung im Tagesgang}

Im Folgenden soll an ausgewählten Beispielen ein Überblick über typische Tagesverläufe der Atmung verholzter Kompartimente gegeben werden. Zugunsten der Übersichtlichkeit werden ausschließlich volumenbezogene Atmungsraten dargestellt. Als wesentliche Einflussgröße der Atmungsaktivität sind außerdem die Xylem- und Lufttemperatur und zur weiteren Charakterisierung der Witterung die photosynthetisch aktive Strahlung (PAR) im Tagesverlauf aufgetragen.

In Abb. 5 sind Tagesgänge der Atmungsraten und der Xylemtemperaturen von Ästen, Stämmen und Grobwurzeln sowie der Lufttemperatur und der PAR verschiedener Messkampagnen aus den Vegetationsperioden 1997 und 1998 dargestellt. Die Atmungsraten der Äste verliefen weitgehend parallel zu den Xylemtemperaturen, wobei die minimalen Werte in den frühen Morgen- und Vormittagsstunden erreicht wurden (Abb. 5 a). Atmungsraten wie Temperaturen stiegen am Vormittag mit zunehmender Einstrahlung und Erwärmung der Luft an. Beim wenig beschatteten Ast 4 war der Anstieg der Atmungsrate am 31.08.97 gegenüber der Temperatur um $2 \mathrm{~h}$ verzögert, während am folgenden Tag beide Kurven zeitgleich anstiegen. Der Temperaturanstieg war wie der Anstieg der Atmungsraten bei diesem Ast am Vormittag beider Tage deutlich steiler als bei den Ästen 2 und 6, so dass ausgehend von gleichen nächtlichen Temperaturen die Temperatur dieses Astes die der anderen am Tag um bis zu $4{ }^{\circ} \mathrm{C}$ überstieg. Die maximalen Atmungsraten traten zeitgleich mit dem Temperaturmaximum am Nachmittag zwischen 15:14 h (Ast 4) und 17:30 h (Ast 6) auf und erreichten bei Temperaturen von 27 (Ast 2 und 6) bzw. $29{ }^{\circ} \mathrm{C}$ (Ast 4) Werte von 109.6 (Ast 2), 244.9 (Ast 4) und $41.6 \mu \mathrm{mol} \mathrm{CO}_{2} \mathrm{~m}^{-3} \mathrm{~s}^{-1}$ (Ast 6). Ast 4 kühlte nach Erreichen des Maximums schneller ab und wies so um 18:00 h die gleiche Temperatur wie die Äste 2 und 6 auf. Während der Nacht kühlten die Äste bis zum Erreichen des Temperaturminimums, dessen Niveau sich zwischen den Messstellen nicht unterschied, weiter ab.

Die Atmungsraten folgten in der Nacht eng dem Temperaturverlauf. Sie sind mit $\mathrm{r}^{2}$-Werten zwischen 0.92 und $0.98 \mathrm{sehr}$ stark mit der Temperatur korreliert und lassen sich daher gut durch die Arrheniusfunktion (8) beschreiben. Mit Ausnahme des zeitlich verzögerten Anstiegs der Atmungs- 
rate von Ast 4 am 31.08. kommt die sehr enge Temperaturbeziehung auch im zeitgleichen Erreichen der Maxima und Minima von Temperatur und Atmungsrate zum Ausdruck.
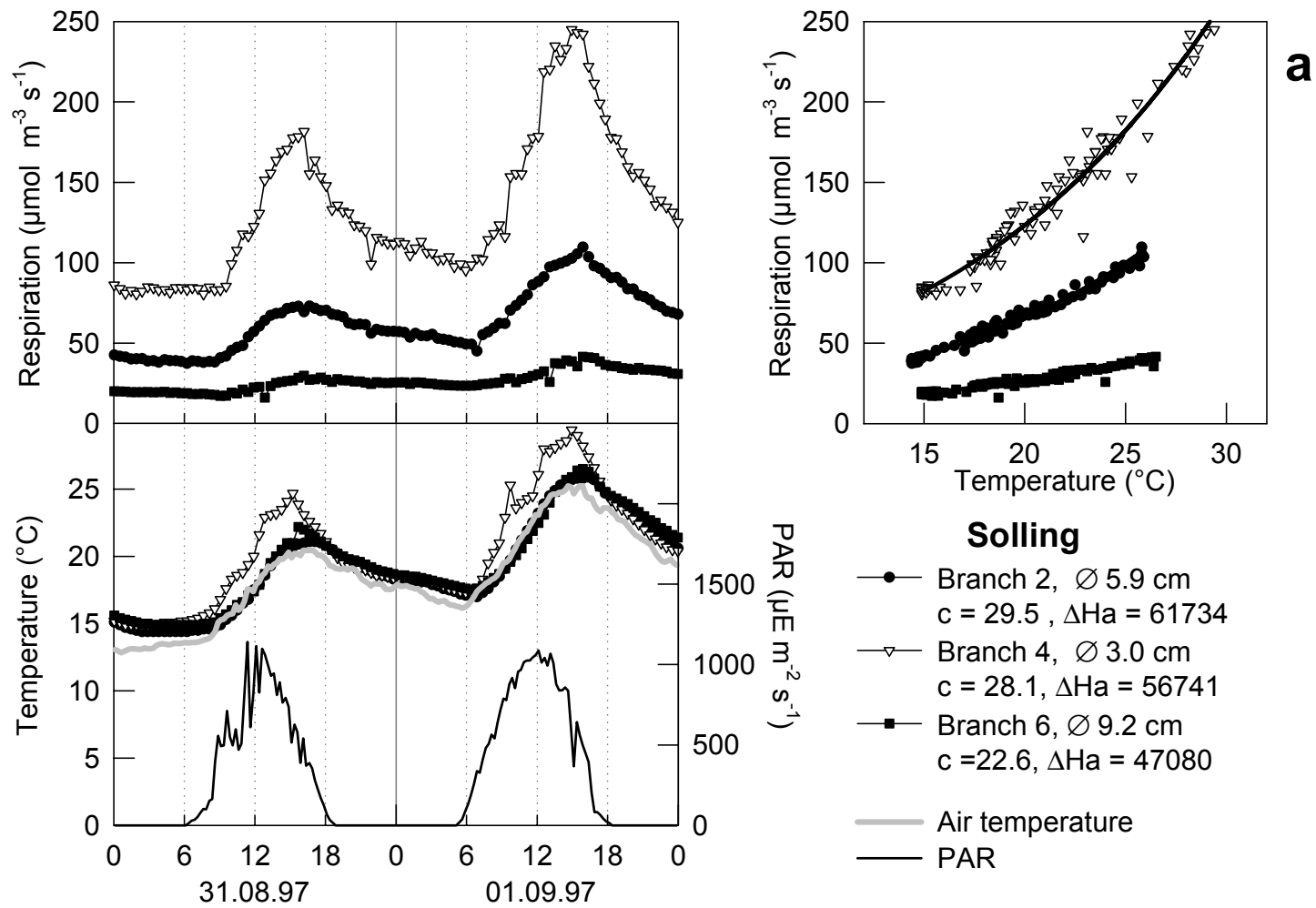

Solling

- Branch 2, $\varnothing 5.9 \mathrm{~cm}$ $\mathrm{c}=29.5, \Delta \mathrm{Ha}=61734$

$\longrightarrow$ Branch 4, $\varnothing 3.0 \mathrm{~cm}$ $\mathrm{C}=28.1, \Delta \mathrm{Ha}=56741$

$\rightarrow$ Branch 6, $\varnothing 9.2 \mathrm{~cm}$ $\mathrm{C}=22.6, \Delta \mathrm{Ha}=47080$

Air temperature PAR
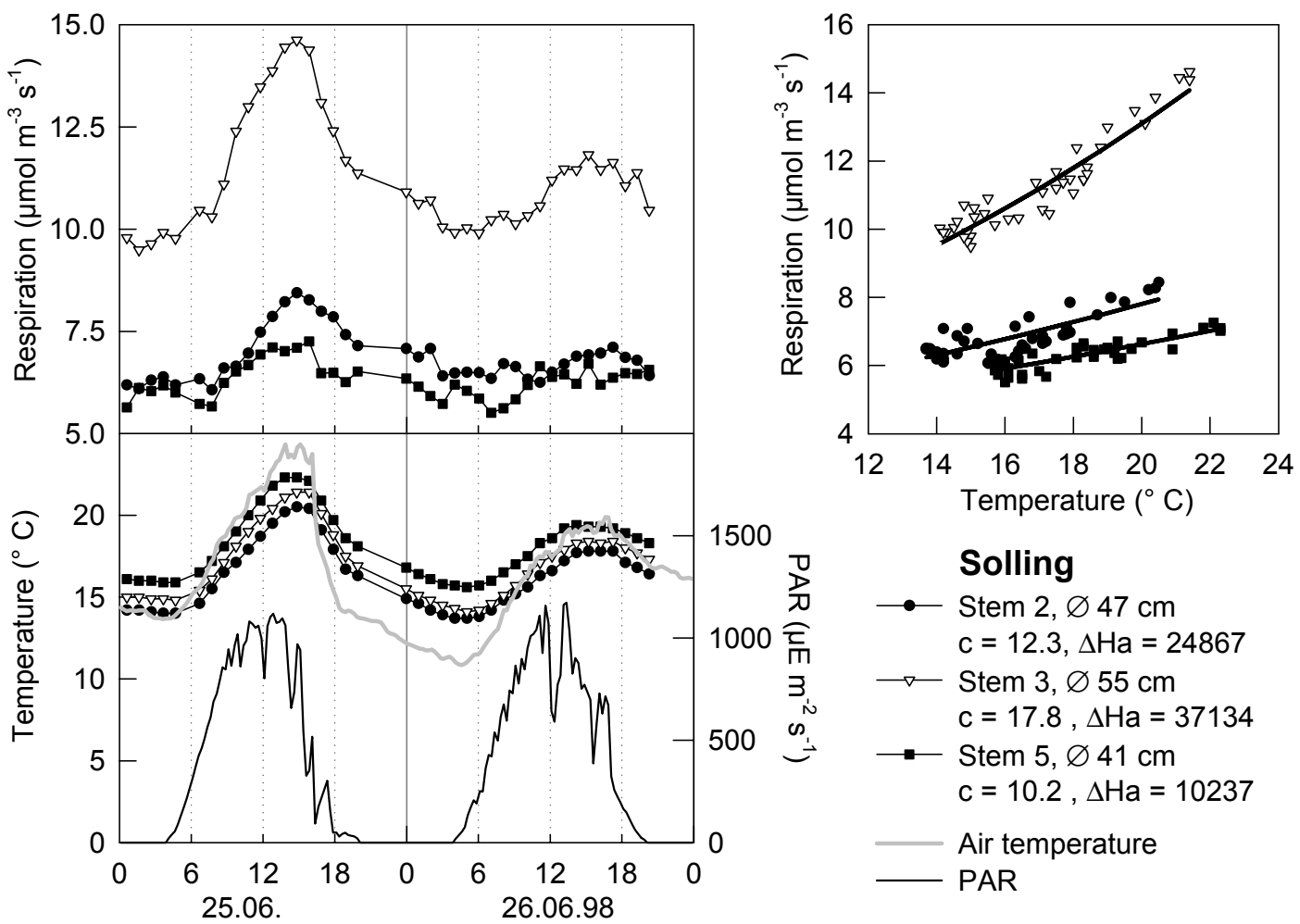

b

Abb 5 a - c: Erklärung und Fortsetzung auf S. 40 

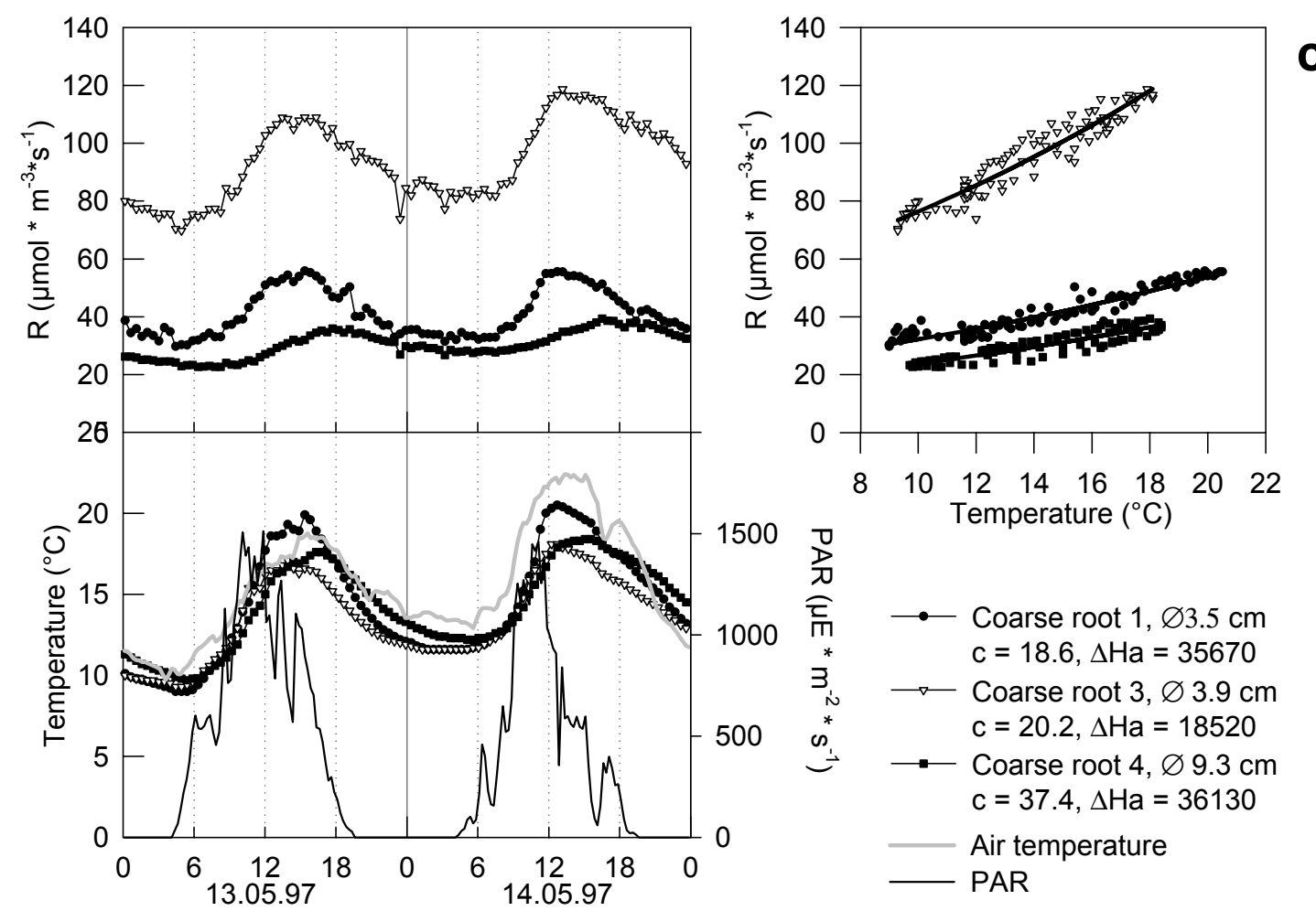

Abb. 5 a - c: Tagesgänge der Atmungsraten und Xylemtemperaturen, der Lufttemperatur und der PAR sowie die Temperaturfunktionen der Atmungsraten von a: Ästen (Solling, August/Septemer 1997), b: Stämmen (Solling, Juni 1998) und c: Grobwurzeln (Göttinger Wald, Mai 1997).

Während bei den Ästen die Amplitude der Xylemtemperatur unter dem Einfluss direkter Strahlung die Amplitude der Lufttemperatur übersteigen konnte, waren die Tagesgänge der Xylemtemperaturen von Stämmen (Abb. 5 b) gegenüber der Lufttemperatur gedämpft. So verlief die Temperaturkurve des Stammxylems bei der Erwärmung am Vormittag wie auch bei der Abkühlung nach dem Erreichen des Maximums am Nachmittag weniger steil als die der Lufttemperatur. Bei einer zeitlichen Auflösung von einer Messung pro Stunde war für die Temperatur des oberflächennahen Xylems der Stämme keine zeitliche Verzögerung beim Erreichen der Tagesminimums und -maximums gegenüber der Luftemperatur zu erkennen. Die zeitlichen Verläufe der Atmungsraten konnten ausgeprägte Tagesgänge zeigen (Stamm 3 und 2) oder wie bei Stamm 5 mit insgesamt niedriger Atmungsaktivität schwächere tageszeitliche Änderungen aufweisen. Wie die Atmungsraten der Äste in Abb. 5 a verliefen auch die Atmungsraten der Stämme parallel zu denen der Xylemtemperaturen, so dass die Tagesminima und -maxima beider Parameter etwa zeitgleich erreicht wurden. Bei allen drei Stämmen sind die Temperaturbeziehungen hochsignifikant und im gewählten Beispiel mit $\mathrm{r}^{2}$-Werten zwischen 0.69 und 0.90 etwas weniger eng als bei den Ästen. Bei $15{ }^{\circ} \mathrm{C}$ bleiben die Atmungsraten der Stämme 2, 3 und 5 mit Werten von 6.5, 10.1 und $5.7 \mu \mathrm{mol} \mathrm{CO} \mathrm{Cm}^{-3} \mathrm{~s}^{-1}$ deutlich niedriger als die der Äste mit 69.2 (Ast 2), 82.3 (Ast 4) und $18.9 \mu \mathrm{mol} \mathrm{CO} \mathrm{m}^{-3} \mathrm{~s}^{-1}$ (Ast 6).

Der in Abb. 5 c dargestellte Tagesgang der Grobwurzeln stellt insofern eine Besonderheit dar, als dass Temperaturamplituden von über $10{ }^{\circ} \mathrm{C}$ nur zu Beginn der Vegetationsperiode bei unvollständig geschlossenem Kronendach auftraten. Außerdem waren die Küvetten nach der zu diesem Zeitpunkt erfolgten Installation der Zuwachsmaßbänder nicht wieder mit Aushub bedeckt worden, um einen deutlichen Tagesgang der Temperatur und eine möglichst deutliche Temperaturantwort der 
Atmungsraten zu erhalten. Gegenüber den Astküvetten waren die Küvetten der Grobwurzeln jedoch nicht direkter Sonneneinstrahlung ausgesetzt.

Wie bereits für die Äste und Stämme beschrieben, zeigten auch die Atmungsraten der Grobwurzeln jeweils einen deutlichen Tagesgang mit einem der Temperatur parallelen Verlauf. Mit dem steilen Temperaturanstieg an den Vormittagen ging nur bei den Grobwurzeln 1 und 3 ein entsprechend steiler Anstieg der Atmungsraten einher. Beide Wurzeln erreichten am 14.05.97 um 12:43 ihre Maximaltemperatur und das Maximum der Atmungsaktivität. Bei Grobwurzel 4 stieg die Temperatur vormittags ebenso steil an. Anders als die Grobwurzeln 1 und 3 setzte sich dieser Anstieg am Nachmittag mit flacherem Kurvenverlauf bis zum Erreichen des Maximums um 15:30 h fort. Die Atmungsrate stieg demgegenüber bis zum Nachmittag nahezu kontinuierlich an und erreichte ca. 30 min nach der Temperatur den Maximalwert. In der Auftragung gegen die Temperatur ist der langsamere Anstieg und die Zeitverzögerung beim Erreichen des Tagesmaximums deutlich als Hysteresisschleife zu erkennen. Die Atmungsraten aller drei Grobwurzeln sind eng mit der Temperatur korreliert $\left(\mathrm{r}^{2}=0.92,0.91\right.$ und 0.80 für die Grobwurzeln 1, 3 und 4).

Bei allen in Abb. 5 dargestellten Beispielen wiesen Temperatur und $\mathrm{CO}_{2}$-Abgabe deutliche Amplituden auf. Die Atmungsrate aller Messstellen standen jeweils in enger Beziehungen zur Temperatur. In Abb. 6 sind die Tagesgänge der Atmungsraten dreier Stämme im Göttinger Wald dargestellt, die an zwei verschiedenen Messterminen bei vergleichbarer Temperaturamplitude sehr unterschiedlich auf Temperaturänderungen reagierten.

Für den Tagesgang im Oktober 1998 (Abb. 6 a) ergaben sich bei einer Amplitude von 3.0 bis $3.2{ }^{\circ} \mathrm{C}$ enge und signifikante Beziehungen zwischen Temperatur und Atmungsrate. Demgegenüber änderte sich die $\mathrm{CO}_{2}$-Abgabe der Stämme 3 und 4 im Juli 1997 nicht mit der Temperatur (Abb. 6 b). Bei Stamm 5 war der Tagesgang der $\mathrm{CO}_{2}$-Abgabe der Temperatur schwach gegenläufig. Die maximale Atmungsrate wurde hier in der Nacht gemessen, während die Temperatur einen typischen Tagesgang zeigte und die höchsten Werte in den frühen Nachmittagsstunden erreichte. Das Fehlen einer signifikanten Temperaturbeziehung ist offensichtlich nicht auf eine $\mathrm{zu}$ geringe Temperaturamplitude bei der Messung im Juli $\left(2.5-3.2^{\circ} \mathrm{C}\right)$ zurückzuführen, da im Oktober 1998 eine Spanne von $3.0^{\circ} \mathrm{C}$ eine signifikante Änderung der Atmungsrate bewirkte.

Noch ausgeprägter als bei Stamm 5 (Abb. 6 b) ist der dem Temperaturverlauf gegenläufige Tagesgang der Atmungsraten der Äste 4 und 6 (Abb. 7 a). Während die Xylemtemperaturen um etwa 9:00 $\mathrm{h}$ anzusteigen begannen und um 12:00 h maximale Werte erreichten, fielen die Atmungsraten ab 8:00 h zunächst für 2-3 Stunden ab und begannen erst am späten Vormittag anzusteigen, um schließlich zwischen 15:00 und 16:00 h das Tagesmaximum zu erreichen. Der Tagesgang der Atmungsraten von Ast 5 verlief zwar gleichsinnig mit der Temperatur und beide Parameter standen in signifikanter Beziehung, jedoch sank auch bei diesem Ast die Atmungsrate am Vormittag des 07.11. zunächst leicht $\mathrm{ab}$ und stieg dann wie schon am Vortag gegenüber der Temperatur zeitverzögert an. Die maximale Atmungsrate wurde erst 2 Stunden nach dem Temperaturmaximum erreicht, so dass bei der Auftragung der Atmung gegen die Temperatur eine deutliche Hysteresisschleife zu erkennen ist.

In Abb. 7 b sind Verläufe der Atmungsraten von Wurzeln dargestellt, die trotz geringer Temperaturamplituden ausgeprägte Tagesgänge mit einem typischen Maximum am Nachmittag und dem Minimum in den frühen Morgenstunden zeigten. Grobwurzel 4 zeigte bei einer Temperaturspanne von $3{ }^{\circ} \mathrm{C}$ noch eine enge Temperaturabhängigkeit der Atmungsraten mit $\mathrm{r}^{2}=0.79$. Die Reaktion auf 

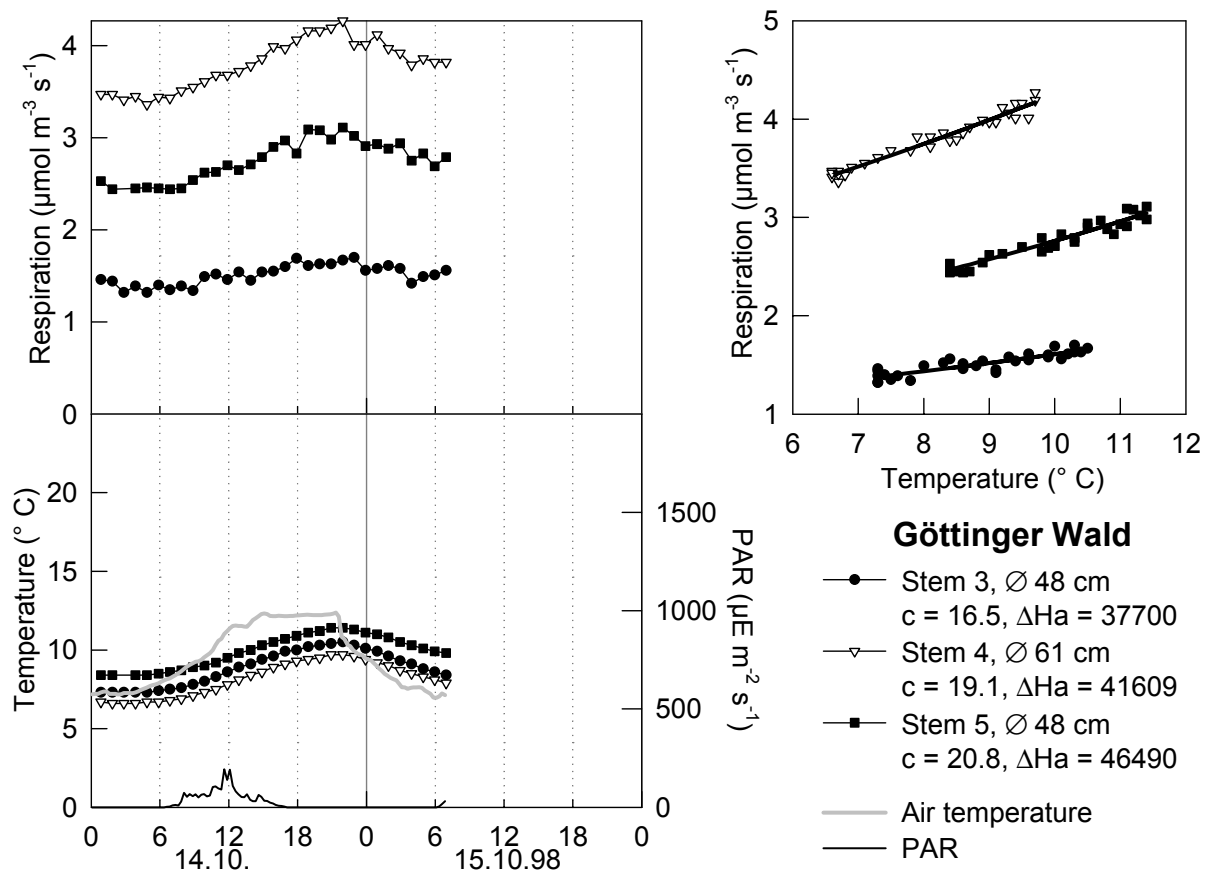

a
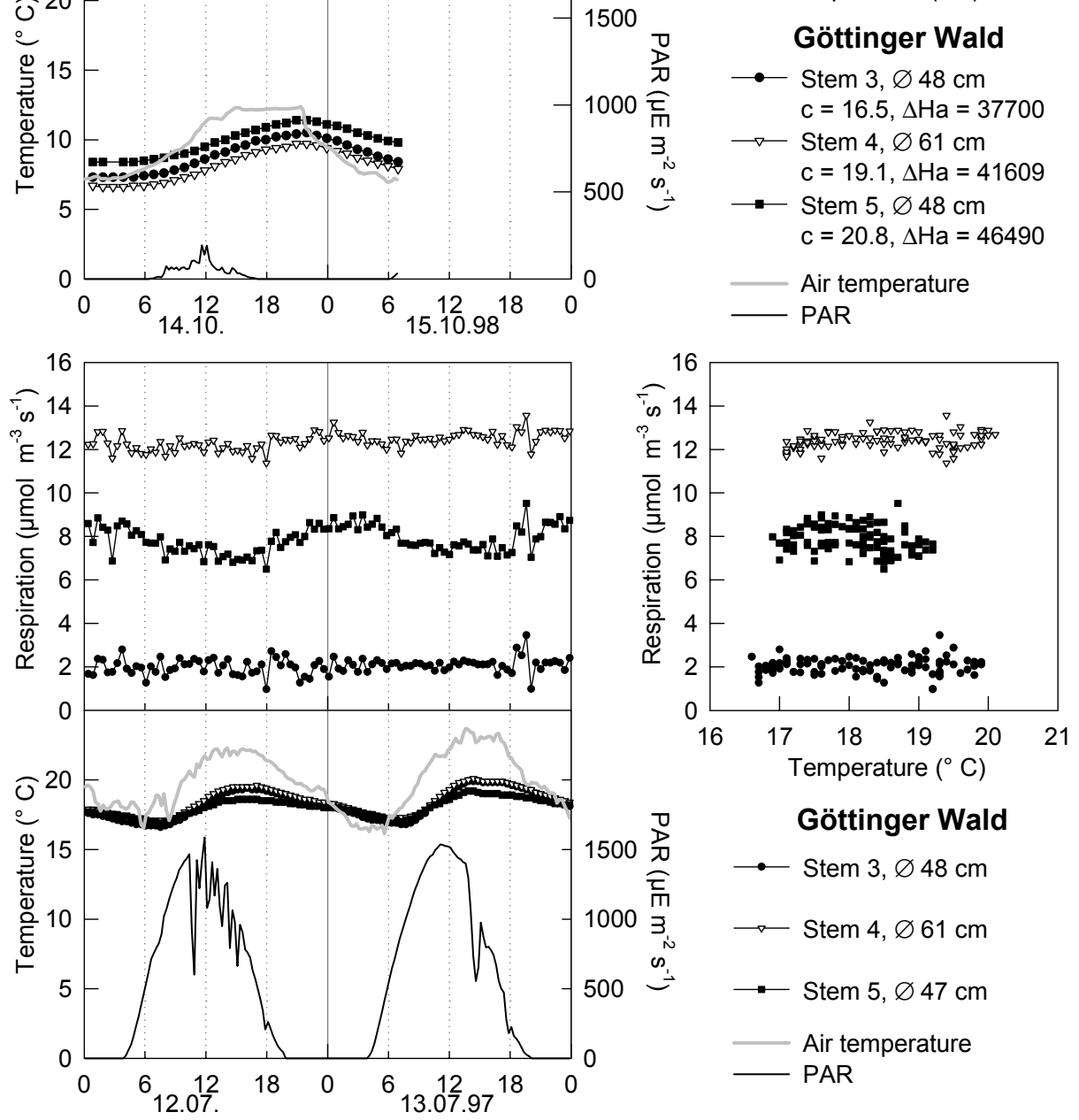

b

Abb. 6 a und b: Tagesgänge der Atmungsraten und Xylemtemperaturen, der Lufttemperatur und der PAR sowie die Temperaturfunktionen der Atmungsraten von Stämmen im Göttinger Wald a: mit signifikanter Temperaturabhängigkeit und b: ohne Reaktion der Atmung auf Temperaturänderungen.

Temperaturänderungen ist mit einem $\mathrm{Q}_{10}$-Wert von 1.97 etwas stärker als die der in Abb. $5 \mathrm{c}$ dargestellte Atmung anderer Grobwurzeln $\left(\mathrm{Q}_{10}=1.68\right.$ - 1.73).

Demgegenüber übersteigt der Temperaturkoeffizient von Grobwurzel 1 (Abb. 7 b) mit $\mathrm{Q}_{10}=9.02$ diese Werte nahezu um den Faktor 5. Bei einer Temperaturänderung von $2.6{ }^{\circ} \mathrm{C}$ erhöhte sich die Atmungsrate von 42.5 auf $79.4 \mu \mathrm{mol} \mathrm{CO} \mathrm{Cm}^{-3} \mathrm{~s}^{-1}$. Die Temperaturabhängigkeit der Atmung ist mit einem $\mathrm{r}^{2}$-Wert von 0.54 weniger eng als die bislang dargestellten Temperaturbeziehungen der Wurzelatmung. 

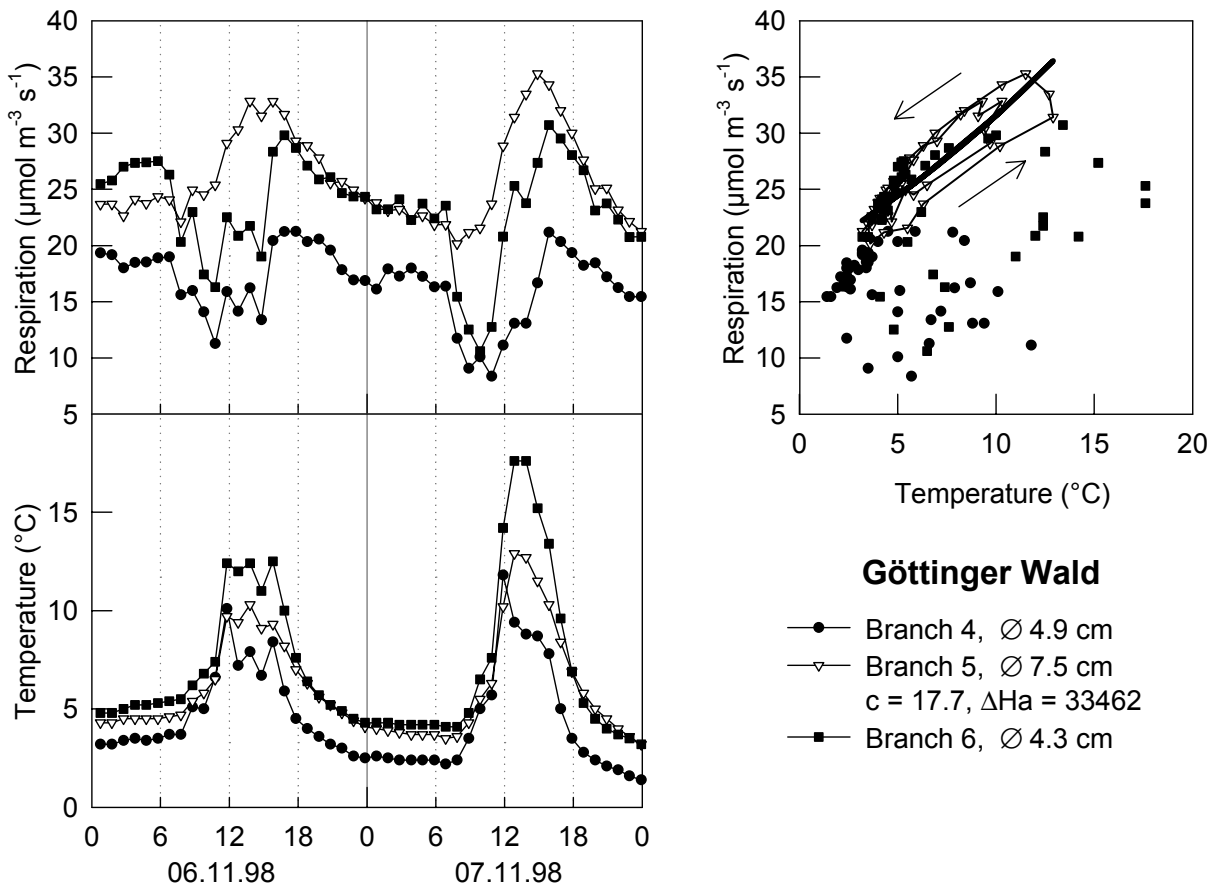

a
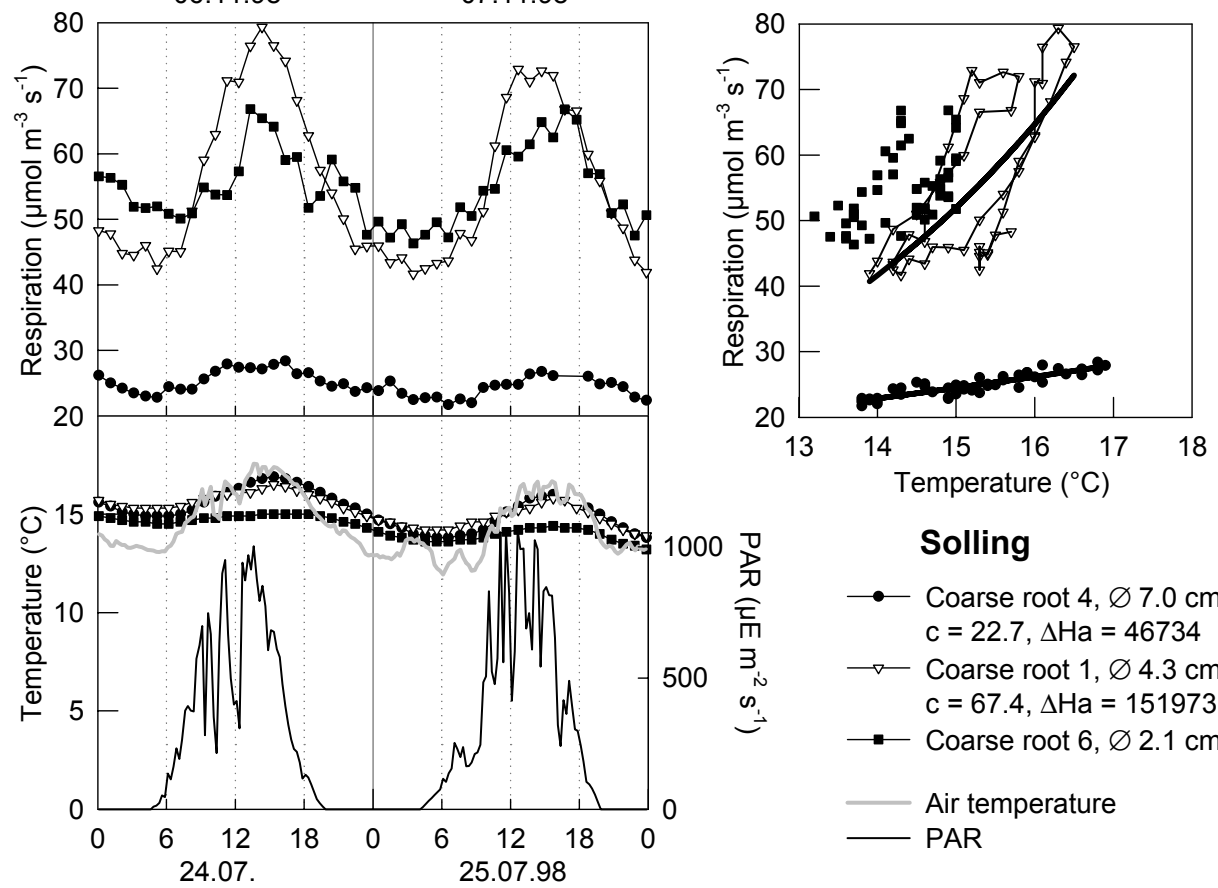

b

Abb. 7 a und b: Tagesgänge der Atmungsraten und Xylemtemperaturen, der Lufttemperatur und der PAR sowie die Temperaturfunktionen der Atmungsraten von a: Ästen (Göttinger Wald, November 1998) und b: Grobwurzeln (Solling, Juli 1998). Die Pfeile in a geben den zeitlichen Verlauf des Temperaturgangs an (Hysteresis-Schleife).

Die Wurzel 6 schließlich erfuhr an beiden Tagen Temperaturänderungen von nur $1.8{ }^{\circ} \mathrm{C}$ und zeigte dabei am Tag Atmungsraten, die die nächtlichen Werte um den Faktor 1.4 überstiegen (66.8 gegenüber $47.2 \mu \mathrm{mol} \mathrm{m}^{-3} \mathrm{~s}^{-1}$ ). Die Atmung war nicht mit der Temperatur korreliert.

Es wird deutlich, dass die Atmungsraten aller Kompartimente sehr unterschiedliche Tagesgänge aufweisen können. Es wurden sowohl Tagegänge der Atmung beobachtet, die parallel zu denen der Temperatur verliefen (Abb. 5 a-c, Abb. 6 a), als auch solche, die einen gegensätzlichen zeitlichen Verlauf von Atmung und Temperatur zeigten (Abb. 7 a). Bei anderen Tagesverläufen wiederum änderte sich die Atmungsrate trotz einer deutlichen Temperaturamplitude nicht (Abb. 6 b). Umge- 
kehrt konnten ausgeprägte Tagesgänge der Atmungsrate beobachtet werden, obwohl sich die Xylemtemperatur kaum änderte (Abb. 7 b).

\subsubsection{Der Einfluss des Temperaturgradienten im Holz auf den Tagesgang der $\mathrm{CO}_{2}$-Abgabe}

Im Folgenden sollen die Ursachen dafür untersucht werden, dass die Atmungsraten nicht immer eng an die Temperaturverläufe gekoppelt waren. Die beobachteten Hysteresisschleifen (Abb. 5c, Grobwurzeln 3 und 4 mit $\mathrm{D}=3.8$ bzw. $9.3 \mathrm{~cm}$ und Abb. 7 a, Ast $5 \mathrm{D}=7.5 \mathrm{~cm}$ ) deuten auf eine Phasenverschiebung der Zeitverläufe von Temperatur und Atmung hin, die in einer Verzögerung der $\mathrm{CO}_{2}$-Abgabe über die Oberfläche begründet sein kann. Ebenso ist es möglich, dass die oberflächennah gemessenen Temperaturen nicht repräsentativ für die der tieferen Holzschichten sind und die Phasenverschiebung zwischen Temperatur und Atmung ein Ausdruck der Phasenverschiebung der Temperaturen im Tiefenprofil des Holzes ist.

Anschließend soll untersucht werden, ob Prozesse wie Rindenphotosynthese und/oder der $\mathrm{CO}_{2}$-Transport mit dem Xylemsaft Ursachen für die Entkopplung von Temperatur und $\mathrm{CO}_{2}$-Abgabe sein können.

In Abb. 8 a sind die Tagesgänge der Atmungsrate der Stammküvette 4 im Solling, die Holztemperatur in verschiedenen Tiefen sowie die Tagesverläufe von Lufttemperatur und PAR dargestellt. Atmungsrate wie Temperaturen zeigten ausgeprägte Tagesgänge. Die Tagesminima und -maxima der oberflächennah gemessenen Holztemperatur traten gegenüber der Lufttemperatur mit einer Verzögerung von null bis drei Stunden auf. Gegenüber der Holztemperatur in $0.5 \mathrm{~cm}$ Tiefe waren die Temperaturen der $1-2 \mathrm{~cm}$ tiefer gelegenen Holzschichten hinsichtlich der Amplitude gedämpft, die Tagesminima und -maxima wurden aber zeitgleich erreicht. Einzige Ausnahme war das Tagesmaximum vom 27.09.98, das in $2.5 \mathrm{~cm}$ Tiefe um $1 \mathrm{~h}$ verzögert auftrat. In größerer Entfernung von der Oberfläche wurden die Tagesmaxima der Temperatur deutlich später als an der Oberflächen beobachtet. In einer Tiefe von $6.5 \mathrm{~cm}$ betrug die Verzögerung 3 Stunden, in $12.5 \mathrm{~cm}$ Tiefe waren es 4 bis $7 \mathrm{~h}$. Auch die Tagesminima traten in diesen Tiefenstufen mit einer Zeitverzögerung von 0 bis 2 bzw. 2 bis 5 Stunden auf. In der Auftragung der Atmungsrate gegen die Temperatur (Abb. 8 b) sind charakteristische Hysteresisschleifen zu erkennen. Diese sind bei der Auftragung gegen die Lufttemperatur am deutlichsten und bei den Holztemperaturen mit zunehmender Tiefe weniger ausgeprägt. Die Abhängigkeit der Atmungsraten von der Lufttemperatur ist nicht signifikant. Für die Holztemperaturen lassen sich signifikante Temperaturfunktionen errechnen, deren $\mathrm{r}^{2}$-Werte bis in eine Tiefe von $6.5 \mathrm{~cm}$ zunehmen, wobei sich der $\mathrm{Q}_{10}$-Wert um mehr als das Doppelte von 1.61 auf 4.03 erhöht.

In Abb. 9 wird bei der Auftragung der Atmungsrate gegen die Temperatur und bei der Berechnung der Temperaturfunktionen eine zeitverzögerte Temperaturantwort der Atmung angenommen. Die Hysteresisschleifen werden dadurch stark abgeschwächt oder sind gar nicht mehr zu erkennen.

Die höchsten $\mathrm{r}^{2}$-Werte ergeben sich bei einer Phasenverschiebung von 4 Stunden gegenüber der Lufttemperatur, von 3 Stunden gegenüber der Holztemperatur in 0.5 und $1.5 \mathrm{~cm}$ Tiefe und von $2 \mathrm{~h}$ gegenüber der Temperatur in $2.5 \mathrm{~cm}$ Tiefe. Bei $6.5 \mathrm{~cm}$ Holztiefe steigt der $\mathrm{r}^{2}$-Wert bei einer Berechnung der Funktion mit Phasenverschiebung nicht weiter an. Für die Temperatur in $12.5 \mathrm{~cm}$ Tiefe besteht in keinem Fall eine signifikante Abhängigkeit der Atmungsraten. Die $\mathrm{Q}_{10}$-Werte liegen zwischen 1.67 bei der Temperaturfunktion für die Luft und 4.03 bei Verwendung der in $6.5 \mathrm{~cm}$ Tiefe gemessenen Xylemtemperatur. 

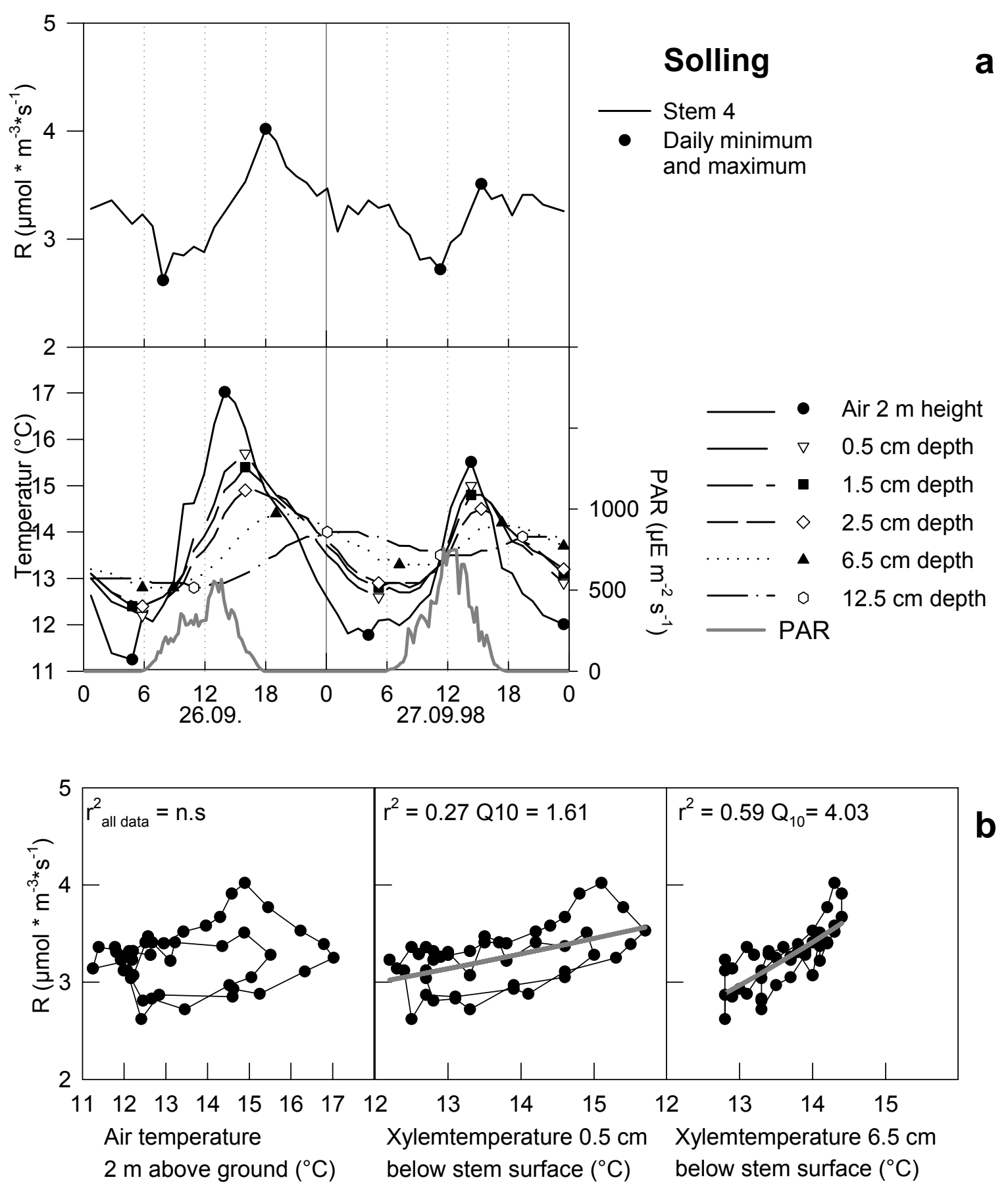

Abb. 8. a und b: a) Tagesgänge der Atmungsraten von Stamm 4 (Solling) sowie der Lufttemperatur, der PAR und der Xylemtemperaturen, die in 0.5, 1.5, 2.5, 6.5 und $12.5 \mathrm{~cm}$ Tiefe unter der Stammoberfläche gemessen wurden. Bei den Tagesgängen sind jeweils das Tagesminimum und -maximum durch Symbole gekennzeichnet. In b) sind die Atmungsraten gegen die Lufttemperatur und die Xylemtemperaturen in 0.5 und $6.5 \mathrm{~cm}$ Tiefe aufgetragen. Temperaturfunktionen sind nur bei signifikanter Abhängigkeit $(\mathrm{P}<0.01)$ abgebildet. 

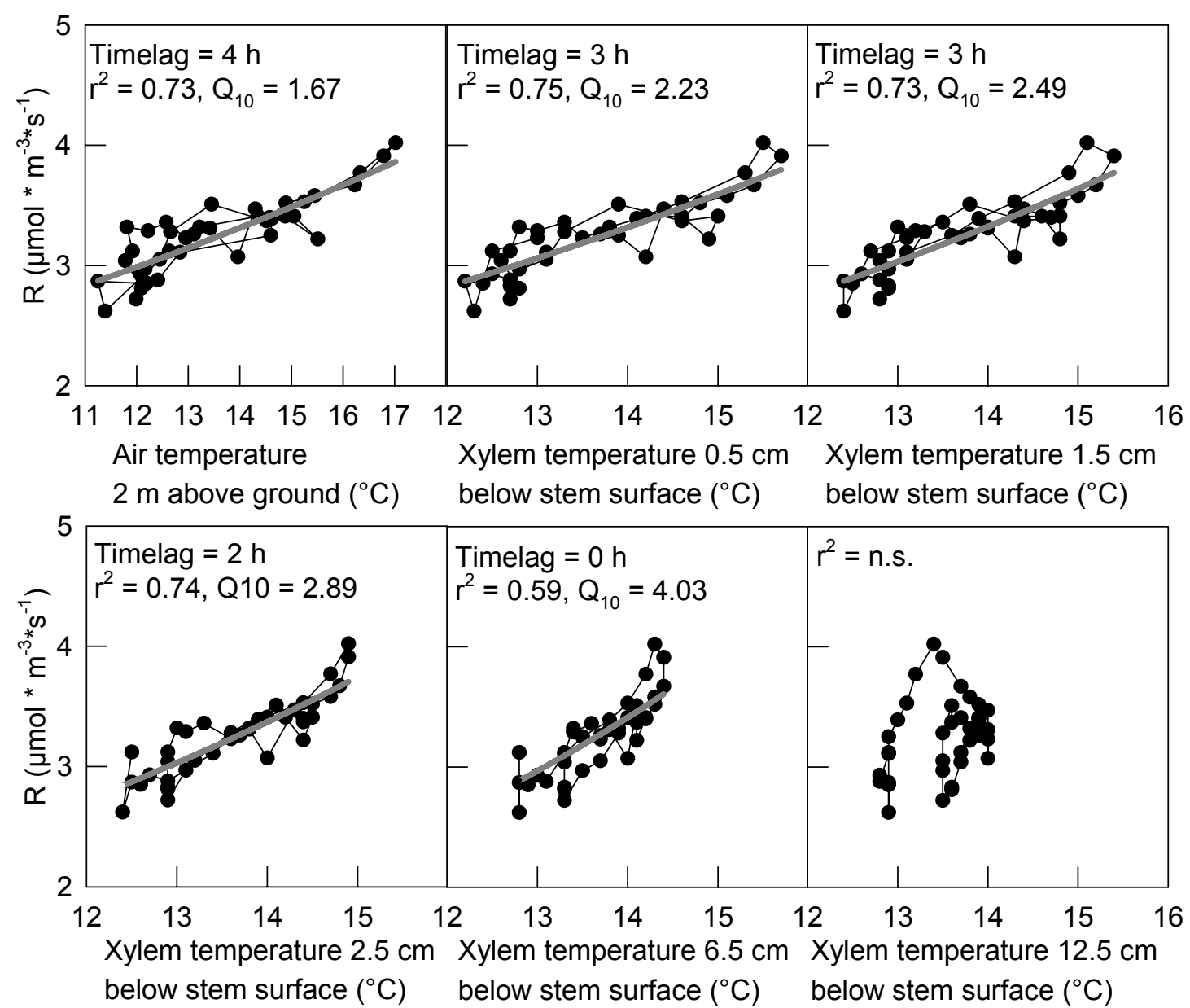

Abb. 9: Auftragung der Atmungsraten von Stamm 4 (Solling) gegen die Lufttemperatur und die Xylemtemperatur in verschiedenen Tiefen. Es wurde jeweils die Zeitverzögerung der Atmung gegenüber der Temperatur berücksichtigt, bei der sich für die Temperaturfunktion der maximale $\mathrm{r}^{2}$-Wert ergab. Funktionen sind nur bei signifikanter Abhängigkeit dargestellt.

\subsubsection{Der Einfluss von Rindenphotosynthese und $\mathrm{CO}_{2}$-Transport im Xylemsaft auf die $\mathrm{CO}_{2}$-Abgabe im Tagesgang}

Um den Einfluss des Lichts auf die $\mathrm{CO}_{2}$-Abgabe zu prüfen wurden die während der Nacht gemessenen Daten separat analysiert. Dabei zeigte sich, dass die in der Nacht gemessenen Atmungsraten deutlich enger mit den Temperaturen von Luft und Xylem in den äußeren drei Tiefenstufen korreliert sind als bei Berücksichtigung aller Daten. Die zusätzliche Berücksichtigung einer Zeitverzögerung hatte bei den Nachtdaten keinen Einfluss auf das Bestimmtheitsmaß. Die Auftragungen der Atmungsraten gegen die Temperatur in Abb. 10 zeigen deutlich die engere Temperaturbeziehung, wobei die nächtlichen Atmungsraten bei gleicher Temperatur über den am Tag gemessenen Werten liegen. Die $\mathrm{Q}_{10}$-Werte der Nachtdaten-Funktionen unterscheiden sich mit Werten zwischen 1.74 für die Lufttemperatur und 2.29 für die Temperatur in $6.5 \mathrm{~cm}$ Tiefe deutlich weniger als bei den Funktionen ganzer Tagesgänge mit Zeitverzögerung (Abb. 9).

In Abb. $10 \mathrm{~b}$ sind berechnete und gemessene Atmungsraten einander gegenübergestellt. Für die Berechnung wurden drei verschiedene Temperaturfunktionen verwendet, die sich zwischen den Atmungsraten und Holztemperaturen in $0.5 \mathrm{~cm}$ Tiefe ermitteln ließen: einerseits für die während der Nacht gemessenen Wertepaare, andererseits für alle Daten ohne und mit dreistündiger Zeitverzögerung (Abb. 10 a, obere Reihe, mittlere Grafik). Mit der Funktion für alle Daten ohne zeitliche 
Verzögerung errechnete sich aus der Temperatur ein typischer Tagesgang für die Atmung, der jedoch am Tag über und in der Nacht unter den gemessenen Atmungsraten lag. Im Beispiel ergeben sich für die Tagstunden in der Summe um 4.2 (Tag 1) bzw. $1.8 \%$ (Tag 2) überhöhte Werte während für die Nacht um $6.5 \%$ zu niedrige Atmungsraten berechnet wurden. Auf Ebene der Tagessummen kompensieren sich diese gegenläufigen Abweichungen weitgehend, so dass die auf dieser Basis berechneten Tagesummen der Atmung gut mit den gemessenen übereinstimmen. Der Tagesgang, der sich aus der Funktion für alle Daten errechnet, für die eine Zeitverzögerung von 3 Stunden angenommen wurde, stellt den Verlauf der gemessenen Atmungsraten gut dar und die berechneten und gemessenen Tagessummen stimmen überein.

Die für die Nachtdaten berechneten Temperaturfunktionen geben die nächtlichen Atmungsraten ebenso gut wieder. Die für die Tageshellphase berechneten Atmungsraten liegen in der Summe um 12.1 (Tag 1) bzw. 8.5 \% (Tag 2) über den gemessenen Werten (bezogen auf die $\mathrm{CO}_{2}$-Abgabe in der Zeit von 06:00- 18:00 h). Diese überhöhten Werte lassen sich dadurch erklären, dass die tatsächlich durch Atmung gebildete $\mathrm{CO}_{2}$-Menge nur zum Teil lokal über die Stammoberfläche in die Küvette abgegeben wurde. Das fehlende $\mathrm{CO}_{2}$ wurde lokal durch Rindenphotosynthese refixiert und/oder mit dem Xylemsaft abtransportiert. Die Summe von Rindenphotosynthese- und $\mathrm{CO}_{2}$-Transportrate kann aus der Differenz zwischen berechneten und gemessenen Atmungsraten ermittelt werden. Bei Stamm 4 wurden an den beiden dargestellten Tagen während der Hellphase $11 \%$ und $10 \%$ des gebildeten $\mathrm{CO}_{2}$ photosynthetisch refixiert oder abtransportiert. Bezogen auf die Tagessumme $(24 \mathrm{~h})$ der Bruttoatmung waren es 5.3 und $5.9 \%$ am 26. und 27.09.98.

Die Temperaturfunktionen der Astatmung aus Abb. 7 a und der Grobwurzelatmung aus Abb. 5 c (Kapitel 4.1.1) wurden ebenfalls unter Berücksichtigung einer Zeitverzögerung und separat für die Nachtdaten berechnet. Die Ergebnisse jeweils einer Messstelle sind in Abb. 11 dargestellt und für alle drei Äste und Grobwurzeln in Tab. 5 zusammengefasst.

In den Auftragungen der Atmungsraten gegen die Temperatur sind in beiden Fällen charakteristische Schleifen zu erkennen. Bei Grobwurzel 4 ist die Temperaturbeziehung für alle Daten mit einem $\mathrm{r}^{2}$-Wert von 0.80 bereits recht eng und steigt bei Annahme einer Zeitverzögerung der Temperaturantwort von zwei Stunden auf 0.95. Der Funktionsverlauf ändert sich nur wenig. Bei separater Analyse der Nachtdaten wird auch hier die tageszeitliche Änderung der Temperaturantwort offensichtlich, wobei die Temperaturbeziehung für alle drei berücksichtigten Nächte im Gegensatz zu denen der Tage einheitlich und sehr eng ist $\left(r^{2}=0.97\right)$. Der Vergleich der aus den Temperaturfunktionen berechneten Tagesgänge der Atmungsrate mit den gemessenen Werten ergibt bei Verwendung der Funktion für alle Daten wie beim oben beschriebenen Beispiel von Stamm 4 eine Unterschätzung der Atmung in der Nacht und höhere Werte am Tag. In der Tagessumme kompensieren sich diese gegenläufigen Abweichungen wiederum. Die mit Zeitverzögerung berechneten Atmungsraten beschreiben den gemessenen Tagesgang und auch die Tagessummen sehr gut und zeigen nur geringe Abweichungen. Die mit der Nachtdatenfunktion berechnete Bruttoatmung $\mathrm{R}_{\text {brutto }}$ stellt die nächtlichen Atmungsraten sehr gut dar und ergibt für den Tag erhöhte Werte. Da die Grobwurzel 4 mit Laubstreu bedeckt war, ist es naheliegend, dass die Reduktion der $\mathrm{CO}_{2}$-Abgabe während der Tagesstunden auf den $\mathrm{CO}_{2}$-Transport mit dem Xylemsaft zurückzuführen ist. Im Mittel der zwei dargestellten Tage wurden in 24 h $6.5 \%$ des durch die Atmung gebildeten Kohlendioxids abtransportiert. 


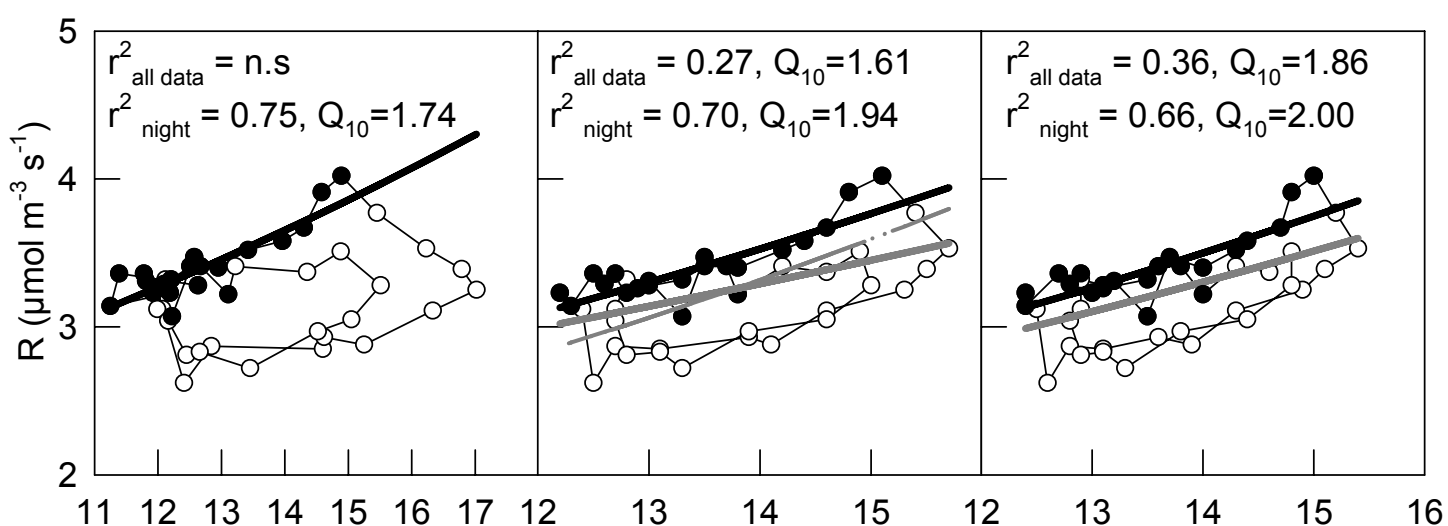

Air temperature

Xylem temperature $0.5 \mathrm{~cm} \quad$ Xylem temperature $1.5 \mathrm{~cm}$

$2 \mathrm{~m}$ above ground $\left({ }^{\circ} \mathrm{C}\right) \quad$ below stem surface $\left({ }^{\circ} \mathrm{C}\right)$

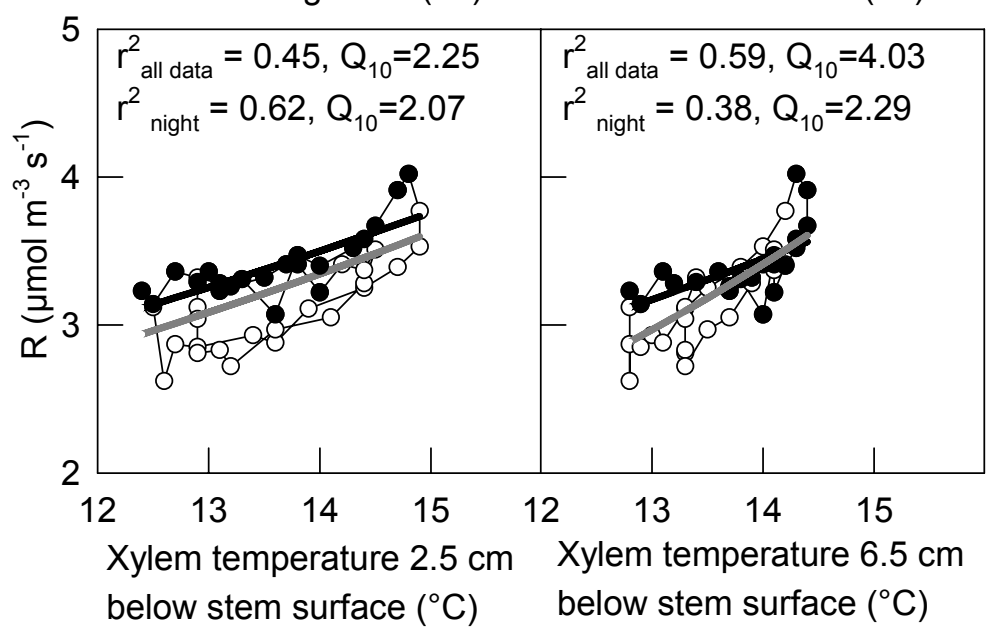

below stem surface $\left({ }^{\circ} \mathrm{C}\right)$

- day

- night data function, timelag $=0 \mathrm{~h}$

all data function, timelag $=0 \mathrm{~h}$

all data function, timelag $=3 \mathbf{h}$, for $T$ at $0.5 \mathrm{~cm}$ $r^{2}=0.75, Q_{10}=2.23$

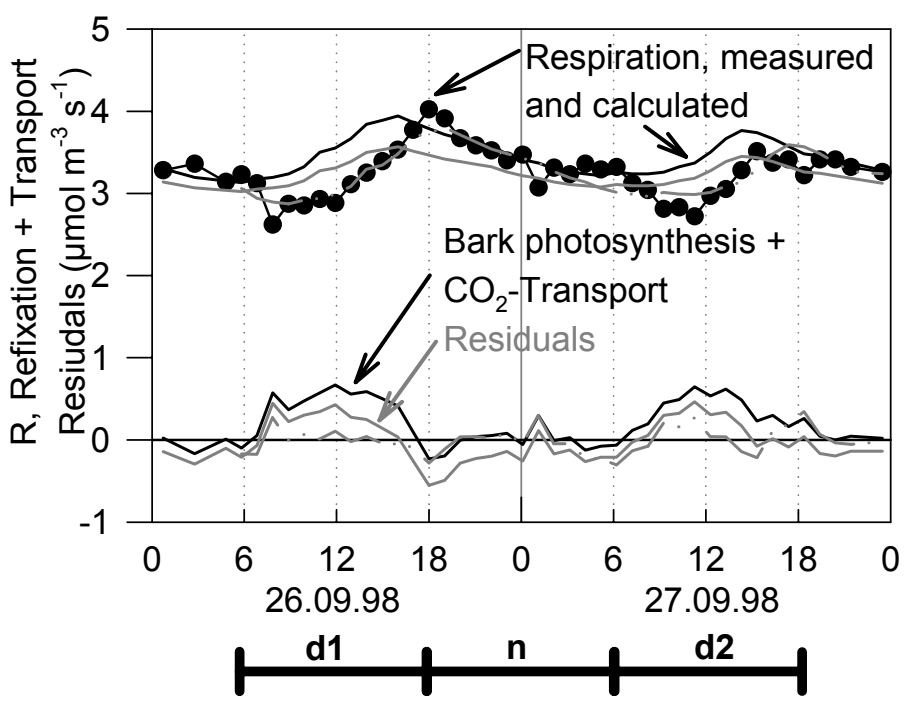

Stem 4, measured

b d1 $89 \%$, n 100\%, d2 $90 \%$

calculated, night data $\mathrm{R}_{\text {brutto }}=\mathbf{d 1} 1$ 157, n 139, d2 $152 \mathrm{mmol} \mathrm{m}^{-3}$ calculated, all data timelag $=0 \mathrm{~h}$ d1 $93 \%$ n $94 \%$ d2 $94 \%$ calculated, all data timelag $=3 \mathrm{~h}$ d1 $89 \%$ n $99 \%$ d2 $90 \%$

Abb. 10 a und b: a) Auftragung der Atmungsraten von Stamm 4 (Solling) gegen die Lufttemperatur und die Xylemtemperatur in 5 verschiendenen Holztiefen. Die Temperaturfunktionen wurden jeweils für alle Daten und nur für die während der Nacht (18:00- 06:00 h) gemessenen Daten berechnet. Bei einer der $0.5 \mathrm{~cm}$-Temperaturfunktionen wurde eine Zeitverzögerung von $3 \mathrm{~h}$ berücksichtigt. b) Vergleich der berechneten mit den gemessenen Atmungsraten. Für die Berechnung wurden die drei verschiedenen Funktionen für die $0.5 \mathrm{~cm}$ Tiefenstufe (a) oben, Mitte) verwendet. Zusätzlich sind die Tagesgänge der Residuen abgebildet. Die Residuen der aus der Nachtdatenfunktion berechneten Atmungsraten $\left(\mathrm{R}_{\text {brutto }}\right)$ entsprechen der Summe der Raten von Rindenphotosynthese und $\mathrm{CO}_{2}$-Transport. Die Prozent-Angaben in der Legende beziehen sich auf die Summe der für die bezeichneten Zeitabschnitte berechneten Bruttoatmung $\mathrm{R}_{\text {brutto }}$. 


\section{Coarse root 4, Göttinger Wald}
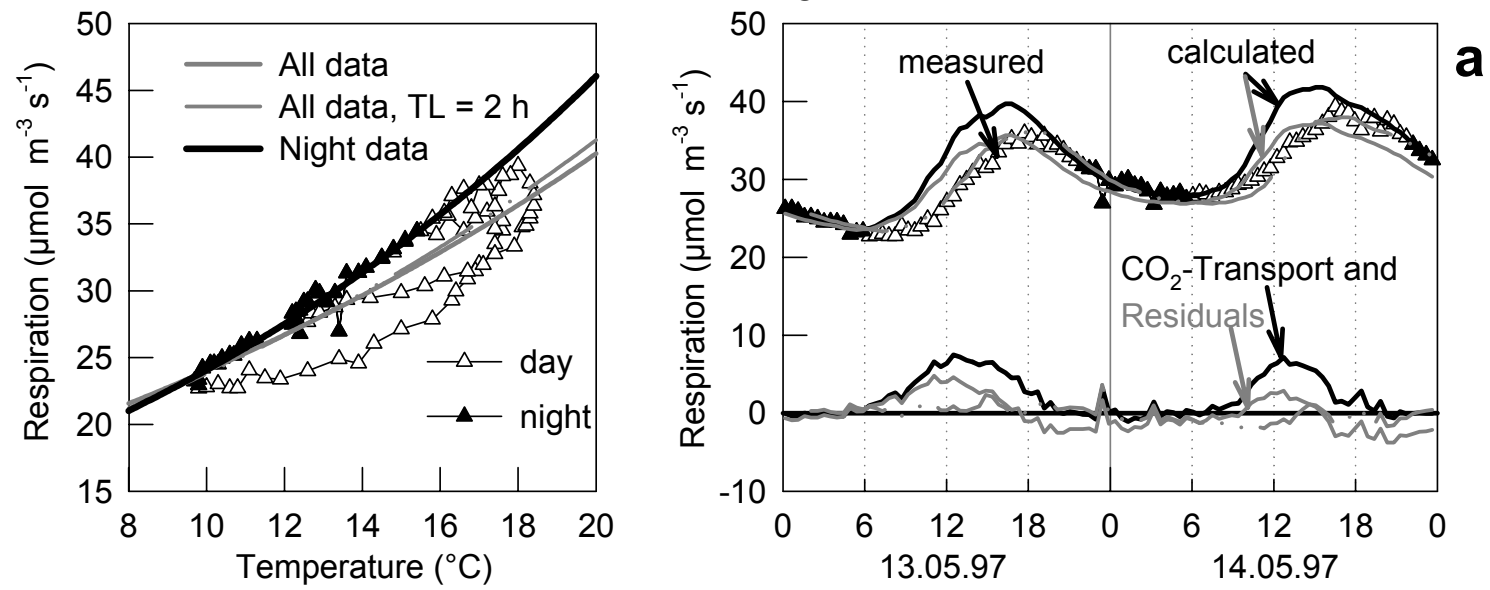

Branch 4, Göttinger Wald
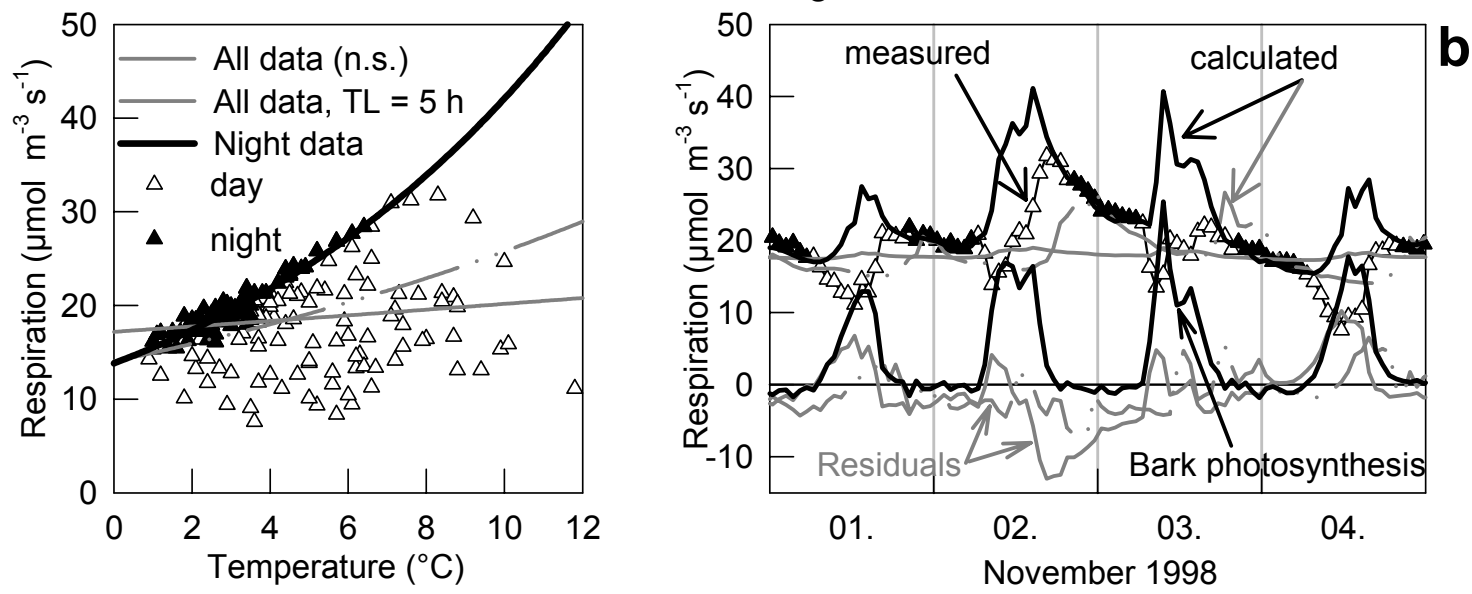

Abb. 11 a und b: Auftragung der Atmungsraten gegen die Temperatur und Tagesgänge der gemessenen und berechneten Atmungsraten von a) Grobwurzel 4 und b) Ast 4 (Göttinger Wald). Es wurden jeweils drei Temperaturfunktionen berechnet: für alle Daten ohne und mit Zeitverzögerung (Timelag, TL) und ausschließlich für die Nachtdaten. Aus diesen Funktionen und den Tagesgängen der Temperatur wurden die Atmungraten berechnet, die Differenz zwischen berechneten und gemessenen Atmungsraten ergaben die Residuen. Die Residuen der aus den Nachtdatenfunktionen berechneten Atmungsraten entsprechen dem $\mathrm{CO}_{2}$-Abtransport bei der Grobwurzel und der Rindenphotosynthese des Astes. Bei der Astatmung sind nur 4 Tagesgänge dargestellt, während die Funktionen auf den Daten von allen 8 Tagesgängen der Kampagne basieren.

Die in Abb. $11 \mathrm{~b}$ dargestellte Astatmung ist ohne Berücksichtigung einer Zeitverzögerung nicht signifikant mit der Temperatur korreliert. Auch bei Annahme einer Phasenverschiebung um 5 Stunden ergibt sich ein maximaler $r^{2}$-Wert von nur 0.37. Demgegenüber sind die nächtlichen Atmungsraten dieser achttägigen Messkampagne eng $\left(\mathrm{r}^{2}=0.88\right)$ und signifikant mit der Temperatur korreliert. Die aus den Temperaturfunktionen für alle Daten berechneten Werte bilden die gemessenen Atmungsraten unzureichend ab. Die mit der Temperaturfunktion für die Nachtdaten berechnete Bruttoatmung gibt die während der Nacht gemessenen Atmungsraten sehr gut wieder. Die Differenz zwischen den berechneten und gemessenen Tageswerten kann in diesem Fall ausschließlich auf Rindenphotosynthese zurückgeführt werden, da während der unbelaubten Phase ein Abtransport von $\mathrm{CO}_{2}$ mit dem Xylemsaft ausgeschlossen werden kann. Die Rindenphotosyntheseraten erreichten während dieser Kampagne bei Ast 4 Maximalwerte von $38.4 \mu \mathrm{mol} \mathrm{m}^{-3} \mathrm{~s}^{-1}\left(0.44 \mu \mathrm{mol} \mathrm{m}^{-2} \mathrm{~s}^{-}\right.$ ${ }^{1}$ ) und damit bis zu $78 \%$ der instantanen Bruttoatmungsraten (07.11.98, 11:52 h, nicht dargestellt). 
Im Mittel wurden während dieser achttägigen Kampagne bei Ast $419.8 \%$ des täglich durch Atmung entwickelten Kohlendioxids durch Rindenphotosynthese refixiert.

In Tab. 5 sind die Ergebnisse dieser Analysen für alle in Abb. 7 a und Abb. 5 c dargestellten Atmungsraten der Äste und Grobwurzeln zusammengefasst. Bei Annahme einer zeitverzögerten Temperaturantwort der Atmungsrate steigt das Bestimmtheitsmaß der Temperaturfunktion um 0.15 - 0.37 bei den Ästen und um 0.03 - 0.15 bei den Grobwurzeln. Die Zeitverzögerung, bei der sich das maximale Bestimmtheitsmaß ergibt, liegt zwischen 1 und 5 Stunden bei der Astatmung und zwischen 0 und 2 Stunden bei der Grobwurzelatmung.

Tab. 5: Bestimmtheitsmaß und $\mathrm{Q}_{10}$-Werte der Temperaturfunktionen der Atmungsraten, die für alle Daten ohne und mit Zeitverzögerung $\left(\mathrm{TL}_{\mathrm{opt}}\right)$, für die sich maximale $\mathrm{r}^{2}$-Werte ergaben, sowie für die während der Nacht gemessenen Daten berechnet wurden. Der Differenz $R_{\text {calc }}-R_{\text {meas }}$ gibt die mittlere Abweichung bzw. die Rindenphotosynthese und den $\mathrm{CO}_{2}$-Transport im Xylemsaft (bei den Nachtdaten) aller Messwerte von 8 Tagesgängen der Astatmung bzw. Tagesgängen der Grobwurzelatmung an. Berechnet wurden die Temperaturfunktionen der in Abb. 7 a und Abb. 5 dargestellten Tagesgänge (grau unterlegt sind die Daten der in Abb. 11 dargestellten Messstellen).

\begin{tabular}{|c|c|c|c|c|c|c|c|c|c|c|c|}
\hline \multicolumn{2}{|c|}{$\begin{array}{l}\text { Temperaturfunk- } \\
\text { tion berechnet für: }\end{array}$} & \multicolumn{3}{|c|}{$\begin{array}{l}\text { alle Daten } \\
\text { ohne } T L \mid \text { bei } T_{\text {opt }} \\
\end{array}$} & \multirow{3}{*}{$\begin{array}{c}\begin{array}{c}\text { Nacht- } \\
\text { daten }\end{array} \\
r^{2} \\
\end{array}$} & \multicolumn{2}{|c|}{$\begin{array}{c}\text { alle Daten } \\
\text { ohne } \mathrm{TL} \mid \mathrm{TL} \mathrm{L}_{\text {opt }}\end{array}$} & \multirow[t]{2}{*}{$\begin{array}{l}\text { Nacht- } \\
\text { daten }\end{array}$} & \multicolumn{2}{|c|}{$\begin{array}{l}\text { alle Daten } \\
\text { ohne } T L \mid \mathrm{TL}_{\text {opt }}\end{array}$} & $\begin{array}{l}\text { Nacht- } \\
\text { daten }\end{array}$ \\
\hline Probe & $\begin{array}{l}\text { Durch- } \\
\text { messer }\end{array}$ & $r^{2}$ & $r_{\text {max }}^{2}$ & $T L_{o p t}$ & & \multicolumn{2}{|c|}{ Q10-Werte } & & \multicolumn{3}{|c|}{$\begin{array}{c}R_{\text {calc }}-R_{\text {meas }} \\
\text { RindenPS } \\
\text { Abweichung } \mathrm{CO}_{2} \text {-Abtransp }\end{array}$} \\
\hline & $(\mathrm{cm})$ & & & (h) & & & & & $(\% \mathrm{~F}$ & eas) & $\left(\% \mathrm{R}_{\text {calc }}\right)$ \\
\hline Ast 4 & 4.9 & n.s. & & 5 & 0.88 & $1.1^{\prime}$ & 2.06 & 2.97 & -2.6 & -2.1 & 19.8 \\
\hline Ast 5 & 7.5 & 0.66 & & 1 & 0.92 & $1 . \varsigma$ & 1.97 & & -0 & & 10.3 \\
\hline Ast 6 & 4.3 & 0.05 & 0.20 & 5 & 0.94 & 1.20 & 1.57 & 3.23 & -2 & -2.8 & 27.4 \\
\hline Wurzel 1 & 4.3 & 0.92 & $0 . c^{2}$ & 0 & 0.60 & 1.68 & 1.68 & 1.52 & -0.1 & -0.1 & -5.6 \\
\hline Wurzel 3 & 3.8 & 0.91 & & 1 & 0.88 & 1.73 & 1.74 & 1.9 & -0 . & -0.1 & 4.7 \\
\hline Wurzel 4 & 9.3 & 0.80 & 0.95 & 2 & 0.97 & 1.69 & 1.75 & 1.86 & -0.2 & -0.1 & 6.5 \\
\hline
\end{tabular}

Bei keinem der Kompartimente besteht eine Beziehung zwischen Probendurchmesser und der Zeitverzögerung, die zum Erreichen maximaler $\mathrm{r}^{2}$-Werte angenommen werden muss. Diese Verzögerung ist z. T. größer als die der Xylemtemperatur von Stämmen in $6.5 \mathrm{~cm}$ Tiefe (Abb. 8 a). Daher kann bei Ästen und Grobwurzeln nicht von einem Zusammenhang zwischen dem zeitlich verzögerten Temperaturverlauf in tieferen Holzschichten und einer verzögerten Temperaturantwort der Atmungsrate ausgegangen werden. Die Tagessummen der mit den Temperaturfunktionen für alle Daten berechneten Atmungsraten stimmen mit den gemessenen Werten überein, ohne dass der Tagesgang der Atmungsraten hinreichend genau wiedergegeben wird. Die für die Tag- und Nachtzeiten gegenläufigen Abweichungen von den gemessenen Werten kompensieren sich in der Summe.

Werden die Temperaturfunktionen nur für die Nachtdaten berechnet, sind die $\mathrm{r}^{2}$-Werte bei allen Ästen und bei Grobwurzel 4 höher als bei Berücksichtigung aller Daten (ohne oder mit Zeitverzögerung). Die niedrigeren $r^{2}$-Werte bei Wurzel 1 und 3 sind auf die geringen nächtlichen Temperaturamplituden zurückzuführen. Die mit diesen Funktionen berechneten Tagessummen liegen bei den Ästen deutlich über den gemessenen Werten, so dass durch Rindenphotosynthese $10 \%$ bis $27 \%$ des durch Atmung gebildeten $\mathrm{CO}_{2}$ refixiert wird. Bei den Grobwurzeln 3 und 4 bleibt die $\mathrm{CO}_{2}$ Abgabe über die Oberfläche durch den Abtransport von $\mathrm{CO}_{2}$ mit dem Xylemsaft hinter der berechneten Bruttoatmung zurück. Bei Wurzel 1 hingegen übersteigen die gemessenen Werte die aus den 
Nachtdaten errechneten Atmungsraten. Eine am Tag überhöhte $\mathrm{CO}_{2}$-Abgabe ließe sich nur mit einer von der Temperatur unabhängigen zirkadianen Rhythmik mit einer gesteigerten Atmungsaktivität während der Lichtphase oder dem Antransport von $\mathrm{CO}_{2}$ mit dem Xylemsaft aus stammferneren Wurzelabschnitten erklären.

\subsubsection{Die Anteile von Rindenphotosynthese und $\mathrm{CO}_{2}$-Transport mit dem Xylemsaft an der Reduktion der $\mathrm{CO}_{2}$-Abgabe gegenüber der Bruttoatmung}

Während der Vegetationsperiode können bei der Messung mit lichtdurchlässigen Küvetten sowohl der $\mathrm{CO}_{2}$-Transport mit dem Xylemsaft als auch die Rindenphotosynthese dazu führen, dass die $\mathrm{CO}_{2}$-Abgabe über die Oberfläche bei Ästen und Stämmen von der Bruttoatmung abweicht. Um die Bedeutung beider Prozesse getrennt voneinander abzuschätzen, wurden die Astküvetten im Göttinger Wald im Juli 1998 nach einer zweitägigen Messkampagne mit Aluminiumfolie abgedeckt und die $\mathrm{CO}_{2}$-Abgabe bei unterbundener Rindenphotosynthese für weitere fünf Tage gemessen. Die Ergebnisse dieser Messung sind in Abb. 12 dargestellt. Zur Verdeutlichung der Wirkung des Abdunkelns sind die Messwerte der Tage abgebildet, die sich hinsichtlich der mittleren Temperatur, der Tagessumme der PAR und des Wasserdampfsättigungsdefizits der Luft am ähnlichsten waren (vergl. Tabelle in Abb. 12).

Atmungsraten wie Temperaturen zeigten an beiden Terminen typische Tagesgänge (Abb. 12 b). Die Temperaturamplituden waren bei den Messungen mit lichtdurchlässigen Küvetten infolge direkter Sonneneinstrahlung ausgeprägter, lagen aber an beiden Tagen über $10{ }^{\circ} \mathrm{C}$. Die Holztemperaturen überstiegen in den Nachmittagsstunden die Lufttemperatur.

Abb. 12 a zeigt die Temperaturbeziehung der Atmungsraten und die für die Nachtdaten berechneten Temperaturfunktionen beider Messphasen. Sowohl mit lichtdurchlässigen wie mit abgedeckten Küvetten ergeben sich für die Temperaturfunktionen der Nachtdaten höhere $r^{2}$-Werte als bei Berücksichtigung aller Daten. Ein Einfluss des Abdunkelns auf den Verlauf der Temperaturfunktionen ist nicht zu erkennen. Bei Ast 2 liegen die am Tag gemessenen Daten unterhalb der Temperaturfunktion. Bei Ast 4 streuen sie ober- und unterhalb der Ausgleichskurve, während die Atmungsraten von Ast 6 insbesondere bei abgedeckten Küvetten oberhalb der Temperaturfunktion liegen.

Die mit diesen Funktionen berechneten Tagesgänge der Bruttoatmung weichen dementsprechend von der gemessenen $\mathrm{CO}_{2}$-Abgabe ab (Abb. 12 b). Die Residuen entsprechen wiederum den Raten von Rindenphotosynthese und $\mathrm{CO}_{2}$-Transport im Xylemsaft.

Für Ast 2 wurden an beiden Tagen Atmungsraten berechnet, die über den gemessenen lagen. Bei der Messung mit lichtdurchlässiger Küvette wurden $10.8 \%$ der Tagessumme des Atmungs- $\mathrm{CO}_{2}$ durch Rindenphotosynthese refixiert und/oder mit dem Xylemsaft abtransportiert. Bei abgedeckter Küvette wurden noch $7.8 \%$ mit dem Xylemsaft abtransportiert. Die maximale Rate von Rindenphotosynthese und $\mathrm{CO}_{2}$-Transport lag bei $193.8 \mu \mathrm{mol} \mathrm{C} \mathrm{m} \mathrm{C}^{-1}\left(1.4 \mu \mathrm{mol} \mathrm{C} \mathrm{m} \mathrm{s}^{-2} \mathrm{~s}^{-1}\right)$ und die $\mathrm{CO}_{2}-$ Transportrate erreichte am 27.07.98 Werte bis zu $109.5 \mu \mathrm{mol} \mathrm{CO} \mathrm{CO}^{-3} \mathrm{~s}^{-1}\left(0.8 \mu \mathrm{mol} \mathrm{CO} \mathrm{Cm}^{-2} \mathrm{~s}^{-1}\right)$. Dies entspricht 26 bzw. $19 \%$ der instantanen Bruttoatmung.

Ast 4 erwärmte sich bei nicht abdeckten Küvetten während des späten Vormittags durch direkten Lichteinfall zwischen 10:00 und 12:00 h besonders rasch. Im Gegensatz zur Temperatur wiesen die Atmungsraten in diesem Zeitraum kein entsprechendes Maximum auf, so dass sich für die Summe von Rindenphotosynthese und $\mathrm{CO}_{2}$-Transport maximale Raten von $249 \mu \mathrm{mol} \quad \mathrm{CO}_{2} \mathrm{~m}^{-3} \mathrm{~s}^{-1}$

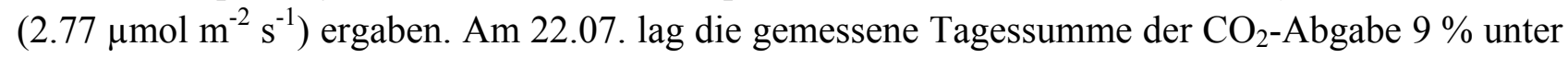
der berechneten Bruttoatmung. Nach dem Abdunkeln der Küvette kehrten sich die Abweichungen 


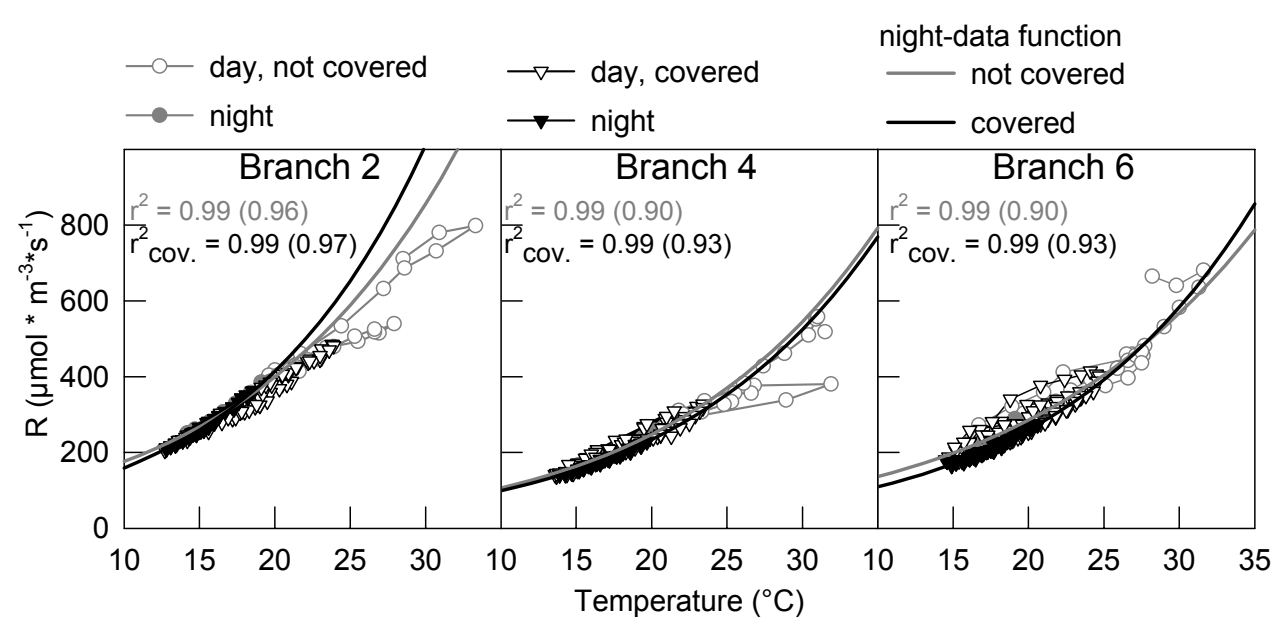

a
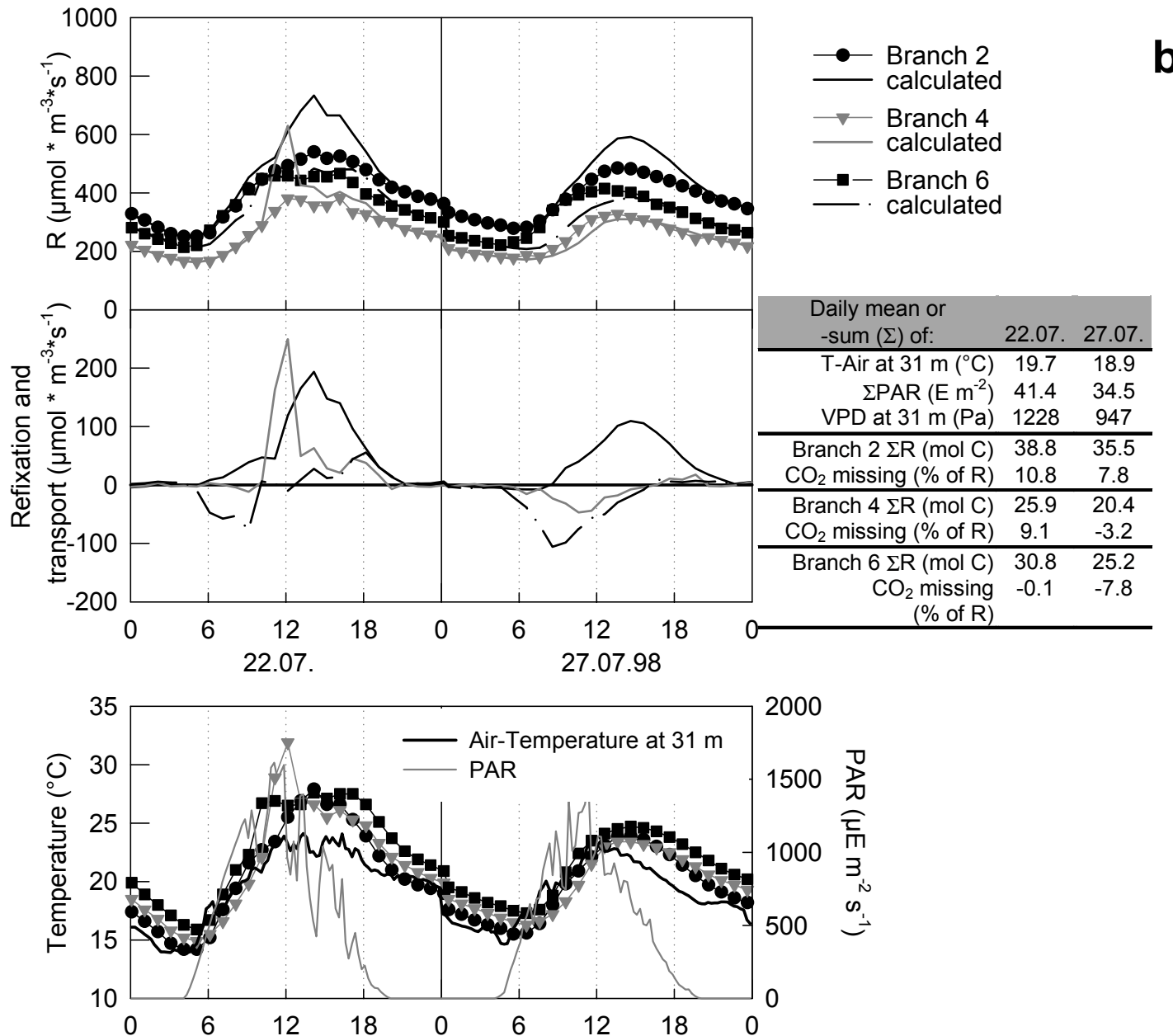

Abb. 12 a und b: a) Temperaturabhängigkeit der Atmungsraten und Temperaturfunktionen für die Nachtdaten der Messung bei lichtdurchlässigen (hellgrau) und bei abgedeckten (schwarz) Küvetten. Die $\mathrm{r}^{2}$-Werte in Klammern gelten für die (nicht dargestellten) Temperaturfunktionen der vollständigen 24-Stunden Datensätze. b) Tagesgänge der Atmungsraten, die mit lichtdurchlässigen (22.07.98) und abgedeckten (27.07.98) Küvetten gemessen wurden sowie die Tagesgänge der aus den Temperaturfunktionen der Nachtdaten berechneten Atmungsraten und der Residuen dieser Funktionen. Die Residuen können als Maß für die Rindenphotosynthese- und $\mathrm{CO}_{2}$-Transportraten aufgefasst werden. Ergänzend sind die Xylemund Lufttemperaturen sowie die PAR im Tagesgang dargestellt. Die Tabelle gibt die Tagesmittelwerte bzw. Summen der Klimaparameter Temperatur, PAR und VPD an sowie die Tagessummen der (berechneten) Bruttoatmung und den prozentualen Anteil der Tagessumme der Residuen, d.h. der Rindenphotosynthese und/oder des $\mathrm{CO}_{2}$-Transports an $\mathrm{R}_{\text {brutto }}$. 
um und die Tagessumme der $\mathrm{CO}_{2}$-Abgabe lag um $3.4 \%$ über der berechneten Bruttoatmung. Bei Küvette 6 ist die Tendenz, dass die berechneten Atmungsraten unter den gemessenen Atmungsraten liegen, noch ausgeprägter. Schon bei der Messung mit nicht abgedeckten Küvetten lagen die gemessenen Raten in den Vormittagsstunden um bis $\mathrm{zu} 76.3 \mu \mathrm{mol} \mathrm{CO} \mathrm{Cm}^{-3} \mathrm{~s}^{-1}$ $\left(0.74 \mu \mathrm{mol} \mathrm{CO} \mathrm{CO}^{-2} \mathrm{~s}^{-1}\right)$ über den berechneten Werten. In den Mittagstunden entsprachen die gemessenen Werte den berechneten Atmungsraten. Nach 14:00 h nahmen die Residuen positive Werten an und erreichten um 18:11 h den Maximalwert von $55.6 \mu \mathrm{mol} \mathrm{m} \mathrm{m}^{-3} \mathrm{~s}^{-1}$. Bei abgedunkelter Küvette lagen die berechneten Raten während der gesamten Hellphase des Tages unter den Messwerten. Maximal wurde $31 \%\left(105 \mu \mathrm{mol} \mathrm{CO} \mathrm{Cm}^{-3} \mathrm{~s}^{-1}\right)$ mehr $\mathrm{CO}_{2}$ abgegeben als nach der Temperaturkurve zu erwarten gewesen wäre. In der Tagessumme überstieg die $\mathrm{CO}_{2}$-Abgabe die Bruttoatmung um $7.6 \%$.

Der Vergleich der Tagessummen der Residuen (Tabelle in Abb. 12) zeigt, dass die $\mathrm{CO}_{2}$-Abgabe bei Ast 2 auch bei der Messung mit abgedeckten Küvetten noch deutlich hinter der Bruttoatmung zurückblieb. In der Annahme, dass die Abweichung der $\mathrm{CO}_{2}$-Abgabe von der Bruttoatmung am 27.07. bei der Messung mit lichtdurchlässigen Küvetten ebenso groß gewesen wäre wie am 22.07., wären etwa $70 \%$ der Tagessumme der Residuen auf den Abtransport von $\mathrm{CO}_{2}$ mit dem Xylemsaft und nur $30 \%$ auf die Refixierung durch Rindenphotosynthese zurückzuführen.

Die Äste 4 und 6 hingegen gaben bei abgedunkelten Küvetten am Tag mehr $\mathrm{CO}_{2}$ ab, als gemäß der Temperaturfunktion zu erwarten war. Dies lässt sich mit dem Antransport von $\mathrm{CO}_{2}$ mit dem Xylemsaft aus basal gelegenen, dickeren Sprossachsen erklären, in denen wegen der längeren Diffusionswege höhere $\mathrm{CO}_{2}$-Konzentrationen auftreten können als in den Ästen. Liegt die $\mathrm{CO}_{2}$ Konzentration des Xylemsafts über dem $\mathrm{CO}_{2}$-Partialdruck des Rinden- und Xylemparenchyms der Äste, so kann $\mathrm{CO}_{2}$ aus dem Xylemsaft zusätzlich zum lokal durch Atmung gebildeten $\mathrm{CO}_{2}$ über die Organoberfläche abgegeben werden. Bei der Atmungsmessung mit lichtdurchlässigen Küvetten wird der Effekt des Antransports durch gleichzeitig ablaufende Rindenphotosynthese vollständig (Ast 4) oder teilweise (Ast 6) kompensiert. In beiden Fällen wird die Rindenphotosynthese unterschätzt und der Antransport nur in Ausnahmefällen offensichtlich.

Da die Tagessummen von PAR und Wasserdampfsättigungsdefizit am 22.07.98 über den Werten des 27.07. lagen, kann davon ausgegangen werden, dass der Transpirationsstrom und damit der Einfluss des $\mathrm{CO}_{2}$-Transports auf die $\mathrm{CO}_{2}$-Abgabe über die Oberfläche am 22.07. mindestens ebenso groß war wie am 27.07. und seine Bedeutung richtig eingeschätzt wird. 


\section{Zusammenfassung:}

1. Die Atmung der verholzten Kompartimente ist im Tagesgang in der Regel eng an den Verlauf der oberflächennahen Xylemtemperatur gekoppelt. Die Temperaturbeziehung lässt sich durch die Arrheniusfunktion beschreiben.

2. Es werden regelmäßig Abweichungen der $\mathrm{CO}_{2}$-Abgabe von der Temperaturbeziehung beobachtet, wobei die Atmungsaktivität trotz deutlicher Temperaturänderungen konstant bleibt und umgekehrt eine deutliche Änderungen der Atmungsaktivität bei nahezu konstanter Temperatur beobachtet werden kann. Ebenso häufig weisen die Temperaturbeziehungen Hysteresisschleifen auf, die auf eine Phasenverschiebung von Temperatur- und Atmungsverlauf hindeuten.

3. Wird für die Atmung im Tagesgang eine zeitverzögerte Temperaturantwort angenommen, so ergeben sich für die Temperaturfunktionen maximale Bestimmtheitsmaße bei einer Phasenverschiebung von 0 bis 6 Stunden, ohne dass ein Zusammenhang zwischen dieser Zeit und dem Durchmesser der Sprossachse oder Wurzel besteht. Eine systematische Zeitverzögerung dieser Größenordnung ist daher nicht anzunehmen.

4. Die während der Nacht gemessenen Atmungsraten sind eng mit der Temperatur korreliert. Die Temperaturfunktionen weisen hier meist höhere $r^{2}$-Werte auf als die für den 24-StundenTagesgang berechneten Funktionen.

5. Aus den Temperaturfunktionen für die Nachtdaten und den Tagestemperaturen des Xylems lässt sich die tatsächlich durch Atmung gebildete $\mathrm{CO}_{2}$-Menge, d.h. die Brutto-Atmungsrate, berechnen. Die apparente $\mathrm{CO}_{2}$-Abgabe ist häufig geringer als die berechnete Bruttoatmung. Ein Teil der durch mitochondriale Atmung gebildeten $\mathrm{CO}_{2}$-Menge wird nicht lokal über die Oberfläche abgegeben.

6. Durch Atmung gebildetes $\mathrm{CO}_{2}$ kann lokal durch Rindenphotosynthese refixiert werden. Die $\mathrm{CO}_{2}$-Abgabe über die Oberfläche, d.h. die apparente oder Netto-Atmungsrate, ist dann geringer als die berechnete Bruttoatmung.

7. $\mathrm{CO}_{2}$ kann mit dem Xylemsaft transportiert werden. In den verholzten Organen kann die $\mathrm{CO}_{2}$ Abgabe über die Oberfläche durch den $\mathrm{Ab}$ - oder Antransport von $\mathrm{CO}_{2}$ vermindert oder erhöht sein. 


\subsubsection{Die Holzatmung im Jahresgang}

Die saisonale und interannuelle Variabilität der Atmungsraten steht in Beziehung zum Witterungsverlauf und zur Rhythmik endogener Aktivitäten. Als Maß für den Einfluss der Witterung geht die Xylemtemperatur wesentlich in die folgenden Betrachtungen ein. Als wesentlicher endogener Prozess beeinflusst der Zuwachs von Biomasse die Atmungsaktivität und wird dieser im zeitlichen Verlauf gegenübergestellt.

In Abb. 13 sind die Jahresverläufe der Atmungsraten zusammen mit denen der Xylemtemperatur für alle drei untersuchten Kompartimente beider Standorte dargestellt. Ein Punkt entspricht dem Mittelwert aller stündlichen Messwerte der 2- bis 14-tägigen Messkampagnen und aller Messstellen des Kompartiments.

Die Atmungsraten aller Kompartimente zeigten ausgeprägte Jahresgänge mit geringen Werten während der Vegetationsruhe und meist zu Beginn der zweiten Jahreshälfte auftretenden Maximalwerten. Das für die Vegetationsruhe charakteristische niedrige Niveau der Atmungsraten stellte sich zwischen Mitte Oktober und Anfang November ein. Die Atmungsaktivität blieb bis Mitte März, 1998 bei den Stämmen im Göttinger Wald bis Ende Mai auf niedrigem Niveau. Mit stärkeren Temperaturänderungen, wie sie im Winter 1997/98 bei den Ästen auftraten, gingen gleichsinnige, aber schwache Schwankungen der Atmungsraten einher. Eine deutliche $\mathrm{CO}_{2}$-Abgabe von 5.6 und $0.8 \mu \mathrm{mol} \mathrm{CO}_{2} \mathrm{~m}^{-3} \mathrm{~s}^{-1}$ wurde auch bei Temperaturen unter dem Gefrierpunkt gemessen, wie sie im Dezember $1998 \mathrm{im}$ Göttinger Wald $\left(\mathrm{T}_{\mathrm{MW}}=-2.6^{\circ} \mathrm{C}\right)$ bei Messungen an den Ästen und im Februar 1998 im Solling bei den Stämmen $\left(\mathrm{T}_{\mathrm{MW}}=-2.5^{\circ} \mathrm{C}\right)$ auftraten. Die Grobwurzelküvetten waren durch die Bedeckung mit Laubstreu und im Winter mit Schnee vor Frost geschützt, so dass die Temperatur und die Atmungsraten im Winter nur geringe Schwankungen zeigten.

Im Frühjahr stiegen Xylemtemperatur und Atmungsraten an. Die Erwärmung erfolgte 1997 bei Stämmen und Grobwurzeln im Göttinger Wald und 1998 im Solling so schnell, dass schon im Mai das Temperaturniveau des darauf folgenden Hochsommers erreicht wurde. Im Gegensatz dazu erwärmten sich die Stämme im Solling 1997 sehr spät und wiesen Ende Juni noch nahezu das gleiche Temperaturniveau wie im Frühjahr dieses Jahres auf. Die Temperaturmaxima wurden zwischen Anfang Juli und Mitte September beobachtet.

Die Atmungsraten folgten dem Temperaturverlauf im Jahresgang, waren aber weniger eng an die Temperatur gekoppelt als auf Ebene des Tagesganges. Insbesondere während der Erwärmung im Frühsommer und der Abkühlung im Herbst wichen die Verläufe von denen der Temperatur ab. Die Atmungsraten stiegen im Frühjahr bei schneller Erwärmung des Holzes nicht entsprechend stark an, so dass die im Mai gemessenen Raten stets unter den Werten lagen, die in den Folgemonaten bei vergleichbaren Temperaturen gemessenen wurden. Umgekehrt traten bei den Stämmen im Solling Ende Juni 1997 maximale Atmungsraten bei Temperaturen auf, die $10^{\circ} \mathrm{C}$ unter dem Jahresmaximum lagen.

Im Hochsommer wurde bei den Ästen im Göttinger Wald eine engere zeitliche Beziehung zwischen Temperatur und Atmung beobachtet. Anders verhielten sich die Stämme im Solling, bei denen die Atmungsraten im August 1998 trotz starker Temperaturänderungen konstant blieben. Im Göttinger Wald änderten sich Atmung und Temperatur der Stämme tendenziell gegenläufig.

Die maximalen Atmungsraten traten im Zeitraum zwischen Ende Juni und Mitte August auf. Eine Ausnahme bildeten die Äste im Göttinger Wald, die 1998 schon um den 6. Juni Atmungsraten auf dem Niveau des Hochsommers zeigten. 
$\mathrm{Ab}$ Mitte August ging die Atmungsaktivität rasch und oft vor der herbstlichen Abkühlung der Sprossachsen zurück. So fielen die Atmungsraten der Äste im Solling zwischen dem 03.08.97 und dem 01.09.97 bei konstanter Temperatur von 173 auf $79 \mu \mathrm{mol} \mathrm{CO} \mathrm{Cm}^{-3} \mathrm{~s}^{-1}$. Auch bei den Stämmen ging die $\mathrm{CO}_{2}$-Abgabe 1997 im Göttinger Wald und 1998 im Solling bei nahezu konstanten Temperaturen deutlich zurück.

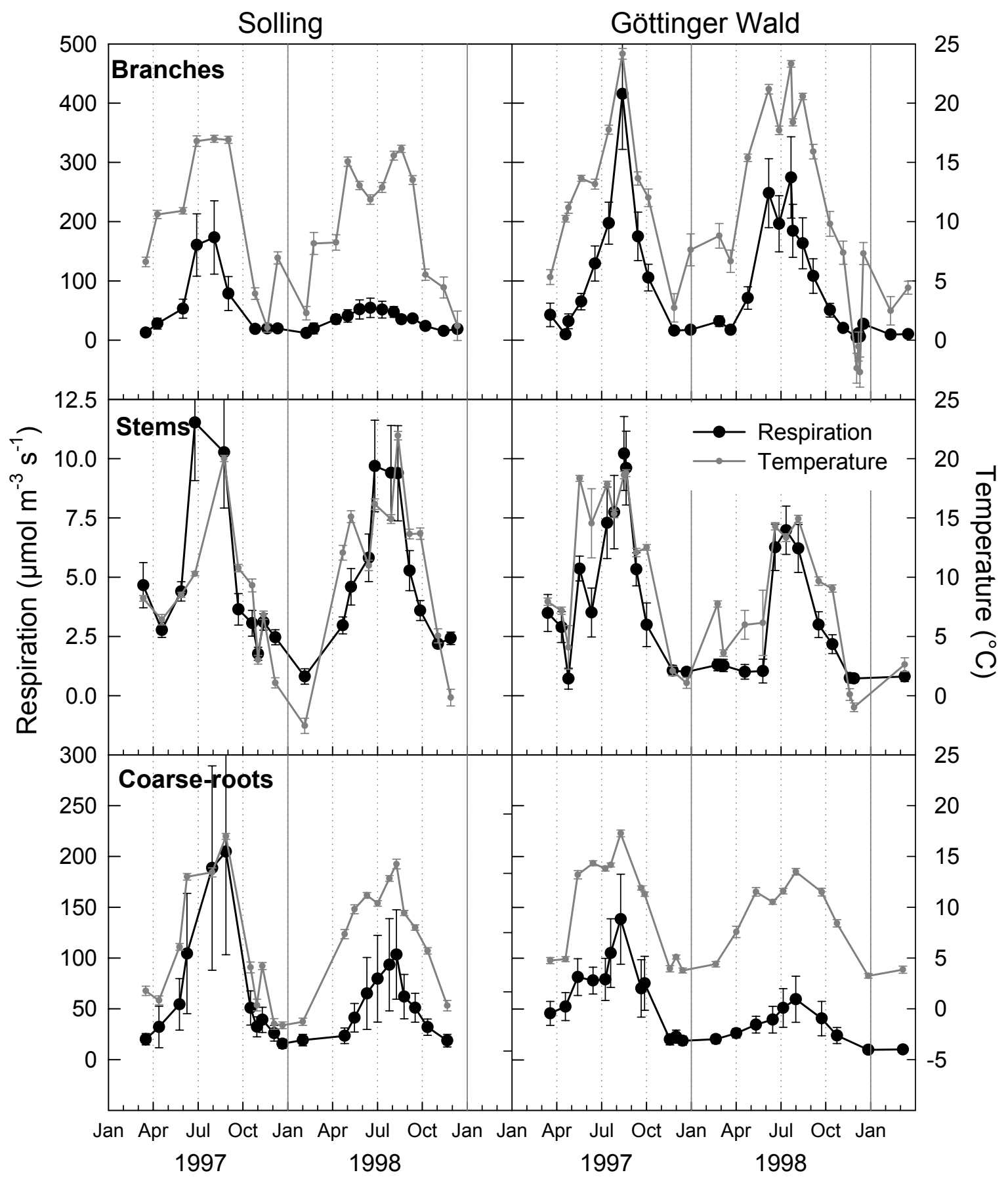

Abb. 13: Zweijahresgänge der mittleren Atmungsraten und Xylemtemperaturen von Ästen, Stämmen und Grobwurzeln im Solling und im Göttinger Wald. Ein Punkt entspricht dem Mittelwert \pm Standardfehler aller stündlicher Messwerte der 2 bis 14-tägigen Messkampagnen $\left(\mathrm{n}_{\min }=19, \mathrm{n}_{\max }=381, \mathrm{n}_{\mathrm{MW}}=121\right.$ je Messstelle) und aller 5 (Solling Stämme) bzw. 6 (alle übrigen) Messstellen. 
Die im Jahresgang auftretende Amplitude der Atmungsrate war bei den Ästen am stärksten. Im Göttinger Wald wurden während des Winterhalbjahres mittlere Raten von $22 \mu \mathrm{mol} \mathrm{CO} \mathrm{m}^{-3} \mathrm{~s}^{-1}$ gemessen. In den Sommermonaten der Jahre 1997 und 1998 stiegen die Werte um das 19- bzw. 13fache auf Jahresmaxima von 416 und $274 \mu \mathrm{mol} \mathrm{CO} \mathrm{CO}^{-3} \mathrm{~s}^{-1}$ an. Im Solling wiesen die Atmungsraten der Äste im Winterhalbjahr ähnliche Werte wie die im Göttinger Wald auf. Ihre sommerlichen Maxima von 173 bzw. $54 \mu \mathrm{mol} \mathrm{CO} \mathrm{C}^{-3} \mathrm{~s}^{-1} 1997$ bzw. 1998 überstiegen die Winterwerte jedoch nur um den Faktor 6 bzw. 2. Der sommerliche Anstieg der Atmungsraten der Äste blieb 1998 also weit hinter dem des Vorjahres zurück.

Die Atmungsraten der Stämme waren während der Vegetationsruhe mit Werten von 1.4 bzw. $2.5 \mu \mathrm{mol} \mathrm{m} \mathrm{m}^{-3} \mathrm{~s}^{-1}$ Göttinger Wald bzw. Solling um das 16- bzw. 8fache geringer als die der Äste. Insbesondere im Göttinger Wald waren die Unterschiede während der Vegetationsperiode noch ausgeprägter. So stiegen die Atmungsraten der Stämme gegenüber den Mittelwerten des Winterhalbjahres um das 6 fache und lagen dann um den Faktor 40 unter den Maximalwerten der Äste. Im Solling stieg die Stammatmungsrate auf Werte, die etwa 6 mal so hoch waren wie die in der Vegetationsruhe. An diesem Standort waren die Astatmungsraten maximal 15 fach höher als die der Stämme.

Die Atmungsraten der Grobwurzeln bewegten sich auf dem Niveau der Astatmung. Von Werten um $25 \mu \mathrm{mol} \mathrm{CO} \mathrm{Cm}^{-3} \mathrm{~s}^{-1}$ während der Vegetationsruhe stiegen sie auf sommerliche Maxima von 138 bis $205 \mu \mathrm{mol} \mathrm{CO}_{2} \mathrm{~m}^{-3} \mathrm{~s}^{-1}$. Eine Übersicht über Jahresmittelwerte und die saisonale Variabilität gibt Tab. 6 .

Tab. 6: Mittlere und maximale volumenbezogene Atmungsraten und Xylemtemperaturen aller drei untersuchten Kompartimente. Gemittelt sind die Atmungsraten jedes Untersuchungsjahres, für das Winterhalbjahr 1997-1998 und für die Vegetationsperioden beider Untersuchungsjahre.

\begin{tabular}{|c|c|c|c|c|c|c|c|c|c|c|c|c|}
\hline & \multicolumn{4}{|c|}{ Äste } & \multicolumn{4}{|c|}{ Stämme } & \multicolumn{4}{|c|}{ Grobwurzeln } \\
\hline & \multicolumn{2}{|c|}{$\begin{array}{l}\text { Göttinger } \\
\text { Wald }\end{array}$} & \multicolumn{2}{|c|}{ Solling } & \multicolumn{2}{|c|}{$\begin{array}{c}\text { Göttinger } \\
\text { Wald }\end{array}$} & \multicolumn{2}{|c|}{ Solling } & \multicolumn{2}{|c|}{$\begin{array}{l}\text { Göttinger } \\
\text { Wald }\end{array}$} & \multicolumn{2}{|c|}{ Solling } \\
\hline & $\mathbf{R}$ & $\mid T$ & & $\mathrm{~T}$ & $\mathbf{R}$ & $\mid T$ & $\mathbf{R}$ & $\mathrm{T}$ & $\mathbf{R}$ & $\mid \mathrm{T}$ & $\mathbf{R}$ & $\mathrm{T}$ \\
\hline \begin{tabular}{|l|l|} 
Zeitrraum & Jahr
\end{tabular} & $\begin{array}{l}\mu \mathrm{mol} \mathrm{CO}_{2} \\
\mathrm{~m}^{-3} \mathrm{~s}^{-1}\end{array}$ & ${ }^{\circ} \mathrm{C}$ & $\begin{aligned} \mu \mathrm{mol} \mathrm{CO}_{2} \\
\mathrm{~m}^{-3} \mathrm{~s}^{-1}\end{aligned}$ & ${ }^{\circ} \mathrm{C}$ & $\begin{array}{l}\mu \mathrm{moll}^{-\mathrm{CO}_{2}} \\
\mathrm{~m}^{-3} \mathrm{~s}^{-1}\end{array}$ & ${ }^{\circ} \mathrm{C}$ & $\begin{array}{c}\mu \mathrm{mol} \mathrm{CO}_{2} \\
\mathrm{~m}^{-3} \mathrm{~s}^{-1}\end{array}$ & ${ }^{\circ} \mathrm{C}$ & $\begin{array}{l}\mu \mathrm{mol}^{-\mathrm{CO}_{2}} \\
\mathrm{~m}^{-3} \mathrm{~s}^{-1}\end{array}$ & ${ }^{\circ} \mathrm{C}$ & $\begin{array}{c}\mu \mathrm{mol} \mathrm{CO}^{-\mathrm{CO}_{2}} \\
\mathrm{~m}^{-} \mathrm{s}^{-1}\end{array}$ & ${ }^{\circ} \mathrm{C}$ \\
\hline Jahres- & 110 & 12.0 & 63 & 10.1 & 5.1 & 12.1 & 4.8 & 8.4 & 66 & 9.9 & 70 & 8.1 \\
\hline mittelwert & 84 & 10.2 & 34 & 9.8 & 2.6 & 7.2 & 5.1 & 11.0 & 32 & 8.6 & 54 & 10.4 \\
\hline 11.1997-04.98 & 22 & 5.6 & 20 & 5.3 & 1.4 & 3.8 & 2.5 & 4.4 & 25 & 5.0 & 24 & 4.6 \\
\hline $05-10,97$ & 181 & 15.7 & 116 & 15.4 & 6.9 & 16.3 & 6.6 & 11.8 & 90 & 13.7 & 138 & 14.2 \\
\hline 98 & 175 & 18.1 & 43 & 13.0 & 4.3 & 11.2 & 6.8 & 15.2 & 45 & 11.7 & 66 & 12.3 \\
\hline Jahres- & 416 & 24.2 & 173 & 17.0 & 10.2 & 18.8 & 11.5 & 20.0 & 138 & 17.3 & 205 & 18.1 \\
\hline maxima & 274 & 23.3 & 54 & 16.1 & 7.0 & 14.9 & 9.7 & 22.0 & 60 & 13.5 & 103 & 15.8 \\
\hline
\end{tabular}

Die Auftragung der Atmungsraten gegen die Temperatur (Abb. 14) ergibt wie bei den Tagesgängen Temperaturbeziehungen, die sich durch die Gleichung (8) beschreiben lassen. Die Atmungsraten sind auch im Jahresgang eng mit der Temperatur korreliert $\left(r^{2}=0.69\right.$ bis 0.86$)$ wobei sich die Funktionen der beiden Untersuchungsjahre nicht signifikant unterscheiden. In Abb. 14 sind daher die Parameter einer für beide Jahre berechneten Temperaturfunktion dargestellt.

Die Temperaturfunktionen für die Jahreswerte sind mit $\mathrm{Q}_{10}$-Werten zwischen 2.41 und 5.06 deutlich steiler als die für die Tagesgänge berechneten Beziehungen, deren mittlere $\mathrm{Q}_{10}$-Werte zwischen 1.8 bei den Stämmen im Solling und 2.7 bei den Grobwurzeln beider Standorte liegen (vergl. Abb. 16). 


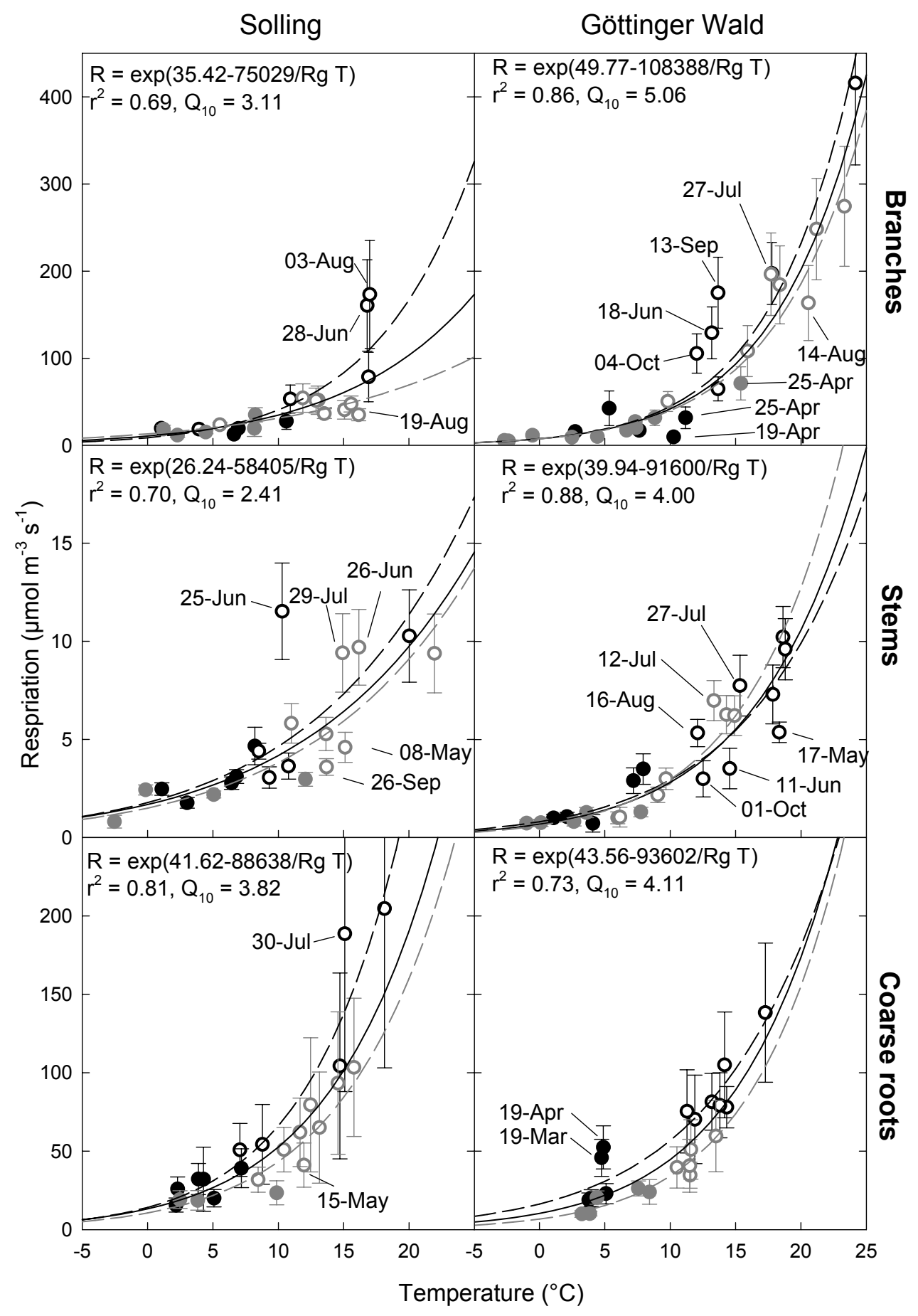

Abb. 14: Auftragung der Atmungsraten gegen die Temperatur. Dargestellt sind die Mittelwerte \pm Standardfehler der Atmungsraten aller sechs Messstellen jeder Messkampagne. Außerdem die Arrheniusparameter der für die Werte beider Jahre berechneten Temperaturfunktion, das Bestimmheitsmaß $\mathrm{r}^{2}$ und der Temperaturkoeffizient $\mathrm{Q}_{10}$ der Funktion (durchgezogene schwarze Linie). Schwarze Symbole und unterbrochene Linie für das Jahr 1997, graue Symbole und unterbrochene Linie für 1998, gefüllte Symbole: November - April, offene Symbole: Mai- Oktober.

Die detaillierte Betrachtung der Temperaturbeziehung zeigt, dass oberhalb der Temperaturfunktion liegende Messwerte in der Zeit zwischen Mitte März und Mitte April oder im Zeitraum der letzten Juni-Dekade bis etwa Mitte August beobachtet wurden. Die unter den Funktionen liegenden Werte wurden im Frühjahr in der Zeit zwischen der dritten April-Dekade und Mitte Juni und zwischen der 
letzten August-Dekade und Ende Oktober gemessen. Einzige Ausnahme sind hier die Werte von September und Oktober, die 1997 an den Ästen im Göttinger Wald gemessen wurden und oberhalb der Temperaturkurve liegen.

Die unterschiedlichen zeitlichen Verläufe von Atmung und Temperatur und die zu bestimmten Jahreszeiten auftretenden charakteristischen Abweichungen der Atmungsraten von der Temperaturfunktion, lassen sich auf endogene Änderungen der Stoffwechselaktivität, bei den oberirdischen Organen namentlich den Holzzuwachs zurückführen.

Die zeitlichen Verläufe der Holzzuwachsraten und der auf $10{ }^{\circ} \mathrm{C}$ normierten Atmungsraten von Ästen und Stämmen beider Standorte zeigten wiederum typische Jahresgänge (Abb. 15). Bei den Grobwurzeln im Göttinger Wald waren die jahreszeitlichen Tendenzen der $10{ }^{\circ} \mathrm{C}$ Atmung schwächer ausgeprägt.

Der Holzzuwachs setzte bei Ästen und Stämmen zeitgleich zwischen Mitte Mai und Mitte Juni ein. Die Zuwachsraten stiegen dann rasch an und erreichten bis Ende Juni hohe, z. T. maximale Werte. Im weiteren Verlauf der Vegetationsperiode blieben die Raten auf diesem Niveau oder stiegen weiter an, bis Ende Juli die Maximalwerte erreicht wurden. Anschließend gingen die Zuwachsraten kontinuierlich zurück wobei der Umfangzuwachs bei den Stämmen bis Ende November andauern konnte. Bei den Ästen fielen die Zuwachsraten im Laufe des Oktobers auf minimale Werte. Auffällig ist der sehr frühzeitige Rückgang des Holzzuwachses der Äste im Solling 1998, bei denen nach einem Wachstumsschub im Juni und Juli kein weiterer Umfangzuwachs registriert wurde.

Der saisonale Verlauf der Zuwachsraten der Grobwurzeln wich von dem der oberirdischen Organe ab. An den Wurzeln im Solling wurde nur bei zwei der sechs Proben ein leicht über die Nachweisgrenze der Umfangmessmethode hinausgehender Zuwachs beobachtet, so dass die mittleren Zuwachsraten gering und ohne jahreszeitliche Tendenz waren. Im Göttinger Wald wurde im September 1997, im März und zwischen Ende Juli und Oktober 1998 Zuwachs an den Grobwurzeln gemessen. In den Phasen maximaler Zuwachsaktivität von Stämmen und Ästen wurde bei den Grobwurzeln kein Umfangzuwachs beobachtet.

Die temperaturnormierten Atmungsraten von Ästen und Stämmen verliefen zu denen ihrer Wachstumsraten weitgehend parallel. Bei einer zeitlichen Auflösung der Messungen von 2 bis 5 Wochen waren weder für den Anstieg im Frühsommer, noch für das Erreichen maximaler Atmungsraten Unterschiede zu den Verläufen der Wachstumsraten zu erkennen. Die Ursache für die Abweichung von diesem Befund bei dem Anstieg der Atmungsraten der Äste vor dem Einsetzen des Holzzuwachses im Frühjahr 1997 ist darin zu sehen, dass die Zuwachsmaßbänder an den Ästen erst in der ersten Juni-Dekade dieses Jahres installiert wurden und so der Zeitpunkt des beginnenden Holzzuwachses vermutlich nicht korrekt erfasst wurde (siehe auch Abb. 37). Der Rückgang der Atmungsraten in der zweiten Hälfte der Vegetationsperiode verlief zwar weniger steil aber zeitgleich mit dem der Wachstumsraten. Eine Ausnahme war der gegenüber dem Holzzuwachs verzögerte Verlauf der Atmungsraten bei den Stämmen im Göttinger Wald 1997. Deren $10{ }^{\circ} \mathrm{C}$-Atmungsrate stieg erst einen Monat nach dem Beginn des Holzzuwachses an und erreichte auch die maximalen Atmungsraten zu einem Zeitpunkt zu dem der Zuwachs bereits rückläufig war.

Die Phase gesteigerter sommerlicher Aktivität der $10^{\circ} \mathrm{C}$-Atmung war bei den Grobwurzeln im Solling gegenüber den Stämmen und Ästen 1997 deutlich und 1998 in Ansätzen weiter in die zweite Jahreshälfte verschoben. Die Grobwurzelatmung im Göttinger Wald zeigte über den gesamten Untersuchungszeitraum eine abfallende Tendenz. Dennoch bestand ein zeitlicher Zusammenhang zwischen Zuwachsaktivität und gesteigertem Atmungsniveau im Spätsommer 1997 und 
1998, sowie im März 1998. Die quantitative Untersuchung des Zusammenhangs zwischen Holzzuwachs und Atmung erfolgt in Kap 4.4.1.1.

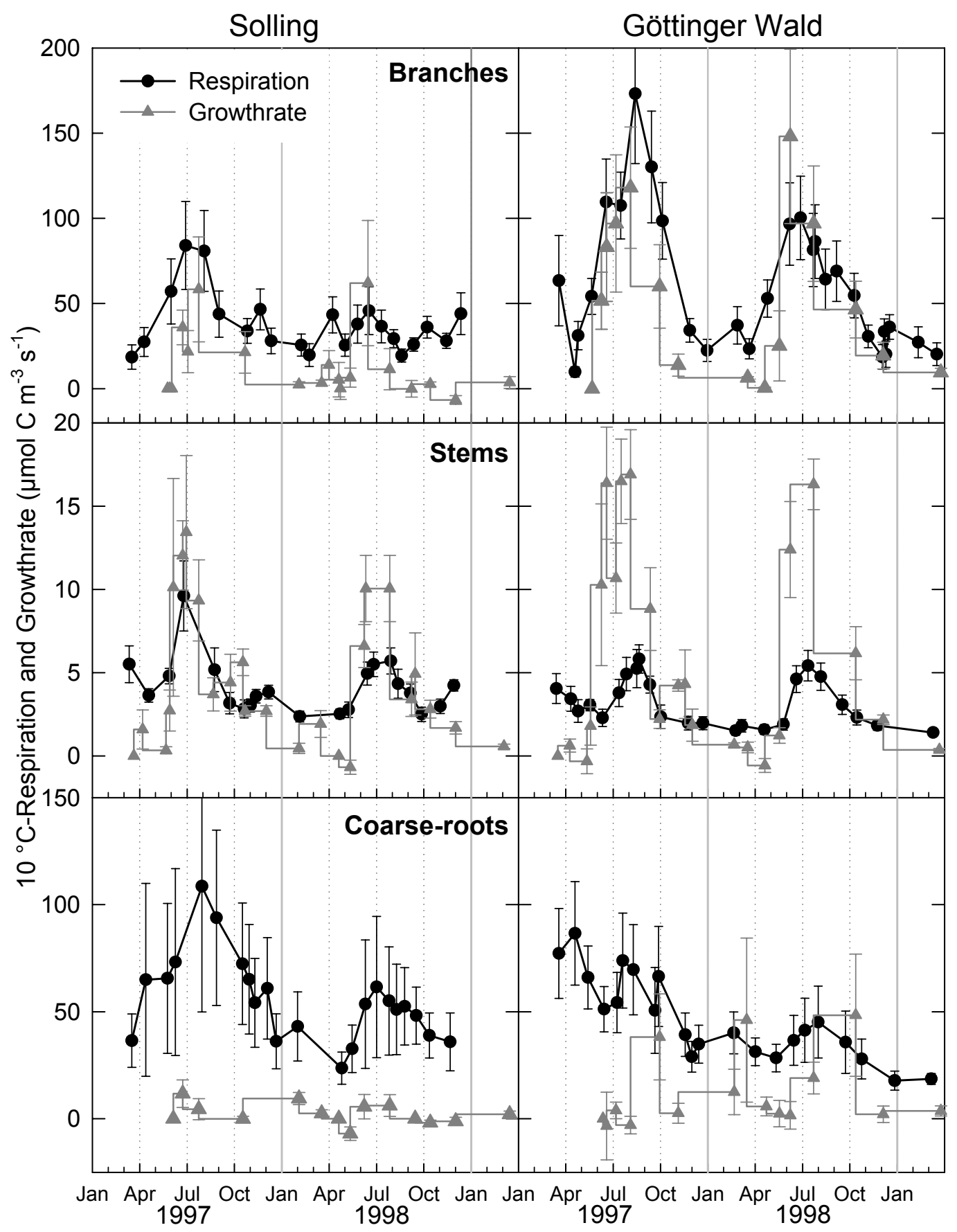

Abb. 15: Zweijahresgänge der $10{ }^{\circ} \mathrm{C}$-Atmungsraten und der mittleren Wachstumsraten. Ein Punkt entspricht dem Mittelwert \pm Standardfehler der temperaturnormierten Atmungsraten bzw. Zuwachsraten von jeweils 6 Messstellen. Die Raten wurden für jede Messstelle berechnet und anschließend gemittelt. Der Berechnung der $10{ }^{\circ} \mathrm{C}$ Atmungsraten lagen die Arrheniusparameter oder der mittlere $\mathrm{Q}_{10}$-Wert zugrunde (Kap. 3.4.1). 


\subsubsection{Die Temperaturabhängigkeit der Holzatmung im Jahresgang}

Aus Abb. 15 wird deutlich, dass die temperaturnormierten Atmungsraten, also das Niveau der Atmungsaktivität, einen deutlichen Jahresgang zeigt, der bei den oberirdischen, verholzten Organen mit dem Jahresverlauf der Wachstumsaktivität zusammenhängt.

Die zeitlichen Verläufe der mittleren $\mathrm{Q}_{10}$-Werte als Maß für die Temperatursensitivität der Atmung sind in Abb. 16 dargestellt. Tatsächlich gemessene $\mathrm{Q}_{10}$-Werte wurden berücksichtigt, wenn die Temperaturbeziehung der Atmung signifikant war. Fehlwerte oder Messreihen ohne signifikante Temperaturbeziehung wurden mit dem Mittelwert der $\mathrm{Q}_{10}$-Werte aller signifikanten Temperaturbeziehungen einer Messstelle ergänzt.

Die dargestellten $\mathrm{Q}_{10}$-Werte wurden ausschließlich für die während der Nacht gemessenen Atmungsraten berechnet, so dass Rindenphotosynthese oder der $\mathrm{CO}_{2}$-Transport mit dem Xylemsaft nicht als Ursachen für eine fehlende Temperaturabhängigkeit in Betracht gezogen werden müssen. Die Atmung war vor allem bei sehr geringen Temperaturamplituden während der Messkampagne nicht signifikant mit der Temperatur korreliert. Bei geringer Temperaturamplitude oder bei dem Wechsel von Frost- und Auftauphasen konnten sich außerdem sehr hohe $\mathrm{Q}_{10}$-Werte $(>10)$ ergeben, die ebenfalls nicht in die folgenden Betrachtungen und die Hochrechnungen der Atmungsraten eingingen.

Die zeitlichen Schwankungen der mittleren $\mathrm{Q}_{10}$-Werte zeigten im Solling nur tendenzielle, im Göttinger Wald keine periodische Verläufe. Bei den Ästen im Solling gingen die $\mathrm{Q}_{10}$-Werte jeweils Anfang April und Anfang bzw. Ende August auf die geringsten Werte des Untersuchungszeitraumes zurück. Die $\mathrm{Q}_{10}$-Werte bei den Stämmen waren tendenziell in der zweiten Hälfte der Vegetationsperiode niedrig oder rückläufig, während sie bei den Grobwurzeln im Frühsommer auf die bereits im Juni beobachteten Minima sanken. Im Göttinger Wald waren keine jahreszeitlichen Tendenzen zu beobachten. Vielmehr zeigten die Verläufe eine hohe kurzfristige Variabilität wie bei den Grobwurzeln oder waren durch das unmittelbare Auftreten von Extremwerten gekennzeichnet.

Die Grobwurzeln reagierten mit $\mathrm{Q}_{10}$-Werten um 2.7 am empfindlichsten auf Temperaturänderungen. Ihre Temperaturkoeffizienten variierten auch am stärksten. Die Temperaturkoeffizienten der Astatmung waren mit mittleren Werten um 2.45 nur wenig geringer. Für die Stammatmung wurden mit Werten von $2.1 \mathrm{im}$ Göttinger Wald und $1.8 \mathrm{im}$ Solling die geringsten $\mathrm{Q}_{10}$-Werte ermittelt und der einzige signifikante Unterschied zwischen den Standorten hinsichtlich dieses Parameters beobachtet.

Aus der Zusammenfassung der $10{ }^{\circ} \mathrm{C}$-Atmungsrate und der $\mathrm{Q}_{10}$-Werte ergeben sich die zeitlichen Verläufe der Temperaturfunktionen als Kennfelder der Atmungsraten, die zusammen mit den gemessenen Atmungsraten in Abb. 17 dargestellt sind. In dieser Darstellung werden die unterschiedlichen Aktivitätsniveaus der Atmungsraten der verschiedenen Kompartimente und Standorte besonders deutlich. So lag das Niveau der Atmungsraten der Äste im Solling während des gesamten Beobachtungszeitraums und über die gesamte beobachtete Temperaturspanne unter dem der Äste im Göttinger Wald.

Es ist auch gut zu erkennen, dass die Atmungsraten der Stämme im Göttinger Wald bei Temperaturen unter $20{ }^{\circ} \mathrm{C}$ die Werte der Solling-Stämme nicht erreichen können, obwohl sie signifikant höhere $\mathrm{Q}_{10^{-}}$Werte aufweisen (Abb. 16). Bei den in den Beständen auftretenden Temperaturen gleicht die höhere Temperatursensitivität das höhere Niveau der $10^{\circ} \mathrm{C}$-Atmungsrate der Stämme im Solling (Abb. 15) nicht aus. 


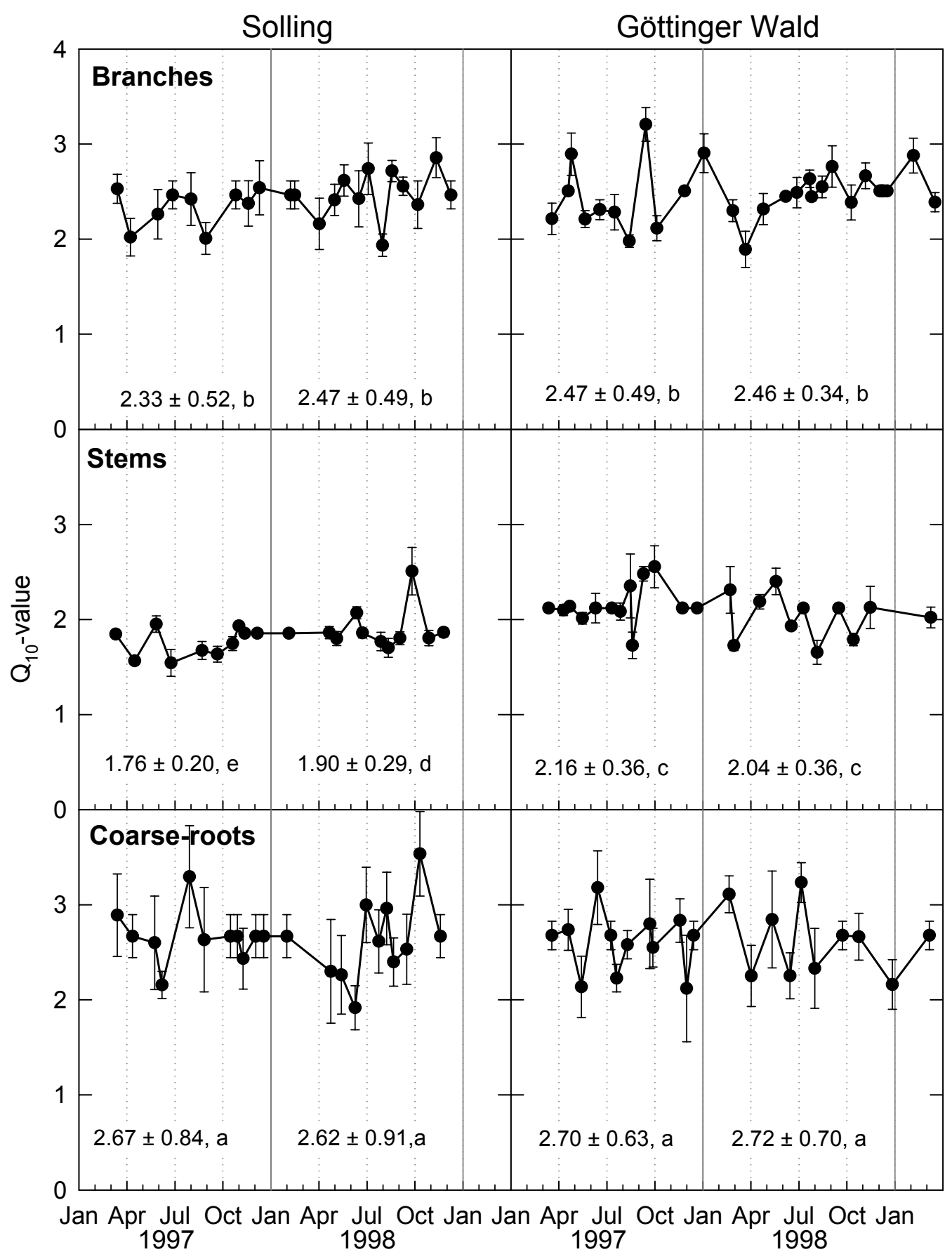

Abb. 16: Jahresverläufe der $\mathrm{Q}_{10}$-Werte der Temperaturabhängigkeit der Holzatmung. Ein Punkt entspricht dem Mittelwert \pm Standardfehler der 6 bzw. 5 (Solling Stämme) $\mathrm{Q}_{10}$-Werte aller Messstellen einer Kampagne. Die Zahlen geben den jeweiligen Jahresmittelwert \pm Standardabweichung an. Signifikant verschiedene Mittelwerte sind durch unterschiedliche Buchstaben gekennzeichnet. 

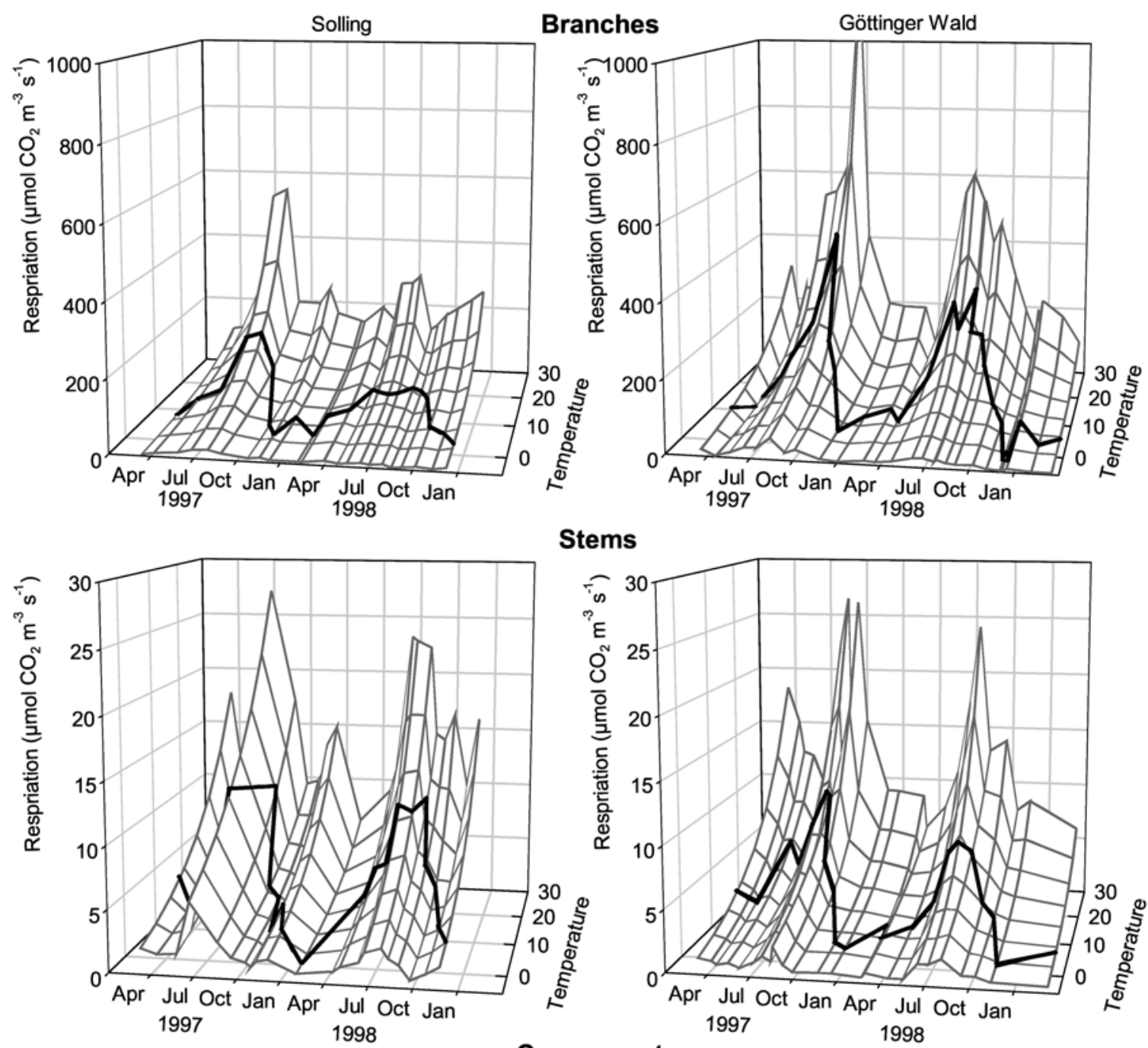

\section{Stems}
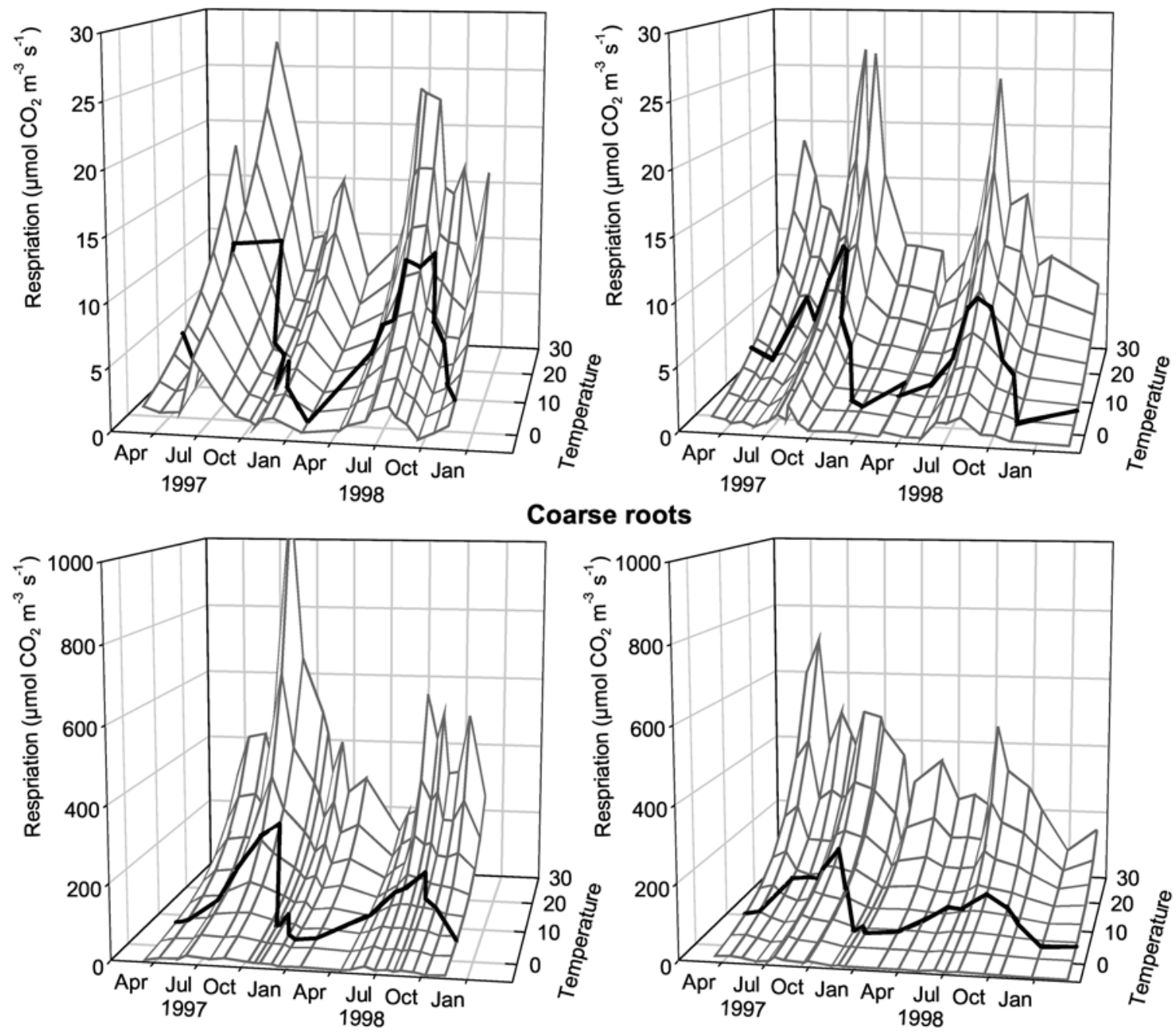

Abb. 17: Zweijahresgänge der Temperaturfunktionen der Atmungsraten (Flächendarstellung) und die Verläufe der gemessenen Atmungsraten (schwarze Linie). 


\section{Zusammenfassung:}

1. Im Winterhalbjahr erreichen die volumenbezogenen Atmungsraten der Stämme im Mittel Werte von $2.0 \mu \mathrm{mol} \mathrm{CO} \mathrm{m}^{-3} \mathrm{~s}^{-1}$. Die Raten der Äste und Grobwurzeln sind 10- bis 12fach höher. Die mittleren Atmungsraten der Sommermonate sind bei den Stämmen (bei ambienten Temperaturen) um den Faktor 2,5 bis 3 höher. Bei Ästen und Grobwurzeln steigen die Raten gegenüber den Werten in der Vegetationsruhe um das 2- bis 9 fache.

2. Im Jahresverlauf ist die Atmung weniger eng an die Temperatur gekoppelt als im Tagesgang. Der ausgeprägte Jahresgang der temperaturnivellierten Atmungsraten und die enge zeitliche Beziehung zum Holzzuwachs zeigen, dass die Atmungsaktivität auf dieser Zeitskala neben der Temperatur wesentlich von der gesamten physiologischen Aktivität von Rinde und Holz beeinflusst wird.

3. Anders als die $10{ }^{\circ} \mathrm{C}$-Atmungsraten zeigen die $\mathrm{Q}_{10}$-Werte keinen Jahresgang, jedoch eine hohe Variabilität. Die $\mathrm{Q}_{10}$-Werte der Stämme betragen im Mittel 1.9. Die Atmungsraten von Ästen und Grobwurzeln reagieren mit $\mathrm{Q}_{10}$-Werten von 2.45 und 2.7 empfindlicher auf Temperaturänderungen als die Stämme.

4. Der Jahresgang der Temperaturantwortkurven zeigt, dass die Standortunterschiede der Atmungsraten bei ambienten Temperaturen von Ästen und Stämmen nicht aus Temperaturunterschieden an den Standorten resultieren, sondern das unterschiedliche Gesamtniveau der Atmungsaktivität widerspiegeln. Diese Unterschiede kommen in den verschiedenen temperaturnormierten Atmungsraten zum Ausdruck und werden auch bei entgegengesetzt differierenden $\mathrm{Q}_{10}$-Werten nicht kompensiert. 


\subsection{Räumliche Variabilität der Atmungsraten}

Um bei dem Vergleich der Atmungsraten von Ästen, Stämmen und Grobwurzeln den Einfluss unterschiedlicher Temperaturen und physiologischer Aktivitätszustände ausschließen zu können, wird in diesem Kapitel die $10{ }^{\circ} \mathrm{C}$-Erhaltungsatmung der Messstellen untersucht (verg. Kap. 3.4.2 und Abb. 35).

Die Ursache für die Variabilität der Erhaltungsatmung ist in den unterschiedlichen Mengenanteilen, der Verteilung und dem Aktivitätsniveau der lebenden Zellen im Rinden- und Holzgewebe zu sehen.

Die Untersuchung der räumlichen Variabilität dient der Prüfung möglicher Bezugsgrößen der Atmungsraten wie z. B. Oberfläche, Gesamt- oder Splintholzvolumen, auf deren Grundlage die Atmungsraten der Messstellen bei der Berechnung der Holzatmung der Bestände auf die Gesamtheit der Organe übertragen werden.

Außerdem wird untersucht, ob die Gehalte an Stickstoff und löslichen Proteinen oder die Menge an umgesetztem TTC ein Maß für die Menge und Aktivität der lebenden Zellen in Rinde und Holz sind und die Variabilität der Atmungsraten erklären können.

Die radiale Verteilung dieser Inhaltsstoffe kann Hinweise auf die Verteilung der Atmungsaktivität innerhalb der Sprossachse geben und die Zusammenhänge zwischen Bezugsgröße und Durchmesser erklären. Außerdem soll anhand der radialen Profile die Splintholz/Kernholzgrenze identifiziert werden.

\subsubsection{Der Einfluss von Bezugsgröße und Durchmesser der Sprossachse}

In Abb. 18 sind die oberflächen- bzw. volumenspezifischen Raten der Erhaltungsatmung bei $10{ }^{\circ} \mathrm{C}$ getrennt nach Standort und Kompartiment dargestellt. Für die Stämme wurde neben dem Gesamtvolumen das Splintholzvolumen als Bezugsgröße verwendet. Die Mächtigkeit des Splintholzes wurde aus der radialen Verteilung der extrahierten TTF-Menge abgeleitet (Kap. 4.2.3).

Die mittleren oberflächenbezogenen Atmungsraten aller drei Kompartimente und beider Standorte lagen zwischen 0.21 und $0.38 \mu \mathrm{mol} \mathrm{CO}_{2} \mathrm{~m}^{-2} \mathrm{~s}^{-1}$ und unterschieden sich bei relativen Standardabweichungen von 37 bis $70 \%$ nicht signifikant. Die jeweils minimalen und maximalen Atmungsraten differierten mindestens um den Faktor 2.1 (Grobwurzeln im Solling). Bei den Ästen im Solling war die höchste Atmungsrate 11-mal höher als die niedrigste.

Deutliche Unterschiede ergaben sich bei der auf das Volumen bezogenen Atmungsaktivität, die bei Ästen und Grobwurzeln im Mittel um das 12- und 16fache über der Atmungsaktivität der Stämme lag. Dabei unterschieden sich die Atmungsraten von Ästen und Grobwurzeln ebenso wenig wie die Raten gleicher Kompartimente an den beiden Standorten. Ein Unterschied zwischen den Standorten ergab sich lediglich bei der Stammatmung, die im Göttinger Wald signifikant niedriger war als im Solling.

Die Variabilität der volumenbezogenen Atmungsraten war bei den Ästen im Solling und den Stämmen im Göttinger Wald ebenso groß wie die der oberflächenbezogenen Atmungsraten dieser Kompartimente. Bei den Ästen im Göttinger Wald sank die relative Standardabweichung von 70 \% auf $51 \%$ wenn anstelle der Oberfläche das Volumen als Bezugsgröße gewählt wurde. Auch bei den Stämmen im Solling ging in diesem Fall die Variabilität zurück (von 39 \% auf 27 \%). Bei den Grobwurzeln hingegen stieg die relative Standardabweichung durch die hohen volumenspezifischen 
Atmungsraten der jeweils dünnsten Wurzeln von 26 \% bzw. 44 \% im Solling bzw. Göttinger Wald auf über $70 \%$. Blieben die dünnen Wurzeln unberücksichtigt, so änderte sich die Variabilität nicht.
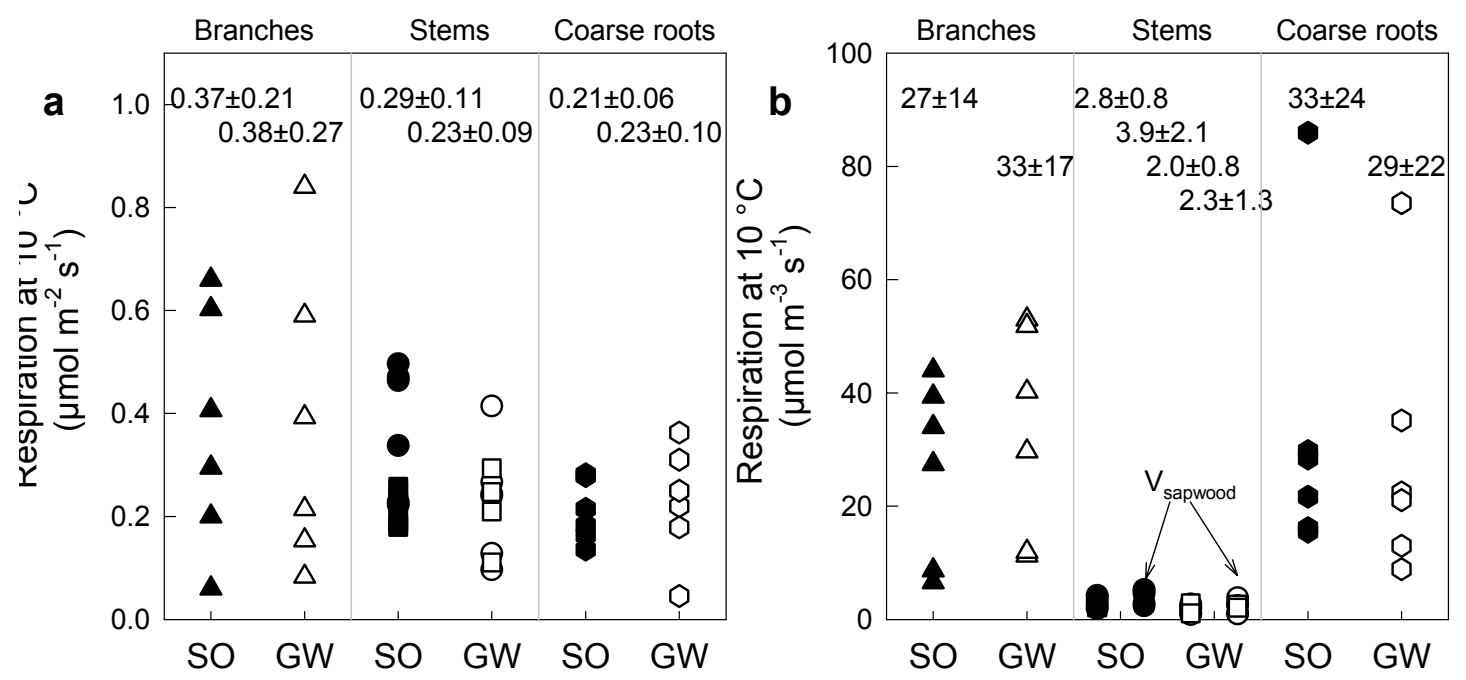

Abb. 18: Vergleich der a) oberflächen- und b) volumenbezogenen $10^{\circ} \mathrm{C}$-Erhaltungsatmung. Sechs Messtellen jedes Kompartiments und Standorts (GW Göttinger Wald, SO Solling). Stämme, an denen das vertikale Profil gemessen wurde, sind mit quadratischen Symbolen dargestellt. Die Zahlen geben Mittelwert \pm Standardabweichung an.

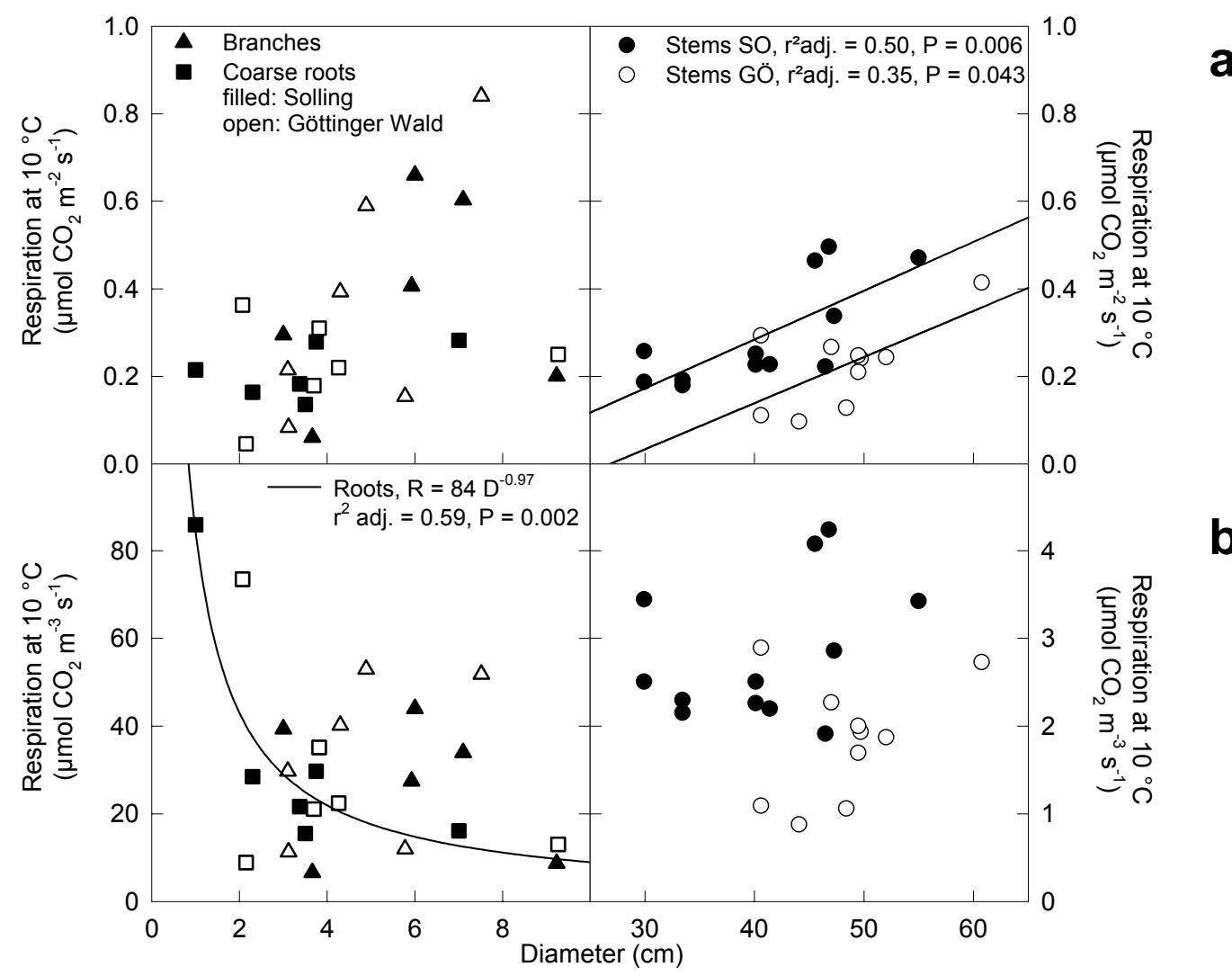

Abb. 19: Beziehung zwischen dem Durchmesser der Sprossachsen und der auf die Oberfläche a) und das Volumen b) bezogenen $10{ }^{\circ} \mathrm{C}$-Erhaltungsatmung. Funktionen sind nur bei signifikanter Abhängigkeit dargestellt $(\mathrm{P}<0.05)$. Die Ordinatenskalierung der volumenbezogenen Atmungsrate der Stämme ist gegenüber der Skalierung bei den Atmungsraten der Äste und Grobwurzeln 20 fach gestreckt. 
In Abb. 19 zeigt sich, dass die oberflächenbezogenen Atmungsraten der Äste und Grobwurzeln nicht mit deren Durchmessern korrelierten, während die Atmungsraten der Stämme mit zunehmendem Durchmesser anstiegen. Werden die Atmungsraten der Messstellen aller Kompartimente zusammenfassend betrachtet, liegen sie auf vergleichbarem Niveau und ändern sich nicht mit dem Durchmesser. Die mittlere $\mathrm{CO}_{2}$-Abgabe bei $10^{\circ} \mathrm{C}$ betrug $0.28 \pm 0.16 \mu \mathrm{mol} \mathrm{m}{ }^{-2} \mathrm{~s}^{-1}$.

Die Variabilität der volumenbezogenen Atmungsraten von Ästen und Stämmen wies keinen Zusammenhang mit dem Durchmesser der Sprossachsen auf. Bei den Grobwurzeln sanken die volumenbezogenen Atmungsraten mit zunehmendem Durchmesser. Die Abnahme lässt sich mit einer Power-Funktion beschreiben.

Um die Datengrundlage zur Untersuchung der Durchmesserabhängigkeit der Atmung zu erweitern, wurden im Göttinger Wald an drei Terminen im Herbst und Winter 1998 Atmungsmessungen an einer größeren Anzahl von Stämmen und Ästen unterschiedlichen Durchmessers durchgeführt (Abb. 20). Die Atmungsraten wurden mit dem mittleren $\mathrm{Q}_{10}$-Wert der Erhaltungsatmung der Kompartimente (Äste $\mathrm{Q}_{10}=2.45$, Stämme $\mathrm{Q}_{10}=2.1$, Abb. 16) und der Oberflächentemperatur auf $10{ }^{\circ} \mathrm{C}$ nivelliert. Die mittleren, auf die Oberfläche bezogenen Atmungsraten der Stämme lagen am 13.11.98 auf gleichem Niveau wie die Erhaltungsatmung bei den Dauermessstellen. Auf das Volumen bezogen ergaben sich für diesen Termin etwa doppelt so hohe Werte. Die am 18. und 28.12.98 gemessene Atmung lag 50 bzw. $75 \%$ unter der oberflächen- bzw. volumenbezogenen Erhaltungsatmung der Dauermessstellen der Stämme (Anhang A-Tab. 1). Die $\mathrm{CO}_{2}$-Abgabe von Ästen wurde nur am 13.11. und 18.12.98 gemessen und lag volumen- wie oberflächenbezogen unter den Werten der Langzeitmessungen.

Die oberflächenbezogene Stammatmung vom 13.11.98 nahm tendenziell mit steigendem Durchmesser zu, die Werte der Astatmung reihten sich in diese Tendenz ein. Die Atmungsraten streuten ebenso stark wie die der Dauermessungen, so dass sich keine signifikante Durchmesserabhängigkeit ergab. Die Raten, die in der zweiten Dezemberhälfte gemessen wurden, zeigten - wie auch für die Stämme in Abb. 19 a dargestellt - signifikante, positive Beziehungen zwischen oberflächenbezogener Atmung und Stammdurchmesser.

Bei Bezug der $\mathrm{CO}_{2}$-Abgabe auf das Holzvolumen, ergab sich für den ersten Termin eine starke Streuung und eine negative Beziehung zwischen Atmungsrate der Stämme und ihrem Durchmesser. Diese Raten waren mit Ausnahme eines $8.5 \mathrm{~cm}$ dicken Stammes nur etwa halb so hoch wie bei Ästen vergleichbaren Durchmessers. Im Dezember gaben alle Stämme pro Volumen- und Zeiteinheit unabhängig vom Durchmesser die gleiche Menge $\mathrm{CO}_{2}$ ab $\left(0.88 \pm 0.33 \mu \mathrm{mol} \mathrm{m}^{-3} \mathrm{~s}^{-1}, \mathrm{n}=43\right)$. Die Atmungsraten der Äste mit Durchmessern zwischen 8.6 und $19.4 \mathrm{~cm}$ waren mit $1.44 \pm 0.54 \mu \mathrm{mol} \mathrm{CO} \mathrm{m}^{-3} \mathrm{~s}^{-1}$ ca. 1.5-mal höher als die Atmungsraten vergleichbar dicker Stämme $\left(\mathrm{D}<20 \mathrm{~cm}, \quad \mathrm{R}=0.9 \pm 0.4 \mu \mathrm{mol} \mathrm{CO} \mathrm{CO}^{-3} \mathrm{~s}^{-1}\right)$ und änderten sich ebenfalls nicht mit dem Durchmesser. 


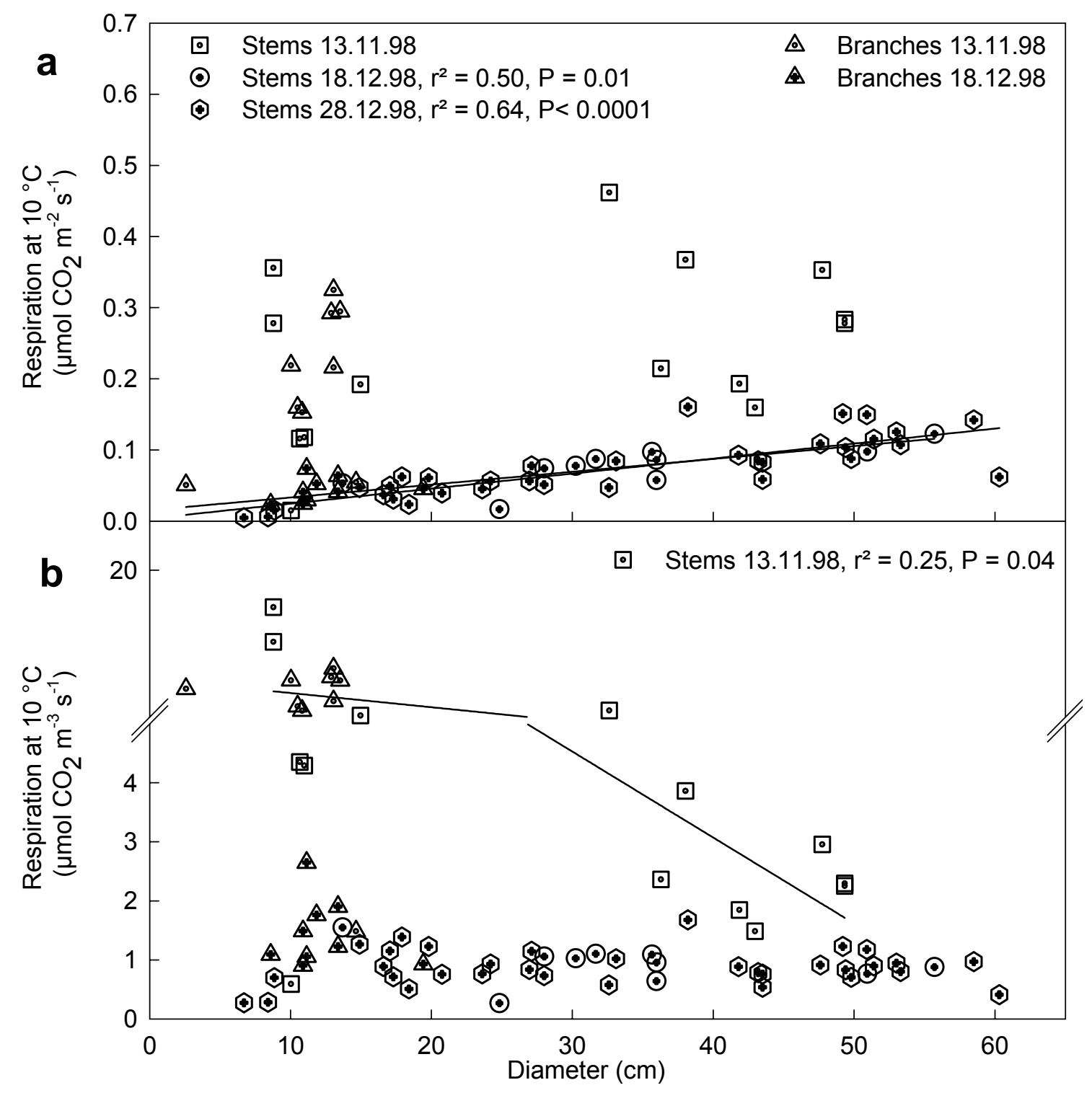

Abb. 20 a und b: Beziehung zwischen a) oberflächen- und b) volumenbezogener $10{ }^{\circ} \mathrm{C}$ Atmungsrate und dem Durchmesser von Stämmen und Ästen. Die Messungen wurden bei drei Messkampagnen im November und Dezember im Göttinger Wald durchgeführt.

\subsubsection{Der Zusammenhang zwischen $\mathrm{CO}_{2}$-Abgabe, Probendimension, Holzinhalts- stoffen und TTC-Umsatz}

Die Atmungsraten stehen in enger Beziehung zu Menge und Aktivität der lebenden Zellen im Rinden- und Holzparenchym. Wenn die Menge der Inhaltsstoffe lebender Zellen, z. B. lösliche Proteine, Stärke oder Stickstoff oder die TTC-Umsatzraten, ein Maß für die Zellzahl oder Zellaktivität ist, kann sie die Variabilität der $\mathrm{CO}_{2}$-Abgabe besser erklären als das Volumen oder die Oberfläche.

Abb. 21 zeigt die Beziehung zwischen der $\mathrm{CO}_{2}$-Abgabe aller Messstellen bei $10{ }^{\circ} \mathrm{C}$ und der Oberfläche, dem Volumen sowie den TTC-Umsätzen und Stoffgehalten. Nach Standorten getrennt wurden für jedes Kompartiment lineare Regressionen berechnet. Ergaben sich für beide Standorte signifikante Beziehungen wurden diese auf Parallelität getestet. Unterschieden sich die Steigungen nicht signifikant, wurden die Geraden mit der gemeinsamen Steigung berechnet und dargestellt. 
Alle übrigen Geraden sind signifikante Funktionen für die Beziehung des jeweiligen Standortes und Kompartiments. Die Bestimmtheitsmaße $\mathrm{r}^{2}$ und Irrtumswahrscheinlichkeiten P aller Regressionsberechnungen fasst Tab. 7 zusammen.

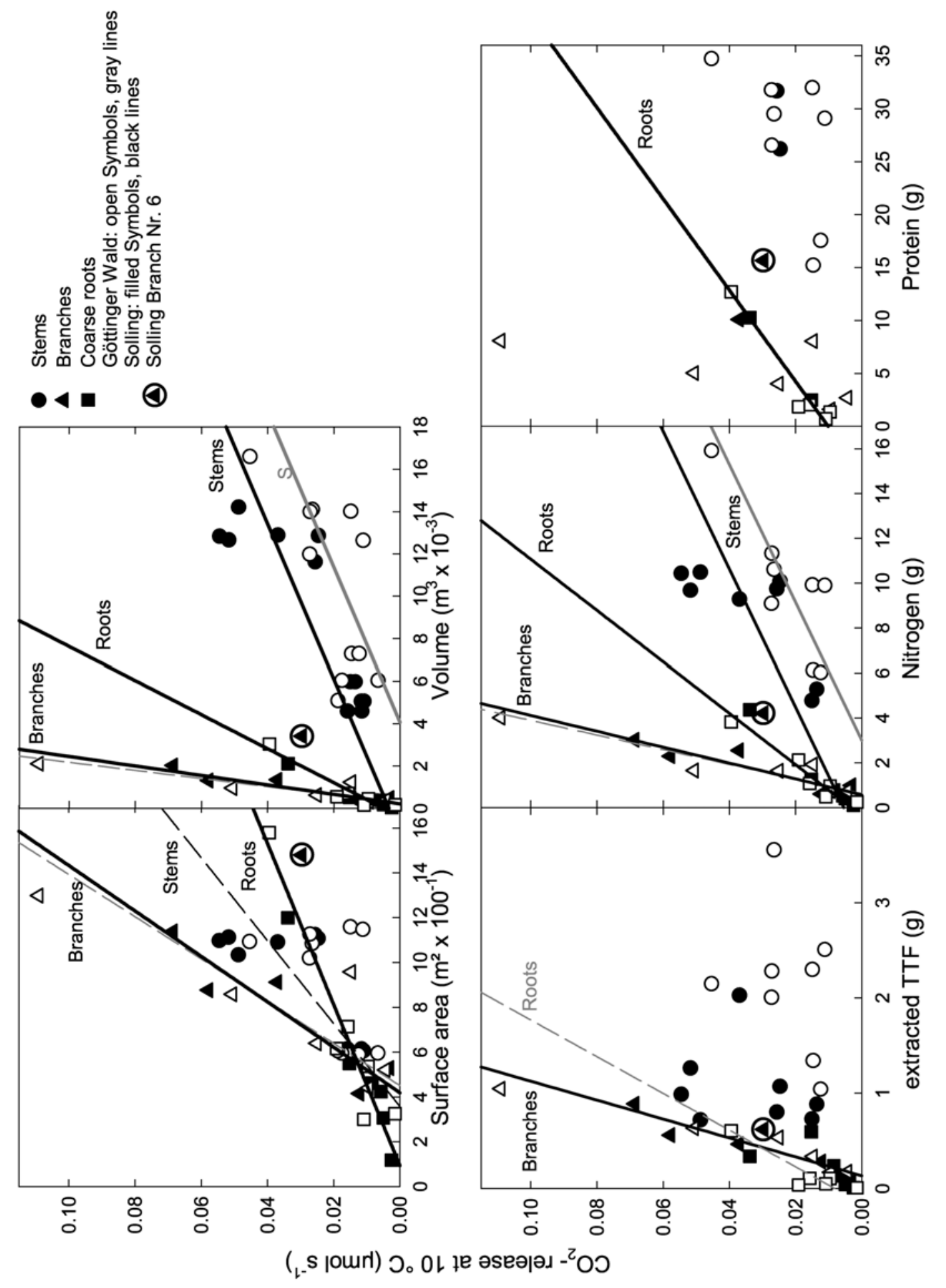

Abb. 21 Beziehung zwischen Erhaltungs- $\mathrm{CO}_{2}$-Abgabe von Ästen, Stämmen und Grobwurzeln bei $10^{\circ} \mathrm{C}$ und Oberfläche, Volumen, der Menge umgesetzten TTC sowie dem Stickstoff- und Proteingehalt. Regressionen sind nur bei signifikanter Beziehung $(\mathrm{P}<5 \%)$ dargestellt. Gestrichelte Linien gelten für den jeweiligen Standort. Fette Linien sind parallele bzw. identische Regressionsgeraden für die Werte beider Standorte, weitere Angaben siehe im Text. 
Tab. 7: Bestimmtheitsmaß $r^{2}$ und Irrtumswahrscheinlichkeit $P$ der in Abb. 21 dargestellten Beziehungen zwischen $\mathrm{CO}_{2}$-Abgabe und Probendimension, Stoffumsatz oder -gehalt. Das Bestimmtheitsmaß signifikanter Beziehungen $(\mathrm{P}<5 \%)$ in Fettdruck. Dunkelgrau hinterlegt: Irrtumswahrscheinlichkeit für den Test auf Parallelität und Abstand der Regressionsgeraden (Nullhypothese: nicht parallel / Abstand >0). Werte für gemeinsame Regressionen sind kursiv gesetzt und nicht in Abb. 21 dargestellt, wenn die Beziehung für die Werte eines der Standorte nicht signifikant war. Die Regressionen für die Äste im Solling wurden mit und ohne Berücksichtigung von Ast Nr. 6 berechnet (siehe Text).

\begin{tabular}{|c|c|c|c|c|c|c|c|c|c|c|c|}
\hline \multirow{2}{*}{$\begin{array}{c}\text { Kompar- } \\
\text { timent }\end{array}$} & \multirow[b]{2}{*}{ Standort } & \multicolumn{2}{|c|}{ Oberfläche } & \multicolumn{2}{|c|}{ Volumen } & \multicolumn{2}{|c|}{ TTF $_{\text {ext. }}$} & \multicolumn{2}{|c|}{ Stickstoff } & \multicolumn{2}{|c|}{ Protein } \\
\hline & & $r^{2}$ & $\mathbf{P}$ & $\mathbf{r}^{2}$ & $\mathbf{P}$ & $\mathbf{r}^{2}$ & $\mathbf{P}$ & $\mathbf{r}^{2}$ & $\mathbf{P}$ & $\mathbf{R}^{2}$ & $\mathbf{P}$ \\
\hline \multirow{5}{*}{$\stackrel{9}{0}$} & Solling & 0.13 & 0.260 & n.b. & 0.393 & 0.76 & 0.014 & 0.15 & 0.245 & n.b & n.b \\
\hline & \begin{tabular}{|r|} 
Solling ohne Ast \\
Nr. 6 \\
\end{tabular} & 0.80 & 0.026 & 0.84 & 0.019 & 0.89 & 0.011 & 0.76 & 0.034 & n.b & n.b \\
\hline & Göttinger Wald & 0.67 & 0.030 & 0.72 & 0.020 & 0.92 & 0.002 & 0.83 & 0.008 & 0.24 & 0.184 \\
\hline & Beide Standorte & 0.40 & 0.016 & 0.23 & 0.066 & 0.86 & $<0.001$ & 0.49 & 0.007 & 0.00 & 0.521 \\
\hline & \begin{tabular}{|r|} 
Beide Standorte \\
ohne SO Ast Nr.6 \\
\end{tabular} & 0.73 & $<0.001$ & 0.75 & $<0.001$ & 0.91 & $<0.001$ & 0.82 & $<0.001$ & 0.10 & 0.253 \\
\hline \multirow{2}{*}{$\begin{array}{c}\text { mit Ast } 6 \\
\text { ohne Ast } 6\end{array}$} & $\mathbf{P}$ nicht parallel & & & & & $0.92 /$ & 0.20 & & & & \\
\hline & / Abstd. >0 & $0.68 /$ & 0.90 & $0.43 /$ & 0.52 & $0.26 /$ & 0.63 & $0.54 /$ & 0.54 & & \\
\hline \multirow{4}{*}{ 点 } & Solling & 0.64 & 0.001 & 0.73 & $<0.001$ & n.b. & 0.569 & 0.51 & 0.028 & n.b. & n.b. \\
\hline & Göttinger Wald & 0.16 & 0.122 & 0.38 & 0.026 & n.b. & 0.486 & 0.65 & 0.010 & 0.24 & 0.126 \\
\hline & Beide Standorte & 0.39 & $<0.001$ & & & n.b & 0.688 & & & 0.26 & 0.076 \\
\hline & $\begin{array}{r}P_{\text {nicht parallel }} \\
\text { / Abstd. }>0 \\
\end{array}$ & & & $0.34 /$ & 0.01 & & & 0.25 & 0.01 & & \\
\hline \multirow{4}{*}{ 道 $\frac{5}{\frac{N}{0}}$} & Solling & 0.95 & 0.001 & 0.94 & 0.001 & 0.19 & 0.217 & 0.97 & $<0.000$ & n.b & n.b \\
\hline & Göttinger Wald & 0.88 & 0.004 & 0.85 & 0.006 & 0.77 & 0.013 & 0.92 & 0.002 & 0.92 & 0.007 \\
\hline & Beide Standorte & 0.92 & $<0.001$ & 0.88 & $<0.001$ & 0.44 & 0.011 & 0.92 & $<0.001$ & 0.94 & $<0.000$ \\
\hline & $\begin{array}{r}\mathbf{P} \text { nicht parallel } / \\
\text { Abstd. }>0 \\
\end{array}$ & \multicolumn{2}{|c|}{$0.28 / 0.22$} & \multicolumn{2}{|c|}{$0.71 / 0.10$} & & & \multicolumn{2}{|c|}{$0.92 / 0.41$} & & \\
\hline
\end{tabular}

Die höchsten $\mathrm{r}^{2}$-Werte ergaben sich für die $\mathrm{CO}_{2}$-Abgabe der Grobwurzeln und den verschiedenen Größen. 97 \% der Variabilität konnten mit unterschiedlichen Stickstoffmengen in den Proben erklärt werden. Ebenso eng war die Beziehung zum Proteingehalt und nur wenig schwächer zur Oberfläche und zum Volumen. Die Regressionsgeraden der beiden Standorte unterscheiden sich nicht, so dass die Beziehungen für beide Standorte gleichermaßen gelten.

Bei den Ästen im Solling ließen sich schwache Zusammenhänge im Wesentlichen auf Ast 6 zurückführen. Dieser Ast mit hohem Durchmesser, also auch mit großer Oberfläche und großem Volumen, wies stets geringe $\mathrm{CO}_{2}$-Abgaben auf. Wurden die Regressionsanalysen ohne die Werte dieses Asts durchgeführt, ergab sich für die Äste ein ähnliches Bild wie für die Grobwurzeln mit signifikanten Beziehungen zu TTC-Umsatz, Stickstoffgehalt, Oberfläche und Volumen. 91 \% der Variabilität der $\mathrm{CO}_{2}$-Abgabe ließen sich bei den Ästen mit den TTC-Umsätzen erklären. Bemerkenswert ist, dass sich beim TTC-Umsatz auch dann eine signifikante Beziehung ergab, wenn der Solling-Ast 6 in die Berechnung einging. Auch bei den Ästen unterscheiden sich die Regressionsgeraden der beiden Standorte nicht.

Bei beiden Kompartimenten bestand ein etwas engerer Zusammenhang zwischen $\mathrm{CO}_{2}$-Abgabe und dem Stickstoffgehalt und/oder dem TTC-Umsatz als mit den Bezugsgrößen Volumen und Oberfläche.

Die $\mathrm{CO}_{2}$-Abgabe der Stämme war deutlich schwächer mit den verschiedenen Größen korreliert. Bei den Göttinger Wald-Stämmen war die Beziehung der $\mathrm{CO}_{2}$-Abgabe zum Stickstoffgehalt, der $65 \%$ 
der Variabilität erklärte, enger als die Beziehung zu Oberfläche und Volumen. Die Stämme des Sollings waren das einzige Kompartiment, bei dem die $\mathrm{CO}_{2}$-Abgabe enger mit der Oberfläche oder dem Volumen zusammenhing als mit den Inhaltsstoffen.

Für die Stämme ergaben sich parallele Regressionsgeraden mit signifikant verschiedenen Ordinatenabschnitten. Das Stammholz im Solling gab bei gleichem Volumen oder Stickstoffgehalt ca. $0.01 \mu \mathrm{mol} \mathrm{CO} \mathrm{CO}^{-1}$ mehr ab als das Stammholz des Göttinger Waldes. Anders als bei den Ästen und Grobwurzeln wurde für die TTC-Umsätze kein signifikanter Zusammenhang zur $\mathrm{CO}_{2}$-Abgabe gefunden.

Wurde die $\mathrm{CO}_{2}$-Abgabe auf den TTC-Umsatz und die Inhaltsstoffe bezogen, variierten die Atmungsraten innerhalb und zwischen den verschiedenen Kompartimenten unterschiedlich stark. Zum Vergleich der Variation zwischen den Kompartimenten wurden die auf verschiedene Größen bezogenen Atmungsraten zu der jeweils maximalen Rate ins Verhältnis gesetzt (siehe Abb. 22, die zugrundeliegenden Werte fasst A-Tab. 2 im Anhang zusammen).

Bei den Ästen war die Streuung der Atmungsraten am geringsten, wenn der TTC-Umsatz als Bezugsgröße diente (rel. Stdabw. 39 \%). Die stärkste Streuung zeigte die auf die Oberfläche oder den Proteingehalt bezogene Astatmung (rel. Stdabw. 64 bzw. 75 \%). Die relative Standardabweichung der Atmungsraten der Stämme lag bei Bezug auf das Volumen und den Stickstoffgehalt zwischen 52 und $54 \%$ und war mit 55 bis $64 \%$ nur wenig größer, wenn die Oberfläche oder der TTC-Umsatz als Bezugsgröße gewählt wurde. Die Grobwurzelatmung zeigte bei Bezug auf die Oberfläche die geringste Variabilität (rel. Stdabw. $37 \%$ ). Im Vergleich zur starken Streuung der TTF- und volumenbezogenen Atmungsraten (rel. Stdabw. 88 und $74 \%$ ) variierte auch die stickstoffbezogene Rate mit $44 \%$ relativer Standardabweichung wenig.

Bei dem Vergleich zwischen verschiedenen Kompartimenten bestand die größte Variabilität bei Bezug der $\mathrm{CO}_{2}$-Abgabe auf das Volumen. Ast- und Grobwurzelatmung überstiegen die Atmung der Stämme um das 8- bis 16fache. Die entsprechenden Verhältnisse der oberflächenbezogenen Raten waren mit Faktoren von 1.3 und 0.9 am geringsten. Eine Zwischenstellung nahmen die Inhaltsstoffe bzw. TTC-Umsätze als Bezugsgröße ein. Pro Gramm Protein gaben die Äste und Grobwurzeln im Göttinger Wald noch 8- bzw. 10mal mehr $\mathrm{CO}_{2}$ ab als die Stämme (die Variation der Solling-Werte blieb hierbei unberücksichtig, da nur jeweils zwei Proben auf den Proteingehalt hin analysiert wurden). Bei Bezug auf den Stickstoff setzten Äste und Grobwurzeln die 5.5fache $\mathrm{CO}_{2}$-Menge frei und bei TTC als Bezugsgröße war der Unterschied zwischen Ast- und Stammatmung mit einem Faktor von 3.3 noch einmal geringer. Demgegenüber unterschied sich die TTC-bezogene Atmungsrate der Grobwurzeln ebenso deutlich von der Atmungsrate der Stämme wie bei Volumenbezug.

Die volumenbezogene Atmungsrate war mit dem mittleren TTC-Umsatz (ebenfalls volumenbezogen) zwar signifikant jedoch nicht sehr eng korreliert $\left(r^{2}=0.23\right)$ (Abb. 23). Ein höheres Bestimmtheitsmaß ergab sich für die Beziehung zwischen volumenbezogener Atmungsrate und der Stickstoffkonzentration aller Messstellen $\left(r^{2}=0.64\right)$. Die Variabilität der Grobwurzelatmung ließ sich zu 71\% durch die mittlere Stickstoffkonzentration des Gewebes erklären. 


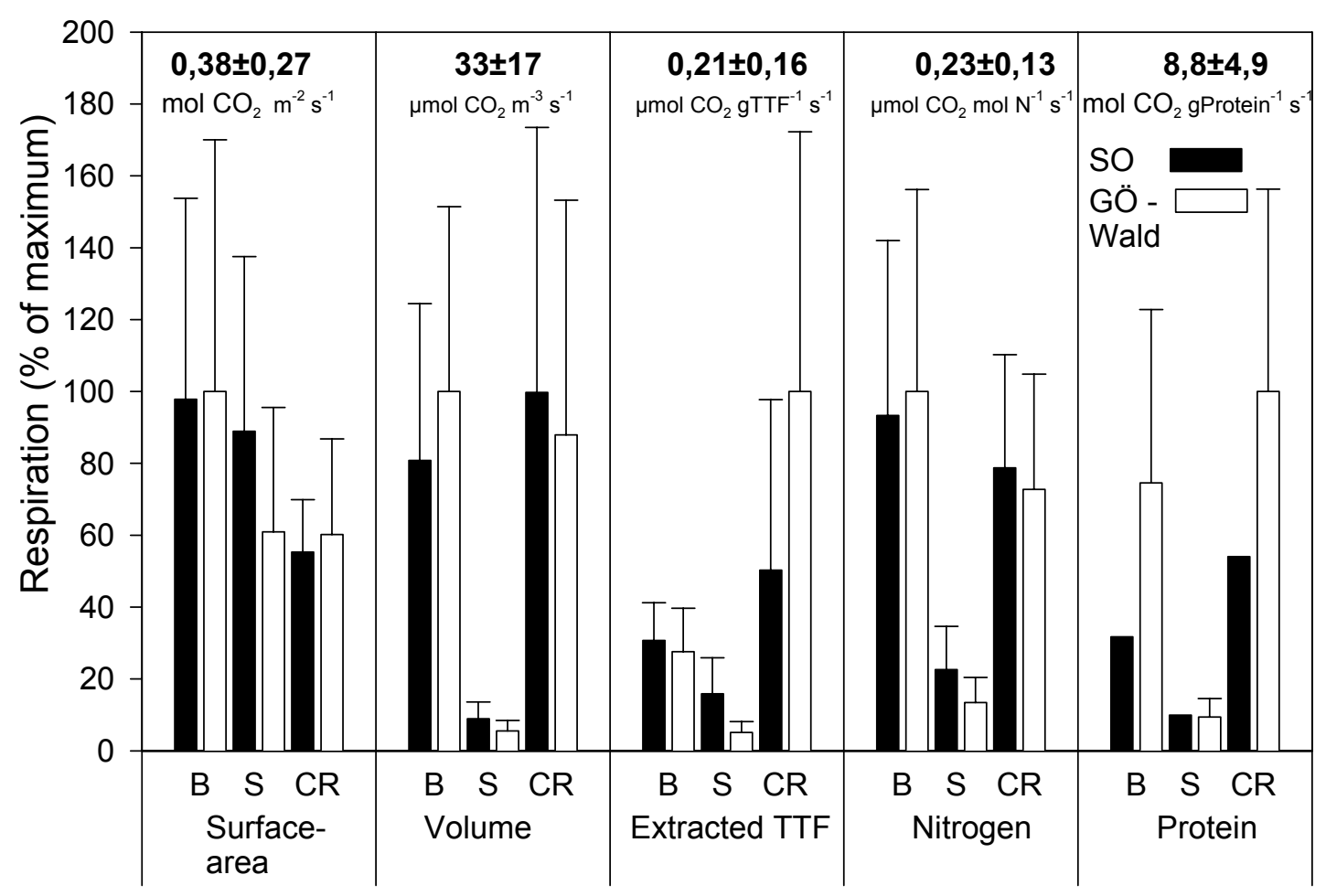

Abb. 22: Erhaltungsatmungsrate von Ästen (B), Stämmen (S) und Grobwurzeln (CR) bei $10{ }^{\circ} \mathrm{C}$ bezogen auf Oberfläche, Volumen, TTC-Umsatz sowie Stickstoff und Proteingehalt. Dargestellt ist die mittlere Atmungsrate \pm Standardabweichung als relativer Anteil des jeweiligen maximalen Mittelwerts. Die Zahlen geben den maximalen Mittelwert \pm Standardabweichung an.

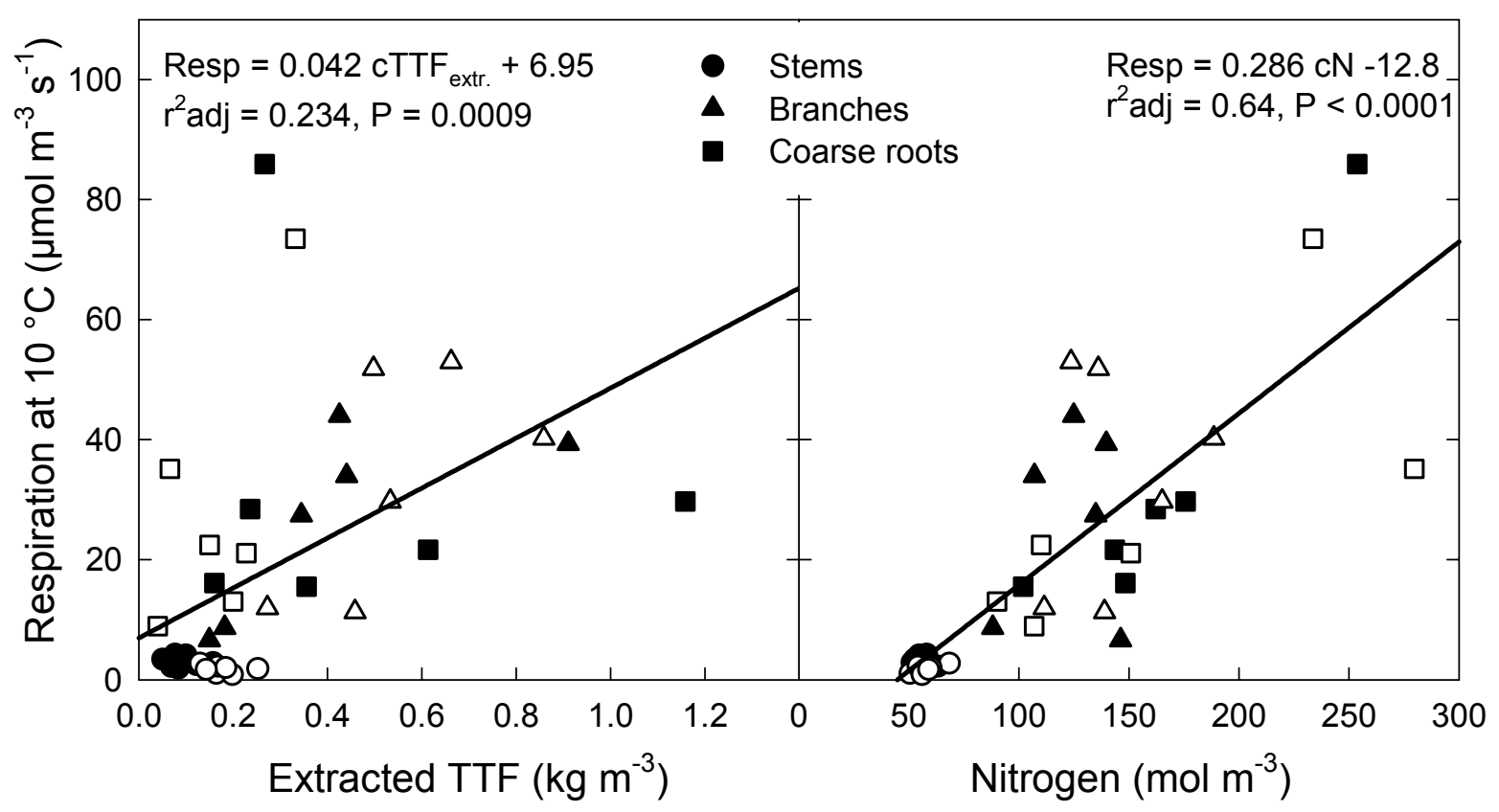

Abb. 23: Beziehungen zwischen volumenbezogener $10^{\circ} \mathrm{C}$-Erhaltlungsatmung und der pro Volumeneinheit extrahierten TTF-Menge sowie der Stickstoffkonzentration. Die Regressionsgeraden berücksichtigen alle Messwerte. Gefüllte Symbole: Solling, offene Symbole: Göttinger Wald. 


\subsubsection{Das radiale Profil des TTC-Umsatzes und der Stickstoffkonzentration}

Mit der Untersuchung der radialen Verteilung der Stickstoffkonzentration und des TTC-Umsatzes sollte einerseits geprüft werden, ob diese Rückschlüsse auf die Splintholzmächtigkeit zulassen. Andererseits sollte auch der Frage nachgegangen werden, ob die Stoffwechsel- und damit die Atmungsaktivität auf bestimmte Bereiche konzentriert ist.

Exemplarisch sind in Abb. 24 einige typische radiale Verläufe der TTC-Umsätze und Stickstoffkonzentrationen einzelner Äste, Grobwurzeln und Stämme dargestellt. Bei allen Ästen und Grobwurzeln war der TTC-Umsatz der Rinde um das 2- bis 17 fache höher als in der äußeren Holzschicht (Ast 4 und Ast 3 im Göttinger Wald). Im Xylem nahm der TTC-Umsatz mit zunehmender Tiefe weiter ab und erreichte in der Mitte der Sprossachsen nur noch 50 bis $70 \%$ der Werte, die in der 1 bis $2 \mathrm{~cm}$ mächtigen, oberflächennahen Xylemschicht gemessen wurden.

Auch die Rinde der Stämme setzte gegenüber der äußeren aktivsten Schicht des Xylems mindestens die doppelte, im Mittel aller Stämme die sechsfache TTC-Menge um. Das Holz wies eine deutliche Schichtung auf. Die verschiedenen Schichten ließen sich durch den sprunghaften Rückgang des TTC-Umsatzes voneinander abgrenzen. So konnten bei Stamm 6 im Göttinger Wald drei Holzschichten unterschieden werden. In den äußeren drei Zentimetern wurden $0.4 \mathrm{mg}$ TTC $\mathrm{cm}^{-3}$ umge-

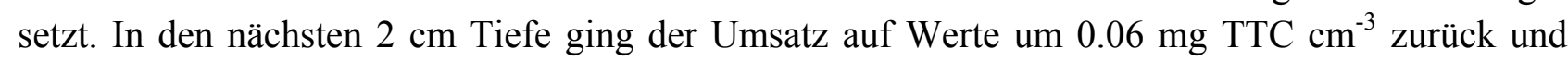
blieb dann in einer $8 \mathrm{~cm}$ mächtigen Schicht nahezu konstant. Nach einem weiteren sprunghaften Rückgang wurden in den folgenden Tiefenstufen bis zur Mitte des Stammes schließlich nur noch
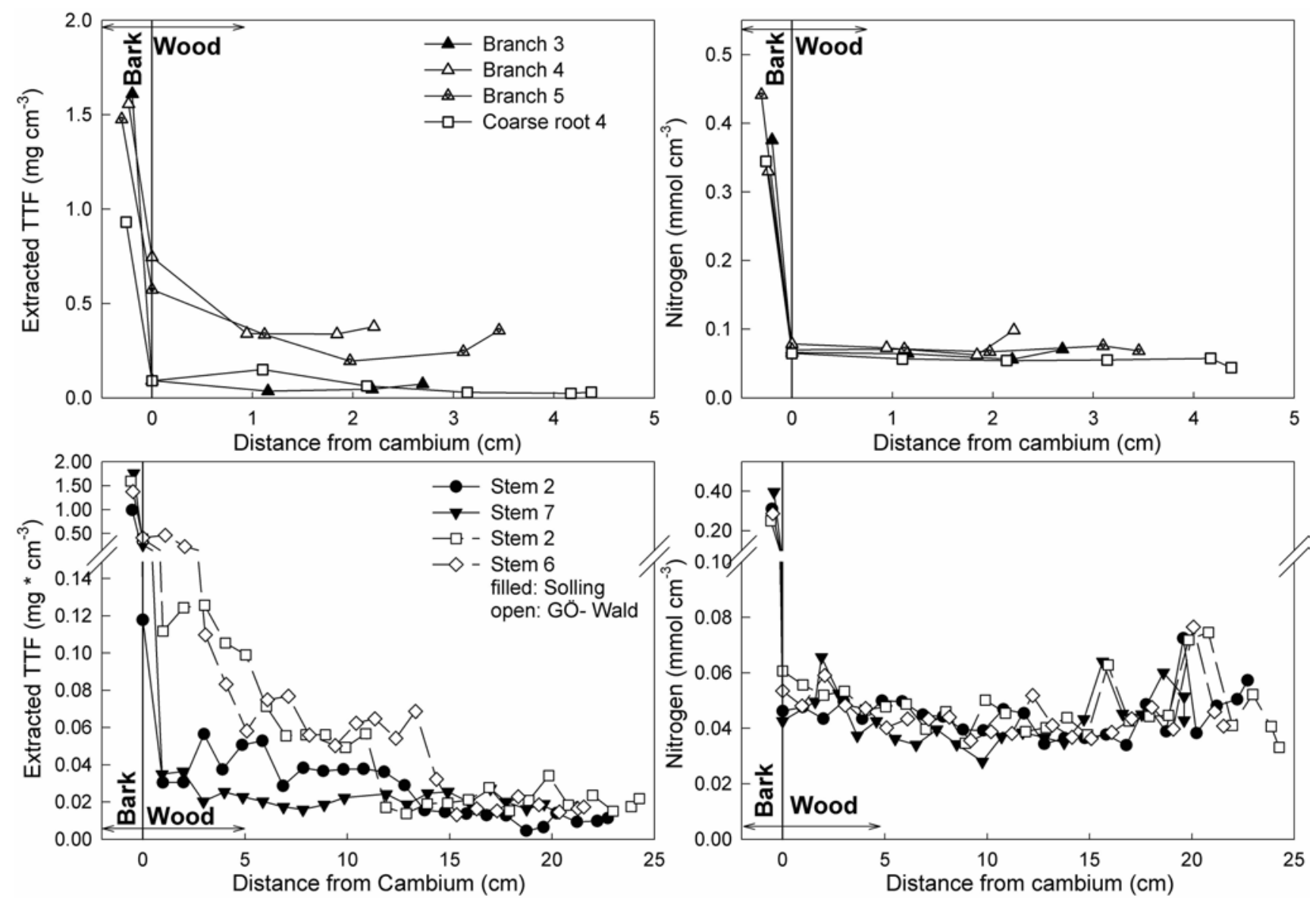

Abb. 24: Die radiale Verteilung des auf das Volumen des Bohrkernstückes bezogenen TTC-Umsatzes und der Stickstoffmenge bei drei Ästen und einer Grobwurzel im Göttinger Wald (oben) sowie je zwei Stämmen im Solling und Göttinger Wald (unten). Ein Punkt markiert die äußere Grenze jedes ca. $1 \mathrm{~cm}$ langen Teilstücks eines Bohrkerns. 


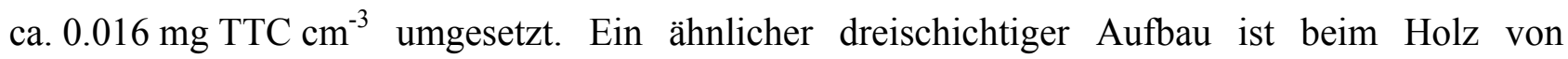
Stamm 2 im Göttinger Wald zu erkennen. Jedoch unterschied sich sowohl das Niveau der TTCUmsätze als auch die Schichtmächtigkeit von Stamm 6. Andere Verläufe zeigten die Stämme 2 und $7 \mathrm{im}$ Solling, die nur in der äußersten Holzschicht mit Umsätzen von $0.12 \mathrm{bzw} .0 .26 \mathrm{mg} \mathrm{TTC} \mathrm{cm^{-3 }}$ gegenüber den tieferen Schichten deutlich höhere Werte aufwiesen. Während bei Stamm 2 der TTC-Umsatz in 2 bis $13 \mathrm{~cm}$ Tiefe um Werte von 0.04 schwankte und dann noch einmal deutlich zurückging, wurden bei Stamm 7 schon in einer Tiefe von $3 \mathrm{~cm}$ niedrige Werte von ca. 0.018 gemessen, die bis zur Mitte des Stammes auf diesem Niveau blieben.

Davon ausgehend, dass das Kernholz durch den Bereich niedrigster TTC-Umsätze charakterisiert werden kann, wurde die Splintholzmächtigkeit der Stämme 2 und 6 im Göttinger Wald und von Stamm 2 im Solling mit 11, 13 und $14 \mathrm{~cm}$ geschätzt. Bei Stamm 7 war keine deutliche Abgrenzung von Splint- und Kernholz möglich. Ingesamt ließen sich bei 9 der 14 Messstellen sprunghafte Änderungen des TTC-Umsatzes beobachten, aus denen für die Berechnung des Splintholzvolumens Splintmächtigkeiten zwischen 11 und $21 \mathrm{~cm}$ abgeleitet werden konnten. Wie die TTC-Umsätze waren auch die Stickstoffgehalte der Rinde deutlich höher als die Stickstoffgehalte im Xylem. Die N-Konzentration der Rinde von Stämmen und Ästen überstieg mit Werten zwischen $0.27 \pm 0.04$ und $0.48 \pm 0.19 \mathrm{mmol} \mathrm{cm}^{-3}$ die Gehalte des Xylems um das 4.3- bis 7.3fache. Im deutlichen Gegensatz zu den TTC-Umsätzen standen die radialen Verläufe innerhalb des Xylems. Die Stickstoffkonzentration war über den gesamten Radius annähernd konstant.

In Abb. 25 wurden die Radien der Stämme in zehn und die der Äste und Grobwurzeln in vier gleichlange Teilstrecken unterteilt und die TTC-Umsätze und Stickstoffgehalte aller Messstellen für jede der Teilstrecken gemittelt. Die Mittelwerte sind gegen den relativen Abstand der Teilstrecke vom Mittelpunkt der Sprossachsen aufgetragen, so dass die radialen Verläufe von TTC-Umsatz und Stickstoffkonzentration von Proben unterschiedlichen Durchmessers vergleichbar sind.

Die TTC-Umsätze der Rinde aller Kompartimente lagen mit Werten zwischen 1.1 und $1.6 \mathrm{mg}$ TTC $\mathrm{cm}^{-3}$ auf vergleichbarem Niveau. Einzige Ausnahme bildeten die Grobwurzeln des Göttinger Waldes mit $0.56 \mathrm{mg}$ TTC $\mathrm{cm}^{-3}$. Im Xylem der verschiedenen Kompartimente wurden verschiedene Umsätze gemessen. So war der TTC-Umsatz der Stämme im Göttinger Wald etwa doppelt so hoch wie im Solling. Auch das Astholz aus dem Göttinger Wald setzte tendenziell mehr TTC um als die Äste des Sollings, ohne dass die Unterschiede signifikant waren. Demgegenüber wiesen Grobwurzeln im Göttinger Wald im Vergleich mit den Solling-Wurzeln über den gesamten Querschnitt nur ca. ein Viertel der TTC-Umsätze auf.

Die radialen Verläufe waren bei den Mittelwerten weniger deutlich ausgeprägt, entsprechen aber den in Abb. 24 dargestellten Ergebnissen der einzelnen Messstellen. So war der TTC-Umsatz des Astholzes in den äußeren Schichten tendenziell höher als im inneren Bereich der Achsen. Unterschiede zwischen äußeren und inneren Schichten waren wegen der starken Variabilität zwischen den Messstellen statistisch nicht zu sichern. Die Umsätze der Grobwurzeln im Göttinger Wald waren in der äußersten Schicht etwa doppelt so hoch wie im Zentrum der Achsen, bei den Proben des Sollings änderten sie sich mit zunehmender Entfernung von der Oberfläche nicht.

Der radiale Verlauf der TTC-Umsätze war beim Stammholz am stärksten ausgeprägt. Dabei ließ sich das Holz wiederum in drei Tiefenstufen unterschiedlicher Umsätze unterteilen. In der äußeren Schicht, die sich über ein Zehntel des Radius erstreckte, wurde mit $0.27 \pm 0.02$ bzw. $0.11 \pm 0.02 \mathrm{mg}$ TTC $\mathrm{cm}^{-3}$ im Göttinger Wald bzw. Solling etwa dreimal so viel TTC umgesetzt wie in der nächst- 
folgenden Schicht, in der sich die Umsätze etwa bis zur Hälfte des Radius auf ähnlichem Niveau bewegten ( 0.089 und $0.033 \mathrm{mg}$ TTC $\mathrm{cm}^{-3}$ im Göttinger Wald und im Solling). Gegenüber diesen Werten betrug der TTC-Umsatz in einem zentralen Zylinder der Stämme mit etwa zwei Fünftel des Radius nur noch ca. 50 bzw. 30 \% bei den Stämmen im Göttinger Wald bzw. Solling.

Die Stickstoffkonzentrationen der Rinde waren im Vergleich zu den TTC-Umsätzen weniger homogen und nach Kompartimenten differenziert. Die höchste Konzentration wies die Rinde der

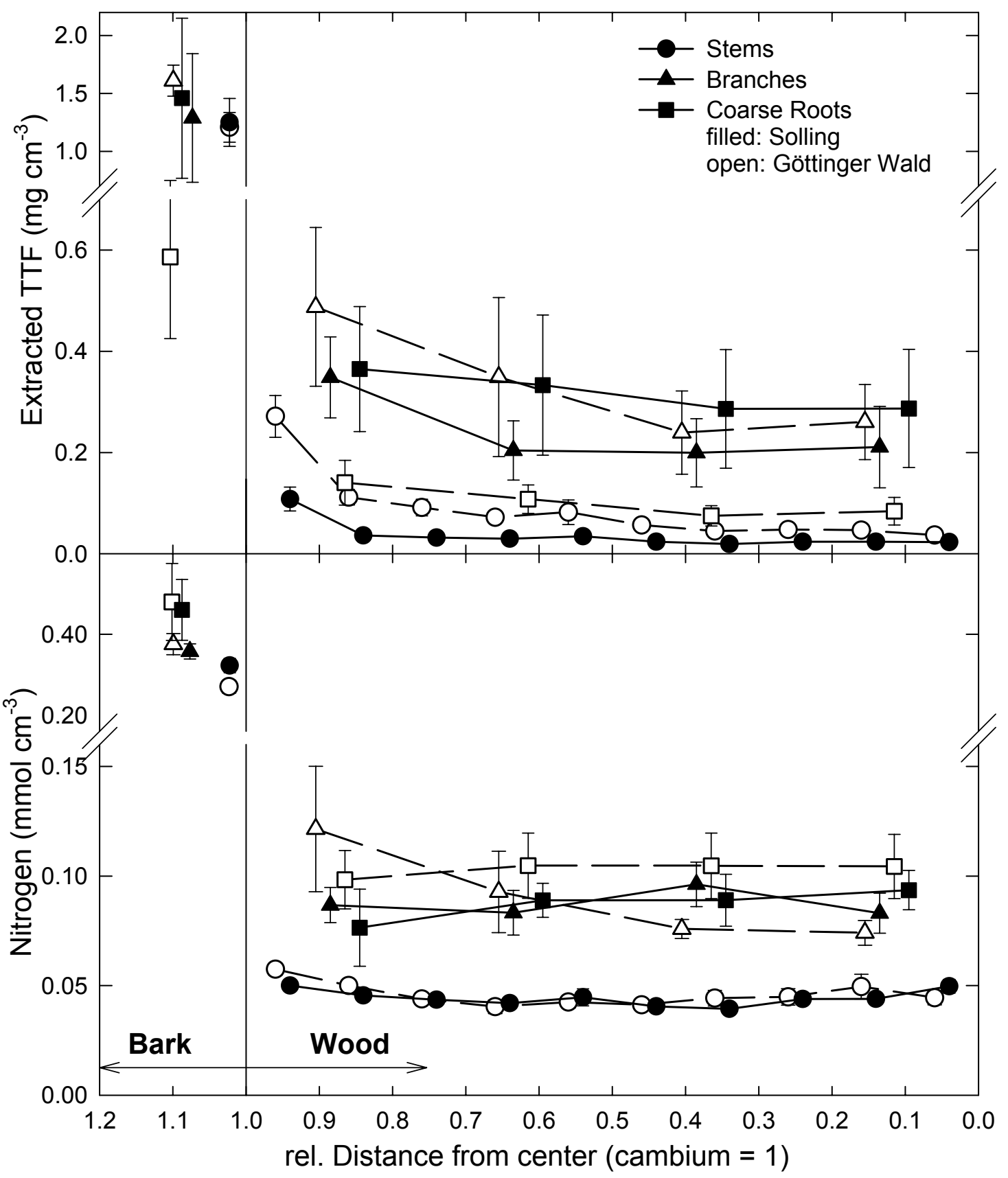

Abb. 25: Die radiale Verteilung der mittleren volumenbezogenen TTC-Umsätze und Stickstoffgehalte von Stämmen, Ästen und Grobwurzeln. Der Radius ist bei den Stämmen in 10, bei Ästen und Grobwurzeln in 4 gleichlange Teilstrecken unterteilt. Die Umsätze bzw. Konzentrationen aller $1 \mathrm{~cm}$ langen Holzproben jeder Messstelle eines Kompartiments und Standortes sind für jede Teilstrecke gemittelt. Die Werte für die Rinde wurden separat gemittelt. Dargestellt sind Mittelwerte \pm Standardfehler (Fehlerbalken z. T. durch die Symbole verdeckt), die zur besseren Unterscheidung um den Mittelpunkt jeder Teilstrecke versetzt aufgetragen wurden. 
Grobwurzeln mit $0.47 \mathrm{mmol} \mathrm{N} \mathrm{cm}^{-3}$ auf. Die Rinde der Äste enthielt $0.37 \mathrm{mmol} \mathrm{N} \mathrm{cm}^{-3}$. Ein signifikanter Unterschied bestand nur zwischen den Stämmen der beiden Standorte mit 0.32 bzw. $0.23 \mathrm{mmol} \mathrm{N} \mathrm{cm}^{-3}$.

Im Xylem der Grobwurzeln beider Untersuchungsflächen und der Äste im Solling war die Stickstoffkonzentration über den gesamten Querschnitt mit $0.092 \pm 0.01 \mathrm{mmol} \mathrm{N} \mathrm{cm}^{-3}$ konstant. Lediglich bei den Ästen des Göttinger Waldes wurde, wie beim TTC, in den äußeren Gewebeschichten eine höhere Stickstoffkonzentration gemessen. Das Holz der Stämme, das an beiden Standorten mit $0.049 \pm 0.004 \mathrm{mmol} \mathrm{cm}^{-3}$ im Mittel nur halb so viel Stickstoff enthielt wie die Äste und Grobwurzeln, zeigte ebenfalls keine ausgeprägte Änderung im radialen Verlauf. Die Konzentration bei den Stämmen im Göttinger Wald ist in den äußeren Schichten nur um ca. 20 \% gegenüber den tiefen Bereichen erhöht.

Bezogen auf die gesamten TTC-Umsätze bzw. Stickstoffgehalte der Messstellen ergab sich, dass ein wesentlicher Anteil der Umsätze bzw. Gehalte dem oberflächennahen Gewebe zuzuordnen ist. Während der mittlere Volumenanteil der Rinde bei Grobwurzeln und Ästen 16 bzw. $12 \%$ ausmachte, entfielen auf die Rinde der Grobwurzeln $45 \%$ des gesamten TTC-Umsatzes und 31 bzw. 55 \% auf die Rinde der Äste vom Solling bzw. Göttinger Wald. Der Stickstoffgehalt der Rinde machte bei den Grobwurzeln $46 \%$ und bei den Ästen 56 bzw. 43 \% gesamten Stickstoffmenge aus. In der Rinde der Stämme, die $4 \%$ des Volumens einnahm, wurden im Mittel 53 und $31 \%$ der gesamten TTC-Menge der Messstellen in Solling und Göttinger Wald umgesetzt. Außerdem sind 23 \% des Gesamtstickstoffs der Stämme in der Rinde enthalten. Da die TTC-Umsätze mit zunehmender Holztiefe abnahmen und im oberflächennahen Xylem viel TTC umgesetzt wurde, konzentrierten sich bei den Stämmen $75 \%$ des gesamten Umsatzes in der äußeren Schicht mit der Dicke von einem Viertel des Radius. Deren Volumen machte knapp 44 \% des Gesamtvolumens aus.

\subsubsection{Die Variabilität der Stammatmung innerhalb eines Baumes}

Bislang wurden die Atmungsraten aller Stämme unabhängig davon betrachtet, ob sich die Messstellen an verschiedenen Individuen ( $\mathrm{S} 1$ bis $\mathrm{S} 6)$ oder an einem einzelnen Stamm befanden $\left(\mathrm{S}_{\mathrm{V}} 7\right.$ bis $\mathrm{S}_{\mathrm{V}}$ 12, Tab. 3).

An einem Individuum jeden Standortes wurden die Stammatmungsraten in drei verschiedenen Höhenstufen - nahe der Stammbasis, in mittlerer Stammhöhe und unterhalb des Kronenansatzes gemessen. Je Höhenstufe war eine Küvette nach Norden und eine nach Süden exponiert.

Für Abb. 26 wurden die volumenbezogenen $10{ }^{\circ} \mathrm{C}$ Atmungsraten gemittelt, die sich aus den vier bis fünf Temperaturfunktionen ergaben, die in die Erhaltungsatmungsfunktion eingingen. Die $10{ }^{\circ} \mathrm{C}$ Erhaltungsatmung der $\mathrm{S}_{\mathrm{V}}$-Bäume lag auf dem gleichen Niveau wie die der übrigen Stämme. Jedoch streuten die Raten innerhalb eines Einzelstammes mit relativen Standardabweichungen von 20 bzw. 59 \% im Solling bzw. im Göttinger Wald stärker als zwischen verschiedenen Individuen des gleichen Standortes (rel. Standardabweichung = 15 bzw. $35 \%$ ).

Hinsichtlich der Exposition zeigten die Atmungsraten der beiden Bäume kein eindeutiges Muster. So unterschieden sich die Raten der Messpositionen gleicher Höhe im Solling nicht signifikant, im Göttinger Wald unterschieden sich die Raten der beiden Messstellen auf mittlerer Stammhöhe und unterhalb der Kronenansatzes. In 9.3 m Höhe war die Atmungsrate der nach Süden exponierten Messstelle ca. 1.5fach höher als auf der gegenüberliegenden Seite. In $16.3 \mathrm{~m}$ unterschieden sich die Raten um das fünffache, jedoch wurde hier die höhere Atmungsaktivität in nördlicher Exposition gemessen. 
Eine Änderung der Atmungsraten mit zunehmender Höhe am Stamm war nur insofern zu erkennen, dass die maximalen Atmungsraten nahe der Kronenbasis gemessen wurden. Die für jede Höhenstufe gemittelten Atmungsraten unterschieden sich bei keinem der beiden Bäume.

Im saisonalen Verlauf waren die Verhältnisse zwischen den Atmungsraten der verschiedenen Messpositionen der $\mathrm{S}_{\mathrm{V}}$-Bäume deutlich stabiler als zwischen den Raten verschiedener Individuen. Wurden die Atmungsraten der Zweijahres-Zeitreihen aller Messstellen jeweils paarweise zueinander in Beziehung gesetzt, ergab die lineare Regressionsanalyse für den $\mathrm{S}_{\mathrm{V}}$-Baum im Solling $\mathrm{r}^{2}$-Werte zwischen 0.70 und $0.96\left(\mathrm{r}^{2}\right.$ median $\left.=0.89\right)$. Bei dem Baum im Göttinger Wald lagen die Werte zwischen 0.30 und $0.91\left(\mathrm{r}^{2}\right.$ median $\left.=0.78\right)$. Mit Ausnahme der Beziehung zwischen den Raten der unteren nach Norden exponierten und den an der Kronenbasis befindlichen Messpositionen im Göttinger Wald waren alle Beziehungen signifikant (Solling: $\mathrm{P}<0.0001$, Göttinger Wald $\mathrm{P}_{\max }=0.008$ ). Auch die Stammatmungsraten der fünf bzw. sechs Individuen im Solling und im Göttinger Wald waren signifikant korreliert $(0.03>\mathrm{P}>0.0001)$, das Bestimmtheitsmaß erreichte im Median jedoch nur Werte von 0.44 bzw. 0.60 im Solling bzw. im Göttinger Wald (Abb. 28).

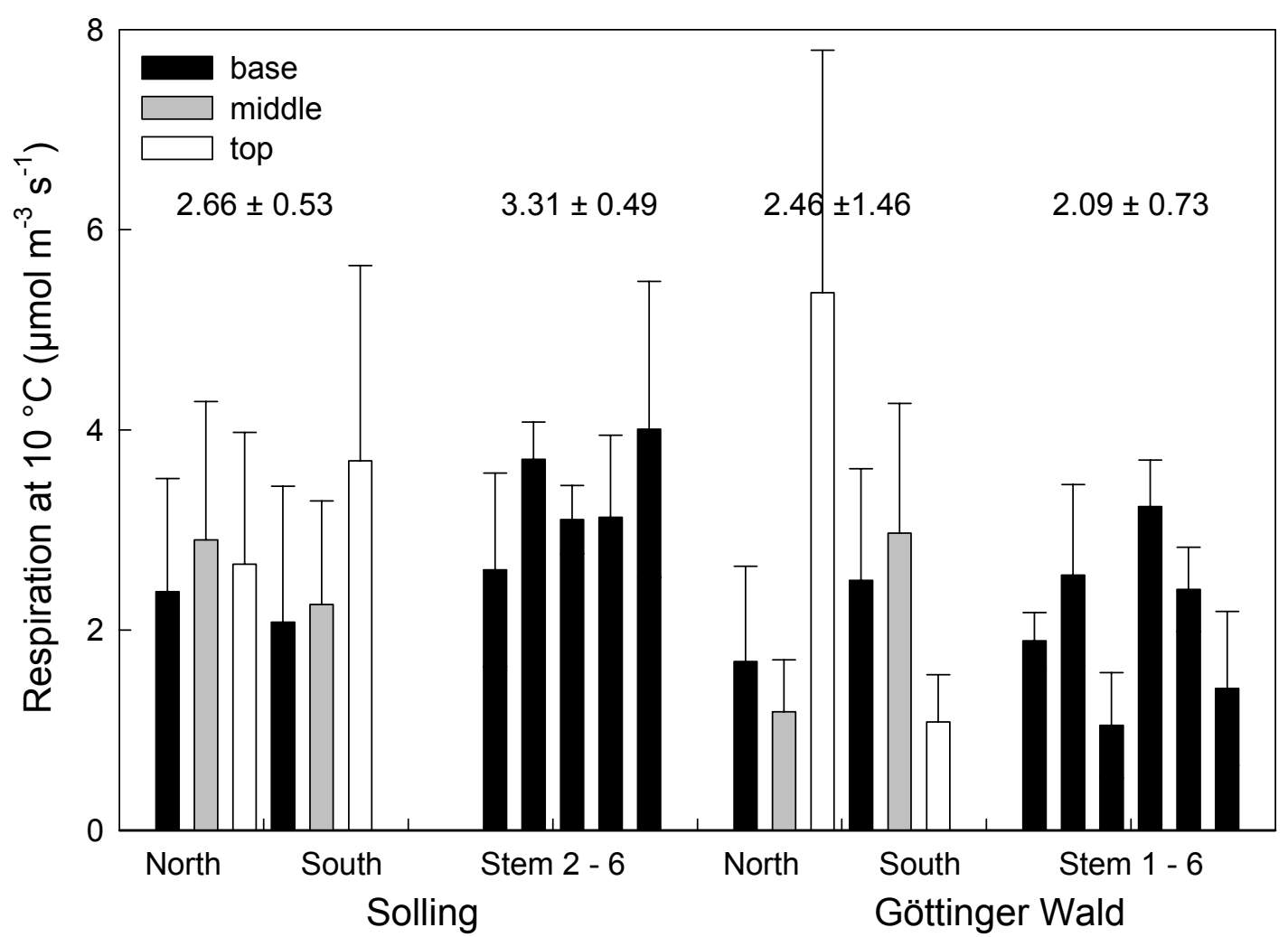

Abb. 26: Volumenbezogene $10{ }^{\circ} \mathrm{C}$-Erhaltungsatmung je eines Stammes in Solling und Göttinger Wald, an denen die Messungen an der Stammbasis, auf mittlerer Höhe und nahe dem Kronenansatz jeweils in nördlicher und südlicher Exposition erfolgten. Gemittelt wurden die Atmungsraten, die mit den Temperaturbeziehungen berechnet wurden, die der Erhaltungsatmungsfunktion zugrunde lagen. Zum Vergleich sind jeweils rechts die $10{ }^{\circ} \mathrm{C}$ Erhaltungsatmungsraten von 5 bzw. 6 Bäumen, an denen Dauermessungen in ca. 2 m Höhe und nördlicher Exposition durchgeführt wurden, dargestellt. 


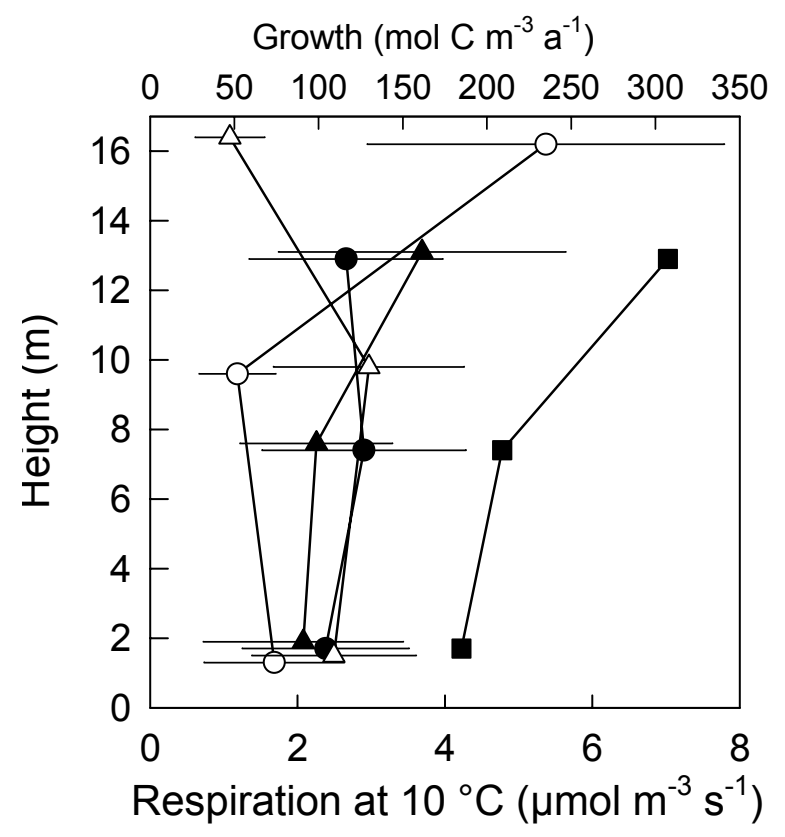

Abb. 27: Höhengradient der mittleren $10{ }^{\circ} \mathrm{C}$ Atmungsrate eines Stammes im Solling (gefüllte Symbole) und im Göttinger Wald (offene Symbole) sowie der Jahreszuwachsrate des Stammes im Solling (ם). In jeder Höhe wurde in nördlicher (A) und südlicher $(\bullet)$ Exposition gemessen. Gemittelt wurden Werte aus der Zeit von November bis Mai (vergl. Text).

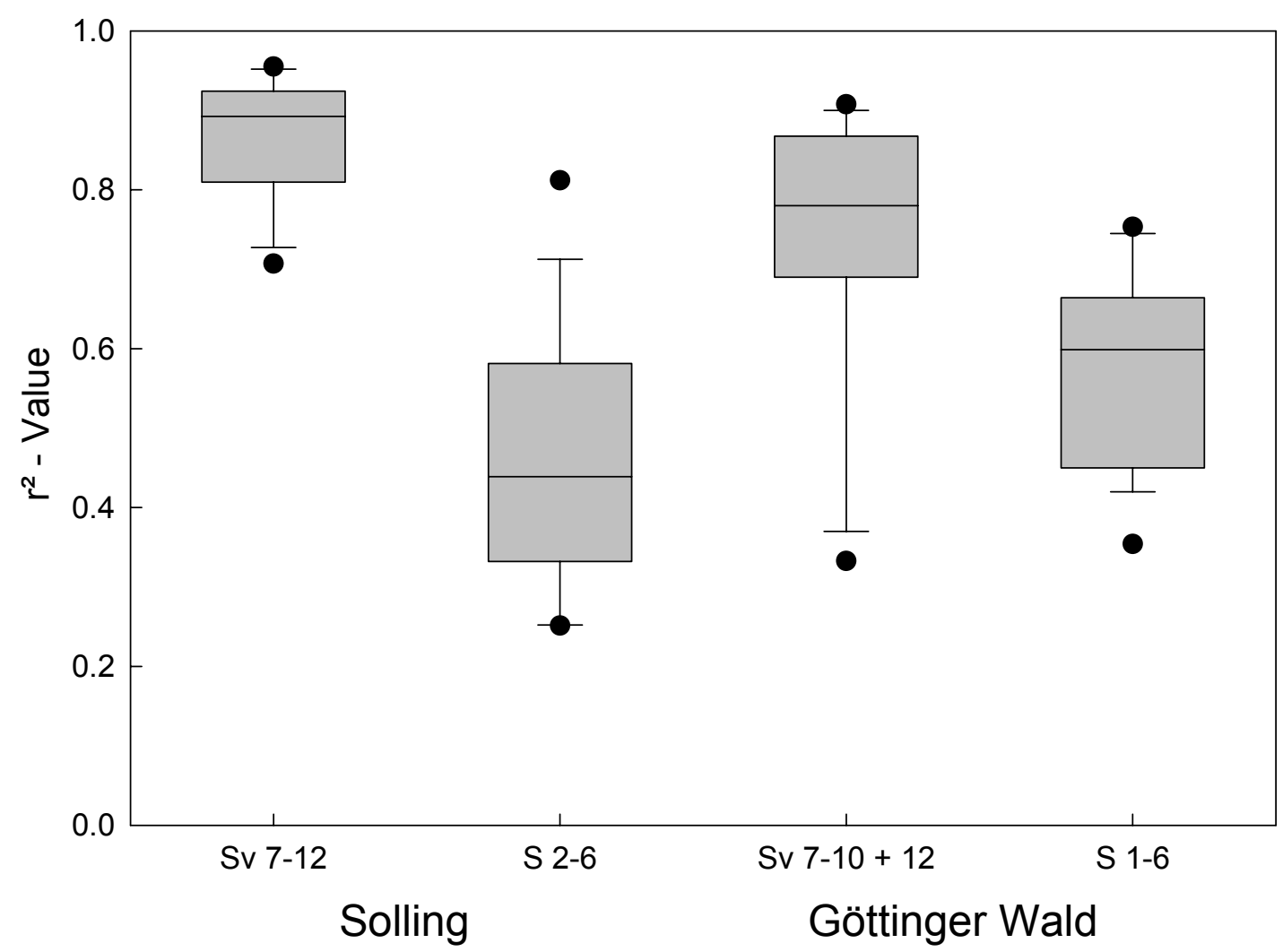

Abb. 28: Verteilung der $\mathrm{r}^{2}$-Werte aller linearen Regressionen für die Beziehungen zwischen den $10^{\circ} \mathrm{C}$-Atmungsraten von sechs Messstellen, die an einem Individuum in unterschiedlicher Höhe und Exposition $\left(\mathrm{S}_{\mathrm{V}} 7\right.$ bis $\left.\mathrm{S}_{\mathrm{V}} 12\right)$ und an fünf bzw. sechs verschiedene Individuen (S 1- S 6) gemessen wurde. Bei der Regressionsberechnung wurden die Atmungsraten des gesamten Untersuchungszeitraumes jeder Messstelle jeweils mit allen anderen Messstellen in Beziehung gesetzt. 


\subsubsection{Der Einfluss der Messposition und der Kronenstruktur auf die Astatmung}

Die Atmungsraten der Äste zeigten keine Abhängigkeit von quantitativ erhobenen Größen, wie absoluter oder relativer Höhe, Inklination oder Exposition (Ergebnisse nicht dargestellt). Auch die Auftragung der $10^{\circ} \mathrm{C}$-Erhaltungsatmung gegen die den Ästen zugeordnete Klasse des Kronenvolumens (Kap. 3.1.5, Tab. 3) zeigte keinen Zusammenhang (Abb. 29). Jedoch wiesen nur solche Äste mittlere und hohe Atmungsraten auf, deren belaubter Anteil der mittleren Kronenschicht oder der Sonnenkrone zuzuordnen war (Abb. 29). Zwei Äste, die im Solling vollständig auf die Schattenkrone beschränkt waren, zeigten zudem die niedrigste Atmungsaktivität. Bei multiplikativer Verknüpfung der Klassen von Kronenposition und Kronenvolumen ergab sich eine signifikante Abhängigkeit der Atmungsrate von diesem Produkt.

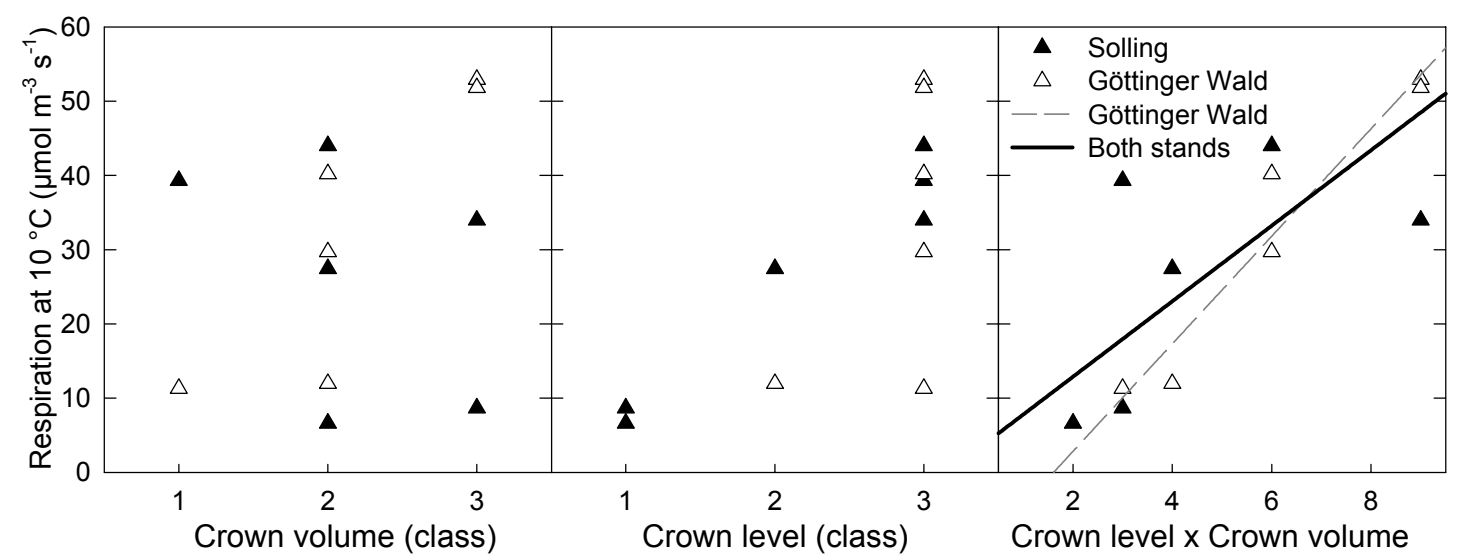

Abb. 29: $10^{\circ} \mathrm{C}$-Erhaltungsatmung der Äste beider Standorte aufgetragen gegen die ihnen zugeordnete Klasse von Kronenvolumen und Kronenposition Göttinger Wald: $\quad \mathrm{y}=7.3 \mathrm{x}-11.6, \mathrm{r}_{\text {adj. }}^{2}=0.92, \mathrm{P}=0.002$ beide Standorte: $\quad \mathrm{y}=5.1 \mathrm{x}+2.7, \mathrm{r}_{\text {adj. }}^{2}=0.58, \mathrm{P}=0.003$

\subsection{Biomasse: Verteilung, Vorräte und Zuwachs.}

Für die Ermittlung der Bestandesvorräte an verholzter Biomasse wurden zur Berechnung des Derbholzvolumens Standardverfahren der Dendrometrie und Forstertragskunde angewandt. Diese wurden zur Berechnung des oberirdischen Gesamtvolumens und dessen Verteilung auf verschiedene Durchmesserklassen mit den Ergebnissen einer erneuten Auswertung der Erntedaten von 30 Buchen (HELLER \& GÖTTSCHE 1986, H. HELLER, pers. Mittlg.) sowie Literaturangaben ergänzt.

\subsubsection{Verteilung der oberirdischen Biomasse auf verschiedene Durchmesserklassen}

In Anlehnung an das zur Ermittlung des Derbholzvolumens oder der Biomasse gebräuchliche Verfahren, die Abhängigkeit der Holzvolumina vom BHD zu nutzen, wurde in einem ersten Ansatz die auf die Durchmesserklassen DK1. 1 - 7 (Tab. 4) verteilten Volumina der Erntebäume direkt mit deren BHD in Beziehung gesetzt. Mit den in der doppelt-logarithmischen Auftragung gefundenen linearen Beziehungen (Daten nicht dargestellt) und der BHD-Verteilung der Bestände (Abb. 32) wurden die Volumenvorräte jeder Durchmesserklasse direkt aus dem BHD ermittelt. Die Summe der Volumina der Durchmesserklassen 1 bis 4 entsprach dem Derbholzvolumen, das mit den Ergebnissen des in Kapitel 3.3.1 beschriebenen Verfahrens verglichen wurde. Diese direkte Bestimmung aus dem BHD lieferte Derbholzvolumina, die 25 bis $100 \%$ über denen lagen, die das 
schließlich verwendete Verfahren ergab. Vor allem die Extrapolation der Volumina zu - gegenüber den Erntebäumen - höheren Durchmessern führte in diesem ersten Ansatz zu durchgängig überhöhten Werten für das Holzvolumen. Das Verfahren kam daher nicht zur Anwendung.

Die relativen Volumenanteile der Durchmesserklassen 2 bis 7 standen in enger Beziehung zum BHD der geernteten Bäume (Abb. 30) und ließen sich durch nichtlineare Funktionen beschreiben. Die Bestimmtheitsmaße der durchgängig signifikanten Kurvenanpassungen lagen zwischen 0.73 (DK1. 6) und 0.98 (DK1. 2). Die verwendeten Funktionen, ihre Parameter und Statistikwerte sind im Anhang (A-Tab. 3) zusammengefasst. Die Daten der Durchmesserklasse 7, dem Feinreisig, konnten um die Werte von 20 weiteren Buchen aus PELLINEN (1986) ergänzt werden. Da die Autorin Äste und Zweige mit einem Durchmesser unter $2 \mathrm{~cm}$ als Feinreisig zusammenfasst, mussten ihre Volumenangaben der hier verwendeten Definition für das Feinreisig ( $\leq 1 \mathrm{~cm})$ angeglichen werden. Aus den Erntedaten der 29 Buchen, die im Solling erhoben wurden, konnte der Volumenanteil des Feinreisigs $(\mathrm{D} \leq 1 \mathrm{~cm})$ am Volumen aller Äste mit $\mathrm{D} \leq 2 \mathrm{~cm}$ mit $48 \%$ bestimmt werden. Mit diesem Prozentsatz wurde aus den Volumenangaben von PELLINEN (1986) das Feinreisigvolumen mit $\mathrm{D} \leq 1 \mathrm{~cm}$ bestimmt. Der Volumenanteil der Durchmesserklasse $1(\mathrm{D} \geq 40 \mathrm{~cm})$ ergab sich aus der Differenz zwischen 100 \% und der Summe der Anteile der Durchmesserklassen DK1 2 - 7.

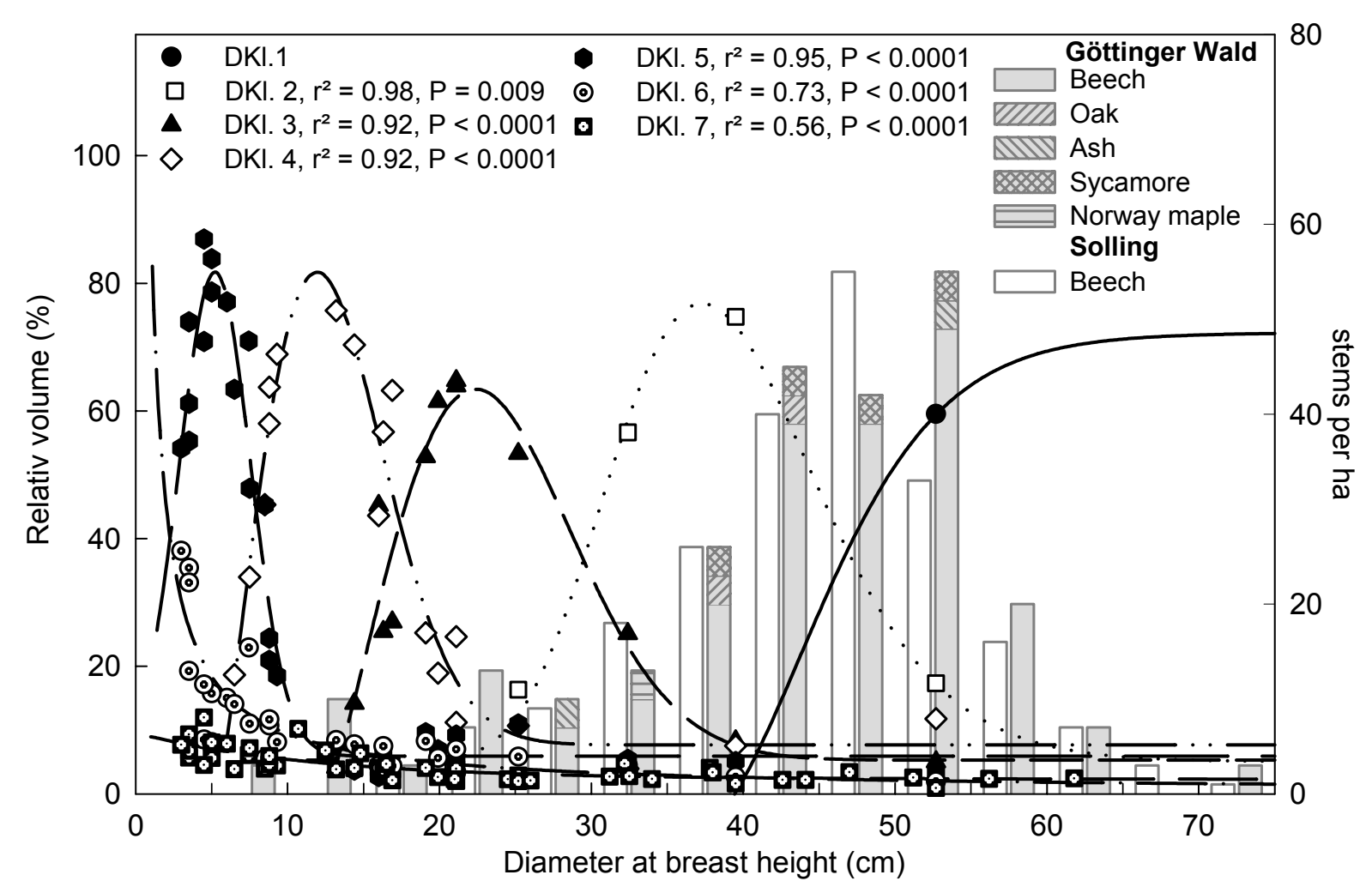

Abb. 30: Beziehung zwischen Holzvolumenanteil (mit Rinde) von Sprossachsen verschiedener Durchmesserklassen am Gesamtvolumen von fraktioniert geernteten Buchen und deren BHD $(n=30$ für DK1 1-6, $n=50$ DK1 7). Funktionen, Parameter und Statistikwerte für die Kurvenanpassungen sind in A-Tab. 3 zusammengefasst. Graue Balken: BHD-Verteilung der Untersuchungsbestände.

Das Gesamtvolumen der oberirdischen Biomasse eines Baumes errechnete sich dann aus dem gemäß Kap. 3.3.1 ermittelten Derbholzvolumen und dessen relativen Anteil am Gesamtvolumen. Dieser entsprach der Summe der relativen Anteile der Durchmesserklassen 1-4, die mit den Funktionen in A-Tab. 3 aus dem BHD des Baumes berechnet wurden. 
Mit diesem Verfahren wurde für zwei bestandesrepräsentative Buchen mit mittleren Durchmessern und mittleren Höhen ein Gesamtvolumen von je $2.6 \mathrm{~m}^{3}$ ermittelt, von dem $90.2 \%$ auf das Derbholz, $8.3 \%$ auf das Reisholz und knapp $1.5 \%$ auf das Feinreisig entfielen (Tab. 8).

Tab. 8: Derbholz- und Gesamtvolumen sowie die prozentuale Verteilung der Volumina auf 7 Durchmesserklassen von zwei für die Untersuchungsbestände repräsentativen Buchen mittleren Durchmessers und mittlerer Höhe.

\begin{tabular}{|c|c|c|}
\hline & Solling & $\begin{array}{l}\text { Göttinger } \\
\text { Wald }\end{array}$ \\
\hline $\mathrm{BHD}(\mathrm{cm})$ & 45.4 & 43.4 \\
\hline Höhe (m) & 29.4 & 31.9 \\
\hline Derbholzformzahl & 0.5005 & 0.5009 \\
\hline Derbholzvolumen $\left(\mathrm{m}^{3}\right)$ & 2.38 & 2.36 \\
\hline Volumenanteil des Derbholzes (\%) & 89.30 & 89.18 \\
\hline Gesamtvolumen $\left(\mathrm{m}^{3}\right)$ & 2.64 & 2.62 \\
\hline \multicolumn{3}{|c|}{ Volumenanteile der einzelnen Durchmesserklassen (\%) } \\
\hline $\begin{array}{ll}\text { DK1. 1: } & \mathrm{D}>40 \mathrm{~cm}\end{array}$ & 31.6 & 20.6 \\
\hline DK1. 2: $40 \geq \mathrm{D}>25 \mathrm{~cm}$ & 45.5 & 56.1 \\
\hline DK1. 3: $25 \geq \mathrm{D}>15 \mathrm{~cm}$ & 5.49 & 5.78 \\
\hline DK1. 4: $15 \geq \mathrm{D}>7 \mathrm{~cm}$ & 7.67 & 7.67 \\
\hline DK1. 5: $\quad 7 \geq \mathrm{D}>3 \mathrm{~cm}$ & 5.93 & 5.93 \\
\hline DK1. 6: $3 \geq \mathrm{D}>1 \mathrm{~cm}$ & 2.32 & 2.41 \\
\hline DK1. 7: $\quad \mathrm{D} \leq 1 \mathrm{~cm}$ & 1.45 & 1.48 \\
\hline
\end{tabular}

\subsubsection{Unterirdische Biomasse}

Das Volumen des Wurzelholzes wurde direkt aus der BHD-Verteilung und der Beziehung zwischen den Logarithmen von Biomasse und BHD berechnet (Abb. 31). Die Umrechnung der Biomasse in Volumeneinheiten erfolgte mit einer konstanten Dichte frischen Wurzelholzes von $506 \mathrm{~kg} \mathrm{~m}^{-3}$, die die Laboruntersuchungen im Rahmen dieser Arbeit ergaben (3.2.4.1). Zur Abschätzung der Verteilung der Wurzelbiomasse standen Daten aus der Arbeit von CONERS (1996) zur Verfügung, in welcher die Grobwurzeln eines in der Lüneburger Heide fraktioniert geernteten Buchen-Wurzelsystems in Wurzelholz $(>7 \mathrm{~cm})$ Derbwurzeln $(7-2 \mathrm{~cm})$ und Grobwurzeln i. e. S. $(2-0.5 \mathrm{~cm})$ unterschieden werden. Die auf die Grundfläche eines Kreises mit $3.8 \mathrm{~m}$ Radius $(0.5 \times$ mittlerer Stammabstand der untersuchten Bestände) hochgerechneten Wurzelvorräte verteilen sich zu $63 \%$ auf die Summe von Wurzelholz und Derbwurzeln. Die verbleibenden 37 \% entfallen auf die Grobwurzeln i. e. S..

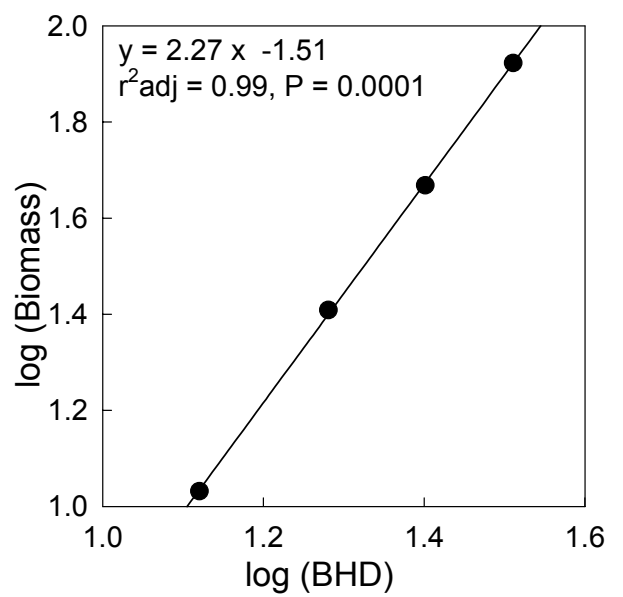

Abb. 31: Beziehung zwischen den Logarithmen der Grobwurzelbiomasse und dem BHD von vier 1968 im Solling geernteten Buchen (HELLER \& GÖTTSCHE 1986). 


\subsubsection{Biomassevorräte und Jahreszuwachs der Bestände}

Datengrundlage für die Berechnung des Bestandesvolumens waren die BHD- und Höhenmessungen der Niedersächsischen Forstlichen Versuchsanstalt vom Januar bzw. September 1996 im Solling und im Göttinger Wald (Abb. 32). Ergänzt wurden die Werte durch Messungen des jährlichen BHD-Zuwachses an jeweils 20 (1996) bzw. 27 (1997 und 1998) bestandesrepräsentativen Buchen (F. SCHIPKA, pers. Mitteilung, eigene Messungen).

Der Jahreszuwachs der Buchen im Göttinger Wald war positiv mit dem BHD korreliert und änderte sich bei den Bäumen im Solling nicht mit dem Durchmesser (Abb. 33). Um die Daten der Forstlichen Versuchsanstalt an den Untersuchungszeitraum anzupassen und den jährlichen Volumenzuwachs zu ermitteln, wurden die BHD-Werte des Sollings um den mittleren Jahreszuwachs erhöht. Für den Göttinger Wald wurde der zu addierende Jahreszuwachs mit Hilfe der linearen Funktion aus dem BHD der einzelnen Bäume bestimmt.

Mit den so angepassten Durchmessern wurden die Volumenvorräte und jährlichen Zuwächse jedes Baumes ermittelt und zum Bestandesvorrat und -zuwachs von oberirdischer Biomasse und Wurzelbiomasse aufsummiert.

$\mathrm{Zu}$ Beginn des Untersuchungszeitraumes lag der Holzvorrat des Bestandes im Solling bei $668 \mathrm{~m}^{3}$ je Hektar, von denen $532 \mathrm{~m}^{3}$ auf die Derbholzfraktion, $56.5 \mathrm{~m}^{3}$ auf das Reisig und $80 \mathrm{~m}^{3}$ auf das Wurzelholz entfielen. In den Jahren 1997 und 1998 nahm der Vorrat gleichmäßig um jeweils $8.0 \mathrm{~m}^{3} \mathrm{ha}^{-1} \mathrm{zu}$, wobei der Derbholzzuwachs $6.4 \mathrm{~m}^{3}$ betrug.

Im Göttinger Wald hat die Buche einen Anteil von $90 \%$ an der Stammzahl. Allein der Bestandesvorrat der Buchen überstieg mit $756 \mathrm{~m}^{3} \mathrm{ha}^{-1}$ den Wert des Sollings um $15 \%$. Zum Vergleich der beiden Standorte und für die Hochrechung der Atmungsraten auf Bestandesebene wurden die BHDWerte der Bäume anderer Arten in gleicher Weise wie die Buchen in die Berechnung mit einbezogen. Der Biomassevorrat erhöhte sich dadurch auf $844 \mathrm{~m}^{3} \mathrm{ha}^{-1}$ und verteilte sich mit 676, 71.6 bzw. $87 \mathrm{~m}^{3}$ auf Derbholz, Reisig und Grobwurzeln. Für den Jahreszuwachs ergab sich mit knapp 14 $\mathrm{m}^{3} \mathrm{ha}^{-1}$ ein fast doppelt so hoher Wert wie für den Bestand im Solling (Tab. 9).

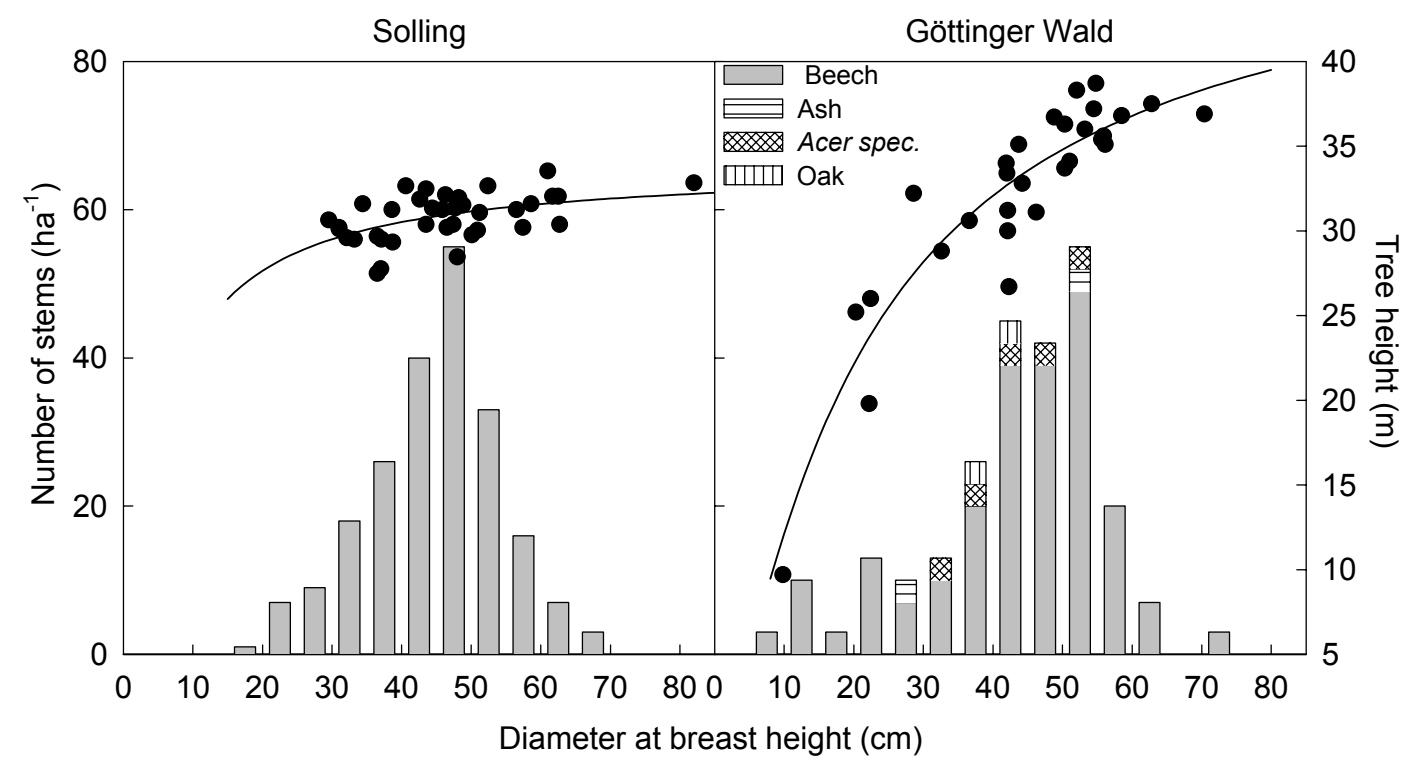

Abb. 32: Durchmesserverteilung, Baumhöhen und BHD-Höhenbeziehung der beiden Untersuchungsbestände. Die Daten wurden von der Niedersächsischen Forstlichen Versuchsanstalt im Januar bzw. September 1996 in Solling bzw. Göttinger Wald erhoben. 


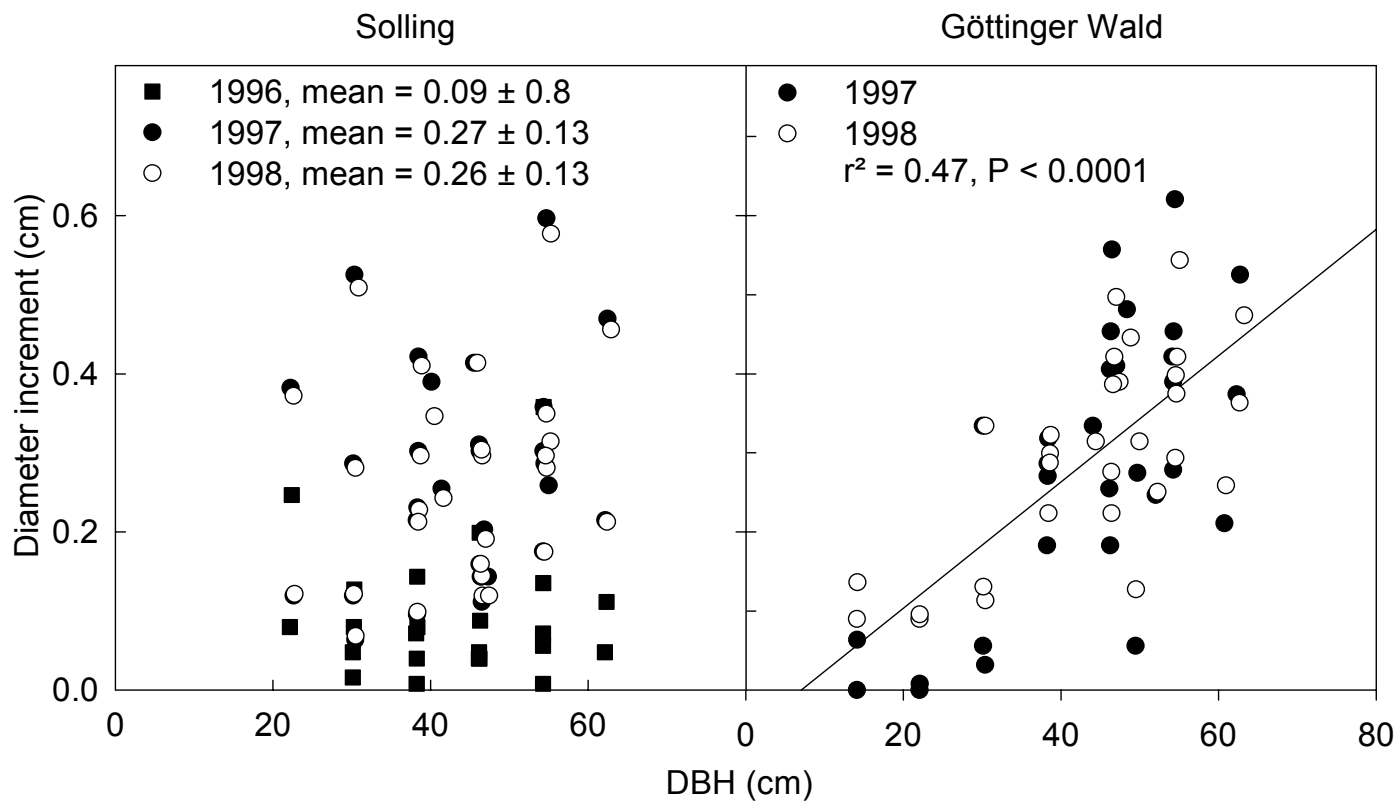

Abb. 33: Beziehung zwischen dem jährlichen Durchmesserzuwachs und dem BHD bestandesrepräsentativer Buchen im Solling und im Göttinger Wald. Die Durchmesser wurden mit hochauflösenden Umfangmaßbändern an 20 (1996) bzw. 27 (1997/98) Bäumen gemessen (F. SCHIPKA, pers. Mitteilung, eigene Messungen).

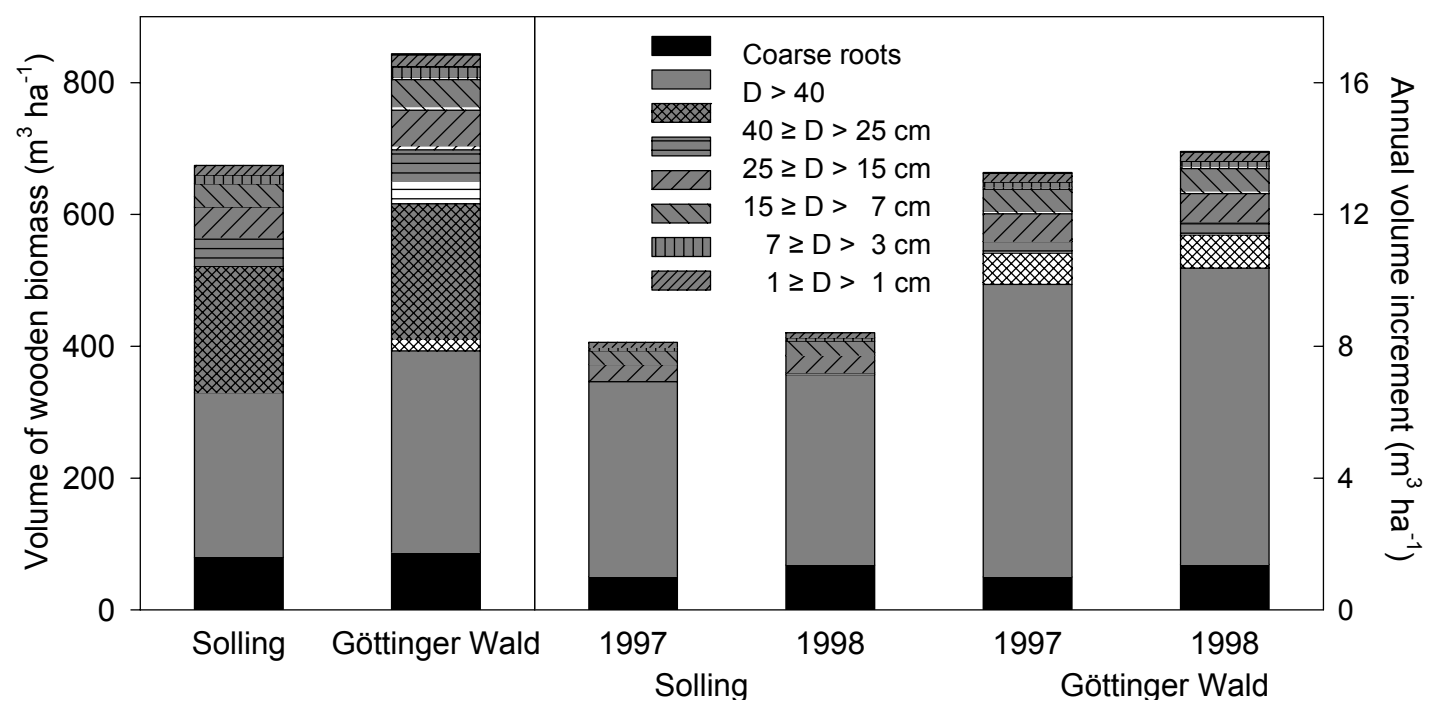

Abb. 34: Volumenvorräte der verholzten oberirdischen Biomasse zu Beginn des Untersuchungszeitraumes, ihre Verteilung auf 7 Durchmesserklassen sowie der Volumenzuwachs während der zwei Untersuchungsjahre. Weiße Anteile der Balken für den Göttinger Wald sind Volumenanteile, die sich aus dem BHD der Bäume anderer Arten errechnen. 
Tab. 9: Vorräte verholzter Biomasse Anfang 1997, ihre Verteilung auf verschiedene Durchmesserklassen der Sprossachsen und der Zuwachs von Derb-, Reis- und Wurzelholz in den beiden Untersuchungsjahren.

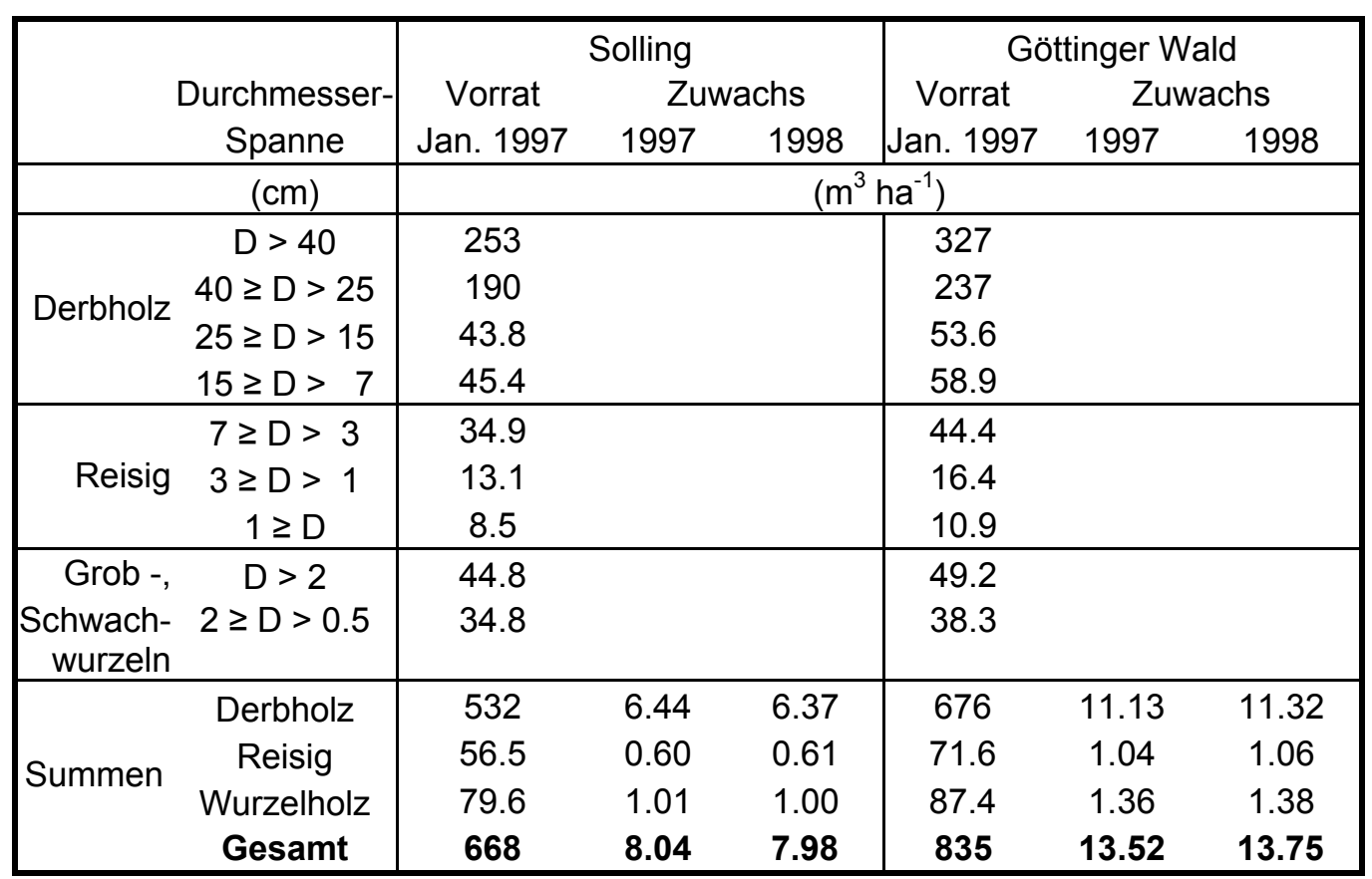

\subsection{Zeitliche und räumliche Hochrechnung der Atmungsraten als Teil der Kohlen- stoffbilanz}

Für die C-Bilanz der Buchenwälder im Solling und Göttinger Wald wurden die Atmungsraten der verholzten Kompartimente zunächst auf Ebene einzelner Küvetten im zeitlichen Verlauf interpoliert. Die Berechnung der Atmungsraten der einzelnen Messstellen und die Erfassung des Holzzuwachses in enger räumlicher Nähe ermöglichte eine quantitative Analyse der Beziehung zwischen Atmung und Holzzuwachs.

Schließlich wurden die Atmungsraten mit den Biomassevorräten auf Bestandesebene hochgerechnet.

\subsubsection{Zeitliche Hochrechnung der Atmungsraten}

Die Atmungsraten wurden auf Ebene des Tagesganges aus den für jede Messstelle und Kampagne ermittelten Temperaturbeziehungen und den stündlichen Werten der Luft- bzw. Bodentemperatur berechnet. In Abb. 35 sind die Temperaturbeziehungen und die daraus berechneten Jahresgänge der Tagessummen von Gesamt- und Erhaltungsatmung jeweils eines Astes, Stammes und einer Grobwurzel beispielhaft dargestellt. Die im Jahresgang verwendeten Symbole verweisen auf die für den entsprechenden Zeitraum verwendeten Temperaturbeziehungen. Zum Vergleich sind außerdem die Tagessummen der gemessenen Atmungsraten dargestellt.

Den Kennfeldern der mittleren Temperaturantwortkurven (Abb. 17) entsprechend war auch das Niveau der Temperaturbeziehungen der einzelnen Messstellen ab Mai erhöht, stieg bis Mitte Juli an und fiel meist erst im November auf das Niveau, das für den Zeitraum von Dezember bis März/April charakteristisch war. Die Temperaturfunktionen der Erhaltungsatmung spiegeln die Temperaturantwortkurven aus diesem Zeitraum wider. In die Temperaturbeziehung für die Erhal 

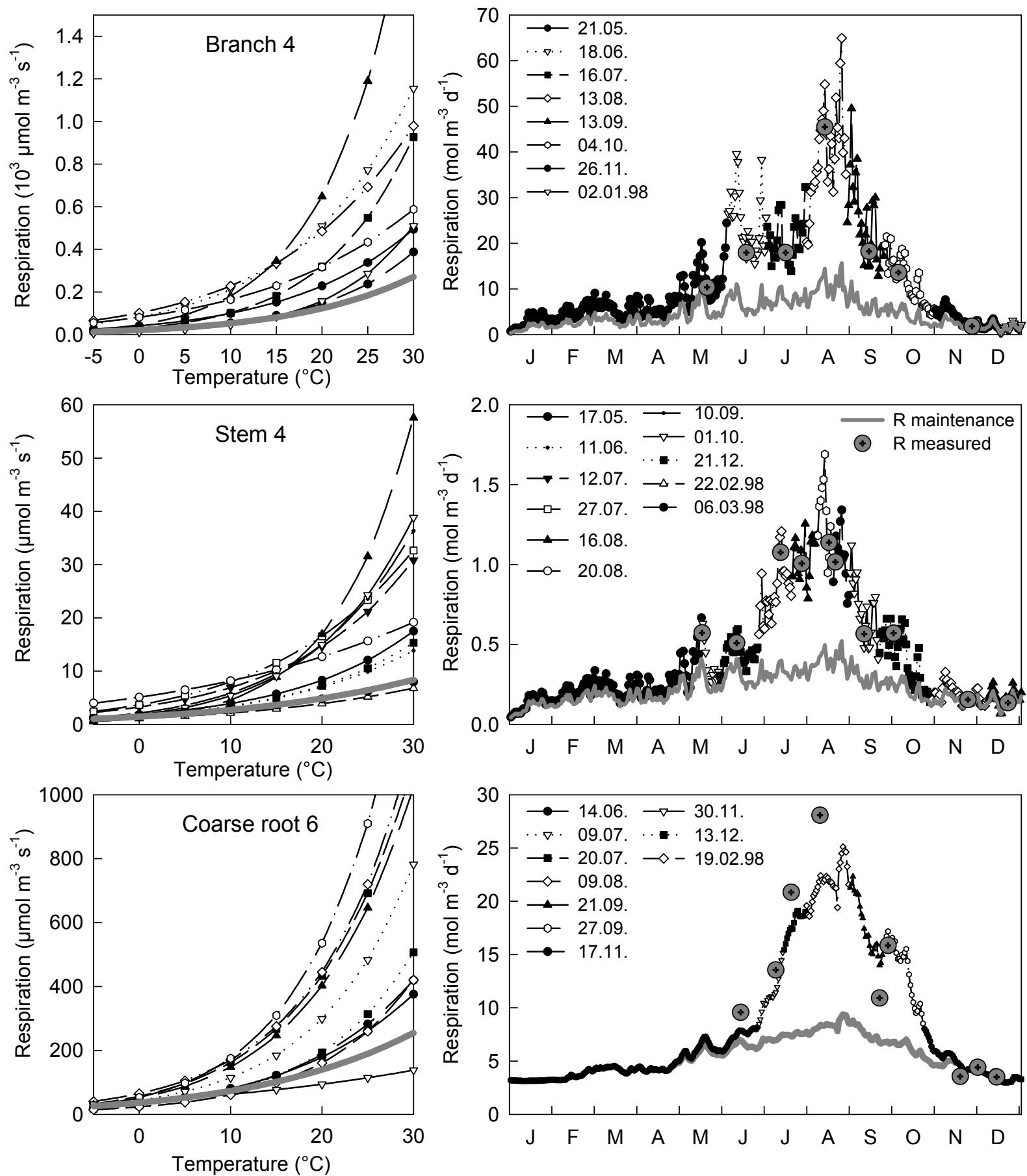

Abb. 35: Temperaturfunktionen der Erhaltungsatmung und der Atmungsraten aller Messkampagnen 1997 eines Astes, eines Stammes und einer Grobwurzel (links) sowie die daraus berechneten Jahresgänge der Atmung (rechts). Für die Erhaltungsatmung $R_{m}$ wurden die 4 bis 5 Temperaturkurven aus der zuwachsfreien Zeit mit dem niedrigsten Ordinatenabschnitt und geringem bis mittlerem $\mathrm{Q}_{10^{-}}$ Wert gemittelt. Die Jahresgänge der Tagessummen von Gesamtatmung (Linien + Symbole) und Erhaltungsatmung (graue Kurve) wurden mit den Temperaturfunktionen aus Luft- bzw. Bodentemperatur berechnet. Zum Vergleich sind die Jahresgänge der gemessenen Atmungsraten (graue Punkte) aufgetragen.

tungsatmung des Astes gingen auch die nicht dargestellten Atmungsraten aus dem Winter 1998/99 ein. Diese wiesen einen flacheren Verlauf und niedrigere Atmungsraten auf, so dass die Beziehung der Erhaltungsatmung unterhalb der dargestellten Kurvenschar liegt. 
Die Tagessummen der berechneten Atmungsraten zeigten im zeitlichen Verlauf wiederum einen ausgeprägten Jahresgang. Die Erhaltungsatmung stieg temperaturbedingt von winterlichen Werten auf 2.5- bis 4 fach höhere Werte in den Sommermonaten an. Die Jahreskurve der Gesamtatmung lag ab Anfang Mai bis Mitte November oberhalb der Erhaltungsatmung und überstieg die winterlichen Atmungsraten um das 4- bis 15 fache. Die Differenz zwischen Gesamt- und Erhaltungsatmung wird als Wachstumsatmung aufgefasst.

Die berechnete Gesamtatmung stimmt bei Ästen und Stämmen gut mit den gemessenen Tagessummen der Atmung überein. Lediglich bei der Grobwurzel fallen stärkere Abweichungen auf. Dies ist auf die unterschiedlichen Temperaturen des Boden und des Wurzelholzes in der Küvette zurückzuführen. Die tägliche und saisonale Temperaturamplitude der Grobwurzeln in den Küvetten war größer als die stark gedämpfte Amplitude der Bodentemperatur in $20 \mathrm{~cm}$ Tiefe, da das stets frisch zugeführte Messgas, dessen Temperatur der Lufttemperatur im Bestand entsprach, einen schnelleren Wärmeaustausch bewirkte. Die Dämpfung der Bodentemperatur wird im Kurvenverlauf des dargestellten Beispiels zu den Terminen im September und Oktober dadurch deutlich, dass die gemessenen Atmungsraten nach einem Kälteeinbruch weit stärker absanken als die aus den Bodentemperaturen berechneten Raten. Im Winter stimmten die Temperaturen und damit die gemessenen und berechneten Atmungsraten der Wurzeln wieder überein.

Tab. 10: Jahressummen der volumenbezogenen Gesamt-, Erhaltungs- und Wachstumsatmung der verholzten Kompartimente. Aufgeführt sind die Mittelwerte \pm Standardabweichung von $\mathbf{n}$ Messstellen, sowie die prozentualen Anteile der Atmung im Zeitraum Mai bis Oktober.

\begin{tabular}{|c|c|c|c|c|c|c|c|c|c|}
\hline \multirow{2}{*}{\multicolumn{2}{|c|}{ Kompartiment }} & \multicolumn{4}{|c|}{1997} & \multicolumn{4}{|c|}{1998} \\
\hline & & $\begin{array}{c}\mathrm{R}_{\mathrm{t}} \\
\mathrm{mol} \mathrm{C} \mathrm{m}^{-3}\end{array}$ & $\mathrm{n}$ & $\mathrm{R}_{\mathrm{m}}$ & $\mathrm{R}_{\mathrm{g}}$ & $\begin{array}{c}\mathrm{R}_{\mathrm{t}} \\
\mathrm{mol} \mathrm{C} \mathrm{m}^{-3}\end{array}$ & $\mathrm{n}$ & $\mathrm{R}_{\mathrm{m}}$ & $\mathrm{R}_{\mathrm{g}}$ \\
\hline \multirow{6}{*}{$\begin{array}{l}\stackrel{\text { D }}{\overline{\bar{O}}} \\
\text { œ }\end{array}$} & Äste & $1642 \pm 1223$ & 6 & 737 & 905 & $947 \pm 520$ & 6 & 691 & 256 \\
\hline & & $83 \%$ & & $71 \%$ & $92 \%$ & $70 \%$ & & $68 \%$ & $75 \%$ \\
\hline & Stämme & $143 \pm 41$ & 9 & 75 & 68 & $161 \pm 66$ & 11 & 70 & 91 \\
\hline & & $79 \%$ & & $69 \%$ & $90 \%$ & $84 \%$ & & $68 \%$ & $97 \%$ \\
\hline & Grobwurzeln & $1669 \pm 1916$ & 6 & 744 & 926 & $1070 \pm 1029$ & 6 & 770 & 300 \\
\hline & & $83 \%$ & & $70 \%$ & $93 \%$ & $72 \%$ & & $66 \%$ & $86 \%$ \\
\hline \multirow{6}{*}{ 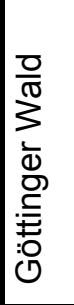 } & Äste & $2941 \pm 1553$ & 6 & 1022 & 1918 & $2001 \pm 1147$ & 6 & 961 & 1040 \\
\hline & & $87 \%$ & & $74 \%$ & $95 \%$ & $84 \%$ & & $73 \%$ & $94 \%$ \\
\hline & Stämme & $106 \pm 53$ & 10 & 59 & 48 & $85 \pm 32$ & 10 & 52 & 33 \\
\hline & & $79 \%$ & & $68 \%$ & $92 \%$ & $78 \%$ & & $66 \%$ & $96 \%$ \\
\hline & Grobwurzeln & $1484 \pm 940$ & 6 & 776 & 709 & $903 \pm 675$ & 6 & 708 & 195 \\
\hline & & $73 \%$ & & $64 \%$ & $81 \%$ & $71 \%$ & & $67 \%$ & $86 \%$ \\
\hline
\end{tabular}

In Tab. 10 sind die mittleren Jahressummen der Gesamtatmung, ihre Verteilung auf Erhaltungs- und Wachstumsatmung und der auf die Vegetationsperiode entfallende Anteil der Atmung zusammengefasst. Die Atmungsraten waren 1998 deutlich niedriger im Vorjahr. Der Rückgang bei Ästen und Grobwurzeln um 32 bis 42 \% gegenüber den Werten von 1997 war dabei stärker ausgeprägt als bei den Stämmen im Göttinger Wald. Bei den Stämmen im Solling ergab sich für 1998 eine leichte Zunahme der respiratorischen $\mathrm{CO}_{2}$-Abgabe.

Dieser Rückgang stimmt mit den unterschiedlichen Witterungsverläufen der Untersuchungsjahre insbesondere während der Sommermonate überein (Kap. 2.3 und Abb. 13). Während der Sommer 1997 strahlungsreich und im August und September überdurchschnittlich warm war, lagen die 
Temperaturen des Frühsommers 1998 leicht und des Hochsommers deutlich unterhalb den Temperaturen des Vorjahres. Außerdem endete die sommerliche Witterung 1998 schon in der letzten August-Dekade mit einer niederschlagsreichen Phase, die bis in den Oktober anhielt und mit einer starken und frühzeitigen Abkühlung der Luft einherging. Während die niedrigeren Temperaturen die Jahressummen der Erhaltungsatmung nicht oder nur schwach beeinflussten, ging die Wachstumsatmung auf 50 bis $20 \%$ der Vorjahreswerte zurück. Inwieweit dies parallel zu einer Änderung der Holzzuwachses im Bereich der Messstellen verlief, wird im folgenden Kapitel untersucht. Wegen der höheren Temperaturen und der erhöhten Stoffwechselaktivität wurden 73 bis $87 \%$ der gesamten jährlichen $\mathrm{CO}_{2}$-Abgabe in den Sommermonaten beobachtet. Der geringere prozentuale Anteil der sommerlichen Erhaltungsatmung an ihrer Jahressumme mit Werten zwischen 64 und $70 \%$ wurde durch den zusätzlichen Bedarf an Energie für die mit dem Holzzuwachs in Zusammenhang stehenden Prozesse kompensiert. Die Stämme und Äste gaben 90 bis $97 \%$ des jährlich durch Wachstumsatmung gebildeten $\mathrm{CO}_{2}$ während der Vegetationsperiode ab. Die Grobwurzeln zeigten oft bis in den November hinein erhöhte Aktivitäten, so dass für den Zeitraum von Mai bis Oktober nur 80 bis $90 \%$ der gesamten Wachstumsatmung berechnet wurden.

\subsubsection{Der Zusammenhang zwischen Jahressumme der Holzatmung und dem Holzzuwachs}

Neben dem Bedarf an Kohlenstoff für den Zuwachs muss bei dem Aufbau neuer Biomasse Energie für den Transport und die Synthese der Rinden- und Holzbestandteile durch Atmung bereitgestellt werden. Der Kohlenstoffbedarf für die im Zusammenhang mit der Biomasseproduktion stehende Atmung wird durch den Wachstumskoeffizienten $r_{G}$ charakterisiert. $r_{G}$ ist der Quotient aus dem Kohlenstoffbedarf für Wachstumsatmung und Zuwachs, also ein Maß für die zusätzliche Kohlenstoffmenge, die der Baum pro mol C im Holzzuwachs für die Atmung aufbringen muss.

Zunächst sollen einige methodische Aspekte der Zuwachsmessungen bei Ästen und Grobwurzeln betrachtet werden. Zur Prüfung der Zuwachsmessung mit Umfangmaßbändern, bei denen ein nachträglich aufgebrachter Nonius die Ablesegenauigkeit erhöhte (Methode 1U), wurden der Umfangzuwachs der Äste im Göttinger Wald mit einer zweiten Methode (Methode 2U) sowie der Durchmesserzuwachs (Methode 3D) erfasst (Kap. 3.2.2). In Abb. 36 a sind den Jahreszuwachswerten der Noniusmaßbänder die Ergebnisse der ergänzenden Methoden 2U und 3D gegenübergestellt.

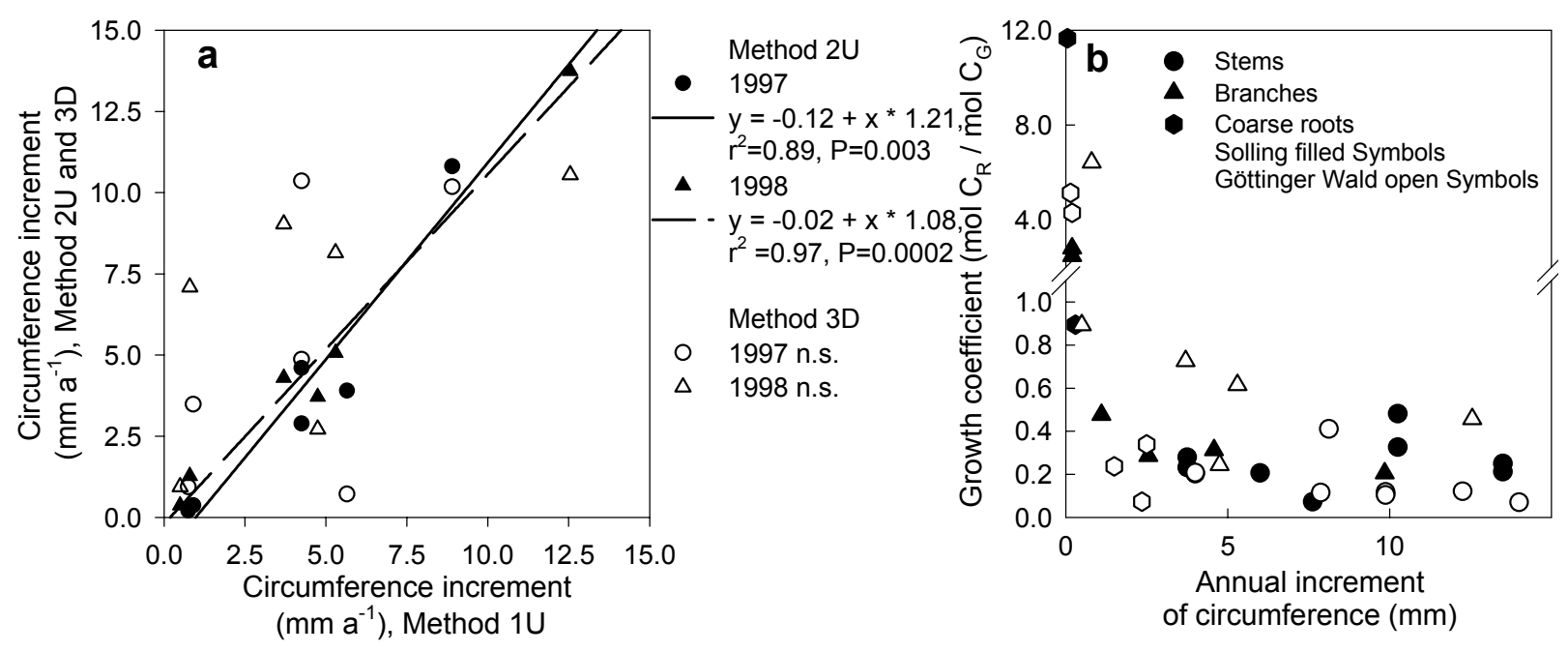

Abb. 36 a und b: Vergleich der drei verschiedenen Methoden zur Bestimmung des Umfangzuwaches von Ästen a). Die Auftragung der Wachstumskoeffizienten gegen den jährlichen Umfangzuwachs verdeutlicht die Grenze der Auflösung der Zuwachsmessung b). Bei Proben, deren Umfangzuwachs unter $1 \mathrm{~mm}$ lag, führte der niedrige Nenner des Quotienten zu überhöhten Wachstumskoeffzienten. 
Dass die Methoden 1U und 2U übereinstimmende Werte für den Jahreszuwachs ergaben, kommt in der signifikanten linearen Beziehung zum Ausdruck, deren Steigung nur wenig von 1 abweicht und deren Achsenabschnitt sich nicht signifikant von 0 unterscheidet. Die Messung des Durchmesserzuwachses ergab zwar vergleichbare Verläufe im Jahresgang (Daten nicht dargestellt), die Jahressummen zeigten jedoch nur geringe Übereinstimmung mit den Ergebnissen der Umfangmessung.

Aus der Auftragung der Wachstumskoeffizienten gegen den Umfangzuwachs (Abb. 36 b) wird deutlich, dass überhöhte Werte für $\mathrm{r}_{\mathrm{G}}$ nur an solchen Messstellen beobachtet wurden, die einen sehr geringen Zuwachs aufwiesen. Bei jährlichen Umfangzuwächsen von mehr als $1 \mathrm{~mm}$, lagen die Koeffizienten zwischen 0.07 und 0.7. In der Zusammenfassung der Wachstumskoeffizienten in Tab. 11 wurden daher nur die Messstellen mit einem jährlichen Umfangzuwachs über $1 \mathrm{~mm}$ berücksichtigt.

Anders als die jährliche Wachstumsatmung, die bei Ästen und Grobwurzeln 1998 um wenigstens $50 \%$ geringer war als im Vorjahr (Tab. 10), lagen die Jahressummen für den Zuwachs bei Ästen und Grobwurzeln im zweiten Untersuchungsjahr um bis zu 89\% über den Werten von 1997 (Tab. 11). Bei den Stämmen im Solling waren diese interannuellen Unterschiede nicht und bei den Göttinger Wald-Stämmen nur tendenziell zu beobachten.

Tab. 11: Mittlerer volumenbezogener Jahreszuwachs und mittlere Wachstumskoeffizienten beider Untersuchungsjahre von Ästen, Stämmen und Grobwurzeln beider Standorte. Für den Zuwachs wurden die Werte der Messstellen gemittelt, deren Umfangzuwachs 1998 über 1 $\mathrm{mm}$ lag. Bei den Koeffizienten gingen die Werte nur dann ein, wenn der Zuwachs des jeweiligen Jahres mehr als $1 \mathrm{~mm}$ ausmachte (Werte der wenig zuverlässigen Messungen 1997 kursiv, vgl. Text).

\begin{tabular}{|c|c|c|c|c|c|c|c|c|c|}
\hline & $\begin{array}{r}\text { Kompar- } \\
\text { timent }\end{array}$ & $\begin{array}{l}\text { Zuwachs } 97 \\
\mathrm{~mol} \mathrm{C} \mathrm{m}^{-3} \mathrm{a}^{-1}\end{array}$ & $\mathrm{~N}$ & $\begin{array}{l}\text { Zuwachs } 98 \\
\mathrm{~mol} \mathrm{C} \mathrm{m}^{-3} \mathrm{a}^{-1}\end{array}$ & $\mathrm{~N}$ & $\begin{array}{c}\mathrm{R}_{\mathrm{g}} \mathrm{G}_{97}^{-1} \\
\mathrm{~mol} \mathrm{~mol}^{-1}\end{array}$ & $\mathrm{~N}$ & $\begin{array}{l}\mathrm{R}_{\mathrm{g}} \mathrm{G}_{98}{ }^{-1} \\
\mathrm{~mol} \mathrm{~mol}^{-1}\end{array}$ & $\mathrm{~N}$ \\
\hline \multirow{3}{*}{ 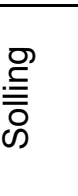 } & Äste & $559 \pm 378$ & 4 & $1170 \pm 758$ & 4 & $1.54 \pm 0.80$ & 2 & $0.32 \pm 0.17$ & 4 \\
\hline & Stämme & $335 \pm 214$ & 9 & $330 \pm 216$ & 9 & $0.25 \pm 0.13$ & 9 & $0.24 \pm 0.14$ & 9 \\
\hline & $\begin{array}{r}\text { Grob- } \\
\text { wurzeln }\end{array}$ & n.b & & n.b & & n.b & & n.b & \\
\hline \multirow{2}{*}{ 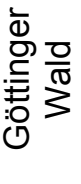 } & Äste & $1512 \pm 727$ & 4 & $1746 \pm 952$ & 4 & $1.32 \pm 0.82$ & 4 & $0.51 \pm 0.28$ & 4 \\
\hline & $\begin{array}{r}\text { Stämme } \\
\text { Grob- } \\
\text { wurzeln }\end{array}$ & $\begin{array}{l}259 \pm 161 \\
868 \pm 655\end{array}$ & $\begin{array}{l}7 \\
3\end{array}$ & $\begin{array}{r}271 \pm 153 \\
1115 \pm 657\end{array}$ & $\begin{array}{l}7 \\
3\end{array}$ & $\begin{array}{l}\mathbf{0 . 2 6} \pm \mathbf{0 . 1 8} \\
0.69 \pm 0.34\end{array}$ & $\begin{array}{l}7 \\
3\end{array}$ & $\begin{array}{l}0.16 \pm 0.12 \\
0.22 \pm 0.13\end{array}$ & $\begin{array}{l}7 \\
3\end{array}$ \\
\hline
\end{tabular}

Die gegensätzliche Entwicklung von Biomassezuwachs und Wachstumsatmung bei Ästen und Grobwurzeln ist im Wesentlichen in einer methodisch bedingten Unterschätzung des Zuwachses für das Jahr 1997 begründet. Die Maßbänder wurden an Ästen und Grobwurzeln am 02.06. bzw. 09.06.1997 im Solling bzw. Göttinger Wald installiert und der Anfangswert als Nullwert für 1997 festgehalten. Bis zum ersten Ablesetermin am 23.06. bzw. 19.06.1997 wurde ein Zuwachs von 10 bis $25 \%$ des gesamten Jahreszuwachses registriert (Abb. 37). 1998 machte der Zuwachs zu diesem Zeitpunkt bereits $50 \%$ des Jahreszuwachses aus. Diese Beobachtung und der Befund, dass bei den Ästen 3 und 4 der Jahreszuwachs von 1997 dennoch knapp über dem des Folgejahres lag, lassen eine z. T. deutliche Unterschätzung des Zuwachses für das erste Untersuchungsjahr vermuten. Die daraus resultierenden Wachstumskoeffizienten für 1997 in Höhe von 0.69 bis 1.54 für die Äste und Grobwurzeln sind somit als deutlich überhöht zu bewerten.

Für alle Messstellen 1998 und für die Stämme von 1997 ergab sich ein mittlerer Wachstumskoeffizient von $0.27 \pm 0.1 \mathrm{~mol} \mathrm{C}_{\mathrm{R}}\left(\mathrm{mol} \mathrm{C}_{\mathrm{G}}\right)^{-1}$, wobei die Äste im Göttinger Wald mit $\mathrm{r}_{\mathrm{G}}=0.51 \mathrm{den}$ 
Maximalwert und die Stämme des gleichen Standortes das Minimum von $r_{G}=0.17$ aufwiesen. Der Zuwachs aller Grobwurzeln im Solling und von drei Wurzeln im Göttinger Wald lag unter der Nachweisgrenze von $1 \mathrm{~mm}$, so dass der Wachstumskoeffizient für Wurzelholz von $0.21 \mathrm{~mol} \mathrm{C}_{R}$ $\left(\mathrm{mol} \mathrm{C}_{\mathrm{G}}\right)^{-1}$ auf einem geringen Stichprobenumfang basiert.

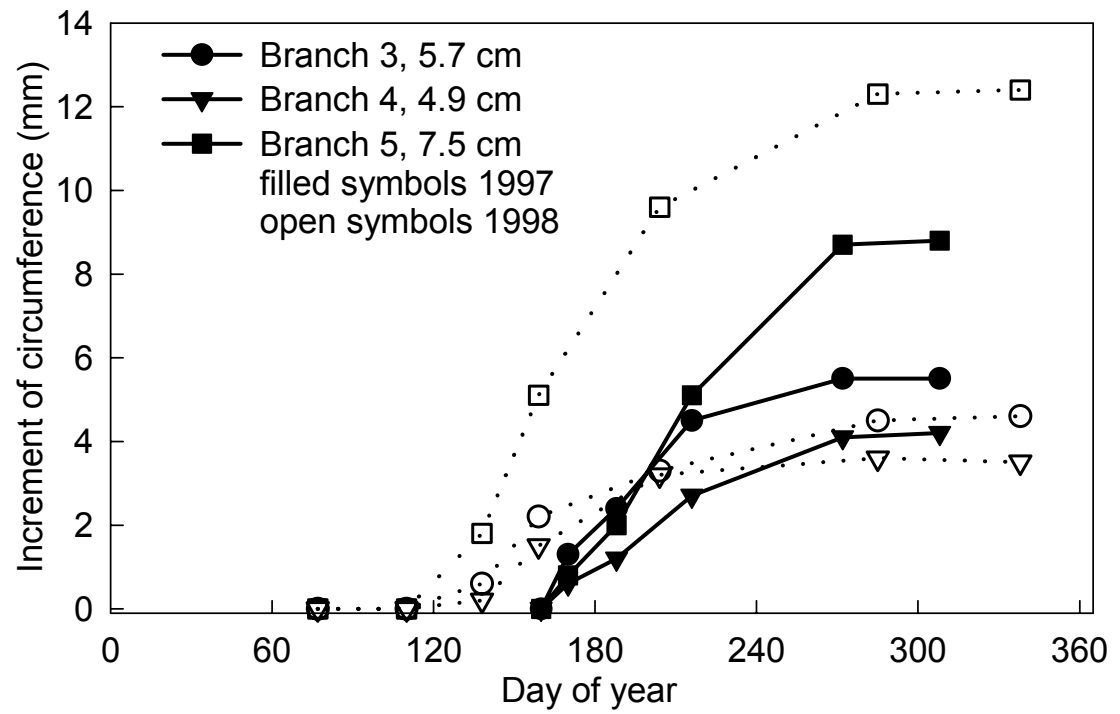

Abb. 37: Jahresverlauf des kumulativen Umfangzuwachses dreier Äste im Göttinger Wald aus Messungen mit Noniusmaßbändern, die Anfang Juni 1997 installiert wurden.
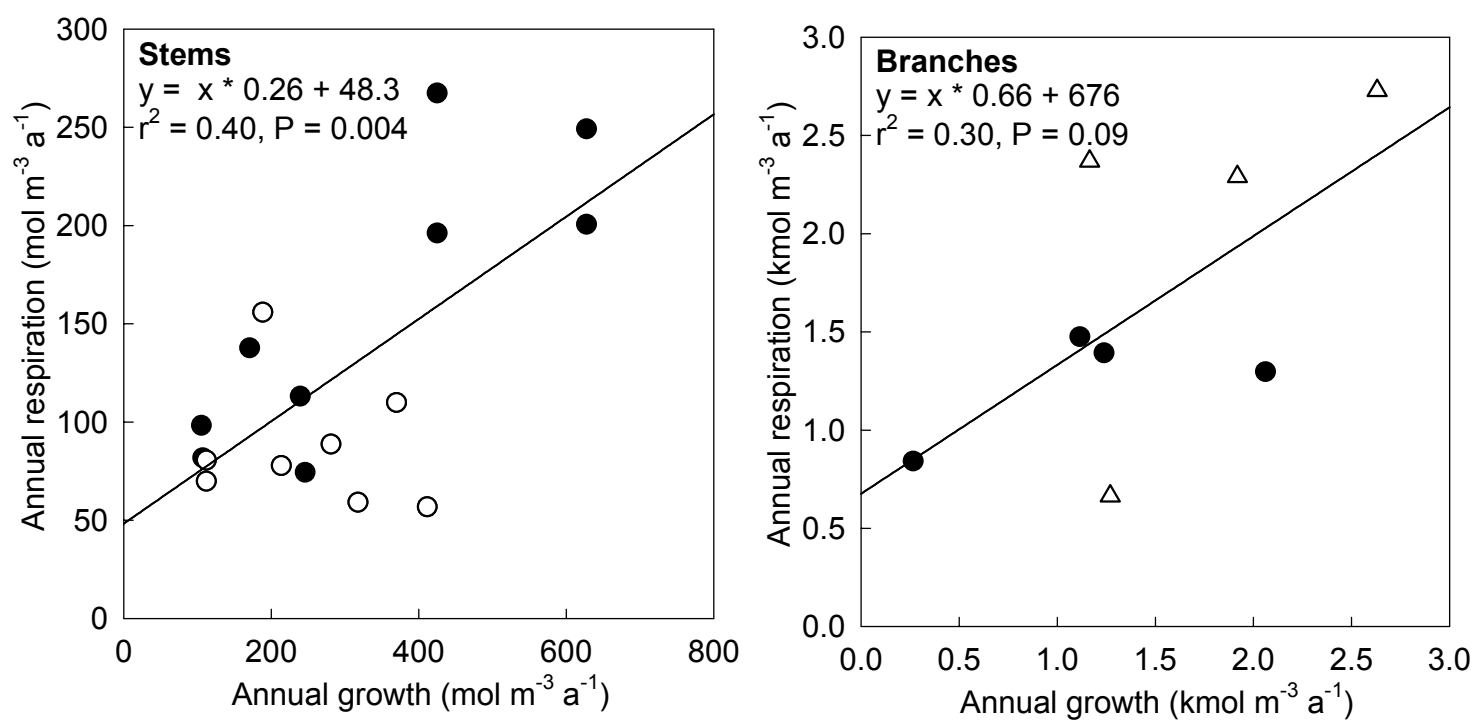

Abb. 38: Auftragung der Jahressumme der Atmung gegen den jährlichen Zuwachs von Stämmen und Ästen für das Jahr 1998. Für die Regressionsberechnung wurden die Werte beider Standorte zusammengefasst. Gefüllte Symbole: Solling, offene Symbole: Göttinger Wald.

Alternativ zur direkten Berechnung der Erhaltungsatmung und des Wachstumskoeffizienten können diese Größen für die Gesamtheit aller Messstellen eines Kompartiments aus der Beziehung zwischen den Jahressummen der Gesamtatmung und des Zuwachses abgeleitet werden (Abb. 38).

Die Jahressumme der Erhaltungsatmung entspricht dabei dem Ordinatenabschnitt der Regressionsgeraden. Bei den Stämmen liegt der Wert mit $48.3 \mathrm{~mol} \mathrm{~m}^{-3} \mathrm{a}^{-1}$ unter der Erhaltungsatmung, die aus 
der zeitlichen Hochrechnung ermittelt wurde $\left(62.5 \mathrm{~mol} \mathrm{~m}^{-3} \mathrm{a}^{-1}\right)$. Die Regressionsgerade für die AstDaten ist nicht signifikant. Aus ihr ließe sich für die Erhaltungsatmung ein Wert ableiten, der um $35 \%$ unter dem mit der Temperaturfunktion berechneten Wert liegt (676 gegenüber $1033 \mathrm{~mol} \mathrm{~m}^{-3}$ $\mathrm{a}^{-1}$ ). Die den Wachstumskoeffizienten entsprechenden Steigungen der Geraden liegen mit 0.23 bzw. $0.66 \mathrm{~mol} \mathrm{C}_{\mathrm{R}}\left(\mathrm{mol} \mathrm{C}_{\mathrm{G}}\right)^{-1}$ bei den Stämmen leicht und bei den Ästen deutlich über den für die einzelnen Messstellen berechneten Mittelwerten von 0.20 und $0.42 \mathrm{~mol} \mathrm{C}_{\mathrm{R}}\left(\mathrm{mol} \mathrm{C}_{\mathrm{G}}\right)^{-1}$.

\subsubsection{Räumliche Hochrechnung der Atmungsraten}

Durch die Kombination der zeitlich interpolierten Daten mit dem Biomassevorrat der Bestände wurde die Atmung auf Bestandesebene extrapoliert. Dazu wurden die Jahresgänge der Atmungsraten der Messstellen nach Kompartimenten getrennt, auf Ebene der Tagessummen gemittelt.

Da sich für die volumenbezogenen Atmungsraten von Stämmen und Ästen keine Beziehung zum Durchmesser finden ließ (Kap. 4.2.1), wurden die Holzvorräte der Durchmesserklassen 1 bis 3 (D $>15 \mathrm{~cm})$ als Stammholz, und der Durchmesserklassen 5 bis 7 (D $\leq 7 \mathrm{~cm})$ als Astholz zusammengefasst und mit den Atmungsraten der jeweiligen Kompartimente multipliziert. Das Holzvolumen der Durchmesserklasse $4(15 \geq \mathrm{D}>7 \mathrm{~cm})$ setzte sich aus Ast- und Stammholz zusammen. Äste und Stämme dieses Durchmessers zeigten bei der Punktmessung am 13.11.98 höhere Atmungsraten als die Stämme mit höheren Durchmessern (Kap. 4.2.1). Dem Volumen dieser intermediären Durchmesserklasse wurde daher im Sinne einer linearen Interpolation eine aus Astund Stammatmung gemittelte spezifische Rate zugeordnet. Für das Holzvolumen der Grobwurzeln wurde zunächst keine Differenzierung nach Durchmesserklassen vorgenommen. Der Jahresgang wurde als Produkt aus dem Volumen des Wurzelholzes und den mittleren Tagessummen der Grobwurzelatmung errechnet (Berechnung nach Gleichung (12)).

In Abb. 39 sind die Zweijahresgänge der Gesamt-, Erhaltungs- und Wachstumsatmung beider Bestände dargestellt, die Monatssummen sind in Tab. 12 zusammengefasst. Hinsichtlich der zeitlichen Verläufe spiegeln die respirativen C-Flüsse von ober- und unterirdischer verholzter Biomasse weitgehend die Jahresgänge der Luft- und Bodentemperatur als wesentliche Eingangsgröße der Berechnung wider. Während die Atmungsraten von Derbholz und Reisig den ausgeprägten Temperaturschwankungen folgten und kurzfristig weite Amplituden der Atmungsaktivität zeigten, waren die Jahresgänge der Grobwurzelatmung wie die Verläufe der Bodentemperatur deutlich ausgeglichener. Die verzögerte Erwärmung des Bodens im Sommer und die langsamere Abkühlung im Herbst führten 1997 bei den Grobwurzeln im Solling zu einer Phasenverschiebung der Atmungsaktivität gegenüber den oberirdischen verholzten Organe. 1998 war dies bei den Wurzeln beider Standorte weniger deutlich ausgeprägt.

Standortunterschiede im Jahresgang zeigten sich vor allem während des heißen Spätsommers 1997. Im Solling stieg die Atmungsaktivität im August gegenüber dem Vormonat bei den Grobwurzeln um $25 \%$ und beim Reisig nur leicht um $10 \%$ an. Beim Derbholz blieben die Werte konstant. Die Grobwurzeln im Göttinger Wald steigerten ihre Atmung im gleichen Maße wie im Solling. Die Atmung des Derbholzes hingegen erhöhte sich um 50 \% und beim Reisig betrug die Steigerung $80 \%$. Die Maximalwerte des Reisigs waren im August mehr als doppelt so hoch wie Werte im Juli. Besonders ausgeprägt war diese Entwicklung bei der Wachstumsatmung. Während diese im Solling beim Derbholz und Reisig im August nicht mehr anstieg, erhöhte sie sich im Göttinger Wald um 60 bzw. $90 \%$. 
Im kühleren Sommer 1998 zeigten beide Standorte ähnliche Unterschiede der zeitlichen Verläufe zwischen den verschiedenen Kompartimenten. Das Reisig wies maximale C-Flüsse bereits im Juni auf und zeigte trotz gleichbleibender oder steigender Temperaturen in den Folgemonaten rückläufige Monatssummen der Atmung. Dagegen waren die Umsätze des Derbholzes erst im Juli, die der Grobwurzeln im Göttinger Wald erst im August maximal.

Bedeutsam für die C-Bilanz der Bestände ist der quantitative Vergleich der Atmung der verschiedenen Kompartimente. Die hohen spezifischen Atmungsraten von Ästen und Grobwurzeln führten dazu, dass der Kohlenstoffbedarf für die Atmung von Reisig und Wurzelholz, deren Volumenanteil nur 9 bis $12 \%$ des gesamten Volumenvorrats der verholzten Biomasse ausmachte (Tab. 9), jeweils die gleiche Größenordnung erreichte wie der Bedarf des Derbholzes.

1997 entfiel im Solling der größte Anteil der Atmung mit $38 \%$ auf die Grobwurzeln, der geringste auf das Reisig (30\%), das auch im folgenden Jahr mit $24 \%$ den geringsten Anteil aufwies. Da die Wachstumsatmung der Stämme 1998 gegenüber dem Vorjahr konstant blieb, die Wachstumsatmung der Äste und Grobwurzeln aber um 70 \% zurück ging, entfiel 1998 der größte Anteil der Holzatmung des Bestandes auf das Derbholz (41\%).

Die Reisigfraktion des Göttinger Waldes, die die höchsten spezifischen Atmungs- und Wachstumsraten aufwies, überstieg mit $45 \%$ des hier berechneten respirativen C-Flusses die Anteile der anderen Kompartimente deutlich. Auf das Derb- und Wurzelholz entfielen 30 und $25 \%$ der Holzatmung des Bestandes. Da die Wachstumsatmung bei den Grobwurzeln 1998 gegenüber 1997 stärker zurückging als bei den Stämmen und Ästen, nahm der Anteil der Grobwurzelatmung an der Gesamtatmung weiter auf $22 \%$ ab. Der Anteil der Reisigatmung blieb 1998 gegenüber dem Vorjahr konstant, während der des Derbholzes leicht anstieg.

Der Buchenbestand im Göttinger Wald hatte mit 52.2 und $35.8 \mathrm{~mol} \mathrm{~m}^{-2} \mathrm{a}^{-1}$ in den Jahren 1997 und 1998 einen 1.5fach höheren Kohlenstoffumsatz im Atmungsstoffwechsel der verholzen Biomasse als der Bestand im Solling. Der wesentliche Anteil an dem höheren Umsatz im Göttinger Wald entfiel dabei auf die Reisigatmung des Bestandes. So überstieg 1997 die spezifische Atmungsrate des Astholzes im Göttinger Wald diejenige der Äste im Solling um das 1.5fache, im Folgejahr sogar um den Faktor zwei. Zusammen mit dem 27 \% höheren Reisig-Vorrat war die Jahressumme der Reisigatmung im Göttinger Wald 2.3- bis 2.7-mal höher als die jährliche Reisigatmung im Solling. Die im Vergleich zum Solling geringeren spezifischen Atmungsraten des Stammholzes im Göttinger Wald werden durch den höheren Volumenvorrat und durch die höheren Atmungsraten der Äste, die bei der Durchmesserklasse 4 in die Jahressumme der Derbholzfraktion eingehen, so weit kompensiert, dass der C-Umsatz des Derbholzes im Göttinger Wald 1997 deutlich und 1998 leicht höher ist als im Solling. Lediglich für den Grobwurzelanteil ergeben sich an beiden Standorten ähnliche Jahressummen. Die niedrigere volumenspezifische Atmungsaktivität der Grobwurzeln im Göttinger Wald wird durch deren höhere Volumenvorräte kompensiert. 


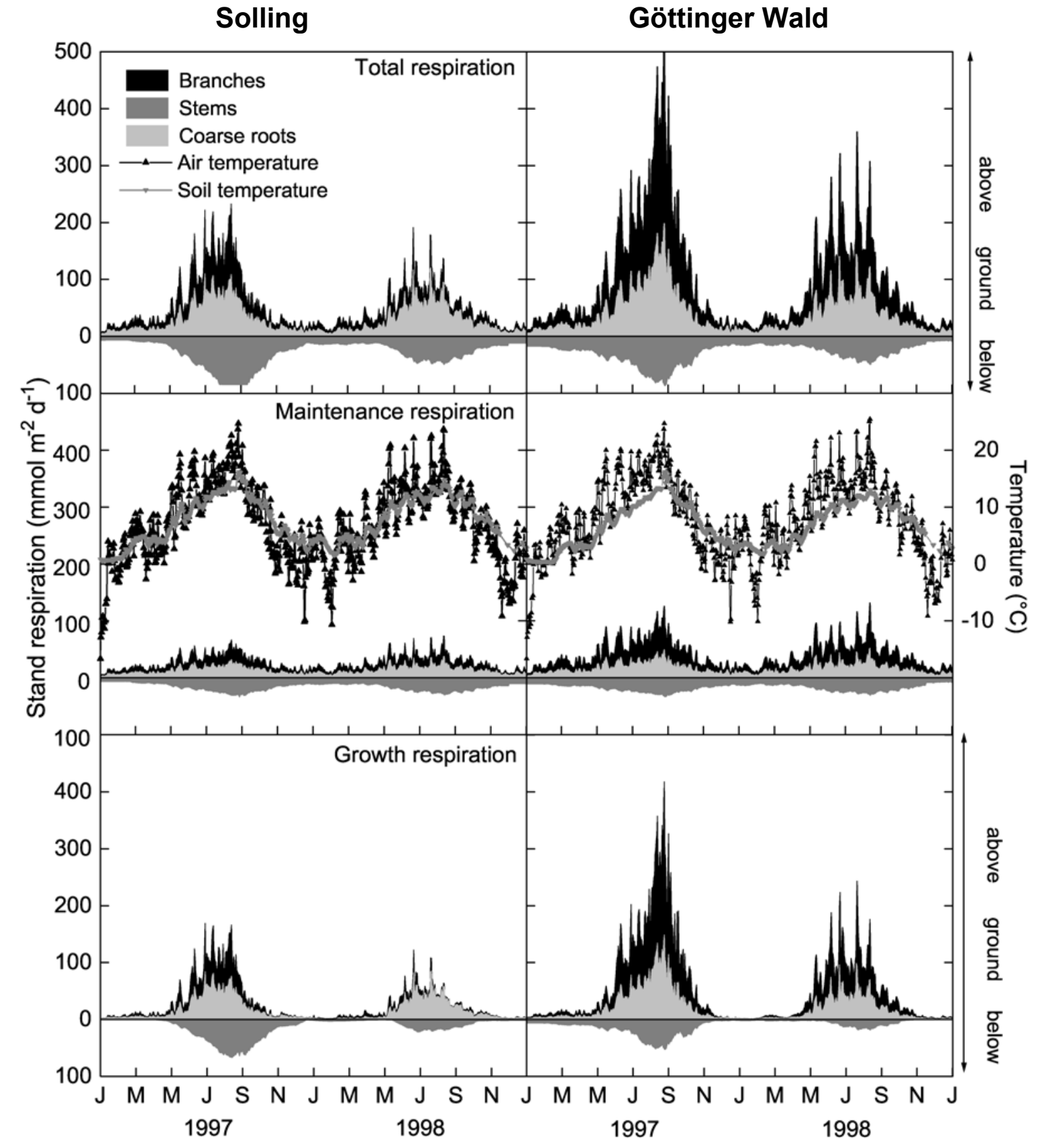

Abb. 39: Zweijahresgänge der auf die Bestandesgrundfläche bezogenen Gesamt-, Erhaltungs- und Wachstumsatmung der Buchen im Solling und im Göttinger Wald. Die gestapelten Flächen setzen sich aus der Atmung von Ast-, Stamm- und Wurzelholz zusammen. Sie schließen den gesamten respirativen C-Fluss der Holzatmung der Bestände ein. Zur Veranschaulichung der Verteilung der C-Flüsse auf die ober- und unterirdischen Anteile sind die Atmungsraten der Grobwurzeln unterhalb der $\mathrm{x}$-Achse jedoch als positive Werte aufgetragen. Ergänzend sind mit der Erhaltungsatmung (mittlere Reihe) die zeitlichen Verläufe der Tagesmittel von Luft- und Bodentemperatur aufgetragen. 
Tab. 12: Monatssummen der Gesamtatmung $R_{t}\left(m o l ~ C m^{-2}\right.$ Bestandesgrundfläche Monat $\left.{ }^{-1}\right)$ der Buchenbestände im Göttinger Wald und im Solling. Die Monatssummen der Erhaltungsatmung sind in Prozent der Gesamtatmung angegeben.

\begin{tabular}{|c|c|c|c|c|c|c|c|c|c|c|c|c|c|c|}
\hline \multirow{3}{*}{ Monat } & \multicolumn{7}{|c|}{ Solling } & \multicolumn{7}{|c|}{ Göttinger Wald } \\
\hline & \multicolumn{2}{|c|}{ Reisholz } & \multicolumn{2}{|c|}{ Derbholz } & \multicolumn{2}{|c|}{ Grobwurzeln } & \multirow{2}{*}{$\begin{array}{c}\text { Total } \\
\mathbf{R}_{\mathrm{t}}\end{array}$} & \multicolumn{2}{|c|}{ Reisholz } & \multicolumn{2}{|c|}{ Derbholz } & \multicolumn{2}{|c|}{ Grobwurzeln } & \multirow{2}{*}{$\begin{array}{c}\text { Total } \\
\mathbf{R}_{\mathbf{t}}\end{array}$} \\
\hline & $\mathbf{R}_{\mathbf{t}}$ & $\begin{array}{c}\mathrm{R}_{\mathrm{m}} \\
\%\end{array}$ & $\mathbf{R}_{\mathbf{t}}$ & $\begin{array}{c}\mathrm{R}_{\mathrm{m}} \\
\%\end{array}$ & $\mathbf{R}_{\mathbf{t}}$ & $\begin{array}{c}\mathrm{R}_{\mathrm{m}} \\
\%\end{array}$ & & $\mathbf{R}_{\mathbf{t}}$ & $\begin{array}{l}\mathrm{R}_{\mathrm{m}} \\
\%\end{array}$ & $\mathbf{R}_{\mathbf{t}}$ & $\begin{array}{c}\mathrm{R}_{\mathrm{m}} \\
\%\end{array}$ & $\mathbf{R}_{\mathbf{t}}$ & $\begin{array}{c}\mathrm{R}_{\mathrm{m}} \\
\%\end{array}$ & \\
\hline \multicolumn{15}{|l|}{1997} \\
\hline Jan & 0.17 & 80 & 0.24 & 65 & 0.21 & 96 & 0.63 & 0.31 & 69 & 0.29 & 69 & 0.53 & 63 & 1.13 \\
\hline Feb & 0.25 & 74 & 0.32 & 65 & 0.20 & 97 & 0.77 & 0.46 & 71 & 0.41 & 69 & 0.54 & 62 & 1.41 \\
\hline Mrz & 0.34 & 70 & 0.41 & 65 & 0.29 & 98 & 1.04 & 0.59 & 71 & 0.52 & 69 & 0.73 & 60 & 1.84 \\
\hline Apr & 0.36 & 68 & 0.43 & 63 & 0.37 & 86 & 1.17 & 0.57 & 71 & 0.53 & 68 & 0.73 & 59 & 1.84 \\
\hline Mai & 0.86 & 50 & 0.90 & 50 & 0.86 & 59 & 2.62 & 1.26 & 61 & 1.11 & 58 & 1.09 & 55 & 3.46 \\
\hline Jun & 1.52 & 34 & 1.79 & 31 & 1.43 & 41 & 4.74 & 2.75 & 33 & 1.99 & 37 & 1.21 & 55 & 5.95 \\
\hline Jul & 2.01 & 28 & 2.39 & 26 & 2.26 & 33 & 6.66 & 3.55 & 29 & 2.72 & 31 & 1.89 & 42 & 8.16 \\
\hline Aug & 2.18 & 33 & 2.39 & 32 & 2.83 & 32 & 7.40 & 6.11 & 23 & 4.12 & 26 & 2.40 & 38 & 12.63 \\
\hline Sep & 0.78 & 58 & 1.03 & 47 & 2.27 & 34 & 4.08 & 3.38 & 24 & 2.20 & 31 & 1.67 & 47 & 7.25 \\
\hline Okt & 0.43 & 73 & 0.56 & 61 & 1.36 & 45 & 2.35 & 1.35 & 38 & 0.93 & 47 & 1.17 & 54 & 3.46 \\
\hline Nov & 0.27 & 80 & 0.42 & 61 & 0.74 & 55 & 1.44 & 0.50 & 66 & 0.47 & 68 & 0.57 & 82 & 1.53 \\
\hline Dez & 0.19 & 91 & 0.30 & 73 & 0.47 & 74 & 0.97 & 0.23 & 95 & 0.33 & 78 & 0.45 & 88 & 1.01 \\
\hline \multicolumn{15}{|l|}{1998} \\
\hline Jan & 0.23 & 91 & 0.26 & 90 & 0.41 & 84 & 0.90 & 0.23 & 98 & 0.29 & 83 & 0.45 & 87 & 0.96 \\
\hline Feb & 0.29 & 77 & 0.28 & 86 & 0.38 & 80 & 0.96 & 0.39 & 83 & 0.36 & 80 & 0.38 & 86 & 1.13 \\
\hline Mrz & 0.35 & 72 & 0.35 & 84 & 0.38 & 85 & 1.08 & 0.38 & 88 & 0.40 & 81 & 0.42 & 85 & 1.21 \\
\hline Apr & 0.44 & 70 & 0.47 & 80 & 0.38 & 96 & 1.28 & 0.76 & 67 & 0.61 & 69 & 0.48 & 88 & 1.85 \\
\hline Mai & 0.70 & 69 & 1.01 & 58 & 0.63 & 87 & 2.33 & 2.01 & 43 & 1.40 & 49 & 0.67 & 90 & 4.08 \\
\hline Jun & 0.95 & 55 & 1.86 & 34 & 1.15 & 60 & 3.95 & 2.99 & 32 & 2.11 & 35 & 0.97 & 76 & 6.07 \\
\hline Jul & 0.76 & 69 & 2.06 & 31 & 1.35 & 57 & 4.18 & 2.70 & 36 & 2.18 & 35 & 1.23 & 64 & 6.11 \\
\hline Aug & 0.57 & 88 & 1.71 & 38 & 1.35 & 62 & 3.63 & 2.39 & 45 & 1.87 & 44 & 1.27 & 65 & 5.53 \\
\hline Sep & 0.49 & 80 & 1.07 & 48 & 1.04 & 68 & 2.61 & 1.38 & 54 & 1.09 & 56 & 0.96 & 73 & 3.43 \\
\hline Okt & 0.36 & 80 & 0.63 & 58 & 0.67 & 85 & 1.66 & 0.73 & 67 & 0.59 & 69 & 0.60 & 92 & 1.92 \\
\hline Nov & 0.16 & 84 & 0.34 & 67 & 0.49 & 88 & 0.99 & 0.31 & 83 & 0.31 & 80 & 0.34 & 99 & 0.97 \\
\hline Dez & 0.15 & 91 & 0.27 & 77 & 0.38 & 87 & 0.81 & 0.26 & 83 & 0.27 & 81 & 0.23 & 100 & 0.76 \\
\hline
\end{tabular}

Jahressummen (mol C $\left.\mathrm{m}^{-2} \mathrm{a}^{-1}\right)$

\begin{tabular}{|c|c|c|c|c|c|c|c|c|c|c|c|c|c|c|}
\hline & \multicolumn{7}{|c|}{ Solling } & \multicolumn{7}{|c|}{ Göttinger Wald } \\
\hline & \multirow{2}{*}{\multicolumn{2}{|c|}{\begin{tabular}{cc}
\multicolumn{2}{c}{ Reisholz } \\
$\mathbf{R}_{\mathbf{t}} \quad \mathrm{R}_{\mathrm{m}}$ \\
\end{tabular}}} & \multicolumn{2}{|c|}{ Derbholz } & \multicolumn{2}{|c|}{ Grobwurzeln } & \multirow{2}{*}{$\begin{array}{c}\text { Total } \\
\mathbf{R}_{\mathbf{t}} \\
\end{array}$} & \multicolumn{2}{|c|}{ Reisholz } & \multicolumn{2}{|c|}{ Derbholz } & \multicolumn{2}{|c|}{ Grobwurzeln } & \multirow{2}{*}{$\begin{array}{c}\text { Total } \\
\mathbf{R}_{\mathbf{t}} \\
\end{array}$} \\
\hline & & & $\mathbf{R}_{\mathrm{t}}$ & $R_{m}$ & $\mathbf{R}_{\mathbf{t}}$ & $\mathrm{R}_{\mathrm{m}}$ & & $\mathbf{R}_{\mathbf{t}}$ & $R_{m}$ & $\mathbf{R}_{\mathbf{t}}$ & $R_{m}$ & $\mathbf{R}_{\mathbf{t}}$ & $R_{m}$ & \\
\hline 1997 & 9.37 & 4.21 & 11.18 & 4.59 & 13.29 & 5.92 & 33.85 & 21.07 & 7.32 & 15.62 & 6.16 & 12.98 & 6.78 & 49.67 \\
\hline 1998 & 5.46 & 3.99 & 10.31 & 4.96 & 8.62 & 6.21 & 24.39 & 14.53 & 6.98 & 11.47 & 5.74 & 8.02 & 6.29 & 34.02 \\
\hline
\end{tabular}




\subsubsection{Fehler der Bilanz}

Die Eingangsgrößen für die Hochrechnung des Bestandes-Kohlenstoffflusses sind die Tagessummen der Atmungsraten und die Biomassevorräte. Die Variabilität dieser Größen pflanzt sich in den Jahressummen der C-Flüsse des Bestandes fort. Die Berechnung der Fehlerfortpflanzung zur Abschätzung der Variabilität ist auf Ebene der Jahresummen der Atmung für die Solling-Daten von 1997 beispielhaft in Tab. 13 zusammengefasst.

Zunächst wurde die Varianz der Volumina der Biomasse für den „Mittelstamm“ des Bestandes (Tab. 8) berechnet. Dabei ergab sich der Fehler $\Delta V_{t}$ des nach Kap. 3.3.3 berechneten Gesamtvolumens $\mathrm{V}_{\mathrm{t}}$ aus dem Standardfehler des Derbholzvolumens $\Delta \mathrm{V}_{\mathrm{d}}$ und den Standard-Schätzfehlern $\Delta \mathrm{DKl}_{\mathrm{i}}$ der Funktionen, mit denen die relativen Volumenanteile der Reisig-Durchmesserklassen 5 bis 7 ermittelt werden. Der Fehler für die Bestimmung des Derbholzvolumen als Abhängige von Höhe und BHD wird von KRAMER \& AKÇA (1982) mit 5 - 7 \% angegeben.

Der Fehler des Gesamtvolumens $V_{t}$ errechnete sich dann nach:

$$
\Delta V_{t}=\sqrt{\left(\frac{\Delta V_{d}}{\operatorname{rel} . V_{d}}\right)^{2}+\left(\Delta \operatorname{rel} . V_{d} \frac{-V_{d}}{\operatorname{rel} . V_{d}^{2}}\right)^{2}}
$$

mit: (17) $\Delta V_{d}=6 \%$ und $\quad$ (18) $\quad \Delta r e l . V_{d}=\sqrt{\sum_{5-7} \Delta D K l_{i}^{2}}$

Die Volumina der Durchmesserklassen berechneten sich als Produkt des Gesamtvolumens $\mathrm{V}_{\mathrm{t}}$ und dem relativen Volumenanteil der Durchmesserklassen 1 - 7. Der Fehler ergab sich aus der demjenigen des Gesamtvolumens und dem Standardschätzfehler der Funktionen, die die Volumenanteile der Durchmesserklassen beschreiben (A-Tab. 3). Die relativen Standardabweichungen der Volumina jeder Durchmesserklasse des mittleren Baumes wurden auf die Bestandesvolumenvorräte der Durchmesserklassen übertragen und so deren Fehler in absoluten Werten ermittelt. Die Division der Variation durch $\sqrt{\mathrm{n}}$ (mit $\mathrm{n}=$ Zahl der in die Volumenberechnung eingegangenen Bäume: 212 im Solling und 77 im Göttinger Wald) berücksichtigte die abnehmende Wahrscheinlichkeit, dass mit zunehmender Anzahl einzelner Volumenberechungen alle Fehler dasselbe Vorzeichen aufweisen.

Die Variabilität der Atmungsraten ging als Standardfehler der mittleren Jahressumme der volumenbezogenen Atmung jedes Kompartiments in die Fehlerberechnung ein. Für das Produkt aus dem Volumen und mittlerer Jahressumme der Atmung ergaben sich dann relative Standardfehler von 13, 20 und 47 \% für die Bestandesatmung von Derbholz, Reisig und Grobwurzeln. In der Summe ergab sich für den Bestand im Solling im Jahr 1997 ein respirativer C-Bedarf der verholzten Kompartimente in Höhe von 34.7 mol C m${ }^{-2}$ mit einem Fehler von $\pm 19 \%$. Die auf dem gleichen Wege berechneten relativen Standardfehler für den Solling 1998 und den Göttinger Wald 1997 und 1998 betrugen in der Jahressumme 15, 11 und $12 \%$. 
Tab. 13: Beispielhafte Berechnung des Fehlers der Jahressumme der Holzatmung für den Bestand im Solling und das Jahr 1997 (Erläuterungen siehe Text).

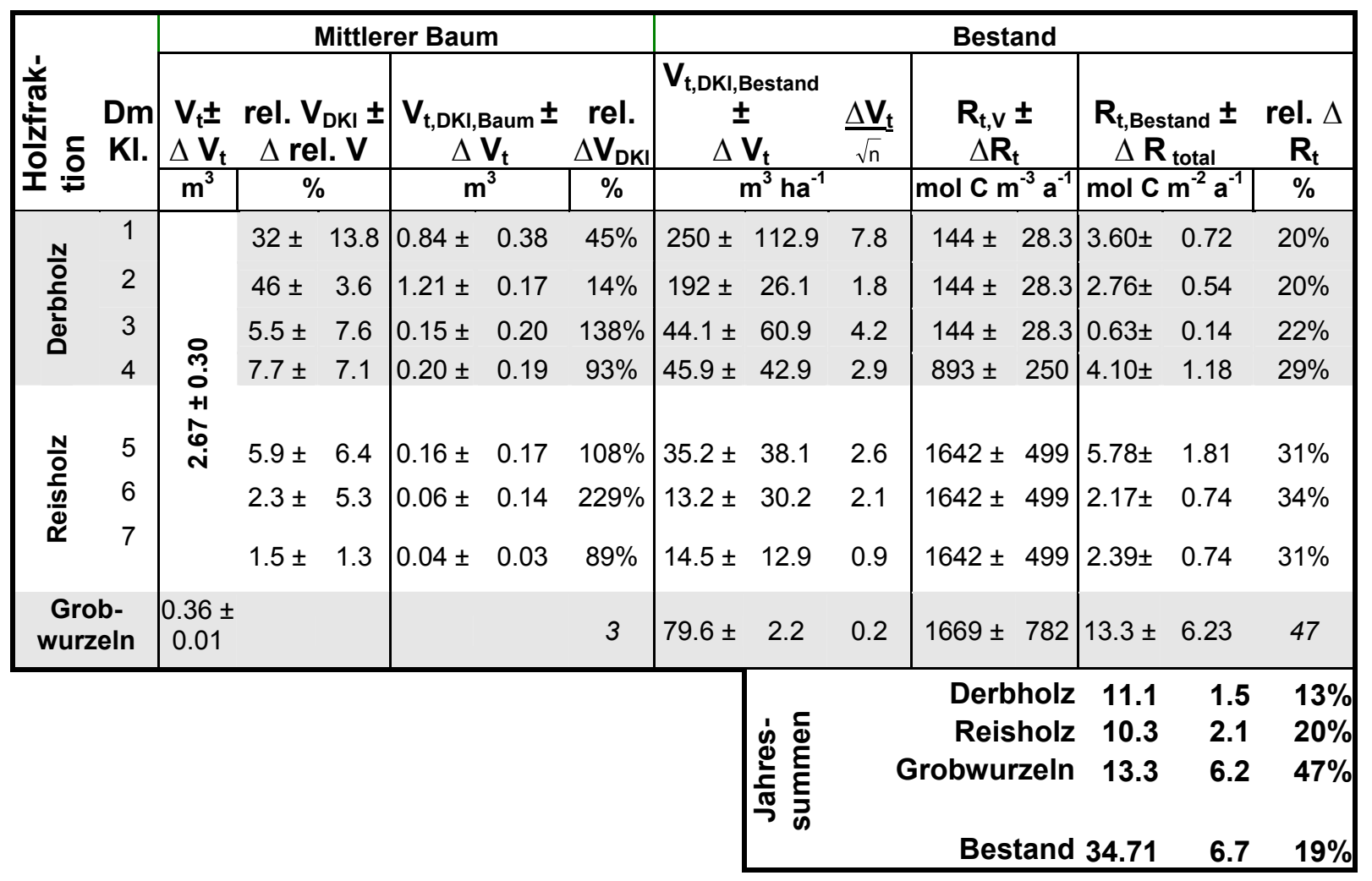

\subsubsection{Erweiterung der Hochrechnung mit Atmungsraten von Feinreisig und Schwachwurzeln}

Die Ergebnisse von Atmungsmessungen an Feinreisig (M. SCHULTE, pers. Mitteilung, D. GRIES, pers. Mitteilung) zeigten, dass die volumenbezogenen Atmungsraten von Zweigen mit einem Durchmesser unter $1 \mathrm{~cm}$ deutlich über denen lagen, die im Rahmen der vorliegenden Untersuchung an Ästen mit höherem Durchmesser ermittelt wurden. Dass auch die Schwachwurzeln $(0.5-2 \mathrm{~cm})$ höhere volumenbezogene Atmungsraten aufwiesen als dickere Wurzeln zeigt die Durchmesserabhängigkeit der hier untersuchten Wurzeln (Abb. 19).

In Abb. 40 ist die volumenbezogene $10{ }^{\circ} \mathrm{C}$-Erhaltungsatmung von Ästen und Grobwurzeln dieser Untersuchung sowie die Spross- und Schwachwurzelatmung von Jungbuchen im Solling (GANSERT 1995) und der Astatmung eines 30-jährigen Buchenbestandes in Frankreich (DAMESIN et al. 2002) gegen den Durchmesser aufgetragen. Zur Temperaturkorrektur wurde an die Atmungsraten und Temperaturen (Tagesmittelwerte), die GANSERT (1995) für das Winterhalbjahr nennt, eine Temperaturfunktion (8) angepasst. Die Daten von DAMESIN et al. (2002) wurden im Dezember 1997 bei mittleren Temperaturen von $10.5{ }^{\circ} \mathrm{C}$ gemessen und daher nicht temperaturkorrigiert.

Bei beiden Kompartimenten besteht eine signifikante Beziehung zwischen volumenbezogenen Atmungsraten und den Durchmessern der Sprossachsen. Mit dieser Funktion wurde die $10{ }^{\circ} \mathrm{C}$ Atmungsrate (x) für Achsen eines Durchmessers berechnet, welcher der Klassenmitte der Durchmesserklassen entsprach. Diese Atmungsrate wurde mit der mittleren gemessen $10{ }^{\circ} \mathrm{C}$-Erhaltungsatmungsrate $\left(\mathbf{O} \mathrm{R}_{\mathrm{MW}}\right)$ der Äste bzw. Grobwurzeln des jeweiligen Standortes ins Verhältnis ge 

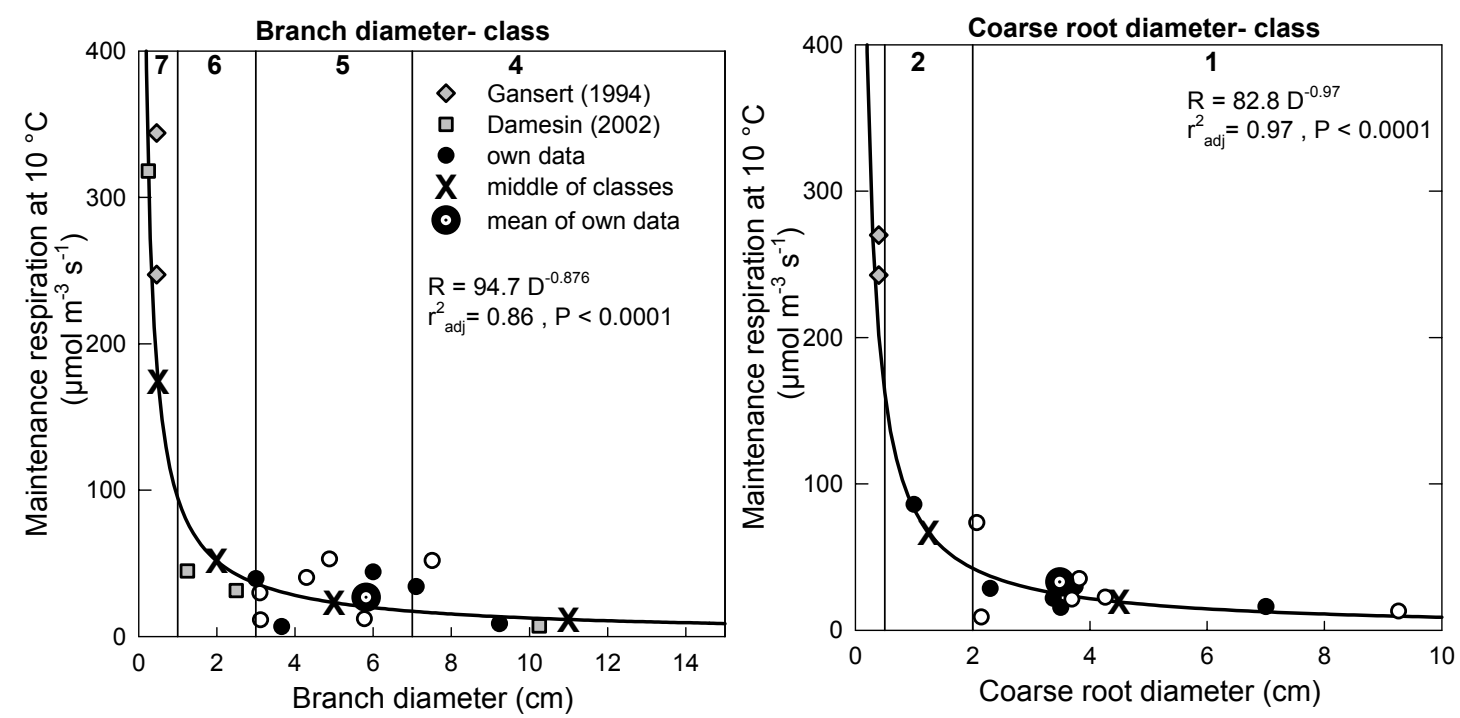

Abb. 40: Beziehung zwischen $10^{\circ} \mathrm{C}$ Erhaltungsatmung und Durchmesser von Ästen und Grobwurzeln nach Daten verschiedener Autoren und der vorliegenden Arbeit. Mit (x) sind die Atmungsraten gekennzeichnet, die mit der Funktion und den mittleren Durchmessern der verschiedenen Klassen berechnet wurden. Mit (O) ist der Mittelwert der Atmungsrate und Durchmesser der im Rahmen der vorliegenden Untersuchung gemessenen Äste und Grobwurzeln dargestellt.

setzt. Für die Astdurchmesserklassen 4-7 im Göttinger Wald ergaben sich Quotienten von 0.35,0.7, 1.56 und 5.2. Die Quotienten für die Derb- und Grobwurzeln i. e. S. betrugen 0.66 und 2.3. Von dem Mittelwert der Solling-Äste wichen die Atmungsraten der entsprechenden Astdurchmesserklassen um Faktoren von 0.43, 0.87, 1.9 und 6.5 ab. Die Quotienten für die Grobwurzelklassen betrugen für den Solling 0.58 und 2.0. Um die Durchmesserabhängigkeit der Ast- und Grobwurzelatmung bei der räumlichen Extrapolation der Atmung auf Bestandesebene zu berücksichtigen wurden die Tagesmittel der Ast- bzw. Grobwurzelatmung mit dem Volumen der Durchmesserklasse sowie dem jeweiligen Faktor multipliziert (siehe Kap. 3.4.3, Gleichung (13)). Entsprechend veränderten sich die Verhältnisse zwischen den Kompartimenten bei der Extrapolation auf Bestandesebene. Die Ergebnisse dieser Berechnung für das Jahr 1998 werden in Tab. 14 den in Kapitel 4.4.2 angegebenen Werten gegenübergestellt. Durch die Vervielfachung der Atmungsraten insbesondere des Feinreisigs und der Schwachwurzeln nahm die Reisigatmung im Solling um das Doppelte, im Göttinger Wald um den Faktor $1.5 \mathrm{zu}$. Die Wurzelatmung erhöhte sich ebenfalls, jedoch nur um 10 bis $30 \%$. Wegen des

Tab. 14: Vergleich der jährlichen Bestandes-CFlüsse verholzter Organe ohne und mit Berücksichtigung der Durchmesserabhängigkeit der Reisigund Wurzelatmung. Werte für das Jahr 1998

\begin{tabular}{|c|c|c|c|c|}
\hline \multirow{4}{*}{$\begin{array}{l}\text { Durchmesser- } \\
\quad \text { klasse I } \\
\text { Holzfraktion }\end{array}$} & \multicolumn{2}{|c|}{ Solling } & \multicolumn{2}{|c|}{$\begin{array}{c}\text { Göttinger } \\
\text { Wald }\end{array}$} \\
\hline & ohne* & mit $^{*}$ & ohne* & mit $^{*}$ \\
\hline & \multicolumn{4}{|c|}{$\begin{array}{l}\text { *Berücksichtigung der Durchmesser- } \\
\text { abhängigkeit der Atmungsraten von } \\
\text { Ästen und Grobwurzeln }\end{array}$} \\
\hline & \multicolumn{4}{|c|}{ 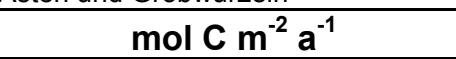 } \\
\hline $\begin{array}{l}\text { oberirdisch } \\
D>40 \mathrm{~cm}\end{array}$ & 4.15 & 4.15 & 283 & 2.83 \\
\hline $40 \geq D>25 \mathrm{~cm}$ & 2.92 & 2.92 & 1.96 & 1.96 \\
\hline $25 \geq \mathrm{D}>15 \mathrm{~cm}$ & 0.68 & 0.68 & 0.45 & 0.45 \\
\hline $15 \geq \mathrm{D}>7 \mathrm{~cm}$ & 2.56 & 1.32 & 6.23 & 2.35 \\
\hline $7 \geq D>3 \mathrm{~cm}$ & 3.38 & 2.93 & 9.03 & 6.33 \\
\hline $3 \geq D>1 \mathrm{~cm}$ & 1.26 & 2.43 & 3.31 & 5.18 \\
\hline $1 \geq \mathrm{D} \mathrm{cm}$ & 0.82 & 5.4 & 2.2 & 11.6 \\
\hline $\begin{array}{r}\text { unterirdisch } \\
D>2.0 \mathrm{~cm}\end{array}$ & 5.41 & 3.16 & 5.03 & 3.33 \\
\hline $2 \geq D>0.5 \mathrm{~cm}$ & 3.21 & 6.51 & 2.99 & 6.87 \\
\hline Derbholz & 10.2 & 9.1 & 11.5 & 7.6 \\
\hline Reisig & 5.46 & 10.7 & 14.5 & 23.1 \\
\hline Wurzelholz & 8.62 & 9.67 & 8.02 & 10.2 \\
\hline Bestand & 24.4 & 29.5 & 34.0 & 40.9 \\
\hline
\end{tabular}


Quotienten von ca. 0.4 für die Durchmesserklasse 4 geht die Stammatmung von Solling und Göttinger Wald um 10 bzw. 30 \% zurück. In der Bilanz steigen die Jahressummen der respirativen C-Umsätze um ca. 20 \% gegenüber den in Kapitel 4.4.2 ermittelten Werten.

\subsubsection{Der Anteil von Rindenphotosynthese und $\mathrm{CO}_{2}$-Transport mit dem Xylemsaft am Kohlenstoffumsatz des Bestandes}

Der Hochrechnung der Holzatmung lagen solche Temperaturfunktionen zugrunde, die an die während der Nacht gemessenen Atmungsraten angepasst waren. Dadurch wurde der Einfluss von Rindenphotosynthese und $\mathrm{CO}_{2}$-Transport mit dem Xylemsaft auf die Ergebnisse der BestandesHolzatmung ausgeschlossen.

Wie in Kapitel 4.1.2 beschrieben, konnten Rindenphotosynthese und $\mathrm{CO}_{2}$-Abtransport einzelner Äste im Tagesverlauf die $\mathrm{CO}_{2}$-Abgabe über die Oberfläche kurzfristig um mehr als $80 \%$ reduzieren. Wurde die Rindenphotosynthese- und die $\mathrm{CO}_{2}$-Transportrate über die Hellphase aufsummiert, so konnte ihr Anteil bis zu $70 \%$ des durch Atmung produzierten Kohlendioxids betragen.

Um den Anteil von Rindenphotosynthese und $\mathrm{CO}_{2}$-Transport für den gesamten Untersuchungszeitraum abzuschätzen, wurde für alle halbstündlichen bzw. stündlichen Atmungswerte die Differenz zwischen berechneter Bruttoatmungsrate und gemessener $\mathrm{CO}_{2}$-Abgabe ermittelt. Die während der Hellphase der Tage errechneten Abweichungen wurden aufsummiert und als Tagessumme von Rindenphotosynthese und $\mathrm{CO}_{2}$-Transport mit der Tagessumme $(24 \mathrm{~h})$ der Bruttoatmung ins Verhältnis gesetzt. Die mittleren anteiligen Tagessummen von Rindenphotosynthese und $\mathrm{CO}_{2}-$ Transportraten sind zusammen mit den maximalen instantanen Raten in Tab. 15 zusammengestellt. Die höchsten Rindenphotosynthese- und $\mathrm{CO}_{2}$-Transportraten wurden bei den Ästen beobachtet. Einzelne Äste erreichten maximale Raten von $6.2 \mathrm{bis} 10.2 \mu \mathrm{mol} \mathrm{m}^{-2} \mathrm{~s}^{-1}$. In der Tagessumme $(24 \mathrm{~h})$ wurde von den Ästen im Solling und im Göttinger Wald während des Winterhalbjahres im Mittel 9.3 und $18.1 \%$ des durch Atmung gebildeten $\mathrm{CO}_{2}$ photosynthetisch refixiert. Im Sommer machte der Anteil der Summe aus Rindenphotosynthese und $\mathrm{CO}_{2}$-Transport bei vielfach höheren Atmungsraten noch 3.3 bis $10.6 \%$ aus.

Die oberflächenbezogenen Raten für Rindenphotosynthese und $\mathrm{CO}_{2}$-Transport von Stämmen und Grobwurzeln lagen mit Maximalwerten zwischen 0.24 und $0.38 \mu \mathrm{mol} \mathrm{m} \mathrm{m}^{-2} \mathrm{~s}^{-1}$ weit unter denen der Äste. Die mittleren Anteile an der Bruttoatmung erreichten bei den Stämmen nur noch 1.8 bis $3.7 \%$, bei den Grobwurzeln lagen die Werte nahe null oder waren negativ. Bei einzelnen Grobwurzeln im Solling lag die gemessene Atmungsrate im Sommerhalbjahr im Mittel um $24 \%$ über der berechneten Tagessumme. Bei diesen Wurzeln wurde $\mathrm{CO}_{2}$ mit dem Xylemsaft antransportiert. Maximale Antransportraten zeigten wiederum die Äste mit bis zu $1.4 \mu \mathrm{mol} \mathrm{m} \mathrm{m}^{-2} \mathrm{~s}^{-1}$, die Raten der Grobwurzeln erreichten höchstens ein Viertel dieser Werte.

Werden die in die Berechnung der Jahresgänge der Atmungsraten eingehenden mittleren Tagessummen der Atmungsraten um den mittleren prozentualen Anteil von $\mathrm{CO}_{2}$-Transport und/oder Rindenphotosynthese des jeweiligen Zeitraumes aus Tab. 15 gesenkt (bzw. bei den Grobwurzeln erhöht), lässt sich analog zu den C- Flüssen in Tab. 12 die um Rindenphotosynthese und $\mathrm{CO}_{2}$ Transport korrigierte Jahresumme des C-Flusses der Holzatmung ermitteln (Tab. 16). Dieser erreichte in den Jahren 1997 und 1998 im Solling 33.3 und $23.9 \mathrm{~mol} \mathrm{~m}^{-2} \mathrm{a}^{-1}$, im Göttinger Wald 46.0 und $31.5 \mathrm{~mol} \mathrm{~m}^{-2} \mathrm{a}^{-1}$. Auf Bestandesebene wurden demnach 1.6 bis $7.6 \%$ der durch die Holzatmung gebildeten $\mathrm{CO}_{2}$-Menge durch Rindenphotosynthese refixiert oder mit dem Xylemsaft abtransportiert. 
Tab. 15: Rindenphotosynthese und $\mathrm{CO}_{2}$-Transport mit dem Xylemsaft als relativer Anteil an der Tagessumme der berechneten Atmungsrate sowie die Spanne oberflächenbezogener Refixierungsraten von Ästen, Stämmen und Grobwurzeln, die während des Winterhalbjahres (Nov. April) und der Vegetationsperiode beider Untersuchungsjahre beobachtet wurden. Der Anteil von Rindenphotosynthese und $\mathrm{CO}_{2}$-Transport wurde über alle vollständigen Tagesgänge (n) gemittelt, die Raten geben die Extremwerte einzelner Küvetten an.

\begin{tabular}{|c|c|c|c|c|c|c|c|c|c|c|c|}
\hline \multirow{4}{*}{\multicolumn{2}{|c|}{$\begin{array}{l}\text { Standort/ } \\
\text { Kompartiment }\end{array}$}} & \multicolumn{6}{|c|}{$\begin{array}{l}\text { mittlere relative Rindenphotosynthese bzw. } \\
\text { Summe von RindenPS und } \mathrm{CO}_{2} \text {-Transport }\end{array}$} & \multicolumn{4}{|c|}{$\begin{array}{l}\text { Rindenphotosynthese- und } \\
\mathrm{CO}_{2} \text {-Transportraten }\end{array}$} \\
\hline & & \multicolumn{3}{|c|}{ Winterhalbjahr } & \multicolumn{3}{|c|}{ Sommerhalbjahr } & \multicolumn{2}{|c|}{ Winterhalbj. } & \multicolumn{2}{|c|}{ Sommerhalbj. } \\
\hline & & \multirow[b]{2}{*}{$\%$} & & \multirow[b]{2}{*}{$\mathbf{n}$} & \multirow{2}{*}{\multicolumn{2}{|c|}{$\%$}} & \multirow[b]{2}{*}{$\mathbf{n}$} & $\min$. & max. & min. & $\max$. \\
\hline & & & & & & & & \multicolumn{4}{|c|}{$\mu \mathrm{mol} \mathrm{m} \mathrm{m}^{-2} \mathrm{~s}^{-1}$} \\
\hline \multirow{3}{*}{ 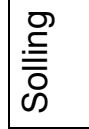 } & Äste & 9.3 & \pm 10.8 & 84 & 3.3 & \pm 10.2 & 275 & -0.28 & 0.78 & -1.38 & 6.2 \\
\hline & Stämme & 1.8 & \pm 3.3 & 73 & 3.7 & \pm 3.7 & 127 & -0.04 & 0.19 & -0.12 & 0.24 \\
\hline & Wurzeln & -0.1 & \pm 3.6 & 20 & -2.6 & \pm 5.6 & 168 & -0.04 & 0.06 & -0.35 & 0.26 \\
\hline \multirow{3}{*}{ 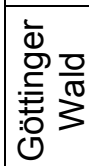 } & Äste & 18.1 & \pm 11.8 & 142 & 10.6 & \pm 9.6 & 305 & -0.23 & 10.2 & -1.03 & 8.7 \\
\hline & Stämme & 2.2 & \pm 3.5 & 33 & 2.8 & \pm 3.3 & 77 & -0.04 & 0.13 & -0.24 & 0.38 \\
\hline & Wurzeln & -1.3 & \pm 4.1 & 112 & 0.5 & \pm 3.6 & 125 & -0.14 & 0.08 & -0.17 & 0.27 \\
\hline
\end{tabular}

Tab. 16: Jahressumme der auf die Bestandesgrundfläche bezogenen C-Flüsse der verschiedenen Holzfraktionen von Solling und Göttinger Wald. In Prozent ist der Anteil angegeben, um den die Flüsse durch die Berücksichtigung der Refixierung und des $\mathrm{CO}_{2}$-Transports von den Werten in Tab. 12 abweichen.

\begin{tabular}{|c|c|c|c|c|c|c|c|c|c|}
\hline \multirow{2}{*}{\multicolumn{2}{|c|}{ Standort Jahr }} & \multicolumn{2}{|c|}{ Reisholz } & \multicolumn{2}{|c|}{ Derbholz } & \multicolumn{2}{|c|}{ Grobwurzeln } & \multicolumn{2}{|c|}{ Total } \\
\hline & & \multicolumn{2}{|c|}{\begin{tabular}{|cc} 
C-Fluss & RindenPS \\
& u./o. $\mathrm{CO}_{2}$ \\
Transp.
\end{tabular}} & \multirow{2}{*}{$\begin{array}{l}\text { C-Fluss } \\
\mathrm{mol} \mathrm{m}^{-2} \mathrm{a}^{-1}\end{array}$} & $\begin{array}{c}\text { RindenPS } \\
\text { u./o. } \mathrm{CO}_{2} \\
\text { Transp. } \\
\%\end{array}$ & \multirow{2}{*}{$\begin{array}{l}\text { C-Fluss } \\
\mathrm{mol} \mathrm{m}^{-2} \mathrm{a}^{-1}\end{array}$} & $\begin{array}{l}\text { RindenPS } \\
\text { u./o. } \mathrm{CO}_{2} \\
\text { Transp. }\end{array}$ & \multicolumn{2}{|c|}{$\begin{array}{ll} & \text { RindenPS } \\
\text { C-Fluss } & \text { u./o. } \mathrm{CO}_{2} \\
\text { Transo }\end{array}$} \\
\hline & & & & & & & & & \\
\hline Solling & 1997 & 9.0 & -4.3 & 10.8 & -3.7 & 13.6 & 2.2 & 33.3 & -1.6 \\
\hline & 1998 & 5.2 & -5.1 & 9.9 & -3.8 & 8.8 & 1.9 & 23.9 & -2.1 \\
\hline Göttinger & 1997 & 18.6 & -11.5 & 14.4 & -7.6 & 13.0 & 0.0 & 46.0 & -7.3 \\
\hline Wald & 1998 & 12.8 & -11.8 & 10.6 & -7.4 & 8.0 & 0.0 & 31.5 & -7.6 \\
\hline
\end{tabular}




\section{Diskussion}

\subsection{Die $\mathrm{CO}_{2}$-Abgabe über die Oberfläche verholzter Organe von Bäumen und die Temperaturabhängigkeit der Holzatmung}

Wie bei allen enzymatisch katalysierten Prozessen steigt auch die Geschwindigkeit der mitochondrialen Atmung im physiologischen Temperaturbereich exponentiell mit der Temperatur an. Ist die Produktion von Kohlendioxid durch die Atmung und die $\mathrm{CO}_{2}$-Abgabe über die Oberfläche verholzter Organe im Gleichgewicht, so ist auch für die $\mathrm{CO}_{2}$-Abgabe pro Zeiteinheit eine enge Temperaturabhängigkeit zu erwarten (SPRUGEL 1990, SPRUGEL \& BENECKE 1991). Diese Temperaturbeziehung lässt sich mit der Arrheniusfunktion (Gleichung (8)) beschreiben (AMTHOR 1989). Die $\mathrm{CO}_{2}$-Abgabe wird um so enger zur Temperatur in Beziehung stehen, je stabiler der physiologische Status des Gewebes ist. So ist auf Ebene von Stunden oder Tagen eine gleichbleibende Temperaturantwort der Atmungsraten zu erwarten. Bei Arten, bei denen sich habitatbedingt der Wechsel von Vegetationsruhe zu Phasen hoher Aktivität in kürzester Zeit vollzieht, kann es phasenweise zu raschen Änderungen der Atmungsaktivität und ihrer Temperaturantwort kommen (HAVRANEK 1981).

Im Rahmen der vorliegenden Untersuchung wurde die Temperaturabhängigkeit der $\mathrm{CO}_{2}$-Abgabe der verholzten Organe von Buchen-Altbäumen auf Ebene der Verläufe über zwei bis fünf Tage ermittelt. Oft folgte die Atmungsrate im Tagesgang der Xylemtemperatur. Die enge Beziehung zwischen Atmung und Temperatur kam dann in den hohen Korrelationskoeffizienten der Temperaturfunktionen zum Ausdruck (Abb. 5). Ebenso häufig wurden aber auch deutliche, z. T. sehr starke Abweichungen der $\mathrm{CO}_{2}$-Abgabe vom Temperaturverlauf beobachtet. So zeigte die Auftragung der Atmung gegen die Temperatur regelmäßig charakteristische Hysteresisschleifen. Außerdem wurden Temperaturänderungen nicht immer von Änderungen der Atmungsraten begleitet, und umgekehrt traten trotz geringer Temperaturschwankungen ausgeprägte Tagesgänge der Atmungsraten auf. Schließlich wurden auch gegenläufige Tagesgänge von Temperatur und Atmungsraten beobachtet, bei denen die Maxima der Atmungsraten während der Nacht bei minimalen Temperaturen und die Minima der Atmungsraten in den warmen Mittagsstunden auftraten.

Von den Temperaturverläufen abweichende Atmungsraten wurden von verschiedenen Autoren dokumentiert (BENECKE 1985, GANSERT 1995, GIESBERT 1997, LAVIGNE \& RYAN 1997, LEVY \& JARVIS 1998, LEVY et al. 1999, CESCHIA et al. 2001) und unterschiedlich interpretiert. Die möglichen Ursachen hierfür sollen im Folgenden diskutiert werden.

\subsubsection{Die Phasenverschiebung von $\mathrm{CO}_{2}$-Abgabe und Temperatur im Tagesgang}

Hysteresisschleifen in Beziehungen periodisch verlaufender Prozesse werden häufig durch Phasenverschiebungen der Prozesse verursacht und können durch die Angleichung der Phase, also die Berücksichtigung einer Zeitverzögerung, eliminiert werden. So wurden von verschiedenen Autoren konstante (RYAN 1990, RYAN et al. 1996, LAVIGNE et al. 1996, LAVIGNE \& RYAN 1997), messstellenspezifische (BOSC et al. 2003) oder variable (STOCKFORS \& LINDER 1998) Zeitverzögerungen bei der Berechnung der Temperaturfunktion der Holzatmung zur Korrektur der Phasenverschiebung berücksichtigt. 
Auch für die Holzatmung der Altbuchen konnte gezeigt werden, dass keine Hysteresisschleife mehr zu erkennen und das Bestimmtheitsmaß der Temperaturfunktion deutlich erhöht war, wenn die Atmung nicht gegen die aktuelle Temperatur sondern gegen diejenige, die eine bis fünf Stunden zuvor gemessen wurde, aufgetragen wurde(Abb.9, Tab. 5). Uneinheitlich war der Effekt der Phasenverschiebung auf den $\mathrm{Q}_{10}$-Wert, der bei einigen Messstellen unverändert blieb, bei anderen deutlich anstieg (Abb. 11 und Tab. 5).

RYAN (1990) sieht die Ursache für einen zeitverzögerten Verlauf der Atmung gegenüber der Temperatur darin, dass die $\mathrm{CO}_{2}$-Abgabe über die Oberfläche verholzter Organe die Atmungsaktivität der Gewebe in verschiedenen Tiefen integriert, während die Temperatur an der Oberfläche oder oberflächenah gemessen wird. Diese Temperatur ist dann für die am Ort der $\mathrm{CO}_{2}$-Bildung wirkende Temperatur nicht repräsentativ. In der Annahme, dass das Xylem in tieferen Gewebeschichten einen maßgeblichen Anteil an der Bildung des Atmungs- $\mathrm{CO}_{2}$ hat und dort der Temperaturverlauf gegenüber der Oberflächentemperatur verzögert ist, kann eine Zeitverschiebung der Temperatur selbst die Hysteresisschleifen erklären.

EKLUND \& LAVIGNE (1995) sowie LAVIGNE (1996) sehen in den hohen Diffusionswiderständen des Xylems, des Kambiums und der Rinde eine mögliche Ursache für eine Phasenverschiebung von Temperaturverlauf und $\mathrm{CO}_{2}$-Abgabe. So müsse die holzinterne $\mathrm{CO}_{2}$-Konzentration unter Einfluss höherer Temperaturen stark steigen bis dies zu einer Erhöhung der $\mathrm{CO}_{2}$-Abgabe über die Stammoberfläche führt. Bei Sprossachsen mit einem hohen Kernholzanteil wird dessen großes Luftvolumen zunächst das $\mathrm{CO}_{2}$ aufnehmen und den Anstieg der $\mathrm{CO}_{2}$-Konzentration verlangsamen, wodurch die Zeitverzögerung der $\mathrm{CO}_{2}$-Abgabe noch verstärkt würde. Auch STOCKFORS \& LINDER (1998) führen die Phasenverschiebung auf einen hohen Diffusionswiderstand zurück. Sie finden einen deutlichen Jahresgang der Phasenverschiebung, der mit dem von EKLUND (1990) beschriebenen Jahresverlauf der $\mathrm{CO}_{2}$-Konzentration im Stamm übereinstimmt und auf eine Änderung des Diffusionswiderstandes des Kambiums zurückgeführt wird.

Ob die Verzögerung des Temperaturverlaufes mit zunehmender Entfernung von der Oberfläche die Hysterese der $\mathrm{CO}_{2}$-Abgabe erklären kann, wurde durch die Messung der Tagesgänge der Temperaturen in verschiedenen Holztiefen überprüft (Kap. 4.1.2). Dabei ergab sich bei einem Stamm im Solling bis in eine Tiefe von $2.5 \mathrm{~cm}$ eine maximale Phasenverschiebung von einer Stunde gegenüber der oberflächennah gemessenen Temperatur. In $6.5 \mathrm{~cm}$ Tiefe hatte der Temperaturverlauf maximal einen 3-stündigen Rückstand (Abb. 8). Wird für das Xylem von Ästen und Grobwurzeln eine ähnliche Verzögerung bei der Erwärmung angenommen, müssten die Maxima von Temperatur und $\mathrm{CO}_{2}$-Abgabe im Zentrum der höchstens $9 \mathrm{~cm}$ dicken Achsen spätestens $2 \mathrm{~h}$ nach denen der Oberflächentemperatur auftreten. Eine Phasenverschiebung der Temperaturantwort der Atmung von zwei bis fünf Stunden, wie sie z.T. für die Atmung von einigen Ästen und Grobwurzeln ermittelt wurde, ist somit allein mit einer Zeitverzögerung des Temperaturverlaufes nicht zu erklären.

Sowohl die Hypothese des phasenverschobenen Temperaturverlaufes als auch die des hohen Diffusionswiderstandes des Gewebes implizieren, dass die in die Berechnung eingehende Phasenverschiebung zum Erreichen des maximalen Bestimmtheitsmaßes der Temperaturfunktion mit zunehmendem Achsendurchmesser ansteigen muss. Dies konnte in der vorliegenden Studie weder bei dem Vergleich der Phasenverschiebung innerhalb eines Kompartiments (vgl. Tab. 5) noch zwischen den verschiedenen Kompartimenten beobachtet werden. Während die $\mathrm{CO}_{2}$-Abgabe der Äste gegenüber der Oberflächentemperatur zeitverzögert verlief, waren bei den Buchenstämmen die Tagesgänge von Temperatur und Atmung an einigen Messterminen im gleichen Zeitraum eng synchro- 
nisiert (Abb. 5 b). Bei der Messung der Astatmung mit lichtdicht abgedeckten Küvetten konnte die Atmung der Temperatur sogar vorauslaufen, so dass andere Prozesse an der Abweichung der Atmung von der Temperaturfunktion wesentlich beteiligt sein müssen. Im Rahmen der vorliegenden Arbeit wurde daher keine Phasenkorrektur bei der Berechnung der Temperaturfunktion vorgenommen.

Bei CESCHIA (2001) variierte die zum Erreichen eines maximalen Bestimmtheitsmaßes anzunehmende Phasenverschiebung zwischen 0 und 12 Stunden. Sie war bei einzelnen Messstellen im Jahresverlauf ebenfalls nicht konstant und zeigten keinen Jahresgang, so dass CESCHIA (2001) bei seiner Datenanalyse keine Phasenkorrektur vornahm.

\subsubsection{Der Einfluss von Rindenphotosynthese und $\mathrm{CO}_{2}$-Transport mit dem Xylemsaft auf die $\mathrm{CO}_{2}$-Abgabe verholzter Baumorgane}

Wird der Gaswechsel verholzter Sprossachsen von Bäumen mit lichtdurchlässigen Küvetten gemessen, muss das Potenzial der Rinde, $\mathrm{CO}_{2}$ photosynthetisch $\mathrm{zu}$ fixieren, berücksichtigt werden (SPRUGEL \& BENECKE 1991). Die $\mathrm{CO}_{2}$-Konzentration im Gewebe der Achsenorgane erreicht wegen der Atmungsaktivität der lebenden Zellen und wegen des hohen Diffusionswiderstandes von Kambium und Rinde in den Sprossachsen Werte von 0.3 bis 26.3 \% (HARI et al. 1991), die die atmosphärische $\mathrm{CO}_{2}$-Konzentration damit um bis zu drei Größenordnungen übersteigen. Im Gegensatz zu den Blättern, die über die Stomata $\mathrm{CO}_{2}$ aus der Atmosphäre aufnehmen, ist das in den Achsenorganen durch die Atmung gebildete $\mathrm{CO}_{2}$ das Substrat für die Rindenphotosynthese. Sie ist daher als Refixierung anzusehen (SPRUGEL \& BENECKE 1991) und wird oft als relativer Anteil der Atmungsrate angegeben.

Die Reduktion der atmungsbedingten $\mathrm{CO}_{2}$-Abgabe verholzter Sprossachsen unter der Einwirkung von Licht wurde von verschiedenen Autoren beschrieben (FOOTE \& SCHAEDLE 1974, 1976a, 1976b, FOOTE \& SCHAEDLE 1978, BENECKE 1985, GANSERT 1995, PFANZ 1999, SCHMIDT et al. 2000, WITTMANN et al. 2001, ASCHAN et al. 2001, DAMESIN 2003). PFANZ et al. (2002) und PFANZ \& ASCHAN (2003) weisen auf das Vorkommen chlorophyllhaltiger Gewebe in der Rinde von Stämmen vieler Baumarten und die weite Verbreitung der Fähigkeit zur Refixierung von Atmungs- $\mathrm{CO}_{2}$ in Sprossachsen von Bäumen hin. Die Abhängigkeit der Rindenphotosynthese von endogenen und klimatischen Faktoren ist ebenso Inhalt verschiedener Untersuchungen (CERNUSAK \& MARSHALL 2000, WITTMANN et al. 2001, ASCHAN et al. 2001, CERNUSAK et al. 2001) wie die Bedeutung für die Kohlenstoffbilanz von Bäumen (GANSERT 1995, STEINBORN et al. 1997, DAMESIN 2003).

GANSERT (1995) konnte an Sprossachsen junger lichtadaptierter Buchen bei künstlicher Beleuchtung eine Reduktion der instantanen $\mathrm{CO}_{2}$-Abgabe um bis zu $70 \%$ nachweisen. Auch unter natürlichen Lichtbedingungen war die $\mathrm{CO}_{2}$-Abgabe gegenüber der Dunkelatmung reduziert. So gaben chloroplastenreiche Triebe tagsüber $(6-20 \mathrm{~h})$ im Durchschnitt $24 \%$ weniger $\mathrm{CO}_{2}$ ab, als durch die Atmung produziert wurde (GANSERT 1995). WITTMAN et al. (2001) und DAMESIN (2003) ermittelten bei diesjährigen Buchenzweigen übereinstimmend Refixierungsraten von 5 bis

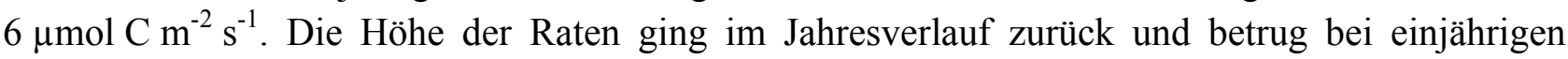
Zweigen nur noch 1 bis $2 \mu \mathrm{mol} \mathrm{C} \mathrm{m} \mathrm{s}^{-2}$. Da auch die Dunkelatmung dieser Zweige deutlich niedriger war, blieb der Anteil der Refixierung an der Atmung mit Werten zwischen 60 und $90 \%$ weiter hoch. Unter Laborbedingungen konnten im Winter geerntete, einjährige Buchenzweige bei Lichtsättigung und $25^{\circ} \mathrm{C}$ sogar Netto-Kohlenstoffgewinne erzielen (DAMESIN 2003). 
Aber auch wenn die Rindenphotosynthese durch Verwendung lichtundurchlässiger Messkammern unterbunden wurde, beobachteten verschiedene Autoren Hysteresisschleifen in der Temperaturbeziehung, z. T. sogar einen Rückgang der $\mathrm{CO}_{2}$-Abgabe bei steigender Temperatur (GEURTEN 1950, NEGISI 1972, 1975, 1978, KAKUBARI 1988, GANSERT 1995, DAMESIN et al. 2002).

NEGISI (1975) fand an warmen strahlungsreichen Tagen regelmäßig einen deutlichen Rückgang der $\mathrm{CO}_{2}$-Abgabe und untersuchte zwei mögliche Ursachen für dieses von ihm als „,daytime depression" bezeichnete Phänomen. So kann der im Tagesgang zunehmend angespannte Wasserstatus im Holz- und Rindenparenchym dessen Atmungsaktivität direkt limitieren. Außerdem kann an warmen strahlungsreichen Tagen, an denen auch hohe Transpirationsraten auftreten, im Xylemsaft gelöstes $\mathrm{CO}_{2}$ vom Ort der Produktion in vertikaler Richtung abtransportiert werden. Bei in vitro-Versuchen an abgeschnittenen Sprossstücken wurde durch das Anlegen eines Soges eine Saftflussgeschwindigkeit erreicht, die der Größenordnung von in situ-Messungen entsprach. Mit der Saftflussgeschwindigkeit nahm hier die $\mathrm{CO}_{2}$-Abgabe über die Rinde im gleichen Maße ab, wie bei Messungen an intakten Bäumen. Diesen Ergebnissen zufolge kann der Rückgang der $\mathrm{CO}_{2}$-Abgabe quantitativ mit dem Abtransport von $\mathrm{CO}_{2}$ mit dem Xylemsaft erklärt werden (NEGISI 1979).

MARTIN et al. (1994) fanden bei Sämlingen von Pinus taeda ebenfalls einen Rückgang der $\mathrm{CO}_{2}$ Abgabe des Stammes bei zunehmender Transpirationsrate. Sie schlossen einen limitierenden Einfluss des Wasserstatus auf die Atmungsaktivität der Sprosse aus, da sich die Xylemwasserpotenziale der stark transpirierenden Pflanzen nicht von den Potenzialen der schwach transpirierenden unterschieden. Sie sehen in dem Abtransport von $\mathrm{CO}_{2}$ die Ursache für die reduzierte $\mathrm{CO}_{2}$-Abgabe über die Stammoberfläche.

HARI et al. (1991) kommen zu dem Ergebnis, dass die $\mathrm{CO}_{2}$-Menge, die mit dem Transpirationsstrom in die Blätter transportiert und dort reassimiliert wird, nur einen geringen Anteil an der gesamten Blattphotosynthese hat, weisen aber auf den weit größeren Einfluss des $\mathrm{CO}_{2}$-Transports auf die Atmungsmessungen hin. Im Gegensatz zu NEGISI (1975) und MARTIN et al. (1994) stellten LEVI et al. (1999) fest, dass unter bestimmten Umständen (hohe $\mathrm{CO}_{2}$-Konzentration des Bodenwassers bei schlechter Belüftung des Bodens) $\mathrm{CO}_{2}$ auch mit dem Xylemsaft in den Stamm transportiert und dort über die Oberfläche abgegeben werden kann. SPRUGEL (1990) sieht im Antransport von $\mathrm{CO}_{2}$ eine mögliche Ursache für die im Vergleich zum Stammholz höheren Atmungsraten der Äste.

EDWARDS \& HANSON (1996) fanden nur schwache bzw. keine Anzeichen für den Transport von $\mathrm{CO}_{2}$ mit dem Xylemsaft.

Im Rahmen der vorliegenden Untersuchung waren die Abweichungen der Atmungsraten der Buchen von den Temperaturverläufen auf die Tagesstunden beschränkt, so dass hier ebenfalls der direkte und/oder indirekte Einfluss des Lichts deutlich wurde. Durch den Ausschluss der während der Hellphase des Tages gemessenen Werte bei der Ermittlung der Temperaturfunktion konnte der Einfluss der Rindenphotosynthese eliminiert werden. Da die Saftflussrate der Buche bis $22 \mathrm{~h}$ auch bei leicht eingeschränkter Wasserversorgung auf unter $10 \%$ der Tagesmaxima sinkt (STROBEL 1997, SCHIPKA 2003), war bei dem während der Sommermonate zur Bestimmung der Temperaturfunktionen berücksichtigen Zeitraum von 22 - $6 \mathrm{~h}$ auch kein Einfluss des $\mathrm{CO}_{2}$-Transportes auf die $\mathrm{CO}_{2}$-Abgabe über die Rinde zu erwarten. Die so ermittelten Temperaturbeziehungen waren trotz der geringeren Amplitude von Atmungsrate und Temperatur ebenso eng, oft deutlich enger als die Beziehung für den gesamten, die Tageswerte einbeziehenden Datensatz. Damit zeigte sich, dass die $\mathrm{CO}_{2}$-Abgabe über die Oberfläche der verholzten Organe der Buche erwartungsgemäß eng mit der Temperatur korreliert ist. Umgekehrt wurde deutlich, dass die $\mathrm{CO}_{2}$-Abgabe über die 
Oberfläche der Äste durch Rindenphotosynthese effizient vermindert und durch den $\mathrm{CO}_{2}$-Transport mit dem Xylemsaft wesentlich beeinflusst werden kann.

$\mathrm{CO}_{2}$-Transport und Refixierung sind bei den verschiedenen Organen von unterschiedlicher Bedeutung. Die Grobwurzeln wurden zwar nach der Installation der Küvetten nicht mit Aushub bedeckt, waren aber schnell von Laubstreu und durch Bioturbation bewegten Boden bedeckt. Somit konnte Rindenphotosynthese ausgeschlossen und die beobachteten diurnalen Unterschiede der Temperaturbeziehungen auf den $\mathrm{CO}_{2}$-Transport mit dem Xylemsaft zurückgeführt werden. Für die Stämme und Äste lassen sich die Effekte von Refixierung und $\mathrm{CO}_{2}$-Transport insofern differenzieren, als dass während der unbelaubten Phase der $\mathrm{CO}_{2}$-Transport mit dem Xylemsaft auszuschließen ist. Bei der Buche treten erst nach dem Blattaustrieb mit einsetzender Transpiration der Blätter nennenswerte Saftflussgeschwindigkeiten auf (STROBEL 1997, SCHIPKA 2003). Während der unbelaubten Phase waren die höchsten Tagesmaxima der Refixierung bei den Stämmen im April und Ende Oktober an warmen, strahlungsreichen Tagen zu beobachten. Dabei wurden mit Werten von

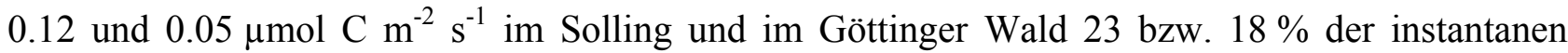
Bruttoatmung refixiert. Im Sommer war die $\mathrm{CO}_{2}$-Abgabe maximal um 0.20 und $0.23 \mu \mathrm{mol} \mathrm{C} \mathrm{m} \mathrm{s}^{-1}$ oder 20 und $22 \%$ gegenüber der Bruttoatmung reduziert (Mittelwerte der Maxima aller Küvetten im Gegensatz zu den Angaben in Tab. 15!). Bei den Messungen im Sommer lagen die Temperaturen 5 bzw. $10{ }^{\circ} \mathrm{C}$ über denen der maximalen Refixierung im April bzw. Oktober, so dass bei sonst gleichen Bedingungen die Rindenphotosynthese als ursächlich betrachtet werden könnte. Da aber der Lichtgenuss in den untersuchten Buchenbeständen am Waldboden von $40 \%$ im April auf 1-5 \% im Juli zurückgeht (Gries 2004, in Vorb.), muss davon ausgegangen werden, dass die im Sommer stark lichtlimitierte Rindenphotosynthese die Werte des Frühjahres oder Herbstes nicht erreichte. Demnach dürfte ein wesentlicher Teil des gegenüber der Bruttoatmung nicht über die Oberfläche abgegebenen Kohlendioxids mit dem Xylemsaft abtransportiert worden sein. Zu dieser Einschätzung kommt auch GRIES (pers. Mitteilung) bei dem Vergleich von Messungen mit lichtdurchlässigen und abgedeckten Küvetten im Solling.

Auch bei den Ästen beider Standorte blieb die gemessene $\mathrm{CO}_{2}$-Abgabe häufig hinter den gemäß der Temperaturfunktion erwarteten Werten zurück. Aus den während des Winterhalbjahres beobachteten Abweichungen ist ein hohes Refixierungspotenzial der Astrinde abzuleiten. Auch die Unterschiede zwischen berechneter und gemessener Atmungsrate während der Sommermonate können mit der Rindenphotosynthese quantitativ erklärt werden. Die Messung mit abgedeckten Küvetten zeigte aber, dass der $\mathrm{CO}_{2}$-Transport mit dem Xylemsaft die $\mathrm{CO}_{2}$-Abgabe der Äste beeinflusst. Wie bei den Stämmen und einigen Grobwurzeln war die $\mathrm{CO}_{2}$-Abgabe einzelner Äste trotz Unterbindung der Rindenphotosynthese geringer als die berechnete Bruttoatmung. Aus dem Vergleich mit der Messung mit lichtdurchlässigen Küvetten konnte geschlossen werden, dass bei dem betreffenden Ast die Reduktion der $\mathrm{CO}_{2}$-Abgabe über die Oberfläche zu ca. $30 \%$ durch Rindenphotosynthese und zu $70 \%$ durch den Abtransport mit dem Xylemsaft erfolgte. Bei einem anderen Ast überstieg die $\mathrm{CO}_{2}$-Abgabe die Bruttoatmung bei abgedeckten Küvetten, so dass, wie bereits für die Grobwurzeln gezeigt wurde, $\mathrm{CO}_{2}$ auch mit dem Xylemsaft antransportiert und über die Oberfläche abgegeben werden kann. Dieser Antransport kann bei Messung mit lichtdurchlässigen Küvetten durch die Rindenphotosynthese kompensiert werden.

Der $\mathrm{CO}_{2}$-Transport mit dem Xylemsaft beeinflusst die $\mathrm{CO}_{2}$-Abgabe über die Oberfläche also in allen drei untersuchten Kompartimenten. Dabei handelt es sich jedoch nicht generell um einen Abtransport wie von NEGISI (1979) und MARTIN et al. (1994) dokumentiert. Sowohl bei einigen Grobwurzeln als auch bei Ästen wird $\mathrm{CO}_{2}$ mit dem Xylemsaft antransportiert und über die Ober- 
fläche abgegeben. Als Antransport aus den Grobwurzeln erklären z. B. LEVI et al. (1999) die hohe $\mathrm{CO}_{2}$-Abgabe von Stämmen. Die von STEINBORN (1997) beobachtete ,negative Rindenphotosynthese", d.h. die über die Dunkelatmung hinausgehende $\mathrm{CO}_{2}$-Abgabe, an zwei von elf Ästen kann ebenso als Antransport von $\mathrm{CO}_{2}$ interpretiert werden wie die Peaks der $\mathrm{CO}_{2}$-Abgabe, die bei NEGISI (1979, Abb. 2) kurz nach Einsetzen des künstlich induzierten Saftflusses auftraten bevor der $\mathrm{CO}_{2}$-Abtransport einsetzte.

$\mathrm{Ob} \mathrm{CO}_{2}$ im Xylemsaft gelöst und abtransportiert oder aus dem Xylemsaft in das Gewebe und dann über die Oberfläche abgegeben wird, hängt von dem $\mathrm{CO}_{2}$-Konzentrationsgradienten zwischen Xylemsaft und Gewebe ab. Die $\mathrm{CO}_{2}$-Konzentration im Gewebe ist um so höher, je höher die Atmungsaktivität und/oder je höher der Diffusionswiderstand für $\mathrm{CO}_{2}$ in radialer Richtung ist. So kann die $\mathrm{CO}_{2}$-Konzentration im Xylem der Stämme wegen der längeren Diffusionswege und des höheren Diffusionswiderstands der dickeren Rinde so hoch sein, dass $\mathrm{CO}_{2}$ im Xylemsaft gelöst und abtransportiert wird. Auch in Ästen und Grobwurzeln kann der Xylemsaft $\mathrm{CO}_{2}$ aufnehmen, wenn der jeweilige Abschnitt eine hohe spezifische Atmungsaktivität aufweist. Der Konzentrationsgradient kann dort umgekehrt sein, wo der Diffusionswiderstand und/oder die Atmungsaktivität des Gewebes geringer ist als in dem in Saftflussrichtung vorgeschalteten Wurzel- oder Sprossabschnitten. Diese Situation ist z. B. für Grobwurzeln mit geringer Atmungsaktivität denkbar. Distal gelegene Fein-, Schwach- und dünne Grobwurzeln können höhere Atmungsaktivitäten aufweisen. Außerdem kann in schlecht durchlüfteten Bodenbereichen die $\mathrm{CO}_{2}$-Abgabe in die Bodenluft vermindert sein. Weist die in der gut belüfteten Küvette befindliche Grobwurzel wegen der begünstigten $\mathrm{CO}_{2}$-Abgabe nach außen und wegen der geringeren Atmungsaktivität eine niedrigere $\mathrm{CO}_{2}$ Konzentration auf, so kann $\mathrm{CO}_{2}$ aus dem heranströmenden Xylemsaft abgegeben werden. Bei Ästen ist diese Situation insbesondere dann denkbar, wenn $\mathrm{CO}_{2}$-reicher Xylemsaft aus dem Stamm nach nächtlicher Aufsättigung die Äste erreicht. Bei stammnahen Ästen mit geringer Atmungsaktivität und im Vergleich zu den Stämmen geringeren Diffusionswiderständen kann $\mathrm{CO}_{2}$ aus dem Xylemsaft in das Gewebe übertreten und über die Oberfläche abgegeben werden. Steigt die Atmungsaktivität im Tagesverlauf temperaturbedingt an, so gleichen sich die $\mathrm{CO}_{2}$-Konzentrationen im Gewebe und Xylemsaft an und der Antransport wird im Tagesverlauf schwächer (Abb. 12, Küvette 6).

\subsubsection{Vergleich der Rindenphotosynthese und $\mathrm{CO}_{2}$-Transportraten mit Literatur- angaben}

In Tab. 17 sind die maximalen Raten der Rindenphotosynthese, die bei Stämmen und Ästen der hier untersuchten Buchen gefunden wurden, den Angaben anderer Autoren gegenübergestellt. Ein möglicher Einfluss des $\mathrm{CO}_{2}$-Transports mit dem Xylemsaft auf die Rindenphotosyntheseraten wird dadurch ausgeschlossen, dass ausschließlich Werte aus Zeiträumen berücksichtigt sind, in denen die Buchen nicht belaubt waren.

Die Äste im Solling und die Stämme beider Standorte zeigen vergleichsweise niedrige Photosyntheseraten. Am besten ist hier die Übereinstimmung mit den Werten von STEINBORN (1997), der die Rindenphotosynthese unter natürlichen Lichtbedingungen ermittelte, während die Werte der anderen Autoren unter künstlicher Beleuchtung gemessen wurden. Die vergleichsweise niedrigen Rindenphotosyntheseraten von unter $0.4 \mu \mathrm{mol} \mathrm{C} \mathrm{m} \mathrm{C} \mathrm{s}^{-1}$ sind vermutlich auf suboptimale Temperatur- und Lichtbedingungen während der Messkampagnen zurückzuführen. Im Gegensatz dazu stehen die Werte der Äste des Göttinger Waldes, die Mitte April 1998 an Strahlungstagen im 
Tab. 17: Absolute und relative Photosyntheseraten der Rinde von Ästen und Stämmen. Die Raten wurden unter künstlicher Beleuchtung z. T. beim Erstellen von Lichtantwortkurven oder unter Freilandbedingungen gemessen. Die Werte der vorliegenden Untersuchung wurden während der Vegetationsruhe (April bzw. Ende Oktober) ermittelt.

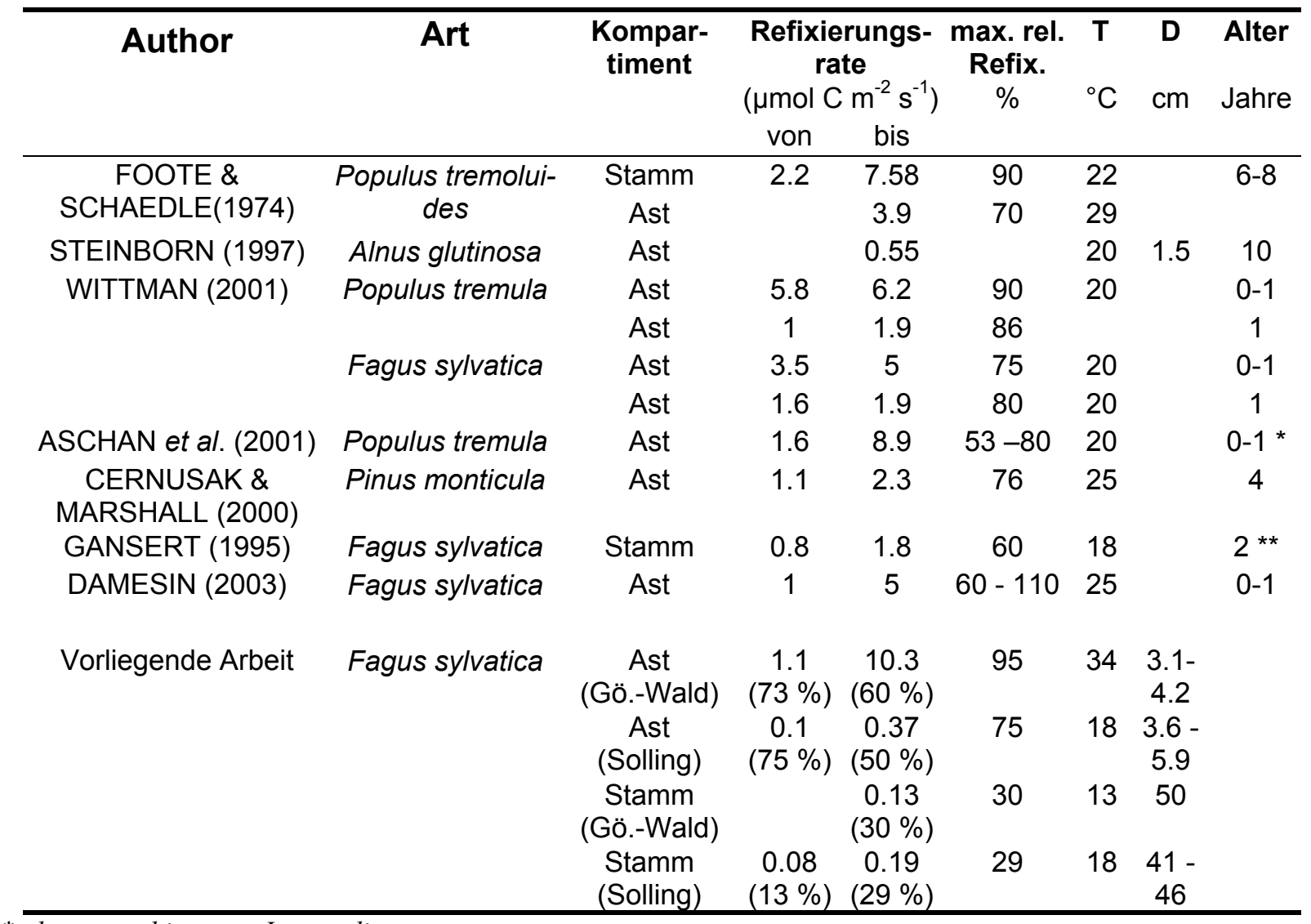

* ältestes und jüngstes Internodium

** umgerechnet aus trockengewichtsbezogenen Raten (Astholzdichte $=580 \mathrm{~kg} \mathrm{~m}^{-3}$ )

Mittel $4.1 \mu \mathrm{mol} \mathrm{C} \mathrm{m} \mathrm{s}^{-1}$ betrugen. Bei hohen Strahlungsintensitäten und bei Temperaturen zwischen 30 und $35{ }^{\circ} \mathrm{C}$ erreichten auch ältere Äste mit einem Durchmesser von 3.0 bis $7.5 \mathrm{~cm}$ Photosyntheseraten diesjähriger Äste von Populus tremula oder Fagus sylvatica. Der Maximalwert eines einzelnen Astes überstieg noch den Höchstwert, den FOOTE \& SCHAEDLE (1974) unter künstlicher Belichtung am Stamm einer 8-jährigen Pappel maßen. Allerdings lag auch die Temperatur des Buchenastes ca. $12{ }^{\circ} \mathrm{C}$ über der des Pappelstammes.

Anders als die absoluten Photosyntheseraten, die um bis zu zwei Größenordnungen variierten, verhielt sich die mit den Bruttoatmungsraten ins Verhältnis gesetzte Refixierung. So erreichte die höchste Refixierungsrate des Astes im Göttinger Wald mit 60 \% etwa den gleichen Anteil an der Bruttoatmung wie die deutlich geringeren Photosyntheseraten bei den Ästen im Solling. Die relative Refixierung der Äste stimmt gut mit den Werten anderer Autoren überein (Tab. 17).

ASCHAN et al. (2001) und CERNUSAK \& MARSHALL (2000) fanden eine enge Beziehung zwischen maximaler Atmungs- und Refixierungsrate, so dass der relative Anteil der Refixierung über einen weiten Bereich unterschiedlicher Atmungsaktivitäten konstant blieb. Dies könnte nicht nur für Sprossachsen gleichen Alters gelten, sondern auch für solche verschiedener Altersklassen mit vergleichbaren Atmungsaktivitäten. CERNUSAK \& MARSCHALL (2000) sehen die Ursache für die enge Beziehung zwischen Atmung und Refixierung nicht in einer direkten Wirkung der Atmungsaktivität, z. B. über die $\mathrm{CO}_{2}$-Konzentration oder in einer generellen Altersabhängigkeit der 
beiden Prozesse. Vielmehr würde die Investition in den Aufbau von Chlorenchym und enzymatischer Photosynthesekapazität in der Rinde auf die Atmungsaktivität der Sprossachse abgestimmt.

Die maximalen Raten, die im Rahmen der vorliegenden Studie für den $\mathrm{CO}_{2}$-Transport mit dem Xylemsaft gemessen wurden, erreichten nicht die Höchstwerte, die NEGISI (1972) und MARTIN et al. (1994) dokumentieren, stimmen aber gut mit der mittleren Angaben von MARTIN et al. (1994) und mit der von LEVY et al. (1999) angegebenen Antransportrate überein (Tab. 18).

Von dem durch die Atmung gebildeten $\mathrm{CO}_{2}$ wurde in den verholzten Organen der Altbuchen maximal $25 \%$ mit dem Xylemsaft abtransportiert. Damit ist auch der relativen Anteil geringer als bei Pinus taeda oder Magnolia obovata (Tab. 18).

Der Antransport konnte bei einigen Grobwurzeln und Ästen der Buche über $30 \%$ der aktuellen $\mathrm{CO}_{2}$-Abgabe ausmachen. Die maximalen Werte liegen in der gleichen Größenordnung wie die Rindenphotosynthese und stimmen im Mittel mit dem Ergebnis von LEVY et al. (1999) überein.

Tab. 18: Maximale Raten des $\mathrm{CO}_{2}$-Transports mit dem Xylemsaft. Die relativen Anteile sind bei Antransport auf die gemessene $\mathrm{CO}_{2}$-Abgabe, bei Abtransport auf die Bruttoatmung bezogen.

\begin{tabular}{|c|c|c|c|c|c|c|}
\hline \multirow[t]{2}{*}{ Autor } & \multirow[t]{2}{*}{ Art } & \multirow[t]{2}{*}{ Kompartiment } & \multicolumn{2}{|c|}{ Antransport } & \multicolumn{2}{|c|}{ Abtransport } \\
\hline & & & $\mu \mathrm{mol} C \mathrm{~m}-2 \mathrm{~s}-1$ & $\%$ & $\mu \mathrm{mol} \mathrm{C} \mathrm{m-2} \mathrm{s-1}$ & $1 \%$ \\
\hline LEVI et al. (1999) & $\begin{array}{l}\text { Combretum } \\
\text { micranthum }\end{array}$ & Stamm & 0.70 & 12 & & \\
\hline \multirow[t]{2}{*}{ MARTIN et al. (1994) } & Pinus taeda & Stamm, Mittelwert & & & 0.18 & 7 \\
\hline & & Stamm, Maximum & & & 4.00 & 45 \\
\hline NEGISI (1972) & Magnolia obovata & Stamm & & & 4.42 & 39 \\
\hline NEGISI (1979) & Pinus densiflora & Stamm & & & 1.89 & 60 \\
\hline \multirow[t]{10}{*}{ Eigene Daten } & Fagus sylvatica & Grobwurzel Gö.-Wald & 0.16 & 12 & 0.18 & 21 \\
\hline & & Grobwurzel 4 Abb. 12 & & & 0.14 & 25 \\
\hline & & Grobwurzel Solling & 0.35 & 33 & 0.26 & 18 \\
\hline & & Growurzel 1 Abb. 8 & 0.25 & 36 & & \\
\hline & & Growurzel 6 Abb. 8 & 0.14 & 22 & & \\
\hline & & $\begin{array}{l}\text { Stamm Göttinger } \\
\text { Wald }\end{array}$ & & & $0.17^{*}$ & $19^{*}$ \\
\hline & & Stämme Solling & & & $0.23^{*}$ & $24^{*}$ \\
\hline & & Ast 2, Abb. 13 & & & 0.79 & 22 \\
\hline & & Ast 4, Abb. 13 & 0.53 & 17 & & \\
\hline & & Ast 6, Abb. 13 & 1.03 & 31 & & \\
\hline
\end{tabular}

*Messung mit lichtdurchlässigen Küvetten im Sommer. Anteile von Rindenphotosynthese sind daher nicht ausgeschlossen.

Die bisher betrachteten absoluten und relativen Maximalwerte dokumentieren vor allem das Potenzial der Rinde, unter optimalen Licht- und Temperaturbedingungen wesentliche Anteile des Atmungs- $\mathrm{CO}_{2}$ durch Photosynthese zu refixieren, aber auch den potenziellen Einfluss des $\mathrm{CO}_{2}$ Transports auf die $\mathrm{CO}_{2}$-Abgabe über die Oberfläche der Rinde. Da unter natürlichen Bedingungen am Standort maximale Photosynthese- und Transportraten nur selten und kurzfristig erreicht werden, kann aus diesen Werten nicht auf die Bedeutung der Prozesse für die Kohlenstoffbilanz auf Organ- oder Baumebene geschlossen werden.

Hinweise hierauf ergeben sich aus den Anteilen der Tagessummen von Rindenphotosynthese und $\mathrm{CO}_{2}$-Transport an der Tagessumme der Bruttoatmung. An einzelnen Tagen wurden bei den Ästen der hier untersuchten Buchen durch Rindenphotosynthese bis zu $55 \%$ des Atmungs- $\mathrm{CO}_{2}$ refixiert. Bei den Stämmen war die Tagessumme der $\mathrm{CO}_{2}$-Abgabe um maximal $16 \%$ reduziert. Die im Vergleich zu den Ästen niedrigeren Werte, die bereits bei den maximalen Photosyntheseraten 
auffielen, sind auf das geringere Oberflächen/Volumen-Verhältnis, also ein geringeres Verhältnis zwischen photosynthetisch aktiven Gewebe und atmender Biomasse zurückzuführen. Ebenso bedeutsam ist der geringere Lichtgenuss des Chlorenchyms der Stammrinde, der einerseits durch die nördliche Exposition der Messstellen begründet ist. Andererseits ist der Lichtgenuss im Stammraum unter natürlichen Bedingungen auch in der nichtbelaubten Phase des Jahres geringer als der Lichtgenuss der Äste (GRIES 2004, in Vorb.) und die dickere Rinde weniger lichtdurchlässig (PFANZ \& ASCHAN 2001).

Während der Vegetationsperiode war der relative Anteil der Differenz zwischen berechneter Bruttoatmung und gemessener $\mathrm{CO}_{2}$-Abgabe bei den Ästen geringer als im Winterhalbjahr. Die schwächere Reduktion der $\mathrm{CO}_{2}$-Abgabe lässt sich vermutlich im Wesentlichen auf den abnehmenden Lichtgenuss im Kronenraum mit dem Laubaustrieb zurückführen (GRIES 2004, in Vorb.). Da Rindenphotosynthese und $\mathrm{CO}_{2}$-Transport nicht getrennt ermittelt wurden, kann auch der Effekt der Rindenphotosynthese durch den Antransport von $\mathrm{CO}_{2}$ mit dem Xylemsaft kompensiert und die Differenz zwischen $\mathrm{CO}_{2}$-Abgabe und Bruttoatmung verringert worden sein (Abb. 12 b, Küvetten 4 und 6). Bei den Stämmen hingegen unterschieden sich weder das im Sommer gemessene Maximum noch der mittlere Anteil der Reduktion der $\mathrm{CO}_{2}$-Abgabe an der Bruttoatmung von den im Winterhalbjahr beobachteten Werten. Wenn die Rindenphotosynthese bei geringerem Lichtgenuss nach dem Laubaustrieb zurückging, müsste dieser Rückgang durch den verstärkten $\mathrm{CO}_{2}$-Abtransport mit dem Xylemsaft kompensiert worden sein.

Wie stark der Transport von $\mathrm{CO}_{2}$ mit dem Xylemsaft die $\mathrm{CO}_{2}$-Abgabe über die Oberfläche beeinflussen kann, wird insbesondere bei den Grobwurzeln deutlich. So lag die $\mathrm{CO}_{2}$-Abgabe um bis zu $24 \%$ über der berechneten Bruttoatmung, d.h. knapp $20 \%$ der täglich abgegebenen $\mathrm{CO}_{2}-\mathrm{Menge}$ wurde mit dem Xylemsaft antransportiert (Abb. 8 b). An anderen Messstellen wurden $15 \%$ des täglich gebildeten Atmungs- $\mathrm{CO}_{2}$ abtransportiert und nicht lokal über die Oberfläche abgegeben. Bei den Ästen kann der $\mathrm{CO}_{2}$-Transport mit dem Xylemsaft untersucht werden, wenn die Rindenphotosynthese durch das lichtdichte Abdecken der Küvetten unterbunden ist. Ein auf 4 Tage beschränktes Experiment im Göttinger Wald ergab, dass bei einzelnen Ästen bis zu 8 \% des täglich abgegebenen Kohlendioxids antransportiert wurde. Bei einem anderen Ast wurde ein ebenso hoher Anteil des durch Atmung gebildeten $\mathrm{CO}_{2}$ abtransportiert (Abb. 12 b).

In Tab. 19 sind die Angaben verschiedener Studien zu den relativen Anteilen der täglichen Rindenphotosynthese und der mit dem Xylemsaft transportierten $\mathrm{CO}_{2}$-Mengen an der Tagessumme der $\mathrm{CO}_{2}$-Abgabe aufgeführt. Der Anteil der Rindenphotosynthese erreichte bei den hier untersuchten Altbuchen maximal solche Werte, wie sie DAMESIN (2003) als Mittelwert für die effizient refixierenden diesjährigen Buchenzweige im Frühsommer nennt. Die mittleren Anteile der Rindenphotosynthese im Winter bzw. der Summe aus $\mathrm{CO}_{2}$-Transport und Rindenphotosynthese während der Vegetationsperiode lagen bei den Ästen an der unteren Grenze der in der Literatur angegebenen Spanne. Hingegen stimmen die Werte der Buchenstämme gut mit den Angaben von STEINBORN (1997) für einen Erlenstamm überein.

Der Anteil des $\mathrm{CO}_{2}$-Abtransports an der Bruttoatmung ist bei den Buchengrobwurzeln und -ästen deutlich geringer als bei Magnolia obovata (NEGISI 1972). Wie NEGISI (1972) ermittelte auch STEINBORN (1997) an einzelnen Ästen eine über der Bruttoatmung liegende $\mathrm{CO}_{2}$-Abgabe, aus der „negative $\mathrm{CO}_{2}$-Abtransport“-Raten resultierte. Dies deutet ebenso auf den Antransport von $\mathrm{CO}_{2}$ mit dem Xylemsaft hin, wie die negativen Abtransport-Werte, die sich in gleicher Größenordnung bei abgedunkelten Buchenästen und -grobwurzeln ergaben. 
Tab. 19: Relativer Anteil der Rindenphotosynthese, der Summe von Rindenphotosynthese und $\mathrm{CO}_{2}$-Transport und des $\mathrm{CO}_{2}$-Transportes an der Tagessumme der $\mathrm{CO}_{2}$-Abgabe über die Oberfläche verholzter Organe.

\begin{tabular}{|c|c|c|c|}
\hline Autor & Art & $\begin{array}{l}\text { relativer Anteil an } \\
\text { der täglichen } \mathrm{CO}_{2-} \\
\text { Abgabe }(\%)\end{array}$ & Anmerkung \\
\hline \multicolumn{4}{|c|}{ Rindenphotosynthese } \\
\hline DAMESIN (2003) & Fagus sylvatica & 20 bis $50 *$ & $\begin{array}{l}\text { diesjährige Zweige, } \\
\text { Herbst/Winter- Frühsommer }\end{array}$ \\
\hline $\begin{array}{l}\text { FOOTE \& SCHAEDLE } \\
(1976 b)\end{array}$ & $\begin{array}{l}\text { Populus } \\
\text { tremuloides }\end{array}$ & 16 bis 18 & \\
\hline $\begin{array}{l}\text { FOOTE \& SCHAEDLE } \\
\text { (1978) }\end{array}$ & $\begin{array}{l}\text { Populus } \\
\text { tremuloides }\end{array}$ & (10 bis 60$)$ & $\begin{array}{l}\text { nur für die Hellphase des } \\
\text { Tages }\end{array}$ \\
\hline \multirow[t]{2}{*}{ eigene Daten } & Fagus sylvatica & $13.7(55)^{\star *}$ & Äste (Winterhalbjahr) \\
\hline & & $2.0(16)^{* *}$ & Stämme (Winterhalbjahr) \\
\hline \multicolumn{4}{|c|}{ Rindenphotosynthese $+\mathrm{CO}_{2}$-Transport } \\
\hline \multirow[t]{2}{*}{ GANSERT (1995) } & Fagus sylvatica & 14 bis 33 & Labor, 2-jährige Buche \\
\hline & & 11 bis 29 & Freiland \\
\hline \multirow[t]{2}{*}{ STEINBORN (1997) } & Alnus glutinosa & 1.4 & Stamm \\
\hline & & $(-10) 15(47)^{\star *}$ & $\begin{array}{l}\text { Äste (Mittelwert nur für Äste mit } \\
\text { positiver Abweichung) }\end{array}$ \\
\hline \multirow[t]{2}{*}{ eigene Daten } & Fagus sylvatica & $7.0(47)^{* *}$ & Äste (Vegetationsperiode) \\
\hline & & $2.0(17)^{* *}$ & Stämme (Vegetationsperiode) \\
\hline \multicolumn{4}{|c|}{$\mathrm{CO}_{2}$-Abtransport } \\
\hline \multirow[t]{2}{*}{ NEGISI (1972) } & Magnolia & $(0) 9(26)^{\star \star}$ & Stämme $(n=13)$ \\
\hline & obovata & $(-13) 5(14)^{\star *}$ & Äste $(n=12)$ \\
\hline \multirow[t]{2}{*}{ eigene Daten } & Fagus sylvatica & -7.9 bis 7.7 & $\begin{array}{l}\text { Äste (Vegetationsperiode, } \\
\text { abgedeckt) }\end{array}$ \\
\hline & & $(-24)-1.1(15)^{\star *}$ & $\begin{array}{l}\text { Grobwurzeln } \\
\text { (Vegetationsperiode) }\end{array}$ \\
\hline
\end{tabular}

* Monatsmittelwerte aus modellierter Rindenphotosynthese

** (Minimum) Mittelwert (Maximum)

Die Mittelwerte der vorliegenden Arbeit für die relative Reduktion der $\mathrm{CO}_{2}$-Abgabe sind stets geringer als die, die in der Literatur angegeben werden. Dies lässt sich zum Teil auf die höhere Effizienz der Rindenphotosynthese bei jüngeren Sprossachsen von Buchen (GANSERT 1995, DAMESIN 2003) oder dünneren Achsen z. B. der Erle zurückführen. Jedoch unterscheiden sich auch die Datengrundlagen für die in Tab. 19 angegebenen Werte. So geht DAMESIN (2003) in ihrer Modellrechung der Rindenphotosynthese von horizontal ausgerichteten Zweigen und optimalen Lichtbedingungen aus. Die Werte von GANSERT (1995) sind aus den Angaben ausgewählter Tage, mit denen das Phänomen der Rindenphotosynthese dargestellt werden soll, ermittelt worden und stellen daher vermutlich eher maximale Werte dar. Die Werte der vorliegenden Untersuchung hingegen umfassen die Ergebnisse aller Messkampagnen in den zwei Untersuchungsjahren und beinhalten eine große Spanne hinsichtlich der Witterungsbedingungen, so dass auch eine Anzahl von Tagen mit suboptimalen Bedingungen für Rindenphotosynthese und $\mathrm{CO}_{2}$-Transport in die Berechnung eingehen. Diese Werte geben den mittleren Einfluss von Rindenphotosynthese und $\mathrm{CO}_{2}$-Transport am Standort daher vermutlich gut wieder.

Anders als die maximale instantane Reduktion der $\mathrm{CO}_{2}$-Abgabe durch Rindenphotosynthese und/oder $\mathrm{CO}_{2}$-Abtransport, die mehr als $80 \%$ bzw. $30 \%$ der Bruttoatmung ausmachen konnte, waren die mittleren Abweichungen bei den Tagessummen von Stämmen und Grobwurzeln gering (-1.1 bis $2 \%$ ). Bei den Ästen im Göttinger Wald wurde die tägliche $\mathrm{CO}_{2}$-Abgabe im Winter um 
$19 \%$ und im Sommer um $10 \%$ durch Rindenphotosynthese und $\mathrm{CO}_{2}$-Transport reduziert und erreichte damit bedeutsamere Anteile an der Bruttoatmung. Eine Abschätzung der Bedeutung der Rindenphotosynthese im Vergleich zu den Jahressummen der gesamten Holzatmung, dem Kohlenstoffgewinn und dem Biomassezuwachs der Bestände folgt in Kapitel 5.5.4.

\subsubsection{Bedeutung der Effekte von Hysterese, Rindenphotosynthese und $\mathrm{CO}_{2}$-Transport für die Bestimmung der Temperaturbeziehung}

Neben der quantitativen Bedeutung von Rindenphotosynthese und $\mathrm{CO}_{2}$-Transport für den Kohlenstoffumsatz verholzter Sprossachsen können diese Prozesse auch den Verlauf der Temperaturantwortkurve der $\mathrm{CO}_{2}$-Abgabe beeinflussen. Abhängig davon, wie Rindenphotosynthese und $\mathrm{CO}_{2}-$ Transport bei der Datenanalyse berücksichtig werden, können sich unterschiedliche Resultate bei der zeitlichen Hochrechnung der Holzatmung über längere Zeiträume ergeben.

Anders als in der vorliegenden Arbeit werden die Temperaturfunktionen meist unter Einbeziehung der in den Tagesstunden gemessenen Atmungsraten ohne oder mit Berücksichtigung einer Zeitverzögerung der $\mathrm{CO}_{2}$-Abgabe gegenüber der Temperatur berechnet. Bei manuellen Messungen der $\mathrm{CO}_{2}$-Abgabe liegen der Temperaturfunktion in der Regel ausschließlich am Tag gemessene Atmungsraten zugrunde (DAMESIN et al. 2002).

Zum exemplarischen Vergleich der Verfahren wurden für einige der in Kap. 4.1.1 dargestellten Tagesgänge jeweils vier Temperaturfunktionen ermittelt, der Tagesgang der Atmung berechnet und zur Tagessumme aufsummiert. Die Resultate der verschiedenen Berechnungen sind in Tab. 20 zusammengefasst. Bei Berücksichtigung des vollständigen Datensatzes zur Ermittlung der Temperaturfunktion wurde die Bruttoatmung in diesen Beispielen in einigen Fällen unter- und in anderen Fällen überschätzt. Die Abweichung lag zwischen 6 und $16 \%$. Die Berücksichtigung einer Zeitverzögerung führte bei zwei Tagesgängen zu einem höheren Bestimmtheitsmaß der Temperaturfunktion, beeinflusste die Tagessumme aber nur wenig. Wurde der Tagesgang mit der Temperaturfunktion für 24 Stunden ohne Zeitverzögerung berechnet, lagen die berechneten Atmungsraten am Tag häufig über den gemessenen Werten und in der Nacht darunter (Abb. 10, GANSERT 1995). In der Summe kompensierten sich die gegenläufigen Abweichungen, so dass die berechnete Tagessumme mit der gemessenen übereinstimmte. Bei Berücksichtigung der Zeitverzögerung, bei der die Temperaturfunktion das maximale Bestimmtheitsmaß erreichte $\left(\mathrm{TL}_{\mathrm{opt}}\right)$, wurde der Tagesverlauf der Atmung oft gut, in Einzelfällen aber nur unzureichend abgebildet (Abb. 10 b und Abb. 11 b). Die Tagessumme stimmte dann dennoch mit der gemessenen $\mathrm{CO}_{2}$-Abgabe überein.

Beide Verfahren eignen sich demnach, die Tagessumme der Netto- $\mathrm{CO}_{2}$-Abgabe bei den aktuellen Temperatur-, Licht- und Transpirationsbedingungen aus der Temperatur zu berechnen. Auch in Hinblick auf die Kohlenstoffbilanz des gesamten Baumes können Rindenphotosynthese und/oder der $\mathrm{CO}_{2}$-Transport insofern vernachlässigt werden, als die Netto- $\mathrm{CO}_{2}$-Abgabe den Bedarf an Kohlenstoff darstellt, der durch die Assimilation der Blätter gedeckt werden muss. Der C-Gewinn durch Rindenphotosynthese oder durch die Refixierung des mit dem Xylemsaft in die Blätter transportierten $\mathrm{CO}_{2}$ kann als baumintern zirkulierender Kohlenstoff unberücksichtigt bleiben, wenn der Netto-Kohlenstofffluss zwischen Bestand und Atmosphäre Inhalt der Untersuchung ist. $\mathrm{CO}_{2}$, das mit dem Xylemsaft antransportiert und über die Oberfläche der verholzten Organe abgegeben wird, entspricht zwar nicht dem lokalen C-Bedarf für den Atmungsstoffwechsel, geht aber in voller Höhe in die Berechnung der Holzatmung des Bestandes ein. Dies kann bei der Hochrechnung der Holz- 
atmung auf Baum- oder Bestandesebene nur dann kompensiert werden, wenn gleichzeitig die $\mathrm{CO}_{2}$ Abgabe derjenigen Bereiche berücksichtigt wird, in denen $\mathrm{CO}_{2}$ abtransportiert wird.

Problematisch kann der Ausgleich der Phasenverschiebung mit konstanten Zeitspannen sein (RYAN 1990, RYAN et al. 1996, LAVIGNE 1996, LAVIGNE et al. 1996), wenn diese nicht durchgängig zu einer besseren Abbildung der Temperaturantwort der Atmung führen. Wird $\mathrm{CO}_{2}$ mit dem Xylemsaft antransportiert, kann die $\mathrm{CO}_{2}$-Abgabe dem Temperaturgang vorauslaufen, so dass die von einer Verzögerung der $\mathrm{CO}_{2}$-Abgabe ausgehende Konstante die Abweichung der Temperaturfunktion weiter verstärkt. Die variable Phasenverschiebung (STOCKFORS \& LINDER 1998) beeinflusst den Temperaturkoeffizienten auf unterschiedliche Weise und variiert bei der Buche sowohl im zeitlichen Verlauf wie auch zwischen den verschiedenen Messstellen. Die Temperaturfunktionen sind daher nicht nur für die aktuellen Licht- und Transpirationsbedingungen, sondern auch für jede Messstelle spezifisch. MARTIN et al. (1994) weisen darauf hin, dass solche Temperaturbeziehungen nur sehr bedingt auf zeitlicher und räumlicher Ebene übertragbar sind.

Die Tagessummen der Holzatmung, die auf Grundlage solcher Temperaturfunktionen berechnet wurden, die an die bei Tageslicht gemessenen Daten angepasst wurden, wichen mit bis zu $18 \%$ am stärksten von der Bruttoatmung ab. Der direkte Einfluss von Rindenphotosynthese und/oder $\mathrm{CO}_{2-}$ Transport führte dazu, dass die Temperaturfunktion und die Abweichung von der Bruttoatmung sehr variabel sind und sich im Extremfall negative Temperaturkoeffizienten ergaben. LAVIGNE (1987, 1988), der die Atmungsraten in den frühen Vormittagsstunden und am Nachmittag maß, fand in der Auftragung der über die Vegetationsperiode gemessenen Atmungsraten gegen die Temperatur für die am Nachmittag gemessenen Werte eine weit höhere Variabilität als für diejenigen, die in den frühen Morgenstunden gemessen wurden. Die Datenpaare der einzelnen Tage eigneten sich zur Ermittlung einer Temperaturfunktion für einzelne Messstellen nicht.

Tab. 20: Vergleich der mit verschiedenen Temperaturfunktionen berechneten Tagessummen der $\mathrm{CO}_{2}$-Abgabe. In die Berechnung der Temperaturfunktionen gehen solche Datenpaare von Atmungsrate und Holztemperatur ein die 1. zwischen 20 und 6 (Ausschluss von Rindenphotosynthese und $\mathrm{CO}_{2}$-Transport $=\mathrm{R}_{\text {brutto }}$ ) 2. über 24 Stunden (ohne und mit Berücksichtigung einer Zeitverzögerung $\mathrm{TL}=$ Timelag) und 3. am Tag zwischen 6 und $20 \mathrm{~h}$ gemessen wurden.

\begin{tabular}{|c|c|c|c|c|c|c|c|}
\hline \multirow{4}{*}{ Standort } & \multirow{4}{*}{ Kompartiment } & \multirow{4}{*}{ Abbildung } & \multicolumn{5}{|c|}{ Temperaturfunktion für die Daten von } \\
\hline & & & \multirow{3}{*}{ Datum } & \multirow{3}{*}{$\begin{array}{c}20-6 \mathrm{~h} \\
\quad R_{\text {brutto }} \\
\mathrm{mol} \mathrm{C} \mathrm{m}^{-3} \mathrm{~d}^{-1}\end{array}$} & \multirow{2}{*}{$\begin{array}{c}24 \mathrm{~h} \\
\text { ohne TL }\end{array}$} & \multirow{3}{*}{$\begin{array}{l}\text { TL } \\
\%\end{array}$} & \multirow{3}{*}{$\begin{array}{c}6-20 \mathrm{~h} \\
\text { ohne TL } \\
\% \\
\end{array}$} \\
\hline & & & & & & & \\
\hline & & & & & $\%$ & & \\
\hline Solling & Grobwurzel 1 & Abb. $7 \mathrm{~b}$ & 25.07 .98 & 4.04 & 116 & & 118 \\
\hline Göttinger Wald & Grobwurzel 4 & Abb. 11 & 13.05 .97 & 2.64 & 93 & 94 & 87 \\
\hline Solling & Stamm 4 & Abb. 10 & 26.09 .98 & 0.30 & 94 & 94 & 87 \\
\hline \multirow[t]{4}{*}{ Göttinger Wald } & Ast 2 & Abb. 12 & 22.07 .98 & 38.76 & 89 & & 88 \\
\hline & abgedeckt & Abb. 12 & 27.07 .98 & 35.49 & 92 & & 92 \\
\hline & Ast 6 & Abb. 12 & 22.07 .98 & 30.5 & 101 & & 106 \\
\hline & abgedeckt & Abb. 12 & 27.07 .98 & 25.2 & 106 & & 113 \\
\hline
\end{tabular}




\subsection{Die Holzatmung im Jahresgang}

Die im Tagesgang exponentielle Abhängigkeit der Atmungsrate von der Temperatur lässt bei einer Amplitude der monatlichen Temperaturmittelwerte von 20 bzw. $16{ }^{\circ} \mathrm{C}$ während der beiden Untersuchungsjahre (Abb. 3) auch im saisonalen Verlauf einen ausgeprägten Jahresgang der Atmungsraten erwarten. Die nicht temperaturnormierten Atmungsraten variierten über einen weiten Bereich. Die in den Sommermonaten beobachteten Maximalwerte waren fünf- bis elfmal höher als die während der Wintermonate gemessenen Raten. Diese Variationsbreite entspricht den Ergebnissen anderer Autoren (Tab. 21), die für das Holz von Grobwurzeln und Stämmen älterer Bäume Steigerungen der Atmungsraten um den Faktor 1.8 bis 7 belegen. Der Anstieg der Atmungsraten von Stämmen junger Bäume (WULLSCHLEGER et al. 1995, GANSERT 1995) und von Astholz ist bei sommergrünen Laubbäumen noch stärker ausgeprägt (Faktor 6 bis 14), auch wenn die Temperaturamplitude mit der des Stammholzes vergleichbar ist (BENECKE 1985, GIESBERT 1997).

Der Jahresverlauf der Atmungsrate wird neben der Temperatur wesentlich vom physiologischen Status des Gewebes beeinflusst. Bereits JOHANSSON (1933) weist darauf hin, dass die Steigerung der Atmungsraten während des Sommers nicht allein auf die saisonale Temperaturänderung, sondern auch auf den erhöhten Energiebedarf für den Aufbau neuer Biomasse zurückzuführen ist. HAVRANEK (1981) beobachtete bei Bäumen an der Waldgrenze in der kurzen Übergangsphase von Vegetationsruhe zur Vegetationsperiode binnen weniger Tage eine deutliche Zunahme der Atmungsaktivität bei nahezu unveränderten Temperaturen. Die Kombination der Temperaturwirkung und der Änderung der physiologischen Aktivität führt dazu, dass die auf saisonaler Zeitskala erstellten Temperaturantwortkurven meist weniger eng sind und gegenüber den auf Grundlage des Tagesganges ermittelten Funktionen häufig höhere Q $_{10}$-Werte aufweisen (RYAN et al. 1994b). Entsprechende Befunde finden sich auch in der vorliegenden Studie. Die auf Ebene der Jahresgänge von Temperatur und Atmungsrate berechneten Temperaturfunktionen wiesen deutlich höhere $\mathrm{Q}_{10}$-Werte auf als die für die Tagesgänge berechneten Funktionen (Abb. 15 und Abb. 17, $\mathrm{Q}_{10, \mathrm{Jahr}}=2.41$ bis 5.06 gegenüber $\mathrm{Q}_{10 \text {,Tagesgang }}=1.73$ bis 2.74 ).

Die Variabilität der Gewebeaktivität wird dadurch besonders deutlich, dass auch die temperaturnormierten Atmungsraten von Ästen, Stämmen oder Grobwurzeln ausgeprägte Jahresgänge aufwiesen. Die Zusammenstellung der Literaturangaben in Tab. 21 zeigt, dass die $10{ }^{\circ} \mathrm{C}$-Atmungsrate während der Vegetationsperiode 1.1- bis 9.1-mal höher als die $10{ }^{\circ} \mathrm{C}$-Erhaltungsatmung des Winterhalbjahres sein kann.

Die bei den Altbuchen festgestellte Steigerung der temperaturnormierten Atmungsraten während der Vegetationsperiode um das 2- bis 3fache der im Winter beobachteten Werte entspricht den Ergebnissen, die von GANSERT (1995) für 10-jährige Buchen im Solling und von anderen Autoren für verschiedene Nadelbäume genannt werden. Dass die Steigerung im Vergleich zu den Angaben für verschiedene Laubbaumarten den unteren Bereich der Spanne markieren, ist zumindest teilweise auf die unterschiedliche Datengrundlage zurückzuführen. Während die minimalen Werte der vorliegenden Arbeit der mittleren winterlichen $10^{\circ} \mathrm{C}$-Atmungsrate entsprechen, handelt es sich z. B. bei den Werten von BENECKE (1985) um die Minima des Winterhalbjahres.

Im Vergleich zu den Werten der 30-jährigen Buchen (DAMESIN et al. 2002, CESCHIA et al. 2002) muss der Unterschied der sommerlichen Aktivitätssteigerung andere Ursachen haben, da bei diesen Werten ebenfalls die über das Winterhalbjahr gemittelte Erhaltungsatmung dem Sommermaximum gegenübergestellt ist. Die höhere Variabilität der Atmungsrate der jüngeren Buchen 
Tab. 21: Zusammenstellung von Literaturangaben $\mathrm{zu}$ volumenbezogenen Atmungsraten verschiedener Baumarten und -kompartimente. Aus den Quellen wurden die Jahresminima- und maxima bei ambienten Temperaturen, sowie die Spanne der auf $10{ }^{\circ} \mathrm{C}$ normierten Atmungsraten übernommen und bei Bedarf umgerechnet. Sofern $\mathrm{Q}_{10}$-Werte angegeben waren, wurden diese verwendet, andernfalls wurden für Angaben zu Fagus sylvatica die $\mathrm{Q}_{10}$-Werte der jeweiligen Kompartimente aus der vorliegenden Untersuchung (Abb. 16), für alle übrigen Baumarten ein Wert von $\mathrm{Q}_{10}=2$ angenommen. Fortsetzung auf der folgenden Seite.

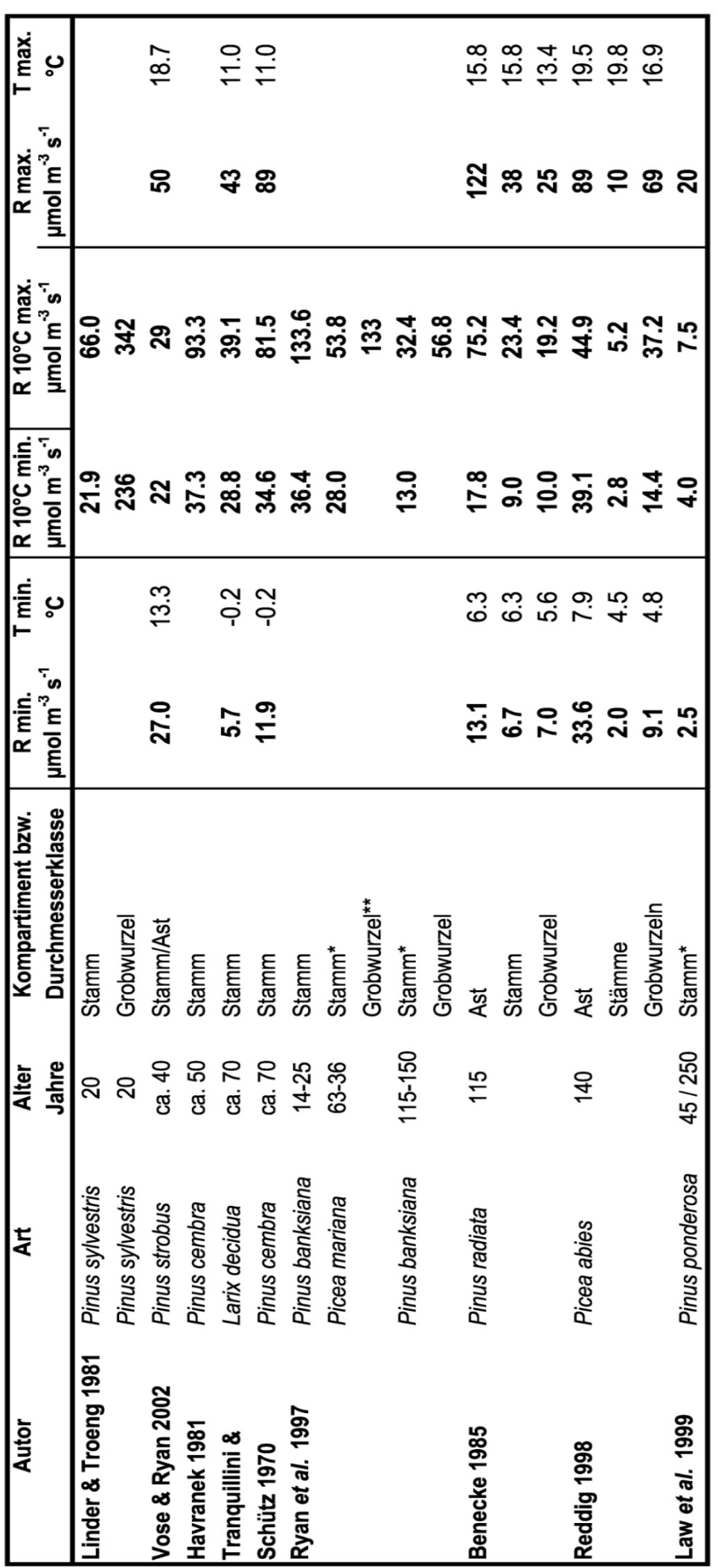


Tab. 21: Fortsetzung von Seite 112

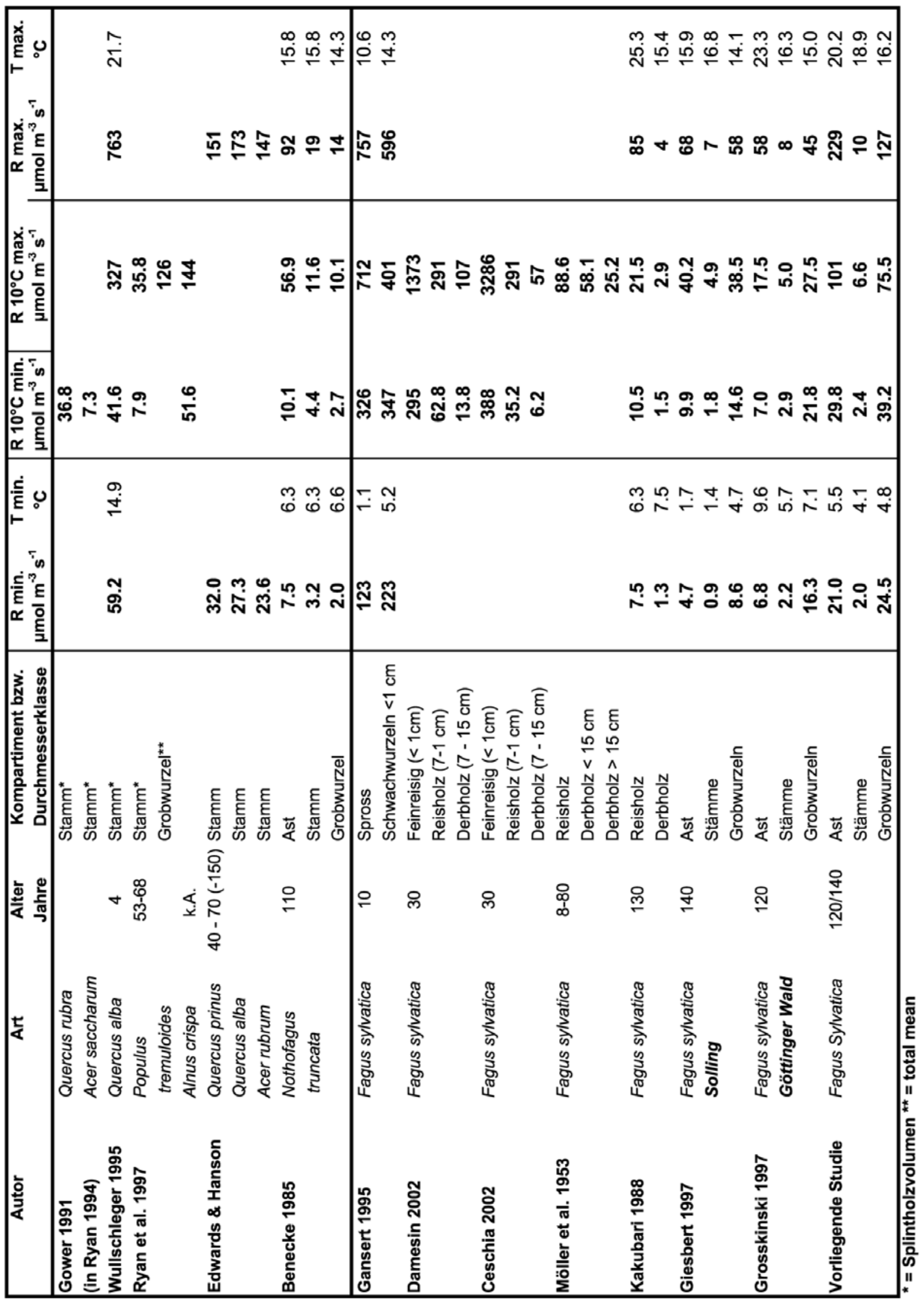


begründet sich in diesem Fall in dem höheren relativen Biomassezuwachs. Die Äste der hier untersuchten Altbuchen steigerten ihr Volumen um maximal $10 \%$, im Mittel waren es $4 \%$ bei Ästen und Grobwurzeln und $1 \%$ bei den Stämmen. Die 30-jährigen Buchen erreichten volumenbezogen relative Zuwachsraten von $6 \%$ bei den Stämmen und bis zu $66 \%$ beim Feinreisig (CESCHIA et al. 2002).

Der große Einfluss des Biomassezuwachses auf die respirative $\mathrm{CO}_{2}$-Abgabe zeigt sich schließlich in der zeitlichen Kopplung der saisonalen Verläufe von temperaturkorrigierter Atmungsrate und Durchmesserzuwachs, wie sie von EDWARDS \& HANSON (1996) und STOCKFORS \& LINDER (1998) beschrieben wird. Jedoch wurden häufig Phasenverschiebungen um Tage bis Wochen beobachtet (STOCKFORS \& LINDER 1998, CESCHIA 2001)

SPRUGEL \& BENECKE (1991) sehen die Ursache für diese Verzögerung darin, dass mit dem Durchmesserzuwachs der saisonale Verlauf von Zellteilung und -streckung erfasst wird, während der größte Massezuwachs und damit der größte Energiebedarf für den Aufbau von Biomasse erst anschließend bei der Ausdifferenzierung der Xylemelemente beim Aufbau der Zellwände und deren Verholzung zu erwarten ist.

Bei den Buchen von Solling und Göttinger Wald waren Zuwachs und temperaturnormierte Atmungsrate ebenfalls zeitlich gekoppelt. Eine Untersuchung dieses Zusammenhangs kann wegen der relativ geringen zeitlichen Auflösung nur tendenziell erfolgen. So sind die in Abb. 15 dargestellten Verläufe von Atmungs- und Zuwachs auf Ebene kurzer Zeiträume schon deshalb nur mit Vorsicht zu interpretieren, weil die Messwerte die Verläufe der beiden Prozesse jeweils für unterschiedliche Zeiträume widerspiegeln. Die Zuwachsraten entsprechen den Mittelwerten zwischen vorangegangener und aktueller Ablesung der Maßbänder und gelten für Zeiträume von 2 bis 6 Wochen. Die $10{ }^{\circ} \mathrm{C}$-Atmungsraten hingegen sind Mittelwerte aktueller Messkampagnen und umfassen meist 2 bis 4, maximal 14 Tage. Entgegen den Ergebnissen der vorgenannten Autoren verlaufen bei Ästen und Stämmen die temperaturnormierte Atmung und der Zuwachs weitgehend parallel. Lediglich in dem weniger steilen Rückgang der Atmungsraten im Spätsommer bei den Ästen im Göttinger Wald in beiden Untersuchungsjahren und bei dem zeitverzögerten Verlauf der Atmungsraten bei den Stämmen im Göttinger Wald im Spätsommer 1997 deutet sich an, dass die Atmungsraten über die Zeit des Durchmesserzuwachses hinaus auf hohem Niveau bleiben können.

Für die Untersuchung des zeitlichen und quantitativen Zusammenhangs ist die Atmungsrate bei ambienten Temperaturen besser geeignet, da sie im Gegensatz zur temperaturnormierten Rate nicht die potentiellen, sondern die aktuellen Kohlenstoffumsätze widerspiegelt. In Abb. 41 ist die nach Kap. 3.4.2 berechnete Wachstumsatmung für die den Zuwachsmessungen entsprechenden Zeiträume gemittelt und ihr Verlauf zusammen mit dem der Zuwachsraten dargestellt. Deutlicher als in Abb. 15 ist hier zu erkennen, dass Wachstum und Wachstumsatmung zeitgleich einsetzten und parallel anstiegen.

Dass die Verläufe von Wachstumsatmung und Wachstum nach dem gemeinsamen Anstieg weiniger einheitlich waren, zeigte sich besonders im Jahr 1997 bei den Ästen und Stämmen des Göttinger Waldes, deren Atmungsrate erst ca. einen Monat nach den Zuwachsrate ihr Maximum erreichte. Übereinstimmend ging die Wachstumsatmung bei allen untersuchten Kompartimenten an beiden Standorten zwischen Ende Juli und Mitte September langsamer zurück als die Wachstumsrate, so dass der für die einzelnen Messkampagnen ermittelte Wachstumskoeffizient in diesem Zeitraum ansteigen würde (siehe hierzu Kapitel 5.5.1).

Dieser Befund deckt sich mit der Hypothese, dass der Massezuwachs gegenüber dem Radialzuwachs, d.h. der Zellteilung und -streckung, verzögert ist und während der Ausdifferenzierung der 
Xylemelemente stattfindet. Die Atmungsraten bleiben daher über die Zeit des Durchmesserzuwachses hinaus erhöht und gehen erst mit abgeschlossener Ausdifferenzierung der Zellen zurück (SPRUGEL \& BENECKE 1991). ESCHRICH (1995) beschreibt den saisonalen Verlauf der Kambiumaktivität 120-jähriger Buchen und die Histologie des neu gebildeten Jahrrings. Er fand Ende Mai, drei Wochen nach einsetzender Teilungsaktivität, nur wenige verholzte Zellen. Während der folgenden Phase maximaler Teilungsaktivität stieg die Zahl der verholzten Zellen ebenso schnell wie die Gesamtzahl neu gebildeter Zellen. Ende Juli waren bei rückläufiger Zuwachsrate schon etwa $80 \%$ der Zellen verholzt. Daraus kann geschlossen werden, dass die Ausdifferenzierung der Xylemelemente zwar zeitverzögert einsetzt, in der Folgezeit aber mit etwas höherer Rate abläuft, so dass nach Abschluss des Durchmesserzuwachses nur noch wenige Zellen nicht ausdifferenziert sind. MORK (1960) und ZUMER (1969) fanden bei Picea abies, dass die Verholzung neugebildeter Zellen nach einem Zeitraum von 14 Tagen abgeschlossen war. Der Energiebedarf für die Ausdifferenzierung der nach dem Abschluss des Durchmesserzuwachses noch vitalen Zellen kann das Andauern eines höheren Atmungsniveaus, wie es in beiden Untersuchungsjahren bei Ästen und Stämmen im Solling und 1998 im Göttinger Wald beobachtet wird, erklären.

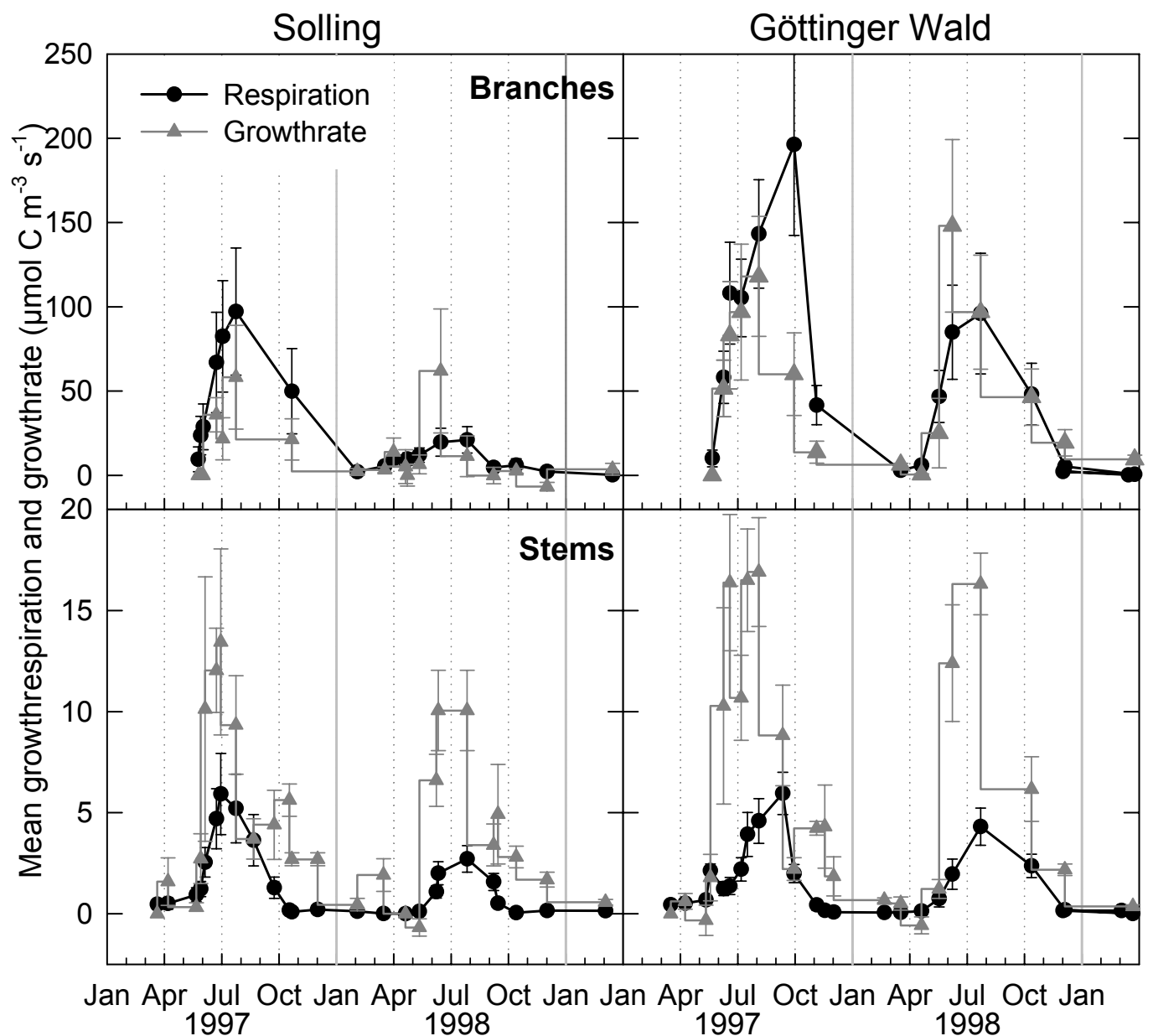

Abb. 41: Zweijahresgänge von Wachtumsatmungs- und Zuwachsrate von Ästen und Stämmen im Göttinger Wald und im Solling. Die Atmungsraten wurden mittels Temperaturfunktion und Tagesgängen der Lufttemperatur berechnet und über die den Zuwachsmessungen entsprechenden Zeiträume gemittelt. 
Dagegen deutet eine mehrwöchige Verzögerung, wie sie 1997 bei Ästen und Stämmen Göttinger Wald bestand, darauf hin, dass neben dem Energiebedarf für den Biomassezuwachs der Bedarf anderer Prozesse die Atmungsraten auf hohem Niveau hält.

Hohe temperaturnormierte Atmungsraten werden außerhalb der Wachstumsphase insbesondere zu Beginn der Vegetationsperiode kurz vor Beginn des Laubaustriebs (SPRUGEL 1990, GANSERT et al. 2002) und im Anschluss an die Phase des Durchmesserzuwachses beobachtet (MALKINA et al. 1985, LAVIGNE 1988, EDWARDS \& HANSON 1996).

SPRUGEL (1990) und GANSERT (2002) sehen die Ursache für den erhöhten Energiebedarf zu Beginn der Vegetationsperiode in der Mobilisation von Speicherstoffen im Rinden- und Holzparenchym für den Laubaustrieb und das Längenwachstum diesjähriger Sprossachsen. Nach Abschluss der Wachstumsaktivität muss der Energiebedarf für das Auffüllen der Speicher von Holz- und Rindenparenchym gedeckt werden. Sowohl das Be- und Entladen des Phloems, als auch die Synthese von Speicherstärke im Rinden- und Holzparenchym benötigen Energie aus der mitochondrialen Atmung.

Dass ein möglicher Zusammenhang zwischen den Verläufen der Atmungsrate und dem Energiebedarf für die am Auffüllen der Speicherparenchyme beteiligten energieverbrauchenden Prozesse insbesondere 1997 bei Ästen und Stämmen im Göttinger Wald hervortritt, kann mit den saisonalen Verläufen der Nettophotosynthese von 1997 begründet werden. Im August und September 1997 blieb die Photosynthesekapazität der Buchenblätter im Göttinger Wald auf hohem Niveau, so dass bei hohen Temperaturen, optimalen Strahlungsbedingungen und ausreichender Bodenwasserversorgung an diesem Standort im August und September $39 \%$ des jährlichen Kohlenstoffgewinns erzielt wurde. Im Solling war die Photosynthesekapazität im August 1997 bereits rückläufig, die Blätter der Sonnenkrone waren seneszent und der Kohlenstoffgewinn ging trotz günstiger Temperatur- und Strahlungsbedingungen stärker zurück (GRIES 2004, in Vorb.). Die für den verhältnismäßig späten Zeitpunkt in der Vegetationsperiode hohen Kohlenstoffgewinne im Göttinger Wald können durch ein hohes Substratangebot im Parenchym der Äste und Stämme die Synthese von Speicherpolysacchariden am Ende der Vegetationsperiode verstärkt und so auch die Atmungsaktivität gefördert haben. GANSERT \& SPRICK (1998) zeigen an 2-jährigen Buchenkeimlingen, dass die Konzentration nichtstruktureller Kohlenhydrate im Holzparenchym auch in der zweiten Hälfte der Vegetationsperiode und nach Abschluss des Sprosswachstums weiter ansteigen kann. Auch bei den Ästen von Altbuchen kann die Konzentration von Speicherkohlenhydraten zwischen Juni und Oktober weiter zunehmen (KÖRNER 2003).

Der Jahresgang der temperaturnormierten Grobwurzelatmung war zwar weniger ausgeprägt als der Jahresgang der Stämme und Äste, erreichte aber im Solling und 1998 im Göttinger Wald nahezu zeitgleich mit der Ast- und Stammatmung im Sommer Maximalwerte. Da im Göttinger Wald nur zwei und im Solling keine der insgesamt zwölf Grobwurzeln einen messbaren Radialzuwachs zeigten, kann insbesondere der Jahresgang der Grobwurzeln im Solling nicht mit der Wachstumsatmung erklärt werden. Auch im Göttinger Wald traten unabhängig vom Radialzuwachs der Wurzeln erhöhte Atmungsraten im Juli und August beider Untersuchungsjahre auf. Nach GÄUMANN (1935, zitiert in LARCHER 1994) beginnt das Auffüllen der Kohlenhydratspeicher bei der Buche in den Wurzeln und setzt sich über das Holzparenchym der Stämme bis in die Äste fort. Das erhöhte Niveau der Atmungsrate der Grobwurzeln in den Sommermonaten kann somit ebenfalls mit dem Umsatz und der Akkumulation nichtstruktureller Kohlenhydrate im Zusammenhang stehen. Dass der respirative Kohlenstoffbedarf für die Umsätze und Transportprozesse in den Speicherparenchymen auch in die Jahressumme der Wachstumsatmung eingehen und in 
verschiedenen Organen unterschiedlich hohe Anteile haben kann, muss auch bei der Interpretation der Wachstumskoeffizienten berücksichtigt werden.

Dass darüber hinaus noch andere Prozesse das Niveau der Atmungsrate beeinflussten, wird bei dem Vergleich der Atmungsraten, die bei der Punktmessung (Kap. 4.2.1, Abb. 20) im Herbst und Winter 1998 ermittelt wurden, deutlich. So lagen die volumenbezogenen Atmungsraten am 17.11.98 bei einer Temperatur von $1.5^{\circ} \mathrm{C}$ im Mittel bei $0.14 \mu \mathrm{mol} \mathrm{CO} \mathrm{Cm}^{-3} \mathrm{~s}^{-1}$. Am 28.12 .98 erreichten die Atmungsraten nur Werte von $0.07 \mu \mathrm{mol} \mathrm{CO}_{2} \mathrm{~m}^{-3} \mathrm{~s}^{-1}$, obwohl die Temperatur an der Stammoberfläche mit $8.4{ }^{\circ} \mathrm{C}$ deutlich über der des Novembertermins lag. Die Zeit zwischen den beiden Messkampagnen war von eine Phase kalter Witterung geprägt. Die Tagesmitteltemperatur lag an 28 von 41 Tagen unter $0{ }^{\circ} \mathrm{C}$ und erreichte ein Minimum von $-9.2{ }^{\circ} \mathrm{C}$.

Die nach kurzfristigem Einwirken niedriger Temperaturen einsetzende Hydrolyse von Speicherpolysacchariden zur Frostabhärtung der Parenchyme hat die Atmungsaktivität im November vermutlich auf erhöhtem Niveau gehalten, während die Stämme Ende Dezember im frostharten Zustand nach einer Phase ohne nennenswerte Witterungsänderung eine minimale Stoffwechselaktivität aufwiesen.

\subsection{Die räumliche und zeitliche Variabilität des Temperaturkoeffizienten $Q_{10}$}

Übereinstimmend mit den Ergebnissen von KAKUBARI (1988), CESCHIA (2001) und DAMESIN et al. (2002) waren die Atmungsraten der Äste, Stämme und Grobwurzeln im Tagesverlauf meist enger mit der oberflächennahen Xylemtemperatur korreliert als mit der Lufttemperatur. Die für die Bruttoatmung errechneten Temperaturkoeffizienten stimmen mit Werten um 2 bei den Stämmen und zwischen 2.4 und 2.7 bei Ästen und Grobwurzeln mit Literaturangaben für verschiedene Baumarten überein. Für die Stammatmung reichen die Angaben von 1.0 und 1.7 (LAVIGNE \& RYAN 1997, Populus tremuloides) bis 3.0 (LAVIGNE 1996, Pinus banksiana), wobei die Angaben wie bei den Buchenstämmen meist nahe einem $\mathrm{Q}_{10}$-Wert von 2 liegen (eine Übersicht geben DAMESIN et al. 2002).

Auch die Angaben für die Buche variieren in diesem Bereich. GANSERT (1995) ermittelte in dreitägigen Messkampagnen für die Temperaturbeziehung der Dunkelatmung von Sprossachsen 10-jähriger Buchen ( $\mathrm{D}=3.5$ bis $4.5 \mathrm{~mm}$ ) Temperaturkoeffizienten von 2.3. DAMESIN et al. (2002) geben für die Stammatmung in $1.3 \mathrm{~m}$ Höhe 30-jähriger Buchen $\mathrm{Q}_{10}$-Werte von 1.8 und eine Spanne von 2.0 bis 3.9 für die Astatmung an. Die Atmung der Stämme wurde dabei mit der $2 \mathrm{~mm}$ unter der Oberfläche und in nördlicher Exposition gemessenen Stammtemperatur in Beziehung gesetzt. Bei den Ästen war die Lufttemperatur in den abgedeckten Küvetten die Eingangsgröße. CESCHIA et al. (2002) maßen die Atmung der Buchen des gleichen Standortes im Folgejahr. Sie erhielten für die Stammatmung $\mathrm{Q}_{10}$-Werte, die in $1.3 \mathrm{~m}$ Stammhöhe zwischen 1.18 bis 1.44 und um 2.04 an der Kronenbasis und damit deutlich unter denen lagen, die DAMESIN et al. (2002) für das Vorjahr nennen. Anders als bei den hier für die Altbuchen gewonnenen Ergebnissen deutet sich eine ausgeprägte interannuelle Variabilität des Temperaturkoeffizienten an. Es scheint jedoch fraglich, ob diese Variabilität auf eine veränderte Reaktionsnorm der Atmung gegenüber der Temperatur zurückzuführen ist. Wahrscheinlicher scheint es, dass die Differenz zwischen den $\mathrm{Q}_{10}$-Werten auf unterschiedliche Mess- und Auswertungsverfahren zurückzuführen ist. Während DAMESIN et al. (2002) die Stammatmung an jeder Küvette manuell erfasst und die Messungen meist auf die Tagesstunden beschränkt sind, wird die $\mathrm{CO}_{2}$-Abgabe 1998 vollautomatisiert über $24 \mathrm{~h}$ aufgezeichnet (CESCHIA 2001). Zwar war die Rindenphotosynthese in den abgedeckten Küvetten in beiden 
Jahren unterbunden, jedoch kann der Einfluss des $\mathrm{CO}_{2}$-Transports bei Berücksichtigung verschiedener tageszeitlicher Abschnitte die Ermittlung des $\mathrm{Q}_{10}$-Wertes in unterschiedlicher Weise beeinflussen (vgl. Kap. 5.1.4).

CESCHIA (2001) gibt schließlich für die Astatmung mit 1.8 deutlich geringere $\mathrm{Q}_{10}$-Werte an als DAMESIN et al. (2002), obwohl beiden Untersuchungen anscheinend dieselben Daten zugrunde lagen (identischer Standort, Zeitraum und Probendurchmesser), so dass wahrscheinlich unterschiedliche Auswertungsverfahren zur Variation der $\mathrm{Q}_{10}$-Werte führen. Da bei keiner der beiden Untersuchungen eine Zeitverzögerung der Atmungsrate gegenüber der Temperatur in die Berechnung der Temperaturfunktion einging (CESCHIA 2001), bleibt die Ursache der interannuellen Variabilität der $\mathrm{Q}_{10}$-Werte unklar, eine Änderung der Reaktionsnorm der Atmung ist sicherlich nicht abzuleiten.

Bei quantitativer Übereinstimmung der $\mathrm{Q}_{10}$-Werte der vorliegenden Untersuchung mit den Angaben von DAMESIN et al.(2002), stimmen auch die Differenzen zwischen den Q $_{10}$-Werten der Stämme einerseits und der Äste und Grobwurzeln andererseits mit den Ergebnissen dieser Autoren überein. CESCHIA (2001) findet zunehmende $Q_{10}$-Werte mit zunehmender Höhe der Messstelle bzw. abnehmendem Durchmesser. Die Differenz von ca. 0.5 zwischen den $\mathrm{Q}_{10}$-Werten von Stamm- und Astatmung stimmt ebenfalls mit den Ergebnissen der vorliegenden Untersuchung überein.

Die verschiedenen $\mathrm{Q}_{10}$-Werte von Stamm-, Ast- und Grobwurzelatmung sind nicht zwingend auf eine unterschiedliche Temperatursensitivität des Atmungsstoffwechsels der verschiedenen Organe zurückzuführen. Sie lassen sich mit der steigenden Wärmekapazität der Sprossachsen mit zunehmendem Durchmesser erklären. Bei den dünneren Ästen erfährt das atmende Gewebe über den gesamten Querschnitt eine ausgeprägte Temperaturänderung, aus der eine entsprechende Änderung der $\mathrm{CO}_{2}$-Produktion und -abgabe resultiert. Im Stamm ist die Temperaturamplitude und mit ihr auch die $\mathrm{CO}_{2}$-Produktion mit zunehmender Entfernung von der Oberfläche deutlich gedämpft und im zeitlichen Verlauf verzögert (Abb. 8). Wird die $\mathrm{CO}_{2}$-Abgabe der Stämme gegen die oberflächennah gemessenen Temperatur aufgetragen, variiert sie weniger stark als die der Äste und der $\mathrm{Q}_{10}$-Wert ist entsprechend niedriger.

Dass die beobachtete Differenz zwischen den $\mathrm{Q}_{10}$-Werten dünner und dicker Sprossachsen auch quantitativ mit der höheren Wärmekapazität der Stämme erklärt werden kann, zeigt eine modellhafte Berechnung der Atmungsraten eines Stammes mit $40 \mathrm{~cm}$ und eines Astes mit $4 \mathrm{~cm} \mathrm{Holz-}$ durchmesser, bei der davon ausgegangen wird, dass:

- $\quad$ sich der diurnale Temperaturverlauf mit einer Sinusfunktion beschreiben lässt.

- die Temperaturamplitude von dem maximalen Wert in der Rinde bis in das Zentrum des Stammes linear auf null zurückgeht.

- der Temperaturrückgang im Querschnitt des Astes dem des Stammes entspricht, so dass im Zentrum des Astes noch eine ausgeprägte Temperaturänderung auftritt.

- die zeitlichen Verläufe der Temperatur mit zunehmender Tiefe um 30 Minuten pro Zentimeter verzögert sind (Abb. 8) und

- die Atmungsraten von Rinde, äußerem Splintholz (20 mm), innerem Splintholz (100 mm) und Kernholz zueinander in einem Verhältnis stehen, das den TTC-Umsätzen im radialen Verlauf entspricht (6.6:2.4:1.5:1, Abb. 25)

Mit diesen Annahmen wird der Tagesgang der Temperaturen im Stamm für 41 Hohlzylinder $(1 \times$ Rinde , $40 \times$ Xylem) mit einer Wandstärke von jeweils $5 \mathrm{~mm}$ und im Astholz für 9 Hohlzylinder mit 2 bzw. 5 mm Wandstärke von Rinde bzw. Xylem und daraus die $\mathrm{CO}_{2}$-Produktion dieses Hohl- 
zylinders im Tagesverlauf berechnet. Wird diese $\mathrm{CO}_{2}$-Abgabe für jeden Zeitpunkt des Tages über den gesamten Querschnitt aufsummiert und gegen die Rindentemperatur aufgetragen, lässt sich der $\mathrm{Q}_{10}$-Wert der gesamten Stamm- bzw. Astatmung ermitteln. Um für die Stammatmung in der Summe einen $\mathrm{Q}_{10}$-Wert von $2 \mathrm{zu}$ erhalten, muss für die Berechnung der $\mathrm{CO}_{2}$-Produktion jedes Hohlzylinders ein einheitlicher $\mathrm{Q}_{10}$-Wert von 2.39 angenommen werden. Wird dieser einheitliche $\mathrm{Q}_{10}$-Wert auch für die verschiedenen Hohlzylinder der Äste angenommen, ergibt sich für die Astatmung ein $\mathrm{Q}_{10}$-Wert von 2.41. Die Differenz zwischen den so berechneten $\mathrm{Q}_{10}$-Werten stimmt gut mit dem Unterschied der gemessenen Werte von Ästen und Stämmen im Göttinger Wald überein.

Voraussetzung dafür, dass die Unterschiede des Temperatureinflusses in verschiedenen Holztiefen auch die $\mathrm{CO}_{2}$-Abgabe und den $\mathrm{Q}_{10}$-Wert beeinflussen, ist, dass auch das Gewebe in größerer Entfernung von der Rindenoberfläche vital und an der $\mathrm{CO}_{2}$-Produktion beteiligt ist. Unterschiedliche Verhältnisse der Atmungsaktivität zwischen Rinde und Holz und innerhalb des Holzes mit zunehmender Tiefe können die Höhe der $\mathrm{Q}_{10}$-Werte wesentlich beeinflussen. Ist die $\mathrm{CO}_{2}$-Produktion auf die Rinde und einen dünnen Bereich des Xylems konzentriert (STOCKFORS \& LINDER 1998), ergibt sich bei einer entsprechenden Modellrechnung kein Unterschied zwischen den $\mathrm{Q}_{10^{-}}$ Werten von dünnen und dickeren Sprossachsen.

Verschiedene Autoren fanden auch deutliche saisonale Verläufe des $\mathrm{Q}_{10}$-Wertes bei verschiedenen Baum- und Ökosystemkompartimenten. So sanken mit zunehmender Tagesmitteltemperatur die $\mathrm{Q}_{10}$-Werte der auf Ebene des Tagesganges ermittelten Temperaturbeziehungen im saisonalen Verlauf bei der Bodenatmung (LLOYD \& TAYLOR 1994) und bei der Dunkelatmung der oberirdischen Organe von Chameacyperis obtusa (HAGIHARA \& HOZUMI 1991). Für die Stammatmung von Pinus banksiana (LAVIGNE 1996) und Picea abies (STOCKFORS \& LINDER 1998) wurden ebenfalls deutliche saisonale Verläufe der $\mathrm{Q}_{10}$-Werte beschrieben. Auch die $\mathrm{Q}_{10}$-Werte der Feinwurzelatmung der Altbuchen in Solling und Göttinger Wald zeigten einen deutlichen saisonalen Verlauf. So fand GRIES (2004, in Vorb.) für eine 4-jährige Messreihe mit steigender Temperatur signifikant abnehmende $\mathrm{Q}_{10}$-Werte.

Die abnehmende Temperatursensitivität bei höheren Temperaturen kann als Akklimatisation von Pflanzen interpretiert werden, die Habitate mit ausgeprägten saisonalen Temperaturschwankungen besiedeln. Der $\mathrm{Q}_{10}$-Wert ist bei niedrigen Temperaturen erhöht, um eine ausreichende Energieversorgung des Gewebes zu gewährleisten und bei hohen Temperaturen erniedrigt, um einen überhöhten Kohlenstoffumsatz zu vermeiden (LARCHER 1994). Als mögliche Mechanismen nennt LARCHER (1994) die Erhöhung des Substratangebots z. B. im Rahmen der Zuckeranreicherung im Gewebe bei Frost, die Bildung von Isoenzymen mit anderer Temperaturabhängigkeit und Veränderungen der chemischen und/oder strukturellen Eigenschaften von Proteinen und Lipiden der Biomembranen.

Bei STOCKFORS \& LINDER (1998) änderte sich der Q $_{10}$-Wert der Stammatmung weniger mit der Temperatur, sondern verlief vielmehr parallel mit dem Jahresgang der Phasenverschiebung zwischen Atmung und Temperatur in den Tagesgängen und mit dem Jahresgang der $\mathrm{CO}_{2}$-Konzentration im Stamminneren, die EKLUND (1990) beschreibt. Die Ursache für die erhöhte $\mathrm{CO}_{2}$ Konzentration im Stamm, für die stärkere Phasenverschiebung und die geringeren $\mathrm{Q}_{10}$-Werte sehen die Autoren in dem erhöhten Diffusionswiderstand des Kambiums, das in der Zeit maximaler Wachstumsaktivität mehrschichtig ist und gegenüber dem einschichtigen Ruhekambium einen höheren Diffusionswiderstand für $\mathrm{CO}_{2}$ aufweist. 
GRIES (2004, in Vorb.) weist darauf hin, dass der Verlauf der Temperaturfunktion der Atmung schon auf der Zeitskala von Stunden und Tagen nicht allein aus der Temperaturabhängigkeit des Atmungsstoffwechsels selbst resultiert. Die Temperaturänderungen wirken auch auf verschiedene energieverbrauchende Stoffwechselprozesse. Diese regulieren über den ATP-Verbrauch die Geschwindigkeit der Atmungsreaktionen (Adenylatregulation verschiedener Reaktionsschritte der Glykolyse, insbesondere der Phosphofructokinase-Reaktion, des Tricarbonsäurezyklus und der oxidativen Phosphorylierung (STRYER 1990)). Im saisonalen Verlauf sind die verschiedenen ATP-verbrauchenden Stoffwechselprozesse in unterschiedlichem Maß an der gesamten Stoffwechselaktivität und dem damit verbundenem Energiebedarf beteiligt. Die Temperatursensitivität dieser Prozesse und ihre wechselnden Anteile am Gesamtenergiebedarf wirken schließlich auf die Atmungsaktivität und beeinflussen die apparente Temperaturabhängigkeit der $\mathrm{CO}_{2}$-Abgabe. Die Atmungsrate zeigt nur dann einen exponentiellen Anstieg mit der Temperatur, wenn auch der Energiebedarf exponentiell ansteigt.

Die $\mathrm{Q}_{10}$-Werte der Holzatmung der hier untersuchten Buchen variierten über einen weiten Bereich, wobei die Grobwurzeln beider Standorte die am wenigsten einheitlichen Verläufe und die des Solling die weiteste Spanne mit Werten von 1.92 bis 3.54 aufwiesen. Saisonale Verläufe der $\mathrm{Q}_{10}$-Werte waren nicht zu erkennen. Dies steht im Gegensatz zu den Ergebnissen der o. g. Autoren, stimmt aber mit den Befunden von HAVRANEK (1981), EDWARDS \& HANSON (1996) und DAMESIN et al. (2002) überein, die ebenfalls eine hohe Variabilität der $\mathrm{Q}_{10}$-Werte, jedoch keinen saisonalen Verlauf beobachten.

Die beobachtete hohe Variabilität der $\mathrm{Q}_{10}$-Werte resultiert nicht aus einer geänderten Temperatursensitivität des Atmungsstoffwechsels selbst, sondern aus einer temperaturbedingten Änderung des ATP-Bedarfs und der daraus resultierenden Verschiebung der Adenylatbegrenzung. Die verholzten Organe der Buchen zeigen eine bedarfsgemäße Änderung der Atmungskapazität, d.h. der temperaturnormierten Atmung. Der apparente $\mathrm{Q}_{10}$-Wert kann dann variieren, wenn sich die physiologische Aktivität des Parenchyms und damit der ATP-Bedarf unabhängig von der mittleren Temperaturen innerhalb von Tagen ändert. Beispielsweise kann ein Anstieg der physiologischen Aktivität bei schwach steigender Temperatur während einer Messkampagne zur Berechnung eines hohen $\mathrm{Q}_{10^{-}}$ Wertes führen, ohne dass daraus eine veränderte Reaktionsnorm gegenüber Temperaturänderungen abzuleiten ist. Eine Anpassung des $\mathrm{Q}_{10}$-Wertes an den saisonalen Temperaturverlauf im Sinne einer Akklimatisation zur Verminderung des respirativen C-Bedarfs kann aus den vorliegenden Ergebnissen nicht abgeleitet werden.

Die Kapazität der Atmung und ihre Temperatursensitivität, die in C-Bilanzmodelle zur Ermittlung des respirativen C-Bedarfs von Waldökosystemen eingehen, werden also wesentlich von der Variabilität verschiedener energieverbrauchender Stoffwechselprozesse und deren Temperaturabhängigkeit beeinflusst. Daher muss bei der Verwendung dieser Modellparameter zur prognostizierenden Modellierung in der Annahme wechselnder Klimaszenarien berücksichtigt werden, dass die sich ändernden klimatischen Bedingungen auch das Substratangebot und die energieverbrauchenden Prozesse beeinflussen, die dann ihrerseits eine Änderungen der Parameter temperaturnormierte Atmung und $\mathrm{Q}_{10}$-Wert bewirken können. 


\subsection{Die räumliche Variabilität der Atmungsrate}

Wird die Atmung verholzter Organe von Bäumen mit Küvettensystemen gemessen, kann mit vertretbarem Aufwand nur ein geringer Teil der gesamten Biomasse von Ästen, Stämmen und Grobwurzeln eines Baumes oder gar eines Waldbestandes untersucht werden. So machte das an den beiden Standorten in Küvetten eingeschlossene Gesamtvolumen des Holzes in dieser Studie 4.5 bzw. 4.9 \% des Volumens eines bestandesrepräsentativen Baumes und 0.18 bzw. 0.16 \% des Holzvorrates pro Hektar von Solling bzw. Göttinger Wald aus. Sollen die Ergebnisse der Küvettenmessungen als Teil einer Kohlenstoffbilanz auf Bestandesebene hochgerechnet werden, muss zunächst die Frage beantwortet werde, wie gut die Messwerte auf die übrigen Anteile der verholzten Biomasse übertragen werden können und wie groß der Bedarf an detaillierten Kenntnissen über die räumliche Variabilität der Atmungsraten ist.

Dass die Atmungsraten der verholzten Organe von Bäumen zwischen verschiedenen Individuen und verschiedenen Organen der Bäume stark variieren, wird in verschiedenen Studien dokumentiert. Die Spanne der Raten hängt von der gewählten Bezugsgröße (Oberfläche, Volumen, Stickstoffgehalt) ab, ist aber auch dann noch groß, wenn die $\mathrm{CO}_{2}$-Abgabe auf die Größe bezogen wird, bei der sich die geringste Variabilität ergibt. Zudem ergeben sich abhängig davon, ob die Atmungsraten verschiedener Individuen oder die Raten verschiedener Organe eines Baumes miteinander verglichen werden, zum Teil unterschiedliche Verhältnisse.

Zum Bespiel variierten die temperaturnormierten, oberflächenbezogenen Atmungsraten der Stämme von Abies amabilis während der Vegetationsperiode um den Faktor 20. Auch die Astatmung dieses Bestandes unterschied sich um das 16fache. Sie lag dabei auf einem ähnlichen Niveau wie die Raten der Stämme (SPRUGEL 1990). Bei NEGISI (1974) variierte die auf die Oberfläche bezogene Atmung verschiedener Stämme um den Faktor 3, bei Bezug auf das Volumen war die Variabilität um ein Vielfaches höher.

Auch bei der Buche weichen die Atmungsraten verschiedener Messstellen stark voneinander ab. VALENTINI et al. (1996) geben für die Stammatmung von Altbuchen mit einem Durchmesser um $40 \mathrm{~cm}$ eine Spanne von 1.3 bis $8.3 \mu \mathrm{mol} \mathrm{CO}_{2} \mathrm{~m}^{-2} \mathrm{~s}^{-1}$ an. DAMESIN et al. (2002) maßen an den Stämmen dominanter Buchen 4fach höhere oberflächenbezogene Raten der Wachstumsatmung als bei unterdrückten Bäumen. Auf das Volumen bezogen unterschied sich die Wachstums- und Erhaltungsatmung derselben Stämme nicht. Auch die oberflächenbezogenen Atmungsraten von Stämmen und Ästen eines einzelnen Baumes variierten maximal um das 4 fache. Im Gegensatz dazu sind die volumenbezogenen Atmungsraten dünner Äste um ein Vielfaches höher als die der Stämme. CESCHIA et al. (2002) beschreiben Unterschiede zwischen den temperaturnormierten, auf das Volumen bezogenen Atmungsraten von Buchenästen und -stämmen um mehr als das 60 fache.

Wie SPRUGEL et al. (1995) hervorheben, ist die Variabilität auch dann hoch, wenn die Atmung auf eine einheitliche Temperatur umgerechnet wird und die nach Abschluss der Wachstumsphase gemessenen Raten der Erhaltungsatmung verglichen werden, also weder von unterschiedlichen Temperaturen noch von variierenden Wachstumsaktivitäten beeinflusst werden.

Um die Ergebnisse der verschiedenen Kompartimente unabhängig vom Biomassezuwachs vergleichen zu können, wurde im Rahmen der vorliegenden Arbeit nur die Variabilität der Erhaltungsatmung untersucht. Die Variation der Wachstumsatmung wird bei der Untersuchung des Wachstumskoeffizienten $r_{G}$ behandelt 
Die räumliche Variabilität der Atmungsrate ändert sich qualitativ und quantitativ mit der jeweiligen Größe, auf die die $\mathrm{CO}_{2}$-Abgabe bezogen wird. Für die Hochrechnung der Atmungsrate auf Bestandesebene muss die Bezugsgröße im Wesentlichen folgende Kriterien erfüllen: Einerseits sollte sie mit geringem Aufwand für den einzelnen Baum oder den gesamten Bestand aus biometrischen Daten wie z. B. BHD und Baumhöhe sowie allometrischen Beziehungen ermittelt werden können. Andererseits sollen die auf diese Größe bezogenen Atmungsraten eine geringe Variabilität zwischen verschiedenen Messstellen aufweisen und/oder es sollte möglich sein, diese Variabilität anhand der Abhängigkeit der spezifischen Atmungsraten z. B. vom Durchmesser der verholzten Achsen zu beschreiben.

Da aus art- und oft auch standortspezifischen allometrischen Beziehungen für viele Untersuchungsflächen die Werte für die Oberfläche, das Gesamt- oder Splintholzvolumen bzw. -trockengewicht einzelner Bäume oder ganze Bestände verfügbar sind, werden die Atmungsraten im Allgemeinen auf diese Größen bezogen und über die entsprechenden Bestandeswerte extrapoliert.

Die Untersuchung der Abhängigkeit der oberflächen- und volumenspezifischen Atmungsraten vom Durchmesser der Achse dient dann einerseits der Beurteilung, wie gut die Bezugsgrößen für die Extrapolation der Atmungsraten auf Bestandesebene geeignet sind und ob eine Differenzierung nach Durchmessern bei der Hochrechnung erforderlich ist. Andererseits werden aus den Durchmesserbeziehungen Rückschlüsse auf mögliche Ursachen für die räumliche Variabilität gezogen. Bevor die Frage behandelt wird, welche Bezugsgrößen für die Extrapolation der Atmungsrate bei den hier untersuchten Buchenbestände geeignet sind, sollen in diesem Kapitel zunächst mögliche Ursachen für die räumliche Variabilität diskutiert werden.

\subsubsection{Die Durchmesserabhängigkeit der Holzatmungsraten}

Die Atmungsrate 2- bis 8-jähriger Stämme von Pinus densiflora an Messstellen unterschiedlichen Durchmessers ist nahezu konstant, wenn sie auf die Oberfläche bezogen wird. Die volumenbezogene Atmungsrate fällt aufgrund des zunehmenden Volumen/Oberflächen-Verhältnisses hyperbolisch mit zunehmendem Durchmesser ab (NEGISI 1974). Dagegen nimmt nach KINERSON (1975) die oberflächenbezogene Atmungsrate von Pinus taeda hyperbolisch mit steigendem Durchmesser ab. Der daraus abzuleitende ebenfalls hyperbolische Rückgang der volumenbezogenen Atmungsraten weist einen deutlich steileren Verlauf auf. Gemäß der von KINERSON (1975) genannten Beziehung ist die Atmungsrate bei Stammabschnitten mit $15 \mathrm{~cm}$ Durchmesser gegenüber solchen Stämmen mit $30 \mathrm{~cm}$ Durchmesser etwa dreifach höher, wenn sie auf die Oberfläche bezogen wird. Bei Bezug auf das Volumen ergäbe sich ein Unterschied um das 10 fache.

Die Ursache für die Variabilität der temperaturnormierten Atmung wird vor allem in der unterschiedlichen Anzahl lebender Zellen im Phloem, Kambium und Xylem gesehen. So findet HAVRANEK (1981) bei Pinus cembra während der Vegetationsperiode eine enge lineare Beziehung zwischen der Zahl der nicht verholzten Zellen des neu gebildeten Jahrringes und der $\mathrm{CO}_{2}$-Abgabe.

Die von NEGISI (1974) gefundene geringe Variabilität der oberflächenbezogenen Atmungsrate ist nach LARCHER (1994) dadurch zu erklären, dass der wesentliche Anteil des Lebendzellvolumens und damit der Atmungsaktivität der Erhaltungsatmung von Phloem, Kambium und dem äußeren Bereich des Xylems zuzuordnen ist. Die Ergebnisse von GOODWIN \& GODDARD (1940), die den radialen Verlauf der Atmungsaktivität der Gewebe in Stämmen von Acer rubrum und Fraxinus nigra untersuchten, scheinen diese Schlussfolgerung zu bestätigen. Sie fanden die maximalen 
Atmungsraten im äußeren Jahrring, etwas geringere Raten im Phloem und Kambium. Das weiter innen liegende Splintholz wies nur noch einen Bruchteil, das Kernholz keine Atmungsaktivität auf. Nach LARCHER (1994) ist darin die über weite Durchmesserbereiche weitgehend konstante oberflächenbezogne Atmungsrate begründet.

Entsprechende Interpretationen führen dazu, dass die $\mathrm{CO}_{2}$-Abgabe bis in die 90er Jahre des letzten Jahrhunderts meist auf die Oberfläche der Stamm- und Astsegmente bezogen wurde (NEGISI 1972, 1974, 1975, 1978, BENECKE 1985, LAVIGNE 1987, 1988). KAKUBARI (1988, 1989) spricht bei seinen Untersuchungen zur Holzatmung von Fagus sylvatica und Quercus acutissima bezeichnenderweise von „bark respiration“. SPRUGEL (1990) nimmt an, dass GOODWIN \& GODDARD (1940) nicht die Erhaltungs- sondern die Wachstumsatmung gemessen haben könnten und die hohen Atmungsraten daher auf die äußeren Schichten des Sprosses konzentriert sind. STOCKFORS \& LINDER (1998) zeigen für Picea abies, dass das Phloem mit 39\% einen weitaus höheren Lebendzellanteil hat als das Xylem und dass $80 \%$ aller lebenden Zellen des Xylems in den äußeren $4 \mathrm{~mm}$ konzentriert sind. Sie sehen für diese Baumart die Befunde von GOODWIN \& GODDARD (1940) bestätigt.

RYAN (1990) fand ebenfalls eine lineare Beziehung zwischen Atmungsrate und Lebendzellanteil des Parenchyms, zeigte aber, dass die lebenden Zellen gleichmäßig über die gesamte Breite des Splintholzes verteilt sind. Anders als bei STOCKFORS \& LINDER (1998) waren die Atmungsraten von Pinus contorta und Pinus engelmannii während der zuwachsfreien Phase enger mit dem Splintholzvolumen als mit der Oberfläche korreliert. Entsprechendes ergab sich bei verschiedenen Koniferen, so bei Abies amabilis (SPRUGEL 1990), Pinus ponderosa (CAREY et al. 1997), und einigen Laubbaumarten, wie Quercus alba und Q. prinus (EDWARDS \& HANSON 1996) oder Populus tremuloides (LAVIGNE \& RYAN 1997). Diese Autoren bezogen die Atmungsraten auf das Splintholzvolumen.

Bei der Buche wurden unterschiedliche Ansätze gewählt. Während MÖLLER et al. (1954), die Atmungsraten auf das Gesamtholzvolumen bezogen und die Abnahme der Atmungsrate mit steigendem Durchmesser mit unterschiedlichen hyperbolische Funktionen für Äste und Stämme beschrieben, verwendeten KAKUBARI (1988) und VALENTINI et al. (1996) die Oberfläche als Bezugsgröße. Beim Vergleich der Ergebnisse von MÖLLER et al. (1954) mit anderen Untersuchungen muss jedoch berücksichtigt werden, dass diese Autoren die Atmungsraten während der Sommermonate maßen und ihre Werte direkt von der Wachstumsaktivität und -atmung beeinflusst waren. VALENTINI et al. (1996) fanden eine exponentielle Zunahme der oberflächenbezogenen Stammatmung mit zunehmendem Durchmesser.

Die Ergebnisse der Dauermessungen der vorliegenden Studie unterschieden sich abhängig davon, ob die Atmungsraten einzelner Kompartimente mit dem Durchmesser in Beziehung gesetzt oder ob die Werte aller Kompartimente zusammengefasst werden. Für jedes Kompartiment ergab sich eine hohe Variabilität, wobei die relativen Standardabweichungen der oberflächenbezogenen Atmungsraten mindestens ebenso hoch waren, wie die der volumenbezogenen Raten (Abb. 18). Eine Durchmesserabhängigkeit bestand für die oberflächenbezogenen Atmungsraten der Stämme, die linear mit dem Durchmesser anstiegen. Außerdem gingen die volumenbezogenen Atmungsraten der Grobwurzeln mit steigendem Wurzeldurchmesser zurück und ließen sich mit einer hyperbolischen Funktion beschreiben, wie sie auch von MÖLLER et al. (1954) für die Astatmung angegeben wird. Wurden die Messstellen aller Kompartimente gemeinsam betrachtet, fiel auf, dass die oberflächenbezogenen Atmungsraten zwar eine große Variabilität aufwiesen, jedoch die gleiche Größenordnung hatten und keine Durchmesserabhängigkeit zeigen. Die volumenbezogenen Raten dagegen 
zeichneten sich durch die weit höheren Werte der Ast- und Grobwurzelatmung gegenüber der Stammatmung aus. Eine Funktion mit hyperbolischen Verlauf kann diesen generellen Unterschied zwischen den Atmungsaktivitäten der verschiedenen Kompartimente in erster Näherung als Funktion des Durchmessers beschreiben (Abb. 43).

Diese Befunde stimmen gut mit den Ergebnissen von DAMESIN et al. (2002) und CESCHIA et al. (2002) aus Untersuchungen an 30-jährigen Buchen überein. DAMESIN et al. (2002) fanden für die volumenbezogene Erhaltungsatmung von Stämmen ebenfalls keine Änderung mit dem Durchmesser, aber einen steilen Rückgang der Atmungsraten innerhalb eines Baumes mit zunehmendem Durchmesser der verholzten Organe. Dabei war die Atmungsaktivität eines $0.25 \mathrm{~cm}$ dicken Astes im Dezember 19-mal höher als die des Stammes mit 40fachem Durchmesser in $0.5 \mathrm{~m}$ Höhe. CESCHIA (2001) fasst die Daten von Messungen an verschiedenen Standorten zusammen und erhält wie MÖLLER et al. (1954), NEGISI (1974) und CAREY et al. (1996) eine Durchmesserabhängigkeit mit hyperbolischen Verlauf.

Die Ergebnisse der Dauermessungen der vorliegenden Untersuchung, insbesondere die geringere Variabilität der oberflächenbezogenen Atmungsraten zwischen den Kompartimenten, lassen entsprechend der Auffassung von LARCHER (1994) und KINERSON (1975) die Schlussfolgerung $\mathrm{zu}$, dass die wesentliche $\mathrm{CO}_{2}$-Menge in den aktiven Geweben von Phloem, Kambium und den äußeren Jahrringen des Xylems, also nahe der Oberfläche gebildet wird, während das weiter innen liegende Holzparenchym verkernt ist und kein $\mathrm{CO}_{2}$ mehr bildet. Entsprechend ist über einen weiten Durchmesserbereich eine konstante oberflächenspezifische Atmungsrate zu erwarten. Darüber hinaus kann dieses einfache Modell aufgrund des mit dem Durchmesser zunehmenden Volumen/Oberflächen-Verhältnisses auch die hohen volumenbezogenen Atmungsraten der Äste und Grobwurzeln gegenüber denen der Stämme erklären. Wird den Ästen und Grobwurzeln die mittlere $10{ }^{\circ} \mathrm{C}$-Erhaltungsatmungsrate der Stämme zugeordnet und mit der Oberfläche und dem Volumen aller Messstellen in eine volumenbezogene Atmungsrate umgerechnet, ergibt sich für die so berechneten Raten von Ästen und Grobwurzeln im Mittel ein ähnliches Verhältnis zu den Raten der Stämme wie bei den gemessenen Werten (Abb. 42 a).
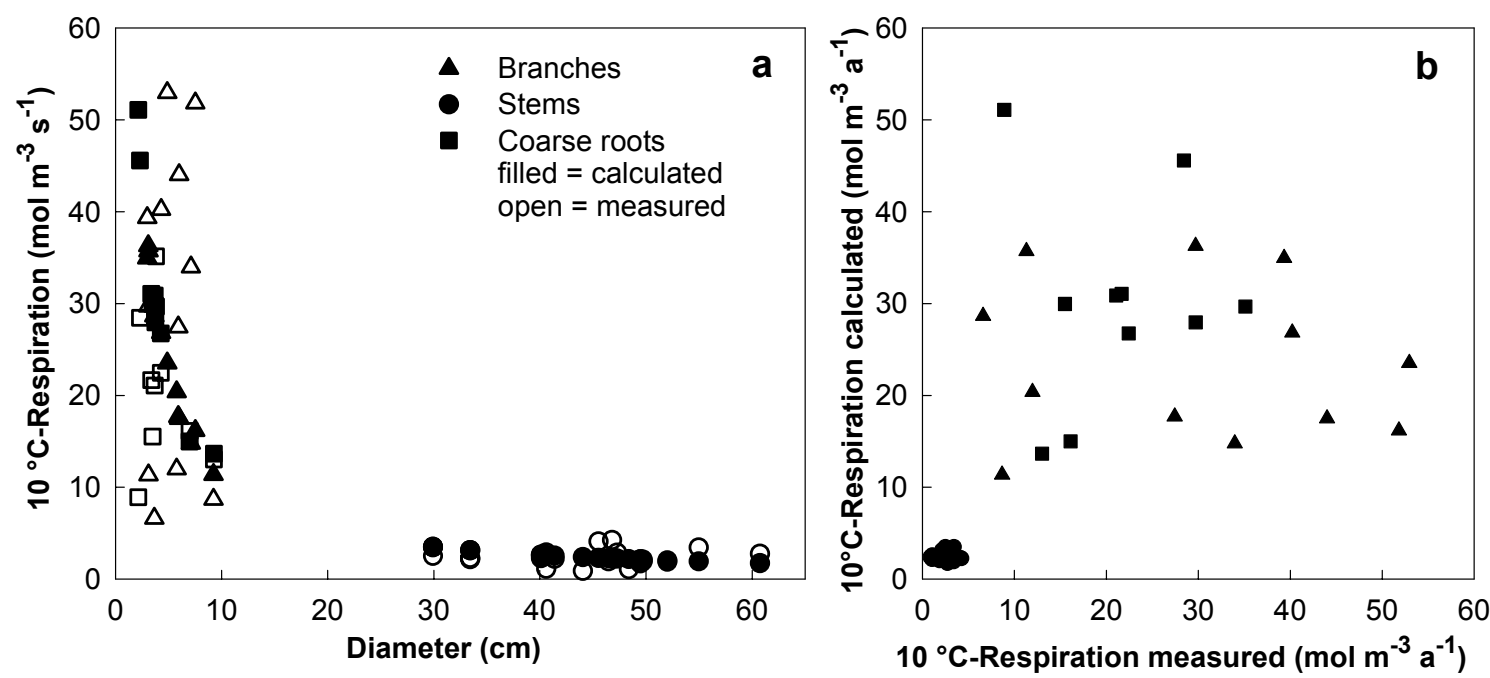

Abb. 42: a) Durchmesserabhängigkeit der gemessenen und berechneten volumenbezogenen Atmungsraten aller Kompartimente. Die berechneten Werte ergeben sich aus der mittleren oberflächenbezogenen Atmungsrate der Stämme, die mit den Oberflächen und Volumina der einzelnen Messstellen in volumenbezogene Raten umgerechnet wurden. b) Auftragung der berechneten gegen die gemessenen Atmungsraten. 
Die Variabilität der volumenbezogenen Atmungsrate innerhalb der einzelnen Kompartimente wird mit diesem Ansatz jedoch nicht wiedergegeben (Abb. 43b). Darüber hinaus widerspricht der Annahme, die oberflächenbezogene Atmungsrate sei über einen weiten Durchmesserbereich konstant, der Befund, dass die Stammatmungsraten der Dauermessstellen linear mit dem Durchmesser anstiegen. Dieses Ergebnis wurde durch die Punktmessungen an einer größeren Zahl von Buchenstämmen bestätigt (Abb. 19 a und Abb. 20 a), bei denen sich ebenfalls eine lineare Abhängigkeit der oberflächenbezogenen Atmungsraten der Stämme vom Durchmesser ergab. Dabei verdoppelte sich die $\mathrm{CO}_{2}$-Abgabe pro Oberfläche, wenn der Durchmesser von 20 auf $50 \mathrm{~cm}$ zunahm. Die volumenbezogenen Atmungsraten hingegen blieben mit zunehmendem Stammdurchmesser nahezu konstant (Abb. 20).

Diese Befunde weisen im Gegensatz zu der Interpretation von LARCHER (1994) und KINERSON (1975) und in Übereinstimmung mit RYAN (1990) und SPRUGEL (1990) darauf hin, dass auch das Xylem in größerer Entfernung zur Oberfläche an der respirativen $\mathrm{CO}_{2}$-Produktion beteiligt ist, so dass die Zunahme der oberflächenbezogenen Atmungsrate dem Achsendurchmesser proportional ist. Für die Stammatmung der Buche wäre damit das Volumen als Bezugsgröße zur Extrapolation der Küvettenmessungen besser geeignet als die Oberfläche. Wenn aber das Xylem eine bedeutsame $\mathrm{CO}_{2}$-Quelle ist, können die im Vergleich zur Stammatmung hohen volumenbezogenen Atmungsraten von Ästen und Grobwurzeln nicht mit dem geringeren Volumen/OberflächenVerhältnis erklärt werden. Die Differenz der volumenbezogenen Atmungsraten würde dann auf eine geringere Atmungsaktivität des Stammxylems hinweisen. Diese Möglichkeit soll in den folgenden Abschnitten erörtert werden.

\subsubsection{Die Variabilität der $\mathrm{CO}_{2}$-Abgabe und des Stickstoff- und Proteingehalts}

Ein direkter Zusammenhang zwischen Atmungsrate und der Zahl lebender Zellen bzw. deren relativen Anteilen am Gesamtvolumen finden HAVRANEK (1981), RYAN (1990) und CESCHIA et al. (2002). HAVRANEK (1981) ermittelte die Menge der noch unverholzten Zellen des diesjährigen Jahrrings mikroskopisch an Bohrkernstücken und fand eine lineare Abhängigkeit der oberflächenbezogenen Gesamtatmung von der betreffenden Zellzahl. Die anderen Autoren färbten lebende Zellen mittels TTC (Kap. 3.2.4.2, RYAN 1990) oder die Proteine mit Coomassie Blau an (CESCHIA et al. 2002) und bestimmten den Anteil lebender Zellen mikroskopisch als relativen Flächenanteil von Quer- oder Tangentialschnitten für den gesamten Achsenquerschnitt. RYAN (1990) fand eine lineare Beziehung zwischen der $\mathrm{CO}_{2}$-Abgabe und dem Lebendzellvolumen in Rinde und Splintholz. CESCHIA et al. (2002), die bei den Stämmen 30-jähriger Buchen keine Verkernung beobachteten, erhielten einen exponentiellen Zusammenhang zwischen relativem Lebendzellanteil und volumenbezogener Atmung.

Im Rahmen dieser Studie ergaben Vorversuche zur direkten, mikroskopischen Bestimmung des Flächenanteils lebender Zellen durch Markierung mit TTF und Stärkefärbung mit lugolscher Lösung uneinheitliche, nicht reproduzierbare Ergebnisse und wurden daher nicht weiter verfolgt (Kap 3.2.4.2).

Als indirektes Maß für die Zahl und/oder die Aktivität lebender Zellen kann der Proteingehalt der Gewebe aufgefasst werden. AMTHOR $(1989,1991)$ und RYAN (1991) weisen auf die enge Beziehung zwischen dem Proteingehalt und der respirativen $\mathrm{CO}_{2}$-Abgabe hin, die insbesondere für Blätter und Sprosse krautiger Arten beschrieben wird. Da ein Großteil des Stickstoffs in pflanzli- 
chen Zellen in den Proteinen gebunden ist (LEXANDER et al. 1970), wird auch zwischen den Atmungsraten verholzter Baumorgane und deren Stickstoffgehalten eine enge Korrelation gefunden (LAVIGNE et al. 1996, MAIER et al. 1998, BOSC et al. 2003). Dass der Stickstoffgehalt ein direktes Maß für den Lebendzellanteil im Xylem der Buche darstellen kann, zeigen die Ergebnisse von CESCHIA et al. (2002). Sie fanden bei Stämmen und Ästen 30-jähriger Buchen eine lineare Beziehung zwischen diesen Größen, so dass die Atmungsrate in gleicher Weise (exponentiell) vom Stickstoffgehalt und vom Volumenanteil der lebenden Zellen abhängt.

Die Korrelation zwischen dem Stickstoff- oder Proteingehalt und der $\mathrm{CO}_{2}$-Abgabe von Grobwurzeln, Ästen und Stämmen der hier untersuchten Buchen war ähnlich eng wie die Abhängigkeit der $\mathrm{CO}_{2}$-Abgabe von der Oberfläche oder dem Volumen der Proben (Abb. 21), so dass sich auch die relative Standardabweichung der Atmungsraten nicht verringerte, wenn die $\mathrm{CO}_{2}$-Abgabe auf die Stickstoff- oder Proteinmenge der untersuchten Holzproben bezogen wurde (Abb. 22). Die mittlere Stickstoffkonzentration im Phloem von Ästen und Grobwurzeln war etwas, im Xylem deutlich höher als in den betreffenden Geweben der Stämme, so dass sich die stickstoffbezogenen Atmungsraten von Ästen und Grobwurzeln weniger stark von den Atmungsraten der Stämme unterschieden als die volumenbezogenen. Dass Äste und Grobwurzeln pro Einheit Stickstoff im Mittel noch die 4.8fache $\mathrm{CO}_{2}$-Menge der Stämme abgaben, zeigt, dass sich die Organe hinsichtlich der Nutzung des Stickstoffs unterscheiden.

Die Variabilität der Atmungsraten von Ästen, Stämmen und Grobwurzeln kann wie bei Pinus contorta (VOSE \& RYAN 2002) mit dem Stickstoffgehalt beschrieben werden (Abb. 23). Dass der Stickstoff jedoch nur einen Teil der Variabilität erklärt, wird nicht nur durch die unterschiedlichen N-bezogenen Atmungsraten der verschiedenen Kompartimente deutlich, sondern auch dadurch, dass die Beziehung zwischen Stickstoffkonzentration der Holzproben und ihren volumenbezogenen Atmungsraten einen negativen Ordinatenabschnitt hat (Abb. 23). AMTHOR (1989) sieht eine mögliche Ursache dafür darin, dass ein Teil des Stickstoffs nicht in den Metabolismus der Zelle eingebunden ist, sondern in Form stickstoffhaltiger Speicherstoffe vorliegt. Dieser Erklärungsansatz ist für die Ergebnisse der vorliegenden Arbeit insbesondere deshalb naheliegend, weil die Probennahme für die C/N-Analysen in der zweiten Märzhälfte 1999, also zu einem Zeitpunkt erfolgte, als die Speicherstoffe in der höchsten Konzentration vorgelegen haben dürften. Andere Autoren finden ebenfalls, dass der Stickstoffgehalt die Variabilität der $\mathrm{CO}_{2}$-Abgabe von Stämmen und Ästen nur zum Teil erklärt (GOODWIN \& GODDARD 1940, LAVIGNE et al. 1996, DAMESIN et al. 2002, BOSC et al. 2003).

\subsubsection{Der TTC-Umsatz als Maß für die Aktivität der lebenden Zellen}

Anders als der zum Teil in Speicherform vorliegende Stickstoff, wird TTC in den Stoffwechsel der Zellen eingebunden und von den Dehydrogenasen des Zellplasmas zu TTF reduziert (ROBERTS 1951, RYAN 1990). Der TTC-Umsatz könnte daher neben der Atmungsrate selbst ein Maß für die Aktivität der lebenden Zellen sein. Nach ROBERTS (1951) wird TTC nicht von spezifischen Dehydrogenasen reduziert. Der TTC-Test spiegelt vielmehr die Kapazität der Zelle wider, Reduktionsäquivalente zur Verfügung zu stellen.

Die Ergebnisse der TTC-Tests geben verschiedene Hinweise darauf, dass das hier verwendete Verfahren Rückschlüsse auf die Gewebeaktivität zulässt:

- Im Gegensatz zu den Stickstoffkonzentrationen, die bei den Stämmen über den gesamten Holzquerschnitt nahezu konstant waren, wiesen die TTC-Umsätze im Querschnitt der Sprossachsen 
ein charakteristisches Tiefenprofil auf, das mit dem übereinstimmt, das sich aus Atmungsmessungen an Holzproben aus unterschiedlicher Distanz von der Oberfläche ergeben hat (MÖLLER \& MÜLLER 1938, PRUYN et al. 2002).

- Bei den Ästen im Solling war die $\mathrm{CO}_{2}$-Abgabe des wenig vitalen, drei Jahre nach Abschluss der Untersuchung abgestorbenen Astes 6 mit hohem Volumen, hoher Oberfläche und hohem Stickstoffgehalt so gering, dass die Beziehung zwischen $\mathrm{CO}_{2}$-Abgabe und diesen Größen nur dann signifikant war, wenn dieser Ast nicht berücksichtig wurde. Nur der TTC-Umsatz zeigte seine geringe Vitalität an, so dass die Beziehung zwischen $\mathrm{CO}_{2}$-Abgabe und TTC-Umsatz signifikant blieb, wenn der Ast einbezogen wurde (Tab. 7, Abb. 21).

- Die Unterschiede der auf die umgesetzte TTC-Menge bezogenen Atmungsraten von Ästen und Stämmen waren geringer als bei Stickstoff- oder Volumenbezug.

Allerdings spiegelte auch der TTC-Test die Atmungsaktivität nicht unmittelbar wider, so dass auch die TTC-bezogenen Atmungsraten zwischen den Kompartimenten variierten. Insbesondere die Unterschiede zwischen Stämmen und Grobwurzeln waren weiterhin groß.

Diese Unterschiede zwischen den TTC-Umsätzen der Organe können verschiedene Ursachen haben. Da das TTC als Oxidationsmittel im Überschuss vorliegt, hängt die Umsatzrate einerseits von der Menge und Aktivität der Dehydrogenasen ab. Andererseits kann der Vorrat an Reduktionsäquivalenten und das Potenzial der Zelle, diese zu regenerieren, die limitierende Größe darstellen. Die Regeneration von Reduktionsäquivalenten kann ihrerseits vom Substrat, d.h. letztlich der Verfügbarkeit von Kohlenhydraten im Holz der verschiedenen Organe beeinflusst werden. Die TTC-Umsatzrate hinge dann indirekt von der Verfügbarkeit der Kohlenhydrate ab. In diesem Fall würde die TTC-Umsatzrate im Laufe der 15-stündigen Inkubationszeit abnehmen und einen Sättigungsverlauf zeigen. Da der zeitliche Verlauf der TTC-Umsatzrate über die Dauer der Inkubationszeit nicht untersucht wurde, kann die potenzielle Bedeutung des Kohlenhydratspeichers für den TTC-Umsatz nicht eingeschätzt werden.

Selbst bei konstanten Umsatzraten ist ein enger Zusammenhang zwischen Atmungsrate und TTCUmsatz nur bedingt zu erwarten. Mit dem TTC-Test wird das maximale Umsatzpotenzial der Zellen erfasst, während die Erhaltungsatmung selbst nach Temperaturnormierung keine Aussage darüber zulässt, wie stark die enzymatischen Kapazitäten von Glykolyse, Citratzyklus und Elektronentransportkette ausgelastet sind. Denkbar ist, dass die Äste und die oberflächennahen Gewebe der Stämme, auf die die variierenden Witterungsbedingungen am stärksten einwirken, höhere Enzymkapazitäten in Reserve halten als die Grobwurzeln, die ausgeglichenere Umgebungsbedingungen erfahren. Erstere besäßen dann auch eine höhere Kapazität, TTC umzusetzen, als die Grobwurzeln, so dass dies die Ursache für höhere TTC-bezogene Raten bei den Grobwurzeln sein kann.

Auch die qualitativen Unterschiede der TTC-Umsätze geben Informationen, die die bislang vermuteten Ursachen für die Variabilität der Atmungsraten unterstützen. So weisen die lebenden Zellen im Xylem von Ästen und Grobwurzeln über den gesamten Querschnitt eine höhere Aktivität auf als das Holz der Stämme. Dies bestätigt die Annahme, dass sich die oberflächenbezogenen Atmungsraten aller Kompartimente nicht deshalb so ähnlich sind, weil nur das Periderm und das oberflächennahe Xylem die bedeutenden Orte der $\mathrm{CO}_{2}$-Produktion sind, sondern weil sowohl die Menge als auch die Aktivität der lebenden Zellen im Xylem der Stämme um so viel geringer sind, dass sich pro Einheit Oberfläche ähnliche Werte für die Atmung ergeben wie bei Ästen und Grobwurzeln. 
Die große Variabilität der radialen Profile der TTC-Umsätze macht außerdem deutlich, dass auch bei den Altbuchen das Splintholzvolumen als Bezugsgröße wenig geeignet ist. Die radialen Verläufe der TTC-Umsätze stimmen mit den Ergebnissen von MÖLLER \& MÜLLER (1938) überein, die bei einer 90-jährigen verkernten Buche keine Atmungsaktivität innerhalb des 50sten Jahrringes feststellten, bei einer 105-jährigen Buche aber auch im Zentrum des Stammes noch deutliche Atmungsaktivität maßen. Anders als bei vielen Koniferen und ringporigen Laubbäumen, die regelmäßig Kernholz ausbilden und deren Splintholz-Kernholzgrenze aufgrund der Eigenfärbung oder durch Anfärbung der Speicherstärke deutlich abzugrenzen ist, war bei keinem der hier untersuchten Buchenstämme ein deutlicher Farbkern ausgebildet. Die Splintholz-Kernholzgrenze wurde anhand der radialen Verläufe der TTC-Umsätze festgelegt. Da die Buche, sofern nicht durch Pilzbefall, Frost oder Trockenheit traumatisiert, wenn überhaupt, dann erst sehr spät verkernt, ist der radiale Verlauf von Indikatoren für die Vitalität der Parenchymzellen bei verschiedenen Individuen sehr variabel (DIETRICHS 1964). Die Variabilität der volumenbezogenen Atmungsrate der Stämme ist im wesentlichen auf die Aktivitätsunterschiede in den äußeren Xylembereichen zurückzuführen. Dieses unterschiedliche Aktivitätsniveau im jüngeren Splintholz und die nicht sicher zu bestimmende Splintholz-Kernholzgrenze führen dazu, dass sich aus dem Bezug der $\mathrm{CO}_{2}$-Abgabe auf das Splintholzvolumen keine Verminderung der relativen Standardabweichung für die Stammatmung ergibt. Somit erscheint, wie bei den von DAMESIN et al. (2002) untersuchten 30-jährigen Buchen, auch bei Altbuchen das Gesamtvolumen als Bezugsgröße geeigneter zu sein.

\subsubsection{Der Einfluss der Messposition am Stamm und in der Krone}

Die räumliche Variabilität der Atmungsrate eines Kompartiments kann einerseits auf unterschiedliche Aktivitäten verschiedener Individuen zurückgeführt werden, andererseits ist es möglich, dass sich auch an verschiedenen Positionen eines Stammes oder in verschiedenen Höhenstufen der Krone unterschiedliche Atmungsraten ergeben.

Für die Abhängigkeit der Stammatmungsraten von der Höhe der Messposition werden unterschiedliche Ergebnisse beschrieben. NEGISI (1974) zeigt, dass die oberflächenbezogene Atmungsrate der Stämme sich nur dann nicht mit dem Durchmesser ändert, wenn die Atmungsraten unterschiedlicher Stämme verglichen werden. Innerhalb eines Stammes geht die oberflächenbezogene Erhaltungsatmungsrate mit zunehmendem Durchmesser des betrachteten Stammabschnittes zurück. TSEL'NIKER et al. (1990) fanden bei Messungen der Stammatmung an Betula pendula während der Sommermonate eine erhöhte Atmungsrate im oberen Stammbereich, der gleichzeitig einen höheren Zuwachs zeigte. Im Frühjahr und Herbst bestanden nur geringe Unterschiede der oberflächenbezogenen Atmungsraten in verschiedenen Höhen am Stamm von Betula pendula, Picea abies und Quercus robur. RYAN et al. (1996) beobachteten weder bei der auf die Oberfläche noch bei der auf das Splintholzvolumen bezogenen Atmungsrate der Stämme von Pinus radiata signifikante Änderungen der Atmungsrate mit der Höhe der Messposition am Stamm. SPRUGEL (1990) fand bei Abies amabilis im unteren Bereich des Stammes höhere oberflächenbezogene Atmungsraten als in größerer Höhe.

Für die Buche geben MÖLLER et al. (1954) eine hyperbolische Abnahme der volumenbezogenen Stammatmung mit zunehmendem Durchmesser an. Diese ist jedoch wie bei NEGISI (1974) auf individuelle Unterschiede zurückzuführen. Werden die Atmungsraten, die MÖLLER et al. (1954) an Stammsegmenten jeweils eines Individuums gemessen haben, als vertikales Profil aufgefasst und 
miteinander verglichen, ergibt sich für die jeweils 2 bis 4 Segmente eines Stammes kein Gradient der Atmungsrate mit zunehmender Stammhöhe.

Bei DAMESIN et al. (2002) und CESCHIA et al. (2002) stieg die volumenbezogene Atmungsrate von Stämmen und Ästen mit zunehmender Höhe. Diese Variabilität beschreibt CESCHIA (2001) ebenfalls mit einer hyperbolischen Funktion in Abhängigkeit vom Durchmesser, der mit der Höhe abnimmt. Während CESCHIA et al. (2002) die Zunahme der Atmung mit der Höhe betonen, fällt aber auf, dass sich die von DAMESIN et al. (2002) in 0.5 und $6.5 \mathrm{~m}$ Höhe gemessenen Stammatmungsraten nicht unterscheiden. CESCHIA et al. (2002) messen die Stammatmung in ca. $1.6 \mathrm{~m}$ und an der Kronenbasis in ca. $11 \mathrm{~m}$ Höhe, nicht aber in mittlerer Stammhöhe. Wird diese unterschiedliche Abstufung am Stamm berücksichtigt, ergibt sich eine gute Übereinstimmung einerseits mit den Ergebnissen von MÖLLER et al. (1954), andererseits mit denen der vorliegenden Untersuchung, in der sich die volumenbezogenen Atmungsraten an der Stammbasis und in mittlerer Höhe nicht unterscheiden. Die Raten an der Kronenbasis können deutlich höher sein als in unteren Stammbereichen. Im Mittel unterscheiden sich die an der Kronenbasis gemessenen Atmungsraten nicht von der Atmung der Stämme an der Stammbasis (Abb. 27). Die höheren Raten und die höhere Variabilität der Atmung an der Kronenbasis kann darin begründet sein, dass hier asymmetrisches Wachstums zu einer unterschiedlichen Gewebe- und Atmungsaktivität führt. Der mögliche Zusammenhang zwischen Wachstumsaktivität und der Variation der Erhaltungsatmung wird im folgenden Kapitel diskutiert.

Entscheidend für die räumliche Extrapolation der Stammatmungsraten ist der Befund, dass sich die an der Stammbasis gemessene Atmungsrate nicht signifikant von der in größerer Höhe gemessenen Atmung unterscheidet. Die über einen weiten Durchmesserbereich festgestellte Einheitlichkeit der volumenbezogenen Atmungsrate ist damit nicht nur für die Atmung verschiedener Individuen unterschiedlichen BHDs, sondern auch für das Stammholz eines Baumes unterhalb des Kronenansatzes anzunehmen.

Anders als bei der Stammatmung fanden RYAN et al. (1996) einen deutlichen Höhengradienten der Astatmung im Kronenraum. Die Äste der oberen zwei Kronendrittel gaben pro Volumeneinheit etwa dreimal mehr $\mathrm{CO}_{2}$ ab als die des unteren Kronendrittels. SPRUGEL (1990) zeigt, dass die Äste des oberen Kronenbereichs signifikant höhere oberflächenbezogene Atmungsraten aufwiesen. Bei der Buche ist der Höhengradient, den DAMESIN et al. (2002) und CESCHIA et al. (2002) von der Kronenbasis in $10 \mathrm{~m}$ Höhe bis in $15 \mathrm{~m}$ Höhe beobachteten, ebenfalls sehr ausgeprägt. Die volumenbezogene Erhaltungsatmung eines $0.25 \mathrm{~cm}$ dicken Astes $50 \mathrm{~cm}$ unterhalb des Wipfels war 17-mal höher und die Atmung eines $1.2 \mathrm{~cm}$ dicken Astes in der Mitte der Krone war noch doppelt so hoch wie die des Stammes an der Kronenbasis mit $5.6 \mathrm{~cm}$ Durchmesser.

Bei den Ästen der hier untersuchten Altbuchen hingegen bestand keine Beziehung zwischen der absoluten oder relativen Höhe der Messposition und der volumenbezogenen Atmungsrate. So wiesen die Äste 4 und 5 im Göttinger Wald die höchsten $10{ }^{\circ} \mathrm{C}$-Erhaltungsatmungsraten $(52 \mu \mathrm{mol}$ $\mathrm{CO}_{2} \mathrm{~m}^{-3} \mathrm{~s}^{-1}$ ) auf. Die $\mathrm{CO}_{2}$-Abgabe des vergleichbar dicken und in gleicher Höhe gemessenen Astes 3 markiert mit $11 \mu \mathrm{mol} \mathrm{CO} \mathrm{Cm}^{-3} \mathrm{~s}^{-1}$ die untere Spanne der Variation der Astatmung an diesem Standort (Abb. 29). Eine deutliche Abhängigkeit der Atmungsrate von der Position der Äste in der Krone wurde dann gefunden, wenn nicht die Höhe der Messstelle selbst, sondern der distal der Messstelle gelegene Anteil des Astes hinsichtlich seiner räumlichen Ausdehnung und der mittleren Höhe des belaubten Bereichs in die Betrachtung eingingen. Hierzu wurden die Äste halbquantitativ jeweils drei Klassen von Kronenvolumen und Kronenhöhe zugeordnet und die Beziehung der $10{ }^{\circ} \mathrm{C}$-Erhaltungsatmung zu diesen Klassen untersucht. 
Während die Atmungsraten der Äste unabhängig davon, ob sie ein geringes, mittleres oder großes Kronenvolumen versorgten, variierten, zeigten nur solche Äste maximale Atmungsraten, deren belaubter Anteil hauptsächlich der Sonnenkrone zugeordnet werden konnte. Äste des unteren und mittleren Kronendrittels wiesen im Mittel geringere Atmungsraten auf. Die multiplikativ miteinander verknüpften Klassenwerte von Kronenvolumen und Kronenhöhe erklären über 57 \% bzw. 90 \% der Variabilität der Atmungsraten aller Äste bzw. der Äste im Göttinger Wald (Abb. 29).

Wird die Analyse der Durchmesserabhängigkeit der Astatmung (Abb. 19) dadurch verfeinert, dass die Atmungsraten verschiedener Kronenschichten getrennt voneinander betrachtet werden, ergibt sich ein enger Zusammenhang zwischen Durchmesser und oberflächenbezogener Atmungsrate und eine deutliche Differenzierung der volumenbezogenen Atmungsraten (Abb. 43). Bleiben die Werte zweier Äste mit abweichenden Atmungsraten (in Abb. 43 durch offene Symbole hervorgehoben) zunächst unberücksichtigt, lässt sich die Variabilität der oberflächenbezogenen Astatmungsraten im oberen Kronendrittel zu 84 \% mit dem Durchmesser erklären. Der Unterschied zwischen den volumenbezogenen Atmungsraten der verschiedenen Höhenstufen ist hochsignifikant $(\mathrm{P}<0.0001)$.
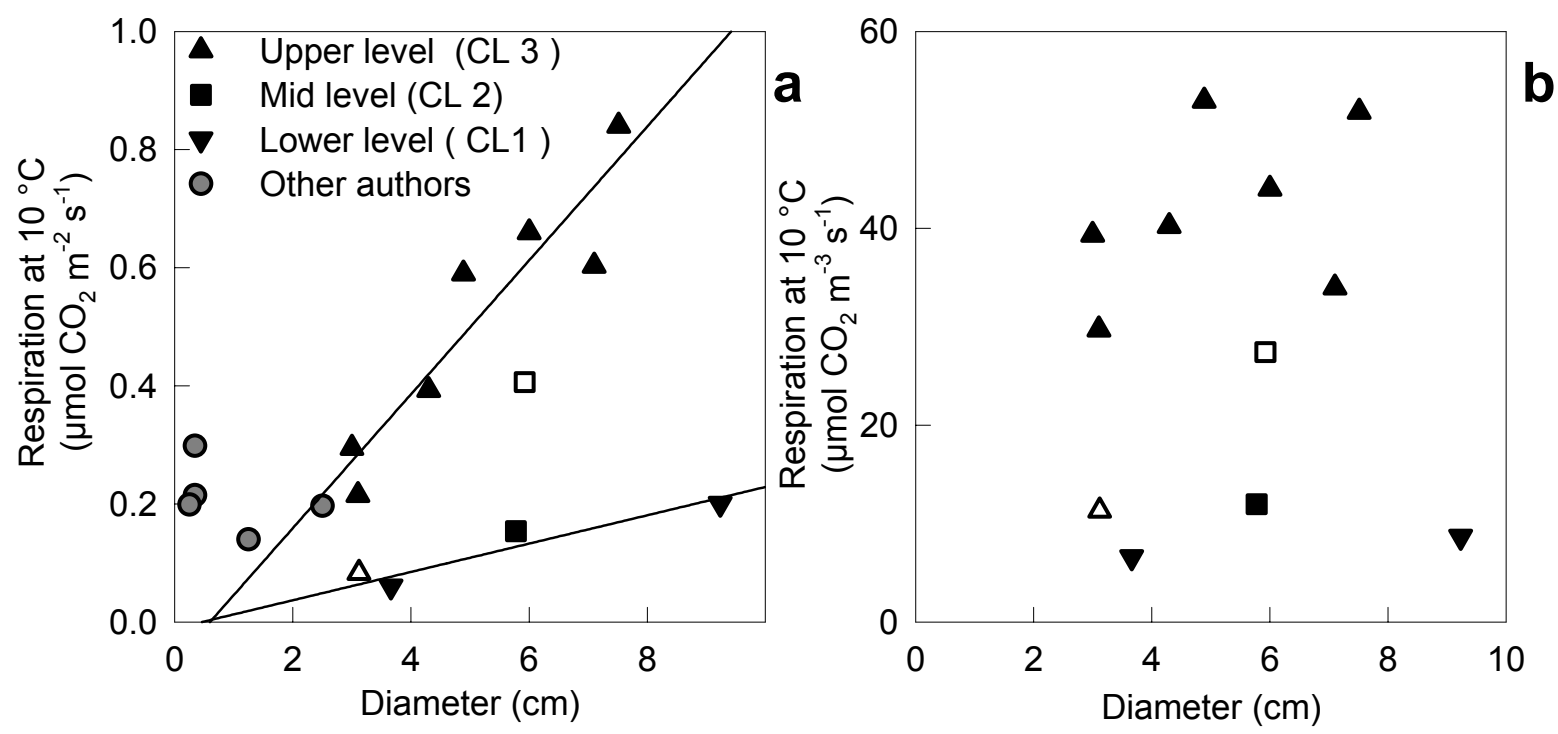

\begin{abstract}
Abb. 43: Durchmesserabhängigkeit der a) oberflächen- und b) volumenbezogenen Atmungsraten der nach Kronenposition differenzierten Äste. Die Werte für die oberflächenbezogenen Atmungsraten von Ästen mit D $<2.5 \mathrm{~cm}$ (graue Punkte) stammen aus Gansert (1995) und Damesin et al. (2002) und sind für Berechnung der Feinreisigatmung von Bedeutung (siehe dazu Kap. 5.5.2). Oberes Kronendrittel: $\mathrm{R}_{10}{ }^{\circ} \mathrm{C}, \mathrm{A}=0.113 \times \mathrm{D}-0.068, \mathrm{r}^{2}$ adj. $=0.84, \mathrm{P}=0.0025$, mittleres und unteres Kronendrittel (nicht signifikant): $\left(\mathrm{R}_{10}{ }^{\circ} \mathrm{C}, \mathrm{A}=0.024 \times \mathrm{D}-0.011, \mathrm{r}^{2}{ }_{\mathrm{adj}}=0.79, \mathrm{P}=0.20\right)$.
\end{abstract}

Die Durchmesserabhängigkeit der oberflächenbezogenen Atmungsraten stimmt somit mit den für die Stämme gefundenen Befunden überein. Die mittlere volumenbezogene Atmungsrate der Äste des oberen Kronendrittels übersteigt die Rate der unteren beiden Kronendrittel um den Faktor 2.8, der dem Befund von RYAN et al. (1996) entspricht.

Die Ursache für die Abweichung der Atmungsrate der zwei Äste ist vermutlich darin zu sehen, dass die Zuordnung zu den Kronenpositionen sich im Wesentlichen an der Höhe des Astes im Kronenraum orientierte und der Ast letztlich dem oberen, mittleren oder unteren Kronendrittel zugeordnet wurde. Dieses Verfahren scheint für den Großteil, jedoch nicht für alle Äste zweckmäßig. So befand sich der belaubte Bereich von Ast Nr. $1(\Delta)$ im Göttinger Wald zwar im oberen Kronendrittel und wurde folglich der Kronenposition 3 zugeordnet. Dieser Ast hatte jedoch nur einen geringen Anteil am Kronenvolumen und wurde von den darüber befindlichen Ästen des über $33 \mathrm{~m}$ 
hohen Baumes und von der in 30 m Höhe befindlichen Plattform des Gerüstturmes beschattet. Ast Nr. 2 (口) im Solling reichte hinsichtlich der Höhe zwar nur in das mittlere Kronendrittel, ragte aber in eine nach Osten und Süden ausgerichtete Kronenlücke, so dass der Lichtgenuss des von diesem Ast versorgten Laubs wahrscheinlich überdurchschnittlich war. Die Sonderstellung dieser beiden Äste widersprechen der räumliche Differenzierung der Astatmung in der Krone nicht, vielmehr ergeben sich daraus zusätzliche Hinweise auf die Ursachen dieser räumlichen Variabilität der Astatmung.

\subsubsection{Die räumliche Variabilität der Erhaltungsatmung: Ursachen und Schlussfolger- ungen für die Extrapolation der Küvettenmessungen}

Die vorausgegangenen Betrachtungen zeigen, dass schon die im Winterhalbjahr gemessene und temperaturnormierte Erhaltungsatmung der Rotbuche innerhalb und zwischen den verschiedenen verholzten Kompartimenten stark variiert, und dass diese Variation auf die unterschiedliche Menge und Aktivität lebender Zellen in Rinde und Xylem zurückzuführen ist.

CESCHIA et al. (2002) nennen zwei Hauptursachen für die mit zunehmendem Durchmesser zurückgehende volumenbezogene Erhaltungsatmung. Einerseits nimmt das Gesamtvolumen gegenüber dem Rindenvolumen, das den höchsten Lebendzellanteil aller Gewebe der Sprossachse aufweist, mit steigendem Durchmesser überproportional zu. Die auf das Gesamtvolumen bezogene Lebendzellzahl der Rinde geht damit zurück. Darüber hinaus nimmt die Konzentration lebender Zellen im Xylem mit steigendem Durchmesser ab. In der Summe sinkt die Menge lebender Zellen pro Volumeneinheit und damit die volumenbezogene Erhaltungsatmung mit zunehmendem Sprossachsendurchmesser.

Die Bedeutung des sich ändernden Volumenanteils der Rinde für die Durchmesserabhängigkeit der volumenbezogenen Atmungsrate muss bei den hier untersuchten Ästen und Stämmen als verhältnismäßig gering eingeschätzt werden. Nach CESCHIA (2001) geht das Rindenvolumen von Zweigen bei einer Durchmesserzunahme von 0.25 auf $1.15 \mathrm{~cm}$ von 21 auf $11 \%$ zurück. In der Annahme, dass sich die volumenspezifische Atmungsaktivität des Rindenparenchyms nicht mit dem Durchmesser und dem Alter ändert, ginge die auf das Gesamtvolumen bezogene Rindenatmung um etwa $50 \%$ zurück. Damit kann der Rückgang der mittleren Erhaltungsatmung dieser Sprossachsen von 388 auf $132 \mu \mathrm{mol} \mathrm{CO}_{2} \mathrm{~m}^{-3} \mathrm{~s}^{-1}$ (mittlere Atmungsrate der Äste und Stämme mit $1 \leq \mathrm{D}<2.6 \mathrm{~cm}$, umgerechnet auf $10^{\circ} \mathrm{C}$, aus CESCHIA et al. 2002) zum Großteil mit dem geringen Volumenanteil der Rinde bei den dickeren Sprossachsen erklärt werden. Bei den hier untersuchten Ästen betrug der Volumenanteil der Rinde etwa 12 und der der Stämme ca. $4 \%$. Bei mittleren Durchmessern von 4.8 bzw. $44 \mathrm{~cm}$ ging die mittlere Erhaltungsatmung von 33 auf $2.4 \mu \mathrm{mol} \mathrm{CO}_{2}$ $\mathrm{m}^{-3} \mathrm{~s}^{-1}$ zurück (Abb. 18). Der Rückgang um mehr als das 10 fache kann daher nur zum Teil auf den geringeren Rindenvolumenanteil der Stämme zurückgeführt werden und ist im Wesentlichen auf die Abnahme des Anteils lebender Zellen im Xylem und den Rückgang der Aktivität des vitalen Gewebes in Rinde und Xylem zurückzuführen.

Den Rückgang des Lebendzellanteils im Xylem mit zunehmendem Durchmesser führen CESCHIA et al. (2002) auf das höhere Alter dickerer Sprossachsen zurück. So finden CAREY et al. (1996) bei Pinus ponderosa eine Abnahme der Atmungsrate mit zunehmendem Stammdurchmesser und Alter. Schon NEGISI (1974) zeigt, dass die Abnahme der volumenbezogenen Atmungsraten mit zunehmendem Durchmesser in enger Beziehung zu dem steigenden Alter der Stammabschnitte steht. Er stellt darüber hinaus dar, dass, wie die Atmung, auch der relative Biomassezuwachs mit steigendem 
Achsendurchmesser und -alter abnimmt. NEGISI (1974) diskutiert, ob die Zuwachsrate als Indikator für die allgemeine physiologische Aktivität und das mittlere Niveau der Atmung eines Stammabschnittes betrachtet werden kann. Diese Annahme wird dadurch bestärkt, dass die oberflächenbezogenen Atmungsraten von Stämmen gleichen Alters mit steigendem Durchmesser und zunehmender Wachstumsaktivität ansteigen. Da NEGISI (1994) seine Untersuchungen im Herbst und im Frühjahr außerhalb der Vegetationsperiode durchführt und der Anteil der Wachstumsatmung als sehr gering einzuschätzen ist, ergibt sich daraus ein deutlicher Hinweis auf eine Beziehung zwischen dem relativem Biomassezuwachs und der Erhaltungsatmung.

In der Formulierung des Zweikomponenten-Modells der Atmung:

$$
\mathrm{R}=\mathrm{kP}+\mathrm{c} \mathrm{W}
$$

mit der Gesamtatmung R, der Bruttophotosynthese P und der Menge lebender Biomasse W entsprechen die Terme $\mathrm{kP}$ der Wachstumsatmung $\mathrm{R}_{\mathrm{g}}$ und $\mathrm{cW}$ der Erhaltungsatmung $\mathrm{R}_{\mathrm{m}}$. Letztere ist innerhalb eines Experiments als konstant anzusehen (McCREE 1970). Das Modell wird aber häufig so interpretiert, dass die Erhaltungsatmung völlig unabhängig vom Wachstum sei. Es ist jedoch mit dem theoretischen Konzept vereinbar und es zeigt sich häufig, dass die Erhaltungsatmung vom Biomassezuwachs abhängt.

Dies ergeben Untersuchungen von AMTHOR (1984) an verschiedenen krautigen Arten, von LAVIGNE (1996) bei Pinus banksiana und von RYAN et al. (1996) bei Pinus radiata. RYAN et al. (1997) fanden bei vier Baumarten borealer Standorte positive Korrelationen zwischen der jährlichen Erhaltungsatmung und der Jahressumme des Biomassezuwachses.

BOSC et al. (2003) beschreiben die räumliche Variabilität der Erhaltungsatmung von Stämmen und Ästen bei Pinus maritima mit einem Modell der Form:

$$
R_{m, V}=a \times V \times \frac{D^{b}}{Y^{c}}
$$

mit den Parametern $\mathrm{a}, \mathrm{b}$ und $\mathrm{c}$ und den Variablen $\mathrm{V}=$ Volumen, $\mathrm{D}=$ Durchmesser und $\mathrm{Y}=$ Alter der Sprossachse. Sie betonen, dass mit dem Quotienten $D^{b} Y^{-c}$ letztlich die über das gesamte Alter des Organs gemittelte Zuwachsrate als Skalierungsgröße eingeht.

Bei der Rotbuche bestehen ebenfalls z. T. sehr enge Beziehungen zwischen temperaturnormierter Erhaltungsatmung von Ästen und Stämmen und ihrem relativen Jahreszuwachs (bezogen auf die Querschnittsfläche). Die unterschiedlichen Atmungsraten der Äste und Stämme 30-jähriger Buchen lassen sich zu 99 \% mit ihren relativen Wachstumsraten erklären (Abb. 44 a). Trotz der weit geringeren Spanne der relativen Wachstumsrate ergibt sich auch für die Altbuchen in Solling und Göttinger Wald eine signifikante Beziehung zwischen dem relativen Jahreszuwachs und der Erhaltungsatmung, die das unterschiedliche Niveau der Atmungsaktivität von Ästen und Stämmen erklärt (Abb. 44 b).

Auch die Beobachtung, dass die volumenbezogene Stammatmung über einen weiten Durchmesserbereich konstant ist (Abb. 20), kann im Zusammenhang mit dem geringeren Wachstum unterdrückter Bäume interpretiert werden. So geht die Baumhöhe der Buchen im Göttinger Wald unterhalb eines BHDs von $45 \mathrm{~cm}$ deutlich zurück. Individuen mit weniger als $40 \mathrm{~cm}$ BHD sind nur noch selten höher als $30 \mathrm{~m}$ und kaum noch am Aufbau des oberen Kronendaches beteiligt (Abb. 32). Mit 
dem geringeren Lichtgenuss und Volumen ihrer Krone einhergehend sind die absoluten Zuwachsraten der Stämme dieser Bäume geringer (Abb. 33). Die relativen Zuwachsraten dieser dünneren Bäume unterscheiden sich aber nur wenig von denen der dominanten Individuen, so dass die volumenbezogene Erhaltungsatmung ebenfalls nur wenig variiert. Dies entspricht den Ergebnissen von NEGISI (1974), der an den Stämmen dominanter Bäume höhere Atmungsraten beobachtete als an den Stämmen unterdrückter Bäume gleichen Durchmessers.

Bei den hier untersuchten Buchen wiesen die Äste der unteren beiden Kronendrittel deutlich geringere relative Wachstumsraten als die Äste der Sonnenkrone auf, so dass auch die Differenzierung der Astatmung im Kronenraum mit dem Status des Astes in der Krone und seiner Wachstumsaktivität im Zusammenhang zu sehen ist.
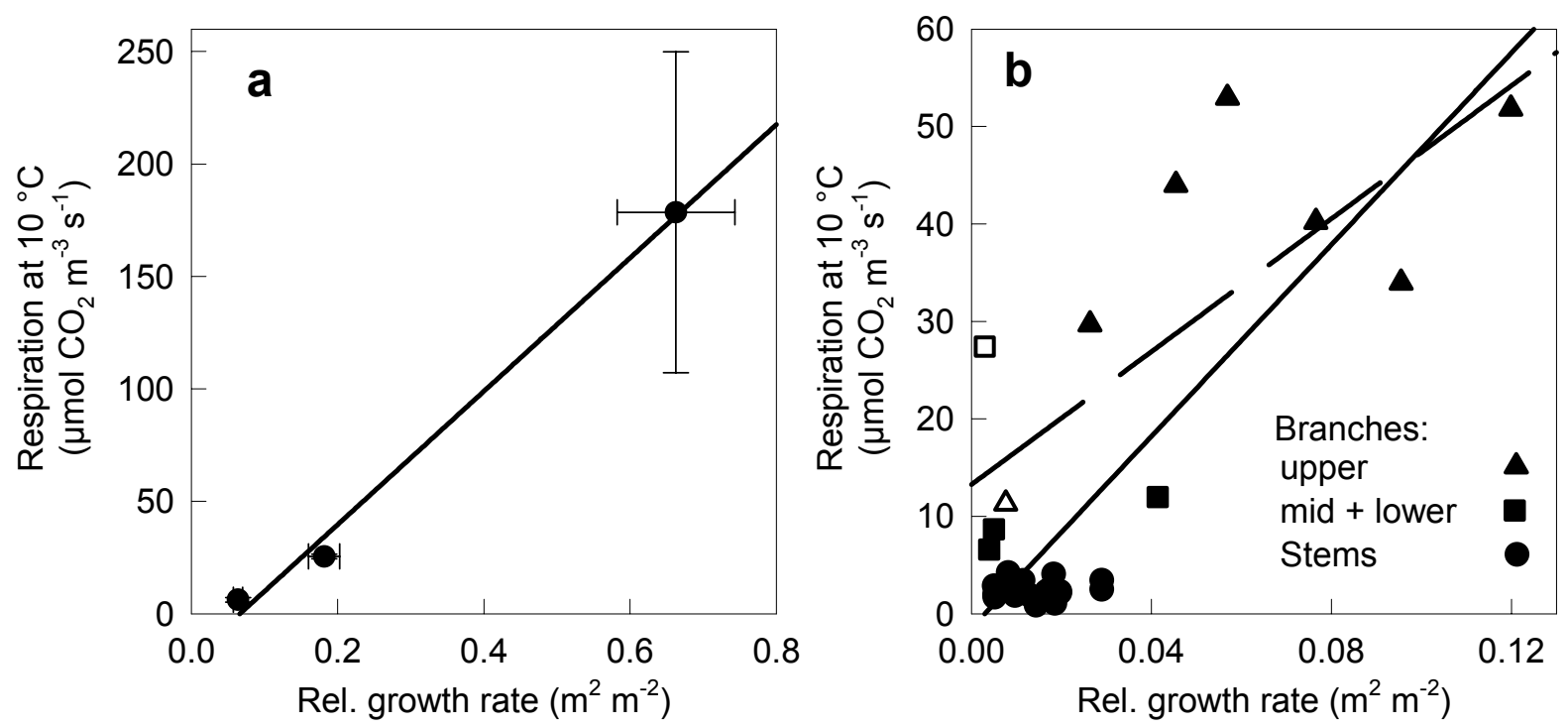

Abb. 44: Die Beziehung zwischen temperaturnormierter Erhaltungsatmung und relativer Wachstumsrate von Ästen und Stämmen 30-jähriger Buchen a) Daten aus CESCHIA et al. (2002), $\mathrm{r}^{2}=$ $0.99, \mathrm{P}=0.053$ ) und $\mathbf{b}$ ) von Ästen und Stämmen der Altbuchen im Solling und Göttinger Wald. Die Werte der Äste mit offenen Symbolen wurden bei den Regressionsberechnungen nicht berücksichtigt.

Durchgezogene Linie: alle Daten, $\mathrm{R}=491 \mathrm{x} \mathrm{RGR}-1.5, \mathrm{r}^{2}=0.69, \mathrm{P}=<0.0001$, Unterbrochene Linie: Astdaten, $\left.\mathrm{R}=341 \times \mathrm{RGR}+13, \mathrm{r}^{2}=0.49, \mathrm{P}=0.021\right)$.

Da die Erhaltungsatmung nach Abschluss der Wachstumsaktivität und Ausdifferenzierung des neugebildeten Gewebes ermittelt wird, ist ein direkter Einfluss des mit dem Zuwachs verbundenen Energiebedarfs und der erhöhten $\mathrm{CO}_{2}$-Abgabe nicht anzunehmen. Die Kopplung der Raten von Zuwachs und Erhaltungsatmung ist daher als Folge einer komplexeren, indirekten Wirkungskette zu sehen, bei der die höhere relative Wachstumsaktivität mit einer allgemein erhöhten metabolischen Aktivität des Gewebes einher geht (AMTHOR 1989, 1998). Mögliche Ursachen für die gesteigerte Erhaltungsatmung in stärker wachsenden Sprossachsen sind der höhere Energiebedarf für den Transport von Assimilaten und Nährstoffen, deren Speicherung und Mobilisierung und vor allem das Bereithalten ausreichender Speicherkapazitäten in Form vitalen Gewebes.

Auf höherer Ebene deuten die Zusammenhänge zwischen der relativen Wachstumsrate und der Erhaltungsatmung von Ästen und Stämmen und deren Status in der Krone bzw. im Bestand darauf hin, dass die Assimilatversorgung eines Astes bzw. Baumes und die, die Photosynthese beeinflussenden Ressourcen, wie der Lichtgenuss, auch für die Variabilität der Erhaltungsatmung als bedeutende Einflussgröße einzuschätzen ist. 


\subsubsection{Die Wahl der geeigneten Bezugsgröße}

Für die räumliche Extrapolation der Atmungsraten lässt sich zusammenfassen, dass die oberflächenbezogenen Atmungsraten aller Kompartimente zwar auf vergleichbarem Niveau liegt, innerhalb der Stämme und Äste jedoch deutliche Durchmesserbeziehungen aufweist, die bei der Hochrechnung gemessener Atmungsraten berücksichtig werden sollten.

Die volumenbezogenen Atmungsraten der verschiedenen Kompartimente variieren zwischen den Stämmen einerseits und den Ästen und Grobwurzeln andererseits um ein Vielfaches. Die Verhältnisse zwischen Atmungsraten aller Kompartimente stimmen mit denen überein, die sich aus einer von MÖLLER et al. (1954) und CESCHIA et al. (2002) beschriebenen Durchmesserbeziehung anhand einer hyperbolischen Funktion ergeben würden. Innerhalb der verschiedenen Kompartimente lässt sich eine entsprechende Durchmesserabhängigkeit jedoch nur für die Grobwurzeln zeigen. Die auf das Volumen bezogenen Atmungsraten der oberirdischen verholzten Organe innerhalb der Gruppen Stämme, Äste der unteren und mittleren Korne und Äste der Sonnenkrone variieren nicht mit dem Durchmesser, wobei Bereiche von 10 bis $60 \mathrm{~cm}$ bei den Stämmen und von ca. 2 bis $10 \mathrm{~cm}$ bei den Ästen berücksichtigt sind. Dünnere Äste und die Stämme junger Buchen, insbesondere die der Feinreisigfraktion $(\mathrm{D}<1 \mathrm{~cm})$, weisen nach den Ergebnissen verschiedener Autoren gegenüber den hier untersuchten Ästen 8- bis 12fach höhere volumenbezogene Erhaltungsatmungsraten auf (GANSERT 1995, DAMESIN et al. 2002, DAMESIN 2003, M. SCHULTE, pers. Mitteilung). Auch dies muss bei der räumlich-zeitlichen Extrapolation der Atmungsraten Berücksichtigung finden. Die Ergebnisse verschiedener Hochrechnungen werden in Kapitel 5.5.2 zusammenfasst und diskutiert.

\subsection{Diskussion der Ergebnisse der zeitlich und räumlich extrapolierten Atmungs- raten}

\subsubsection{Die Anteile von Erhaltungs- und Wachstumsatmung und des respirativen Kohlenstoff- bedarf für den Holzzuwachs}

Für die prognostizierende Extrapolation der Holzatmung ist die Kenntnis der Höhe der Erhaltungsatmung und des Wachstumskoeffizienten $r_{G}$, d.h. des Kohlenstoffbedarfs für die Wachstumsatmung pro Einheit Kohlenstoff, der im Biomassezuwachs festgelegt wird, von zentraler Bedeutung. Die Effizienz der Kohlenstoffnutzung beim Aufbau neuer Biomasse und der respirative Kohlenstoffbedarf für den Erhalt ausdifferenzierten lebenden Gewebes haben wesentlichen Einfluss auf die Produktivität von Pflanzenbeständen. So wird für die Abnahme der Produktivität von Wäldern mit zunehmendem Bestandesalter der zunehmende Energie- und Kohlenstoffbedarf für die Erhaltsatmung der akkumulierten Biomasse diskutiert (RYAN \& WARING 1992, GOWER et al. 1996, HUNT et al. 1999, MAKELA \& VALENTINE 2001).

\subsubsection{Verfahren zur Differenzierung von Erhaltungs- und Wachstumsatmung}

Grundlage für die Ermittlung des Wachstumskoeffizienten $r_{G}$ ist die Differenzierung der gesamten $\mathrm{CO}_{2}$-Abgabe in die Komponenten Erhaltungs- und Wachstumsatmung. Da die Komponenten während der Wachstumsphase nicht unabhängig voneinander gemessen werden können, erfolgt ihre Bestimmung indirekt. Hierfür werden verschiedene Methoden vorgeschlagen, von denen bei Untersuchungen der Atmung verholzter Organe die „mature tissue“-Methode (AMTHOR 1989, 
SPRUGEL 1990) besonders verbreitet ist. Dabei wird die Atmungsrate, die in Phasen gemessen wird, in denen kein Radialzuwachs zu beobachten ist, ausschließlich der Erhaltungsatmung zugeordnet und vereinfachend angenommen, dass die so bestimmte Erhaltungsatmungsrate bei einer gegebenen Referenztemperatur und ihre Temperatursensitivität im Jahresverlauf konstant ist. Der saisonale Verlauf der Erhaltungsatmung lässt sich dann mit Hilfe der Temperaturbeziehung aus dem Jahresgang der Temperatur berechnen. Die Gesamtatmung ergibt sich aus den sich saisonal verändernden Temperaturbeziehungen (Abb. 35) und ebenfalls aus dem saisonalen Temperaturverlauf. Die Differenz zwischen Gesamt- und Erhaltungsatmung entspricht dann der Wachstumsatmung. Der Wachstumskoeffizient $r_{G}$ schließlich ergibt sich aus dem Verhältnis zwischen den Jahressummen von Wachstumsatmung und Holzzuwachs (RYAN et al. 1997, AMTHOR 2000).

Die Annahme, dass Erhaltungsatmung und ihr Temperaturkoeffizient im saisonalen Verlauf konstant sind, ist der wesentliche Kritikpunkt dieser Methode. SPRUGEL \& BENECKE (1991) weisen darauf hin, dass die temperaturnormierte Atmungsrate schon während der wachstumsfreien Phasen z. B. unter dem Einfluss von Frostereignissen, variieren kann und nicht immer konstant ist. LINDER \& TROENG (1981) und STOCKFORS \& LINDER (1998) maßen bei Pinus sylvestris und Picea abies variierende temperaturnormierte Atmungsraten, wobei die im Anschluss an die Wachstumsphase gemessenen Werte unter denen lagen, die im Frühjahr vor Beginn der Vegetationsperiode ermittelt wurden. Sie interpretieren diese Ergebnisse als Akklimatisierung der Erhaltungsatmung an das Temperaturregime. Dabei soll vermutlich im Sinne von LARCHER (1994) das Niveau der Erhaltungsatmung während der Sommermonate abgesenkt und ein hoher Kohlenstoffverlust vermieden werden. Im Winterhalbjahr wäre die Erhaltungsatmung auf erhöhtem Niveau um eine ausreichende Energieversorgung des Zellstoffwechsels zu gewährleisten. STOCKFORS \& LINDER (1998) legen der Berechnung der jährlichen Erhaltungsatmung nach der ,,mature tissue“Methode die im Frühjahr gemessenen Atmungsraten zugrunde. Die für den Zeitpunkt nach Ende der Vegetationsperiode berechnete Erhaltungsatmung liegt dann über den in dieser Zeit gemessenen Werten. Die Autoren folgern daraus, dass die mit dieser Methode berechnete Erhaltungsatmung die akklimatisierte Erhaltungsatmung während der Vegetationsperiode überschätzt.

Als Zeichen der Temperaturanpassung der Erhaltungsatmung werden auch die Ergebnisse von HAGIHARA \& HOZUMI (1991) interpretiert, die zeigen, dass der Q ${ }_{10}$-Wert von Chamaecyparis obtusa im saisonalen Verlauf mit steigender Temperatur zurückgeht. Eine geringere Sensitivität wirkt bei hohen Temperaturen einer überhöhten Steigerung der Erhaltungsatmungsraten entgegen (Kap.5.3, LARCHER 1994). Die von HAGIHARA \& HOZUMI (1991) angegebenen $Q_{10}$-Werte sind jedoch die Temperaturkoeffizienten der Gesamtatmung aller oberirdischen Organe eines Baumes, die sich bei Blättern, Ästen und dem Stamm im saisonalen Verlauf zu unterschiedlichen Anteilen aus Wachstums- und Erhaltungsatmung zusammensetzt. Ob die beobachtete Temperaturabhängigkeit der $\mathrm{Q}_{10}$-Werte so auch für einzelne Kompartimente oder die Erhaltungsatmung (siehe LARCHER 1994) gilt, ist aus der Untersuchung von HAGIHARA \& HOZUMI (1991) nicht unmittelbar abzuleiten.

Der von PAEMBONAN et al. (1992) dargestellte Rückgang der Erhaltungsatmung von Chamaecyparis obtusa während der Vegetationsperiode wird ebenfalls vielfach als Akklimatisation, d.h. als Reduktion der Erhaltungsatmung bei hohen Temperaturen aufgefasst (STOCKFORS \& LINDER 1998, DAMESIN et al. 2002), aus dem eine Überschätzung der Erhaltungsatmung nach der „mature tissue“-Methode resultieren würde. PAEMBONAN et al. (1992) verwenden zur Differenzierung von Wachstums- und Erhaltungsatmung die von McCREE (1970) vorgeschlagene Regressionsmethode. Diese setzt einen Gleichgewichtszustand zwischen Photosynthese- und Wachstums- 
rate voraus, der bei krautigen Pflanzen unter Versuchbedingungen bei konstanten Temperaturen erreicht werden kann. Besteht dieses Gleichgewicht nicht, können der Einfluss der Temperaturänderung und zeitverzögerte Verläufe der Wachstumsatmung (Kap. 5.2) gegenüber der Photosynthese zu deutlichen Fehleinschätzungen des Verhältnisses zwischen Wachstums- und Erhaltungsatmung führen (McCREE 1970, AMTHOR 1989, HANSEN et al. 1998). Da PAEMBONAN et al. (1992) den Gaswechsel aller oberirdischen Organe eines Baumes gemeinsam unter natürlichen Licht- und Temperaturbedingungen messen, ist es fraglich, ob das verwendete Verfahren geeignet ist, Rückschlüsse über den Jahresgang der Erhaltungsatmung der verholzten Sprossachsen und mögliche Temperaturanpassungen zu ziehen.

Während die Erhaltungsatmung, die aus Messwerten der wachstumsfreien Phasen berechnet wird, bei Akklimatisation der Atmungskapazität (temperaturnormierte Atmungsrate) an höhere Temperaturen in der Vegetationsperiode zu hoch eingeschätzt würde, besteht nach SPRUGEL \& BENECKE (1991) ebenso die Möglichkeit, dass für die Erhaltungsatmung mit der ,mature tissue“Methode zu geringe Werte angenommen werden. So kann die Atmung, die etwa einen Monat nach Abschluss des Radialzuwachses ein niedriges Niveau erreicht und im weiteren Verlauf weitgehend konstant bleibt, unter dem Einfluss stärkerer Fröste noch einmal auf minimale Werte sinken. SPRUGEL \& BENECKE (1991) sehen in der Atmungsaktivität, die wenige Wochen nach Ende der Wachstumsphase und/oder vor Beginn der Vegetationsperiode gemessen wird, die für die Vegetationsperiode repräsentative Erhaltungsatmung, die in die Berechnung der sommerlichen Erhaltungsatmung eingehen sollte. Demgegenüber könnte die Erhaltungsatmung unterschätzt werden, wenn die Jahresminima der Atmung, die in strengen Wintern deutlich unter den Werten der Übergangszeiten liegen können, Grundlage für die Berechnung sind.

Ein Rückgang der temperaturnormierten Atmungsraten im Zusammenhang mit starken Frostereignissen wurde bei den Punktmessungen auch an den Stämmen der Altbuchen im Göttinger Wald beobachtet (Kap. 5.2). Die Stammatmung war am 28.12 .98 bei ca. $8{ }^{\circ} \mathrm{C}$ nur etwa halb so hoch wie die im November bei einer mittleren Temperatur von $1.5^{\circ} \mathrm{C}$ gemessene. An den Dauermessstellen variierten die temperaturnormierten Atmungsraten der verholzten Organe der Altbuchen im Solling und Göttinger Wald im Verlauf des Winterhalbjahres wenig. Minimale Atmungsraten traten meist in einem Zeitraum zwischen Mitte Oktober und Ende November auf und blieben dann weitgehend konstant (Abb. 15 Stämme Göttinger Wald). Ein leichter Anstieg nach dem Erreichen eines niedrigen Niveaus Anfang November, wie er in beiden Untersuchungsjahren Ende November und im Dezember bei den Ästen und Stämmen im Solling auftrat, kann im Zusammenhang mit der Ausbildung von Frosthärte oder der Reparatur von Frostschäden stehen.

Anders als bei LINDER \& TROENG (1981) und STOCKFORS \& LINDER (1998) unterschieden sich die jeweils am Ende des Winters gemessenen Atmungsraten nicht von den im Anschluss an die Wachstumsphase beobachteten Minimalwerten, so dass sich kein Hinweis auf eine Akklimatisation der Erhaltungsatmung ergibt. Auch der Jahresverlauf der Temperaturkoeffizienten (Abb. 16) deutet nicht auf eine Änderung der Temperatursensitivität in Abhängigkeit von der mittleren Temperatur der Atmungsmessung hin.

Die interannuelle Variabilität der $10^{\circ} \mathrm{C}$-Erhaltungsatmung war gering, so dass bei der Berechnung der Erhaltungsatmung Temperaturfunktionen aus den Winterhalbjahren 1997/98 und 1998/99 zusammengefasst werden konnten. Dadurch, dass nur Temperaturbeziehungen mit mittlerer Steigung und geringer $10^{\circ} \mathrm{C}$-Erhaltungsatmung berücksichtigt und solche Temperaturantwortkurven mit sehr hohen $\mathrm{Q}_{10}$-Werten ausgeschlossen wurden, konnte bei der Extrapolation zu höheren Temperaturen eine Überschätzung der Erhaltungsatmung vermieden werden. Auf diese Weise 
wurde nur das rechnerische Minimum als Erhaltungsatmung aufgefasst. Das hat zur Folge, dass auch außerhalb der Wachstumsphase positive Werte für die Wachstumsatmung auftreten konnten, wie z. B. im Solling, wo die Atmungsraten im November und Dezember vermutlich im Zusammenhang mit der Ausbildung von Frosthärte ansteigen. Dieser Anstieg wird mit dem hier gewählten Verfahren fälschlich der Wachstumsatmung zugeordnet, macht jedoch insgesamt weniger als $5 \%$ der jährlichen Wachstumsatmung des Bestandes aus (Abb. 39). Anders ist der Anstieg der Wachstumsatmung im Frühjahr, der sich vor dem Einsetzen des Radialzuwachses ergeben konnte, zu bewerten (Abb. 39). Der erhöhte Energiebedarf im Frühjahr steht zwar nicht im Zusammenhang mit dem Biomassezuwachs im Bereich der Messstelle, sondern vermutlich mit der Mobilisierung der Speicherstoffe für den bevorstehenden Blattaustrieb und das Wachstum der Jahrestriebe (SPRUGEL 1990, GANSERT et al. 2002). Auf Ebene des Baumes ist dieser Anteil der Atmung korrekterweise der Wachstumsatmung zuzuordnen (AMTHOR 2000) und entspricht der Atmungskomponente, die SPRUGEL (1990) als wachstumsbezogene Erhaltungsatmung bezeichnet.

STOCKFORS \& LINDER (1998) favorisieren alternative Verfahren, die sich an die von SPRUGEL (1990) beschriebene Regressionsmethode anlehnen und die Differenzierung von Erhaltungs- und Wachstumsatmung während der Vegetationsperiode erlauben. Die Gesamtatmung wird mit Strukturparametern wie der Oberfläche, dem Gesamt- oder Splintholzvolumen sowie der aktuellen Wachstumsrate mittels multipler Regressionsanalyse korreliert. Das Verfahren setzt aber eine enge zeitliche Kopplung von Zuwachsaktivität und Wachstumsatmung voraus. Dies ist insbesondere bei verholzten Organen von Bäumen nicht immer gegeben, da, wie in Kapitel 5.2 dargestellt, der saisonale Verlauf der Atmung gegenüber dem des Umfangzuwachses häufig zeitlich verzögert ist. Die quantitative Untersuchung des Zusammenhangs zwischen Biomassezuwachs und Atmungsrate während der Wachstumsphase ist auf der Zeitskala weniger Tage oder Wochen daher nur eingeschränkt möglich (SPRUGEL 1990). STOCKFORS \& LINDER (1998) gehen von einer Zeitverzögerung der Atmungsraten gegenüber dem Umfangzuwachs aus und verwenden bei ihren Analysen die 1 bis 25 Tage vor der Atmungsmessung ermittelte Wachstumsrate, bei der sich die engste Beziehung ergibt. Dieser Ansatz konnte in der vorliegenden Studie nicht verfolgt werden, weil die zeitliche Auflösung der Zuwachsmessungen vergleichsweise gering war. Außerdem variierten die Wachstumsraten insbesondere zu Beginn der Wachstumsphase kurzfristig sehr stark. Eine vergleichbare Variation wurde bei den Atmungsraten auch dann nicht beobachtet, wenn bei dem Versuch, die beiden Prozesse zu synchronisieren, eine zeitliche Verzögerung von 0 bis 40 Tagen berücksichtig wurde (Abb. 41). Die Wachstumsatmung und der Wachstumskoeffizient konnte im Rahmen der vorliegenden Untersuchung mit dem Regressionsverfahren auf der Zeitskala von Tagen oder Wochen nicht sinnvoll berechnet werden, so dass die quantitative Analyse der Beziehung zwischen Atmung und Wachstum, wie oben beschrieben, auf Grundlage der Jahressummen von Holzzuwachs und -atmung erfolgte.

\subsubsection{Literaturvergleich der Anteile von Wachstums- und Erhaltungsatmung sowie der Wachstumskoeffizienten}

Auf die Erhaltungsatmung entfielen im Jahr 1997 bei den Altbuchenbeständen in Solling und Göttinger Wald zwischen 35 und 55 \% der jährlichen $\mathrm{CO}_{2}$-Abgabe. Das Astholz wies die geringsten Anteile und die höchste Wachstumsatmung auf (Tab. 12).

In der Literatur reichen die Angaben für den Anteil der Erhaltungsatmung an der gesamten jährlichen $\mathrm{CO}_{2}$-Abgabe verholzter Organe von $15 \%$ (WULLSCHLEGER et al. 1995, Quercus 
alba) bis $88 \%$ (LAVIGNE 1996, Pinus banksiana). Bei Pinus contorta steigt der Anteil der Erhaltungsatmung mit zunehmendem Bestandesalter von 22 auf $63 \%$ bei 40- und 245-jährigen Beständen, wobei jedoch der absolute Wert der Erhaltungsatmung nahezu konstant und die Wachstumsatmung der Altbäumen deutlich geringer ist (RYAN \& WARING 1992). An einem einzelnen Messtermin während der Vegetationsperiode variierte der Anteil der Erhaltungsatmung zwischen den Stämmen verschiedener Bäume von 81 \% im unteren Stammbereich unterdrückter Bäume bis 27 \% im oberen Stammbereich vitaler Bäume (SPRUGEL 1990).

Die Werte der vorliegenden Studie stimmen gut mit den Angaben für 30-jährige Buchen überein, deren Erhaltungsatmung 1997 auf Bestandesebene 50 \% (DAMESIN et al. 2002) und in der Kohlenstoffbilanz diesjähriger Zweige 55 \% ausmachte (DAMESIN 2003). CESCHIA (2001) gibt für den gleichen Bestand und das Jahr 1998 einen Anteil der Erhaltungsatmung zwischen 35 und $43 \%$ an.

Die Jahressummen der spezifischen Atmungsraten der Altbuchen zeigten einen ausgeprägten interannuellen Unterschied. Die Gesamtatmung wies 1998 Werte auf, die z. T. unter $60 \%$ der Vorjahreswerte lagen. Dieser Rückgang betraf im Wesentlichen die Wachstumsatmung, die um das 1.8- bis 3.5fache abnahm. Die Erhaltungsatmung, deren temperaturnormierte Raten keine interannuelle Variation aufwiesen und die sich definitionsgemäß nur mit der Temperatur ändert, ging um maximal $12 \%$ zurück. Dementsprechend betrug ihr Anteil im zweiten Untersuchungsjahr 61 bis $78 \%$ der Gesamt- $\mathrm{CO}_{2}$-Abgabe.

Die Ursache für die interannuelle Variabilität ist in den deutlich verschiedenen Witterungsverläufen der beiden Untersuchungsjahre zu sehen, die sich unterschiedlich auf Erhaltungs- und Wachstumsatmung auswirken. Obwohl die Jahresgänge der Temperaturverläufe sehr unterschiedlich waren und die Temperaturen im Sommer 1997 um 2.25 bis $2.6{ }^{\circ} \mathrm{C}$ (Differenz für die Zeitspanne von Juni bis September) über denen des Folgejahres lagen, unterschieden sich die Jahresmittelwerte nur wenig $\left(0.3{ }^{\circ} \mathrm{C}\right)$, da die erste Jahreshälfte des zweiten Untersuchungsjahres überdurchschnittlich warm war. Die durch die Wärme im Frühjahr 1998 erhöhten Erhaltungsatmungsraten glichen die gegenüber dem Vorjahr geringeren Raten des Sommers soweit aus, dass in der Jahressumme nur geringe Differenzen bestanden.

Anders verhielt sich die Wirkung der Witterung auf die Wachstumsatmung, die sich auf die unterschiedlichen Verläufe während der Vegetationsperiode beschränkte. Die mittlere Wachstumsatmung des Zeitraums Juni bis September war 1998 nur halb so hoch wie im Vorjahr. Im Vergleich zu 1997 war der Sommer 1998 nicht nur kühler, auch die Strahlungssumme war im Zeitraum von Mai bis September deutlich geringer. Schließlich war die Vegetationsperiode 1998 durch das Einsetzen feuchtkühler Witterung im September noch verkürzt. Die ungünstigeren Witterungsbedingungen 1998 wirkten sich einerseits auf den Kohlenstoffgewinn der Bestände aus, der 1998 im Solling und im Göttinger Wald 14 und $17 \%$ unter dem des Vorjahres lag (GRIES 2004, in Vorb.), andererseits vermindern kühlere Temperaturen auch die Teilungsaktivität des Kambiums (KÖRNER 2003), so dass der Biomassezuwachs und damit einhergehend die Wachstumsatmung direkt temperaturbedingt und auch über das Substratangebot reduziert gewesen sein kann.

Für das Stammholz der Altbuchen ergaben sich Wachstumskoeffizienten zwischen 0.16 und 0.25, ohne dass signifikante interannuelle Unterschiede beim Biomassezuwachs und den Koeffizienten auftraten. Die Wachstumskoeffizienten derjenigen Grobwurzeln im Göttinger Wald, bei denen der Zuwachs die Nachweisgrenze der Umfangzuwachsmessung überstieg, bewegten sich auf gleichem Niveau. Für die Äste im Solling und Göttinger Wald wurden Werte von 0.31 und 0.51 ermittelt. 
Diese Wachstumskoeffizienten liegen innerhalb der Spanne von 0.12 bis 0.76 , die für das Stammholz verschiedener Koniferen angegeben werden (CHUNG \& BARNES 1977, RYAN et al. 1997). Bei sommergrünen Laubbäumen reichen die Angaben von 0.13 (CESCHIA et al. 2002) bis 0.38 (RYAN et al. 1997). Als Maximalwerte für die Stämme 30-jähriger Buchen geben CESCHIA et al. (2002) 0.27, DAMESIN et al. (2002) $0.38 \mathrm{~mol} \mathrm{~mol}^{-1}$ an. Der über alle Kompartimente der Altbuchen gemittelte Wachstumskoeffizient von 0.27 stimmt mit dem theoretischen Wert von 0.25 überein, den PENNING DE VRIES (1974) für die Synthese von Holz aus dessen chemischer Zusammensetzung und den biochemischen Reaktionswegen zur Synthese und Polymerisation der Strukturmoleküle ermittelt.

In der Differenz zwischen den Wachstumskoeffizienten der Stämme und Äste kommt vermutlich der unterschiedliche Anteil der „wachstumsbezogenen Erhaltungsatmung“ in den verschiedenen Kompartimenten zum Ausdruck. Die Atmung, die die Energie für das Be- und Entladen des Phloems sowie für den Transport, die Synthese und Mobilisierung von Speicherstoffen bereitstellt, wird mit dem hier gewählten Verfahren zur Differenzierung von Wachstums- und Erhaltungsatmung weitgehend der Wachstumsatmung zugeordnet (Kap. 5.5.1.1). Im Astholz der Buchen ist der Anteil nichtstruktureller Kohlenhydrate etwa viermal höher als im Stammholz (KÖRNER 2003). Ist auch der Kohlenhydratumsatz und der damit verbundene respirative C-Bedarf im Speichergewebe von Rinde und Holz der Äste höher, resultiert daraus eine höhere Wachstumsatmung. Wird das gespeicherte Substrat in den Aufbau der Blätter und das Längenwachstum der Jahrestriebe und nicht in den Biomassezuwachs des Astes im Bereich der Messstelle investiert, ergeben sich für das Astholz schließlich höhere Wachstumskoeffizienten.

Die große interannuelle Variabilität der Wachstumsatmung lässt vermuten, dass nicht nur der an den Holzzuwachs gekoppelte Energiebedarf, sondern auch der Bedarf variiert, der im Zusammenhang mit dem Aufbau und der Mobilisation von Speicherstoffen steht. Die Wachstumskoeffizienten für Holz, die aus Gaswechsel- und Radialzuwachsmessungen bestimmt werden, sind somit keine Konstanten, sondern weisen eine deutliche räumliche und vermutlich auch interannuelle Variabilität auf. Dies muss berücksichtigt werden, wenn die Wachstumsatmung von Waldbeständen aus dem Biomassezuwachs und diesen Wachstumskoeffizienten errechnet werden soll (SPRUGEL \& BENECKE 1991).

\subsubsection{Die Bestandesatmung: die Abhängigkeit der Ergebnisse von dem zur Extra- polation der Daten gewählten Modell}

Zentrales Ziel der vorliegenden Studie ist die Bestimmung des jährlichen Kohlenstoffbedarfs zweier Altbuchenbestände für die Atmung der verholzten Organe. Die Ergebnisse der Berechnung hängen wesentlich davon ab, wie detailliert die Kenntnisse über die zeitliche und räumliche Variabilität der Atmungsrate einzelner Messstellen sind und wie diese bei der Berechnung des saisonalen Verlaufs und der Hochrechnung auf Bestandesebene berücksichtigt werden.

DAMESIN et al. (2002) ermitteln die Jahressummen der oberirdischen Holzatmung anhand der unterschiedlichen volumen- und oberflächenbezogenen Atmungsraten von Stämmen und Ästen verschiedenen Durchmessers sowie den entsprechenden Strukturparametern eines 30-jährigen Buchenbestandes. Sie erhalten Werte von $27 \mathrm{~mol} \mathrm{C} \mathrm{m}^{-2}$ Bestandesgrundfläche und Jahr mit volumenbezogenen und $32 \mathrm{~mol} \mathrm{C} \mathrm{m}^{-2} \mathrm{a}^{-1}$ mit oberflächenbezogenen Raten. Weit größere Abweichungen ergeben sich, wenn das unterschiedliche Niveau der Atmungsraten von Ästen und Stämmen vernachlässigt wird und die Bestandesatmung allein über die volumen- oder oberflächenbezogene 
Atmungsrate der Stämme auf den Bestand extrapoliert wird. DAMESIN et al. (2002) nennt hierfür eine Wertespanne von 17 - 43 mol C m$~^{-2} \mathrm{a}^{-1}$, GRANIER et al. (2000) geben für denselben Bestand abhängig von der Berechnungsgrundlage Jahreswerte von 17 bis $89 \mathrm{~mol} \mathrm{C} \mathrm{m}^{-2}$ an.

Die im Rahmen der vorliegenden Untersuchung ermittelten Ergebnisse unterscheiden sich ebenfalls abhängig von dem Maß vereinfachender Annahmen bei der räumlichen Hochrechnung der Atmungsraten. In Kap. 4.4.2 erfolgt die Berechnung der Bestandesatmung in einem ersten Ansatz aus dem Jahresgang der Temperatur und der gemessenen, saisonal variierenden Temperaturantwort der volumenbezogenen Atmungsraten. Bei der räumlichen Hochrechnung werden die Tagessummen der volumenspezifischen Atmungsraten von Ästen, Stämmen und Grobwurzeln mit dem Volumenvorrat des jeweiligen Kompartiments multipliziert und zum jährlichen Kohlenstoffbedarf aufsummiert. Dabei werden dem gesamten Reisigvolumen $(\mathrm{D}<7 \mathrm{~cm})$ die Atmungsraten der Äste und dem Derbholzvorrat mit Durchmessern über $15 \mathrm{~cm}$ die der Stämme zugeordnet. Der Volumenanteil des Derbholzes mit Durchmessern zwischen 7 und $15 \mathrm{~cm}$ wird mit der aus Stamm- und Astatmung gemittelten Rate multipliziert (Kap.3.4.3). In Kap. 4.4.2.2 wird dieses empirische Verfahren um zusätzliche Informationen hinsichtlich der räumlichen Variabilität der Atmung erweitert, indem für die volumenspezifischen Atmungsraten von Ästen und Grobwurzeln eine hyperbolische Durchmesserabhängigkeit (Abb. 40) berücksichtigt wird. Die so ermittelte jährliche Holzatmung ist ca. 40 \% höher als die Jahressumme, die sich aus dem ersten, einfachen Ansatz ergibt. Im Einzelnen wird für die Grobwurzeln eine leicht erhöhte Jahressumme berechnet, die Werte für den oberirdischen C-Bedarf sind um 18 bis 34 \% höher. Besonders bedeutsam ist, dass die jährliche Atmung des Feinreisigs um ein Vielfaches ansteigt, während die Atmung von Derb- und Reisholz zurückgeht bzw. sich nur wenig ändert. Diese insbesondere bei einzelnen Durchmesserklassen sehr ausgeprägten Unterschiede verdeutlichen den großen Einfluss vereinfachender Annahmen auf die Ergebnisse der Hochrechnung.

\section{Erweiterung der Berechnungsgrundlagen bei der räumliche Hochrechung der oberirdischen Holzatmung}

Es ist naheliegend, für eine zuverlässige Schätzung der jährlichen Holzatmung der Buchenbestände alle verfügbaren Informationen bezüglich der zeitlichen und räumlichen Variabilität der spezifischen Atmungsraten in die Berechnungen einfließen zu lassen. In weiter ergänzten Berechnungen wird die in Kap. 5.4.4 diskutierte Differenzierung der Astatmung durch die Kronenposition der Blätter des jeweiligen Astes berücksichtigt und die oberirdische Bestandesatmung über die volumen- und oberflächenspezifische Atmungsrate der Kompartimente ermittelt. Der so berechnete Kohlenstoffbedarf für die Holzatmung ist unter den Ziffern 1c und 1d in Tab. 22 den Ergebnissen aus Kap. 4.4.2 (1a) und 4.4.2.2 (1b) gegenübergestellt.

Zur Berücksichtigung der Differenzierung der Astatmung in Abhängigkeit vom Kronenniveau wird der Volumenvorrat des Reisigs entsprechend der vertikalen Verteilung der Blattflächen (GRIES 2004, in Vorb.) im Verhältnis $2: 3$ auf das obere und die unteren zwei Kronendrittel verteilt. Die Anpassung der Atmungsraten an die jeweilige Kronenposition erfolgt analog zu dem in den Kapiteln 3.4.3 und 4.4.2.2 beschriebenen Verfahren. Das heißt, aus der mittleren Erhaltungsatmungsrate aller Messstellen des oberen bzw. der beiden unteren Kronendrittel (Abb. 43) und der mittleren Atmungsrate aller Äste eines Standortes wird ein Quotient errechnet, der neben der mittleren Tagessumme der spezifischen Astatmungsrate und dem Reisigvolumenvorrat der jeweiligen Kronenschicht als Faktor in die Hochrechnung der täglichen $\mathrm{CO}_{2}$-Abgabe eingeht. 
Bei der räumlichen Extrapolation über die volumenspezifische Atmungsrate (Methode 1c) wird die Durchmesserabhängigkeit der Astatmung in der Weise berücksichtigt, dass in die Berechnung der in Kap. 4.4.2.2 angegebene Quotient für das Feinreisig als zusätzlicher Faktor eingeht. Dem Reisholz $(\mathrm{D}=1-7 \mathrm{~cm})$ wird für jedes Kronenniveau eine einheitliche volumenspezifische Atmungsrate zugeordnet. Demgegenüber geht in die Hochrechnung über die oberflächenbezogenen Atmungsraten (Methode 1d) deren Durchmesserabhängigkeit ein, die über lineare Beziehungen der Atmungsraten der Stämme und der Äste unterschiedlicher Kronenposition beschrieben werden kann (Abb. 20 und Abb. 43). Eine Ausnahme stellen wiederum die Atmungsraten des Feinreisigs dar, die nicht dem linearen Verlauf der Regression folgen, sondern ebenso hoch sind wie die der Äste mit Durchmessern von $2 \mathrm{~cm}$. Dem Feinreisig wird daher die gleiche oberflächenbezogene Atmungsrate zugeordnet, wie der Durchmesserklasse von 1 bis $3 \mathrm{~cm}$. Die Berechnung der Atmungsrate des Derbholzes mit Durchmessern von $7-15 \mathrm{~cm}$ erfolgt mit der mittleren spezifischen Atmung der Äste des unteren Kronendrittels und der Stämme.

Geht die räumliche Variabilität der Astatmung auf diese Weise in die Berechnung der oberirdischen Holzatmung der Bestände ein, ergeben sich für den jährlichen Kohlenstoffbedarf des Reisigs im Mittel um $25 \%$ geringere Werte als bei Methode 1b (Kap. 4.4.2.2), die von einer hyperbolischen Durchmesserabhängigkeit der Astatmung ausgeht. In den geringeren Werten spiegelt sich einerseits der höhere Volumenanteil wider, der den unteren beiden Kronendritteln zugeordnet wurde, andererseits weichen die spezifischen Atmungsraten der unteren Kronenpositionen stärker vom jeweiligen Mittelwert der Messstellen ab, so das die spezifische Atmungsrate insgesamt geringer ist. Die Verwendung der Atmungsrate des unteren Kronenniveaus hat auf das Ergebnis des respirativen CBedarfs des Derbholzes mit Durchmessern von 7 bis $15 \mathrm{~cm}$ nur geringen Einfluss, die Gesamtatmung des Derbholzes ist etwas geringer. Erfolgt die Hochrechnung auf Grundlage der oberflächenbezogenen Atmungsraten unter Berücksichtigung der Durchmesserabhängigkeit, ist der Kohlenstoffbedarf von Derb- und Reisholz noch einmal ca. $10 \%$ geringer als bei der Extrapolation über die volumenspezifische Atmung. Die Differenz resultiert vorwiegend aus dem um bis zu $55 \%$ geringeren Kohlenstoffbedarf des Feinreisigs.

Um zu beurteilen, welche der in Tab. 22 unter der Ziffer 1 aufgeführten Ergebnisse der oberirdischen Holzatmung als zuverlässige Schätzung zu bewerten sind, sollen die verschiedenen Positionen und die Ursachen für ihre Variabilität bei der Hochrechnung noch einmal zusammenfassend betrachtet werden.

\section{Der Anteil der Atmung der intermediären Durchmesserklasse mit D = 7-15 cm}

Da die Berechnung der Jahressumme des respirativen Kohlenstoffbedarfs für das Derbholz mit Durchmessern über $15 \mathrm{~cm}$ bei den Ansätzen 1a bis 1c in gleicher Weise erfolgt, ist die gegenüber den Ergebnissen von Methode 1a geringere Derbholzatmung auf die niedrige spezifische Atmungsrate der Äste zurückzuführen. Diese geht zu $50 \%$ in die Atmung der Durchmesserklasse $7-15 \mathrm{~cm}$ ein. Trotz des geringen Anteils dieser Durchmesserklasse am Derbholzvolumen $(<5 \%)$ macht die für sie berechnete Atmungsrate 30 bzw. 55 \% der Derbholzatmung im Solling und Göttinger Wald aus, wenn, wie bei Methode 1a, mit einer mittleren Atmungsrate extrapoliert wird, ohne nach Durchmesser oder Kronenniveau zu differenzieren. Dieser hohe Anteil resultiert aus der hohen spezifischen Atmungsrate der Äste, deren Zweijahresmittel die Stammatmung im Solling bzw. Göttinger Wald um das 9- bzw. 24fache übersteigt. Aus der Verringerung der spezifischen Atmungsrate um 60 bis $70 \%$ bei den Berechnungen nach Methode $1 \mathrm{~b}$ und 1c resultiert die in der Summe 12 bis $35 \%$ geringere Derbholzatmung. Der große Einfluss der Astatmung auf die 
Atmungsrate dieser Durchmesserklasse, die auch bei den Ergebnissen nach Ansatz 1b bis 1d noch 18 bis $30 \%$ der Derbholzatmung ausmacht, wirft die Frage auf, ob die lineare Interpolation der spezifischen Atmungsraten von Stämmen und Ästen die Situation im Bestand realistisch widerspiegelt. Eine Fehleinschätzung der Atmung dieser Durchmesserklasse läge dann nahe, wenn ein großer Anteil ihres Volumenvorrates aus Stammholz bestünde, so dass die spezifische Atmungsrate der Stämme mit stärkerem Gewicht einfließen müsste. Jedoch spricht schon der geringe Anteil von Bäumen mit Durchmessern unter $20 \mathrm{~cm}$ BHD, bei denen ein wesentlicher Teil des Stammholzes auf die betreffende Durchmesserklasse entfällt, gegen diese Vermutung (Abb. 32). Detaillierte Analysen der Erntedaten (Daten nicht dargestellt) zeigen, dass in beiden Beständen über $95 \%$ des Volumens dieser Durchmesserklasse im Kronenraum lokalisiert ist. Für die Atmung kann somit eine intermediäre Stellung zwischen Ästen und Stämmen angenommen werden.

Ein Hinweis darauf, dass die spezifische Atmungsrate dennoch vergleichsweise hoch eingeschätzt wird, ergibt sich aus der Punktmessung vom 13.11.1998. Die dabei im unteren Kronendrittel untersuchten Äste mit Durchmessern von 9 bis $14 \mathrm{~cm}$ wiesen im Mittel doppelt so hohe volumenspezifische Atmungsraten wie die Stämme auf. Geht als Atmung des Derbholzes dieser Durchmesserklasse die um den Faktor 2 erhöhte volumenspezifische Stammatmungsrate in die Berechnung der Bestandesatmung ein, ergibt sich im Vergleich zu den Werten von Methode 1c für den Solling eine unveränderte, für den Göttinger Wald eine $17 \%$ geringere Jahressumme für die Derbholzatmung, dessen gesamte oberirdische Holzatmung dann $4 \%$ geringer ist.

Die Derbholzatmung kann also bei linearer Interpolation der volumenspezifischen Ast- und Stammatmung stark überschätzt werden, wenn die Astatmung nicht entsprechend ihrer Durchmesserabhängigkeit oder dem Kronenniveau differenziert wird. Die gesamte oberirdische Holzatmung kann allein dadurch gegenüber dem minimalen Referenzwert (Methode 1d) bei der Methode 1a um bis zu $25 \%$ höher sein. Die in Tab. 22 für die Methoden $1 \mathrm{~b}$ bis $1 \mathrm{~d}$ angegebenen Werte für die Derbholzatmung können aufgrund der Ergebnisse der Punktmessung als oberer Wert einer realistisch anzusehenden Spanne betrachtet werden, deren untere Grenze etwa 20 \% darunter liegt.

\section{Die Bedeutung der Feinreisig-Atmung}

Variabler und mit größerem Einfluss auf die berechnete oberirische Holzatmung sind die Ergebnisse der Feinreisigatmung, die gegenüber denen der Methode 1a 1.8- bis 6fach höhere Werte erreicht (Tab. 22). Hohe volumenspezifische Atmungsraten von Buchenästen und „Stämmen“ unter $1 \mathrm{~cm}$ Durchmesser wurden von verschiedenen Autoren gemessen (GANSERT 1995, DAMESIN et al. 2002, DAMESIN 2003, D. GRIES pers. Mitteilung) und müssen bei der Extrapolation berücksichtigt werden. DAMESIN et al. (2002) ermitteln für Sprossachsen bis $5 \mathrm{~mm}$ Durchmesser einen Anteil an der gesamten oberirdischen Holzatmung von 23 bis $31 \%$. Wird die Feinreisigatmung nach Methode 1c oder 1d ermittelt, so liegt ihr Anteil mit Werten von 14 bis $35 \%$ in einer vergleichbaren Größenordnung. Bei der Beurteilung der in Tab. 22 zusammengefassten Ergebnisse muss beachtet werden, dass beide Ansätze, denen die volumenbezogene Atmungsrate zugrunde liegt, von einer hyperbolischen Durchmesserabhängigkeit der Atmungsrate ausgehen (Abb. 40).

Da die Funktion im Durchmesserbereich unter $1 \mathrm{~cm}$ eine maximale Steigung aufweist, ist der Quotient, mit dem die mittlere Atmungsrate der Messstellen auf die des Feinreisigs skaliert wird, besonders sensitiv gegenüber dem gewählten Durchmesser, mit dem die Erhaltungsatmung des Feinreisigs aus der Durchmesserfunktion ermittelt wird (Abb. 40). Mit Durchmessern, die vom hier verwendeten Wert $(\mathrm{D}=5 \mathrm{~mm}) \mathrm{um} \pm 2 \mathrm{~mm}$ abweichen, ergeben sich für den Bestand im Göttinger 
Wald für das Jahr 1997 Summen der Feinreisigatmung zwischen 8.5 und $17.8 \mathrm{~mol} \mathrm{C} \mathrm{m}^{-2} \mathrm{a}^{-1}$. Basiert die Berechnung auf der oberflächenbezogenen Atmung, ist nicht der Quotient, mit dem die Atmungsrate skaliert wird, sondern die Oberfläche selbst (Kap. 3.3.3) die gegenüber dem angenommen Durchmesser sensitive Größe.

Trotz dieser Unsicherheit stellt allein durch die Berücksichtigung der hohen Atmungsraten des Feinreisigs die mit den Methoden 1c und 1d errechnete Feinreisigatmung gegenüber Methode 1a die bessere Schätzung dar. Wird der Berechnung der mittlere Durchmesser des Feinreisigs der 1996 vermessenen Buche von $3.2 \mathrm{~mm}$ zugrunde gelegt, kann die jährliche $\mathrm{CO}_{2}$-Abgabe des Feinreisigs über den in Tab. 22 angegebenen Werten liegen.

\section{Die nach Methode 1c und 1d berechnete Holzatmung der Bestände kann als die beste Schätzung betrachtet werden.}

Zusammenfassend sind die in Tab. 22 mit den Methoden 1c und 1d ermittelten Jahressummen der Atmung als die zuverlässigste Schätzung zu betrachten. Für den respirativen Kohlenstoffbedarf des Derbholzes kann von einer guten Näherung ausgegangen werden. Die Reisholzatmung scheint auf Grundlage der volumenbezogenen Atmungsrate ohne weitere Differenzierung nach Durchmesserklassen dargestellt werden zu können, wenn die räumliche Differenzierung im Kronenraum, die bislang nur in Ansätzen erfasst ist, berücksichtig wird. Besonders hervorzuheben ist die große Bedeutung der Feinreisigatmung, die trotz des geringen Volumenanteils von 1 bis $2 \%$ die gleiche Größenordnung erreichen kann wie die Reis- und Derbholzatmung und zu 14 bis $35 \%$ an der respirativen $\mathrm{CO}_{2}$-Produktion der oberirdischen verholzten Organe beteiligt ist. Die Kenntnisse hinsichtlich des zeitlichen, vor allem aber der räumlichen Variabilität der Feinreisigatmung der Buche beschränken sich bislang im wesentlichen auf die Arbeiten von CESCHIA (2001) und DAMESIN et al. (2003). Ebenso wichtig wie die spezifische Atmungsrate selbst ist die genaue Kenntnis des Biomassevorrates des Feinreisigs.

\section{Die Bedeutung der zeitlichen Variabilität des $\mathbf{Q}_{10}$-Wertes}

Neben den komplexeren Verfahren sind in Tab. 22 unter den Ziffern 2 und 3 Ergebnisse von Berechnungen zusammengestellt, bei denen vereinfachende Annahmen hinsichtlich der zeitlichen und räumlichen Extrapolation auf die Bestandesebene gemacht werden.

Unter Ziffer 2 sind Ergebnisse zusammengefasst, mit denen der Einfluss des Q $_{10}$-Wertes und der Temperaturantwortkurven auf die Berechnung der oberirdischen Holzatmung abgeschätzt werden soll. Die räumliche Hochrechnung entspricht dem Ansatz 1a. Unter Ziffer 2a erfolgt die zeitliche Interpolation mit den Jahresmittelwerten der $Q_{10}$-Werte aller Messstellen eines Kompartiments (Abb. 16). Stärker vereinfachend erfolgt die Berechnung bei Methode 2b, bei der die saisonalen Verläufe mit einem einheitlichen $\mathrm{Q}_{10}$-Wert von 2 für alle Kompartimente ermittelt werden. Im Ansatz 2c schließlich werden nicht die für die nächtlichen Atmungsraten bestimmten Temperaturbeziehungen, sondern die für die vollständigen Datensätze verwendeten Temperaturantwortkurven berücksichtigt (Kap. 5.1.4).

Aus keiner der vereinfachenden Annahmen resultiert ein nennenswerter Unterschied in der Jahressumme der oberirdischen Bestandesatmung. Zu entsprechenden Befunden gelangt auch SPRUGEL (1990), dessen Resultate unabhängig davon sind, ob die Atmungsraten mit einem $Q_{10}$-Wert von 2 oder 2.3 verrechnet werden. Die geringe zeitliche Variabilität des $\mathrm{Q}_{10}$-Wertes lässt bei der Bestimmung der Holzatmung der Buchenbestände ein deutlich vereinfachtes Verfahren der zeitlichen Interpolation zu. Der Einfluss der im saisonalen Verlauf kurzfristig variierenden Temperatur- 
antwort wird in der Jahressumme nivelliert, die saisonale Variabilität der temperaturnormierten Atmungsrate überdeckt die kurzfristige Temperaturwirkung.

Tab. 22: Vergleich der Ergebnisse der Jahressummen oberirdischer Holzatmung, bei deren Berechnung die räumliche Variabilität der volumen- (1a-c, 3a, 3b) oder oberflächenspezifischen (1d, 3c, 3d) Atmungsraten sowie die Variabilität des $\mathrm{Q}_{10}$-Wertes (2a-c) in unterschiedlicher Weise berücksichtigt wurde (Erläuterungen im Text).

\begin{tabular}{|c|c|c|c|c|c|c|c|c|}
\hline \multirow{2}{*}{ Methode } & \multicolumn{4}{|c|}{ Solling } & \multicolumn{4}{|c|}{ Göttinger Wald } \\
\hline & \multicolumn{2}{|c|}{1997} & \multicolumn{3}{|c|}{$\begin{array}{l}1998 \\
\underset{(\%)}{\operatorname{mol~CO}} \mathrm{m}^{-2} \mathrm{a}^{-1}\end{array}$} & 1997 & \multicolumn{2}{|c|}{$\begin{array}{c}1998 \\
\text { Derbholz } \\
\text { Reisholz } \\
\text { Feinreisig }\end{array}$} \\
\hline \multirow{3}{*}{$1 a$} & & 11.0 & & 10.2 & & 15.6 & & 11.5 \\
\hline & 20.3 & 7.9 & 15.6 & 4.6 & 36.7 & 17.9 & 26.0 & 12.3 \\
\hline & & 1.4 & & 0.8 & & 3.2 & & 2.2 \\
\hline \multirow{3}{*}{$1 b$} & & 8.9 & & 9.0 & & 10.0 & & 7.6 \\
\hline & $\begin{array}{l}21.2 \\
(34)\end{array}$ & 9.1 & $\begin{array}{l}19.6 \\
(26)\end{array}$ & 5.3 & $\begin{array}{l}43.5 \\
(19)\end{array}$ & 16.7 & $\begin{array}{l}30.7 \\
(18)\end{array}$ & 11.5 \\
\hline & & 9.1 & & 5.3 & & 16.8 & & 11.6 \\
\hline \multirow{3}{*}{$1 \mathrm{c}$} & & 8.7 & & 8.8 & & 9.5 & & 7.2 \\
\hline & $\begin{array}{l}23.0 \\
(13)\end{array}$ & 6.6 & $\begin{array}{l}11.2 \\
(10)\end{array}$ & 3.9 & $\begin{array}{l}33.1 \\
(-10)\end{array}$ & 12.2 & $\begin{array}{c}23.5 \\
(-9)\end{array}$ & 8.4 \\
\hline & & 7.7 & & 4.5 & & 11.5 & & 7.9 \\
\hline \multirow{3}{*}{$1 d$} & & 8.3 & & 8.1 & & 8.6 & & 6.9 \\
\hline & $\begin{array}{l}17.3 \\
(-15)\end{array}$ & 5.8 & $\begin{array}{l}13.5 \\
(-14)\end{array}$ & 3.4 & $\begin{array}{l}25.2 \\
(-31)\end{array}$ & 10.6 & $\begin{array}{l}17.9 \\
(-31)\end{array}$ & 7.1 \\
\hline & & 3.2 & & 1.9 & & 6.0 & & 4.0 \\
\hline \multirow{3}{*}{$2 a$} & & 11.4 & & 10.4 & & 15.9 & & 12.0 \\
\hline & $\begin{array}{c}20.9 \\
\text { (3) }\end{array}$ & 8.0 & $\begin{array}{r}10.0 \\
\text { (2) }\end{array}$ & 4.7 & $\begin{array}{r}31.4 \\
\text { (2) }\end{array}$ & 18.2 & $\begin{array}{l}27.3 \\
(5)\end{array}$ & 13.0 \\
\hline & & 1.4 & & 0.8 & & 3.3 & & 2.3 \\
\hline \multirow{3}{*}{$2 b$} & & 11.2 & & 10.3 & & 15.8 & & 12.1 \\
\hline & $\begin{array}{c}20.3 \\
(0)\end{array}$ & 7.7 & $\begin{array}{c}15.7 \\
(1)\end{array}$ & 4.6 & $\begin{array}{c}36.8 \\
(0)\end{array}$ & 17.9 & $\begin{array}{c}27.8 \\
(7)\end{array}$ & 13.3 \\
\hline & & 1.4 & & 0.8 & & 3.2 & & 2.4 \\
\hline \multirow{3}{*}{$2 c$} & & 10.8 & & 10.3 & & 15.1 & & 11.3 \\
\hline & $\begin{array}{c}19.7 \\
(-3)\end{array}$ & 7.6 & $\begin{array}{c}15.4 \\
(-1)\end{array}$ & 4.4 & $\begin{array}{c}35.2 \\
(-4)\end{array}$ & 17.0 & $\begin{array}{c}25.6 \\
(-1)\end{array}$ & 12.2 \\
\hline & & 1.4 & & 0.8 & & 3.0 & & 2.2 \\
\hline \multirow{3}{*}{$3 a$} & & 9.1 & & 9.3 & & 13.8 & & 10.6 \\
\hline & $\begin{array}{l}28.3 \\
(39)\end{array}$ & 8.5 & $\begin{array}{l}\mathbf{2 0 . 5} \\
(31)\end{array}$ & 4.9 & $\begin{array}{l}49.0 \\
(34)\end{array}$ & 15.5 & $\begin{array}{l}34.9 \\
(34)\end{array}$ & 10.7 \\
\hline & & 10.7 & & 6.2 & & 19.7 & & 13.6 \\
\hline \multirow{3}{*}{$3 b$} & & 7.6 & & 8.4 & & 7.3 & & 5.7 \\
\hline & $\begin{array}{c}8.5 \\
(-58)\end{array}$ & 0.7 & $\begin{array}{r}9.3 \\
(-41)\end{array}$ & 0.8 & $\begin{array}{c}8.0 \\
(-78)\end{array}$ & 0.7 & $\begin{array}{c}6.3 \\
(-76)\end{array}$ & 0.5 \\
\hline & & 0.1 & & 0.1 & & 0.1 & & 0.1 \\
\hline \multirow{3}{*}{$3 c$} & & 7.4 & & 7.7 & & 6.6 & & 5.6 \\
\hline & $\begin{array}{c}8.1 \\
(-60)\end{array}$ & 0.6 & $\begin{array}{c}8.5 \\
(-46)\end{array}$ & 0.7 & $\begin{array}{r}7.3 \\
(-80)\end{array}$ & 0.6 & $\begin{array}{c}0.2 \\
(-76)\end{array}$ & 0.5 \\
\hline & & 0.1 & & 0.1 & & 0.1 & & 0.1 \\
\hline \multirow{3}{*}{$3 d$} & & 9.7 & & 10.2 & & 10.3 & & 8.7 \\
\hline & $\begin{array}{l}\mathbf{2 4 . 2} \\
(19)\end{array}$ & 7.3 & $\begin{array}{l}25.4 \\
(63)\end{array}$ & 7.6 & $\begin{array}{l}25.7 \\
(-30)\end{array}$ & 7.7 & $\begin{array}{l}21.8 \\
(-16)\end{array}$ & 6.5 \\
\hline & & 7.3 & & 7.6 & & 7.7 & & 6.6 \\
\hline
\end{tabular}




\section{Der Einfluss vereinfachender Annahmen bei der räumlichen Hochrechnung der ober- irdischen Holzatmung}

Unter Ziffer 3 sind Ergebnisse zusammengefasst, deren Berechnung die räumliche Variabilität der spezifischen Atmungsraten in unterschiedlicher Weise vereinfachend berücksichtigt. Die zeitliche Extrapolation erfolgt wie unter Ziffer 1. In Ansatz 3a wird analog zu Methode 1b eine hyperbolische Funktion für die Durchmesserabhängigkeit der volumenbezogenen Atmungsraten zugrunde gelegt. Bei der Berechnung der Funktion werden aber nicht nur die Atmungsraten der Äste (Methode 1b, Abb. 40) sondern auch die des Derbholzes berücksichtigt. Somit erfolgt eine Korrektur der Atmungsraten aller sieben Durchmesserklassen. Hieraus resultiert eine jährliche Bestandesatmung der verholzten Organe, die für beide Standorte und Untersuchungsjahre die Werte aller anderen Berechnungen übersteigt. Neben den hohen Werten für die Feinreisigatmung, deren Ursachen bereits diskutiert wurden, ergeben sich aufgrund eines höheren Kohlenstoffbedarfs der Durchmesserklassen 3 und $4(25 \geq D>7 \mathrm{~cm})$ gegenüber den Referenzwerten der Methoden 1c und $1 \mathrm{~d}$ im Göttinger Wald deutlich höhere Raten für die Stammatmung.

In die Berechnungen der Ergebnisse $3 b$ bis $3 d$ gehen ausschließlich die Atmungsraten der Stämme ein. Dabei wird die Bestandesatmung als Produkt von volumenbezogener Atmungsrate und Bestandesvolumen (3b) oder als Produkt von Holzoberfläche und oberflächenspezifischer Atmungsrate ermittelt (3c). Letzteres wird entsprechend der Durchmesserabhängigkeit der Stammatmung korrigiert (Abb. 20). Die unter 3d genannten Werte entsprechen - bezugnehmend auf den Befund, dass die oberflächenspezifischen Atmungsraten verschiedener Kompartimente am wenigsten variieren (Abb. 22) - dem Produkt von oberflächenspezifischer Stammatmung und der Holzoberfläche der Bestände.

Die große Bedeutung der Reisholz- und Feinreisigatmung ist in den vorangegangen Abschnitten deutlich geworden, so dass die oberirische Holzatmung erwartungsgemäß geringer ist, wenn die Berechnung allein auf Messungen der Stammatmung basiert. Die Atmungsraten des Derbholzes werden leicht, die des Reisigs $(\mathrm{D}<7 \mathrm{~cm})$ jedoch um das 10- bis 36fache unterschätzt, so dass die Jahressummen 32 bis $78 \%$ unter den Werten der Berechnungsansätze 1c und 1d liegen. Die geringste Abweichung von diesen Referenzwerten ergibt sich unter Vernachlässigung jeder Durchmesserbeziehung aus dem Produkt von gesamter Holzoberfläche und oberflächenbezogener Stammatmung. Der hohe Wert für den Solling 1998 spiegelt aber die Problematik der unkritischen Verwendung dieses Ansatzes wider, der die hohe interannuelle Variabilität der Atmung des Astholzes nicht berücksichtigt und bei dessen Anwendung Abweichungen vom Referenzwert möglich sind, die mit bis zu $12 \mathrm{~mol} \mathrm{~m}^{-2} \mathrm{a}^{-1}$ fast die gleiche Größenordnung erreichen wie die Kohlenstoffmenge im jährlichen Stammzuwachs des Bestandes im Solling.

\subsubsection{Die Holzatmung als Teil der Kohlenstoffbilanz}

\section{Vergleich der oberirdischen und gesamten Holzatmung mit Angaben in der Literatur}

Der jährliche Kohlenstoffbedarf für die oberirdische Holzatmung liegt entsprechend der im vorangegangnen Kapitel als beste Schätzung eingestuften Berechnung zwischen 13.5 und $23.5 \mathrm{~mol} \mathrm{C} \mathrm{m}$ im Solling und zwischen 17.8 und $33.1 \mathrm{~mol} \mathrm{C} \mathrm{m}^{-2}$ im Göttinger Wald. Das Reisholz, das rund $10 \%$ des Volumenvorrates ausmacht, ist mit 40 bis $70 \%$ an der jährlichen $\mathrm{CO}_{2}$-Abgabe beteiligt. Diese Werte stimmen gut mit der Spanne überein, die DAMESIN et al. (2002) mit 27.2 bis 32.2 und 
CESCHIA (2001) mit 20.4 und $24.1 \mathrm{~mol} \mathrm{C} \mathrm{m}^{-2} \mathrm{a}^{-1}$ für einen 30-jährigen Buchenbestand ermitteln. Auch bei den jüngeren Buchen sind die Äste, auf die nur ein kleiner Teil der Reisholzfraktion entfällt, zu mindestens $40 \%$ an der oberirdischen Holzatmung beteiligt.

Die Ergebnisse für diese Buchenwälder liegen deutlich über der Holzatmung, die für verschiedene Koniferenbestände der borealen Zone mit 2.2 und $7.92 \mathrm{~mol} \mathrm{C} \mathrm{m}^{-2} \mathrm{a}^{-1}$ (RYAN et al. 1997) und der gemäßigten Klimate mit 8.09 und $4.5 \mathrm{~mol} \mathrm{C} \mathrm{m}^{-2} \mathrm{a}^{-1}$ (RYAN \& WARING 1992, Pinus contorta, LAW et al. 1999, Pinus ponderosa) angegeben werden. Andere Untersuchungen nennen für die Holzatmung von Koniferenwäldern den Altbuchenbeständen ähnliche z. T. aber auch deutlich höhere Werte. So geben z. B. XU et al. (2001) für einen 8-jährigen Pinus ponderosa Bestand einen Wert von $17 \mathrm{~mol} \mathrm{C} \mathrm{m}^{-2} \mathrm{a}^{-1}$ an, LAVIGNE et al. (1996) beziffern allein die Erhaltungsatmung von Abies balsamea mit 10 bis $40 \mathrm{~mol} \mathrm{C} \mathrm{m}^{-2} \mathrm{a}^{-1}$. RYAN et al. (1996) messen in unterschiedlich wasserund stickstoffversorgten Pinus radiata-Beständen eine Holzatmung von 31 bis $61 \mathrm{~mol} \mathrm{C} \mathrm{m}^{-2} \mathrm{a}^{-1}$. KINERSON (1975) schließlich gibt in seiner Studie an Pinus taeda einen Jahreswert von $104 \mathrm{~mol} \mathrm{C} \mathrm{m}^{-2} \mathrm{a}^{-1}$ für die oberirdische Holzatmung an.

Auch die Spanne der für Laubwälder angegebenen Werte der Holzatmung, die aus Küvettenmessungen auf den Bestand hochgerechnet wurde, ist groß. Sie reicht von 6.5 bis $10.3 \mathrm{~mol} \mathrm{C} \mathrm{m}^{-2} \mathrm{a}^{-1}$ für Populus tremuloides-Bestände in der borealen Zone (RYAN et al. 1997) bis $130 \mathrm{~mol} \mathrm{C} \mathrm{m}^{-2} \mathrm{a}^{-1}$ für tropische Regenwälder (YODA 1967). Laubwälder der gemäßigten Klimate weisen einen ähnlichen Kohlenstoffbedarf für die Holzatmung wie die Altbuchenbestände auf. EDWARDS \& HANSON (1996) beziffern die oberirdische Holzatmung eines Eichenmischwaldes mit 12.4 bis $17 \mathrm{~mol} \mathrm{C} \mathrm{m}^{-2} \mathrm{a}^{-1}$. Für einen 50-jährigen Bestand von Liriodendron tulipifera und einen Eichen-Kiefernmischwald sind die Angaben mit 55 und 35 - $46 \mathrm{~mol} \mathrm{C} \mathrm{m}^{-2} \mathrm{a}^{-1}$ höher als die für die hier untersuchten Buchenbestände (WOODWELL \& BOTKIN 1970, EDWARDS et al. 1980). Die Holzatmung eines tropischen Regenwaldes von 18.3 bis $30 \mathrm{~mol} \mathrm{C} \mathrm{m}^{-2} \mathrm{a}^{-1}$ zeigt mit den Altbuchen übereinstimmende Werte (RYAN et al. 1994a).

Seit Beginn des vergangenen Jahrzehnts wird zur Ermittlung der Kohlenstoffbilanz von Wäldern vermehrt der $\mathrm{CO}_{2}$-Austausch zwischen den Waldbeständen und der Atmosphäre mit der EddyKovarianz-Methode erfasst. Die Atmung der oberirdischen Organe wird dabei als Differenz zwischen der Gesamtatmung des Bestandes und der mit Küvettensystemen bestimmten Bodenatmung berechnet. Die Holzatmung kann bei laubwerfenden Bäumen (unter Vernachlässigung der Atmung des Unterwuchses) dann nur während der Vegetationsruhe ermittelt werden. Die in der Vegetationsperiode gemessene oberirdische Atmung beinhaltet auch die Blattatmung, die hinsichtlich des saisonalen Verlaufs der Wachstumsatmung und der Bedeutung anderer sie beeinflussender Faktoren (Transport- und Reparaturprozesse, Seneszenz) deutlich von der Holzatmung abweichen kann. Für verschiedene Buchenwälder Europas liegt die mit der Eddy-Kovarianz-Methode bestimmte oberirdischen Atmung zwischen 6.5 und $54 \mathrm{~mol} \mathrm{C} \mathrm{m}^{-2} \mathrm{a}^{-1}$ (LONGDOZ et al. 2000). Die Summe der hier untersuchten Altbuchenbestände aus oberirdischer Holzatmung und Blattatmung, die GRIES (2004) auf Grundlage von Küvettenmessungen auf die Bestandesebene extrapoliert,

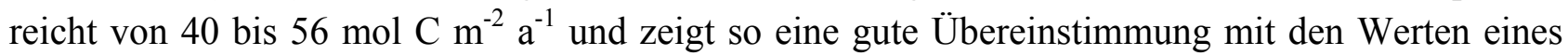
80-jährigen Buchenbestandes in Dänemark (PILEGAARD et al. 2001) und den für 1998 genannten Werten 30-jähriger Buchen in Frankreich (LONGDOZ et al. 2000).

Die unterirdische Holzatmung geht bislang erst bei wenigen Untersuchungen als separat gemessene Größe in die Ermittlung der Kohlenstoffbilanz ein. Der auf die Bestandesgrundfläche bezogene C-Bedarf für die Grobwurzelatmung der Altbuchen beträgt 8.6 bis $13.3 \mathrm{~mol} \mathrm{C} \mathrm{m}^{-2} \mathrm{a}^{-1}$ und stimmt mit den Angaben von RYAN et al. (1997) für Populus tremuloides und Picea mariana (10 mol Cm ${ }^{-2}$ 
$\mathrm{a}^{-1}$ ) ebenso überein wie mit der Grobwurzelatmung von Pinus radiata, die RYAN et al. (1996) mit 6.7 bis $16.5 \mathrm{~mol} \mathrm{C} \mathrm{m}^{-2} \mathrm{a}^{-1}$ angeben.

\section{Sind die Angaben zur Atmung verholzter Organe auf Bestandesebene vergleichbar?}

Die Bestandesatmung der verholzten Organe integriert eine Vielzahl verschiedener Faktoren, wie Bestandesalter, -struktur und -dichte, Biomassevorräte und -zuwachs, die klimatischen Bedingungen und schließlich art- und zum Teil organspezifische Atmungsraten, so dass die möglichen Ursachen für die große Variabilität der jährlichen Holzatmung der Waldbestände vielfältig sind. Zudem wird der Vergleich der Ergebnisse dadurch erschwert, dass, wie im vorangegangenen Kapitel dargestellt, unterschiedliche Datengrundlagen und Extrapolationsverfahren die Resultate maßgeblich beeinflussen können. RYAN et al. (1994a) weisen in einem Vergleich der Kohlenstoffumsätze verschiedener tropischer Regenwälder darauf hin, dass auch unter Berücksichtigung aller Unsicherheiten bei der Bestimmung von Biomasse und Kohlenstoffflüssen vor allem solche Untersuchungen besonders hohe Werte für die jährliche Holzatmung nennen, bei denen die Hochrechnung über die oberflächenbezogene Atmungsrate und die Oberfläche der verholzten Biomasse erfolgt. Dass dieses Verfahren zu sehr hohen Werten führen kann, zeigen die Ergebnisse von GRANIER et al. (2000) sehr deutlich (Kap.5.5.2). Demgegenüber liefert die Hochrechnung über die oberflächenbezogenen Atmungsraten der Stämme bei den hier untersuchten Altbuchen eine recht gute Schätzung der jährlichen Holzatmung (Tab. 22, Methode 3d). Dies zeigt, dass dieses Verfahren nicht generell zu überhöhten Werten führt.

Wird die Holzatmung über die volumenspezifischen Atmungsraten extrapoliert, sind bei der Buche die im Vergleich zum Stammholz hohen volumenspezifischen Atmungsraten von Ästen und Grobwurzeln von wesentlicher Bedeutung für das Resultat. Aus der Berechnung der jährlichen Holzatmung allein auf Grundlage der volumenspezifischen Stammatmung resultieren hingegen die niedrigsten Jahressummen. Zwar unterscheidet sich die volumenspezifische Astatmung bei Pinus strobus (VOSE \& RYAN 2002) und Eucalyptus saligna (RYAN et al. 2004) nicht von der Stammatmung und bei Nothofagus truncata stimmen volumenbezogene Grobwurzel- und Stammatmung überein (BENECKE 1985), so dass bei diesen Arten die Übertragung der (splintholz-)volumenbezogenen Stammatmung auf die Volumenvorräte von Reisholz und Grobwurzeln möglich erscheint. Bei anderen Baumarten jedoch, werden übereinstimmend mit den Ergebnissen der vorliegenden Studie gegenüber der Stammatmung deutlich höhere volumenspezifische Raten bei den Ästen (NEGISI 1974, BENECKE 1985, SPRUGEL 1990, RYAN et al. 1996, REDDIG \& GRIES 1999, CESCHIA 2001, BOSC et al. 2003) und bei den Grobwurzeln (LINDER \& TROENG 1981, RYAN et al. 1996, RYAN et al. 1997, REDDIG \& GRIES 1999, VOSE \& RYAN 2002) angegeben, so dass bei diesen Arten die verbreitete Methode zur Ermittlung der Bestandesatmung allein auf Grundlage von Atmungsmessungen an Stämmen und einer Hochrechnung über das gesamte (Splint-) Holzvolumen die Holzatmung deutlich unterschätzen kann. Insofern ist es bemerkenswert, dass die niedrigsten der o. g. Angaben für die oberirdische Holzatmung aus solchen Untersuchungen stammen, bei denen die Astatmung nicht separat ermittelt wurde (RYAN \& WARING 1992, RYAN et al. 1994a, RYAN et al. 1997, LAW et al. 1999), und dass solche Studien, die die Ast- und/oder Grobwurzelatmung separat einbeziehen, mittlere bis hohe Werte für die oberirdische (RYAN et al. 1996, LAW et al. 1999, CESCHIA 2001, DAMESIN et al. 2002) bzw. gesamte Holzatmung (RYAN et al. 1997) angeben.

Das Verhältnis zwischen den Jahresummen der Holzatmung von Solling und Göttinger Wald ist in beiden Untersuchungsjahren etwa gleich. Die höhere Holzatmung im Göttinger Wald ist im 
Wesentlichen auf die unterschiedlichen Biomassevorräte und auf die im Mittel höheren volumenspezifischen Atmungsraten der Äste zurückzuführen. Die vergleichbaren Werte des jüngeren Buchenbestandes in Frankreich, dessen Biomasse nur etwa ein Fünftel der Altbuchenbestände beträgt, resultieren aus den im Mittel deutlich höheren spezifischen Atmungsraten (DAMESIN et al. 2002). Weil das Stammholz der jüngeren Bäume höhere volumenspezifische Atmungsraten aufweist, finden auch RYAN et al. (1997) bei einem Vergleich von 14- und 65-jährigen Pinus banksiana Beständen trotz unterschiedlicher Biomassevorräte vergleichbare Jahressummen für die oberirdische Holzatmung.

\section{Der Anteil des Kohlenstoffbedarfs der Holzatmung am Kohlenstoffgewinn}

Die Bedeutung der oberirdischen bzw. gesamten Holzatmung ( $\mathrm{R}_{\text {Wood,ag }} \mathrm{bzw} . \mathrm{R}_{\text {Wood }}$ ) für die Kohlenstoffbilanz der Waldökosysteme lässt sich aus ihrer Relation zu anderen Kohlenstoffflüssen abschätzen. In der Literatur werden die Verhältnisse zwischen $\mathrm{R}_{\text {Wood }}$ und Bruttophotosynthese GPP, Nettophotosynthese $A_{\text {netto }}$ (definiert als Summe der Nettophotosynthese am Tag: $A_{\text {netto }}=$ GPP $\mathrm{R}_{\text {Leaf,daytime), Bestandesatmung }} \mathrm{R}_{\text {Stand }}$ oder der autotrophen Atmung $\mathrm{R}_{\text {Tree }}$ angegeben.

Wie die absoluten Werte für die jährliche Holzatmung sind auch die Angaben für ihre Anteile an der Bruttoprimärproduktion in der Literatur mit einer Spanne von 2.5 bis $50 \%$ recht uneinheitlich. Nach RYAN et al. (1997) und LAW et al. (1999) ist die oberirdische Holzatmung gegenüber der des Bodens und der Blätter mit Abstand die kleinste Komponente. Für sie werden 2.5 bis 9 bzw. $6 \%$ der GPP aufgewendet, während die Blattatmung ca. $17 \%$ und die Bodenatmung bis zu $70 \%$ der GPP verbrauchen. Ein geringer Kohlenstoffbedarf für die oberirdische Holzatmung wird mit $6 \%$ von $A_{\text {netto }}$ (EDWARDS \& HANSON 1996) auch für sommergrüne Laubwälder gemäßigter Breiten und mit 8 bis $13 \%$ der GPP (RYAN et al. 1994a) für tropische Regenwälder angegeben. XU et al. (2001) ermitteln für Pinus ponderosa ein $\mathrm{R}_{\text {Wood,ag }}: \mathrm{R}_{\text {Stand }}-$ Verhältnis von 0.1 und nach GOULDEN et al. (1996b) macht die Holzatmung eines Laubmischwaldes knapp $5 \%$ der Bestandesatmung aus. Bei einem 80-jährigen Buchenbestand in Belgien werden GPP und $\mathrm{R}_{\text {Stand }}$ mit der Eddy-Kovarianz-Methode (VALENTINI et al. 2000) und die Bodenatmung durch Küvettenmessungen bestimmt (LONGDOZ et al. 2000). Danach ergibt sich für die gesamte oberirdische Atmung (inklusive Blattatmung!) ein Anteil von $5 \%$ an der Bruttoprimärproduktion. Diesen Untersuchungen zufolge ist die oberirdische Holzatmung selbst in Waldbeständen mit hohen Kohlenstoffumsätzen, wie Jungbeständen (XU et al. 2001) oder Regenwäldern (RYAN et al. 1994a), mit maximal $13 \%$ und im Mittel um $6 \%$ der GPP eine für die Kohlenstoffbilanz fast zu vernachlässigende Position.

Diesen Ergebnissen stehen die Resultate älterer Studien gegenüber, die den Kohlenstoffbedarf der Atmung von Stämmen und Ästen deutlich höher einschätzen. Für tropische Regenwälder geben KIRA \& SHIDEI (1967) 26 \%, MÜLLER \& NIELSEN 50 \% (1965, zitiert in RYAN et al. 1994a) der GPP an. Nach WOODWELL \& BOTKIN (1970) und EDWARDS et al. (1980) beträgt der Anteil von $\mathrm{R}_{\text {Wood,ag }}$ an $\mathrm{A}_{\text {netto }}$ in sommergrünen Laubwäldern 30 bis 36 \%. RYAN et al. (1994b) geben in ihrer Übersicht für verschiedene Kiefernarten Werte zwischen 8 und $33 \%$, im Mittel $20 \%$ an $\left(\mathrm{R}_{\text {Wood,ag }}: \mathrm{A}_{\text {netto}}\right)$. Auch eine Anzahl neuerer Untersuchungen kommen zu dem Befund, dass die oberirdische Holzatmung stärker am Kohlenstoffumsatz beteiligt ist. Während DAMESIN et al. (2002) für einen 30-jährigen Buchenwald mit 26 bis $31 \%$ der von GRANIER et al. (2000) mit der Eddy-Kovarianz-Methode ermittelten GPP ebenso hohe Werte wie z. B. EWARDS et al. (1980) angeben, liegen die meisten Werte in einem Bereich zwischen 12 und $23 \%$ (RYAN \& WARING 1992, 12 bis $15 \%$, RYAN et al. 1996, 15-21\%, CESCHIA 2001, 20-23\%). Der respirative 
Kohlenstoffbedarf der Stämme und Äste der Altbuchen stimmt mit 11 bis $16 \%$ und 13 bis $20 \%$ der GPP von Solling und Göttinger Wald gut mit diesen Angaben überein. Auch der Anteil der gesamten Holzatmung an der Bruttoprimärproduktion von 18 bis $28 \%$ entspricht Ergebnissen solcher Untersuchungen, die auch die Grobwurzelatmung durch Küvettenmessungen erfassen (Tab. 23). So beträgt das Verhältnis von $\mathrm{R}_{\text {Wood }}$ : GPP eines Pinus radiata- Bestandes 0.19 bis 0.27 (RYAN et al. 1996), das in Schwarzfichten- und Espenwäldern der borealen Zone um 0.20 (RYAN et al. 1997).

Wie bei den absoluten Werten der Bestandesatmung ist auch der Vergleich der Verhältnisse von Holzatmung zu Kohlenstoffgewinn nur sehr begrenzt möglich, da die Verwendung unterschiedlicher Verfahren bei der Bestimmung der Holzatmung und des Kohlenstoffgewinns von Waldbeständen z. T. erhebliche Unsicherheiten beinhalten. Beispielsweise kann das $\mathrm{R}_{\text {Wood,ag }}$ : GPPVerhältnis der hier untersuchten Altbuchen abhängig davon, welche Methode bei der Hochrechnung der Holzatmung Anwendung findet (Tab. 22), Werte zwischen 0.043 und 0.29 annehmen und so nahezu die gesamte in der Literatur angegebene Spanne umfassen. Bei der Bestimmung der GPP ist ebenfalls je nach Methode eine erhebliche Variabilität möglich. So zeigen GOULDEN et al. (1996b), LAVIGNE et al. (1997) und LAW et al. (1999), dass die mit der Eddy-KovarianzMethode gemessene Atmung z. T. deutlich unter den mit Küvetten gemessenen Werten liegt. Diese in der Nacht gemessene und für den Tag berechnete Bestandesatmung und die daraus ermittelte GPP kann daher tendenziell zu geringe Werte liefern, aus denen schließlich erhöhte $\mathrm{R}_{\text {Wood }}$ : GPP Verhältnisse resultieren. GRANIER et al. (2000) erhalten für den 30-jährigen Buchenbestand mit Eddy-Kovarianz einen Bruttokohlenstoffgewinn von $103 \mathrm{~mol} \mathrm{C} \mathrm{m}^{-2} \mathrm{a}^{-1}$. Auf Bestandesebene extrapolierte Photosynthesemessungen an einzelnen Blättern liefern sehr ähnliche Werte (109 mol $\mathrm{C} \mathrm{m}^{-2} \mathrm{a}^{-1}$ ). Die Summe aus Bestandesatmung (Eddy-Kovarianz) und Biomassezuwachs (aus allometrischen Beziehungen und Stammzuwachsmessungen) abzüglich der heterotrophen Bodenatmung ergibt eine GPP von $117 \mathrm{~mol} \mathrm{C} \mathrm{m}{ }^{-2} \mathrm{a}^{-1}$. Messungen mit „Branchbags“ liefern für das gleiche Jahr Werte zwischen 153 und $175 \mathrm{~mol} \mathrm{C} \mathrm{m}^{-2} \mathrm{a}^{-1}$.

Die GPP der Buchenbestände in Solling und Göttinger Wald ermittelt GRIES (2004, in Vorb.) auf Grundlage von Photosynthesemessungen an Einzelblättern. Da in seiner modellierenden Extrapolation eine potenzielle Hemmung der mitochondrialen Atmung der Blätter im Licht (BROOKS \& FARQUHAR 1985, VILLAR et al. 1995) unberücksichtigt bleibt, kann die in Tab. 23 genannte GPP überhöht sein. Dieser Fehler ist jedoch als gering einzuschätzen, da die indirekte Bestimmung ergab, dass die Dunkelatmung der Blätter bei einer Lichtstärke von PAR $=800 \mu \mathrm{E}$ ungefähr $80 \%$ des bei Dunkelheit gemessenen Wertes erreicht.

Auch wenn diese Unsicherheiten berücksichtigt werden, ist bemerkenswert, dass sich besonders geringe Anteile für die Holzatmung an $\mathrm{R}_{\text {Stand }}$ oder GPP wiederum bei solchen Untersuchungen ergeben, bei denen die Holzatmung für die einzelnen Kompartimente ermittelt und extrapoliert wird. Wie bei RYAN et al. (1994a) basiert die Berechnung der oberirdischen Holzatmung von GOULDEN et al. (1996), RYAN et al. (1997) und LAW et al. (1999) ausschließlich auf Messungen der Stammatmung, die über das Splintholz- oder Gesamtvolumen auf den Bestand extrapoliert werden. Allerdings zeigen RYAN et al. (2004) für rasch wachsende Eucalyptus saligna-Bäume auf Hawaii auch, dass sich bei dieser Art die volumenspezifischen Atmungsraten von Stämmen und Ästen nicht unterscheiden und geben für 7-jährige Bäume den Anteil der oberirdischen Holzatmung an der GPP mit $7 \%$ an. Solange die Untersuchungen der räumliche Variabilität der Holzatmung nicht auch die Variabilität in der Baumkrone und des Wurzelholzes einbeziehen, ist es nur bedingt sinnvoll, den Anteil der Holzatmung für die Kohlenstoffbilanz abzu- 
schätzen und die Bedeutung der Holzatmung zwischen den Beständen einer oder verschiedener Arten oder in unterschiedlichen Klimaten zu vergleichen.

Die Problematik der hohen methodisch bedingten Variabilität muss auch bei dem Vergleich der Ergebnisse verschiedener Buchenwälder berücksichtigt werden. Den bisherigen Ausführungen zufolge scheint der Anteil von $\mathrm{R}_{\text {Wood,ag }}$ an der GPP in Abhängigkeit vom Standort, der Bestandesdichte und dem Alter über einen weiten Bereich zu variieren, wenn das für den Solling ermittelte Minimum von $11 \%$ dem von DAMESIN et al. (2002) angegebenen Maximalwert von $31 \%$ für den 30-jährigen Buchenbestand in Frankreich gegenübergestellt wird. Die Spanne der Werte für den Buchenwald in Frankreich ergibt sich jedoch allein aus den abweichenden Angaben, die DAMESIN et al. (2002) und CESCHIA (2001) für die oberirdische Holzatmung des gleichen Bestandes und das Jahr 1997 machen, so dass die Variabilität auf unterschiedliche Datengrundlagen und Extrapolationsverfahren zurückzuführen ist. Die Variabilität der GPP ist darin noch unberücksichtigt. Die Angaben zur Holzatmung der Altbuchenbestände in Tab. 23 variieren ebenfalls aufgrund verschiedener Extrapolationsverfahren, weil die Wertespanne für jeden Standort und jedes Jahr den Ergebnissen der Methoden 1d und 1c entspricht. Werden die methodischen Unterschiede durch die Festlegung auf ein Verfahren, im Folgenden auf die Methode 1c (Tab. 22), ausgeschlossen, ist eine weitergehende Analyse möglich. Die Variation der absoluten und relativen Werte spiegelt dann im Wesentlichen die räumliche und interannuelle Variabilität der Holzatmung wider.

Tab. 23: Vergleich der Jahressummen der oberirdischen und unterirdischen Holzatmung mit der autotrophen Bestandesatmung, der im Holzzuwachs festgelegten Kohlenstoffmenge, der Rindenphotosynthese und der Bruttoprimärproduktion. Die Daten für GPP, für die Feinwurzel- und Blattatmung aus GRIES (2004, in Vorb.). Die Rindenphotosynthese aus relativer Reduktion der nach Methode 1c berechneten oberirdische Holzatmung (vgl. Kap 4.4.2.3). In Klammern: die gesamte Rindenphotosynthese bei Annahme einer Reduktion der jährlichen Feinreisigatmung um $40 \%$ nach Ergebnissen für einjährige Triebe (DAMESIN 2003).

\begin{tabular}{|c|c|c|c|c|}
\hline \multirow{3}{*}{$\begin{array}{c}\begin{array}{c}\text { Komponenten der } \\
\text { Kohlenstoffflüsse }\end{array} \\
\text { Oberirdische Holzatmung } \\
\text { (Methode } 1 \mathrm{~d}-1 \mathrm{c} \text {, vergl. Tab. 22) }\end{array}$} & \multicolumn{2}{|c|}{ Solling } & \multicolumn{2}{|c|}{ Göttinger Wald } \\
\hline & \multicolumn{4}{|c|}{$\mathrm{mol} \mathrm{C} \mathrm{m}^{-2} \mathrm{a}^{-1}$} \\
\hline & $17.3-23.0$ & $13.5-17.2$ & $25.2-33.1$ & $17.9-23.5$ \\
\hline Grobwurzelatmung & 13.3 & 8.6 & 13.0 & 8.0 \\
\hline Autotrophe Atmung & 83 & 68 & 89 & 76 \\
\hline Oberirdischer Holzzuwachs & 15.2 & 15.0 & 26.3 & 26.8 \\
\hline Grobwurzelzuwachs & 2.0 & 2.0 & 2.7 & 2.7 \\
\hline $\begin{array}{c}\text { Rindenphotosynthese } \\
\text { und } \mathrm{CO}_{2} \text { - Transport im Xylemsaft }\end{array}$ & $\begin{array}{c}0.9 \\
(3.7)\end{array}$ & $\begin{array}{c}0.7 \\
(2.3)\end{array}$ & $\begin{array}{c}3.2 \\
(6.5)\end{array}$ & $\begin{array}{c}2.3 \\
(4.5)\end{array}$ \\
\hline $\begin{array}{c}\text { Bruttoprimärproduktion } \\
\text { der Blätter }\end{array}$ & 142 & 122 & 167 & 138 \\
\hline
\end{tabular}

Die Auftragung von $\mathrm{R}_{\text {Wood,ag }}$ bzw. $\mathrm{R}_{\text {Wood }}$ gegen die GPP der Altbuchenbestände zeigt, dass die Holzatmung eng an den Kohlenstoffgewinn gekoppelt ist. Die Variabilität der Atmung lässt sich zu mehr als 96 \% mit der Variation der GPP erklären. Nach JANSSENS et al. (2001) ergibt sich für die mit Küvetten gemessene Bodenatmung und die durch Eddy-Kovarianz ermittelte Bestandes- 
atmung für verschiedene Wälder in Europa ebenfalls eine enge Abhängigkeit von der GPP ( $\mathrm{r}=0.76$

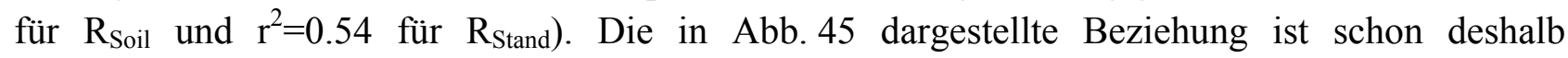
bemerkenswert, weil $\mathrm{R}_{\text {Wood }}$ bzw. $\mathrm{R}_{\text {Wood,ag }}$ und GPP unabhängig voneinander aus Küvettenmessungen der $\mathrm{CO}_{2}$-Umsätze von Blättern und Holz zeitlich und räumlich auf Bestandeswerte extrapoliert wurden. Während bei der Holzatmung einzig die Luft- und Bodentemperatur als Klimavariable in die Berechnung eingeht, wird die Photosynthese hauptsächlich vom Strahlungsklima, d.h. der PAR als Klimavariable beeinflusst. Auch wenn PAR und Lufttemperatur im saisonalen Verlauf ihrerseits aneinander gekoppelt sind und so die Hochrechnung von GPP und Atmung gleichsinnig beeinflussen können, kann bei der Atmung nicht von einem reinen Temperatureffekt ausgegangen werden. In Kapitel 5.2. wurde gezeigt, dass die saisonale Variabilität der Holzatmung nur zum Teil durch die Temperatur zu erklären ist und wesentlich vom Verlauf der Wachstumsaktivität beeinflusst wird.

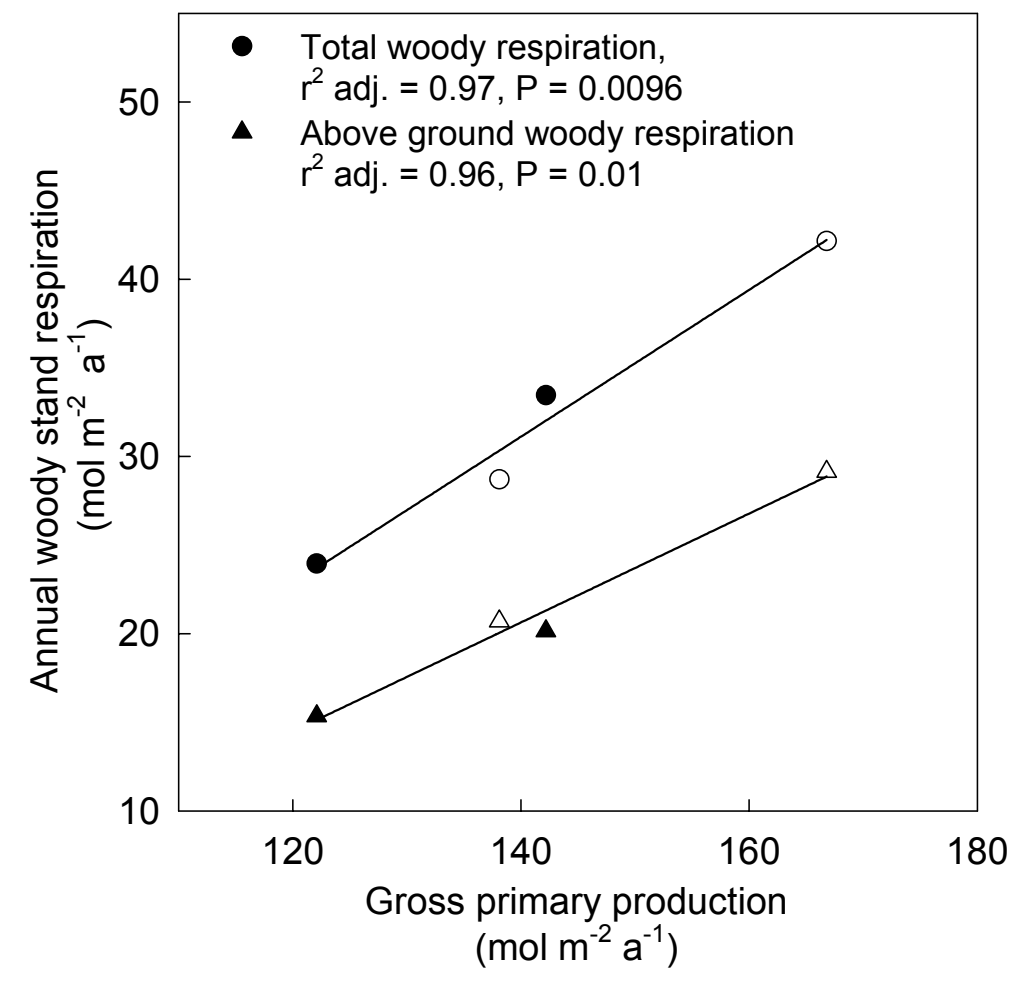

Abb. 45: Beziehung zwischen oberirdischer und gesamter jährlicher Holzatmung und Bruttoprimärproduktion von Solling (gefüllte Symbole) und Göttinger Wald (offene Symbole). Bruttoprimärproduktion der Altbuchenbestände nach GRIES (2004 in Vorb.).

Ausgehend davon, dass Atmungs- und Wachstumsaktivität eng zusammenhängen, kann die Beziehung zwischen GPP und Atmung als direkte Wirkung des Substratangebots auf die Wachstums- und Atmungsaktivität der verholzten Organe interpretiert werden. Dabei zeigt die Atmung von Ästen und Grobwurzeln eine stärkere interannuelle Variabilität als die der Stämme (Tab. 22), so dass auch deren Zuwachsaktivität stärker von der Variabilität der GPP abhängig sein könnte. Ein direkter Nachweis hierfür konnte wegen der unvollständigen Zuwachsmessungen in 1997 nicht erbracht werden. Es gibt jedoch Hinweise darauf, dass der Zuwachs der Äste im ersten Untersuchungsjahr höher gewesen ist (Kap. 4.4.1.1). Neben der Kopplung der Wachstumsaktivität an die GPP kann ein hohes Substratangebot auch im Zusammenhang mit dem Stoffumsatz in den Kohlenhydratspeichern zu einer gesteigerten Atmungsaktivität führen (Kap. 5.2). Auch hier kann die Variation des Substratangebots stärker auf die Atmung von Ästen und Grobwurzeln wirken, da deren spezifische Speicherkapazität höher ist als die des Stammholzes (KÖRNER 2003). Außerdem zeigen die hier untersuchten Grobwurzeln einen Anstieg der temperaturnormierten Atmungsraten während der Sommermonate, die nicht mit der Wachstumsaktivität, sondern mit der sommerlichen 
Substratzufuhr synchronisiert war. Für eine höhere Bedeutung des C-Umsatzes im Speicher des jüngeren, aktiveren Holzes spricht schließlich auch der höhere Wachstumskoeffizient der Äste (Kap. 4.4.1.1). Somit wäre bei diesen Organen eine hohe Atmungsaktivität weniger eng an deren hohe Wachstumsraten gebunden, während dennoch eine enge Beziehung zur GPP besteht.

Auch die relativen Anteile der Holzatmung an der GPP sind an den Bruttokohlenstoffgewinn gekoppelt. Zwar ist die Beziehung weniger eng als bei den absoluten Werten, doch lässt sich auch die geringe Variabilität von $\mathrm{R}_{\text {Wood,ag }}$ bzw. $\mathrm{R}_{\text {Wood }}$ : GPP zu 92 und 97 \% mit der GPP erklären (P = 0.03 und 0.04). Die allgemein formulierte Annahme von Ryan et al. (2004), dass die Kohlenstoffinvestition in die Holzatmung unabhängig von Bestandesalter, -dichte oder der mittleren Temperatur des Standortes den gleichen Anteil an der GPP ausmacht, kann in diesem engen Sinne für die Ergebnisse der vorliegenden Studie nicht bestätigt werden. Der höhere Anteil der Holzatmung bei steigender GPP ist vielmehr ein Hinweis darauf, dass eine verstärkte Kohlenstoffallokation in das Holzparenchym dann erfolgt, wenn der Bedarf anderer Kohlenstoffsenken, wie Blattaufbau und entwicklung, Längenwachstum der Jahrestriebe oder die Erneuerung der Feinwurzeln und möglicherweise ein basaler Bedarf der Kohlenhydratspeicher gedeckt ist. Dass die Variation der anteiligen Holzatmung beim Vergleich verschiedener Buchenbeständen unterschiedlichen Alters dennoch sehr gering ist, wird im folgenden Abschnitt dargestellt.

\section{Ist die Holzatmung die Ursache für den Rückgang der Produktivität von Wäldern mit zunehmendem Bestandesalter?}

Die verschiedenen Ergebnisse für den Anteil des Kohlenstoffbedarfs für die Holzatmung am Kohlenstoffgewinn von Waldbeständen führen bei zentralen Fragen der Wachstumsdynamik von Waldökosystemen zu unterschiedlichen Schlussfolgerungen. So sehen KIRA \& SHIDEI (1967) in dem hohen respirativen Kohlenstoffbedarf der oberirdischen Holzatmung in sommergrünen Laubwäldern und tropischen Regenwäldern die Hauptursache für den Rückgang der Produktivität von Wäldern mit zunehmendem Bestandesalter. Sie gehen davon aus, dass LAI und Kohlenstoffgewinn gleichaltriger Waldbestände bis zum vollständigen Kronenschluss auf einen Maximalwert ansteigen und in der weiteren Bestandesentwicklung ein leicht unter dem Maximum liegenden Gleichgewichtswert erreichen, der mit weiter steigendem Bestandesalter nahezu unverändert bleibt. Während auch die Blattatmung eng dem zeitlichen Verlauf des LAI folgt und nach Kronenschluss konstant bleibt, nimmt der Kohlenstoffbedarf der Atmung der nicht photosynthetisch aktiven Gewebe mit zunehmender Biomasse zu und limitiert schließlich die für den Zuwachs verbleibende Kohlenstoffmenge. Diese „Atmungstheorie“ findet weitgehende Akzeptanz, so dass bis heute die Verschiebung des Verhältnisses zwischen Holz- und Blattbiomasse als wesentliche, z. T. als einzige Ursache für den Rückgang der Produktivität von Wäldern mit zunehmendem Alter betrachtet wird (LONG \& SMITH 1992, BARNES et al. 1998). Nach LARCHER (1994, S. 135) wird das Verhältnis zwischen grünen und nichtgrünen Geweben um so ungünstiger, je größer die Bäume werden, was dazu führt, dass „der Ertrag der Photosynthese nur noch für die Lauberneuerung und die Atmung der enorm angewachsenen Spross- und Wurzelmasse ausreicht“ und „der Holzzuwachs zum Stehen“ kommt „wenn der Laubanteil unter 1 \% der Gesamtmasse abnimmt“.

Der Hypothese liegt die Annahme zugrunde, dass vor allem die Erhaltungsatmung proportional mit der im Bestand akkumulierenden Biomasse zunimmt. RYAN \& WARING (1992) zeigen für einen 245-jährigen Pinus contorta-Bestand, dass dessen Erhaltungsatmung kaum höher ist als die eines 40-jähriger Bestandes, weil sich weder splintholzvolumenspezifische Atmungsrate noch Splintholz- 
vorrat wesentlich unterscheiden. Der Unterschied der Produktivität von $3 \mathrm{zu} 14 \mathrm{~mol} \mathrm{C} \mathrm{m} \mathrm{m}^{-2} \mathrm{a}^{-1}$ lässt sich mit der geringen Differenz der Erhaltungsatmung nicht erklären. Die Autoren zeigen, dass die Blattleitfähigkeit der Altbäume geringer ist und stellen der „Atmungstheorie“ die Hypothese gegenüber, dass der Rückgang der Produktivität das Resultat einer geringeren Assimilation, d.h. einer Abnahme der GPP in älteren Beständen bei hydraulischer Limitierung ist.

Die vorliegende Studie ist zwar nicht daraufhin angelegt, die Hypothese von KIRA \& SHIDEI (1967) für die Buche zu prüfen, jedoch deutet schon der Befund, dass der deutlich geringere Holzzuwachs im Solling gegenüber dem des Bestandes im Göttinger Wald nicht mit einer entsprechenden Differenz der Erhaltungsatmung zu erklären ist, gegen die Atmungshypothese. Darüber hinaus kann mit dem Vergleich von Ergebnissen verschieden alter Buchenbestände eine falsche Zeitreihe darauf hin geprüft werden, ob die aus der Atmungstheorie abzuleitende Erwartung bestätigt werden kann, dass der Anteil der Holzatmung an der GPP in älteren Bestände mit hohem Vorrat nicht assimilierender Biomasse zunimmt. STICKAN et al. (1994) berechnen die Kohlenstoffbilanz einer Buche, die repräsentativ für die Individuen eines 10-jährigen Dickichts ist, das sich in der Windwurflücke eines Altbestandes nahe der B1-Fläche im Solling entwickelt hat. In einem dreijährigen Untersuchungszeitraum verbraucht die oberirdische Sprossatmung 13 bis $19 \%$ der jährlichen Nettophotosynthese, die sich aus den Tagessummen der während der Hellphasen ermittelten Nettophotosynthese errechnet. Wird die Sprossatmung mit der der Hauptwurzel der Jungbuchen als Äquivalent zur Holzatmung $\mathrm{R}_{\text {Wood }}$ zusammengefasst, macht diese 23 bis $31 \%$ der Nettophotosynthese aus. Die entsprechenden Werte der hier untersuchten Altbäume zeigen mit 13 bis $22 \%$ für die oberirdische Holzatmung und 21 bis $33 \%$ für die gesamte Holzatmung im Vergleich zu den 10-jährigen Buchen eine hohe Übereinstimmung.

Im vorangegangenen Abschnitt wurden die Anteile des respirativen Kohlenstoffumsatzes der Altbestände der GPP denen eines 30-jährigen Buchenbestandes gegenübergestellt. Es wurde gezeigt, dass der von CESCHIA (2001) und DAMESIN et al. (2002) untersuchte Bestand trotz des deutlich geringeren Biomassevorrates einen höheren Anteil der GPP in die oberirdische

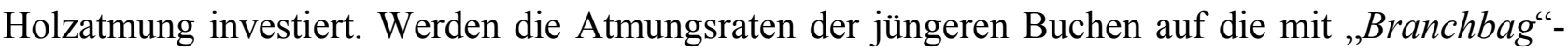
Messungen ermittelte Spanne der GPP bezogen (153 - $176 \mathrm{~mol} \mathrm{C} \mathrm{m}^{-2} \mathrm{a}^{-1}$, GRANIER et al. 2000), so ergibt sich für die oberirdische Holzatmung der 30-jährigen Buchen ein Anteil an der GPP von 12 bis $21 \%$, der sich ebenfalls nicht von den entsprechenden Werten der 120-jährigen Buchen des Göttinger Waldes (17 - 20 \%) und 150-jährigen Bäume im Solling (14 - 16 \%) unterscheidet.

Es zeigt sich also, dass der Anteil des Kohlenstoffgewinns, den die Buchen in die Holzatmung investieren, bei Beständen sehr verschiedener Altersstufen kaum variiert und Unterschiede in der Produktivität, wie sie z. B. auch zwischen dem 30-jährigen Bestand in Frankreich und dem Bestand im Solling bestehen, nicht auf eine höhere Holzatmung der Solling-Buchen zurückzuführen ist.

Um die Beziehung zwischen Holzatmung und GPP für diese falsche Zeitreihe zu untersuchen, können für die Berechnung der GPP des Buchendickichts aus den Angaben von STICKAN et al. (1994) folgende Annahmen gemacht werden:

1. Das Verhältnis zwischen den Jahressummen der mitochondrialen Atmung der Blätter in den Tagesstunden steht bei den Jungbuchen im gleichen Verhältnis zur Nachtatmung wie bei den Altbäumen am gleichen Standort (Faktor 2.7, GRIES 2004, in Vorb.)

2. Die Bestandesdichte des Dickichts beträgt 4.8 Bäume pro Quadratmeter (die Angaben verschiedener Untersuchungen reichen von 3 bis 6.6, STICKAN et al. 1994, GANSERT 1995). 
Bei der Auftragung der oberirdischen Holzatmung gegen die GPP verschieden alter Buchenbestände ergibt sich eine lineare Beziehung, die zeigt, dass die Substratversorgung für die Holzatmung bedeutender ist als Standort, Bestandesstruktur und -alter (Abb. 46).

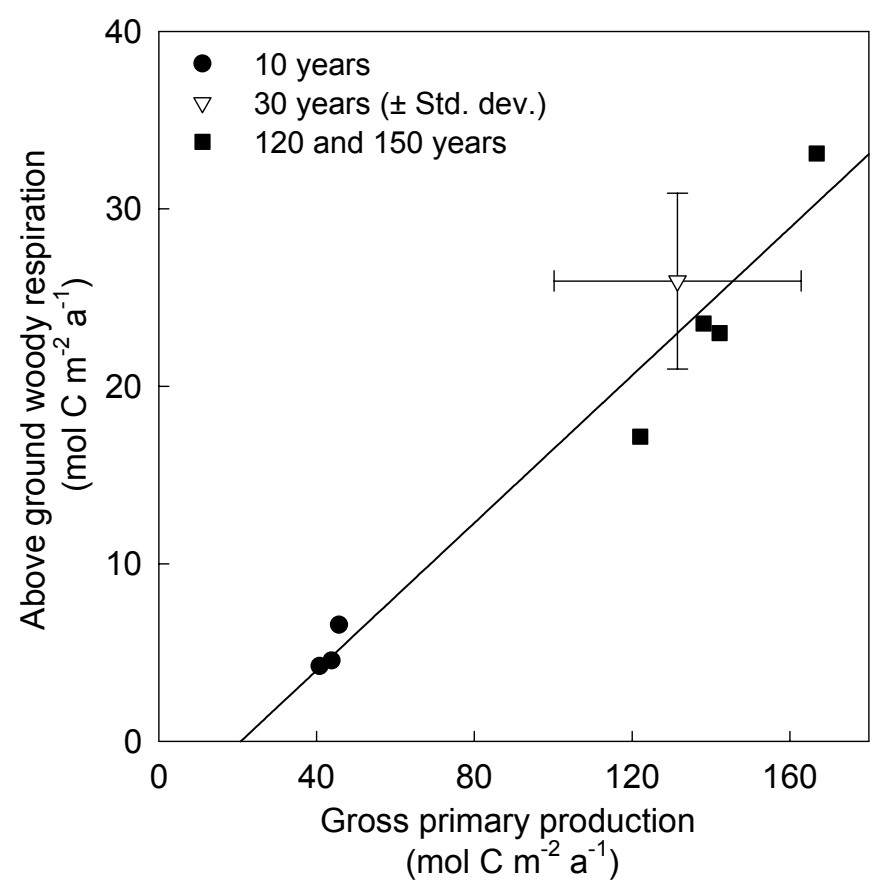

Abb. 46:Beziehung zwischen der jährlichen oberirdischen Holzatmung von vier verschiedenen Buchenbeständen unterschiedlichen Alters und der GPP. Für den 30-jährigen Buchenbestand wurden alle Angaben, die für

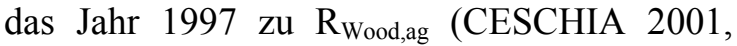
DAMESIN et al. 2002) und zur GPP (GRANIER et al. 2000) gemacht wurden, gemittelt.

$\mathrm{R}_{\text {Wood,ag }}=$ GPP x $0.208-4.3$, $\mathrm{r}^{2}$ adj. $=0.95, \mathrm{P}<0.0001$.

\subsubsection{Die Bedeutung der Rindenphotosynthese für die Kohlenstoffbilanz der Buchenwälder}

Obwohl eine Vielzahl von Untersuchungen für verschiedene Baumarten gezeigt haben, dass die instantane respirative $\mathrm{CO}_{2}$-Abgabe von Ästen und Stämmen durch die photosynthetische Refixierung des $\mathrm{CO}_{2}$ in der Rinde deutlich reduziert sein kann (Kap.5.1.3) und auch beachtliche Anteile der täglichen $\mathrm{CO}_{2}$-Abgabe refixiert werden können (Kap. 4.4.2.3), liegen bislang keine Schätzungen des jährlichen Anteils am Kohlenstoffumsatz ganzer Bäume oder Baumbestände vor. Für die modellierende Extrapolation sind, wie bei der Holzatmung selbst, detaillierte Kenntnisse über die raum-zeitliche Variabilität der Rindenphotosynthese und ihre Abhängigkeit von Klimafaktoren, wie Licht und Temperatur, sowie der Einfluss endogener Faktoren, z. B. der Holzatmung und Transmissivität der Rinde, erforderlich. Darüber hinaus muss das Lichtklima an der Oberfläche von Ästen und Stämmen hinreichend genau beschrieben werden.

Die Bedeutung der Rindenphotosynthese für die Kohlenstoffbilanz ganzer Bäume oder Baumbestände ist weitgehend unklar. RYAN et al. (1997) vermuten aber, dass die im Vergleich zu drei Koniferenarten hohe Effizienz, mit der Populus tremuloides den Kohlenstoffgewinn in der Biomasse festlegt, zumindest teilweise auf eine hohe Kapazität ihrer Rindenphotosynthese zurückzuführen ist. CESCHIA (2001) sieht seine vergleichsweise hohen Werte für die Holzatmung darin begründet, dass bei seinen Messungen mit lichtundurchlässigen Küvetten die $\mathrm{CO}_{2}$-Refixierung durch die Rinde unterbunden wird.

DAMESIN (2003) führt eine umfassende Untersuchung über den Zuwachs, die Atmung und die Rindenphotosynthese diesjähriger Buchenzweige durch. Von der innerhalb eines Jahres durch Atmung gebildeten $\mathrm{CO}_{2}$-Menge dieser Äste werden $40 \%$ durch Rindenphotosynthese refixiert.

Im Rahmen der vorliegenden Untersuchung wird die tägliche Rindenphotosynthese aus der Differenz zwischen der berechneten Tagessumme der Bruttoatmung und der gemessenen 
Tagessumme der $\mathrm{CO}_{2}$-Abgabe berechnet und mit der täglichen $(24 \mathrm{~h})$ Bruttoatmung ins Verhältnis gesetzt. Die Anteile, um die die $\mathrm{CO}_{2}$-Abgabe durch die Rindenphotosynthese und den Transport von $\mathrm{CO}_{2}$ mit dem Xylemsaft der Bruttoatmung abweichen, werden für jeden Standort und jedes Kompartiment über alle Messungen des Winterhalbjahres und des Sommerhalbjahres gemittelt. In der Annahme, dass diese Anteile für den jeweils betrachteten Zeitraum, den Standort und das Kompartiment repräsentativ sind, kann die Jahressumme der Rindenphotosynthese (sowie des $\mathrm{CO}_{2}$ Abtransportes) berechnet werden, indem in die Hochrechung nur der Anteil der täglichen Bruttoatmung eingeht, der nicht über die Oberfläche abgegeben wird. In Tab. 23 sind die nach Methode $1 \mathrm{c}$ berechneten Jahressummen der Rindenphotosynthese (inkl. $\mathrm{CO}_{2}$-Abtransport) angegeben.

Entsprechend dieser Schätzung werden zwischen 3.9 und 9.8 \% der jährlichen oberirdischen Holzatmung im Solling und im Göttinger Wald durch die Rindenphotosynthese lokal und nach dem $\mathrm{CO}_{2}$-Transport in den Blättern refixiert. Erreichte die Rindenphotosynthese des Feinreisigs im Mittel den hohen Anteil, den DAMESIN (2003) für die Jahrestriebe von Jungbuchen angibt, würden in der Summe 13 bis $20 \%$ des durch Holzatmung freigesetzten $\mathrm{CO}_{2}$ refixiert (Tab. 23, in Klammern). Diese als maximale Schätzung einzustufenden Werte übersteigen die im Biomassezuwachs der Äste und Grobwurzeln festgelegte Kohlenstoffmenge immerhin um das Doppelte. Bezogen auf den jährlichen Kohlenstoffgewinn der Altbuchen ist der Anteil von 2 bis $4 \%$ aber von relativ geringer Bedeutung für die Kohlenstoffbilanz des Bestandes. 


\section{Zusammenfassung}

Im Rahmen der vorliegenden Studie wurde die Atmung der ober- und unterirdischen verholzten Sprossachsen von Altbuchen in einem Kalk- und einem Sauerhumusbuchenwald an den Standorten Göttinger Wald und Solling untersucht. Ziel war die Bilanzierung der damit verbundenen Kohlenstoffflüsse. Dabei wurde der Frage nachgegangen, in welchem Zusammenhang die zeitliche und räumliche Variabilität der Atmung mit der Variation endogener Prozesse und den Verläufen der Witterung steht und wie diese Zusammenhänge der extrapolierenden Modellierung zur Berechnung der Holzatmung auf Bestandesebene dienen können.

Zur Messung der Atmungsaktivität wurde die $\mathrm{CO}_{2}$-Abgabe der verholzten Organe mit einem Infrarot-Gasanalysator im offenen System an einer Mehrkanal-Küvetten-Messanlage erfasst. An jedem Standort waren jeweils sechs Äste, Stämme und Grobwurzeln an einer Position und ein weiterer Stamm an 6 Positionen in unterschiedlicher Höhe und Orientierung mit Messküvetten versehen, in denen zeitgleich mit der $\mathrm{CO}_{2}$-Abgabe die oberflächennahe Xylemtemperatur gemessen wurde. In den Jahren 1997 und 1998 erfolgte etwa einmal monatlich an jedem der Kompartimente die Aufzeichnung von 2 bis 14 Tagesgänge von Atmung und Temperatur sowie die Messung des Umfangzuwachses nahe den Küvetten. Im Anschluss an den zweijährigen Zeitraum wurden die untersuchten Sprossachsen auf ihren Gehalt an Stickstoff, löslichem Protein und den TTC-Umsatz der lebenden Zellen analysiert

Die Atmungsraten der Stämme lagen im Winterhalbjahr im Mittel bei $2 \mu \mathrm{mol} \mathrm{C} \mathrm{m} \mathrm{m}^{-3} \mathrm{~s}^{-1}$ und stiegen während der Vegetationsperiode auf maximale Werte zwischen 7 und $11.5 \mu \mathrm{mol} \mathrm{C} \mathrm{m} \mathrm{m}^{-3} \mathrm{~s}^{-1}$ an. Bei

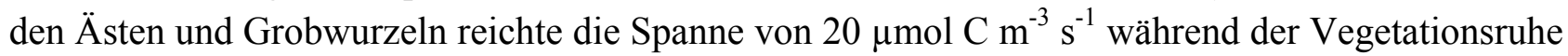

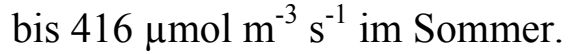

Im Tagesgang verlief die $\mathrm{CO}_{2}$-Abgabe oft parallel zur Temperatur, jedoch konnten regelmäßig auch zeitverzögerte, ganz von der Temperatur unabhängige oder sogar zur Temperatur gegenläufige Tagesgänge der Atmung beobachtet werden. Die während der Nacht gemessene Atmungsrate war stets eng mit der Temperatur korreliert, wobei sich für die Stämme geringere Temperaturkoeffizienten $\left(\mathrm{Q}_{10}=1.9\right)$ ergaben als für die Äste (2.45) und Grobwurzeln (2.7). Dies konnte in einem Modell allein mit dem Effekt der unterschiedlichen Wärmekapazität auf den zirkadianen Verlauf der Holztemperaturen erklärt werden. Die Entkopplung der $\mathrm{CO}_{2}$-Abgabe vom Temperaturverlauf am Tage ist darauf zurückzuführen, dass an einer gegebenen Messstelle zusätzlich zum lokal durch Atmung gebildeten $\mathrm{CO}_{2}$ auch mit dem Xylemsaft antransportiertes $\mathrm{CO}_{2}$ austreten kann und Atmungs- $\mathrm{CO}_{2}$ durch Rindenphotosynthese refixiert oder mit dem Xylemsaft abtransportiert werden kann.

Dabei erreichte die Rindenphotosynthese maximale Raten von $10.2 \mu \mathrm{mol} \mathrm{C} \mathrm{m} \mathrm{m}^{-2}$. Durch den Anoder Abransport im Xylemsaft wurde bis zu $1 \mu \mathrm{mol} \mathrm{CO} \mathrm{CO}^{-2} \mathrm{~s}^{-1}$ mehr oder weniger über die Rinde abgegeben. Gegenüber der vermutlich wahren lokalen Atmungsrate konnte die aktuelle $\mathrm{CO}_{2}$ Abgabe über die Oberfläche durch Rindenphotosynthese um mehr als $80 \%$ vermindert sein und $30 \%$ des $\mathrm{CO}_{2}$ mit dem Xylemsaft an- oder abtransportiert werden. Über das Winterhalbjahr bilanziert lag der Anteil des durch Rindenphotosynthese refixierten $\mathrm{CO}_{2}$ an der Bruttoatmung von Stämmen und Ästen im Mittel bei 2 bzw. $15 \%$. Während der Vegetationsperiode wurden bei Wurzeln im Mittel $1.5 \%$ des abgegebenen $\mathrm{CO}_{2}$ mit dem Xylemsaft antransportiert. Bei Stämmen und Ästen war die $\mathrm{CO}_{2}$-Abgabe bei einer Kombination der Prozesse Rindenphotosynthese und $\mathrm{CO}_{2}$-Transport im Mittel um 3.2 bzw. 7 \% reduziert. 
Der Anstieg der Atmungsraten während der Vegetationsperiode um das 3- bis 18fache der im Winterhalbjahr gemessenen Werte lässt sich nicht allein mit der für die Tagesgänge gefundenen Temperaturabhängigkeit der Atmung erklären. Auf der Zeitskala des Jahresgangs waren die Atmungsraten weniger eng mit der Temperatur korreliert und die Temperaturkoeffizienten lagen mit Werten zwischen 2.4 bis 5.06 deutlich über den $\mathrm{Q}_{10}$-Werten der Temperaturantwortkurven der Tagesgänge. Die bei Stämmen und Ästen ausgeprägten und bei den Grobwurzeln in Ansätzen beobachteten Jahresgänge der temperaturnormierten Atmungsraten verdeutlichen die weit über den direkten Temperatureinfluss hinausgehende Steigerung der Atmungskapazität und/oder -Aktivität während der Vegetationsperiode. Diese Steigerung steht vor allem im Zusammenhang mit einem erhöhten Energiebedarf für den Aufbau neuer Biomasse. Nach der „mature tissue“-Methode ergaben sich für Stamm- und Astholz mittlere Wachstumskoeffizienten von 0.23 bzw. 0.43 mol C $_{\text {veratmet }}$ pro mol $\mathrm{C}_{\text {Zuwachs. }}$.

Die auf Grundlage der für das Winterhalbjahr gefundenen Temperaturbeziehungen berechnete, volumenbezogene $10{ }^{\circ} \mathrm{C}$-Erhaltungsatmung nimmt bei dem Vergleich der Messstellen aller Kompartimente hyperbolisch mit zunehmendem Durchmesser der Sprossachsen ab. Stickstoffgehalte und TTC-Umsätze deuten darauf hin, dass dieser Rückgang auf eine abnehmende Konzentration und Aktivität lebender Zellen in den Parenchymen zurückgeht.

Die oberflächenbezogenen Atmungsraten von Ästen und Grobwurzeln unterscheiden sich nicht von denen der Stämme. Der Vergleich der volumenbezogenen Atmungsraten innerhalb einzelner Kompartimente zeigt, dass die oberirdischen Sprossachsen in die drei Gruppen Stammholz, Äste der Schattenkrone und Äste der Sonnenkrone unterschieden werden können, deren volumenbezogene Erhaltungsatmung sich jeweils nicht mit dem Durchmesser ändert und bei Bezug auf die Oberfläche linear ansteigt. Innerhalb dieser Gruppen steigt auch der absolute Biomassezuwachs mit dem Durchmesser, der relative Biomassezuwachs jedoch nicht.

Zwischen den Gruppen nimmt der relative Durchmesserzwachs in der genannten Reihenfolge zu, so dass die Variabilität des Biomassezuwachses die Unterschiede der volumenbezogenen Atmungsraten zwischen den verschiedenen Gruppen ebenso erklärt, wie die fehlende Durchmesserabhängigkeit innerhalb der Gruppen.

Die bestandesflächenbezogenen C-Flüsse der Holzatmung wurden berechnet auf Basis:

- der saisonal variierenden Temperaturbeziehungen der gemessenen Atmungsraten von Stämmen, Ästen und Grobwurzeln, die ausschließlich an nächtliche Messwerte angepasst wurden,

- der Holzvorräte in 7 Durchmesserklassen, die aus einer Kombination forstlicher Standardverfahren zur Schätzung des Derbholzvolumens mit differenzierten Biomasseschätzungen in fein aufgelösten Durchmesserklassen auf der Grundlage vollständiger Baumernten ermittelt wurden. Die Vorräte von Feinreisig und Ästen wurden zusätzlich anteilig zwei Kronenhöhenbereichen, der Sonnen- und Schattenkrone, zugeordnet,

- einer nach Durchmesser und Kronenhöhenbereich vorgenommenen Zuordnung der ermittelten Atmungsraten von Feinreisig und Ästen in Sonnen- und Schattenkrone, Stämmen und Grobwurzeln auf die Vorräte der 7 Durchmesserklassen und des Grobwurzelvolumens.

- der kontinuierlich gemessenen Vertikalprofile von Luft- und Bodentemperaturen.

Der jährliche Kohlenstoffbedarf für die Holzatmung der Bestände in Solling und Göttinger Wald lag 1997 bei 36.1 und $46.1 \mathrm{~mol} \mathrm{C} \mathrm{m}^{-2} \mathrm{a}^{-1}$. Davon entfielen auf Grobwurzeln, die nur $11 \%$ Anteil am Holzvolumen hatten, 30 bzw. $36 \%$ und auf Reisholz, das nur $8.5 \%$ des Holzvolumens ausmacht, 
40 bis 50\%. Die standörtlichen Unterschiede waren bei gleichen spezifischen Atmungsraten auf die unterschiedlichen Holzvolumenvorräte der beiden Bestände zurückzuführen.

1998 lag die Holzatmung bei geringerer Substratversorgung aus der Blattphotosynthese und geringerem Holzzuwachs um 30 \% unter den Vorjahreswerten. Der Rückgang war bei Grobwurzeln und Reisig stärker ausgeprägt als beim Stammholz.

Auf Bestandesebene war die Atmung der verholzten Sprossachsen ein- bis zweimal so hoch wie die Blattatmung und zwei- bis vierfach höher als die Feinwurzelatmung. Der Anteil der Holzatmung am jährlichen Bruttokohlenstoffgewinn (GPP) der Blätter lag zwischen 21 und 28 \%. Eine enge Beziehung zwischen den standörtlichen und interannuellen Variationen von GPP und Holzatmung deutet darauf hin, dass der Kohlenstoffbedarf für die Holzatmung der Bestände nur kurzfristig von der Temperatur, langfristig über die Substratversorgung und das Wachstum reguliert wird. 


\section{Summary}

In this work the respiration of woody organs above and below ground in mature beech on one calcareous and one acid location was investigated. The studied stands were located at Göttinger Wald and at Solling, southern Lower Saxony.

The aim of the study was to investigate the net carbon flux and to search for interrelations between temporal and spatial variations of respiration on one hand and endogenous processes and climate on the other. These relations were further used for modelling respiration of woody organs at stand level.

The respiratory activity was measured as $\mathrm{CO}_{2}$-efflux from woody organs with a multi-channelcuvette device. The superficial xylem temperature was recorded simultaneously. Perspex chambers were installed on six branches, stems and coarse roots in each stand. On one additional stem in each stand, chambers were installed at three stem heights and in two orientations at each height. Between two and 14 daily courses of respiration and temperature as well as the circumference increments close to each cuvette were recorded monthly in each compartment during 1997 and 1998. Subsequent to the two-year measurement period the sampled tissues were harvested and analysed for $\mathrm{N}$, soluble proteins and the TTC-conversion capacity of living cells.

Respiration rates of stems were around $2 \mu \mathrm{mol} \mathrm{C} \mathrm{m} \mathrm{s}^{-1}$ during the winter, increasing to maximum values between 7 and $11.5 \mu \mathrm{mol} \mathrm{C} \mathrm{m}^{-3} \mathrm{~s}^{-1}$ during the growing seasons. Branches and coarse roots showed rates from $20 \mu \mathrm{mol} \mathrm{C} \mathrm{m} \mathrm{S}^{-1}$ in the winter to $416 \mu \mathrm{mol} \mathrm{C} \mathrm{m} \mathrm{m}^{-3} \mathrm{~s}^{-1}$ in the summer. Daily courses of $\mathrm{CO}_{2}$-flux usually paralleled those of temperature. However, delayed, seemingly inverted or temperature independent $\mathrm{CO}_{2}$-flux curves occurred. Respiratory rates were generally closer correlated with temperature during night than at day time. Furthermore, stems showed a lower mean temperature coefficient $\left(\mathrm{Q}_{10}=1.9\right)$ than branches $\left(\mathrm{Q}_{10}=2.45\right)$ and coarse roots $\left(\mathrm{Q}_{10}=2.7\right)$. A simple mechanistic model explained the latter result as possibly due to the different thermal capacities affecting the circadian rhythms of wood temperature.

Temperature-independent variation of $\mathrm{CO}_{2}$ release during the day is probably caused by simultaneous release of allochtonous $\mathrm{CO}_{2}$ from, or difusion of local respiratory $\mathrm{CO}_{2}$ into the xylem sap as well as re-fixation of respiratory $\mathrm{CO}_{2}$ by corticular photosynthesis.

Maximal corticular photosynthesis was $10.2 \mu \mathrm{mol} \mathrm{m} \mathrm{s}^{-1}$, and maximal $\mathrm{CO}_{2}$ release and absorption by xylem sap were both about $1 \mu \mathrm{mol} \mathrm{m} \mathrm{m}^{-2} \mathrm{~s}^{-1}$. Compared to the presumed true respiration rate, actual $\mathrm{CO}_{2}$ release rates were reduced by corticular photosynthesis by up to $80 \%$, and by xylem transport by up to $30 \%$. Total refixation of respiratory $\mathrm{CO}_{2}$ by corticular photosynthesis during the leafless period was estimated as $2 \%$ of gross respiration in stems and $15 \%$ in branches. About $1.5 \%$ of the total $\mathrm{CO}_{2}$ released by coarse roots over the vegetation period originated from the xylem sap, not from local respiration. In stems and branches, the combined effect of corticular photosynthesis and xylem transport reduced total vegetation period $\mathrm{CO} 2$ release by 3.2 and $7 \%$, respectively.

Respiration rates increased 3- to 18-fold during the vegetation period compared to winter values. This increase can not solely be ascribed to warmer summer temperatures, based on short-term temperature sensitivities exhibited in daily courses.

On an annual time scale, respiration rates were less closely correlated to tissue temperature than in daily courses. Long term $\mathrm{Q}_{10}$ values of 2.4 to 5.06 exceeded the coefficients found for the temperature response in daily courses. The annual course of the $10^{\circ} \mathrm{C}$ respiration rates, which was 
more pronounced for stems and branches than for coarse roots, clearly shows the increase of respiratory capacity and activity during the growing period due to the higher energy requirements for growing tissues. The mean growth coefficients according to the ,mature tissue "-method were $0.23 \mathrm{~mol} \mathrm{C}_{\text {respired }}$ per mol $\mathrm{C}_{\text {Growth }}$ for wood of stems and $0.43 \mathrm{~mol} \mathrm{C}_{\text {respired }}$ per mol $\mathrm{C}_{\text {Growth }}$ for branches.

The volume-based $10{ }^{\circ} \mathrm{C}$ maintenance respiration calculated from the temperature dependence of respiration observed during winter decreased hyperbolically with increasing sample diameter across all compartments. The nitrogen concentrations and TTC-conversion data suggest, that this might be a result of a decreasing fraction of live cell volume and activity in the parenchyma of larger organs. The area-based respiration rate of branches and coarse roots was similar to that of stems. Comparing respiration rates within and among compartments revealed that the above ground organs could be differentiated into the following three groups: stem wood, shadow branches, and sun branches. Within each of these groups volume-based respiration rate did not change with organ diameter, but area-based rates linearly increased with diameter. Accordingly, within each of the three groups the absolute biomass increment was correlated with diameter, but the relative increment was not. Across the three groups, the relative diameter increment increased from stems to shade branches and to sun branches.

In conclusion, this emphasizes the importance of relative biomass increment, as its variance across the three groups explains the variance among their respiration rates, while its constancy within each group explains the absence of a diameter dependence of volume-based respiration.

Stand level C-fluxes of woody tissue respiration were calculated based on:

- seasonally varying temperature relationships of stems, brances and coarse roots derived from respiration rates and temperatures measured half-hourly during several-day courses at least once a month. Confounding effects of xylem transport and corticular photosynthesis on respiratory $\mathrm{CO} 2$ release were avoided by using only night time measurements.

- wood stores in seven diameter classes, that were determined using a combination of standard forestry methods for determining coarse wood volume and relationships between stem diameter and wood volume fractions in seven diameter classes that were derived from complete harvests of 30 trees.

- Twigs and branches were additionally defined as sun- or shade canopy. Assigning parameters of temperature-respiration relationships obtained from twigs, shade and sun branches, stems and coarse roots to woody tissue in the seven diameter classes according to sample diameter and canopy height

- continuously measured vertical profiles of air and soil temperatures

In 1997, annual carbon demand for woody tissue respiration at stand level was $36.1 \mathrm{~mol} \mathrm{C} \mathrm{m}^{-2} \mathrm{a}^{-1}$ at Solling and $46.1 \mathrm{~mol} \mathrm{C} \mathrm{m}^{-2} \mathrm{a}^{-1}$ at Göttinger Wald. 30 and $36 \%$ of this was consumed by coarse roots alone, which represent only $11 \%$ of the total wood volume. Twigs and branches, which represent $8.5 \%$ of the total wood, consumed 40 to $50 \%$. Differences between stands could be ascribed to differences in stocks of wood and not to different specific respiration rates.

The respiration of woody organs was $30 \%$ lower in 1998 than in the year before. This might be a result of the lower photosynthetic carbon supply and diameter increment. This inter-annual difference was more pronounced in coarse roots and branches than in stems. 
At stand level, respiration of woody organs was equal to, or up to twice as high as leaf respiration, and between two and four-fold higher than fine root respiration.

Total woody tissue respiration consumed 21 to $28 \%$ of annual gross primary production (GPP). A close correlation between the inter-site and interannual variations of GPP and annual total woody tissue respiration suggests that the respiratory carbon demand is directly influenced by temperature only in the short term, but is primarily regulated by carbon supply and growth on longer time scales. 


\section{Literaturverzeichnis}

AMTHOR J.S. 1984: The role of maintenance respiration in plant growth. Plant, Cell and Environment 7: 561-569.

AMTHOR J. S. 1989. Respiration and Crop Productivity. Springer, New York, Berlin, Heidelberg. 215 S.

AMTHOR J.S. 1991: Respiration in a future, higher $\mathrm{CO}_{2}$-world. Plant, Cell and Environment 14: 13-20.

AMTHOR J. S. 1998: A note on the report by M.B. Lavigne and M.G. Ryan relating stem maintenance respiration rate to stem growth rate. Tree Physiology 18: 69.

AMTHOR J.S. 2000: The McCree-de Wit-Penning de Vries-Thornley respiration paradigms: 30 years later. Annals of Botany 86[1]: 1-20.

ASCHAN G. \& PFANZ H. 2003: Non-foliar photosynthesis - a strategy of additional carbon acquisition. Flora 198: 81-97.

ASCHAN G., WITTMANN C. \& PFANZ H. 2001: Age-dependent bark photosynthesis of aspen twigs. Trees 15[7]: 431-437.

ATKIN O.K., EDWARDS E.J. \& LOVEYS B.R. 2000: Response of root respiration to changes in temperature and its relevance to global warming. New Phytologist 147[1]: 141-154.

BARNES B. V. et al. 1998. Forest Ecology. Wiley, New York. 774 S.

BARTSCH N. \& BAUHUS J. 1990: Effekte der Naturverjüngung auf den Stoff- und Wasserhaushalt. Berichte des Forschungszentrums Waldökosysteme, Universität Göttingen, 61 S.

BENECKE U. 1985: Tree Respiration in Steepland Stands of Nothofagus truncata and Pinus radiata, Nelson, New Zealand. Estaplishmend and Tending of Subalpine Forest: Research and Management .

BERGEL D. 1973: Formzahluntersuchungen an Buche, Fichte, europäischer Lärche und japanischer Lärche zur Aufstellung neuer Massentafeln. Allgemeine Forst- und Jagdzeitung 144: 117-124.

BOSC A., DE GRANDCOURT A. \& LOUSTAU D. 2003: Variability of stem and branch maintenance respiration in a Pinus pinaster tree. Tree Physiology 23: 227-236.

BROOKS A. \& FARQUHAR G.D. 1985: Effect of Temperature on the $\mathrm{CO}_{2} / \mathrm{O}_{2}$ Specificity of Ribulose-1,5Bisphosphate Carboxylase Oxygenase and the Rate of Respiration in the Light - Estimates from GasExchange Measurements on Spinach. Planta 165[3]: 397-406.

BURGER H. 1939: Holz, Blattmenge und Zuwachs. IV. Mitteilung. Ein 80-jähriger Buchenbestand. Mitteilungen der schweizerischen Anstalt für das forstliche Versuchswesen 21: 307-348.

BURGER H. 1949: Holz, Blattmenge und Zuwachs. X. Mitteilung. Die Buche. Mitteilungen der schweizerischen Anstalt für das forstliche Versuchswesen 26: 419-468.

CAREY E.V., CALLAWAY R.M. \& DELUCIA E.H. 1997: Stem respiration of ponderosa pines grown in contrasting climates: Implications for global climate change. Oecologia 111[1]: 19-25.

CAREY E. V., DELUCIA E. H. \& BALL J. T. 1996: Stem maintenance and construction respiration in Pinus ponderosa grown in different concentrations of atmospheric $\mathrm{CO}_{2}$. Tree Physiology 16: 125130. 
CERNUSAK L. A. \& MARSHALL J. D. 2000: Photosynthetic refixation in branches of Western White Pine. Functional Ecology 14: 300-311.

CERNUSAK L. A.et al. 2001: Carbon isotope discrimination in photosynthetic bark. Oecologia 128: 24-35.

CESCHIA E. 2001: Environmental Effects on Spatial and Seasonal Variations of Stem Respiration in European Beech and Norway Spruce., S.

CESCHIA E.et al. 2002: Spatial and seasonal variations in stem respiration of beech trees (Fagus sylvatica L.). Annals of Forest Science 59: 801-812.

CESCHIA E.et al. 2001: The effects of elevated $\left[\mathrm{CO}_{2}\right]$ on stem growth and respiration in Beech and Norway spruce, submitted to Trees. Trees .

CHUNG H.H. \& BARNES R.L. 1977: Photosynthate allocation in Pinus taeda I. Substrate requirements for synthesis of shoot biomass. Canadian Journal of Forest Research 7: 106-111.

CONERS H. 1996: Untersuchungen zu Struktur und Funktion des Wurzelsystems konkurrierender Buchen und Eichen in einem Mischbestand. Diplomarbeit. Universität Göttingen.

DAMESIN C. 2003: Respriation and photosynthesis characteristics of current-year stems of Fagus sylvativa: from seasonal pattern to an annual balance. New Phytologist 158: 465-475.

DAMESIN C. et al. 2002: Stem and branch respiration of beech: from tree measurements to estimations at the stand level. New Phytologist 153: 159-172.

DEUTSCHER WETTERDIENST 1999: Monatlicher Witterungsbericht der Jahre 1997 - 1998. Deutscher Wetterdienst, Offenbach.

DIERSCHKE H. \& SONG Y. 1982: Die Vegetation der Untersuchungsfläche des SFB 135 und ihrer Umgebung im Göttinger Wald. 1: 3-8. Göttingen. Kurzmitteilungen aus dem Sonderforschungsbereich 135 an der Universität Göttingen.

DIETRICHS H. 1964: Chemisch-Physikalische Untersuchungen über die Splint-Kern-Umwandlung der Rotbuche (Fagus sylvatica.L.). Ein Beitrag zur Frage der Holzverkernung. Mitteilungen der Bundesforschungsanstalt für Forst- und Holzwirtschaft, Reinbek Hamburg .

EDWARDS N.T. \& HANSON P.J. 1996: Stem respiration in a closed-canopy upland oak forest. Tree Physiology 16: 433-439.

EDWARDS N. T.et al. 1980. Carbon metabolism in terrestrial ecosystems. in D. E. Reichle editor. Dynamic properties of forest ecosystems. pp 499-536.

EKLUND L. 1990: Endogenous levels of oxygen, carbon dioxide, and ethylene in stems of Norway spruce trees during one growing season. Trees 4: 150-154.

EKLUND L. \& LAVIGNE M. B. 1995: Restricted lateral gas movement in Pinus strobus branches. Trees 10: 83-85.

ELLENBERG H., MAYER R. \& SCHAUERMANN J. 1986. Ökosystemforschung - Ergebnisse des SollingProjekts 1966-1986. Ulmer, Stuttgart. 507 S.

ESCHRICH W. 1995. Funktionelle Pflanzenanatomie.393 S.

FOOTE K. C. \& SCHAEDLE M. 1974: Seasonal Field Rates of Photosynthesis and Respiration in Stems of Populus-Tremuloides. Plant Physiology 62. 
FOOTE K. C. \& SCHAEDLE M. 1976a: Physiological Characteristics of Photosynthesis and Respiration in Stems of Populus tremuloides Michx. Plant Physiology 58: 91-94.

FOOTE K. C. \& SCHAEDLE M. 1976b: Stem Cuvette for Bark Photosynthetic and Respiratory Studies. Photosynthetica 10: 307-\&.

FOOTE K. C. \& SCHAEDLE M. 1978: The Contribution of Aspen Bark Photosynthesis to the Energy Balance of the Stem. For.Sci. 24: 569-573.

GANSERT D. 1995: Die Wurzel- und Sproßrespiration junger Buchen (Fagus sylvatica L.) in einem montanen Moder-Buchenwald. Diss. Universität Göttingen, 164 S.

GANSERT D.et al. 2002: Seasonal variation of branch respiration of a treeline forming (Betula ermanii Cham.) and a montane (Fagus crenata Blume) deciduous broad-leaved tree species on Mt. Fuji, Japan. Flora 197: 186-202.

GANSERT D. \& SPRICK W. 1998: Storage and mobilization of nonstructural carbohydrates and biomass development of beech seedlings (Fagus sylvatica L.) under different light regimes. Trees Structure And Function 12: 247-257.

GÄUMANN E. 1935: Der Stoffhaushalt der Buche (Fagus sylvatica L.) im Laufe eines Jahres. Ber.schweiz.Bot.Ges. 44[157]: 334.

GEURTEN I. 1950: Untersuchung über den Gaswechsel von Baumrinden. Forstwissenschaftliches Centralblatt Cb.69: 704-753.

GIESBERT C. 1997: Aspekte der Respiration nicht assimilierender Organe von Buchen-Altbäumen in einem submontanen Sauerhumus-Buchenwald. Unveröff. Diplomarbeit. Univ. Göttingen, $111 \mathrm{~S}$.

GOODWIN R. H. \& GODDARD D. R. 1940: The oxygen consumption of isolated woody tissues. American Journal of Botany 27: 234-237.

GOULDEN M.L. et al. 1996a: Exchange of carbon dioxide by a deciduous forest: response to interannual climate variability. Science 271: 1576-1578.

GOULDEN M. L.et al. 1996b: Measurements of carbon sequestration by long-term eddy covariance: Methods and a critical evaluation of accuracy. Global Change Biology 2: 169-182.

GOWER S. T., MCMURTRIE R. E. \& MURTY D. 1996: Aboveground net primary production decline with stand age: Potential causes. Trends in Ecology \& Evolution 11: 378-382.

GRANIER A.et al. 2000: Carbon balance of a young beech forest over a two year experiment. Functional Ecology 14: 312-325.

GRIES D. 2004: Saisonale und interannuelle Variabilität von Bestandesphotosynthese, autotropher Bestandesatmung und Kohlenstoffbilanz zweier Altbuchenbestände, in Vorb.

HAGEMEIER M. 2002: Funkionale Kronenarchitektur mitteleuropäischer Baumarten. Diss. Universität Göttingen, $154 \mathrm{~S}$.

HAGIHARA A. \& HOZUMI K. 1991. Respiration. in A. S. Raghavendra editor. Physiology of Trees. Wiley\&Sons, New York pp 87-109.

HANSEN L. D.et al. 1998: Misconceptions about the relation between plant growth and respiration. Botanica Acta 111: 255-260. 
HARI P., NYGREN P. \& KORPILATHI E. 1991: Internal circulation of carbon within a tree. Canadian Journal of Forest Research 21: 514-515.

HAVRANEK W.M. 1981: Stammatmung, Dickenwachstum und Photosynthese einer Zirbe (Pinus Cembra L.) an der Waldgrenze. Mitteilungen der Forstlichen Bundesanstalt Wien 143: 443-467.

HELLER H. \& GÖTTSCHE D. 1986. Biomasse-Messungen an Buche und Fichte. in H. Ellenberg, R. Mayer, and J. Schauermann editors. Ökosystemforschung - Ergebnisse des Solling-Projekts 19661986. Ulmer, Stuttgart pp 109-127.

HERTEL D. 1999: Das Feinwurzelsystem von Rein- und Mischbeständen der Rotbuche (Fagus sylvatica L.): Struktur, Dynamik und interspezifische Konkurrenz. Diss. Cramer, 190 S.

HUNT E. R., LAVIGNE M. B. \& FRANKLIN S. E. 1999: Factors controlling the decline of net primary production with stand age for balsam fir in Newfoundland assessed using an ecosystem simulation model. Ecological Modelling 122: 151-164.

JANSSENS I.A. et al. 2001: Productivity overshadows temperature in determining soil and ecosystem respiration across European forests. Global Change Biology 7[3]: 269-278.

JOHANSSON N. 1933: The relation between the tree-stem's respiration and its growth. Svenska skogsvårdföreningens Tidskrift 10: 53-136.

KAKUBARI Y. 1988: Diurnal and Seasonal Fluctuations in the Bark Respiration of Standing Fagus sylvatica L. Trees at Solling, West Germany. Journal of the Japanese Forestry Society 70[2]: 64-70.

KAKUBARI Y. 1989: Diurnal and Seasonal Fluctuations in the Bark Respiration of Standing QuercusAcutissima Trees in Nakaizu, Japan. Annales des Sciences Forestieres 46: S529-S531.

KINERSON R. S. 1975: Relationship between plant surface area and respiration in loblolly pine. Journal of Applied Ecology 12: 965-971.

KIRA T. \& SHIDEI T. 1967: Primary production and turnover of organic matter in different forest ecosystems of the western Pacific. Japanese Journal of Ecology 17: 70-87.

KÖRNER C. 2003: Carbon limitation in trees. Journal of Ecology 91: 4-17.

KRAMER H. \& AKCA A. 1982. Leitfaden für Dendrometrie und Bestandesinventur. Sauerländer's Verlag, Frankurt a.M. 251 S.

LARCHER W. 1969: Anwendung und Zuverlässigkeit der Tetrazoliummethode zur Feststellung von Schäden in pflanzlichen Geweben. Mikroskopie 25: 207-218.

LARCHER W. 1994. Ökophysiologie der Pflanzen., 5 .394 S.

LAVIGNE M.B. 1987: Differences in stemrespiration responses to temperature between balsam fir trees in thinned and unthinned stands. Tree Physiology 3: 225-233.

LAVIGNE M.B. 1988: Stem growth and respiration of young balsam fir trees in thinned and unthinned stands. Canadian Journal of Forest Research 18: 483-489.

LAVIGNE M. B. 1996: Comparing stem respiration and growth of jack pine provenances from northern and southern locations. Tree Physiology 16: 847-852.

LAVIGNE M. B., FRANKLIN S. E. \& HUNT R. J. 1996: Estimating stem maintenance respiration rates of dissimilar balsam fir stands. Tree Physiology 16: 687-695. 
LAVIGNE M. B. \& RYAN M. G. 1997: Growth and maintenance respiration rates of aspen, black spruce and jack pine stems at northern and southern BOREAS sites. Tree Physiology 17: 543-551.

LAVIGNE M. B.et al. 1997: Comparing nocturnal eddy covariance measurements to estimates of ecosystem respiration made by scaling chamber measurements at six coniferous boreal sites. Journal Of Geophysical Research Atmospheres 102: 28977-28985.

LAW B.E., RYAN M.G. \& ANTHONI P.M. 1999: Seasonal and annual respiration of a ponderosa pine ecosystem. Global Change Biology 5[2]: 169-182.

LEVY P.E., ALLEN S.J. \& JARVIS P.G. 1999: The effect of aqueous transport of $\mathrm{CO}_{2}$ in xylem sap on gas exchange in woody plants. Tree Physiology 19: 53-58.

LEVY P. E. \& JARVIS P. G. 1998: Stem $\mathrm{CO}_{2}$ fluxes in two Sahelian shrub species (Guiera senegalensis and Combretum micranthum). Functional Ecology 12: 107-116.

LEXANDER K.et al. 1970: Quantities and Qualities of Leaf Protein Concentrates from Wild Species and Crop Species Grown Under Controlled Conditions. Annals of Applied Biology 66: 193-216.

LINDER S. \& TROENG E. 1981: The seasonal variation in stem and coarse root respiration of a 20-year old scots pine (Pinus sylvestris L.). Mitteilungen der Forstlichen Bundesversuchsanstalt Wien 142: 125139.

LLOYD J. \& TAYLOR J. A. 1994: On the Temperature-Dependence of Soil Respiration. Functional Ecology 8: 315-323.

LONG J. N. \& SMITH F. W. 1992: Volume Increment in Pinus contorta var. latifolia - the Influence of Stand Development and Crown Dynamics. Forest Ecology and Management 53: 53-64.

LONGDOZ B., YERNAUX M. \& AUBINET M. 2000: Soil $\mathrm{CO}_{2}$ efflux measurements in a mixed forest: impact of chamber disturbances, spatial variability and seasonal evolution. Global Change Biology 6: 907-917.

LOOMIS W. D. 1969: Removal of Phenolic Compounds during the Isolation of Plant Enzymes. Methods in Enzymology 8: 555-563.

LOOMIS W. D. \& BATTAILE J. 1966: Plant phenolic compounds and the isolation of plant enzymes. Phytochemistry 5: 423-438.

LOWRY O. H. 1951: Protein measurement with the Folin Phenol Reagent. Journal of Biological Chemistry 193: 265-275.

LOZAN J. L. 1992. Angewandte Statistik für Naturwissenschaftler. Paul Parey, Berlin, Hamburg. 237 S.

MACILWAIN C. 1997: Kyoto meeting will seek to build bridge over troubled water. Nature 390: 215-216.

MAIER C. A., ZARNOCH S. J. \& DOUGHERTY P. M. 1998: Effects of temperature and tissue nitrogen on dormant season stem and branch maintenance respiration in a young loblolly pine (Pinus taeda) plantation. Tree Physiology 18: 11-20.

MAKELA A. \& VALENTINE H. T. 2001: The ratio of NPP to GPP: evidence of change over the course of stand development. Tree Physiology 21: 1015-1030.

MAKOWKA I., STICKAN W. \& WORBES M. 1991: Jahrringbreitenmessung an Buchen (Fagus sylvatica L.) im Solling; Analyse des Klimaeinflusses auf den jährlichen Holzzuwachs. Berichte des Forschungszentrums Waldökosysteme der Universität Göttingen Reihe B 18: 83-159. 
MALHI Y., BALDOCCHI D.D. \& JARVIS P.G. 1999: The carbon balance of tropical, temperate and boreal forests. Plant, Cell and Environment 22[6]: 715.

MALKINA I. S., YAKSHINA A. M. \& TSELNIKER Y. L. 1985: Relationship Between $\mathrm{CO}_{2}$ Evolution by the Trunk and Gas- Exchange of the Leaves in Oak. Soviet Plant Physiology 32: 593-599.

MARTIN T.A., TESKEY R.O. \& DOUGHERTY P.M. 1994: Movement of respiratory $\mathrm{CO}_{2}$ in stems of lobolly pine (Pinus taeda L.) seedligs. Tree Physiology 14[5]: 481-495.

MATZNER E. 1985: Auswirkungen von Düngungen und Kalkung auf des Elementumsatz und die elementverteilung in zwei Waldökosystemen im Solling. Allg.Forstzeitschrift 40: 1143-1147.

MCCREE K. J. 1970. An equation for the rate of respiration of white clover plants grown under controlled conditions. Pages 221-229 in Setlik, I. editor. Wageningen: Centre for Agricultural Publishing and Documentation.

MEIWES K.-J., BEESE F. \& PRENZEL J. 1981: Variabilität chemischer und physikalischer Eigenschaften eines Bodens auf Muschelkalk. Mitteilungen der Deutschen Bodenkundlichen Gesellschaft 32: 609622 .

MÖLLER C. M. \& MÜLLER D. 1938: Aanding I AEldre Stammer. Det forstlige Forsogsvæsen i Danmark 15: 113-138.

MÖLLER C. M., MÜLLER D. \& NIELSEN J. 1954: Respiration in Stem and Branches of Beech. Det forstlige Forsogsvæsen i Danmark 21: 273-301.

MORK E. 1960: On the relationship between temperature, leading shoot increment and the growth and lignification of the annual ring in Norway spruce (Picea abies L.), (in Norwegian, Engl. summary). Medd.Norske Skogforsoksvers. 56: 229-261.

MORTIMER C. E. 1987. Chemie, Basiswissen der Chemie., 5 Thieme, Stuttgart, New York. 660 S.

NAGEL J. 1999: Konzeptionelle Überlegungen zum schrittweisen Aufbau eines waldwachstumskundlichen Simulationssystems für Nordwestdeutschland. Schriften aus der Forstlichen Fakultät der Universität Göttingen und der Niedersächsischen Forstlichen Versuchsanstalt, 122 S.

NAGEL U. \& WUNDERLICH H. G. 1976. Geologisches Blockbild der Umgebung von Göttingen., Veröffentlichungen des Niedersächsischen Instituts für Landeskunde und Landesentwicklung an der Universität Göttingen . $50 \mathrm{~S}$.

NEGISI K. 1972: Diurnal Variation of $\mathrm{CO}_{2}$ Release from the Bark of a Standing Magnolia obovata Tree. Journal of the Japanese Forestry Society 54[8]: 257-263.

NEGISI K. 1974: Respiration rates in relation to diameter and age in stem or branch sections of young Pinus densiflora Trees. Bull.Tokyo Univ.Forests 66: 209-222.

NEGISI K. 1975: Diurnal Fluctuations of $\mathrm{CO}_{2}$ Release from the Stem Bark of Standing Young Pinus Densiflora Trees. Journal of the Japanese Forestry Society 57[11]: 375-383.

NEGISI K. 1978: Daytime Depression in Bark Respiration and Radial shrinkage in Stem of a Standing Young Pinus densiflora Tree. Journal of the Japanese Forestry Society 60[10]: 380-382.

NEGISI K. 1979: Bark Respiration Rate in Stem Segments Detached from young Pinus densiflora Trees in Relation to Velocity of Artificial Sap Flow. Journal of the Japanese Forestry Society 61[3]: 88-93. 
PAEMBONAN S.A., HAGIHARA A. \& HOZUMI K. 1992: Long-term respiration in relation to growth and maintenance processes of the aboveground parts of a hinoki forest tree. Tree Physiology 10[1]: 101110.

PELLINEN P. 1986: Biomasseuntersuchungen im Kalkbuchenwald. Diss. Universität Göttingen, 145 S.

PENNING DE VRIES F.W.T., BRUNSTING A.H.M. \& VAN LAAR H.H. 1974: Products, requirement and efficiency of biosynthesis: A quantitative approach. Journal of Theoretical Biology 45: 339-377.

PFANZ H. 1999: Photosynthetic performance of twigs and stems of trees with and without stress. Phyton Annales Rei Botanicae 39: 29-33.

PFANZ H. \& ASCHAN G. 2001: The existence of bark and stem photosynthesis in woody plants and its significance for the overall carbon gain. An eco-physiological and ecological approach. Progress In Botany 62 VOL 62: 477-510.

PFANZ H.et al. 2002: Ecology and ecophysiology of tree stems: corticular and wood photosynthesis. Naturwissenschaften 89: 147-162.

PILEGAARD K. et al. 2001: Two years of continuous $\mathrm{CO}_{2}$ eddy flux measurements over a Danish beech forest. Agricultural and Forest Meteorology 107[1]: 29-41.

PRUYN M. L., GARTNER B. L. \& HARMON M. E. 2002: Respiratory potential in sapwood of old versus young ponderosa pine trees in the Pacific Northwest. Tree Physiology 22: 105-116.

REDDIG H. \& GRIES D. 1999: Woody tissue respiration in Picea abies. Verhandlungen der Gesellschaft für Ökologie 29: 117-123.

ROBERTS L. W. 1951: Survey of Factors Responsible for Reduction of 2,3,5-Triphenyltetrazolium Chloride in Plant Meristems. Science 113: 692-693.

RYAN M.G. 1990: Growth and maintenance respiration in stems of Pinus contorta and Pinus engelmannii. Canadian Journal of Forest Research 20: 48-57.

RYAN M.G. 1991: Effects of climate change on plant respiration. Ecological Applications 1[2]: 157-167.

RYAN M.G. et al. 2004: An experimental test of the causes of forest growht decline with stand age, submitted to ecological monographs. Ecological Monographs in press.

RYAN M.G. et al. 1994a: Woody tissue-respiration for Simarouba amara and Minquartia guianensis, two tropical wet forest trees with different growth habits. Oecologia 100: 213-220.

RYAN M.G. et al. 1996: Foliage, fine-root, woody-tissue and stand respiration in Pinus radiata in relation to nitrogen status. Tree Physiology 16: 333-343.

RYAN M. G., LAVIGNE M. B. \& GOWER S. T. 1997: Annual carbon cost of autotrophic respiration in boreal forest ecosystems in relation to species and climate. Journal Of Geophysical Research Atmospheres 102: 28871-28883.

RYAN M.G. et al. 1994b: Dark Respiration in Pines. Ecological Bulletins Copenhagen 43: 50-63.

RYAN M.G. \& WARING R.H. 1992: Maintenance respiration and stand development in a subalpine lodgepole pine forest. Ecology 73: 2100-2108.

SCHIPKA F. 2003: Blattwasserzustand und Wasserumsatz von vier Buchenwäldern entlang eines Niederschlagsgradienten in Mitteldeutschland. Dissertation Mathematisch-Naturwissenschaftliche Fakultäten der Georg-August-Universität Göttingen, 155 S. 
SCHMIDT A. 1967: Der rechnerische Ausgleich von Bestandeshöhenkurven. Forstwissenschaftliches Centralblatt 86: 370-382.

SCHMIDT J., BATIC F. \& PFANZ H. 2000: Photosynthetic performance of leaves and twigs of evergreen holly (Ilex aquifolium L.). Phyton Annales Rei Botanicae 40: 179-190.

SPRUGEL D.G. 1990: Components of woody-tissue respiration in young Abies amabilis (Dougl.) Forbes trees. Trees 4: 88-98.

SPRUGEL D. G. \& BENECKE U. 1991. Measuring woody-tissue respiration and photosynthesis. in J. P. Lassoie, and T. Hinckley editors. Techniques and approaches in forest tree ecophysiology. CRCPress Inc., Boston pp 329-355.

SPRUGEL D.G., BROOKS J.R. \& HINCKLEY T.M. 1996: Effects of light on shoot geometry and needle morphology in Abies amabilis. Tree Physiology 16: 91-98.

SPRUGEL D. G., HINCKLEY T. M. \& SCHAAP W. 1991: The Theory and Practice of Branch Autonomy. Annual Review of Ecology and Systematics 22: 309-334.

SPRUGEL D. G.et al. 1995. Respiration from the Organ Level to the Stand. in W. K. Smith, and T. M. Hinckley editors. Resource Physiology of Conifers. Acquisition, Allocation, and Utilization. Academic Press, San Diego pp 255-300.

STEINBORN W.H. et al. 1997: $\mathrm{CO}_{2}$-Gaswechsel von Achsenorganen der Schwarzerle (Alnus glutinosa). Landschaftsentwicklung und Umweltforschung 107: 7-22.

STEPONKUS P. L. \& LANPHEAR F. O. 1967: Refinement of the Triphenyl Tetrazolium Chloride Method of Determining Cold Injury. Plant Physiology 42: 1423-1426.

STICKAN W. et al. 1994: Modelling the influence of climatic variability on carbon and water budgets of beech saplings (Fagus sylvatica L.) based on field data. Ecological Modelling 75/76: 331-343.

STOCKFORS J. \& LINDER S. 1998: Effect of nitrogen on the seasonal course of growth and maintenance respiration in stems of Norway spruce trees. Tree Physiology 18: 155-166.

STROBEL J. 1997: Der Wasserhaushalt eines Buchenwaldes im Mitteldeutschen Trockengebiet. Diplomarbeit, Albrecht von Haller Inst., Univ. Göttingen, 113 P.

STRYER L. 1990. Biochemie., 3 Spektrum der Wissenschaft Verlagsges. mbH, Heidelberg. 1127 S.

TSEL'NIKER YU.L., MALKINA I.S. \& YAKSHINA A.M. 1990: Vertical respiration gradient of spruce, oak and birch stems. Lesovedenie 4: 11-18.

ULRICH B. 1981: Ökologische Gruppierungen von Böden nach ihrem chemischen Bodenzustand. Zeitschrift für Pflanzenernährung und Bodenkunde 144: 289-305.

VALENTINI R.et al. 1996: Seasonal net carbon dioxide exchange of a beech forest with the atmosphere. Global Change Biology 2: 199-207.

VALENTINI R.et al. 2000: Respiration as the main determinant of carbon balance in European forests. Nature 404: 861-865.

VILLAR R., HELD A. A. \& MERINO J. 1995: Dark Leaf Respiration in Light and Darkness of An Evergreen and A Deciduous Plant-Species. Plant Physiology 107: 421-427.

VOGEL M. 1992: Anwendung der automatischen Radialzuwachsfeinmessung im Ökologischen Messfeld Tharandt und Darstellung erster Ergebnisse. Fakultät für Bau-, Wasser- und Forstwesen der TU Dresden, 192 S. 
VOSE J. M. \& RYAN M. G. 2002: Seasonal respiration of foliage, fine roots, and woody tissues in relation to growth, tissue N, and photosynthesis. Global Change Biology 8: 182-193.

WITTMANN C., ASCHAN G. \& PFANZ H. 2001: Leaf and twig photosynthesis of young beech (Fagus sylvatica) and aspen (Populus tremula) trees grown under different light regime. Basic and Applied Ecology 2[2]: 145-154.

WOODWELL G. M. \& BOTKIN D. B. 1970. Metabolism of Terrestrial Ecosystems by Gas Exchange Teechniques: The Brookhaven Approach. in D. E. Reichle editor. Analysis of Temperate Forest Ecosystems. Springer, Heidelberg, New York pp 73-85.

WULLSCHLEGER S. D., NORBY R. J. \& HANSON P. J. 1995: Growth and maintenance respiration in stems of Quercus alba after four years of $\mathrm{CO}_{2}$ enrichment. Physiologia Plantarum 93: 47-54.

XU M.et al. 2001: Ecosystem respiration in a young ponderosa pine plantation in the Sierra Nevada Mountains, California. Tree Physiology 21: 309-318.

YODA K. 1967: Comparative ecological studies on three main types of forest vegetation in Thailand III. Comunitiy respriation . Nature and Life in SE Asia 5: 83-148.

ZUMER M. 1969: Annual ring formation on Norway spruce in mountain forest. (In Norwegian, Engl. summary). Medd.Norske Skogforsoksvers. 97: 165-184. 


\section{Anhang}

\section{Daten}

A-Tab. 1: Vergleich der oberflächen- und volumenbezogenen $10{ }^{\circ} \mathrm{C}$ Atmungsraten der Punktmessungen mit den $10^{\circ} \mathrm{C}$-Erhaltungsatmungsraten der Dauermessungen (Kap: 4.2.1, Abb. 20) (Mittelwerte \pm Standardabweichung)

\begin{tabular}{cccccc}
$\begin{array}{c}\text { Kompar- } \\
\text { timent }\end{array}$ & Messkampagne & $\begin{array}{c}\text { Oberfläche } \\
\mu \mathrm{mol} \mathrm{m} \mathrm{m}^{-2}\end{array}$ & $\begin{array}{c}\text { Volumen } \\
\mu \mathrm{mol} \mathrm{m} \mathrm{m}^{-3} \mathrm{~s}^{-1}\end{array}$ & \\
\hline \multirow{3}{*}{ Stämme } & Dauermessung & $0.23 \pm 0.09$ & $1.90 \pm 0.65$ & 10 \\
& 13.11 .98 & $0.24 \pm 0.12$ & $4.71 \pm 4.25$ & 14 \\
& 18.12 .98 & $0.08 \pm 0.03$ & $0.93 \pm 0.32$ & 10 \\
\multirow{2}{*}{ Äste } & 28.12 .98 & $0.07 \pm 0.04$ & $0.87 \pm 0.30$ & 33 \\
\hline & 13.11 .98 & $0.12 \pm 0.06$ & $4.29 \pm 1.48$ & 9 \\
\hline
\end{tabular}

A-Tab. 2: Vergleich der $10{ }^{\circ} \mathrm{C}$ Erhaltungsatmung aller kompartimente und Standorte bezogen auf Oberfläche, Volumen, TTC-Umsatz, Stickstoff- und Proteingehalt. Angegeben ist der Mittelwert \pm relative Standardabweichung.

\begin{tabular}{|c|c|c|c|c|c|c|c|c|c|c|c|c|c|}
\hline \multirow{3}{*}{$\frac{\text { Standort }}{\text { SO }}$} & \multirow{2}{*}{$\begin{array}{r}\text { Bezugs- } \\
\text { größe => } \\
\text { Organ }\end{array}$} & \multirow{2}{*}{$\begin{array}{l}\text { Oberfläche } \mathbf{n} \\
\mu \mathrm{mol} \mathrm{CO} \mathrm{C}_{2} \mathrm{~m}^{-2} \mathrm{~s}^{-1}\end{array}$} & \multirow{2}{*}{\multicolumn{2}{|c|}{$\begin{array}{l}\text { Volumen } n \\
\mu m o l ~ \mathrm{CO}_{2}{ }^{\mathrm{m}-3} \mathrm{~s}^{-1}\end{array}$}} & \multirow{2}{*}{\multicolumn{3}{|c|}{$\begin{array}{l}\text { TTF-Umsatz } n \\
\mu \text { mol CO } \text { gTTF }^{-1} \mathrm{~s}^{-1}\end{array}$}} & \multirow{3}{*}{\multicolumn{3}{|c|}{$\begin{array}{l}\text { Stickstoff } \\
\mu \mathrm{mol} \mathrm{CO} \\
\mathrm{mol} \mathrm{N}^{-1} \mathrm{~s}\end{array}$}} & \multirow{2}{*}{\multicolumn{3}{|c|}{$\mid \begin{array}{l}\text { Protein } \\
\mu \mathrm{mol} \mathrm{CO}\end{array} \mathrm{gProt}^{-1} \mathrm{~s}^{-1}$}} \\
\hline & & & & & & & & & & & & & \\
\hline & Äste & $0,37 \pm 57 \% 6$ & $27 \pm 54 \%$ & 6 & $0,066 \pm$ & $4 \%$ & & & $0,22 \pm 52 \%$ & 6 & 2,8 & & \\
\hline \multirow{5}{*}{ Gö-Wald } & Stämme & $0,34 \pm 5$ & $2,9 \pm 52 \%$ & 8 & 0,034 & & & & $0,052 \pm 53 \%$ & 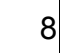 & 0,87 & & \\
\hline & Grobwurzel & $0,21 \pm 26 \% 6$ & $33 \pm 74 \%$ & 6 & $0,11=$ & & & & $0,18 \pm 40 \%$ & & 4,7 & & \\
\hline & Äste & $0,38 \pm 70 \% 6$ & $33 \pm 51 \%$ & 6 & $0,059=$ & & & & $0,23 \pm 56 \%$ & 0 & & & \\
\hline & Stämme & $0,23 \pm 57 \% 8$ & $1,8 \pm 54 \%$ & 8 & 0,011 & & & & $0,031 \pm 52 \%$ & of & 0,82 & $5 \%$ & \\
\hline & Grobwurzel & $0,23 \pm \mathbf{4 4} \% \quad 6$ & $29 \pm 74 \%$ & 6 & $0,21 \pm$ & $2 \%$ & & & $0,17 \pm \mathbf{4 4 \%}$ & & $8,8 \pm$ & $56 \%$ & \\
\hline \multirow{3}{*}{$\begin{array}{c}\text { Beide } \\
\text { Standorte }\end{array}$} & Äste & $0.38 \pm 64 \% 12$ & $30 \pm$ & 012 & $0.063 \pm$ & $39 \%$ & 12 & & $0.22 \pm 54 \%$ & 12 & $5.6 \pm$ & 75 & $\%$ \\
\hline & $\mathrm{mme}$ & $0.28 \pm 58 \% 16$ & $2.4 \pm$ & o 16 & $0.022 \pm$ & $79 \%$ & b & & $0.042 \pm 57 \%$ & 16 & $0.83 \pm$ & $53 \%$ & 10 \\
\hline & robwurzel & $0.22 \pm 37 \% 12$ & $31 \pm$ & 612 & $0.16 \pm$ & $88 \%$ & 12 & & $0.18 \pm 42 \%$ & 12 & $7.6 \pm$ & $63 \%$ & \\
\hline
\end{tabular}


A-Tab. 3: Verteilungsfunktionen, Bestimmtheitsmaß, Irrtumswahrscheinlichkeit und FunktionsParameter für die Beschreibung der Beziehung zwischen rel. Volumen der Holzdurchmesserklassen am Gesamtvolumen und dem BHD einer Buche (vgl. Abb. 30)

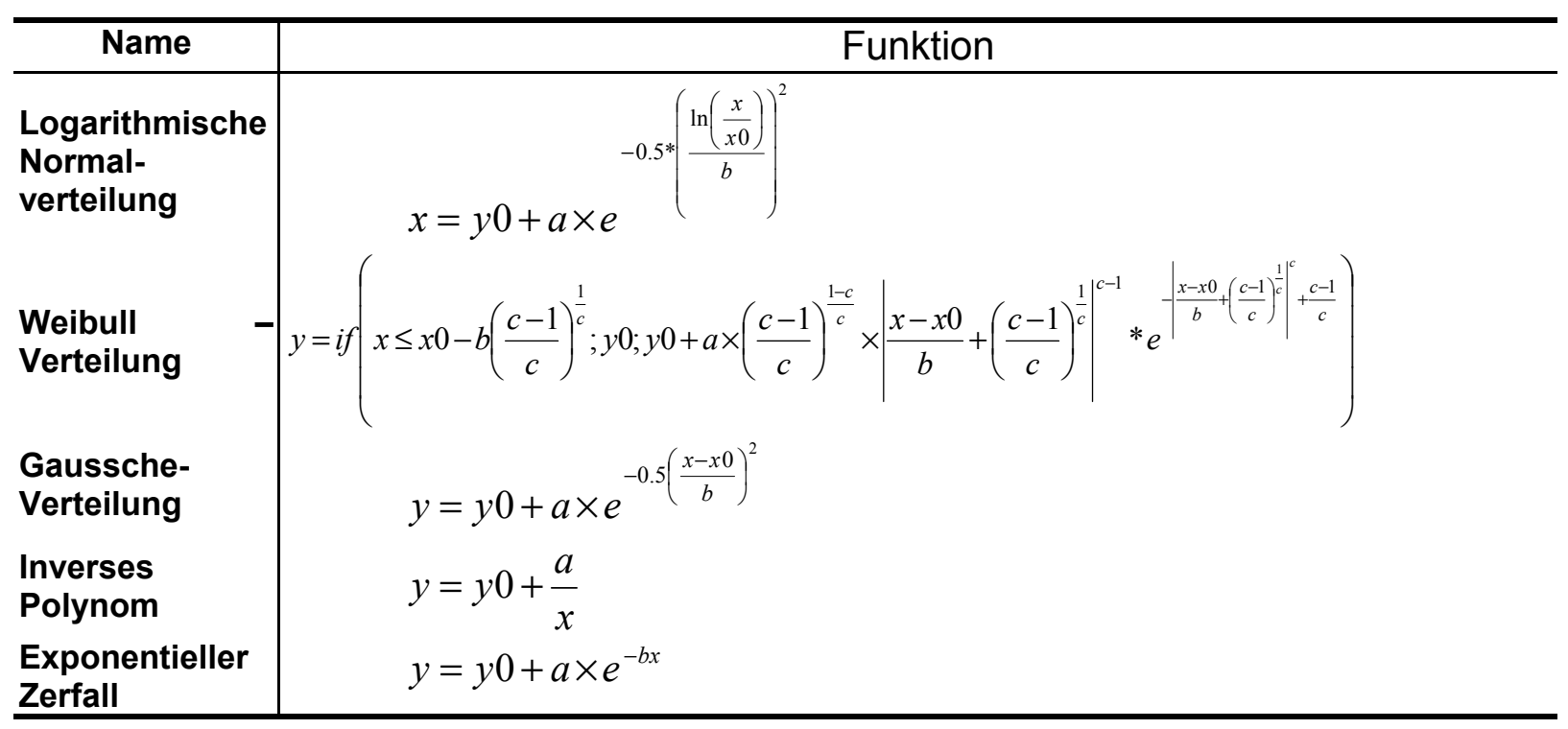

\begin{tabular}{|c|c|c|c|c|c|c|c|c|}
\hline \multirow{2}{*}{$\begin{array}{l}\text { Durchmesser- } \\
\text { Klasse }\end{array}$} & \multirow[b]{2}{*}{ Funktion } & \multirow[b]{2}{*}{$r^{2}$} & \multirow[b]{2}{*}{$\mathbf{P}$} & \multicolumn{5}{|c|}{ Parameter } \\
\hline & & & & $\mathbf{a}$ & b & c & xo & Yo \\
\hline $\begin{array}{c}\text { DKI. } 2 \\
40 \geq D>25 \mathrm{~cm}\end{array}$ & $\begin{array}{l}\text { Logarithmische } \\
\text { Normalverteilung }\end{array}$ & 0.99 & 0.0088 & 71.73 & 0.1835 & & 37.31 & 5.072 \\
\hline & Weibull Verteilung & 0.89 & 0.0001 & 58.12 & 12.32 & 2.112 & 22.38 & 5.281 \\
\hline $\begin{array}{c}\text { DKI. } 4 \\
15 \geq \text { D }>7 \mathrm{~cm}\end{array}$ & Weibull Verteilung & 0.92 & $<0.0001$ & 74.06 & 8.270 & 2.065 & 11.96 & 7.672 \\
\hline $\begin{array}{c}\text { DKI. } 5 \\
7 \geq \mathrm{D}>3 \mathrm{~cm}\end{array}$ & $\begin{array}{l}\text { Gaussche } \\
\text { Verteilung }\end{array}$ & 0.96 & $<0.0001$ & 75.83 & 2.334 & & 5.233 & 5.933 \\
\hline $\begin{array}{c}\text { DKI. } 6 \\
3 \geq \text { D > } 1 \mathrm{~cm}\end{array}$ & $\begin{array}{l}\text { Inverses } \\
\text { Polynom }\end{array}$ & 0.73 & $<0.0001$ & 90.59 & & & & 0.3230 \\
\hline $\begin{array}{c}\text { DKI. } 7 \\
1 \geq D\end{array}$ & $\begin{array}{l}\text { Exponentieller } \\
\text { Zerfall }\end{array}$ & 0.74 & $<0.0001$ & 8.9351 & 0.0951 & & & 1.3322 \\
\hline
\end{tabular}




\section{Index of figures}

Fig. 1: Geographic location of the study plots.

Fig. 2: Climate data from the weather stations at Silberborn and Göttingen: Annual means 1991-1990 (DEUTSCHER WETTERDIENST 1999) $(1 \mathrm{y}$-axis division $=$ $10{ }^{\circ} \mathrm{C} / 20 \mathrm{~mm}$ precipitation).

Fig. 3: Annual course of monthly temperature means and precipitation sums in 1997 and 1998 as compared to long-term average values.

Fig. 4: Simplified overview of the multi-channel-cuvette device for measuring $\mathrm{CO}_{2}$ efflux from branches, stems and coarse roots at a continuous airflow. For fine root respiration measurements in still air (accumulation method, shaded area) see GRIES 2004.

Fig. 5: Daily courses of respiration rates and xylem temperature, air temperature and PAR, as well as the temperature dependence of respiration rates of a: branches, $b$ : stems and c: coarse roots.

Fig. 6: Daily courses of respiration rates and xylem temperature, air temperature and PAR, as well as the temperature dependence of respiration rates of branches at Göttinger Wald a: with significant temperature dependence and b: with respiration unaffected by temperature variations.

Fig. 7: Daily courses of respiration rates and xylem temperature, air temperature and PAR, as well as the temperature dependence of respiration rates of (a) branches and (b) coarse roots. Arrows in (a) indicate the time course of temperature changes (hysteresis-loop).

Fig. 8.: a) Daily courses of respiration rates of stem no. 4 (Solling) and air temperature, PAR and xylem temperature measured $0.5,1.5,2.5,6.5$ and $12.5 \mathrm{~cm}$ below the stem surface. Daily maxima and minima are indicated by symbols in the daily courses. Respiration rates are plotted against the air and xylem temperature 0.5 and $6.5 \mathrm{~cm}$ below stem surface in figure $b$. Only significant $(\mathrm{p}<0.01)$ temperature relationships are shown.

Fig. 9: Respiration rates plotted against air and xylem temperature at different depths in stem no. 4 (Solling). Temperature functions are time lag adjusted to obtain a maximum $r^{2}$. Only significant correlations are shown.

Fig. 10: a) Respiration rates plotted against air and xylem temperature at 5 different wood depths in stem no. 4. Temperature curves were calculated for all data or exclusively for night-time data 6:00 pm-6:00 am, respectively. For comparison, the effect of a $3 \mathrm{~h}$ time lag on the temperature relationship is shown for $0.5 \mathrm{~cm}$ wood depth (dashed line, top panel, center). b) Comparison of calculated and measured respiration data. Three different functions for the 0.5 -depth were used for the calculation (fig. a) above, middle). Daily courses of the residuals are plotted additionally. The residuals of the respiration rates $\left(\mathrm{R}_{\text {brutto }}\right)$ modeled using the temperature response function of night-time respiration equal the sum of the rates of the bark respiration and $\mathrm{CO}_{2}$-transport by xylem sap. The percent-values in the table correspond to the sum of gross respiration of each time period. 
Fig. 11: Respiration rates plotted against temperature and daily courses of measured and calculated respiration rates of a) coarse root no. 4 and b) branch no. 4 (Göttinger Wald). Three temperature response curves were calculated for each sample: for all data with and without time lag (TL) and exclusively for the night time data. These curves were further used for calculating respiration rates based on daily temperature courses. Residuals were calculated as the difference between calculated and measured respiration rates. The residualsof the night-time-based respiration rates correspond to the $\mathrm{CO}_{2}$-transport by xylem sap in the coarse root and to the combined effect of $\mathrm{CO}_{2}$ transport and corticular photosynthesis in the branch. Only four daily courses are shown for branch respiration, whereas the functions are based on all eight daily courses recorded.....

Fig. 12: a) Temperature dependence of night time respiration rates and temperature functions for measurement in light transparent (light grey) and covered (black) cuvettes. $\mathrm{r}^{2}$-values within parentheses correspond to temperature functions of complete 24-h-data (functions not shown). b) Daily courses of respiration in light transparent (22.07.98) and covered cuvettes (27.07.98). The residues can be used as an estimate of the bark photosynthesis and the $\mathrm{CO}_{2}$-transport rate. Xylem- and air temperatures are shown additionally. The table shows the daily means or sums of temperature, PAR and VPD, as well as the calculated daily sums of gross respiration and the proportion of the residuals of $\mathrm{R}_{\text {brutto }}$.

Fig. 13: Two-year curves of mean respiration rate and xylem temperature of branches, stems and coarse roots in the Solling and Göttinger Wald. Each point corresponds to the mean \pm standard error of all hourly data points of a 2-14-day-measurement (number of hourly data points per measurement $\mathrm{n}_{\min }=19, \mathrm{n}_{\max }=381, \mathrm{n}_{\text {mean }}=121$ ) averaged over all 5 (Solling, stems) or 6 (other) sampling points of the respective compartments.

Fig. 14: Respiration rates plotted against xylem-temperature. Means \pm standard errors for each of the six sites during each measurement period. The Arrhenius parameters for the values of the temperature function of the two years, $r^{2}$ and the temperature coefficient $\mathrm{Q}_{10}$ (solid black line) are given additionally. Black symbols and dashed line: 1997, gray symbols and dashed line: 1998, filled symbols: November-April, open symbols: May-October.

Fig. 15: Two-year curves of the $10{ }^{\circ} \mathrm{C}$-respiration rates and the mean growth rates. Each point corresponds to mean \pm standard error of the temperature normalized respiration rate or growth rate from six measuring points. The calculations of the $10{ }^{\circ} \mathrm{C}$-respiration rates were based on the Arrhenius parameters or the mean Q10value (Chapter 3.4.1).

Fig. 16: Annual-curves of the Q10-values of woody tissue respiration. Each point corresponds to mean \pm standard error of six or five (Solling, stems) $\mathrm{Q}_{10}$-values of all sample points during one campaign. Numbers shown in graphs are annual means \pm standard errors. Significantly different means are marked by different letters.

Fig. 17: Two-year curves of temperature functions of respiration rates (mesh plot) and annual courses of measured respiration rates (solid black line). 
Fig. 18: Comparison of a) area- and b) volume-based $10^{\circ} \mathrm{C}$-maintenance respiration. Six measurement sites per compartment and location (GW Göttinger Wald, SO Solling). Square symbols represent stems on which vertical profiles were measured. Means and standard errors are given.

Fig. 19: Relationship between diameter of woody organs and area- (a) or volume-based (b) $10{ }^{\circ} \mathrm{C}$-maintenance respiration. Only significant functions are shown $(\mathrm{P}<$ $0.05)$. The scale of the respiration rates of stems are 20 -fold compared to the scale for branches and coarse roots.

Fig. 20: Relationship between a) area- and b) volume-based $10{ }^{\circ} \mathrm{C}$-maintenance respiration and diameter of stems and branches. The measurements were conducted during three periods in November and December at Göttinger Wald.

Fig. 21: Relationship between maintenance- $\mathrm{CO}_{2}$-efflux from branches, stems and coarse roots at $10{ }^{\circ} \mathrm{C}$ and area, volume, TTC-conversion and nitrogen and protein contents. Only significant regressions $(\mathrm{p}<5 \%)$ are shown. Dashed regression lines are for individual sites, Broad lines indicate parallel or statistically identical regressions for both stands.

Fig. 22: Maintenance respiration of branches (B), stems (S) and coarse roots (CR) at 10 ${ }^{\circ} \mathrm{C}$ as based on area, volume, TTC-conversion, as well as nitrogen and protein contents. Mean respiration rate \pm standard error are given as proportion of the corresponding maximum mean value.

Fig. 23: Relationship between area-based $10^{\circ} \mathrm{C}$-maintenance respiration and amount of extracted TTF per volume, as well as the nitrogen concentration. The regressions include all data. Filled symbols: Solling, open symbols: Göttinger Wald.

Fig. 24: Radial distribution of the volume-based TTC-conversion and nitrogen content in three branches and one coarse root at Göttinger Wald (above) and two stems each at Solling and Göttinger Wald (below). Each data point shows the outermost border of each approx. $1 \mathrm{~cm}$ long part of a wood core.

Fig. 25: Radial distribution of the mean volume-based TTC-conversion and nitrogen content of the stems, branches and coarse roots. The radius is partitioned into 10 and 4 sections for woody tissue of stems and branches respectively. TTCconversion and $\mathrm{N}$-content of all $1 \mathrm{~cm}$ core samples are averaged for each section. Values for bark-tissue are averaged separetely. Mean values \pm standard error are given. For clarity, datapoints of each section are offset.

Fig. 26: Volume-based $10^{\circ} \mathrm{C}$ maintenance respiration rate of one stem in the Solling and one at Göttinger Wald. Respiration was measuered at three different heights (base and middle of the stem and base of the crown) and in northern and southern orientation. Respiration rates were calculated and averaged by using the same temperature response curves from which maintenance respiration temperature function was calculated. These data from the height gradients are compared with the mean respiration rates at $2 \mathrm{~m}$ height of 6 and 5 different stems at Göttinger Wald and Solling, resp..

Fig. 27: Stem height gradient of mean $10^{\circ} \mathrm{C}$ respiration (November to May average, see text) of one stem at Solling (filled symbols) and one at Göttinger Wald (open symbols) as well as annual diameter increment of the stem at Solling (annual 
increment data for Göttinger Wald stem lost due to accident ?). North and south sides were sampled at each height.

Fig. 28: Stem respiration varies more between tree individuals than between different sampling points along one individual stem. Distribution of $r 2$ values of all linear relationships among $10^{\circ} \mathrm{C}$-respiration rates of different sampling points along one stem ( $x$-axis $S_{V} 7-12$ and $S_{V} 7-10+12$ ), or between tree individuals (five individuals at Solling, $\mathrm{x}$-axis S 2-6; six individuals at Göttinger Wald, $\mathrm{x}$-axis S 16). Linear regressions between $10{ }^{\circ} \mathrm{C}$-respiration rates were calculated for all possible combinations between sampling points or individuals, resp., using all data from the entire observation period.

Fig. 29: $10^{\circ} \mathrm{C}$ maintenance respiration of the branches of both sites plotted (left) vs. estimated canopy volume occupied by the leaf area the branch supports (in classes from 1-3), or (center) vs. canopy level of leaf area supported by the branch, or (right) by a combination of both.

Fig. 30: Relationship between wood volume fraction (with bark) in different diameter classes (DKl) and stem diameter at $1.3 \mathrm{~m}(\mathrm{dbh})$. Based on complete harvests of 30 trees for DK1 1-6 and 50 trees for DK1 7. Equations and parameters are given in Tab. A3. Shaded bars: dbh distribution in the two stands.

Fig. 31: Relationship between log coarse root biomass and stem diameter at $1.3 \mathrm{~m}$ of four trees harvested at Solling in 1968 (HELLER \& GÖTTSCHE 1986).

Fig. 32: Distribution of stem diameters at $1.3 \mathrm{~m} \mathrm{(dbh)}$ and tree heights as well as relationship between tree height and dbh for the two stands, according to a survey by the Niedersächsische Forstliche Versuchsanstalt, January 1996 at Solling, September 1996 at Göttinger Wald

Fig. 33: Relationship between annual diameter increment and stem diameter at $1.3 \mathrm{~m}$ (dbh) for trees representative of the stem diameter distribution of each stand. Diameter increments of 20 (1996) or 27 trees (1997/98) were measured using high-resolution increment tapes (this study, and F. SCHIPKA, pers. comm.).

Fig. 34: Volume stores of above ground wood in seven diameter classes, and volume increment during the two study years. White areas of bars for Göttinger Wald represent total wood volume of tree species other than beech.

Fig. 35: (Left) Temperature response functions of all 1997 respiration data sets, and of maintenance respiration, for a branch, a stem and a coarse root. (Right) Annual course of total and maintenance respiration calculated from these functions and measured temperatures with an hourly time step. For deriving temperature functions of maintenance respiration $\left(\mathrm{R}_{\mathrm{m}}\right)$, the four to five functions with the lowest basal respiration rate and low to intermediate $\mathrm{Q}_{10}$ values obtained in the non-growing season were averaged. Lines and symobls: Total respiration; gray line: Maintenance respiration; gray circles: measured rates.

Fig. $36 \mathrm{a}$ and $\mathrm{b}$ : Comparison of the three methods used for measuring circumference increment of branches. (b) A plot of growth coefficients ( $\mathrm{C}$ respired/C in new growth) vs. annual circumference increment clearly shows the resolution limit of the methods. For samples with circumference increments smaller than $1 \mathrm{~mm}$, underestimation of circumference increments caused overestimation of growth coefficients. 
Fig. 37: Annual course of the cumulative circumference increment of three branches at Göttinger Wald obtained with high resolution tape dendrometers, which were installed at the beginning of June 1997.

Fig. 38: Annual sums of respiration plotted against biomass increment in stems and branches 1998. Regressions are based on data from both locations. Filled symbols: Solling, open symbols: Göttinger Wald.

Fig. 39: Biennial courses of total, maintenance and growth respiration per unit ground area of the two beech stands at Solling and at Göttinger Wald. Stacked areas represent branch, stem and coarse root respiration, respectively. To demonstrate the distribution of carbon fluxes between above- and belowground fractions, coarse root respiration is plotted in downward y-direction below the $\mathrm{x}$-axis. Daily means of air and soil temperatures are shown in the center panel.

Fig. 40: Relationship of $10{ }^{\circ} \mathrm{C}$ maintenance respiration and diameter of branches and coarse roots; data from this study and from several authors. (x) rates calculated for mean class diameters using the exponential function shown. (0) mean respiration rates and diameters of branches and coarse roots sampled in this study.

Fig. 41: Biennial courses of growth respiration and growth rates of branches and stems at Göttinger Wald and at Solling. Growth respiration was calculated as the difference between total and maintenance respiration calculated from temperature response functions shown in Fig. 35 with an hourly time step. Growth respiration rates were then averaged over the intervals between circumference measurements.

Fig. 42: Graph supporting the view that most respiratory activity is concentrated in the cortex and youngest xylem layers. (a) Open symbols: Diameter depencende of measured volume-based respiration rates of all compartments. Filled symbols are volume-based rates calculated from sample volumes and surface areas, assuming that all compartments have surface-area-based respiration rates like those measured for stems. (b) graph of rates calculated as in (a) versus measured rates

Fig. 43: Diameter dependence of (a) surface area-based and (b) volume-based respiration rates of branches in three different canopy heights.Values for surface area-based respiration rates of branches with $\mathrm{D}<2.5 \mathrm{~cm}$ (gray points) are from Gansert (1995 and Damesin et al. (2002) and are referred to in connection with the calculation of twig respiration (see chapter. 5.5.2). Upper third of canopy: $\mathrm{R}_{10}{ }^{\circ} \mathrm{C}, \mathrm{A}=0.113 \times \mathrm{D}-0.068, \mathrm{r}_{\text {adj. }}^{2}=0.84, \mathrm{P}=0.0025$; Center and lower thirds: $\mathrm{R}_{10}{ }^{\circ} \mathrm{C}, \mathrm{A}=0.024 \mathrm{x} \mathrm{D}-0.011, \mathrm{r}_{\text {adj. }}^{2}=0.79, \mathrm{P}=0.20$.

Fig. 44: Relationship between $10{ }^{\circ} \mathrm{C}$ maintenance respiration and relative growth rate of branches and stems: (a) of 30 year-old beech (calculated based on data in CESCHIA et al. 2002, $\left.\mathrm{r}^{2}=0.99, \mathrm{P}=0.053\right)$ and (b) of mature beech at Göttinger Wald and Solling. Branch data marked with open symbols not included in regression analyses.

Fig. 45: Relationship between annual sums of above ground or total woody tissue respiration and GPP of the mature beech stands at Solling (filled symbols) and Göttinger Wald (open symbols). GPP according to Gries (2004). 
Fig. 46: Relationship between annual aboveground woody tissue respiration and GPP of four beech stands of different age. $\mathrm{R}_{\text {Wood,ag }}$ and GPP shown for the 30 year-old beech stand are averages of various values given for 1997 in CESCHIA 2001, DAMESIN et al. 2002, and GRANIER et al. 2000, respectively. 


\section{Index of tables}

Tab. 1: Mean temperature and annual precipitation at the meteorological stations Silberborn and Göttingen. Climatic data of 1997 and 1998 compared with long term climatic characteristics. Photosynthetically active radiation (PAR) was measured at the study sites at a height of $30 \mathrm{~m}$ (Solling) and $42 \mathrm{~m}$ (Göttinger Wald) above the canopy. Shading indicates specific differences of the two years.

Tab. 2: Site characteristics of the two investigated beech stands. Diameter at $1.3 \mathrm{~m}$ (BHD) and tree height were provided by the Niedersächsische Forstliche Versuchsanstalt. LAI by HERTEL (1999).

Tab. 3 : Dimensions, situation and orientation of stem, branch and coarse root positions sampled continually....

Tab. 4: Upper and lower limits of the wood diameter classes 1-7.

Tab. 5: $\mathrm{r}^{2}$ and temperature response coefficent $\left(\mathrm{Q}_{10}\right)$ calculated for $24 \mathrm{~h}$ datasets with and without a time lag adjustment, or for the data measured at night-time only. The difference $\mathrm{R}_{\text {calc }}-\mathrm{R}_{\text {meas }}$ represents the error of the model and the amount of corticular photosynthesis and $\mathrm{CO}_{2}$ transport by xylem sap. Temperature functions were calculated for the daily courses shown in Fig. 7 a and ig 5.

Tab. 6: Mean and maximum volume-based respiration rates and xylem temperatures of branches, stems and coarse roots. Means were calculated for various time periods......57

Tab. 7: $\mathrm{r}^{2}$ and $\mathrm{P}$-values of the correlations between $\mathrm{CO}_{2}$-release and sample dimension, TTC-conversion, protein or nitrogen content shown in Fig. 21. Shaded areas: P values of tests for similarity of slopes and offsets. Regression parameters for pooled data are printed in italics and are not shown in Fig. 21 if the regression for one single stand was not significant.

Tab. 8: Wood volume of two trees representative for the two stands an its distribution into 7 diameter classes.

Tab. 9: Stocks of woody biomass of the investigated stands in January 1997, its distribution into different diameter classes, and wood increment of stems, branches and coarse roots in 1997 and 1998.

Tab. 10: Annual sums of total, maintenance and growth respiration of woody biomass (mean values $\pm \mathrm{SD}, \mathrm{n}=$ number of sampling pointss) and the percentage of respiration during the growing season.

Tab. 11: Mean volume-based wood increment and mean growth coefficients. Values were ignored if the diameter increment was less than $1 \mathrm{~mm}$ per year. (presumably incorrect data of branches and coarse roots for 1997 in italics).....

Tab. 12: Monthly sum of total respiration $\mathrm{R}_{\mathrm{t}}\left(\mathrm{mol} \mathrm{C} \mathrm{m}{ }^{-2}\right.$ ground area month $\left.{ }^{-1}\right)$ at the beech stands at Göttinger Wald and at Solling. Maintenance respiration $\mathrm{R}_{\mathrm{m}}$ is given as a percentage of $\mathrm{R}_{\mathrm{t}}$

Tab. 13: Error calculation for the annual respiration in 1997 at the Solling site

Tab. 14: Annual totals of woody-tissue respiration at the stand level calculated with and without considering diameter dependence of branch and coarse root respiration. .96

Tab. 15: Corticular photosynthesis and $\mathrm{CO}_{2}$ transported by xylem sap relative to the daily sum of local respiratory $\mathrm{CO}_{2}$. Additionally shown: the range of surface area based 
corticular photosynthesis rates and the sums of corticular photosynthesis and $\mathrm{CO}_{2}$ - transport. Mean values are calculated for the dormant season (November April) and for the summer months (May - September) of both years. Relative rates of corticular photosynthesis and $\mathrm{CO}_{2}$-transport are calculated for $24 \mathrm{~h}$ measurementsof $n$ daily courses. Rates of photosynthesis and $\mathrm{CO}_{2}$-transport are maximum values at single sampling points.

Tab. 16: Annual totals of Cfluxes per $\mathrm{m}^{2}$ ground area calculated separately for different fractions of woody organs. Deviations of fluxes from values in Tab. 12 that are caused by corticular photosynthesis and $\mathrm{CO}_{2}$-transport are shown as percentages of total respiration.

Tab. 17: Absolute and relative rates of corticular photosynthesis of twigs, branches and stems. Data reported by other authors were measured under artificial or natural light conditions. Data of the present study were measured in April and at the end of October.

Tab. 18: Maximum rates of $\mathrm{CO}_{2}$ transport by the xylem sap. Percentages are based on measured daily $\mathrm{CO}_{2}$ release if $\mathrm{CO}_{2}$ was transported towards the measuring point, or on local respiratory $\mathrm{CO}_{2}$ release if $\mathrm{CO}_{2}$ efflux was reduced by $\mathrm{CO}_{2}$ transport

Tab. 19: Corticular photosynthesis, sum of corticular photosynthesis and $\mathrm{CO}_{2}$-transport, or $\mathrm{CO}_{2}$-transport, relative to the daily totals of $\mathrm{CO}_{2}$-release by woody organs.

Tab. 20: Comparison of daily sums of respiratory $\mathrm{CO}_{2}$ release calculated with different temperature response functions. Response functions were calculated from data sets including either (1) only night time data measured between 20 and 6 hours, thus excluding corticular photosynthesis and $\mathrm{CO}_{2}$ xylem transport, or (2) all data, with or without correction for an assumed time lag (TL), or (3) only day time data measured between 6 and 20 hours.

Tab. 21: Compilation of literature data on volume-based respiration rates of various tree species and compartments. Annual minimum and maximum values at ambient temperature as well as the observed range of rates normalized to $10^{\circ} \mathrm{C}$ were obtained directly or after recalculation from the source data.

Tab. 22: Comparison of annual sums of aboveground woody tissue respiration calculated with different assumptions about the spatial variability of volume-based (1ac, $3 \mathrm{a}, 3 \mathrm{~b})$ or surface area-based $(1 \mathrm{~d}, 3 \mathrm{c}, 3 \mathrm{~d})$ respiration rates and about the temporal variability of $\mathrm{Q}_{10}$ values.

In detail, the following assumptions were made:

1 a) assignment of volume-based respiration rates to diameter classes according to equation (12) but otherwise no diameter dependence was considered

$1 \mathrm{~b})$ for diameter-classes $4-7$, diameter dependence of branch respiration rates (Fig. 40) was considered according to equation (13).

$1 \mathrm{c})$ volume-based branch respriation rates and volume stores for diameter classes 4- 7 are differentiated between shadow and sun crown (see Fig. 43 b).

$1 \mathrm{~d})$ calculated using the surface area-based respiration rates considering diameter dependence and spatial variation as shown in Figures 20 a) and 43 a)

2 Assignment of rates to diameter classes as in 1 a) but seasonal variation of temperature coefficients was simplified by using a) the annual course of mean 
$\mathrm{Q}_{10}$ for each compartment (Fig. 16), b) the annual mean of $\mathrm{Q}_{10}$-values (numbers in Fig. 16) and c) a constant $Q_{10}=2$ for all compartments.

3 a) Volume based branch and stem respiration rates were assigned to diameter classes according to a hyperbolic function (Fig. 42 a filled symbols),

For $3 \mathrm{~b}$ ) to d) only stem respiration rates were considered and stand respiration was calculated as a product of (b) volume-based respiration and the total above ground wood volume, or ( $\mathrm{c}$ and $\mathrm{d}$ ) of surface area based respiration and the total above ground wood surface area. For c), diameter dependence of surface area based stem respiration (Fig. 20) was considered, whereas for d) it was not.

Tab. 23: Comparison of annual sums of above- and belowground woody tissue respiration with total autotrophic stand respiration, with the amount of carbon fixed annually in wood growth, with corticular photosynthesis, and with gross primary production. 



\section{Danksagung}

Die vorliegende Arbeit entstand im Rahmen des Teilprojekts A7-f am Forschungszentrum Waldökosysteme der Universität Göttingen (Vorhaben „Veränderungsdynamik von Waldökosystemen“) und wurde vom Bundesministerium für Bildung, Wissenschaft und Technologie unterstützt.

Zuerst möchte ich Herrn Prof. Dr. Michael Runge für die Überlassung des interessanten Themas und sein stetes Interesse danken. Seine inhaltlichen Anregungen waren mir bei der Ausarbeitung der Untersuchungsergebnisse ein zusätzlicher Ansporn.

Ganz besonders danke ich Dr. Dirk Gries für seine vorbildliche und freundschaftliche Betreuung. Mit seiner uneingeschränkten Bereitschaft, alle Fragen ausführlich mit mir zu diskutieren, mich nicht nur in jeder Hinsicht zu ermutigen, sondern auch mit Rat und Tat zu unterstützen, trug er maßgeblich zum Gelingen dieser Arbeit bei.

Für die Einführung in den Umgang mit der „Atmungsanlage“, das unvergleichliche Teamwork während der zweijährigen Freilandarbeit und ihre Toleranz mit mir als „Mitbewohner“ des Arbeitszimmers danke ich Claudia Giesbert sehr herzlich.

Dafür, dass sich die Messkampagnen häufig wie Wald-Ausflüge anfühlten, danke ich dem ganzen C-Bilanz-Team: Claudia Giesbert, Heike Reddig, Imke Kolloge, Nilufar Nassiri und Dirk Gries. Das Forschen hat mit euch allen viel Freude gemacht.

Eine große Hilfe bei den Laboruntersuchungen waren Jutta Czernitzki und Ute Schlonsog. Ihnen sei dafür herzlich gedankt.

Die Zuwachsdaten für das Jahr 1997 stellte Dr. Florian Schipka zur Verfügung. Herrn Dr. Hans Heller danke ich für die Überlassung der Messprotokolle der Baumernten aus dem „SollingProjekt" und sein stetes Interesse. Seine Hinweise zu den lange zurückliegenden Untersuchungen machten die Erarbeitung der Holzvolumina erst möglich.

Bei Herrn Thorsten Möhlenhoff von der Niedersächsischen Forstlichen Versuchsanstalt bedanke ich mich für die unbürokratische Überlassung der biometrischen Daten der Untersuchungsbestände und den Crash-Kurs in forstlicher Biometrie.

Die Klimadaten stellte das Institut für Bioklimatologie der Forstlichen Fakultät zur Verfügung, wofür ich mich bedanken möchte.

Für die mühevolle Arbeit, das Manuskript kritisch $\mathrm{zu}$ lesen und für die vielen hilfreichen Anregungen danke ich Dirk Gries, Christoph Fühner und Florian Schipka.

Am abschließenden Korrekturlesen beteiligten sich mit großem Einsatz Marina Röderstein, Sandra Korn, Alexandra Erfmeier, Claudia Giesbert, Cathi Meinen, Melanie Manegold und Heike Scholz. Dafür bin ich Ihnen sehr dankbar.

Allen Mitarbeiterinnen und Mitarbeitern der Abteilung Ökologie und Ökosystemforschung des Albrecht-von-Haller-Instituts möchte ich für das tolle Arbeitsklima und die stets anregenden Diskussionen danken.

Schließlich gilt mein Dank Marion Marschall, die mich während der gesamten Zeit dieses Projektes mit großer Geduld unterstützte, wenn nötig aufmunterte und die Dinge um mich herum oft klarer sah als ich selbst. 